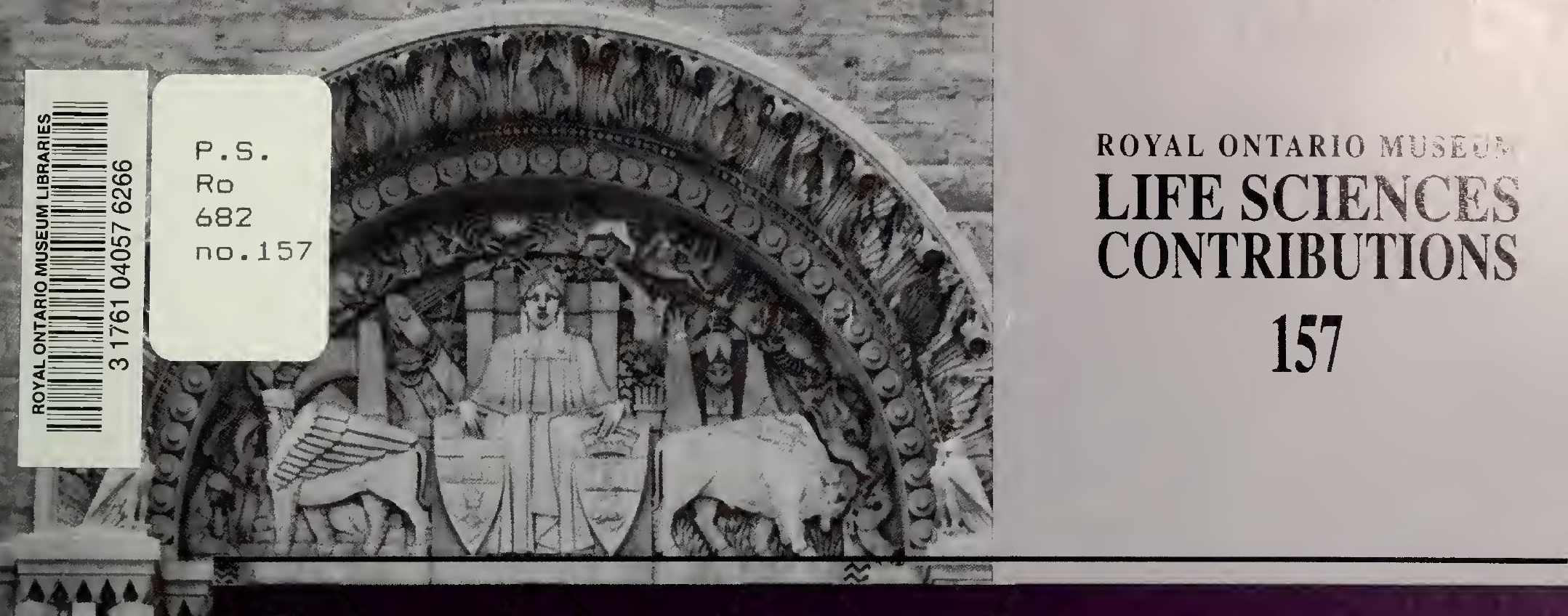

43

Classification AND

EVOLUTION OF THE

ORASEMINAE IN THE

OLD WORLD,

INCLUDING REVISIONS

of Two Closely

RELATED Genera of

EUCHARITINAE

(HYMENOPTERA :

EUCHARITIDAE)



John Michacl Heraty

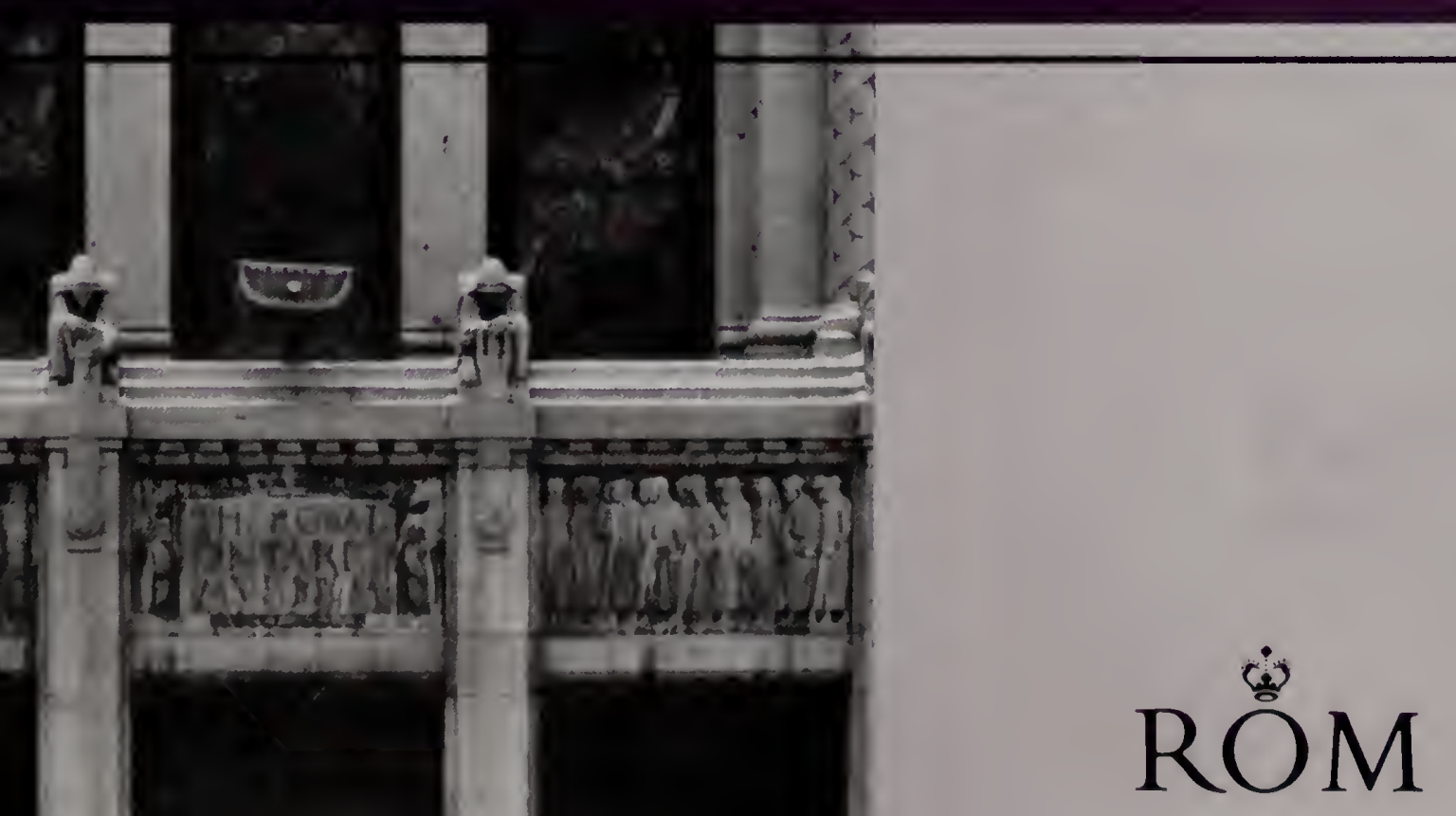


Digitized by the Internet Archive in 2011 with funding from Royal Ontario Museum 


\section{CLASSIFICATION AND EVOLUTION OF THE ORASEMINAE IN THE OLD WORLD}




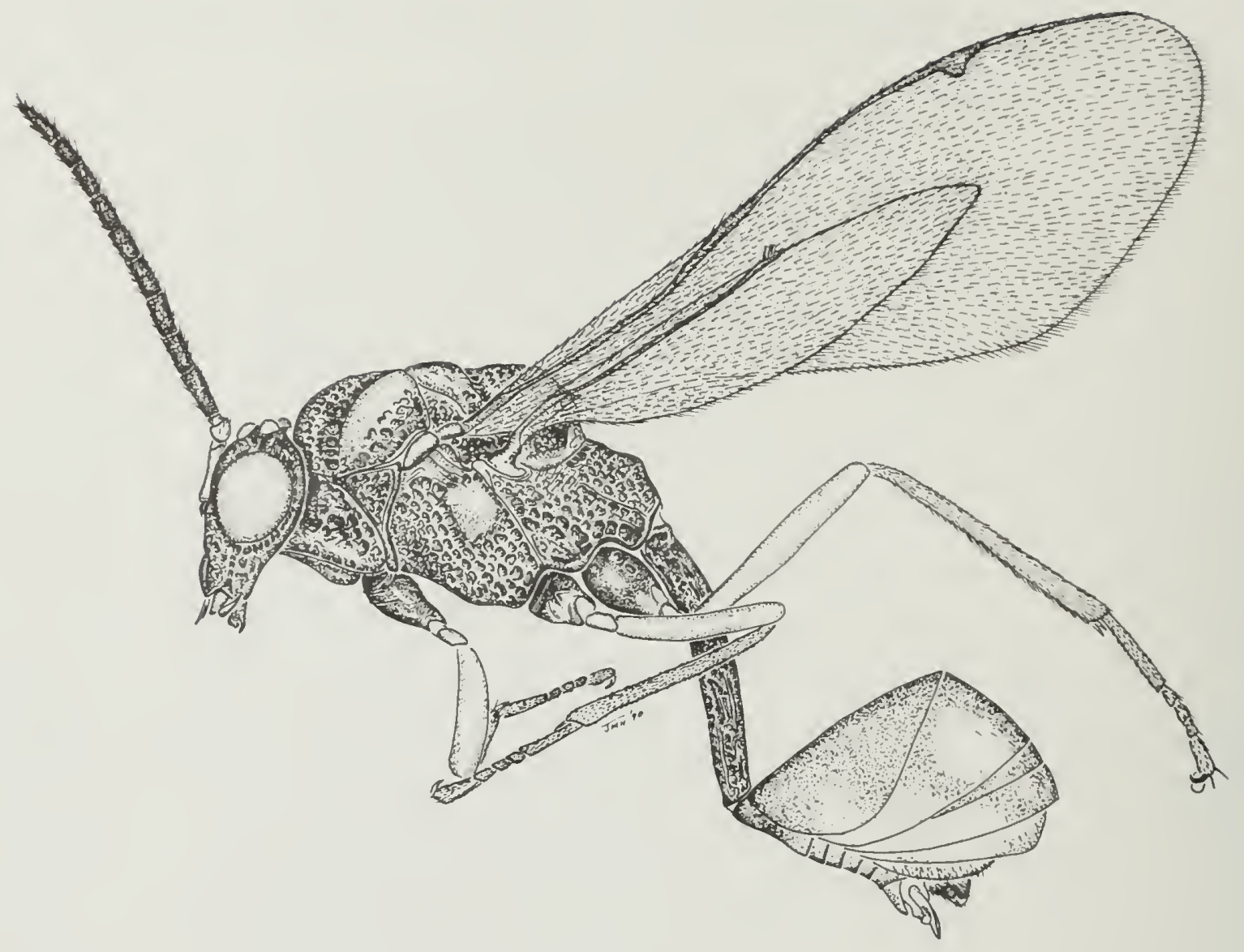

Habitus of Orasema bouceki, ô. 


\section{Classification and Evolution OF THE ORASEMINAE IN THE OLD WORLD, INCLUDING Revisions of Two Closely Related Genera OF EUCHARITINAE (HYMENOPTERA: EUCHARITIDAE)}

John Michael Heraty

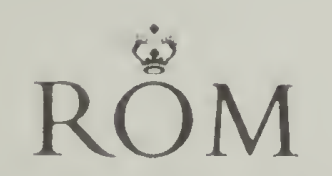

ROYALONTARIO MLSELM 
All rights reserved. No part of this publication may be reproduced, stored in a retrieval system or data base, or transmitted, in any form or by any means, electronic, mechanicall, photocopying. or otherwise. without the prior written consent of the publisher.

First published in 1994 by the Royal Ontario Museum, 100 Queen's Park, Toronto, Ontario M5S 2 C6.

Publication date: I November 1994

ISBN 0-88854-4I2-X

ISSN 0384-8159

\section{Canadian Cataloguing in Publication Data \\ Heraty, John Michael \\ Classification and evolution of the Oraseminae in the old world, including revisions of two closely related genera of Eucharitinae (Hymenoptera: Eucharitidae) \\ (Life sciences contributions; no. 157) \\ Includes bibliographical references. \\ ISBN 0-88854-412-X \\ 1. Eucharitidae - Classification. 2. Insects - Classification. I. Royal Ontario Museum. II. Title. \\ III. Series.}

QL568.E75H4 $1994 \quad 595.79 \quad$ C94-931709-8

\section{ROYAL ONTARIO MUSEUM PUBLICATIONS IN LIFE SCIENCES}

The Royal Ontario Museum publishes books on a variety of subjects in the life sciences, including Life Sciences Contributions, a numbered series of original scientific publications. All manuscripts considered for publication are subject to the scrutiny and editorial policies of the Life Sciences Editorial Board, and to independent refereeing by two or more persons, other than Museum staff, who are authorities in the particular field involved.

\section{LIFE SCIENCES EDITORIAL BOARD}

Senior Editor: K. A. Coates

Editor: D. H. Collins

Editor: R. D. James

External Editor: C. S. Churcher

\section{Manuscript Editor: K. A. Coates \\ Production Editor: Andrea Gallagher Ellis}

Dr. John Michael Heraty is currently a postdoctoral fellow at the Smithsonian Institution, Washington, D.C., and a research associate of the Royal Ontario Museum. Toronto. Correspondence should be addressed to the author \% Department of Entomology, University of California, Riverside, California, U.S.A. 9252]

The Royal Ontario Museum is an agency of the Ontario Ministry of Culture, Tourism and Recreation.

Printed and bound in Canada 


\section{Contents}



Biology and Immature Stages of Orasemorpha 24

Biology and Immature Stages of Orasema 24

Biology and Immature Stages of Neoloshamus 26

Biology and Immature Stages of Eucharitini 27

Host-Ant Relationships of Eucharitidae 28

Conclusions on Biology and Immature Stages 30

Revision of Oraseminae and Psilocharitini (Eucharitinae) 3 I

Key to Genera of Oraseminae and Psilocharitini 31

Revision of the Old World Oraseminae 32

Timioderus Waterston 32

Key to Species of Timioderus 33

T. peridentatus sp. nov. 34

T. refringens Waterston 35

T. acuminatus sp. nov. 36 
T. coromula sp. nov. 37

T. ramosus sp. nov. 37

Indosema Husain and Agarwal 38

I. indica Husain and Agarwal 39

Orasemorpha Bouček 40

Key to Species of Orasemorpha 42

O. xeniades (Walker) 43

O. myrmicae (Girault) 44

O. tridentata (Girault) 45

O. goethei (Girault) 46

O. pyttalus (Walker) 47

O. sparsepilosa sp. nov. 48

O. v'aridentata (Girault) 49

O. didentata (Girault) 50

O. eribotes (Walker) 51

Orasema Cameron 54

Key to Old World Species of Orasema 57

O. communis Risbec 59

O. seyrigi Risbec 61

O. uichancoi (Ishii) 62

O. ishii sp. nov. 64

O. bouceki sp. nov. 65

O. promecea sp. nov. 66

O.rugulosa sp. nov. 67

O. striatosoma sp. nov. 68

O. fraudulenta (Reichensperger) 70

O. koghisiana sp. nov. 71

O. glabra sp. nov. 72

O. assectator Kerrich 74

O. nigra sp. nov. 75

O. initiator Kerrich 76

O. synempora sp. nov. 77

O. valgins (Walker) 79

Revision of Psilocharitini (Eucharitinae) 81

Psilocharis gen. nov. 81

Key to Species of Psilocharis 83

$P$. aenigma sp. nov. 84

$P$. monilicera sp. nov. 85

$P$. pentella sp. nov. 85

$P$. pacifica sp. nov. 86

P. dahmsi sp. nov. 87 
$P$. joanmeae sp. nov. 88

P. theocles (Walker) 89

P. afra sp. nov. 90

P. hypena sp. nov. 91

Neolosbanus gen. nov. 93

Key to Species of Neolosbamus 96

N. gemma (Girault) 98

N. w'usheanus sp. nov. 99

N. apoanus sp. nov. 100

$N$. storeyi sp. nov. 101

N. watanabei sp. nov. 102

N. purpureoventris (Cameron) 103

N. townesi sp. nov. 104

N. laeviceps (Gahan) 105

N. tainanensis sp. nov. 106

N. pilosus sp. nov. 107

N. nepalensis sp. nov. 108

N. palgravei (Girault) 109

N. gressitti (Watanabe) 114

N. kokureanus sp. nov. 114

N. anapetus sp. nov. 115

N. violaceus sp. nov. 116

Summary 118

Acknowledgements 120

Literature Cited 121

Figures 127

Appendix 1: Character Matrix Used for Phylogenetic Analyses 173

Appendix 2: New Synonymies 174

Appendix 3: New Combinations 174

Appendix 4: Lectotypes Designated 174

Appendix 5: New Taxa Described 174 



\title{
Classification and Evolution of the Oraseminae in the Old World, Including Revisions of Two Closely Related Genera of Eucharitinae (Hymenoptera: Eucharitidae)
}

\begin{abstract}
The Oraseminae and Eucharitinae are hypothesized to form a monophyletic group in Eucharitidae (Hymenoptera: Chalcidoidea). These 2 subfamilies are redefined to incorporate new information from species found in the Old World. Phylogenetic methods were used to analyse morphological characters of adults and immature stages, and behavioural characters. The Oraseminae was determined to be a monophyletic group; however, character states used previously to define the group were found to be homoplastic and resulted in misclassification of some species. New characters derived from the ovipositor and immature stages are used to define the subfamily. Monophyly of the Eucharitinae is supported by adult and larval features. The limits of Eucharitinae are expanded to include 2 new genera with an independent prepectus that were formerly regarded as Oraseminae, and the subfamily is subdivided into 2 new tribes based on the presence of an independent prepectus (Psilocharitini) or a fused prepectus (Eucharitini).

Keys to genera and species, descriptions, and biogeographic information are provided for the 4 genera of Oraseminae and the 2 genera placed in the Psilocharitini. Descriptions of immature stages and behaviour are provided. Four genera (with type species in parentheses) included in the Oraseminae are Indosema Husain and Agarwal. I species (I. indica Husain and Agarwal); Orasema Cameron, 16 species in Old World (O. stramineipes Cameron); Orasemorpha Bouček, 9 species (Eucharomorpha viridis Girault); and Timioderus Waterston, 5 species (T. refringens Waterston). Two new genera of Eucharitinae are described: Neolosbamus, 16 species (Orasema palgravei Girault), and Psilocharis, 9 species (Orasema theocles Walker). Fifty-six species of Eucharitidae are treated, of which 33 are described as new. Timioderus includes 4 new species (type locality in parentheses): $T$. acuminatus (Cape Prov., South Africa), T. coromula (Grahamstown, South Africa), T. peridentatus (Mossel Bay, South Africa), and T. ramosus (Aliwal North. South Africa). One new species of Orasemorpha is described, O. sparsepilosa (Moree, Australia). Orasema includes 9 new species: O. bouceki (Kokoda, Papua New Guinea), O. glabra (Klaserie, South Africa), O. ishii (Tungpu, Taiwan), O. koghisiana (Koghis M(ns, New Caledonia), $O$. nigra (Royal Natal N. P.. South Africa), O. promecea (Baiyer Riv., Papua New Guinea), $O$. mrgulosa (New Britain. Papua New Guinea), O. synempora (Mi Webb. Australia), O. striatosoma (Kampala, Uganda). Psilocharis includes 8 new species: P. acnigma (Ambohitsitondrona, Madagascar), P. afra (Kalinzu Forest, Uganda), P. dahmsi (Swart Valley, Papua New Guinea), $P$. hypena (Tenompok, Sarawak, Malaysia), P. joanneae (Mt Webb N. P.. Australia), P. monilicera (Grahamstown, South Africa), P. pacifica (MI Dalaikoro, Fiji), and $P$. pentella (Aceh. Sumatra). Neoloshanus includes 11 new species: $N$. anapetus (Mayoyao, Philippines). N. apoanus (Mt Apo. Philippines), N. kokureanus (Kokure, Solomon Islands). N. nepalensis (Godavari, Nepal). N. pilosus (Fyan. Vie(nam). N. storeyi (Nondugl, Papua New Guinea), N. laiwanensis (Wufeng, Tailwan), N. townesi
\end{abstract}


(Kalssam Pass, Palpua Neu Guinea), N. riolacens (Baiyer Riv., Papua New Guinea), N watumabei (Malyoyao, Philippines), and N. wusheanus (Wushe. Taiwan).

The following new combinations are proposed: Orasemorpha myrmicae (Girault), Orasema frandulenta (Reichensperger); Psilocharis theocles (Walker), Neolosbanus gemma (Girault), Neolosbanus purpureoventris (Walker), Neoloshanus laeviceps (Gahan), Neolosbanus palgravei (Girault), Neolosbanus gressitti (Watanabe), and Stilbula ranomafanae (Risbec). Lectotypes are designated for 9 species.

The following new synonymies are proposed: Parasemora Gemignani = Orasema Cameron; Orasema viridicyanea Risbec = Timioderns refringens Waterston; Eucharomorpha wheeleri Brues = Orasemorpha tridentata (Girault); Encharomorpha dubia Girault, E. fuscipes Girault, E. partiglabra Girault, and E. viridis Girault = Orasemorpha eribotes (Walker); Psilogaster nishickai Ishii and Nagasawa, Losbanus petersoni Hedquist, and Orasema indica Snchalatha and Narendran = Neolosbanus palgravei (Girault).

A parsimony analysis of 36 taxa using 62 characters resulted in 20 trees of 183 steps. Only 16 of 45 genera of Eucharitinae were used in the analysis of relationships among genera with a free prepectus, but these represent the major lineages that have some known biological information. The phylogeny of Eucharitidae is correlated with ant hosts. Myrmicinae are postulated as the ancestral host of Oraseminae. and Ponerinae as the ancestral host for Eucharitinae. Correlations between ant-host subfamilies with the phylogeny for Eucharitidae suggest adaptation to new hosts through colonization rather than coevolution. Phylogenetic relationships among species of Oraseminae and basal Eucharitinae are used to analyse the historic biogeography.

\section{Introduction}

The Eucharitidae (Hymenoptera: Chalcidoidea), as based on the subfamilies Oraseminae and Eucharitinae (sensu Graham, 1969; Burks, 1979; Heraty, 1985), is a monophyletic group united by characters of adults, including a digitate labrum with digits arranged in the same plane (Darling, 1983a, 1988a), falcate or sickle-shaped mandibles (except in Timioderus Waterston), obliterated malar sulcus, and a pronotum that is ventral to the mesoscutum and not visible in dorsal view (Heraty, 1985, 1989). Monophyly of Eucharitidae is also supported by characters of first-instar larvae, which include reduction in number of dorsal setae and loss of spiracles (Heraty and Darling, 1984).

The Oraseminae and Eucharitinae are parasites of ants (Heraty and Darling, 1984: Darling, 1988a; Heraty, 1985). Three additional subfamilies, Akapalinae, Echthrodapinae, and Philomidinae, were recognized and included in the Eucharitidae by Bouček $(1978,1988)$. None of these subfamilies is known to be a parasite of ants, and the close relationships between them and the other eucharitine subfamilies have been questioned (Darling, 1988a, 1992; Heraty, 1990). Before these subfamilial relationships can be assessed, it is necessary to understand the bounds and relationships of the Oraseminae and Eucharitinae (Eucharitidae s.s.). In treat- ing the Oraseminae of the Old World tropics, it became apparent that existing definitions of both subfamilies were not adequate and needed to be reevaluated.

The Eucharitidae is by far the largest and most diverse group of hymenopteran parasitoids that attack eusocial insects. Forty-seven genera and 394 species of Eucharitidae are known from every zoogeographical region of the world. Eucharitids are notably absent from New Zealand and a few of the smaller oceanic islands, and are relatively poorly represented throughout the Palaearctic region. The family is most abundant in numbers both of individuals and of species in tropical regions (Heraty, 1985). No genera are shared between the Nearctic and Palacarctic regions and only a few New World genera (Orasena Cameron, Kapala Fabricius, and Pseudochalcura Ashmead) have species in the Old World tropics also (Heraty, 1985, 1986).

Species of Eucharitidae s.s. attack a wide range of ant hosts, and recent taxonomic changes in the group (cf. Bouček, 1988) indicate a general congruence between ant hosts and eucharitid genera. Adult females deposit their eggs away from the host in plant tissue using a wide variety of methods (Clausen, 1940a, 1940b, 1940c, 1941). The first-instar larva is the active stage that is responsible for gaining access to the ant host. 
Brief taxonomic reviews of the Eucharitidae are presented in Heraty (1985) and Bouček (1988). Walker (1862) first recognized the family and proposed the name Eucharidae. It was divided into 2 subfamilies when Kirby (1886) erected a second subfamily Eucharissinae for what are now recognized as derived members of the Eucharitinae (Bouček, 1988). Bouček (1978) suggested inclusion of the Philomidinae within the Eucharitidae, and Burks (1979) erected the subfamily Oraseminae to include the single genus Orasema Cameron. Oraseminae was later defined by Heraty (1985) and Bouček (1988). Bouček (1988) recognized 5 subfamilies of Eucharitidae: Philomidinae, Echthrodapinae, Akapalinae, Oraseminae, and Eucharitinae. The Echthrodapinae and Akapalinae were described as new subfamilies to encompass 2 genera (Bouček, 1988). The Echthrodapinae and Philomidinae are parasitoids of stem- or ground-nesting bees, respectively (Michener, 1969; Bouček, 1988; Darling, 1992). Based on morphology of immature stages, Philomidinae have been placed as sister group to the Perilampidae + Eucharitidae, although this relationship is not supported by adult characters (Darling 1988a, 1992). The biology of Akapalinae is unknown. Only Oraseminae and Eucharitinae are known to be parasites of ants.

Oraseminae has been defined by several symplesiomorphic character states which include a freely articulating prepectus, antenna with an annular basal flagellomere or ring segment (Bouček, 1988; Heraty, 1985), and the first phragma ventrally inflected behind the pronotum (Heraty, 1989). Morphology of the immature stages is known in detail only for members of Orasema Cameron, which show alternate states to the Eucharitinae. These states include separation of tergites I and 1I, lack of a complete tergopleural line, and presence of cranial setae (Heraty and Darling, 1984; Johnson et al., 1986). The Oraseminae was regarded as a monophyletic group based solely on possession of a subapically expanded and strongly ridged ovipositor. The absence of an expanded ovipositor from some of the species included by Bouček (1988) within Orascma prompted this study of Old World Eucharitidae.

According to Steyskal (1980), the correct subfamily name should be Orasematinae and all species of Orasema should have neuter endings to conform to the Latin stem of sema. Cameron often created euphonic words for genera without regard to their classical origin (Bouček, pers. comm., 1991). Translation of the Greek ora- (sign, token, or mark) and the Latin -sema (edge or region) does not refer to any peculiar attribute of this genus, and Dalla Torre (1898) referred to the name Orasema as "Entomol. obscura," supporting the lack of any intentional meaning by Cameron. Of 7 gemeric names of Eucharitidac proposed by Cameron. none can be translated to mean any feallure of the respective genera. Thus, Orasema should be treated as an arbitrary combination of letters. The type species, Orasema stramineipes Cameron, does not have a gender-specific ending and does not imply Cameron's intentions. If no gender was attributed or implied by the author, and if the ending is clearly a natural Latin feminine (as in - ma), then that gender is appropriate to the ending (Article 30d; ICZN, 1985). By treating Orasema as being of feminine gender, no changes are required for previously described species, and the usage of Oraseminae is maintained.

Heraty (1985) recognized 4 genera in Oraseminae: Orasema Cameron, Losbanus Ishii, Psilogastrellus Ghesquière (in part), and Parasemora Gemignani. Several species belonging to distantly related genera of Eucharitidae were incorrectly placed in the genus Psilogastrellus (= Psilogaster Blanchard, 1840), which is based on the type species Psilogaster cupreus Blanchard (Bouček, 1988). Psilogastrellus fraudulentus Reichensperger and the genera Parasemora and Losbamis are here placed in Orasema, and species previously placed in Losbamus are herein transferred to 3 different genera. The Oraseminae as recognized here and by Bouček (1988) consists of 4 genera: Indosema Husain and Agarwal (1 species), Orasema (16 Old World species, 80-100 New World species), Orasemorpha (9 species), and Timioderus (5 species).

Orasema is the most speciose genus of Oraseminae and is the only circumtropical genus. Forty-two species are described, of which 37 occur in the New World (Table 1). Orasema was revised by Gahan (1940), who based his study on fewer than 300 specimens. I can segregate the New World species into at least 6 different species groups, and the Old World species described herein cannot be directly placed within any of these groups. However, the range in morphology among Old World species is equivalent to that among the most dissimilar species groups of the New World. Considerable biological information is available for species of Orasema from around the world and indicates very conservative morphology and habits of immature stages. Putative synapomorphies for Oraseminae based on the behaviour of largely New World Orasema include internal parasitism during the first instar, use of a thysanopteran or homopteran intermediate host to gain access to the ant host, and parasitism of Myrmicinac (Formicidac).

Monophyly of the subfamily Eucharitinae was supported previously by the anterior fusion of the prepectus to the pronotum and complete internal enclosure of the mesothoracic spiracle, the loss of the antennal ring segment, and the formation of the first phragma as a strong anterior internal ridge above the dorsal margin of the pronotum (Graham. 1969; Rick. 1970): Heraty. 1985. 1989; Boučck. 1988). Boučck (1988) extended Eucharitinac to include Anorasema Boučck and 
Orasema Cameron, 1884:105

"e'l'u Gahain, 1940:443

argemina Gemignani, 1933:489

ancerviridis Gahan, 1940:448

bukeri Gahan, 1940:452

bedmeri Gahan, 1940:447

biasiliensis Brethes, 1927:331

cameromi Howard. 1896:133

cockerelli Gahan, 1940:453

coloradensis Wheeler, 1907:12

costaricensis Wheeler and Wheeler, 1937:164

delicanlla (Walker), 1862:377

delue Gemignani, 1937:161

festiva Fabricius, 1804:157

fierchei (Gemignani), 1933:192

gemignanii DeSantis, 1968:8

(maculata Westwood) [= Obeza. Heraty 1985]

mimura Ashmead, 1888:188

minutissima Howard, 1897:84

neomericana Gahan. 1940:450

occidentalis Ashmead, 1892:355

pireta Heraty, 1993:171

rapo (Walker), 1839:66

robertsoni Gahan, 1940:451

salebrosa Heraty, 1993:17]

simplex Heraty, 1993:171

simulatrix Gahan, 1940:450

sixaolae Wheeler and Wheeler, 1937:163

smithi Howard, 1896:134

stramineipes Cameron, 1884:105

susanae Gemignani, 1947:6

terana Gahan, 1940:440

tolteca Mann. 1914:183

vianai Gemignani. 1937:162

violacea Ashmead, 1888:187

(violacea) Gemignani, 1947:8 [= O. gemignanii DeSantis] ivirdis Ashmead, 1895:553

whecleri Wheeler, 1907:14

norcesteri (Girault), 1913a:62

xamthopus (Cameron), 1909:433
Neotropical

Neotropical

Nearctic

Nearctic

Nearctic

Neotropical

Neotropical

Nearctic

Nearctic

Neotropical

Neotropical

Neotropical

Neotropical

Neotropical

Neotropical

Nearctic

Neotropical

Nearctic

Nearctic

Neotropical

Neotropical

Nearctic

Neotropical

Neotropical

Nearctic

Neotropical

Neotropical

Neotropical

Neotropical

Nearctic

Nearctic

Neotropical

Nearctic

Nearctic

Nearctic

Neotropical

Neotropical
Missiones, Argentina

Las Flores, Argentina

Uvalde, Texas, U.S.A.

Fort Collins, Colorado, U.S.A.

Ridgeway, Colorado, U.S.A

Sao Paulo, Brazil

Grenada, West Indies

Albuquerque. New Mexico, U.S.A.

Colorado, U.S.A.

Zent, Costa Rica

Australia (?) [error]

Tigre, Argentina

Central America

Puerto San Blas. Argentina

Isla Martin Garcia. Argentina

Florida, U.S.A

St. Vincent. West Indies

Organ Mtns. New Mexico, U.S.A.

Los Angeles, California. U.S.A.

Paraguay

Brazil

South Florida, U.S.A.

Argentina

Argentina

Oracle. Arizona, U.S.A.

Limon Prov., Costa Rica

Grenada, West Indies

Bugaba, Panama

Prov. Mendoza, Argentina

Denison, Texas, U.S.A.

San Miguel, Mexico

Cruz Colorada, Argentina

East Florida, U.S.A

Tepic, Mexico

Austin, Texas

Paraguay

Argentina 
Gollumiella Hedqvist, which both have a fused prepectus but have a distinct anelliform first flagellomere and the first phragma inflected behind the pronotum (Heraty, 1992). The subfamily Eucharitinae is here redefined to encompass 2 new genera that have an unfused prepectus: Neolosbamus gen. nov. (16 species), and Psilocharis gen. nov. (9 species).

In this paper. four aspects of the systematics of Oraseminae and Eucharitinae are treated: (1) a phylogenetic hypothesis is presented for the Oraseminae,
Psilocharitini, and Eucharitini (for genera with known host or larval information); (2) the biology of Oraseminae and Eucharitinae is reviewed, and new information is presented on the biology and morphology of immature stages for Orasema and Neolosbanus; (3) revisionary studies are presented for 6 genera that belong to the Oraseminae and Psilocharitini: and (4) the biogeography of the Oraseminae and Psilocharitini is presented and based, where possible, on the phylogenetic hypotheses.

\section{Materials and Methods}

Specimens of Eucharitidae were examined from over 90 museums in North and South America. Europe, Japan, Australia, and Taiwan. More than 7000 specimens belonging to the Oraseminae were accumulated, with the majority of this material represented by New World specimens. The large amount of material examined has allowed for a relatively thorough treatment of the world species, which has been useful for defining generic and geographical boundaries of taxa.

Museum acronyms are based largely on the system offered by Arnett and Samuelson (1986) with some deviations after Heppner and Lamas (1982). Material referred to in the text was borrowed from the following institutions: American Entomological Institute. (AEI). Gainesville, United States (H. Townes): American Museum of Natural History (AMNH), New York, United States (M. Favreau); Aligarh Muslim University (AMUA), Aligarh, India (S. Faroogi, no loan); Australian National Insect Collection (ANIC), Canberra, Australia (1. Naumann); British Museum (Natural History) $(\mathrm{BMNH})$, London, England (J. Noyes and Z. Bouček); Bernice P. Bishop Museum (BPBM), Honolulu, United States (G. Nishida); California Academy of Sciences (CAS). San Francisco, United States (W. Pulawski); Canadian National Collection (CNC). Agriculture Canada, Otlawa, Canada (G. Gibson and C. Yoshimoto); Entomological Institute, Faculty of Agriculture. Hokkaido University (EIHU), Sapporo, Japan (S. Takagi); Indian Agricultural Rescarch Institute (IARI), New Delhi. India (S. 1. Farooqui): Illinois Natural History Survey (INHS). Champaign. United States (W. LaBerge): Personal Collection of John M. Heraty (JMH): Entomological Lahoratory. Faculty of Agriculture, Kyushu University (KUEC), Fukuoka, Japan (Y. Hirashima); Muscum of Comparative Zoology (MCZ), Cimbriclge, United States (S. Shaw); Muscum National d'Histoire Naturelle (MNHP). Paris, France (J. Rasplus); Museum of Victoria
(MUV), Victoria, Australia (K. Walker); Museum Zoologicum Bogoriense (MZB), Bogor, Indonesia (M. Amir): National Institute of Agro-environmental Sciences (NIAS), Ibaraki, Japan (K. Konishi); Queensland Museum (QMB), Brisbane, Australia (E. C. Dahms); Royal Ontario Museum (ROM). Toronto, Canada (D. C. Darling); South Australian Museum (SAMA). Adclaide, Australia (E. Matthews): South African Museum (SAMC), Capetown. South Africa (H. Robertson); Texas A \& M University (TAMU), College Station. United States (H. R. Burke); Taiwan Agricultural Research Institute (TARI), Taichung, Taiwan (L.-Y. Chou); University of Queensland (UQIC), St. Lucia, Australia (M. Schneider); National Museum of Natural History, Smithsonian Institution (USNM), Washington. D.C.. United States (E. E. Grissell); West Australian Museum (WAM). Perth, Australia (T. Houston); Zoologisches Forschunginstitut und Muscum "Alexander Koenig" (ZFMK), Bonn, Germany (H. Roer): Zoologisches Museum. Humboldı-Universität (ZMHB), Berlin. Germany (F. Koch); Zoologisk Museum, Universitets Zoologiske Museum (ZMUC). Copenhagen, Denmark (B. Peterson).

\section{DESCRIPTIVE FORMAT}

Each description is based on the total number of specimens examined. Mensural character states. where possible, are based on a representative sample of 10 females and 10 males over the geographical range of the species. except for total length of the body, which is based on all of the examined specimens. Descriptions of the opposite sex are based only on character states and measurements that deviate or exeed ranges presented in the description. which is usually based on females. 


\section{TERMS}

Terms follow Heraty (1985) for external characters and detanls of kength measures, and Heraty (1989) for internal morphology of the mesosoma. Terms lor immature stages follow Heraty and Darling (1984) and Heraty and Barber (199(0). Some modilications of terms for structures are adopted from Bouceh (1988), and Gibson (1989), which are discussed in the following section on descriptive morphology. There have been several works in the past few years dealing with morphological terms and attributes of Chalcidoidea (Schaulf, 1984: Heraty, 1985, 1986, 1989; Gibson. 1985. 1986. 1989; LaSalle, 1987; Woolley, 1988; Boučeh, 1988: Huber, 1988). In particular, Gibson (1986). Huber (1988), and Bouček (1988) provide indepth discussions of characters and previously used terms in an iltempt to standardize terms for use in descriptive analysis. Unfortunately, there are still differences of opinion, even with respect to major terms such as the use of mesosoma or thorax. One hopes for the emergence of a standard nomenclature for the field that will minimize future discussions of morphology. Reference to certain abbreviations and length measures are summarized in Figures $6,27,31-32,43,48,63,198,211$, and 217-219.

\section{Measurements and Abbreviations}

The following abbreviations are used in the text: Fl-Fll, antennal flagellomeres following pedicel and including the anellus; MPS, multiporous plate sensilla; LOL, lateral ocellar line-minimum distance between lateral (posterior) ocelli; OOL, ocellar-ocular line-minimum distance between lateral ocellus and dorsal margin of eye; SSS (Fig. 63), scutoscutellar sulcus; TSA (Fig. 63), transscutal articulation. Head height was measured from the top of the median ocellus to the apex of the clypeus. Interocular distance is the minimum separation of the eyes at their inner dorsal margin. Length of the malar space (MS) is the minimum distance between the ventral margin of the eye and the lateral margin of the oral fossa (Fig. 32a). Forewing length was measured from the apex of the humeral plate to the wing apex. Width of the forewing was measured as the maximum width perpendicular to the forewing margin at the stigmal vein. Mesosomal width was measured across the mesoscutum at the transscutal articulation and does not include the lateral flange of the mesoscutum just anterior to the tegula. Mesothoracic length is measured from the anterior margin of the mesoscutum to the posterior ventral margin of the frenum.

\section{Setation}

The term microtrichia is reserved for setae that are barely visible using light microscopy at high magnification (75x), whereas hair is used for a long, narrow, and observably flexible seta. The term pilose refers to dense, shorter setae as found on the disc of the forewing. Setae maly be adpressed (decumbent), subdecumbent, semierect, or erect (Bouček, 1988).

\section{Sculpture}

Sculpture has a wide range of interpretation within the literature on Hymenoptera. This makes it difficult to express similar features across groups (Gibson. 1989). Recent attempts have been made to standardize sculpture terminology in Hymenoptera (Eady, 1968; Harris, 1979), and more specifically in Chalcidoidea (LaSalle, 1987: Bouček, 1988: Gibson, 1989). LaSalle (1987) and Harris (1979) presented excellent scanning electron microscope (SEM) photographs of various sculpture types; however. until a general atlas of microsculpture is available for Chalcidoidea, it will be difficult to define accurately various patterns of sculpture (Bouček, 1988).

The most commonly used terms in this work are as follows: aciculate (ac, Fig. 223): finely striate as if scratched by needle; alveolate: having a regular network of broad depressions with slightly rounded, narrow septa; areolate (ar, Fig. 240): having an irregular network of broad depressions with sightly rounded narrow septa; carinate: having one or more raised, longitudinal ridges; coriaceous (Fig. 33): leatherlike with minute septa; crenulate (cr, Fig. 256): scalloped and evenly rounded with sharp dividing septa: foveate (fo, Fig. 232): having deep, regular depressions or pits with irregular dividing septa (finer sculpture is foveolate); glabrate (gl, Fig. 189): smooth or nearly so, shiny and almost devoid of all sculpture, allows for isolated and minute sculpture and/or scattered fine setae: glabrous (gs. Fig. 197): completely smooth and polished and devoid of any hairs or setae; granulate: minutely verrucose and appearing like sandpaper even under high magnification: imbricate (im. Fig. 222): having overlapping sculpture like shingles or scales of fish; piliferous punctate (pp, Fig. 208): having circular to oval indentations with broad interstices, each depression associated with small seta; reticulate (re. Fig. 191): having a fine, regular network of raised septa (minute alveolate); ribbed: having longitudinal, parallel, and strongly raised ridges; rugose (ru, Fig. 187): having rough, raised sculpture with smooth septa and no regular patterns evident, dividing septa may be prominent (strongly rugose) or hardly raised above surface (weakly rugose) (finer sculpture is rugulose); scabrous: having rough, sharp-walled septa in irregular pattern, septa often raised in one direction and rasplike (finer sculpture is scabriculous); strigate: having fine. longitudinal raised lines; lerrucose: covered with fine, irregularly shaped spots which could be lobes or wartlike protuberances or small circular depressions (hard to tell).

Mixed sculpture types have 2 descriptors linked by a hyphen, with the dominant sculpture type first. Specific terms used in descriptions can be correlated with the illus- 
trations provided. Relative terms such as weak, fine, prominent, or strong are used within descriptions to refer to carinae, separating walls of areolae, or other sculpture types. Definitions of this type are for comparative purposes only and are avoided whenever possible as distinguishing features in key couplets. Fine is usually used in reference to weak carinae or to areolae that are closely set with narrow interstices.

\section{Colour}

The use of colour in delimiting taxa can have severe drawbacks due to the effects of different preservation techniques and specimen age on the nature of the colour (Huber, 1988). There can be marked differences in colour of specimens depending on whether they are air-dried or critical-point dried. Colour change caused by long-term alcohol storage can be slowed considerably by storage at low temperatures (Huber, 1988). Although quality of colour (hue or intensity) can change with time, the pattern and base colour remain largely unchanged and can be useful descriptive tools. This is particularly evident in colour patterns of the scape, coxae, femur, and hind tibia. The head and mesosoma range from black to a strong metallic lustre of green, blue, or violet, and sometimes have iridescent reflections (combinations of colours).

\section{Head}

Bouček (1988) provided an extensive description of the structural features of the chalcidoid head. Some features peculiar to Eucharitidae are listed below. In some taxa, a narrow transverse depression on the vertex extends from the lateral ocellus to the dorsal margin of the eye, here termed the ocellar-ocular groove (OCG, Fig. 92). The malar space may be spanned by a narrow depression termed the malar depression (MD, Figs. 95, 223). This depression is not associated with a fine groove or line as in other Chalcidoidea and is often poorly defined when present. The dorsal margin of the occiput is often carinate. Homology of this carina with a similar carina of Torymidac is uncertain but the term applied is the same (occipital carina). The clypeus is margined dorsally by the epistomal sulcus, and laterally by the clypeogenal suture (E. C, Fig. 205; Richards, 1977). The apical margin of the clypeus (CLY) has a distinct glabrous flange or ventral projection called the anteclypeus (A, Fig. 190) after Snodgrass (1935) and Habu (1960). The region dorsal to the clypeus is often swollen and may be bordered laterally hy the frontogenal sulcus (F. Fig. 205: Richards. 1977; Matsuda, 1980). The labrum is usually flattened and digitate with an elongate seta at the apex of each digit (Figs. 187-205; Darling. 1988a). The gena extends behind the mandible to the hypostomal carina. Medial to the hypostomal carina, the hypostoma may project as a small lobe behind each mandible (cf. Richards, 1977). The projec- tions of the hypostoma are not considered homologous with the postgenal extensions found in the Eucharitinae (Heraty, 1985, 1986). Mandibular dentition is presented as number of teeth on the specimen's right and left mandible. respectively: for example. $3 / 2$ dentate means right mandible with 3 teeth and left mandible with 2 teeth.

\section{Antennae}

The antennae of Oraseminae and Psilocharitini are almost all strongly geniculate with an elongate scape and a welldefined pedicel. Antennal segments (or flagellomeres) are numbered Fl-Fl1, including the basal anellus or ring segment as Fl. The first segment (F1) is either anelliform or absent from all members of the Oraseminae; if present it can be recognized by its absence of multiporous plate sensilla (Bouček, 1988: Gibson, 1989). Funicular segments are between the anellus (FI) and clava, and in some taxa may include F2 to F10. The terminal clava may be comprised of 1 to 3 fused segments (F9-FII). In most cases individual segments of the clava cannot be identified: if apparent they are not counted individually in the total of antennal segments (clava counts as 1 segment). The term clava or club is somewhat erroneous within the Eucharitidae as it is often not distinguished from the preceding segments. Fused segments of the clava can usually be viewed with transmitted light, and II segments can be distinguished in most species of Orascminae. Becausc of variability in the degree of fusion of segments in the clava, counts of funicular segments are more reliable in the determination of reductions in antennal segments.

\section{Mesosoma}

Terms for the mesosoma follow Heraty $(1985,1989)$ and Gibson (1986). Mesosoma refers to the combined thorax and first abdominal segment found in the Apocrita. The term lateral lobe (Fig. 63) refers to the mesoscutal lateral lobe (Gibson, 1986. Heraty, 1989), side lobe (Heraty, 1985), or scapulae (Bouček. 1988). Axilla refers only to the dorsal axillar surface (Fig. 63: Gibson, 1986: Heraty, 1989). Scutellum refers only to the dorsal area defined by the scutoscutellar sulcus anteriorly. frenal line posteriorly. and axillular sulci laterally or maximum dorsal width if the axillar sulci are absent (Fig. 63). The posterior region of the scutellum may be separated by a frenal line to form a frenal area. Descriptions of the frenal line refer only to the dorsal aspect (Fig. 63). The central region of the propodeum delimited by the postspiracular sulci laterally is termed the propordeal disc (Heraty, 1985). The supracoxal flange is a sharp ridge that extends between the postspiracular sulcus and the propodeal foramen above the hind coxal (Boučet, 1988). The callus is a usually swollen area between the postspiracular suleus and the metepimeron and may have a distinct patch of elongate hairs: a small pointed "nit" is found on the dorsal medial 
apect of the callus ol some taxil (CN, Fig. 224). The nib is dilficult to observe and the ciallus must be viewed at an shlopue angle to highliglut the protuberance. The mesopleuron is divided posteriorly into an upper and lower mescepimeron separated by a ransepimeral sulcus (Gibson. 19s(3). The anterior region of the mesopleuron is the menepisernum. A wedge-shaped sternaular area marhed by areolate-rugose or foveate sculpeure is often found anterior and ventral to the lemoral groove (SA. Fig. 224). This is not considered homologous to the sternaulus of Ichneumonoidea, even though it is in a similar locaton. The pronotum is usually irregularly sculptured laterally with a broadly impressed median longitudinal sulcus. here !emed the pronotal sulcus (Fig. 219).

\section{Wings}

Termis follow Bouček (1988) for nomenclature and vein delinitions (Fig. 43). The speculum (SP) is recognized as a bare area just posterior to the parastigmal vein and base of the marginal vein (Fig. 122). Absence of the speculum refers to an even pilosity of this region. Because the apex of the postmarginal vein is difficult to resolve, measures of length are prone to error: therefore, only large differences in length were considered as diagnostic.

\section{Metasoma}

The metasoma of Eucharitidae consists of a distinct petiolc, comprised of the first metasomal tergite, and the gaster (Bouček. 1988; Gibson, 1989). The petiole is well developed in most genera and is fused ventrally in all except females of Timioderus Waterston. Numbering of gastral tergites follows Gibson (1989): $\mathrm{Mt}_{2}$ to $\mathrm{Mt}_{7} ; \mathrm{Mt}_{8}$ and $\mathrm{Mt}_{9}$ are fused into a syntergum. The first metasomal sternite is absent (see discussion of $\mathrm{Ms}_{2}$ in Phylogenetic Analysis). The second metasomal (= first gastral) sternite $\left(\mathrm{Ms}_{2}\right)$ is constricted at the base in some taxa by a transverse sulcus which is often crenulate and deeply impressed (Fig. 256). Five gastral sternites are present in females, designated $\mathrm{Ms}_{2}$ to $\mathrm{Ms}_{6}$, with the last sternite termed the hypopygium. Males have 7 gastral sternites designated $\mathrm{Ms}_{2}$ to $\mathrm{Ms}_{8}$.

Terms of lemale genitalia follows Bouček (1988). The ovipositor stylets are formed by the paired first valvulae and fused second valvulate (Fig. 31). The ovipositor sheaths are usually elongate and subtriangular and the apical gonostylus may be separated from the basal second valvifer by an oblique suture (Figs. 51, 257). In many orasemine taxa, the first and second valvulac are expanded and strongly ridged for piercing plant tissue. Notable features of the first valvulae are the ventral subapical ridge (observed in prolile), and the longitudinal ridge of fine teeth that occurs laterally between the apex and subapical ridge (SAR, LT, Figs. 31, 262). The apex of the second valvula may have several strong transverse ridges, or lateral teeth and a smooth median dorsal area. The ovipositor in some taxa may be strongly curved forward but dorsal and ventral aspects are used as if the ovipositor is straight (i.e., second valvula is always dorsal).

Genitalia of males are generally not useful for identilication at the species level although some taxa show specialized features. Terms follow Heraty (1985, 1986: Fig. 103). Genitalia are referred to as being "typical" il the genitalic capsule is narrow, a small median process is present, the parameres are narrow and moderately elongate (length is about $0.6 \times$ width of basiparameres), the digitus is flat and disclike with 3 to 5 marginal teeth (strong conical structures in marginal sockets), and the aedeagus is subovate apically (Fig. 274).

\section{Sexual Dimorphism}

Sexes are readily distinguishable based on the relative length of the petiole, the shape of the gaster, sometimes the number of antennal segments, and the presence or absence of an ovipositor or genitalia that usually are visible externally. More subtle differences can also be observed. Males are usually less robust than females: the mesosoma is slightly smaller in proportion to body size, sculpture may be more prominent, coloration is darker, and metallic reflections, if present. tend to be more extensive.

\section{BIOGEOGRAPHIC REGIONS}

The 4 major geographical distributions of Oraseminae and Psilocharitini within the Old World tropics are based on the presence of unique endemic species or genera: Ethiopian, Malagasy, Indo-Pacific, and Australian (Fig. 282). These regions are derived from a composite of distributions for Oraseminae and Eucharitinae (Figs. 275-280).

The Indo-Australasian region is composed of a fragmented complex of islands that make it difficult to assign areas of endemism for the purpose of this study. Two major regions were recognized from southeast Asia: the Australian region (Australia excluding north Queensland), and the Indo-Pacific region (excluding Australia except for north Queensland). The 2 regions are apparent because of several disjunct distributions of species and genera of Oraseminae and Psilocharitini. The Indo-Pacific region can be further divided into a number of subregions as proposed by Gressitt (1956) and adopted by Schuh and Stonedahl (1986): Indo-Chinese subregion (mainland Asia from eastern India to Taiwan and including the Okinawa lslands, and Japan), Malayan subregion (Vietnam, southern Thailand, Cambodia, Malaysia. Borneo, Sumatra, and Java), Philippine subregion (Philippine lslands), Sulawesi subregion (Sulawesi, Timor), Papuan subregion (eastern Indonesia, Papua New Guinea, Caroline Islands, Solomon Islands, and north 
Queensland, Australia), and Polynesian subregion (Pacific islands east of the above regions). Extension of the Indo-Pacific region to include New Guinea. Cape York, and the Polynesian islands recognizes a general similarity in both insect and plant distribution (Gressitt. 1956, 1982; Schuh and Stonedahl, 1986). For purposes of this study, the Indo-Chinese subregion is shifted slightly west to accommodate the Indian record of Indosema, and north to include the Japanese islands of Honshu, Kyushu, and Tsushima, which are on the marginal distribution of
Schuh and Stonedahl's (1956) Indo-Pacific subregion. Also, the Malayan subregion is here divided into east and west to recognize the distinct fauna of Borneo (east Malayan).

The Ethiopian region was not subdivided. No species of Oraseminae or Psilocharitini were shared between Africa and Madagascar, and except for a single record from Cameroon, all of the Ethiopian taxa are located in southern and eastern Africa (Figs. 275-277).

\section{Phylogenetic Analysis}

There has been an increasing number of attempts to understand the higher classification of Chalcidoidea based on analyses of apomorphic character states (see Heraty and Darling, 1984; Gibson, 1986; Darling, 1988a, 1992; Schauff, 1984, 1991; Woolley, 1988). Within the Eucharitidae, recent attempts were made to understand classification above the generic level by means of an analysis of the larval characters of Philomidinae (Darling, 1992), Perilampidae (sensu Bouček, 1988), and Eucharitidae (Heraty and Darling, 1984). However, a phylogenetic treatment of Eucharitidae has been hampered by the need for a thorough treatment of taxa in the Old World, including the description of several new taxa. In Bouček's (1988) work on the Australasian Chalcidoidea, most of the nomenclatural problems were solved. Several species were reclassified in different and/or new taxa, which made the relationships of certain groups clear. Summaries of host relationships for Eucharitidae published prior to Bouček's reorganization show very little congruence of genera with host taxa (Wheeler and Wheeler, 1937; Clausen, 1940c; Johnson, 1988). The revised classification has greatly increased the correlation of genera of Eucharitidae with the subfamilies and genera of host Formicidae.

The Oraseminae was originally erected to encompass only the genus Orasema (Burks, 1979). Heraty (1985) and Bouček (1988) defined the subfamily based on presence of a free prepectus, presence of an anellus, constriction of the first gastral sternite, and presence of an expanded ovipositor. The first 2 character states are plesiomorphic within Chalcidoidea and are of no value in elucidating relationships (Gibson, 1986). The last 2 character states were considered as unique within the Chalcidoidea and were thought to be synapomorphies supporting a monophyletic Oraseminae. However, Darling (pers. comm., 1988) observed a similar constriction in Perilampiclac, including Chrysolampinac, and the state is now interpreted as plesiomorphic. Examination of
Old World Oraseminae revealed that an expanded ovipositor is not present in all Oraseminae, as defined above. Thus, there appeared to be no defining features for the subfamily.

A study was therefore made of the distribution of character states within the Oraseminae s.l. (Eucharitidae with unfused prepectus). Under any hypothesis, the phylogenetic relationships of the Oraseminae cannot be tested without comparison to the more derived Eucharitinae, especially when the monophyly of the Oraseminae s.l. is questionable. Genera of Eucharitinae with known biologies were therefore included in the analysis. Only 16 of the 45 known genera of Eucharitinae (sensu Bouček. 1988) were treated. However, these genera represent a diverse sampling of taxa within the Eucharitinae and are what I believe to be indicative of the major groups.

The outgroup taxa chosen for the Eucharitidae were Chrysolampinae and Perilampinae, which together have been regarded as the sister group of the Eucharitidae (Bouček, 1956: Graham, 1969: Heraty and Darling, 1984). Bouček (1988) questioned this relationship and alluded to the possibility of a more distant relationship of these families within the pteromaloid lineage. ln any case, the monophyly of Chrysolampinae + Perilampinae (exclusive of the Eucharitidac) has not yet been resolved and various classifications place the Chrysolampinae in either the Pteromalidac (Riek, 1970; Burks, 1979) or Perilampidac (Graham, 1969; Bouček, 1988; Darling and Miller, 1991). In the most recent classification. Boučck (1988) placed Chrysolampinac within Perilampidac. That classification is adopted here even though larval characters suggest that Chrysolampinae is the sister group to Eucharitidac + Perilampidae (Heraty and Darling. 1984: Darling. 1992). Character states of the adult that support Chrysolampinac + Perilampinac include the presence of external pores on the ventral surface of the male scape and fusion of the first 2 gastral tergites dorsally. However, both states of the last character occur within 
Chrşol:mupmate. Resolution of this contlice in outgroup classiticatton $1 \mathrm{a}$ as not an objective of this analysis. The polarily of characker states was evaluated against both the Pleromalinate (Peromalidate). which are regarded as the general outgroup for the Eucharitidae and Perilampidae (Graluam, 1969: Heraly and Darling, 1984: Bouček, (4) 8 ), and a survey of other lamilies of Chalcidoidea. Mos of the polarity decisions were straightforward and plesiomorphic states were assumed to be those representative of a generalized pteromalid. The use of any of the 3 other subfamilies included by Bouček (1988) in Eucharitidac would not affect the polarity of most characters.

Nineteen characters were evaluated in a previous study of phylogenetic relationships between the Eucharitidae. Perilampinae, and Chrysolampinae (Heraty and Darling, 1984). For that publication, larval characters were known for only a few species of Orasema and a published account of Losbanus (now Orasema) michancoi. Conflicts in characters within Oraseminae s.l. suggested that character states within Orasema were autapomorphic reductions (Heraty and Darling. 1984). Acquisition of several new taxa and the opportunity to examine material used in previous studies by other authors allowed for a reevaluation of character states within Orasema and related taxa.

The character states coded for adults presented severa] problems, homoplasy being the largest. For almost every character state that was evaluated in Oraseminae, the state was found elsewhere, often within Eucharitinae where it was clearly a parallel loss or gain. This problem is partly a result of the diversity of form that occurs in the Eucharitidae. The large number of taxa and characters that were evaluated, with all of the confounding homoplasy, required computer analysis using parsimony algorithms. I agree with Alexander (1990) that the results of computer parsimony may not always be a reflection of evolution because of noise encountered in large data sets. One way of dealing with this problem is to use the analysis to identify homoplasy and to direct efforts to the evaluation of character states that are incongruent with cladistic hypotheses. Noise should not necessarily confound scenarios that are based on sound character analysis; rather, it should act as a strong test of the arguments.

\section{ANALYTICAL METHODS}

Character states and taxa included in these analyses were selected during the course of revisionary studies and an ongoing analysis of the world species of Eucharitidae. Over the past several years, I have had the opportunity to examine representatives of almost all of the genera of Eucharitidae and Perilampidac as well as of several undescribed genera. One theme became evident: the more taxa that are examined, the more difficult it is to recognize uniquely derived character states in the Eucharitidac! Extensive morplological studies will be necessary to uncover the value of some of these cluaracters.

Morphological studies were carried out on the musculature of the mesosoma of several eucharitine taxa and Orasema (Heraty, 1989). In this study, additional information was obtained tbrough additional morphological studies of the mesosoma, internal and external morphology of the first gastral sternite $\left(\mathrm{Ms}_{2}\right)$, the scape of males. and the structure of antennal flagellomeres. Homology of some structures, such as the pores on the scape of males in Psilocharitini and Perilampidae (see discussion of character 3 ), needs to be determined through more detailed studies. In order to avoid making a priori assumptions regarding character states, coding of character states between taxa was conservative. Therefore, although there are considerable differences in the morphology of pores on the scapes of Perilampidae and some Eucharitinae (e.g., external openings in Perilampidae are not evident in Eucharitidae), the character states were coded as the same. This introduced considerable homoplasy into the data matrix and lowered the consistency index of certain characters, while not altering the resultant cladogram to a great degree. Certainly, characters that are shown to be homoplastic need to be reevaluated for homology.

The analysis includes the genera and species groups studied in this revisionary work and several species in each of the genera of Eucharitinae listed in Appendix 1. The Orasema uichancoi-group was divided into a communis OTU (Operational Taxonomic Unit) which included $O$. communis and $O$. seyrigi $(\mathrm{CO}$; code for OTU in data matrix); it also contained a uichancoi OTU (UI), which included all of the Indo-Pacific species. Psilocharis was divided into 3 monophyletic groups that were based on the character analysis of species within the generic treatment, and included the following species: $P$. aenigma (AE), $P$. monilicera $+P$. pentella + $P$. afia $+P$. hypena (AF), and $P$. dahmsi $+P$. pacifica + $P$. joanneae $+P$. theocles $(\mathrm{TH})$. The Neolosbanus palgravei-group was divided into 2 OTUs represented by $N$. townesi $+N$. laeviceps (TO), and $N$. taiwanensis + $N$. pilosus $+N$. palgravei $+N$. nepalensis (PA). All other OTUs represent genera or species groups as represented in the following generic revisions. The Orasema uichancoi-group is similar to the $O$. festiva-group of species in Central and South America. The majority of New World Orasema are closest to the $O$. assectator-group (AS) of species with respect to the phylogenetic character set. In Orasema, larval information for characters 50, 56, and 57 is known only for New World species, and this information was included as data for the $O$. assectator-group. Character states for Gollumiella and Anorasema are based on my revisionary study of these genera (Heraty, 1992). The Eucharitinae s.s. refer to the Eucharitini excluding 
Gollumiella and Anorasema. The genus Schizaspidia is a speciose group containing 35 described species, a few of which exhibit character states of the ovipositor that directly conflict with those found in the Oraseminae (see character discussions). Adults of these taxa are otherwise identical with other species of Schizaspidia and there was no reason to code them as a different OTU. Chalcura montana (Ishii) was treated as a separate OTU $(\mathrm{CH}$ MONTANA). I do not consider this species as closely related to other Chalcura.

Characters were coded as binary variables $(0,1)$ or as multistate characters $(0,1,2)$. Coding of character states reflects presumed polarity (plesiomorphic $=0$ ), but polarity of all characters was established in the analysis using outgroup comparisons (Maddison, Donoghue, and Maddison, 1984). Table 2 lists the plesiomorphic state at the first ingroup node resulting from the analysis. All character states were treated as unordered in the analysis with the exception of the number of male funicular segments (character 4 ) and the impression of the femoral groove (character 29) which was ordered with a userdefined tree.

\section{CHARACTER ANALYSIS}

Characters can be divided into 3 distinct sets: external adult characters, internal adult characters, and larval characters (including some aspects of behaviour). External characters of adults were verified in as many species for each OTU as possible. Examination of internal characters involved dissections of exemplars from each genus; however, internal characters are generally conservative (Heraty, 1989). Complete information on larval morphology and behaviour are known for only a small proportion of Eucharitidae, but representative information is known for several different taxa. Character state descriptions and distributions are presented in Table 2 and Appendix 1. An attempt was made to minimize the number of character states that were chosen for each character. The following discussion deals with characters that either cannot be adequately treated in Table 2 or are discussed at greater length elsewhere (Heraty and Darling, 1984; Heraty, 1985, 1986, 1989: Darling, 1988a; Heraty and Barber. 1990).

Character 1: Anelliform first flagellomere. The presence of a distinct ancllus is generally regarded as plesiomorphic within the majority of Chalcidoidea (Königsmann, 1978: Schauff, 1984: Gibson, 1986). An ancllus is present and distinet in Chrysolampinac and Perilampinac: the loss of an ancllus in Eucharitidac is thus apomorphic. The ancllus of most Eucharitidae treated here is typical for other chalcidoids. In Anorasema, the ancllus is present (Boučck, 1988: Heraty, 1992). In Gollumiella, the balsal Hagellomere may be anclliform to elongate like the following segments, or partially to completely fused with F2 (Heraty, 1992). The anellus is absent from all Eucharitinae s.s. (Heraty, 1985; state 1). In Neolosbanus and Gollumiella, the anellus undergoes various degrees of fusion with the second flagellomere. Multiple states for terminal OTUs were generally coded as anellus present.

Character 2: Length of scape. A geniculate antenna. with an elongate scape, is regarded as plesiomorphic within Chalcidoidea (Königsmann, 1978; Gordh, 1979; Gibson, 1986). The scape is long and slender in Chrysolampinae and Perilampinae. The length of the scape is reduced in some groups of Eucharitidae until it becomes broader than long and the antenna is no longer elbowed (e.g., Tricoryna and Stilbula; state 1). As discussed by Gibson (1986), it is difficult to assign an arbitrary value to the length:width ratio in order to define the antenna as geniculate or non-geniculate. A value of $4 x$ longer than broad is adequate to distinguish the elongate scape of the majority of Oraseminae and Psilocharitini: however, reductions in length of the scape in Timioderus, Indosema, and other Eucharitinae are obvious.

Character 3: Scape of males. Distinct pores (visible on SEM) on the scape of males are found in Torymidae (Goodpasture, 1975), Eulophidae (Schauff, 1991), and at least some Eupelmidae (Gibson, 1990). Males of Chrysolampus, Euperilampus, and Perilampus (all Perilampidae) also have small pores on the ventral surface of the scape (state 0; Smulyan, 1936; Darling. 1983a. 1983b, 1986). These pores are clearly visible under high magnification and may be openings for internal glands (Darling, 1983b). The pores found in these various groups indicate that presence may be plesiomorphic. The scape of males in species of Psilocharis. Neoloshamus, and 1 species of Golhumiella has a ventral patch of small pores that is visible in slide preparations (Figs. 141-142, 167). These pores are associated with an apical expansion of the scape in Neoloshamus and Gollumiella. Examination of this region using SEM did not reveal external punctures coincident with the pores found on slide preparalions. Scattered minute openings were found in Neolosbanus townesi. N. anapetus, and N. purpureorentris, but were not found on the scapes of orasemine species or other Eucharitinae examined. Homology with pores found in the ingroup and outgroup could not bo confirmed but the states were both given the same code. Absence of pores from the scape in slide preparations was considered apomorphic (state 1).

Characters 4 and 5: Number of funicular segments of males and females. The flagellomeres between the andlus, if present, and the teminal unfused segment (clava) are the funicular segments (Fig. 48). The segmentation of slide-mounted antennac of Chrysolempus and Chrysomolla show 7 funicular segments with a fused 3 - 


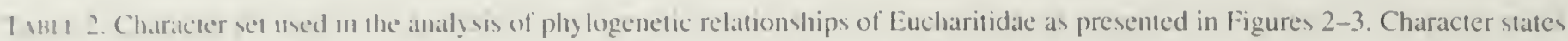
are presented in presumed orcker from plesionorphic to apomsorphic. Values in parentheses following character decriptions are the charwher vater chonen for the internote between the outgroup and Eucharitidae as selected by PAUP. the consistency index, and the retenmon maten. Differme undeces lor charackers that had different distributions on different tree topologies are separated by a slash.

Intennal

\section{Heald}

Annellıform fïrst thagellomere: 0 . present; 1 absent $(0,0.33,0.87)$.

Length of scape: 0 , length greater than $3 \times$ width; 1 , length less than $3 \times$ width $(0,0.50,0.88)$.

Scape of male: 0, with distinct pores: 1 , smooth (?, 0.50, 0.86).

Number of funicular segments of male (excluding anellus and clava): 7-9 (7, 0.50, 0.88).

Number of funicular segments of female: $7-9(7,0.33,0.20)$.

Secondary basal segmentation of funicular segments: 0 , absent: 1 . present $(0,0.33,0.78)$.

Antennal branches of male: 0 , absent: 1. lamelliform; 2. ramose $(0,0.50,0.60)$.

Facial sculpture: 0, smooth; 1. rugulose: 2, reticulate; 3, carinate $(0,0.60,0.50)$.

Scrobal depression: 0 , even depression; 1 , smooth linear channels; 2 , crenulate channels $(0.0 .67,0.50)$.

Malar depression: 0, present; 1, absent $(2,0.50,0.75)$.

Anteclypeus: 0 . distinct; 1 , indistinct $(0,1.0,1.0)$.

Apex of clypeus: 0 . linear; 1, lobed $(0,0.50 / 1.0,0.50 / 1.0)$.

Mandibles: 0 , dentate and broadly curved: 1, falcate: 2 reduced $(0,1.0,1.0)$.

Form of labrum: 0, digits absent, setae marginal; 1, digitate with adoral digits (Perilampinae only); 2, planar and digitate; 3 . reduced in size; 4 , complete loss (Darling, 1988a) $(2,1.0,0)$.

Number of labral digits or marginal setae: 0 , more than $5: 1,4(0,0.33,0.73)$.

Posterior genal margin: 0, open: 1, closed (Heraty. 1985, 1986) $(0,0.50,0)$.

Mouthparts: 0 , large; 1 , much reduced $(0,0.33,0.50)$.

Dorsal occipital margin: 0 , rounded: 1 , carinate $(0,0.25,0.77)$.

\section{Mesosoma}

19. Prepectus: 0, freely articulating with pronotum: 1 , fused with pronotum on different plane; no internal rod: 2 , fused with pronotum on same plane, no internal rod; 3 , fused with pronotum and associated with internal prepectal rod (Perilampus only) (Heraty, 1989) $(0,1.0,1.0)$.

20. Shape of prepectus: 0. narrowed ventrally, reaching tegula and evenly sculptured: 1, triangular and sculptured. reaching tegula; 2, narrowed ventrally and foveate dorsally; 3, subtriangular, broadly separated from tegula: 4. upper half fingerlike, narrowly scparated from tegula; 5 , narrowly separated from tegula and sinuate posteriorly $(1,0.62 / 0.71,0.83 / 0.89)$.

21. Profile of pronotum: 0, visible in dorsal view; 1, hidden (Heraty, 1985; Bouček, 1988) (0, 1.0, 1.0).

22. Scutoscutellar sulcus: 0, diagonal to TSA, dividing axillae; 1, transverse and carinate internally, axillac transverse; 2, transverse with prominent internal carina (Heraty, 1989) $(0,1.0,1.0)$.

23. Notauli: 0, present; I, absent $(0,0.50,0.50)$.

24. Transscutal articulation: 0 , present; 1 , absent $(0,1.0,1.0)$.

25. Mesoscutal ridge (internal): 0, absent; 1, present (Heraty, 1989) $(0,0.50,0.89)$.

26. Mesothoracic spiracle (internal): 0 , not enclosed dorsally: I, enclosed by sclerotized cuticle dorsally: 2, broadly enclosed (Heraty, 1989) $(0,1.0,1.0)$.

27. Frenal groove on scutellum: 0, present; 1, absent; 2, as in Perilampinac (0, 0.33/0.29, 0.43/0.29).

28. Propodeal sculpture: 0 , evenly sculptured; 1, smooth $(0,0.5,0.89)$.

29. Femoral groove: 0, rounded and shallow; 1, broadly and evenly impressed; 2, narrow and foveate (0, 1.0. 1.0). Ordered using character state tree, $1 \leftrightarrow 0 \leftrightarrow 2$.

30. Lateral axillar surface: 0 . large; 1 , reduced (Heraty. 1989) $(0,0.33,0.33)$.

31. Scutellar spine morphology: 0, absent; 1, short and bifurcating; 2, long and bifurcating, united basally; 3, long spines, not united basally $(0,0.75,(0.67)$.

32. Mesepistemum: (), ventral margin linear; 1, ventral margin broadly rounded and swollen anterior to mid coxa: 2. wedgeshaped anterior to inid coxa (Heraty, 1989) (0, 0.40, (0.82). 


\section{Wings}

33. Wing setae: 0 , large and dense: 1 , small or absent $(0,0.33,0.33)$.

34. Hind wing vein: 0 , well developed: 1 , medially indistinct (Heraty, 1985) $(0,0.50,0.75)$.

35. Stigmal vein: 0 , perpendicular; I, sharply angled to apex of wing; 2 , round $(0,0.40,0)$.

36. Postmarginal vein: 0 , long: 1 , short $(0,0.14,0.46)$.

37. Speculum of forewing: 0 , setose (absent); 1 , present $(1,0.20,0.64)$.

\section{Metasoma}

38. Petiole of female: 0 , transverse and not fused ventrally: 1 , transverse and fused ventrally: 2 , elongate and fused ventrally ( 2 . $1.0,1.0)$.

39. Base of petiole: 0 , tapered, associated with transverse petiole; 1 , truncate basally with dorsal flange; 2 , tapered basally, associated with elongate petiole; 3 , truncate basally, without dorsal flange $(0,1.0,1.0)$.

40. Sternal constriction: 0 . present; 1 , absent $(0.0 .50,0.92)$.

41. $\mathrm{Ms}_{2}$ of males: 0 , no anterior projection: I. expanded cup-shaped anterior region projecting forward under petiole $(0,1.0,1.0)$.

42. Expansion of valvulae: 0 , acicular; 1 , expanded $(0,0.25 / 0.20,0.79 / 0.71)$.

43. Lateral apex of first valvula: 0 , smooth; 1 , with diagonal ridges; $2,3-4$ teeth; 3 , several minute teeth $(0,0.50,0.70)$.

44. Apex of second valvula: 0 , dorsal ridges small or absent; 1, strong dorsal ridges, ridges diagonal and coalescing; 2, lateral teeth; 3 , strong transverse ridges $(0,0.60,0.80)$.

45. Hypopygial setae: 0 , small or absent; 1 , single row of elongate hairs; 2 , dense cluster of apical setae $(0,0.50,0.82)$.

46. Gonostylus: 0 , separated: 1 , fused $(0,0.50,0.93)$.

47. Number of hind tibial spurs $(2.0 .50,0.50)$.

\section{Immatures}

48. Egg shape: 0 , stalked: 1, elliptical (Heraty and Darling, 1984) $(1,0.50,0.50)$.

49. Setal pattern of tergite III: 0 , ventral spine present; 1 , ventral spine absent $(0,0.50,0.75)$.

50. Dorsal setae of first instar: 0, presence on tergites VII, IX, and XI; 1, loss of setae on tergite XI; 2, loss of setie on VII, IX, and XI; 3, loss of setae on all but T I and II (Heraty and Darling, 1984) (I, 1.0, 0).

51. Tergites 1 and II of first instar: 0, separated: 1, fused (Heraty and Darling. 1984) (0, 1.0, 1.0).

52. Tergopleural line on first instar: 0, ibsent; 1. present (Heraty and Darling. 1984) (0, 0.5. 0.86).

53. Caudal cerci on first instar: 0, absent; 1, present (Heraty and Darling, 1984) $(1,0.5,0)$.

54. Caudal pad on first instar: 0, absent: 1, present (Heraty and Darling. 1984) (1, 1.0. 0).

55. Antenna on lirst instar: 0, present; 1, absent (Heraty and Darling, 1984) (1, 1.0, 0).

56. Cranial setae on first instar: 0. present: 1 , absent (Heraty and Darling, 1984) (?. 0.33, 0.33).

57. Postlabium of first instar: 0 , not expanded; 1 , expanded $(1,1.0,0)$.

58. Labial plate of first instar: 0 , absent; 1 , present; 2 , secondary $(0,1.0,0)$.

59. Third-instar type: 0, hymenopteriform; 1, pustulate as in Perilampus; 2, pustulate as in Orasema; 3, as in Chalcura; 4, as in Stilbula; 5, as in Eucharis (sce Smith, 1912; Clausen, 1940b) (0/1/2/3, 1.0/0.83, 1.0/0.83).

60. Pupa: 0, chalcidiform; 1, pustulate over petiole $(0,1.0,1.0)$.

\section{Behavioural}

61. Number of eggs laid with each oviposition: 0,1 egg: 1, 1-10 eggs: 2, more than 10 eggs (1, 1.0, 1.0).

62. Attachment of first instar to host: 0 , external; 1 , internal $(0,0.5,0.5)$. 
segmented clatsa (Darlmg. 1986). The segments of the clal a In Perlampinac appear lo be more closely appressed, again giring a 7-segmented funicle. Seven segments are common in Pteromalidac also, so the 7-segmented funicle was chosen as the plesiomorphic state for hoth outgroup laxil. Within Eucharitidac, the number of funicular segments is variable and depends on the degree of fusion in terminal segments and the interpretation of the ancllus. The number of funicular segments of males (character 4) varied from $710 \%$ : this character was treated as ordered to provide a grouping of species within Neoloshanus that had 8 or 9 funicular segments. Unordering this character resulted in no resolution among species groups of Neoloshanus.

Bouck and Noyes (1987) referred to the absence of multiporous plate sensilla ("Iongitudinal sensilla") as a characteristic of Eucharitidae. Multiporous plate sensilla were found in almost all of the Eucharitidae examined (absent in males of the Neolosbamus gemma-group and Anorasema), although they are reduced in size and recessed into depressions within the Eucharitinae s.s.

Character 6: Secondary basal segmentation of flagellomeres. The antennae of Psilocharis theocles, Neolosbanus palgravei, N. townesi, N. purpureoventris, and Gollumiella show a distinct secondary segmentation at the base of the funicular segments (Figs. 213-214, 216), which is not unlike the separation between the anellus and F2 (Figs. 211,215). In Gollumiella, coded as present, the segmentation forms a cuplike flange overlapping the base of the flagellomere (Heraty, 1992). Observation of this character state is difficult and will require a broad survey for its distribution using SEM. No secondary segmentation was observed in Oraseminae or other Eucharitinae, with the exception of Chalcura, which has a weak basal flange similar to that of Gollumiella. Secondary segmentation undergoes parallel development in Psilocharitini, Gollumiella, and Chalcura, although it may be plesiomorphic for Eucharitinae.

Character 8: Facial sculpture. Sculpture of the frons and lower face is a variable attribute but it is important in the separation of some lineages of Oraseminae. A completely smooth face is found in Chrysolampinae and most Perilampinae and is regarded as the plesiomorphic state (state 0; Figs. 189, 193-205). Within Eucharitidae, 4 states were recognized with facial sculpture further divided into rugulose (state 1; Figs. 187-188), reticulate (state 2; Fig. 191), and vertically carinate (state 3). Rugulose and carinate sculpture patterns were broadly defined to include several variants, whereas smooth and reticulate could be more accurately dehimited.

Character 9: Scrobal depression. A relatively smooth or evenly rounded scrobal depression was regarded as plesiomorphic and was found in the outgroup taxa as well as most of the Eucharitinac. In Psilocharis and Orasema glabre, there are 2 smooth cliannels that terminate in a small depression at about $0.6-0.8 \times$ the distance between the toruli and median ocellus (state 1; Figs. 127. 194-195, 197). State 2. crenulate furrows bordering a raised median area and reaching the median ocellus, is found only in the Neoloshanns gemma-group (Figs. 153-154), although they may be similar to the condition found in Orasema uichancoi (Fig. 188). The homology of the 2 states is uncertain.

Character 10: Malar depression. A malar sulcus (visible as a distinct line) is present in some species of Chrysolampinae and Perilampinac. Its presence is regarded as plesiomorphic within the Perilampidae based on its widespread distribution in the Pteromalidae. Absence of a distinct suture is an autapomorphy of Eucharitidae that was not coded for in the analysis. However, a linear depression of the malar space, in a position similar to the malar sulcus of Perilampidae, occurs in some taxa of Eucharitidae (Figs. 95, 223). This depression is absent in Perilampidae (state 0 ), and its presence in some Eucharitidae is treated as a derived state (state 1). An apomorphic development of the depression into a broad foveate groove only in some members of the $O$. uichancoi-group was not included in the data matrix (see discussion of phylogeny in revision of Orasema).

Character 11: Anteclypews. The anteclypeus (A, Figs. 190, 198), a distinct area along the apical margin of the clypeus, is found in Perilampidae and most Eucharitidae (state 0 ). The margin of the clypeus is rounded and lacks any distinct area in species of Neolosbanus. Some specimens of $N$. purpureoventris have the apex of the clypeus on a different plane so that it appears marginate in some views (Fig. 210). This was considered as an independent development, and the clypeus was coded as for other Neoloshanus. A similar reduction of the anteclypeus occurs in some species of Austeucharis, Chalcura, and Schizaspidia although they are probably not homologous character states.

Character 12: Apex of clypeus. In the Neolosbanus purpureoventris-and $N$. palgravei-groups, the anteclypeus is strongly produced over the base of the mouthparts as a semicircular lobe (state 1; Figs. 200-204). The lobe is less strongly developed in $N$. townesi (of the palgrarei-group) and the $N$. gressitti-group, and is considered as absent. It is possible that character 12 is coupled with character II and that together they should be treated as a single apomorphy. Separate coding for characters II and 12 would be the same as combining them and treating the character as ordered.

Character 13: Mandibles. The plesiomorphic state is interpreted as broad, opposable mandibles, which broadly join or overlap along their apical margin in the same plane as the ventral margin of the head (state 0 ). Apomorphic differences in the mandibles of 
Chrysolampinae and Perilampinae were disregarded. Falcate or sickle-shaped mandibles that fold in a plane perpendicular to the ventral margin of the head (vertical) are regarded as an autapomorphy of Eucharitidae (state I). Reductions of the mandibles occur in various genera. including Pseudometagea and Eucharis (state 2), and the mandibular configurations of Timioderus and Indosema are extreme. In Indosema, the mandibles are completely lost. In Timioderus, the mandibles are reduced and elongate, or in the case of Timioderus peridentatus, 3/2 dentate, enlarged, and cup-shaped (Figs. 28, 39) as is typical of the Perilampinae and Pteromalidae. This is treated as a reversal to the plesiomorphic state.

Characters 14 and 15: Labrum. A labrum having marginal digits arranged in the same plane is regarded as an autapomorphy of Eucharitidae, with a larger number of digits as the groundplan state for the Chrysolampinae and Perilampinae (state 0; Darling, 1988a). In Orasema and the basal Eucharitinae, the labrum is distinctly 4-digitate (state 1) with only minor variations in the number of digits (4-5). Number of digits, presence or absence of digits, and shape of the labrum are highly variable in Orasemorpha, Timioderus, and Indosema. In the Eucharitinae s.s., the labrum is usually 9-16 digitate (state 0 ), with a 4-digitate labrum found in some species of Pseudometagea and Pseudochalcura.

Character 18: Occipital carina. An occipital carina is found at the junction of the vertex and the occiput behind the lateral ocelli in most Eucharitidae. Such a carina is not considered to be homologous with the occipital carina found in Torymidae. An occipital carina is not found in the 3 other subfamilies of Eucharitidae. and Perilampidae. and is rare in Pteromalidae: therefore it is regarded as a derived character state in the Eucharitidae. In most taxa, the carina is stable for all members of a genus. However, a weak carina is found in some individuals of Orasema koghisiana and $O$. valgius. In both cases, the carina is associated with weak striae along the vertex that become consolidated into a single carina. and this was not coded as present.

Characters 19 and 26: Fusion of the prepectus; mesothoracic spiracle. Fusion and shape of the prepectus can be correlated with changes in internal muscle attachments (Heraty, 1989). Fusion of the prepectus in most Perilampinae (character 19: state 3 ) is considered as independent from that in Eucharitidae because an internal apodeme is present, and the mesothoracic spiracte is not enclosed by cuticle dorsally (character 26: state 0): Heraty, 1989). Fusion of the prepectus is coded differently in Anorasema and Gollumiella where the prepectus lies on a different plane from the pronotum (character 19; state 1). Dorsal enclosure of the mesothoracic spiracle (character 26: state 1) was observed in Anorasema, but was diflicult to assess on the smaller Gollumiella and therefore was coded as missing, although it did appear to be enclosed. Enclosure of the spiracle and lack of an internal apodeme suggest that the fusion is homologous with Eucharitinae s.s.

The fusion of the prepectus on the same plane (character 19, state 2) in Eucharitinae was considered as the final step in a transformation series from the fused pronotum in Gollumiella and Anorasema, which is on a different plane (state I); the perilampine type was considered autapomorphic and unrelated to states 1 and 2. Coding the prepectal fusion in Eucharitinae as 2 separate states rather than a single state allows for more freedom in the placement of Anorasema and Gollumiella based on other characterstate distributions.

Character 20: Shape of prepectus. The shape of the prepectus was divided into 5 states. In Chrysolampinae and Perilampinae, the prepectus extends to the tegula and is usually narrowed ventrally (state 0 ; as in Fig. 222) or broad and triangular (state 1; as in Fig. 217), and was coded as a multiple state in both outgroup taxa (cf. figures in Bouček. 1978, 1988; Darling. 1983b, 1986, 1988b). Character states 0 and 1 are represented in the Pteromalidae. In Oraseminae, the prepectus is usually triangular (not strongly narrowed ventrally), cvenly sculptured, and reaches the tegula (state 1; Figs. 27, 51, 83. 98. 217-218, 220). A similar prepectus is known only for Psendometagea (Eucharitinae). In some Oraseminae and in Neolosbanus and Psilocharis the prepectus is triangular dorsally and foveate, but strongly narrowed ventrally (state 2: Figs. 222-225, 227-228). In Stillula and related genera, including some species of Schizaspidia, the prepectus is reduced in length and broadly separated from the tegula (state 3: cf. Heraty, 1989, figs. 13, 15). In Chalcura, Austencharis, and some members of Schizaspidia, the prepectus is strongly narrowed for most of its height and dorsally forms a foveate, fingerlike extension to the tegula (state 4; cf. Bouček, 1988, figs. 945-946). Lastly, the prepectus of Kapala and related laxa is narrowly separated from the tegula and is sinuate along the posterior margin (state 5: cf. Heraty. 1989. (ig. 3).

Character 25: Mesoscutal ridge. An internal mesoscutal ridge appears to be an autapomorphy of the Eucharitinac s.s. (state 1: Heraty, 1989). A mesoscutal ridge is distinct in Indosema, but absent from other Oraseminae. Psilocharitini, and Anorasema (state (0). Individuals of Gollumiella were too small to atlow for resolution of the states of this character, but the mesoscutum appeared to lack the ridge. and was coded as state 0.

Character 28: Propodeal sculpture. The plesiomorphic state for Perilampidac and most Eucharitinate is to have the propodeum evenly sculptured. In some Orasema and all Psilocharitini, the propodeal dise is smooth execpt for a median carinal or alveolate furrow (state 2). In both groups. this state is associatted with an evenly rounded 
and glabrous callus. The propodeum is flat and smooth in some Kapula, hut dhis was not considered as homologous (1) the smooth propodeum described ahove. State 1 was merpreted as being derived independently in Orasema and Pulocharitini

Clumacter 29: Femoral gronese. An evenly rounded or mdisinet femoral groove was interpreted as the pleviomorphic state (state ()). In Psilocharis, the femoral groove is broidly and evenly impressed, and is associated with a foveate sternaular areat anteriorly (state 1; Figs. 222-225). In Neoloshomus, the lemoral groove is narrow and foveate, with or without an associated foveate sternatular area (state 2; Figs. 226-234). The character was ordered using a character-state tree so that there was a one-step difference from the ancestral state and a twostep difference between the derived states. There was no reason to assume that one state was transitional to the other, and ordering was used to eliminate additional hypotheses for the Psilocharitini lineage (e.g., gemmagroup as ancestor to Psilocharis).

Character 32: Mesepisternum. The plesiomorphic state for the mesepisternum is a straight ventral margin (in lateral view) with no expansion anterior to the mid coxa (Pteromalinae and Chrysolampinae, state 0: Figs. $219,221-228)$. The ventral margin of the mesepisternum is strongly expanded in most species of Orasema, Orasemorpha, Timioderus, and Indosema (state 1; Figs. $27,51,217-218,220)$. A similar expansion of the mesepisternum occurs in the Stilbula and related taxa (cf. Heraty, 1989, figs. 15, 17). In Perilampinae, Chalcura, Schizaspidia, Kapala, Isomerala, and Austeucharis, the mesepisternum extends as a strong wedge anterior to the mid coxae (state 2; cf. Heraty, 1989. fig. 13).

Character 35: Stigmal rein. The shape of the stigmal vein is differentiated into 3 states, listed in Table 2. In most Eucharitidae, the stigmal vein is usually quadrate to more than $3 \times$ longer than broad, associated with a welldeveloped marginal vein, and perpendicular to the forewing margin (state 0 ). The angle of the stigmal vein to the anterior margin is important in separating the Neoloshanus purpureoventris-group (state 1; Fig. 169) from other groups of Neoloshanus (state 0; Figs. 162-165). Timioderus and the outgroup taxa were coded as having character state 1 although homology of these occurrences is questionable. A circular stignal vein associated with a reduced marginal vein is a synapomorphy of the Obeza clade (state 2).

Character 36: Postmarginal vein. The length of the postmarginal vein relative to the marginal vein was treated as a binary variable. A long postmarginal vein was defined as being more than $0.5 \times$ longer than the marginal vein, and often reached to the extreme apex of the wing.

Charucter 38: Petiole of female $\left(M_{t},\right)$. Three states are recognized based on shape and degree of ventral fusion of the petiole: state 0, petiole short, broader than long, and not fused ventrally, with ventral margins broadly separated (Figs. 27, 35); state 1, petiole short but fused ventrally (Fig. 256); state 2, petiole longer than broad, cylindrical. and fused ventrally. Within the Eucharitidae, states 0 and 1 are found only in Timioderus, Indosema, and Orasemorpha. Chrysolampinae has all 3 states and Perilampinae has both state 1 and state 2. The petiole is not lused ventrally in Chrysomalla (Chrysolampinae) (personal observation) and in Rhicnocoelia (Pteromalidac) (Heydon, 1989). Heydon suggested that lack of fusion of the petiole is plesiomorphic, but at the same time he placed Rhicnocoelia as a derived member of the Sphegigasterini. Multiple character states found in the outgroup make it difficult to assess polarity within the Eucharitidae. Treating this character as ordered and with the ancestral state fixed as 0 had no effect on the results of the analysis. The character was treated as unordered. State 2 was chosen as the plesiomorphic state for Eucharitidae.

Character 39: Base of petiole. The shape of the base of the petiole was differentiated into 4 states. In the plesiomorphic state (state 0 ), the base of the petiole tapers to the condyle of the short petiole, and is associated with a short petiole as found in Perilampidae, and some Oraseminae. Alternate states occur in the Perilampidae and include an elongate petiole with a strong basal flange in Chrysolampus, and a transverse petiole with a strong dorsal flange in some Perilampus. These states were disregarded as they are unique derivations in each group. In all Eucharitinae, excluding Psilocharis, the base is gradually narrowed and inserts into the propodeal foramen, the condyle is small and indistinct. and the petiole is elongate (state 2). In most Orasema the base of the petiole is truncate basally and abruptly narrowed to the basal condyle of the petiole, and the basal margin has a distinct basal flange (state 1). The petiole is abrupt but lacks a dorsal margin in Psilocharis (state 3). State 0 is plesiomorphic for Eucharitidae. Because state 2, which is associated with an elongate petiole, is closely linked with character 38 , it would be more apomorphic.

Character 40: Sternal constriction. A medial constriction of the second metasomal sternite, $\mathrm{Ms} s_{2}$, is interpreted as plesiomorphic (state 0) in the Eucharitidae, and its absence as apomorphic (state 1). The constriction originates at the anterodorsal margin of $\mathrm{Ms}_{2}$ at the point of articulation with the petiole, and curves posteriorly, delineating a semicircular or subtriangular anterior region (Figs. 27, 35, 51, 54, 61, 74, 78, 126, 138, 256, 258). The anterior region may be strongly developed and shelflike with a broad crenulate constriction (Fig. 256), smooth and broadly rounded with a narrow smooth constriction (Fig. 258 ), or a short band with a broad crenulate furrow as in Chrysolampus oblongiscutella Girault (Chrysolampinae). 
Different configurations were not distinguished in this analysis. Presence was established by a distinct constriction. The shallow indentation found in the Neolosbamis gemma- and purpureoventris-groups (Fig. 273), or conditions in which the anterior region is differentiated only by sculpture (Fig. 172) were coded as absent (state 1).

Internally, the constriction is associated with a continuous band of muscles which converge on a median ventral ridge within the petiole. Interpretation of homology with muscles presented in Snodgrass (1956) for the honeybee metasoma was not possible. Each of the gastral sternites is connected by a fine network of antecostal muscles that abut on either side of the antecosta of each segment. However, the antecostal muscles between segments $\mathrm{Ms}_{2}$ and $\mathrm{Ms}_{3}$ originate on the anterior dorsolateral margin of $\mathrm{Ms}_{2}$ and insert broadly along the antecosta of $\mathrm{Ms}_{3}$, suggesting that the antecostal ridge has been lost or reduced to the dorsal margin of $\mathrm{Ms}_{2}$. The muscles attaching to the constriction insert posterior to, and underneath (laterally), the antecostal muscles, arguing against the homology of these 2 muscle groups. The attachment and shape of the muscle group attaching to the constriction suggest that it may act as a levitator of the sternite with respect to the petiole. The same muscle group is present in a similar position in eucharitine taxa where the constriction is absent.

The constriction and distinct anterior region are prominent in all members of the Perilampinae. Within the Chrysolampinae, the character has multiple states: Chrysomalla has a broad anterior region and smooth constriction (state 0); Chrysolampus and Brachyelatus have a narrow anterior region with crenulate furrow (state 0 ); and some species of Chrysolampus have a sculptured anterior region lacking a constriction (state 1). A prominent constriction on $\mathrm{Ms}_{2}$ was also found in Torymus (Bucher, 1948) and Podagrion (both Torymidae), Dipara, and Lelaps (Pteromalidae; cf. Yoshimoto, 1977, figs. $1-2$ ), as well as in some other pteromalids and scattered members of Eulophidae. A broad anterior region and narrow constriction was also observed in Philomides thodesiensis Risbec, but was absent from other members of the Philomidinae. The muscles and their homology need to be studied on a broader scale within the Chalcidoidea to determine their value in classification. Only presence or absence of the constriction is treated here.

Character 41: Ms $s_{2}$ of males. In Timioderns, Indosema, and Orasemorpha, the anterior region of the second metasomal sternite projects ecphalad beneath the petiole (Figs. $35,54,75,78)$. The anterior region is expanded and cupshaped. and when contracted, fits securcly against the ventral surface of the petiole. A similar expansion of $\mathrm{Ms}_{2}$ is found in both sexes of the Psendometagea schwerriigroup (cf. Heraty, 1985, figs. 50-51). Psemdometagea schwarzii Ashmead also shows an indistinct constriction of the anterior region and a folding of the anterior margin similar to that of Orasemorpha didentata (Fig. 78). The phylogenetic position of Pseudometagea and general differences in morphology of the sternite suggest that the projection in Pseudometagea is not homologous with that found in Orasemorpha, Timioderus, and Indosema. Inclusion of this autapomorphy as a multiple state for Pseudometagea did not affect the analysis, but it was not included in the final data matrix. A forward projection of the sternite was not found in the outgroup taxa and was therefore regarded as apomorphic.

Character 42: Expansion of valuulae. The ovipositor exhibits various shapes from being acicular or needlelike (Figs. 264-265, 271-272), having a strong subapical expansion (Figs. 262, 266-267), or being evenly expanded along its entire length (Figs. 268-270). An acicular ovipositor is found in the outgroup taxa and other Chalcidoidea, and is regarded as plesiomorphic. Only 2 states are recognized, acicular (state 0 ) and expanded (state 1), because it is difficult to partition differences between subapically expanded and evenly expanded. Curvature of the ovipositor was proposed as a character system but was abandoned because of problems in partitioning states within the expanded ovipositor types. In almost all species of Orasema, the ovipositor shows a marked forward curvature that is so pronounced in some species that the second valvula becomes ventral to the first (Figs. 93, 262). The curvature is likely associated with the habit of ovipositing parallel to the lcaf surface as shown for Orasema (Fig. 4). The ovipositor is slightly curved and elongate in Timioderus and Orasemorpha. Indosema has a straight ovipositor that is articulated in a unique manner, and is flipped forward between the coxac in some preserved specimens. In Neolosbamus, the ovipositor is expanded but straight and, in the case of $N$ palgravei, associated with a slightly different oviposition behaviour (Figs. 18-19). Of all the specics observed in Orasema, $O$. communis is the only species that has a straight ovipositor with diagonal ridges at the apex of the first valvula. Anorasema and a lew species of Schizaspidia possess a straight or curved ovipositor. respectively, which suggests 2 different modes of oviposition.

Character 4.3: Lateral apex of first raliula. Four character states are recognized for structures found along the lateral apex of the lirst valvula: state 0, processes absemt (Figs. 265, 270, 272): state 1, diagonal ridges (Fig. 267) state 2, 3 to 4 lateral tecth (Figs. 259, 26.3): and state 3. row of 6 to 10 minute teeth (Fig. 261).

Chardeter 44: Apex of second valvela. Strong transverse riclges (state I: Figs. 29, 31, 99, 267, 269) or lateral teeth (state 2: Figs. 52, 128b, 270) are sometimes found on the second valvula. These ridges are ahsent from Anorasema and Chakero momana. Minute dorsal ridger 


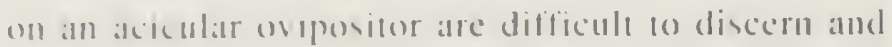
nederen were aflen sbserved with SEM that were nol visihle whl heht microscops. The presence of minule ridges (Figs. 26.5. 272) 11 is coded the same as when completely alheml, and trealled als the plesiomorphic state. Presence of fatcral teeth wats often distinct (Fig. 270), or subject io merpretalion batsed on the prominence of the medial rideses (Fig. 201. coded as teeth present).

Character 45: Mypoprgial setae. Three distinct setal paltems ate recognized at the apex of the hypopygium $\left(\mathrm{M}_{0}\right)$ : state 0 . small or minute setae subapically (Figs. 27, $51,61,74,113,126,172,262)$ : state 1, single row of clongate hairs along posterior margin (Figs. 149, 264): state 2. cluster of elongate setae around apex of hypopygium. Absence or presence of minute setae (character state 0$)$ was regarded as plesiomorphic. Character state 1 is unique within the Chalcidoidea and supports a relationship between the Psilocharis and Gollumiella + Anorasema. However, Psilocharis a'nigma lacks the setae but definitely belongs to this genus. Conflicts with other characters render the character homoplastic.

Charucter 46: Gonostylus. The plesiomorphic condition is interpreted as a complete separation of the gonostylus from the second valvifer by a diagonal suture (Fig. 257 ); absence of the suture is considered apomorphic.

Character 48: Egg shape. Heraty and Darling (1984) used the stalked egg as an autapomorphy for the Eucharitidae. Egg shape can be determined from ovarian eggs dissected from the gaster. Species that deposit a stalked egg possess a dumbbell-shaped ovarian egg which is narrower at one end, and those that deposit cylindrical eggs (Perilampinae) have a cylindrical ovarian egg. Critical-point-dried specimens offered an opportunity to survey the ovarian eggs, often with very little damage to the gaster. Some ovarian eggs were recovered from representatives of genera that were air-dried, if the gaster was already split open or crushed. Cylindrical eggs (state 0) are found in both Timioderus and Indosema whereas their apparent sister group, Orasemorpha, has distinctly dumbbell-shaped ovarian eggs. Chrysolampus sysimbri has also been shown to possess stalked eggs (Darling and Miller, 1991). Ovarian eggs of Chrysolampurs sp. (from West Australia) and Chrysomalla hesperis are lapered and fusiform. Eggs of Eucharitidae are more distinctly stalked and are probably independently derived; however, Chrysolampinae were coded as possessing a stalked egg in the analysis (state 1).

Characters 49-58: Characters of first-instar larvac. The characters of the planidial larva were treated by Heraty and Darling (1984); a reevaluation of some states for Oraseminac is presented here. Differences from states colled for Oraseminae in Heraty and Darling (1984) include the following: a tergopleural line is absent in Orasema, Obeza, Stilbula, and Psendochalcwra (character
49. discussed further in biology section): and character states presented for Neolosbamus lacviceps were verified in N. palgravei (same as Eucharitinae s.s.). A hatchetshaped labial plate (character 5.5. state 1) is found in all Eucharininae. A similar labial plate oceurs in only 1 undescribed species of Orasema (Heraty, 1990, lig. 18b: stale 2): coding this as the same character state increatsed the number of possible tree lopologies only within Eucharitini.

Character) 59: Third-instar lariae. The third-instar larvae have characteristic shapes within major lineages of Eucharitidae (see Clausen, 1940b). The larva of Orasema is unusual in that it has enlarged pustules (state 2: Fig. 11) that have been identified in diverse species groups (striatosoma-, assectator-, and uichancoi-groups). Categorizing larvae within the Eucharitinae is somewhat arbitrary: however, the third instar of $N$. palgravei was coded the same as for Chalcura (state 3) based on the enlargement of the mesothorax behind the head (Fig. 24). Perilampus has a pustulate third-instar larva but the enlargements are bandlike over the entire dorsum (Smith. 1917); its larval shape was therefore coded as a separate character state (state 1) from Orasema.

Character 60: Pupa. The presence of pustules along the dorsal margin of the petiole (state 1: Fig. 12) is known only in Orasema. As for the larval pustules, this state is known for a wide variety of Orasema.

Character 61: Number of eggs deposited. Three character states are recognized: 0, I egg: 1, 3-10 eggs: and 2. more than 10 egg. The distinction is clear in most cases. All members of Orasema, Neoloshamus laeviceps, and $N$. palgra'ei deposit single eggs in punctures. Members of the Eucharitinae s.s. deposit large numbers of eggs $(60-10000)$ in a single oviposition and usually in cavities within plant tissue. In Gollumiella antennata, a circle of 100 eggs is deposited around a thrips egg; this was treated as character state 2 although it is different from anything known for the Eucharitinae (some Eucharitinale scatter eggs over the leaf surface but not in association with an intermediate host). Oviposition habits in the outgroup taxa are poorly known and suggest that either single (as in Perilampus chrysopae) or few eggs (as in Perilampus fulvicornis) maly be the ancestral state (Clancy, 1946: Laing and Heraty, 1981). Chrysolampus deposits from 1 to 12 eggs into plant tissue (Darling and Miller, 1991): because of this variability. Chrysolampinae were coded as unknown.

Character 62: Atachment of first instar. External attachment to the host is known for Perilampidae and almost all Eucharitinate, and is regarded as plesiomorphic (state 0). lnternal attachment during the early stages of the first instar followed by external development on the pupa (state 1) is known only for Orasema and Psendometagea. 


\section{PARSIMONY ANALYSIS}

Character state distributions were analysed using the Phylogenetic Analysis Using Parsimony program (PAUP Version 3.0n; Swofford, 1990) using various addition sequences and holding different numbers of initial trees. OTUs consisted of groups of species, and a large number of taxa had multiple states (i.e., 0 and 1) for certain characters (Appendix 1). Of the 62 character states in the data matrix. 34 of 47 characters of adults, 2 of 11 characters of immatures, and I of 2 behavioural characters had multiple states for at least 1 OTU. The following results are based on having multistate characters treated as uncertain (steps not added at terminal nodes), and having character-state transformations analysed using the delayed transformation algorithm (DELTRAN). The DELTRAN algorithm makes the fewest assumptions of character state change: derived states are therefore not postulated for sister groups in which a character is unknown (i.e., larval characters 59 and 60 are synapomorphies of Orasema but are unknown in other genera of Oraseminae). DELTRAN also delays changes of states for multistate taxa to the terminal OTU, so fewer models or assumptions of character state change are proposed at interior nodes.

Analyses were carried out using 2 subsets of the data matrix presented in Table 2 and Appendix 1. These were chosen to differentiate between characters of adults and morphology of immatures plus behaviour. All characters were treated as unordered except for characters 4 and 29. which were ordered to provide additional resolution within the Psilocharitini (see discussion for each character). The ordering of binary characters has no effect on tree topology or number of steps (always a one-step difference between states). Unordered multistate characters have no a priori assumption of transformation (one-step difference from all states), whereas ordering such characters requires an ad hoc hypothesis of transformation (i.c.. $0 \rightarrow$ $1 \rightarrow 2$ requires 2 steps between states 0 and 2 ). Unordered multistate characters support only those taxat that have the same character state and not taxa that share a different character state; therefore, the order of transformation is determined largcly by other characters. This can introduce a source of instability into the data set, but 1 believe that unordered characters are the preferred first step in an analysis. Ordering of the number of antennal segments (character 4 ) is a logical progression (i.c. $7 \leftrightarrow$ $8 \leftrightarrow 9$ segments). Ordering of character 29 by a character state tree was done to remove additional hypotheses of a transition series between the 2 derived states. For both characters, ordering had minimal effects on the analysis, as discussed below.

In the first data matrix, characters of adults plus egg shape (characters 1-48. Table 2) were analysed (characters with least amount of missing data), and al strict consensus solution for the resulting 18 trees is shown in
Figure 1 (Tree length $=156: \mathrm{CI}=0.51: \mathrm{Rl}=0.79$ ). $\ln$ the second data matrix, characters of adults and immatures. as well as behavioural information (characters $1-62$, Table 2), were analysed, and a strict consensus solution for the resulting 20 trees is shown in Figure 2 (Tree length $=183: \mathrm{CI}=0.53: \mathrm{RI}=0.79$ ). Ordering character 29 did not affect tree length. Ordering character 4 added one extra step for the transition in Eucharitinae from 7 to 9 funicular segments. No shorter trees or trees of different topology were found using these different approaches.

The consensus solution from matrix 2 (Fig. 2) had a higher resolution of relationships within Eucharitinae by including larval and behavioural characters than by using characters of adults alone (matrix 1, Fig. 1). The group of taxa classified as Oraseminae was resolved in both data sets. Larval stages are unknown in Gollumiella and Anorasema, and the increased resolution of this group with the Eucharitini is due to the inclusion of character 61 , which refers to the increased number of eggs deposited by Gollumiella. Because relationships proposed for the complete data set (matrix 2) provided the strongest evidence of group relationships, and are based on the minimum number of a priori hypotheses concerning character polarity, character state distributions were analysed only for the results of this analysis.

Of the 62 characters, 15 had a unit consistency index of 1.0 and were informative (unit retention index $=1.0$ ) on all trees (characters 11, 13, 19, 21-22, 24, 26, 29. 38-39, 41, 51, 58, 60-61: Table 2). Eight characters were treated as autapomorphies (unit retention index $=0$ ) for either terminal taxa or Eucharitidae on all trees $(14,16$, 35, 50, 53-55, 57: Table 2), and were therefore not inlormative for determining relationships within Eucharitidae. Twenty-nine characters had a CI of less than 1.0, but had a uniform model of character state change on all trees. Characters with alternate models of character state change on different tree topologies are marked by narrow bars on Figure 2. Characters 12, 20,27, 42, and 59 can differ by one step on different tree topologies and had 2 different CI values that were tree dependent (Table 2).

\section{DISCUSSION OF PHYLOCGENY}

The phylogeny presented in Figure 2 represents the most parsimonious solution for the distribution of character states within the Eucharitidae using the simplest assumptions of character state ordering. A character analysis using only characters of adults does not resolve basal relationships among Eucharitinac (Fig. 1). The additional information provided by larval and behavioural characters is necessary to give increased resolution (Fig. 2). Anthost data were not included in the analysis but subfamilies of ant hosts show a strong correlation with the phylogeny presented here (see Tathle 4). I recognize 3 groups 
of Eucharitudac based on the character analysis as presented in Figures I and 2: the Oriseminae is recognized as a monophyletic group that includes Indosema, Orasema, Orasemorpha, and Timioderus; the Psilocharitini includes the genera Neolosbamms and Psilocharis: and the Eucharitini includes the genera Anesosema. Gollumiella, and the Eucharitinae s.s. (after Graham. 1969; Rick, 1970; and Heraty, 1985), following the classification of Eucharitinae proposed by Bouček (1988). A formal classification of 2 tribes within Eucharitinae is proposed here to distinguish members of the subfamily with an independent or fused prepectus.

Alternate hypotheses of relationships were examined by changing the topology of basal taxa and observing changes in the number of steps and relative indices. Each alternate hypothesis resulted in longer trees and slightly lower CI and RI values. Placement of either the Timioderus + Indosema lineage or Orasemorpha as ancestral to other Eucharitidae fixes the expanded and strongly ridged ovipositor as a groundplan state and requires at least 2 reversals to an acicular ovipositor. Placing Psilocharis as ancestral, with Oraseminae and Neolosbanus as monophyletic, increased the number of steps to 187. Members of Psilocharis are phenetically very similar to some Chrysolampinae, but otherwise there is no support for the hypothesis that they represent the basal lineage of Eucharitidae. Perhaps the most interesting change was the placement of Anorasema as sister group to Psilocharitini + (Gollumiella + Eucharitinae s.s.). This resulted in a tree length of 184 which is only one step longer than the most parsimonious tree. Members of Anorasema are phenetically very similar to species in the Orasema uichancoi-group and both share an increased number of male funicular segments, elongate and pilose forewing, and smooth face. All of the alternate hypotheses above involve changes in taxa where larval stages are unknown. I believe that the most parsimonious solution presented in Figure 2 is the most accurate portrayal of relationships among major lineages of Eucharitidae based on the information available, and forms a sound basis for derivation of a new classification.

The following discussion is restricted to generic level relationships based on the hypothesis presented in Figure 2. Relationships within genera are discussed within the body of each revision.

\section{Eucharitidae}

The monophyly of the Eucharitidae is supported by 5 autapomorphies: mandibles falcate (character 13), labrum with marginal digits arranged in the same plane (14), labral digits initially reduced in number to 4 or 5 (15), and pronotum not visible from above (21). The mandibular and labral character states are lost or modified in at least a few Eucharitidae (i.e., Timioderus, Indosema, and
Psendometagea). An additional autapomorphy for Eucharitidae not coded in the analysis is the absence of a malar sulcus or suture, which is found in both states in the outgroup and is present in many Pteromalidac. The reduced number of labral digits is interpreted in the analysis as a groundplan character for Eucharitidae, with a 4-digitate labrum found in the majority of Orasema, Psilocharitini, Gollumiella + Anorasema, and Pseudometagea within the Eucharitini. However, the majority of species within the Eucharitini possess a multidigitate labrum (8-16 digits). Seven funicular segments for females (5) and a setose speculum (37) are indicated as groundplan states for Eucharitidae (Table 2), but both character states probably are plesiomorphic for Eucharitidae + Perilampidae.

Character states of eggs and immature stages provide the strongest support for monophyly of the family. Heraty and Darling (1984) proposed stalked eggs (48) as an autapomorphy of Eucharitidae. A single character of the first-instar larva that supports the monophyly of Eucharitidae is loss of dorsal setae on tergites VII and IX (58). Larval characters 53-58 were previously shown to support monophyly of the Perilampinae and Eucharitidae (Heraty and Darling, 1984). This analysis suggests that presence of cranial setae (56) (found in some Orasema) and absence of a labial plate (58) are groundplan states of Eucharitidae. Within Orasema, a labial plate is known only in Orasema tolteca Mann, which suggests that it may be plesiomorphic for Eucharitidae (Heraty, 1990). Heraty and Darling (1984) also proposed that loss of a single spiracle in the first instar (present only in Perilampinae and Philomidinae) was a synapomorphy of Eucharitidae. In addition, ant parasitism supports monophyly of Eucharitidae s.s.

\section{Oraseminae}

The Oraseminae is a monophyletic group that includes Orasema, Orasemorpha, Indosema, and Timioderus. Monophyly is supported by 5 synapomorphies: scape of males without pores (3), mesepisternum broadly rounded (32), ovipositor expanded (42), first valvula with lateral teeth (43), and second valvula with lateral teeth (44). Additional characters supporting this clade are the anterior curvature of the ovipositor and perhaps the habit of depositing eggs parallel to the leaf surface (Fig. 3), a habit correlated with ovipositor shape. Absence of pores from the scape of males may be plesiomorphic for Eucharitidae if the fine pores are independently derived in Psilocharitini and Gollumiella. The presence of serrate and lamellate (versus cylindrical) flagellar segments (7) in Timioderus and the presence of an anellus (1) in Gollumiella, Anorasema, and Psilocharitini negates the use of these character states for diagnosing the subfamily (sensu Heraty. 1985). Immature stages and behaviour 
may offer 4 additional character states to support the monophyly of Oraseminae: loss of a ventral spine on tergite III (49), larva pustulate (59), pupa pustulate over petiole $(60)$, and internal parasitism of the host in the first instar (62). However, the immature stages of Orasemorpha, Indosema, and Timioderus are unknown and these character states can be attributed only to Orasema. The Myrmicinae are the ant hosts (60) for Orasemorpha and the main hosts for Orasema (Table 3; see also Table 4); they are predicted to be the hosts for Timioderus and Indosema.

If larval characters are excluded as possible synapomorphies of Oraseminae, then the only support for monophyly of Orasema is that the base of the petiole is truncate and that it has a dorsal flange (39). The monophyly of the Orasemorpha clade is supported by the presence of a short, transverse petiole in females (38) and an anterior projection of $\mathrm{Ms}_{2}$ in males (41). The unfused petiole of Timioderus is either a reversal or a parallel development with some Chrysolampinae; however, the basic structure of the petiole is the same in all 3 genera within that clade, and is unique for Eucharitidae. These results support both cylindrical eggs and a ventrally separated petiole as derived states.

\section{Eucharitinae}

The limits of the Eucharitinae are expanded to include Neolosbanus and Psilocharis. Previous definitions of the Eucharitinae were limited to the Eucharitinae s.s., which was based on complete fusion of the prepectus (19), absence of an anellus (1), variously modified antennal flagellomeres (7), and usually an acicular ovipositor (42) (Burks, 1979; Heraty, 1985). Bouček (1988) included Gollumiella (as Losbanus) and Anorasema in the Eucharitinae and showed that both had an anelliform F1 (1) and 13-segmented antenna. By including Psilocharitini with the Eucharitinae s.s., monophyly of the subfamily is supported by the presence of an occipital carina (18), loss of a constriction from the first gastral sternite (37), elongate and tapered petiole basally (39). and loss of the constriction from $\mathrm{Ms}_{2}$ (40). The occipital carina is lost in some Eucharitinae, and the base of the petiole changes in Psilocharis. A weak basal constriction within the Eucharitinae is known only for Anorasema. Characters of the first-instar larva that support monophyly of the Psilocharitini + Eucharitini are fusion of tergites I and II (51), presence of a distinct tergopleural line (52), absence of cranial setae (56). and presence of a labial plate (58). Character 52 undergoes a reversal in the Ohezer-clade, and the labial plate may be a groundplan state for Eucharitidac. The Clalcura type of third-instar larva (59) is treated as a synapomorphy of Eucharitinac based on its similar occurrence in both Chalcura and Neolostranus, but it undergoes major changes in the rest of the Eucharitinae. Based on a shared ponerine ant host for Neolosbanus and other Eucharitinae, this host subfamily could also be treated as a synapomorphy at this level.

Monophyly of Psilocharitini is supported by the following: base of flagellomeres with secondary segmentation (6), genal depression distinct (10), prepectus narrowed ventrally and foveate (20), propodeum smooth and polished (28), postmarginal vein elongate (36), speculum present (37), and callus polished and slightly swollen. Character 10 is lost in derived species of Neolosbanus; 36 and 37 undergo reversals in single species of Neolosbanus and Psilocharis, respectively, and also show homoplasy within Orasema. Larval characters are unknown for Psilocharis, but if similar to Neolosbanus. then they would be plesiomorphic for Eucharitinae and offer no supporting characters at this level. One possible larval synapomorphy is ventral fusion of the cranial extensions (VFM, Fig. 13), which is discussed in the following section on biology. Within Eucharitinae, Psilocharitini is distinguished by the independent prepectus and the presence of an anellus in almost all species; however, these are plesiomorphic features at this level.

Monophyly of Psilocharis is supported by the following: scrobal depression with smooth channels (9), femoral groove broadly impressed (29), and petiole truncate basolaterally (39). The latter 2 characters are unique attributes of Psilocharis. The petiole is always elongate and strongly ribbed and the lateral margins at the base can be flared laterally. Scrobal channels are also found in Orasema glabra and are lost in some species of Psilocharis. The genus Neoloshamus is supported by absence of a distinct anteclypeus (11), presence of a narrow and sinuate femoral groove (29), and fusion of the gonostylus to the second valvifer (46). Characters 11 and 29 are unique attributes of Neolosbanus whereas character 46 is shared with Eucharitini.

Monophyly of the Eucharitini is supported by the following: absence of pores from the scape of males (3), dorsal enclosure of the mesothoracic spiracle (26), and fusion of the gonostylus to the second valvifer (46). Again, if pores on the male scape are derived states for the Psilocharitini and I species of Gollumiella, then absence would be a plesiomorphic character state. Fusion of the prepectus (19) is treated as 2 character states that support the different lineages within Eucharitini. If these groups are indeed monophyletic, then fusion of the prepectus would be a synapomorphy of the Eucharitini (Heraty, 1992). There are no larval characters supporting this clade other than an increase in the number of eggs laid (61). Other members of the Eucharitini usually deposit their eggs in clusters of 60 to $10000 \mathrm{cggs}$, and only Schizaspidia antennata is known to insert only 3 to 4 eggs into oviposition punctures. as do Oraseminac and Psilocharitini. Single or few eggs deposited in punctures 


\begin{tabular}{|c|c|c|c|c|c|}
\hline Tala & Country & Ant Host* & Plant Ilost (Family)** & $\begin{array}{l}\text { Imnature } \\
\text { Stages } \\
\text { Known }\end{array}$ & Reference \\
\hline \multicolumn{6}{|l|}{ Orasemorpha } \\
\hline O.eribotes & Australia & Pheidole sp. & & & Bouček, 1988 \\
\hline O. mirmicae & Australia & Pheidole sp. & & & PS [BMNH] \\
\hline O. tridensata & Australia & Pheidole provima & & & Brues, 1934 \\
\hline O. reniades & Australia & $\begin{array}{l}\text { Pheidole } \\
\text { tasmaniensis }\end{array}$ & & & PS [BMNH] \\
\hline \multicolumn{6}{|l|}{ Orasema } \\
\hline$O$. fraudulenta & Africa & $\begin{array}{l}\text { Pheidole } \\
\text { megacephala }\end{array}$ & & third, pupa & Reichensperger, 1913 \\
\hline O. wichancoi & Philippines & & $\begin{array}{l}\text { Celtis (Fagaceae) } \\
\text { Lencaena (Leguminoseae) }\end{array}$ & egg, planidium & Ishii, 1932 \\
\hline $\begin{array}{l}\text { O. sp. } \\
\text { (nr rugulosa) }\end{array}$ & $\begin{array}{l}\text { Solomon } \\
\text { Islands }\end{array}$ & Pheidole sp. (W) & & pupa & PS [USNM] \\
\hline O. assectator & India & Pheidole sp. & Ceanorhus (Theaceae) & egg to pupa & Das, 1963; Kerrich, 1963 \\
\hline O. initiator & India & & Ceanothus & & Kerrich, 1963 \\
\hline O. valgins & Australia & Pheidole sp. (W) & & & Girault, 1913b \\
\hline \multicolumn{6}{|l|}{ Neolosbanus } \\
\hline N. gemmia & Australia & Hypoponera sp. (S) & & pupa & PS [JMH] \\
\hline \multirow[t]{6}{*}{ N. palgravei } & Australia & Hypoponera sp. (S) & Flindersia (Rutaceae) & egg to pupa & PS [JMH, TAMU] \\
\hline & & & Tetrasynandra (Monimaceae) & & PS [JMH] \\
\hline & & & Macaranga (Euphorbiaceae) & & PS [JMH] \\
\hline & & & Lygodium (Schizaeaceae) & & PS [JMH] \\
\hline & Malaysia & & Rutaceae & egg, planidium & PS [JMH] \\
\hline & & & Schizaeaceae & & PS [JMH] \\
\hline$N$. laeviceps & Sri Lanka & & Artocarpus (Moraceae) & planidium & Clausen, 1940b, 1940c \\
\hline
\end{tabular}

* Ant determinations by S (= S. Shattuck, ANIC) and W (= E. O. Wilson, MCZ); PS = Present Study.

** Eggs were deposited into leaves for all known plant associations. 
may also occur in Anorasema and Chalcura montana, which also have an expanded ovipositor.

Monophyly of Anorasema and Gollumiella was discussed in detail by Heraty (1992). Monophyly of the Eucharitini s.s. (excluding Anorasema and Gollumiella) is supported by the following: loss of anellus (1), increased number of labral digits (usually 9 to 16; character 15), fusion of the prepectus in same plane (19), transverse axilla (22), presence of internal mesoseutal ridge (25), and wedge-shaped mesepisternum (32). Character 32 undergoes considerable change within this clade. No characters of immatures support this clade. The majority of species deposit their eggs in large numbers into spaces within preformed plant cavities (flower bracts, under bud scales, etc.; see Clausen, 1940a, 1940b, 1940c), which represents a major shift in ovipositional strategies within the family. Relationships of genera within this clade, as presented in Figures 1 and 2, are tentative and represent only an initial hypothesis of relationships. However, the relationships proposed for Eucharitinae are congruent with ant hosts, even though ant hosts were not included within the character matrix used to build the tree.

\section{CONCLUSIONS ON PHYLOGENY}

Characters of adults are highly variable within Eucharitidae and new information based on the taxa described here creates problems in defining Eucharitidae at both the family and the subfamily level. More conservative characters such as larval morphology and behavioural information provided additional resolution necessary to examine relationships among Eucharitidae. The Oraseminae has been redefined and forms a monophyletic group containing many of the species of Oraseminae as defined by Bouček (1988). Two groups are supported within the Oraseminae: the Orasemorplia clade and Orasema. The limits of the Eucharitinae are extended to include the genera Neolosbanus and Psilocharis within the tribe Psilocharitini. All Eucharitinae with a fused prepectus are included in the Eucharitini. Larval and behavioural characters are congruent with the cladogram constructed using characters of the adults alone, and offer more unique and unreversed (non-homoplastic) characters to support the proposed relationships.

\section{Biology}

Information on the first-instar larva, other immature stages in the ant nest, oviposition habits, and ant host is available for 18 of the 40 known genera of Eucharitidae. In some groups such as Orasema, Stilbula, and Schizaspidia, there is considerable information on every life stage and often for more than 1 species, allowing for some generalizations on life history. Morphology of the immature stages, and in particular the selerotized planidium, is conservative at the generic level and above, and can be useful in positing relationships at higher taxonomic levels (Heraty and Darling. 1984). Along with information on ant hosts and oviposition strategies, inclusion of such characters within a phylogenetic analysis can serve to test, supplement, and refine hypotheses derived from studies of adult morphology. In this section, biologies of the known members of Oraseminac and Eucharitinae are treated on a comparative basis. Trends in the evolution of morphological characters and some behavioural traits were considered in the earlier section on phylogeny.

All Eucharitidae s.s. are parasites of ants. Parasitism is indirect in that oviposition occurs in plant tissue away from the host (Clausen, 1940b, 1940c, 1941). Eggs may be laid singly or in clusters of up to several thousand (Clausen, 1940b, 1941: Johnson el al.. 1986). Upon hatching. the first-instar larvac. termed planidia, actively sech out adult ants or thrips (Thysanoptera) for tramsport to the ant nest (Clausen, 1940b, 1941; Wilson and Cooley, 1972; Johnson et al., 1986). The planidium transfers to an ant larva where it remains as a first instar until the ant pupates (Clausen, 1940b, 1941). In Orasema, the planidium burrows just under the larval cuticle and later becomes external when the ant pupates (Wheeler, 1907). In most Eucharitinae, the planidium is always external (Clausen, 194lc). Pupation and emergence take place within the ant nest. Adults leaving the nest are ready to mate and lay eggs.

The function and morphology of the ovipositor suggest a major dichotomy in the Eucharitidae. Five genera of Oraseminae and Psilocharitini, plus a few species of Schizaspidia (Eucharitinae), have an expanded ovipositor. The structure of this ovipositor is unique within the Chalcidoidea, and in Orasema and Schizaspidia the ovipositor is used as a tool to hollow out a chamber in leaf tissue where 1, or rarely up to 4 . eggs are deposited (Clausen. 1940b; Johnson et al.. 1986). This is in sharp contrast to the acicular ovipositor generally found in the Eucharitinae (Heraty, 1985). The acicular ovipositor is used to pieree plant tissue and deposit a mass of eggs into pre-cxisting cavities between bud scales or in undeveloped flower buds. Some eucharitines simply seatter egg. over the leaf surface and Obea is known to deposit eggs into the tissue of fruits (Heraty and Barber. 1990). 
Table 3 is a smmmary of life-history informanton for llawe species of Oraseminae (Old World) and Pilocharitini for which the ant host or immature stages are known. Additional information on habits of New World Oraseme is found in Heraty $(1990)$ and will be formalls treated in a future publication. Within the limited list of plant associations, 21 specics of Oraseminac are associated with 31 plant genera distributed in 22 families of plants (Heraty, 1990). In the Old World, plant hosts of Oraseminac are known only for Orasema, and they are Fagaceac, Leguminoseac. and Theaceac (Table 3). Psilocharitini have a broad host range and species of Neoloshanis have been collected on at least 7 families of plants (Table 3). Ant hosts are more restricted with records of 8 genera of ants in 4 subfamilies for both Oraseminae and Psilocharitini (Tables 3 and 4). The following sections present new and previously published information on the biology of 3 genera of Oraseminae and Neolosbanus, and provides a review of the biology of the Eucharitini (Eucharitinae s.s.). Orasema and Neolosbanus are considered as representative of their respective groups.

\section{BIOLOGY AND IMMATURE STAGES OF ORASEMORPHA}

Four species of Orasemorpha have been reared from the ant genus Pheidole (Table 3). The pupa of $O$. tridentata was described as having the margins of the abdominal tergites "raised and carinate, the edge of the second tergite projecting as a distinct, sharp tooth on each side not far from the median line" (Brues, 1934:205). These structures may be similar to those described for Orasema, but no mention was made of pustules along the dorsal margin of the petiole, a feature known only for Orasema. Pupae were not recovered along with the type material of $O$. $t r i-$ dentata $(=$ wheeleri $)$ which is located at the MCZ.

\section{BIOLOGY AND IMMATURE STAGES OF ORASEMA}

The biology and immature stages of the genus Orasema were described in detail for several species (Wheeler, 1907; Clausen, 1940c, 1941; Parker, 1942; Wheeler and Wheeler, 1937: Das, 1963; Heraty and Darling, 1984; Johnson et al., 1986). There is a remarkable consistency of both oviposition habits and morphology of immature stages in Orasema. A generalized biology is presented below. Specific reterences to differences among species groups are only briefly discussed.

\section{Oviposition Behaviour}

Parker (1942) and Das (1963) described details of adult oviposition behaviour for Orasema. The ovipositor is inserted forward into the leaf, and eggs are deposited parallel to and just under the surface of the plant tissue (Fig. 4). Females of most species have been observed to deposit single eggs into punctures. The punctures are either scattered over the plant surface or placed in short. straight rows into the stems, the underside of leaves, or the involucral bracts of various plants (Fig. 3; Parker. 1942; Das, 1963; Johnson et al., 1986). Orasema wichancoi (Ishii) was reported to lay eggs in short alternating double rows on the undersurface of leaves (Ishii, 1932). In most cases, plant tissue surrounding the length of the oviposition puncture became brown. Plant tissue was observed to become scarified around the oviposition punctures of $O$. sp. nr aenea on leaves of Muhlenbeckia (Parker, 1942).

Choice of plants in which species of Orasema oviposit does not appear to be restricted. Females of Orasema are known to oviposit in leaves of tea (Theaceae), mango (Anacardiaceae), and oak (Fagaceae); involucral bracts of composite flower heads; or even into young banana fingers (Museaceae) (Johnson et al., 1986). In Orasema viridis Ashmead, females oviposit in undeveloped flower buds of Haplopappus (Compositae) as well as Sphaeralcea (Malvaceae) (Johnson et al., 1986). Orasema tolteca Mann and $O . \mathrm{sp}$. nr aenea have been observed to oviposit on 4 or 5 different families of plants (Heraty, 1990). Within a species, Orasema is generally consistent in its choice of plant structure for oviposition. All of the Old World species are known only to oviposit directly into leaves (Table 3).

\section{Egg (Fig. 4)}

Stalked eggs as typical for Eucharitidae; white with smooth chorion and short anterior stalk, apical thickening of stalk indistinct (Parker, 1942; Heraty and Darling, 1984; Johnson et al., 1986). The egg stalk. is usually bent over the side of the egg within the oviposition chamber (Fig. 4), not erect as observed for Neolosbanus (Fig. 18). Mature eggs have a heavily sclerotized (darkened) firstinstar larva occupying almost the entire egg body, with the head oriented toward the stalk.

\section{First Instar (Figs. 5-9)}

The planidium of Orasema differs from those of other Eucharitidac in that tergites I and II are separated dorsally, the mid-ventral seta on tergite 111 is absent, and the pleural region of tergite IX is separated into a leaflike ventral plate. A general discussion of characters in relation to Eucharitinac and the outgroup family Perilampidae was presented in Heraty and Darling (1984). Heraty and Darling (1984) and Johuson et al. (1986) reported the 
absence of a labial plate from Orasema as a loss from the groundplan state of the Eucharitidae (present in all Eucharitinae). A weakly sclerotized labial plate was observed in 1 undescribed species of Orasema from Mexico, which may offer support for this hypothesis. Heraty and Darling (1984) suggested that the weak lines of desclerotization extending from the base of the setae (Fig. 6) may be a reduced tergopleural line. In Orasema tolteca, a faint area of desclerotization is apparent along the tergites in a position homologous to the tergopleural line in Eucharitinae (Fig. 15) and is distinct from the lines of weakness associated with the setal bases. An additional feature found in all species of Orasema examined is the presence of a broad, ventral extension of the cranium, which remains separated medially (VFM, Figs. 13-14).

The planidium of Orasema uichancoi, originally described and illustrated by lshii (1932), was reexamined and 3 character states were shown to be incorrectly described or illustrated: tergites I and II are separated dorsally (not fused), labial plate is not apparent (Ishii showed it as present), and the ventral region of tergite IX is separated into a leaflike plate (not shown by lshii).

The means by which planidia gain access to the ant nest is unknown, but an intermediate host association with thrips has been shown for Orasema sp. on Frankliniella occidentalis (Pergande) (western flower thrips) (Wilson and Cooley, 1972; specimens examined); Orasema sp. on Microcephalothrips abdominalis and Frankliniella sp. (Beshear, 1974); O. coloradensis Gahan on Sericothrips sp.; $O$. viridis Ashmead on immature thrips (Johnson et al., 1986); and $O$. assectator on Empoasca flavescens (F.) (tea leafhopper) or Scirtothrips dorsalis Hood (tea thrips) (Das, 1963). I found additional associations with thrips for 5 other species of Orasema. Planidia remain either lightly attached to the surface of the thrips abdomen (Fig. 5) or burrow into the thrips and feed, without causing distention of the body segments of the planidia (Wilson and Cooley, 1972; Johnson et al., 1986). Planidia of Orasema are often found attached to an immature thrips.

One hypothesis to explain this phoretic behaviour is that ants capture thrips laden with planidia and carry them to the nest as food for the brood. Attempts to prove this direct transfer have not been successful, but uncler laboratory conditions, a worker of Pheidole crassicomis Emery was observed in the laboratory to pick up a thrips, with attached planidia, and carry it to the brood pilc. Clausen (1940b) dismissed the possibility of the thrips as an intermediate step to the ant host because no ants were known 10 "tend" thrips, but he neglected to consider the possibitity of predation by the ants. There are reliable records of Wasmannia auropunctata (Roger) preying upon the cocoa thrips in Trinidad (Ananthakrishnan. 1984), of Azteca chartifox as a control for thrips in Brasil
(Ananthakrishnan, 1984), and of Pheidole megacephala (Fabr.) as a significant predator of Liothrips in Hawaii (Reimer, 1988). Both Wasmannia and Pheidole are known hosts of Orasema.

The habits of the early larval stages of Orasema within the ant nest were described by Wheeler (1907). Wheeler and Wheeler (1937), and Das (1963). I obtained additional information for Orasema sp. on Pheidole dentata Mayr and Solenopsis xyloni $\times$ geminata, and for $O$. xanthopus (Cameron) on Solenopsis sp. (? invicta from Matto Grosso. Brazil; material collected by D. Wojcik and D. Jouvenaz, Gainesville, Florida, United States: vouchers in ROM). The habits of the first instar were the same in all of the species. Unfed planidia were found attached to the dorsal surface of the second-instar ant larva and burrowed under the cuticle of the third instar (Figs. 7-9). On Pheidole dentata, planidia burrowed just behind the cephalic region (Fig. 8), whereas locations were more variable for $O$. xanthopus. Planidia extracted from the host larva show an initial distention of the ventral and unsclerotized regions of the body. Larvae complete a considerable amount of feeding within the host and become greatly distended (Fig. 8). Upon pupation of the host. larvae become external (Fig. 9) and move to the ventral region of the thorax of the host, between the deformed pupal legs (Fig. 10). First-instar larvae show extreme distention in the final stages with the tergites strongly separated.

\section{Second Instar}

This instar is more typically hymenopteriform, white, and very weakly sclerotized with a single pair of mesothoracic spiracles (propneustic). The head region is weakly delineated, with a small pair of pincerlike mandibles. This stage is virtually identical to other second-instar larvac described within the Eucharitidac. The second instar remains attached to the host in the ventral region of the host thorax.

\section{Third Instar (Figs. 10-11)}

This instar is white and membranous with 2 thoracic and 6 to 7 abdominal spiracles evident. 9 enlarged dorsolateral tubercles, a smaller series of lateral tubercles continuing onto the prothoracic segment, a pair of medially divided tubereles lateral to the oral region, the ventral surface of abdominal segments finely ridged, and the oral region lacking mandibles and consisting of fine striac convergent on midline. The structure of the third-instar larval undergoes a series of changes from the early third instar (Fig. 10) to the prepupal stage largely based on the definition of tubercles. Prepupal stages are more prominently tuberculate, and precursors of the antennal segments are evident along ventrolateral matrgins.

Third-instar larvate complete development on the host. 
and then detach themselves and are free within the brood pule. The shrivelled host remains, termed phthisergates (atter Whecker 19(17. 1910), stay within the ant colony.

\section{Pupa (Fig. 12)}

The pupal has 3 enlarged tubercles along the dorsal margin of petiolar region. the gaster has raised transverse bands. and lateral and subventral tubercles are often present on abdominal ridges. The gaster of males is smaller than that of females. The structure of the pupa was seen to be consistent across broad groups within Orasema based on data from $O$. fraudulenta (striatosoma-group; Reichensperger, 1913), Orasema assectator (assectatorgroup), and Orasema sp. nr rugulosa (uichancoi-group) (Table 3). The structure of the pupae of these species supports the enlarged tubercles over the petiole as a unique character of Orasema. Diagnostic characters for species of Orasema are found in the shape and prominence of tubercles on the gastral ridges.

Pupation and emergence of adults take place within the ant nest. Adults of Pheidole and Solenopsis were observed tending and carrying the adults and pupae of Orasema within the nest. Workers were observed transporting pupae by the dorsal tubercles over the petiole. Reichensperger (1913) suggested that the tubercles of larvae and pupae might be secretory and act in ant appeasement. Vander Meer, Jouvenaz, and Wojcik (1989) found that pupae and adults of Orasema sp. collected in the nest of Solenopsis shared the same cuticular hydrocarbon profile of the host brood. The authors proposed that Orasema may be utilizing colony odour or producing a mimicking compound, but they downplay the latter hypothesis. More work needs to be carried out, possibly with a focus on the tubercles of the third-instar larva and the pupa of Orasema.

\section{BIOLOGY AND IMMATURE STAGES OF NEOLOSBANUS}

Habits for Neoloshanus are based largely on data collected by me from 2 populations of $N$. palgravei observed in the undergrowth of rainforests in north Queensland, Australia, and Selangor, Malaysia. The within-nest larval stages were collected from Hypoponera nesting in rotten wood at the Australian location. Supplemental information was provided by published accounts for $N$. laeviceps (Clausen, 1940b, 1940c, 1941), a pupa of $N$. gemma dissected from a cocoon of Hypoponera, and museum records of plant hosts.

\section{Oviposition Behaviour}

Adults of $N$. palgravei deposited eggs singly into the underside of broad-leaf plants belonging to the plant families Rutaceae. Monimiaceac. Euphorbiaceac, and
Lygodimm (Schisacaceate. Eggs were deposited at approximately a 45-degree angle to the leaf surface, with the stalk of the egg erect and slightly protruding from the opening (Fig. 18). The plant tissue showed no reaction to freshly deposited eggs (Fig. 18), but became scarified and swollen around the opening as eggs matured (Fig. 19). Oviposition punctures were either scattered over the underside of the leaf (both locations) or deposited alternately in short double rows of about 20 eggs (Malaysian only). The density of oviposition was extremely high at both sites and the entire underside of new growth was saturated with punctures. Plants recovered from the wounds, and older leaves showed decreasing levels of scarification. Neoloshanus laeviceps deposited eggs singly into leaves of Artocarpus (Moraceae) (Clausen, 1940b). Clausen illustrated a puncture of $N$. laeviceps with $3 \mathrm{eggs}$, but he stated in the text that eggs were deposited singly. Neoloshanus townesi was collected from leaves of Castanopsis (Fagaceae) and bamboo (Poaceae) in Papua New Guinea (Table 3). There are no oviposition records for species in the N. gemma- or N. purpureoventrisgroups, but $N$. gemma was collected from flowers and 1 collected adults of $N$. purpureoventris on broad-leaf understorey plants in Taiwan and Thailand.

\section{Egg (Figs. 17-19)}

Undeveloped eggs of $N$. palgravei are white with a smooth chorion. Mean length of egg body (Australian population) is $0.14 \mathrm{~mm}(\mathrm{SD}=0.01, \mathrm{n}=6)$; mean length of anterior stalk is $0.07 \mathrm{~mm}(\mathrm{SD}=0.01)$. The anterior stalk has a thickened apical extension with a mean length of $0.07 \mathrm{~mm}(\mathrm{SD}=0.01)$. Mature eggs have a lightly sclerotized first-instar larva occupying almost the entire egg body, with the larval head oriented towards the stalk (Fig. 17). Eggs of $N$. purpureoventris are the same, and those of $N$. laeviceps are similar but lack an apical extension (Clausen. 1940b). These eggs are similar to those of other Eucharitidae (Clausen, 1940c; Heraty and Darling, 1984).

\section{First Instar (Figs. 13-14, 20)}

Planidia of $N$. palgravei are similar to those described for Eucharitinae (Heraty and Darling. 1984) and possess the following characteristic states: distinct labial plate; dorsal fusion of tergites I and Il: distince tergopleural line separating pleural region on tergites II-VIII; and 2 ventral setae on tergite III. Tergite IX shows a partial invagination of the ventrolateral region of the tergite that is similar to, but less pronounced than, that in Orasema. Unique character states for Neoloshanus include a relatively broad ventral margin of the cranium, which is fused medially (Figs. 13-14), and tergites lightly sclerotized and pale brown in colour. The terminal segments of the planidium of $N$. laciceps (illustrated in Clausen, 1940c) are similar to the Malaysian $N$. palgranei but have the ter- 
gopleural line continuing on tergite $1 \mathrm{X}$.

Planidia of $N$. palgravei collected in Malaysia showed strong differences from the Australian larvae in the following states: cranium dorsally with raised median area (Fig. 14); seta present at lateral fusion of tergites I and II; ventral margins of tergites $\mathrm{IV}-\mathrm{IX}$ strongly sculpted along posterior margin; caudal cerci short; body length significantly shorter (Malaysian, $0.12 \pm 0.01$ [SD] mm, $\mathrm{n}=10$; Australian, $0.14 \pm 0.01 \mathrm{~mm}, \mathrm{n}=10$; Student's t. $\mathrm{p}<$ $0.01)$. The Australian population possesses a larger seta with tuberculate base on tergite VI (Fig. 13), which is unknown for other Eucharitidae. Additional collections of larvae may reveal correlations with the minor differences in adults of $N$. palgravei such that separate species may be warranted.

First-instar larvae of $N$. palgravei move by a looping motion or can jump for a distance of about $10 \mathrm{~mm}$ as described for other Eucharitidae by Clausen (1940c). No intermediate host associations were observed on the plants, and host ants were observed only on the ground. The high density of eggs and the jumping habits of the larvae suggest that they "rain" down upon the forest litter. Within the nest of Hypoponera several partially fed firstinstar larvae were found attached on either side of the head capsule of mature host larvae (Fig. 20), and on 1 larva within the host cocoon.

\section{Second Instar (Figs. 2I-23)}

This instar is more typically hymenopteriform, white, and very weakly sclerotized; the spiracles and mouthparts are not discernible (Fig. 21). The first-instar exuvium remains attached to ventral surface. Several second-instar larvae ( 1 per host) were found attached to mature prepupae of Hypoponera within the host cocoon (Fig. 22). Only I second instar was attached to a deformed pupa with the pupal legs exposed (Fig. 23), as is more typical for other known Eucharitidae.

\section{Third Instar (Fig. 24)}

This instar is white and poorly sclerotized, with spiracles and body segmentation not apparent, entire dorsal surface minutely tuberculate, and exuvium of first instar not attached. The shape of the third instar is similar to those of Chalcura, Schizaspidia, and Stilbula (Clausen, 1923, 1928, 1940c), and of Pscudochalcura (Heraty and Barber, 1990).

\section{Pupa (Fig. 25)}

The pupa of Neoloshanus palgravei is typically chalcidoidlike except for raised ridges along the metasomal tergites, as in other Eucharitidac. The cocoon of Hypoponera was open at the caudal end, and remains of the host were not found with the pupa. A single female pupa of $N$. gemmo was collected in 1 of the colonies of
Hypoponera, which was also parasitized by $N$. palgravei (Fig. 26). The mature pupa was similar to N. palgravei. except for characters that distinguish the adults of the 2 species (especially the clypeus and profile of the mesosoma), and to pupae of Eucharitinae.

\section{BIOLOGY AND IMMATURE STAGES OF EUCHARITINI}

The oviposition habits of several species were reviewed by Clausen (1940a, 1940b. 1940c, 1941) and the ant-host records were reviewed by Wheeler and Wheeler (1937) and Johnson (1988). Significantly less information has been published on the immature stages within the ant colony, and what little there is, is based on the following species: Austencharis fasciiventris (Brues) (Brues, 1919), Chalcura deprivata (Walker) (Clausen, 1940c). Eucharis esakii Ishii (= scutellaris Gahan) (Clausen, 1940c). Kapala terminalis (Clausen, 1940c), Psendochalcura gibbosa (Provancher) (Wheeler, 1907; Heraty and Barber, 1990), Pseudometagea schwarzii (Ashmead) (Ayre, 1962), Schizaspidia convergens (Walker) (Clausen, 1940c), Stilbula cyniformis Rossi (Parker, 1937), and Stilbula tenuicornis (Ashmead) (Clausen, 1923).

\section{Oviposition Behaviour}

Adults of Eucharitinae usually deposit large numbers of eggs into preformed cavities in plant tissue (Clausen, 1940a, 1940b, 1940c, 1941: Heraty and Darling, 1984). In a few cases, eggs are scattered on the undersurface of a leaf (e.g., Kapala terminalis; Clausen, 1940b), are placed in an erect position on a leaf surface in association with thrips eggs (Gollumiella antennata (Gahan): Clausen, 1940b, 1941), or are deposited into fruit (Obeza floridana (Ashmead); Heraty and Barber, 1990). In Schizaspidia antennata Gahan and Schizaspidia nasua (Walker) (= Kapala foveatella Girault), 1 to 4 eggs are deposited into oviposition punctures in the leaf tissuc (Clausen, 1940b: Ishii, 1932). The majority of Eucharitinae, including the 43 described species of Schizaspidia, have an acicular ovipositor, which is used for penetrating plant tissue. In the above 2 species of Schizaspidia, the ovipositor is subapically expanded and strongly ridged, as in Orasema. In Anorasema and Chalcura montana (Girault), the ovipositor is expanded along its length, but smooth.

\section{Egg}

The eggs are stalked (as is typical for Eucharitidae) and white and have a smooth chorion: the anterior stalk sonetimes has terminal thickening (Heraty and Darling. 1984).

\section{First Instar (Figs. 15-16)}

The larva of Austeuclearis implesd (Walker) (new information on larva removed from body of holotype: Fig. 15) 
1 1 pecal for most species in the subfamily as described In Ilerall and Datrling (1984). Releviut character states are discussed under Neolostramis. The planidia of Obeza floridana (Fig. I0). Srilbula. and Psendochalcura are aty pical for the sublamily: they lack the tergopleural line and hate only I ventral seta on tergite III. These features appear to he characteristic of a group of genera within the Euchatritinate (Heraty and Barber, 1990).

Generally, the planidia of Eucharitinae gain entrance to the nest by various means of phoretic attachment to worker ants, independent of any intermediate insect carrier (Clausen, 1923, 1940b, 1941; Ayre, 1962; Heraty and Barber. 1990). One case is known involving an obligatory thrips association. Clausen (1940a, 1940b, 1941) described females of Gollumiella antennata (Gahan) depositing their eggs "vertically, regularly spaced and in numbers of up to 100 , in the immediate vicinity of a freshly deposited thrips egg." Oviposition could be induced only in the presence of the thrips egg. The eggs all hatch simultaneously and the planidia attach themselves to the young thrips. Clausen was not successful in determining the relationship between the thrips and an ant host for $G$. antemata.

Upon entering the host colony, the planidium remains as an external parasite of the host larvae in Chalcura deprivata (?)*, Eucharis scutellaris (?), Kapala terminalis, Psendochalcura gibbosa, Schizaspidia convergens (?), Stilbula cyniformis, and Stilbula renuicornis (Clausen, 1923, 1941; Parker, 1937; Heraty and Barber, 1990). Pseudometagea schrarzii is the only species of Eucharitinae known to burrow into the larval cuticle, where it overwinters with its host (Ayre, 1962; verified in my collections from Windsor, Ontario, Canada).

\section{Second Instar}

This is similar to the second instar larvae described for Orasema (Clausen, 1940c, Heraty and Barber. 1990).

\section{Third Instar}

This instar is typically hymenopteriform, lacking pronounced ridges or protuberances (Clausen, 1923, 1940c; Heraty and Barber, 1990).

\section{Pupa}

The pupa is typically chalcidoidlike. In Austencharis, Chalcura, Schizaspidia, Stilhula, and Kapala, the pupae can have marked vesicular swellings on the head and mesosoma, but pronounced ridges or protuberances over the petiolar region are lacking (Wheeler. 1907; Clausen. 1940c; Ayre, 1962; Heraty and Barber. 1990).

\footnotetext{
* Question marks in parentheses refer 10 my difficulty in interpreting Clausen's comments regarding actual observations on the larvae of these genera.
}

\section{IIOST-ANT RELATIONSHIPS \\ (OF EUCHARITII)AE}

There is little information that can be gained for assessing host relationships within Eucharitidac by looking at taxa that are considered to be closely related to Eucharitidae. Chrysolampinae are primary parasitoids of Curculionidac and Nitidulidae (Darling. 1986). Perilampinae parasitize a wide variety of hosts including Curculionidac (Platypodinae) by Monacon Watersion (Bouček, 1978), Anobiidae by Steffanolampus Peck (Bouček, 1978), Eumeninae (Vespidae) by Krombeinius Bouček (Darling. 1988b). Ichneumonidae by Euperilampus Walker (Darling, 1983a, 1983b), and Chrysopidae. Tachinidae. and Hymenoptera (Diprionidac and Ichneumonoidea) by Perilampus Latreille (Darling, 1983a). Echthrodape and Plilomides are both parasitoids of bees. Only Eucharitidae s.s. are parasitoids of ants. Chrysolampinae exhibit a similar method of egg deposition to New World Orasema by depositing eggs into seed pods, at random with respect to presence or absence of the host (Darling and Miller, 1991), but otherwise there are few similarities with other taxa on methods of gaining access to the host.

Information on the ant hosts of Eucharitidae is summarized in Table 4. Some genera (Orasema and Eucharis) show a very broad host range, with species found on several different genera, or even on different subfamilies of ants. In other genera (Austeucharis, Chalcura, and Tricoryna), the hosts are restricted to I genus of ants. Orasema have been reared most often from myrmicine ants belonging to the genus Pheidole Westwood, with scattered records in the New World from Solenopsis Westwood, Wasmannia Roger, and Tetramorium Mayr (Wheeler and Wheeler, 1937; Bouček, 1988). Two notable exceptions are Orasema coloradensis Ashmead, which was found associated with Formica (Formicinac) (Johnson et al.. 1986), and a museum record of Orasema rapo Walker, which was reared from the army ant Eciton quadriglume (Haliday) (Ecitoninae) (Heraty, 1990). In the Old World, Orasema and Orasemorpha are known only from Pheidole.

In the Psilocharitini. 2 species of Neoloshanus have been reared from the ponerine ant genus Hypoponera. Hosts of Eucharitini are generally restricted to the Ponerinae and Formicinae (Table 4), with a few notable exceptions. The Australian genus Austencharis has been reared from Mymecia Fabricius (Myrmeciinae) (Brues. 1919). Eucharis adscendens Fabricius and Psilogastrellus punctatus (Foerster) were reared from Messor barbarus Linnacus (Ponerinae) in Europe (Fahringer and Tölg, 1912); other members of both genera, which are sister laxa, were reared from Formica Linnć and Cataglyphis Focrster (Formicinac). Species belonging to 2 closely related genera of eucharitines. Kapala and Galearia Brullé. have been associated with nests of Pogonomyrme. 
TABLE 4. Ant hosts of the Eucharitidae. Genera of Eucharitidae are listed in a hierarchy based on the cladogram presented in Figure 2. Psilogastrellus was not included in the cladistic analysis, but is the sister group of Eucharis. Rearings from host-ant genera presented in parentheses do not belong to the same ant subfamily as the most common records (presented in last column). Ant genera in which subfamilies are not listed are Eciton (Ecitoninae), Formica (Formicinae), and Messor (Ponerinae). Numbers in parentheses refer to literature listed below the table.

\section{ORASEMINAE}

Orasema

Orasemorpha

EUCHARITINAE

Psilocharitini

Neolosbamus

\section{Eucharitini}

Chalcura

Austeucharis

Schizaspidia

Kapala

Isomerala

Tricoryna

Propsilogaster

Psendometagea

Eucharis

Psilogastrellus

Obeza

Stilbula

Stilbuloida

Psendochalcura
Pheidole (4-5, 11-13, 16). Solenopsis (13-16).

Tetramorimm (16), Wasmannia (13), (Formica, 10; Eciton, 16) Myrmicinae

Pheidole $(13,16)$

Myrmicinae
Hypoponera (16) Ponerinae

Odontomachus $(3,13)$, Rhytidoponera (16), (?Myrmecia, 3) Ponerinae Myrmecia $(3,13)$

Odontomachus $(3,13,16)$, Gnamptogenys (16)

Odontomachus (4, 13, 16), Pachycondyla (13)

Ectatomma (13)

Rhytidoponera $(13,16)$

Rhytidoponera (16)

Lasius (1.7)

Formica (2, 4, 13), Cataglyphis (13), (Messor, 13)

Cataglyphis (2), (Messor, 2, 13)

Camponotus (6)

Camponotus (13), Polyrachis (13)

Camponotus $(3,13)$, Calomytmex (13)

Camponotus $(8,13)$
Myrmeciinae

Ponerinae

Ponerinae

Ponerinae

Ponerinae

Ponerinae

Formicinae

Formicinae

Formicinae?

Formicinae

Formicinae

Formicinae

Formicinae

1. Ayre (1962); 2. Bouček (1956); 3. Bouček(1988); 4. Clausen (1941); 5. Das (1963); 6. Davis and Jouvenaz (1990); 7. Heraty (1985); 8. Heraty (1986); 9. Heraty and Barber (1990); 10. Johnson et al. (1986); 11. Kerrich (1963); 12. Van Pelt (1950); 13. Wheeler and Whecler (1937); 14. Williams and Whitcomb (1973); 15. Wojcik (1988): 16. Unpublished museum records.

Note: Wheeler and Wheeler (1937) is a summary of all rearing information prior to that year and should be examined for more detailed information. 
Mayr (Mfrmenale) (Wheeler, 1907: Gemignani, 1933). Neither Kiapala nor Galearia have been taken from within a colony of Pogenommenex, and 1 regard some of the associations listed above for Encharis, Kapala, and Galemita as doubsul and in need of verification.

In order to evaluate coevolution between hosts and parasites, the phylogenetic relationships of each group can be compared for congruence (Kistner, 1979; Mitter and Brooks. 1983). Brown (1954) proposed 2 main lineages of ants; the poneroid lineage, which included the Dorylinae, Ponerinae, and Myrmicinae (this last subfamily was considered as derived from the poneroid tribe Ectatommatini); and the myrmecoid lineage, which included the Myrmeciinae as sister group to the Aneuritinae and Formicinac (Wilson, Carpenter, and Brown. 1967; Wilson, 1971). Taylor (1978) proposed a slightly different phylogeny with the Myrmeciinae as sister group to the poneroid lineage. Baroni-Urbani (1989) proposed the Myrmeciinae + Ponerinae as sister group to the Myrmicinae + Pseudomyrmecinae, although he strongly questioned the relationships between these 4 subfamilies. Hölldobler and Wilson (1990) adopted a similar scheme but included the army ants as sister group to Myrmicinae + Ponerinae, and placed Formicinac as the most basal (extant) subfamily of ants. More recent studies have suggested that the Myrmicinae (together with Pseudomyrmecinae and Myrmeciinae) either form the sister group of the Ponerinae, which shares derived character states with army ants (Bolton, 1990; Ward, 1990; Shattuck, 1992) or belong to a group including Myrmecinae and Formicinae (Baroni-Urbani. Bolton, and Ward, 1992). If these lineages are compared with the cladogram produced for eucharitid genera (Fig. 2), distinctive host correlations are apparent although they do not necessarily correlate with any of the suggested evolutionary schemes proposed for ants (i.e., Formicinae are considered as a basal ant lineage, but are hosts to more highly derived Eucharitinae).

Without a shared host for the Oraseminae or Eucharitinae (ignoring the single-host records from Formica and Eciton, and disputed records for Eucharitinae), it is impossible to determine that either Myrmicinae or Ponerinae could be the ancestral hosts for Eucharitidae. The phylogenetic relationships of Eucharitinae suggest that the Ponerinae are the ancestral hosts for the Eucharitinae. The genus Austewcharis is unique in its parasitism of Myrmeciinae. Tricoryna and Propsilogaster are both parasites of Rhytidoponera Mayr. and under some tree topologies are considered as sister groups. The shift to hosts in the Formicinae appears to be a derived trait within Eucharitidac. The genera Obeza. Stilbula, Stilhuloida, and Psendochalcura are a monophyletic group within Eucharitinae, and Componotus species are the hosts for almost all of the species in these genera (Table 4). Pseudomelagea and Encharis + Psilogastrellus are placed within a monophyletic group that includes the Obeza-clade, and all are parasites of Formicinae. Within the Eucharitinae, these 3 taxa are probably more distantly related and may represent sepirate colonizations of Formicinae. The Formicinae are distantly related to the Myrmicinae and Ponerinae, and a shift in host to this subfamily would be regarded as a colonizing host adaptation.

\section{CONCLUSIONS ON BIOLOGY AND IMMATURE STAGES}

Almost no homoplasy occurs for characters based on morphology of immature stages and the biological traits of the genera under study (Fig. 2). The 2 subfamilies are strongly separated by behaviour, morphology of immature stages, and ant host. In the phylogenetic analysis it was proposed that the expanded ovipositor, and hence oviposition into chambers formed in leaf tissue, arose at least four times in Eucharitidae. The inclusion of Neoloshanus within the Eucharitinae is supported by biological traits and features of the immature stages which are unlikely to be convergent (i.e., fusion of tergites I and II). This would suggest that the phylogeny is robust and can be used to predict possible hosts and behavioural traits within the Eucharitidae.

Strategies of Eucharitidae for gaining entry to the nest of the ant host are extremely variable (see Clausen, 1940a, 1940c, 1941). Dispersal mechanisms of planidia through placement of eggs by adults or by activity of the larva determine the likelihood of success on different host ants. Development of new dispersal mechanisms by Eucharitidae probably forms the basis of host shifts to different genera of Formicidae. Host shifts by eucharitids within groups of closely related species or genera of host ants would be expected, because related ant genera are likely to have similar foraging strategies. In the New World, species of Orasema have developed associations with Solenopsis, Tetramorium, and Wasmannia, which are probably all ants that are predators of thrips, or would at least have a similar foraging pattern (size of prey, search area, etc.) to the proposed ancestral host ant. Pheidole. Major shifts in the group of ants that are parasitized by Eucharitidae may be associated with changes in dispersal of planidia, through either first-instar behaviour or oviposition habits of adult eucharitids. Each change in oviposition behaviour or dispersal of larvae must accommodate the behaviour of the ant host, and adaptation to a new host may result in the rapid evolution of a new group within Eucharitidae. 


\section{Revision of Oraseminae and Psilocharitini (Eucharitinae)}

In his revision of the Australasian Chalcidoidea, Bouček (1988) provided revisionary notes and a generic key for the Oraseminae, which provided a new foundation for study of the Southeast Asian fauna. New information on species from the Old World tropics has led to a classification that removes from the genus Orasema (sensu
Bouček, 1988), species that are now assigned to 2 new genera and are here placed in the Eucharitinae. In the following revision, descriptions and keys are provided for the 6 genera and 56 species that are found in the Old World tropical regions. Boldface type refers to prominent character states useful for recognition.

\section{Key to Genera of Oraseminae and Psilocharitini}

\begin{abstract}
Prepectus distinctly separate from pronotum (Figs. 217-234): anellus usually present; hypopygium usually bare or with minute subapical setae, but if hypopygium with transverse brush of long setae (Figs. 149, 264), then propodeal disc smooth and shining laterally (Psilocharis): antenna usually simple or at most with blunt dorsal projections (Figs. 47-49); apex of scutellum always rounded, never with apical projections . .2
\end{abstract}

- Prepectus fused to pronotum, sometimes with shallow furrow along line of fusion; anellus usually absent, but if present, then face smooth, hypopygium often with transverse brush of long setae, and propodeal disc evenly areolate (Gollumiella and Anorasema); antenna of male often with elongate branches; apex of scutellum rounded, emarginate, or with elongate projections

Eucharitini (Eucharitinae, see Bouček, 1988)

2(1) First gastral sternite $\left(\mathrm{Ms}_{2}\right)$ with transverse furrow delimiting small crescentic anterior region (Figs. 74, 78, 113, 126, 256, 258. 260. 262); dorsal occipital margin usually rounded, rarely with carina; face usually with raised coriaccous, rugose, or reticulate sculpture, rarely smooth, but not pitted (Figs. 187-192); hypopygium without long hairs, cither minute or bare; ovipositor expanded and ridged, usually curved ventrally toward head (Fig. 262).

Oraseminae; 3

First gastral sternite ( $\mathrm{Ms}_{2}$ ) evenly rounded and not constricted (Figs. 268, 271), in some cases with vague medial constriction (Fig. 273): dorsal occipital margin with distinct carina; face smooth or pilted (Figs. 193-209); hypopygium with or without tranverse row of long hairs; ovipositor expanded or acicular, and usu- ally straight (Figs. 264-272), but weakly curved in some $N$. palgravei

Psilocharitini (Eucharitinae); 6

3 (2) Transscutal articulation (between mesoscutum and axilla) obliterated (Figs. 36. 50); mandible usually reduced, maxilla and labium minute or absent, or maxilla lobate and without palpi ......4

Transscutal articulation complete (Figs. 235-246); mandible falcate, maxilla and labium usually large, palpi 1- to 3-segmented (Figs. 189-190)

.5

4 (3) Body with metallic blue or green colours; head and mesosoma strongly sculptured and either coriaceous or rugulose; body length at least $3.5 \mathrm{~mm}$ (Fig. 27): anellus present: mandible truncate or spatulate, maxilla small: Africa.

Timioderus Waterston, p. 32

Body black or brown; head and mesosoma almost smooth; length about $2 \mathrm{~mm}$ (Fig. 5l): anellus absent; mandibles absent. maxilla enlarged and lobate; India

Indosema Husain and Agarwal, p. 38

5 (3) Base of petiole gradually narrowed to large knoblike condyle, and lacking dorsal flange (Figs. 58, 67): petiole of female transverse (Figs. 58, 67), hence gaster sessile or nearly so (Figs. 6lb, 256): petiole of malc about (wice as long as broad, but then distal third or half supported ventrally by swolten anterior expansion of first gastral sternite (antcrior margin of $\mathrm{Ms}_{2}$ advanced; Fig. 78): Australia

Orasemorpha Boncek, p. 40

Base of petiole truncated, lateral and dorsal margins sharp and abruptly narrowed to small condyle (dorsal view. Figs. 94. 105, 120, 132). and ustatly with a sharp dorsal flange (rarely 
reduced. cf. Fig. 121); both sexes with petiole usually more than twice as long as broad (rarely as long an broidl in some females): in bolls seses anterior margin of first gastral sternite (Ms, ) meering apex of petiole (Figs. 113, 126); circumstropical and Nearctic

Orasema Cameron, p. 54

6 (2) Base of petiole abruptly narrowed laterally (truncated) (dorsal view, Figs. 144-145), rarely with dorsal flange ( $P$. pacifica); clypeal margin straight with well-clefined and narrow anteclypeus (Figs. 194-198); anteclypeus with marginil row of fine setae extending ventrally over labrum (AS, Fig. 198): femoral groove broad and evenly impressed (Figs. 223-225), often reticulate: hypopygium usually with long brush of hairs (Figs. 149, 264), rarely with only few long sclac; ovipositor acicular (Fig. 264): Old World tropics..........Psilocharis gen. nov.. p. 81

Base of petiole gradnally narrowed laterally and dorsally (dorsal view, Fig. 159): clypeal margin strongly lobate or slightly rounded, anteclypeus absent (smoothly rounded to apex) (Figs. 199-210): anteclypeus rarely with row of fine setae (gemma-group); femoral groove narrow and foveate (Figs. 227-234), rarely absent (Fig. 226); ovipositor acicular or expanded; hypopygium bare or with few small sublateral setae, never elongate; mostly Indo-Pacific.

Neolosbanus gen. nov., p. 93

\section{Revision of the Old World Oraseminae}

\section{Timioderus Waterston}

Timioderus Waterston, 1916:413. Type species: Timioderus refringens Waterston; by original designation.

Originally assigned to the Perilampidae (Waterston, 1916). Timioderus was correctly placed in the Oraseminae by Bouček (1988). The mandibles of Timioderus are not falcate as they are for the rest of the Eucharitidae, and may be well developed and toothed (as for most Chalcidoidea), truncate, or long and chiselshaped. Timioderus is regarded as the sister group of Indosema, with which it shares the absence of a transscutal articulation, reduced mandibles, and cylindrical egg without a stalk. Timioderus is similar to Orasemorpha in having the scape and petiole short, the gastral terga sculptured, the wing setae generally small, and the face and mesosoma strongly sculptured. The flagellum of Timioderus is cylindrical, serrate, or ramose, but the basal anellus is retained in all species. The first gastral sternite $\left(\mathrm{Ms}_{2}\right)$ of males is modified as an anteriorly protruding cup that holds the apex of the petiole, and the point of articulation with the gaster is markedly posterior to the anterior margin of the first sternite. This mode of articulation is also found in males of Indosema and Orasemorpha.

\section{GENRIC DESCRIPTION}

Head transverse to subtriangular, $] .0-1.3 \times$ as broad as mesosoma; median ocellus anterior to lateral ocellus, latcral ocellus almost touching occiput (Fig. 34). Face, vertex, and gena sculptured; scrobal depression sluallow and poorly defined, reaching median ocellus; ocellar-ocular groove present or absent: occiput granulate to finely striate in circular pattern; occipital carina absent. Malar depression absent; hypostoma small and not separated from gena by hypostomal carina. Clypeus transverse, epistomal sulcus lacking, apex only slightly rounded, not extended over labrum; anteclypeus narrow, distinct from postclypeus, and bare. Labrum 4- or 5-digitate or flaplike with apical setae. Mandibular shape variable, usually reduced; maxilla and labium strongly reduced. extending only half distance between foramen and clypeal margin. stipes forming 2 elongate lobes, labium globose or slightly urn-shaped, palpi not visible. Antenna 10- to $12-\mathrm{seg}-$ mented: scape short and stout, $2.1-3.3 \times$ as long as broad. usually reaching median ocellus; pedicel short; anellus present and glabrous: funicle 6- to 8-segmented, segments cylindrical, serrate, or ramose, without basal secondary segmentation but with seattered MPS: basal flagellomeres less than $2.0 \times$ as long as broad. terminal 3 to 4 segments fused into distinct clava.

Mesosoma witl dorsum evenly sculptured. coriaceous. or rugulose. Notauli as broad shallow depressions anteriorly or absent. TSA obliterated dorsally but suture present laterally below dorsal margin of lateral axillar surface (Fig. 36). SSS broadly curved, meeting apparent posterior margin of mesoscutum. Scutellum with frenal area separated dorsally by weak sculpture, broadly rounded: axillular sulcus absent. Metanotum extended laterally as small smooth flange overlapping base of propodeum and partly covering propodeal spiracle. the latter close to dorsal margin of propodeum: metanotum strongly excavated. 
Propodeal disc relatively flat, foramen strongly arched; callus pronounced, bare, or setose, separated from mesepimeron by vertical furrow defining anterior callar region; postspiracular furrow and metepimeral sulcus marked by deep groove; ventral margin of propodeum above hind coxa even and strongly ridged, without lateral processes. Mesopleuron finely sculptured; mesepimeron evenly swollen and lacking transepimeral sulcus; femoral groove narrow and deeply impressed, without strong sculpture; sternaular area of mesepisternum evenly rounded (no distinct sulcus or foveae). Prepectus reaching tegula as broad triangular lobe, gradually narrowed ventrally. Coxae and femora finely sculptured; number of tibial spurs diagnostic for species; hind tarsi $0.5 \times$ length of tibia, basitarsus short.

Wing. Veins of fore and hind wings broad and well defined. Forewing 2.3-2.5 $\times$ as long as broad, subtruncate at apex (Figs. 43-44); disc with dense short hairs or microtrichiae, marginal fringe minute; basal area bare; speculum absent (pilose); costal cell pilose ventrally; submarginal vein with sparse minute setae dorsally; marginal vein $0.2 \times$ as long as wing and as densely pilose as rest of wing; stigmal vein about $2 \times$ as long as wide, angled 45 degrees relative to anterior margin of wing; postmarginal vein narrow and short, about equal in length to stigmal vein.

Metasoma with petiole less than $0.7 \times$ length of hind coxa in both sexes. Petiole of female broader than long, strongly pinched dorsally so as to form small upper and large lower lobe, narrowed basally to knoblike condyle (Fig. 37); petiole not fused ventrally, ventral margins broadly separated. Petiole of male longer than broad, glabrous and slightly expanded at apex, not fused ventrally, often held in vertical aspect on material examined. Gastral terga finely rugulose; gaster of female as long as head and mesosoma; gaster of male slightly longer than hind femur; $\mathrm{Mt}_{2}$ of female less than $0.6 \times$ length of gaster; $\mathrm{Ms}_{2}$ with broad, smooth basal constriction, anterior region of female small and crescent-shaped (Fig. 27) and anterior region of male a forward-protruding, cuplike structure extending under petiole (Fig. 35). Hypopygium with patch of minute setae on each side of midline. $\mathrm{Ms}_{8}$ of male rounded and setose. Cercus with several short setae of equal length. Ovipositor sheath broad, not reaching cercus, gonostylus distinctly separated basally and setose. Ovipositor subapically expanded, slightly curved anteriorly (Figs. 29, 31); first valvula with single strong subapical ridge followed by lateral line of several small teeth; second valvula broad with several small lateral teeth, and smooth medially. Genitalia of males with parameres elongate and bearing several long setae, digitus large and disc-shaped with several stout marginal spines; aedeagus subtruncate.

\section{PHYLOGENETIC RELATIONSHIPS}

The 5 known species are partitioned into 3 groups. $T$. peridentatus is regarded as basal based on a quadrate head, large mandibles, cylindrical flagellum, and digitate labrum. The coriaceous or reticulate sculpture of the mesosoma and occiput are regarded as synapomorphies for $T$. coronula and $T$. ramosus; rugose sculpture, as found in $T$. peridentatus and some Orasemorpha, and a circularly carinate occiput are regarded as plesiomorphic. A relationship between $T$. refringens and $T$. acuminatus is not justified by synapomorphies. Tentative relationships proposed among species of Timioderus are (peridentatus $+(($ coronula + ramosus $)+$ acuminatus + refringens $))$.

\section{BIOLOGY}

Unknown. The form of the ovipositor suggests that eggs are deposited in plant tissue into chambers formed by the ovipositor. Ovarian eggs are cylindrical and rounded at the ends with no evidence of an apical projection.

\section{DISTRIBUTION}

Africa (Fig. 275).

\section{Key to Species of Timioderus}

Mandible large, each tridentate and slightly cupshaped along inner margin, apex overlapping base of opposing mandible (Figs. 28, 39); head subtriangular, $1.4 \times$ as broad as high; funicular segments cylindrical and moderately setose ....... T. peridentatus sp. nov., p. 34

Mandible small and narrow with apex acuminatc, truncatc. or with 2 blunt tecth (Figs. 32, 40, 42): head usually strongly transverse, $1.5-1.7 \times$ as broad as high (Figs. 30, 32-33); funicular segments variable in shape.
2 (1) Head and dorsum of mesosoma rugulose-arcolate (Figs. 27, 36); occiput circularly carinate: callus with several small hairs dorsally (Fig. 27): hind tibia with 1 or 2 apical spurs ......................

- Head coriaceous or granulate (Fig. 33), dorsum of mesosoma coriaccous; occiput granulate or reticulate, at most with fine strigac; callus barc: hind tibia usually with 0 or 1 apical spurs (but ? of $T$. corronula with 2). 4

3 (2) Funicular segments in both sexes cylindrical. 
segments clearly separated (Fig. 45); mesoscutum with narrow medial longitudinal band of bright blue; mandible with 2 blunt teeth (Fig. 32) T. refringens Waterston, p. 35

Funicular segments of female serrate, segments of male lamellate (Figs. 48-49); mesoscutum at most with narrow longitudinal band of greenish blue bordered by broad reddish bands; mandible acuminate apically (Fig. 42).

T. acuminatus sp. nov., p. 36

4(2) Funicular segments of both sexes cylindrical or slightly serrate, apex of each segment with brush of fine setae that reaches following segment, with setae strongly adpressed (Fig. 38); calcar short and peglike; hind tibia with 1 spur (rarely 2) T. coronula sp. nov., p. 37

- Funicular segments of female serrate, segments of male strongly lamellate; setae in both sexes adpressed or semi-erect in both sexes but segments clearly separated at apex (Figs. 46-47); calcar absent; hind tibia with spur reduced or absent T. ramosus sp. nov., p. 37
Timioderus peridentatus sp. nov.

Figs. 28, 36-37, 39

\section{TYPE MATERIAL}

Holotype, + , "Mossel Bay,/ Cape Province./ May, 1921." "S. Africa./ R. E. Turner./ Brit. Mus./ 1921-248." "HOLOTYPE/ Timioderus/ peridentatus/ Heraty." Deposited in BMNH.

Paratypes: SoUTH AfrICA: Cape Province: Ceres, ii.1921 (), xii.1924 (ठ̋), R. E. Turner (all BMNH); Oudtshoorn, x.1951 (1,+ SAMC).

\section{DIAGNOSIS}

Recognized by having the mandible well developed and tridentate (Figs. 28, 39), labrum digitate (Fig. 39), head subtriangular, scape narrow, flagellomeres cylindrical, calcar prominent, and mesosoma rugulose-areolate.

\section{FEMALE}

Length, $3.4 \mathrm{~mm}$. Head and mesosoma dark metallic green with faint reddish and blue reflections, anterior half of mesoscutum dark violet medially; propodeum and variable patches on mesepimeron sometimes dark metallic blue; petiole, gaster, and coxae dark brown with bluishgreen lustre; antennal flagellum, mandible, and femora dark brown; scape, pedicel, anellus, apex of femora, and rest of legs yellowish brown. Wings hyaline, venation clear.

Head subtriangular, 1.4-1.5 $\times$ as broad as high; occiput deeply emarginate and slightly invaginated; median ocellus separated by slightly more than own diameter from occiput; LOL 1.2-1.4× OOL. Face relatively flat, rugose; scrobal depression broadly impressed above toruli, with irregular striae extending in a circular pattern around toruli, scrobal depression dorsally rugose; vertex broad, rugose, and strongly depressed lateral to lateral ocelli, shallow ocellar-ocular groove between posterior ocellus and eye margin; dorsal occipital margin rounded; occiput circularly carinate. Eyes separated by $1.9-2.0 \times$ their height. Malar space 0.8-1.0x height of eye. Clypeal region rugulose, lateral margin weakly impressed, tentorial pit deep; supraclypeal region glabrate or rugulose medially. Labrum distinctly 5- or 8-digitate with pronounced stiff seta at apex of each digit (Fig. 39); digits short and placed irregularly around margin. Mandible well developed, with tip overlapping base of opposing mandible; each mandible tridentate, apical tooth elongate and acuminate, basal teeth subequal; mandibles twisted basally and folded over each other when closed, inner surface cup-shaped; short row of long setae along outer ventral margin of each mandible; maxilla and labium strongly reduced. Antenna 11 -segmented; scape relatively narrow, 3.0-3.3x as long as broad, ventral surface distinctly flattened below pedicel; pedicel globose; anellus present; flagellum 1.1-1.4× height of head; funicle 7-segmented, segments cylindrical, surface scabriculous with sparse, semi-erect setae basally and more densely setose apically; F2 2.0-2.5x as long as wide, following segments subequal in length; clava as long as last 2 funicular segments.

Mesosoma with dorsum rugulose-areolate, sculpture fine and closely spaced anteriorly but becoming coarser and more rugose toward apex of scutellum. Mesoscutum with notauli vaguely impressed. Scutellum with frenal line represented by narrow glabrous band laterally, nearly obliterated dorsally, sculpture of frenal area similar to scutellum, frenum rounded in profile and slightly exceeding metanotum. Metanotum with lateral excavations smooth and with weak crenulae. Propodeal disc evenly rugose with septa widely spaced and irregular; callus with posterior region swollen, globular, and rugose with several fine hairs dorsally. Mesepimeron smooth to weakly rugose ventrally, swollen medially, and not divided by transepimeral sulcus; femoral groove broadly and deeply 
impressed, slightly crenulate along anterior margin; mesepisternum rugulose-areolate to scabriculous laterally. Prepectus and pronotum evenly rugulose. Proepisternum smooth to weakly reticulate. Coxae weakly coriaceous, mostly smooth; femora robust and expanded medially, imbricate with dense short setae; tibiae with dense adpressed setae; calcar long; hind tibia with 2 large spurs. Forewing $2.2-2.3 \times$ as long as broad.

Metasoma with petiole (Fig. 37) and gaster typical for genus; terga sparsely setose. $\mathrm{Ms}_{2}$ without basal constriction. Ovipositor typical for genus.

\section{MALE}

Agrees with female except for the following: head, mesosoma, and gaster dark blue; antenna dark brown; scape, coxa and femora with violet lustre: calcar large: hind tibia with 2 small spurs; petiole with lateral flange.

\section{VARIATION}

The paratype females differ from the holotype by having the mesepimeron entirely rugose (versus smooth), and proepisternum weakly reticulate (versus smooth).

\section{DISCUSSION}

The well-developed and slightly twisted mandibles are similar to those of Perilampidae and Chrysolampinae (Pteromalidae). However, the apical tooth is elongate and more typical of the shape found in most Eucharitidae. The labrum is digitate (Fig. 39) and similar to that of other Oraseminae except that it has 5 rather than the more typical 4 digits. The labrum is reduced in almost all other Timioderus (Figs. 4l-42); its presence in this species is regarded as plesiomorphic.

\section{DISTRIBUTION}

South Africa (N, Fig. 275). Sympatric with $T$. acuminatus.

\section{ETYMOLOGY}

Combination of the words Perilampidae and Latin dentatils. meaning toothed; referring to the similarity with nonfalcate mandibles possessed by Perilampidac.

\section{Timioderus refringens Waterston}

Figs. 32, 41, 43, 45

Timioderus refringens Waterston, 1916:413-417. Malawi: Monkey Bay [BMNH, examine(l].

Orasema viridicyanea Risbec. 1958:150-152. Zimbabwe:

Penkridge [SAMC, examined]. New synonymy.
TYPE MATERIAL

Lectotype of Timioderus refringens (here designated), $q$, "Type." "NYASALAND./ LAKE NYASA./ MONKEY BAY./ 1:VI:1915/ DR. W. A. LAMBORN." "MB/ 6.1.5." "J. WATERSTON DET./ Timioderus/ refringens Wtst./ q." "B.M. TYPE/ HYM./ 5-374." Specimen complete, head buried in glue.

Paralectotypes: labelled as above with yellow-bordered co-type labels ( $2 q q$ ). Holotype of Orasema viridicyanca, + , "Orasema/ viridicyanea Risbec/ Type/ Penkridge, S. Rhodesia/ I6.I.1928/ R. H. R. Stevenson." "SAMA 30C7." Adult parts mounted under 2 coverslips on slide: under first coverslip, head and mesosoma with right foreleg and mid legs attached, metasoma. ovipositor, hind leg, and wings; under second coverslip, foreleg and 3 fragments of flagellum.

\section{NOTES ON SYNONYMY}

The only noticeable differences between the holotype of $O$. viridicyanea and that of T. refringens is in the possession of a lighter (almost uniformly yellowish brown) scape and a weak posterior flange on the prepectus, differences which I do not consider of value in separating these specimens as different species.

\section{DIAGNOSIS}

This species was well described and illustrated by Waterston (1916). It is diștinguished from other species of Timioderus by the following: dorsum of mesosoma rugose-areolate with narrow medial band of bright blue coloration, otherwise dark green with red and blue reflections: head transverse (a. Fig. 32); occiput circularly striate: mandibles narrow and elongate with 2 short apical teeth (b. Fig. 32); funicular segments cylindrical in both sexes with short semi-erect setae, apical setae not bridging segments, and segments well separated (Fig. 45); calcar well developed; hind tibia with 1 or 2 elongate spurs; and gastral terga densely setose.

\section{VARIATION}

There is some variation in the degree of bluish coloration of the head and mesosoma, which is often more extensive in males; however, the narrow medial band on the mesoscutum is consistent.

\section{DISTRIBUTION}

Kenya, Malawi, Mozambique. South Africa, Tanzania, Uganda, and Zimbabwe (R, Fig. 275).

\section{MATERIAL EXAMINED}

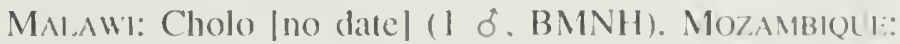
Rihatla |no date| (1 f. BMNH). KeNY A: Kongolai. Pohot. July (I ó. BMNH). Solth AFrica: Cape Provines: Transkei. Port St. John|sl [l'ondoland|. April to May and 
February (159?. $230^{\circ} \delta^{\circ}$ BMNH): Tramsvatal: Fontaine nr P'retoria: Noohetsi; Pretorial; September and January to February ( $39 \& .10$. BMNII, SAMC, USNM); Natal: Inchanga: Weenen: December and February $(4 q q$. $30^{\circ}$. BMNH). Tavzania: Tanga, September ( $1 \delta^{\circ}$. BMNH). Uganda: Serere, August ( $1 \delta^{\circ}, \mathrm{BMNH}$ ). ZiNbabWE: Matopo Hills. April (I $\delta$, BMNH).

\section{Timioderus acuminatus sp. nov.}

Figs. 27, 29, 42, 48-49

\section{TYPE MATERIAL}

Holotype, \&. "S. Africa/ R. E. Turner./ Brit. Mus./ 1925210." "Cape Province./ Ceres./ April. 1923." "HOLOTYPE/ Timioderus/ acuminatus/ Heraty." Deposited in BMNH.

Paralypes: South Africa: Cape Province: Ceres, i.1921

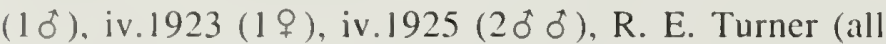
BMNH); Cape Peninsular. 25.xii.1971, H. and M. Townes (1 9 AEI): Transkei: Umtata, 18.ii-18.iii.192[?], [no collector] (1 ठ์. BMNH).

\section{DIAGNOSIS}

Recognized by having head and mesosoma rugulose-areolate, flagellum of female serrate (Fig. 48), flagellum of male lamellate (Fig. 49), mandibles acuminate (Fig. 42), calcar small, hind tibia with 1 or 2 small spurs, and head subtriangular. This species is morphologically similar to $T$. peridentatus but differs in the structure of the antennal flagellum, mandibles, and stouter scape.

\section{FEMALE}

Length, $3.4 \mathrm{~mm}$. Head and mesosoma dark metallic green with strong red and blue reflections, mesoscutum with 2 broad submedian bands of reddish colour bordering a narrow medial band of greenish blue; propodeum, lower half of mesosoma, and coxac dark metallic blue: gaster dark brown with greenish red reflections: femora dark brown with faint green reflections; antenna dark brown; apex of femora and rest of legs yellowish brown. Wings hyaline, venation clear yellowish brown.

Head subtriangular, 1.5-1.6× as broad as high; occiput deeply emarginate, not invaginated; median ocellus separated by $1.5 \times$ own diameter from occiput; LOL 1.0-1.3x OOL. Face broadly impressed around toruli, strongly rugulose; scrobal depression broadly impressed above toruli, with finer coriaceous or rugulose sculpture; vertex rugulose, ocellar-ocular groove absent; dorsal occipital margin acute; occiput circularly carinate. Eyes separated by $2.0-2.2 \times$ height of eye. Malar space $0.8-0.9 \times$ height of eye. Clypeal region rugulose or glabrate, lateral margins indistinct. Labrum rectangular and broader than long with single digits on each ventrolateral corner, each digit slightly longer than broad and with long terminal seta. Mandibles narrow and elongate, broadly overlapping at tips, apex acuminate and without teeth. Antenna 11-segmented; scape $2.1 \times$ as long as broad, ventral surface llat and glabrate: pedicel subglobose: ancllus present: flagellum 1.2× head height; funicle 7 -segmented, F2 cylindrical, following segments slightly serrate (Fig. 46), surface strongly scabriculous, with moderately dense adpressed setae, apical segments more densely setose; F2 $1.1 \times$ as long as broad, following segments subequal in length; clava as long as preceding 2 funicular segments.

Mesosoma with dorsum uniformly rugulose-areolate (may be more finely rugulose anteriorly). Mesoscutum without notauli. Scutellum with posterior margin of frenal groove weakly carinate, frenal area finely rugulose, frenum rounded in profile and exceeding metanotum. Metanotum with lateral excavations carinate. Propodeum rugulose-areolate; callus with posterior region strongly swollen and rugulose, glabrate laterally bare or with patch of fine hairs dorsally. Mesopleuron rugulose-areolate laterally; femoral groove narrow and deeply impressed, glabrous medially and along anterior margin. Prepectus and pronotum rugulose-alveolate. Proepisternum, coxae, and femora weakly coriaceous or reticulate; calcar and hind tibial spurs small (hind tibiae of holotype with 2 and 1 spurs, both hind tibiae of paratype with 1 spur). Forewing $2.4 \times$ as long as broad.

Metasoma with petiole and gaster typical for genus, petiole and $\mathrm{Ms}_{2}$ hidden; terga rugulose and sparsely setose. Ovipositor as in Fig. 29.

\section{MALE}

Length, $2.5 \mathrm{~mm}$. Scape brown with iridescent reflections and mesoscutum more evenly reddish in colour. Antenna with basal funicular segments lamellate; F2 slightly higher than broad, apex cup-shaped, and outer, medial edge emarginate; following flagellar segments subequal in length and width, F8 serrate; clava with 2 incompletely fused segments; funicular segments with dense, semierect setae. Petiole $0.7 \times$ length of hind coxa, glabrous. Gaster slightly longer than hind femur. Genitalia typical for genus; aedeagus broad and rounded apically.

\section{VARIATION}

One paratype female (AEl) differs in having the head more distinctly transverse $(1.6 \times)$ but is otherwise similar. It is much darker in colour with the dorsum of the mesosoma black with reddish reflections and the medial band of green very reduced. the lower face with strong reddish rellections, the scape dark metallic green, and the antenna black. Other structures are also darker in colour and there is almost no blue coloration. In addition. the scrobal depression is rugulose (rather than coriaceous), the clypeus is glabrate, and the mesopleuron is reticulate- 
rugulose. Otherwise, this individual is similar to the other specimens.

\section{BIOLOGY}

Ovarian eggs dissected from the gaster were cylindrical, rounded apically, and with a small apical nib at one end.

\section{DISTRIBUTION}

South Africa (Cape Province) (A. Fig. 275).

\section{ETYMOLOGY}

From Latin acuminatus, meaning pointed; referring to the mandibles.

\section{Timioderus coronula sp. nov.}

Figs. 35,38

\section{TYPE MATERIAL}

Holotype, ơ, "SOUTH AFRICA/ Grahamstown/ A. Watsham: 12: 73." "R.100." "Timioderus." "HOLOTYPE/ Timioderus/ coronula Heraty." Deposited in BMNH.

Paratype: Nigeria: Zaria, Dumbi Wood, 30.jv.1972. J. C. Daining ( $1 \%, \mathrm{BMNH})$.

\section{DIAGNOSIS}

Recognized by having flagellar segments of both sexes cylindrical or slightly serrate, each segment with a crown of dense elongate setae that reach the following segment, head sculpture granulate, and mesoscutum coriaceous to finely reticulate.

\section{MALE}

Length, $2.5 \mathrm{~mm}$. Dark metallic green with strong bluish reflections; mesoscutum with submedian band of reddish colour bordering narrow mectial band of greenish blue: head mostly metallic blue: antenna, petiole, and base of gaster dark brown; apex of femora and rest of legs yellowish brown. Wings hyaline, venation light brown.

Head transverse, I.7x as broad as high; occiput broadly emarginate, not invaginated; median ocellus separated by slightly more than its own diameter from occiput: LOL I.I $\times$ OOL. Face broadly impressed around toruli, sculpture granulate (very fincly reticulate): scrobal depression shallow, lateral margins obscure, glabrous above toruti: vertex broad, evenly granulate. ocellar-ocular groove narrow and well defined; dorsal occipital margin rounded; occiput granulate with very weak circular strigae. Eycs separated by $2.4 \times$ their height. Malar space $1.0 \times$ height of cyc. Lateral margin of supraclypeal area broadly impressed and glabrous. Labrum hidden. Mandible narrow and elongate. tip broadly overlapping opposing mandible, each with 2 poorly defined asymmetrical teeth apically: maxilla and labium greally reduced. Antenna
11 -segmented; scape $2.3 \times$ as long as broad, ventral surface slightly emarginate and glabrous; pedicel subglobose; anellus present; flagellum $1.6 \times$ height of head; funicle 7-segmented, each segment slightly serrate, surface granulate, with short, dense adpressed setae, apex with crown of dense adpressed setae that reach base of following segment (segments appearing fused) (Fig. 38); F2 $1.2 \times$ as long as broad, following segments subequal in length; clava elongate, slightly shorter than apical 3 funicular segments.

Mesosoma with dorsum strongly coriaceous to finely reticulate. Mesoscutum with notauli broadly impressed anteriorly. Scutellum with frenal line narrow and weakly impressed, sculpture of frenal area coriaceous, frenum vertical in profile and only slightly exceeding metanotum. Metanotum with lateral excavations coriaceous. Propodeum evenly coriaceous: callus with posterior region strongly swollen coriaceous and lacking setae. Mesepimeron coriaceous to reticulate, swollen medially. and lacking transepimeral sulcus; femoral groove deeply and narrowly impressed, glabrous along anterior margin; mesepisternum finely reticulate to coriaceous laterally. Prepectus and pronotum evenly coriaceous. Proepisternum finely reticulate. Coxae coriaceous and bare; femora umbilicate with minute adpressed setae dorsally; tibiae with dense, short, adpressed setae; calcar small; hind tibia with single small spur. Forewing $2.4 \times$ as long as broad.

Metasoma with petiole glabrous, $0.5 \times$ length of hind coxa. Gastral terga rugulose and bare. Ms 2 broadly constricted and glabrous. Genitalia typical for genus.

\section{FEMALE}

Agrees with male except for following: mesoscutum mostly reddish: scape, pedicel, and legs ycllowish brown. anellus light brown; face mostly rugulose, scrobal depression coriaceous to granulate; lateral margin of clypeus hardly impressed; clava with 2 fused segments; notauli not impressed: hind tibia with 2 well-developed spurs.

\section{DISTRIBUTION}

Nigeria and South Africa (Cape Province) (C, Fig. 275).

\section{ETYMOLOGY}

From Latin coromula; relerring to the apical crown of dense setae on the funicular segments.

\section{Timioderus ramosus sp. nov.}

Figs. 30-31, 33-34, 40, 46-47

\section{TVPE, MATERINL.}

Holotype. 9. "Aliwal North./ Cape Province./ 4350 ft. |1.325 m|/ 1-13.i.1923." "S. Alrica//R. E. Tumer.//3rit. 
Mus./ [1) 23-70." •HOLOTY'PE/ Timioderus/ ramosus Heral!." Card mumnted, right mid leg mounted separate1y. Larsi broken on left lore and mid legs. Deposited in B.MNH.

Parilypes: Sot 111 Al.RicA: Cape Province: Aliwal Nortli, $1325 \mathrm{~m}, 1-13.1 .1923, \mathrm{R}$. E. Tumer $\left(1\right.$ \&, $\left.10 \delta^{\circ} \delta^{\circ}, \mathrm{BMNH}\right)$ : Aliwal North, xii. 1922, R. E. Turmer (1 ठ์, BMNH).

\section{DINGTOSIS}

Recognized by having the head and mesosoma coriaceous (Fig. 33), antenna of female weakly serrate (Fig. 46), antemna of male strongly lobate (Fig. 47), mandible spatulate. calcar lacking, and hind tibia with I small spur or none.

\section{FEMALE}

Length, 2.9-3.4 mm. Dark metallic green with red and blue reflections: mesosoma patterned with variable patches of reddish coloration, darker ventrally with more bluish coloration; gaster, coxae, and femora dark brown with strong greenish reflections; antenna dark brown; apex of femora and rest of legs yellowish brown.

Head transverse, 1.5-1.6x as broad as high; occiput broadly emarginate, not invaginated; median ocellus separated by $1.5 \times$ own diameter from occiput: LOL 1.1-1.2× OOL. Face broadly depressed around toruli, coriaceous; scrobal depression broad and shallow, with lateral margin obscure, glabrous just above toruli; vertex evenly coriaceous, not impressed lateral to ocelli, the ocellar-ocular groove shallow; dorsal occipital margin rounded; occiput reticulate. Eyes separated by $2.1 \times$ their height. Malar space $0.8 \times$ height of eye. Clypeus coriaceous to weakly rugulose, lateral margin weakly impressed, with tentorial pits deep; supraclypeal region glabrate. Mandibles narrow, tips slightly crossing when closed, apex chiselshaped; maxilla and labium extremely reduced. Antenna 10- or 11 -segmented; scape $2.5 \times$ as long as broad, flat ventrally; pedicel globular; anellus present; flagellum $1.2 \times$ height of head; funicle 6 - or 7 -segmented, the segments cylindrical to slightly serrate, surface strongly reticulate with short adpressed setae; F2 $1.3 \times$ as long as broad, following segments subequal in length, F8 partial-
Iy fused to clava, clava as long as F6-F8.

Mesosoma with dorsum mostly coriaceous; scutellun weakly striate-rugose, broadly impressed and smooth anterior to frenum. Mesoscutum with notauli obliterated. Scutellum with frenal line narrow and weakly impressed, frenal area coriaccous, frenum rounded in profile and only slightly exceeding metanotum. Metanotum with lateral cxcavations carinate, coriaceous medially. Propodeum evenly coriaceous; callus with posterior region strongly swollen, coriaceous, and lacking setae. Mesepimeron evenly coriaceous, swollen, and not divided by transepimeral sulcus; femoral groove narrow and glabrous; mesepisternum coriaceous laterally. Prepectus and pronotum evenly coriaceous. Lateral lobes of proepisternum coriaceous, medial plate rugulose. Coxae and femora weakly coriaceous to smooth, coxae bare, femora with moderately dense minute setae; hind tibia with dense covering of minute setae; calcar absent; hind tibia with 1 small spur or none (absent on holotype). Forewing 2.3-2.5x as long as broad.

Metasoma with petiole and gaster typical for genus. gastral terga rugulose and bare: $\mathrm{Ms}_{2}$ glabrous with weak basal constriction. Ovipositor typical for genus.

\section{MALE}

Length, 2.5-2.9 mm. Colour as for female or more completely bluish in coloration including dorsum and gaster. Antenna 1 l-segmented; basal funicular segments strongly lamellate. with dense semi-erect short setae; F2 1.6x higher than broad, apex of F2 cup-shaped, following segments subequal in length and size of lamella, F8 serrate; clava as long as F7 plus F8. Petiole $0.5 \times$ length of hind coxa, glabrous. Gaster slightly longer than hind femur. Genitalia typical for genus.

\section{DISTRIBUTION}

South Africa (O, Fig. 275).

\section{ETYMOLOGY}

From Latin ramosus, meaning branching: referring to the projections of the male flagellomeres.

\section{Indosema Husain and Agarwal}

Indosema Husain and Agarwal, 1983:103-104. Type species: Indosema indica Husain and Agarwal; by original designation.

Indosema is regarded as the sister group of Timioderus based on the reduced labium, obliterated transscutal articulation, transverse petiole of both sexes, and cylindrical ovarian eggs. Indosema also shares several character states with both Timioderus and Orasemorpha, including having the scape stout, ocelli arranged in an equilateral triangle, occipital carina lacking. stigma robust, mesepimeron ventrally expanded, and first gastral stemite of male $\left(\mathrm{Ms}_{2}\right)$ expanded and cuplike under the petiole. Female Indosema have the first gastral sternite constrict- 
ed, the ovipositor subapically expanded, and the clypeus transverse apically. Unique features of Indosema within Oraseminae are the head and mesosoma brown and smooth or lightly reticulate, frenal area indistinct, forewing with microtrichiae, and $\mathrm{Mt}_{2}$ less than $0.3 \times$ length of gaster. Indosema also has the ability to pivot the ovipositor forward between the coxae so that it may be directed cephalad and parallel to the body during oviposition. The mobility of the ovipositor coincides with a strong medial notch in the hypopygium to accept the ovipositor.

\section{GENERIC DESCRIPTION}

Head transverse, $1.1 \times$ as broad as mesosoma; median ocellus anterior to lateral ocellus, lateral ocellus almost touching occiput. Face including vertex and gena weakly reticulate; scrobal depression shallow, not reaching median ocellus; ocellar-ocular groove absent; occiput weakly coriaceous; occipital carina absent. Malar depression absent; hypostoma small, not separated from gena by hypostomal carina. Clypeus transverse, epistomal sulcus lacking, apex slightly rounded or linear, not extended over labrum; anteclypeus narrow and bare, distinct from postclypeus. Labrum reduced (not discernible). Mandibles absent; maxilla enlarged, lobate, and sclerotized (resembling mandibles), palpi and labium absent. Antenna 10-segmented: scape short and stout, $1.5-2.0 \times$ as long as broad, not reaching median ocellus; pedicel as long as broad; anellus absent; funicle 7-segmented, segments cylindrical and without basal secondary segmentation but with dense MPS; basal flagellomeres less than $1.5 \times$ as long as broad, terminal 3 segments fused into indistinct clava.

Mesosoma with dorsum smooth or finely reticulate. Mesoscutum with notauli weakly impressed. TSA obliterated dorsally, with suture present laterally to dorsal margin of lateral axillar surface. SSS only vaguely impressed (Fig. 50). Scutcllum with frenal area and scutcllum finely reticulate, separated by transverse glabrous band representing frenal line; axillular sulcus lacking. Mctanotum extended laterally as small flange overlapping base of propodeum, not covering spiracle which is close to dorsal margin of propodcum. Propodeal disc rounded, with fine reticulate sculpture and laint central furrow; callus pronounced and setose, with anterior vertical furrow (ol Timioderus and Orasemorpha) indistinct: postspiracular furrow and metepimeral sulcus clearly impressed: ventral margin of propodeum above hind coxa evenly rounded and without latcral processes. Mesoplcuron finely reticulate latcrally including femoral groove; mesepineron cvenly swollen and lacking transepimeral sulcus; femoral groove broadly and decply impressed; sternaular area of mesepisternum evenly rounded (no distinct sulcus or foveac). Prepectus reaching tegula as broad triangular lobe, gradually narrowed ventrally. Coxae and femora lightly sculptured; tibiae with spurs 1-1-1/2; hind tarsus $0.7 \times$ as long as tibia.

Wing. Veins of fore and hind wings broad and well defined. Forewing $2.4 \times$ as long as broad, subtruncate at apex; disc appearing glabrous but pilose with minute setae, the marginal fringe absent; basal area bare; speculum absent (pilose); costal cell bare; wing veins lacking any apparent setae; marginal vein $0.3 \times$ as long as wing: stigmal vein barely distinguishable from marginal vein: postmarginal vein narrow and about twice as long as apparent length of stigmal vein.

Mctasoma with petiole in both sexes smooth and transverse, less than $0.5 \times$ length of hind coxa, narrowed basally, and fused ventrally. Gastral terga smooth. basal terga with sparse minute setae, following terga with transverse band of fine setae; gaster of both male and female as long as head and mesosoma (Fig. 54); $\mathrm{Mt}_{2}$ in both sexes less than $0.6 \times$ length of gaster; $\mathrm{Ms}_{2}$ with narrow basal constriction, the anterior region of female crenulate, that of male projecting forward and forming cuplike projection under petiole. Hypopygium bare. $\mathrm{Ms}_{8}$ of male narrowly rounded and setose. Cercus with few elongate setae. Ovipositor sheath broad, reaching cercus, gonostylus separated and sparsely setose. Ovipositor broadly expanded along entire length. only slightly expanded subapically, and straight (Fig. 51); first valvula with weak subapical ridge followed by lateral line of 10 minute teeth; second valvula with several strong lateral teeth, smooth medially. Genitalia of male with parameres short and bearing few short setae, digitus disc-shaped and bearing several stout marginal spines: aedeagus narrow and subacute.

\section{DISTRIBUTION}

Northem India (1, Fig. 275).

\section{Indosema indica Husain and Agarwal}

Figs. 50-54

Indosema indica Husain and Agarwal, 1983:104-106. India: Uttar Pradesh: Aligarh [AMUA, not examined].

\section{DIAGNOSIS}

The single species known for this genus can be recognized based on the generic features. The female was well described by Husain and Agarwal (1983). The male is similar to the female except for having the gaster narrow and elongate, and $\mathrm{Ms}_{2}$ constricted but only slightly projecting below the base of the petiole. The male is appiarcntly being described by Husain (Dr. S. I. Faroogi. IARI. New Delhi, India, pers. comm. ) and will not be further discussed here. 
$131010(i)$

Collected on leaves of Ricumus ('ommmunis L. (calstor bean) (Husan and Agarwal, 1983). This plant has large everafloral nectaries which may have attracted adult $l$. indica for feeding. My own observations and Boučk (pers. comnı. 1990) suggest that I. indica is associated will short grasses. Bouček (1988) speculated that it may use a short leguminous plant, possibly related to Lotus, as a plant host for oviposition. The form of the ovipositor suggests that eggs are deposited in plant lissuc within chambers formed by the ovipositor. Ovarian eggs are cylindrical and rounded at the ends with no evidence of an apical projection.

\section{DISTRIBLTION}

Northern India (1, Fig. 275).

\section{MATERIAL EXAMINEI)}

INDIA: Delhi, 14.iv.42, H. U. Klıan, on Brinjal ( 1 \& BMNH): New Delhi, IARI area. 10,26-28.x.79. Bouček (I $\left.+.9 \delta^{\circ}, \mathrm{BMNH}\right)$; IARI. 26.x.79, C. S. Roy (4ㅇ․ IARI); IARI farm. l l.vii.83, B. Lal (I $\%$, IARI); IARI, 9-10.vii 90, J. Heraty (7\% $q, 1 \delta, J M H$, TAMU); Uttar Pradesh: Aligarh, 8.x.1980, T. Husain (1 $q$ paratype, BMNH); Aligarh, 11.x.79, vii.80, M. Hayat (2ठㅎ $\mathrm{BMNH}$ ).

\section{Orasemorpha Bouček}

Eucharomorpha Girault, 1913b [December]: 94-95. Type species: Eucharomorpha viridis Girault, by original designation. Preoccupied by Eucharomorpha Girault, 1913a [September]: 157. Type species: Eucharomorpha worcesteri Girault, by subsequent designation (Gahan and Fagan, 1923:58). Latter genus correctly treated as junior synonym of Orasema Cameron (Bouček, 1988:519).

Orasemorpha Bouček, 1988:518-519. Replacement name and redescription.

The taxonomic history of this genus was provided by Bouček (1988). A redescription of the genus is presented here for comparison with other orasemine taxa. Orasemorpha shares some character states with Timioderus, including a stout scape, a vertical furrow dividing the callus, a strongly arched propodeal foramen. sculptured gaster (some species), and the first gastral sternite extended under the petiole in males. Orasemorpha is distinguished from Timioderus and Inclosema by the falcate mandibles, the digitate labrum, and a complete transscutal articulation. The strongly sculptured face, transverse head, short petiole, and first sternite of males distinguish this genus from Orasema.

\section{GENERIC IJESCRIPTION}

Head subtriangular (Figs. 55, 66. 73, 76, 187). 1.5-1.6x as broad as high, 1.2-1.6x as broad as mesosoma; median ocellus anterior to lateral ocellus, lateral ocellus close to occipital margin (Figs. 57, 69, 77). Face, vertex, and gena strongly sculptured; scrobal depression shallow and poorly defined, partially including median ocellus; ocellar-ocular groove weakly defined, sometimes marked by weak striac; occiput with elongate reticulate sculpture, occipital carina absent. Malar depression absent; hypostoma well developed, separated from gena by hypostomal carina. Clypeus transverse, apical margin linear, not extended over labrum, with epistomal sulcus shallow: anteclypeus narrow and bare or with minute setae, distinct from postclypeus. Labrum 4- to 7-digitate. Mandibles falcate, $2 / 2,3 / 2$, or $3 / 3$ dentate: maxilla and labium reduced, palpi short and broad, not segmented. Antenna 10- (questionable) to 13-segmented; scape short and stout but reaching median ocellus, cylindrical, and slightly flattened just below pedicel; pedicel short and globose; anellus usually present and glabrous; funicle usually 8-segmented, rarely 7-or 9-segmented, segments cylindrical, without basal secondary segmentation, and with scattered MPS; basal funicular segments less than $2.0 \times$ as long as broad, last 2 to 3 segments fused into clava.

Mesosoma with dorsum evenly sculptured, finely or coarsely rugose. Notauli deeply impressed along entire length and narrowly crenulate, angled to midline but well separated at TSA. TSA present. SSS angled and meeting TSA at midline. Scutellum with frenal area weak rugose, semicircular in dorsal view, usually with weak median depression; axillular sulcus lacking. Metanotum extended laterally as smooth flange overlapping base of propodeum and partly covering spiracle which is close to dorsal margin of propodeum. Propodeal disc broadly rounded and sculptured, foramen strongly arched; callus swollen and glabrous, separated from mesepimeron by vertical furrow defining anterior callar region; postspiracular furrow shallow: ventral margin of propodeum above hind coxa even and strongly ridged, without lateral processes. Upper mesepimeron swollen and glabrous or weakly rugulose, lower mesepimeron sculptured or smooth, transepimeral sulcus impressed but not prominent; femoral groove broadly impressed; sternalar area of mesepisternum 
evenly rounded (no distinct sulcus or foveae), mesepisternum swollen ventrally between fore and mid coxae. Prepectus reaching tegula as broad triangular lobe, only slightly narrowed ventrally. Coxae and femora weakly sculptured; tibiae with spurs 1-1-2; hind tarsi $0.6 \times$ as long as tibia.

Wing. Veins of fore and hind wings broad and well defined. Forewing 2.3-2.4× as long as broad, subtruncate to broadly rounded apically; disc densely pilose, with marginal fringe present or absent; basal area, speculum, and costal cell with pilosity diagnostic for species; submarginal vein with sparse dorsal setae; marginal vein $0.3 \times$ as long as forewing and densely pilose; stigmal vein broad, sessile to club-shaped; postmarginal vein long and narrow, $0.3-0.6 \times$ as long as marginal vein.

Metasoma with petiole of female transverse, in dorsal view posterior half $3-5 \times$ as broad as long, apical margin broadly emarginate dorsally; anterior half strongly pinched dorsally (Figs. 58, 67), narrow upper region glabrous, longer than broad and extending upward into propodeal foramen; petiole gradually narrowed basally to knoblike condyle, and fused ventrally. Petiole of male as in female but less than twice as long as broad, cylindrical but broader apically, and shorter than hind coxa. Gastral terga sculptured or smooth, gaster of female as long as head and mesosoma, gaster of male slightly longer than hind femur; $\mathrm{Mt}_{2}$ of female less than $0.6 \times$ as long as gaster; $\mathrm{Ms}_{2}$ constricted by broad transverse crenulate or striate furrow, anterior region of female small and crescent-shaped, anterior region of male protruding forward as cuplike structure extending under petiole (Fig. 78). Hypopygium with patch of fine setae on each side of midline or bare. $\mathrm{Ms}_{8}$ of male rounded and setose. Cercus with several setae of equal length. Ovipositor sheath broad, not reaching cercus, gonostylus distinctly separated basally and setose (Fig. 257). Ovipositor subapically expanded. only slightly curved anteriorly; first valvula with subapical ridge followed by lateral line of 3 to 4 sharp teeth; second valvula broad with several strong lateral teeth, smooth medially. Genitalia of male with parameres elongate and bearing few long setae; digitus disc-shaped. with several short marginal spines: aedeagus broad, subacuminate at apex.

\section{PHYLOCFNETIC RELATIONSHIJS}

Within Orasemorpha, 2 groups of species can be recognized. The differences between these groups are minor and I have not recognized them as formal species groups. The first group includes 4 species, $O$. xeniades, $O$. myrmicae, $O$. goethei. and $O$. tridentata. These species all have a relatively smooth, black mesosonia and glabrate gaster. The antennal flagellum of $O$. reniades and $O$. ridemata is strongly narrowed basally, which 1 consider as a derived state compared to the rest of the Eucharitidae. The states attributed to the antenna of $O$. myrmicae, especially a reduced number of funicular segments, are questionable and presently unknown for $O$. goethei. The loss of a marginal fringe from the forewing is a derived state that separates $O$. goethei, O. myrmicae, and $O$. tridentata from $O$. reniades. The second group of species includes 5 species, $O$. didentata, $O$. eribotes, $O$. pytallus, $O$. sparsepilosa, and $O$. varidentata. These species have the head and mesoscutum strongly rugose, the gastral terga densely setose, and the eyes almost always setose (bare in males of $O$. eribotes). In $O$. sparsepilosa and $O$. pyttalus, the setae of the head and mesosoma are long and dense. Orasemorpha varidentata, $O$. didentata, and $O$. eribotes are similar morphologically and exhibit only small differences in setation and shape of the mesosoma.

Within Orasemorpha, of the 2 groups that are evident based on gastral sculpture and setation, it is difficult to polarize character states based on the outgroup. The narrowed antennal flagellum of the first group (including $O$. xeniades) could be derived (but possibly not shared by all members). If Timioderus were used as the outgroup, then the rough sculpture, setose gaster, and broad antennal flagellum would be plesiomorphic. However, using either Indosema or some species groups of Orasema could reverse all but the antennal characters. Setose eyes are not found elsewhere in the Oraseminae and are found only in some species of Gollumiella and genera in the basal Eucharitinae. Tentative relationships proposed among species of Orasemorpha are ((myrmicae + goethei + tridentata + xeniades $)+(($ pyttalus + sparsepilosa $)+($ didentata + eribotes + varidentata $)))$.

\section{BIOLOGY}

Orasemorpha didentata, O. eribotes, O. myrmicae, and $O$. tridentata have been reared from 2 different species of Pheidole. Wheeler obtained pupae of. $O$. tridentata from a colony of Pheidole proxima Mayr (Brues, 1934), the pupae of which would have been invaluable for comparison with Orasema. Unfortunately these specimens could not be located at the MCZ. The form of the ovipositor suggests that eggs are deposited in plant tissue into chambers formed by the ovipositor. Ovarian eggs are smooth and stalked as is typical of most Eucharitidae.

\section{DISTRIBUTION}

Australia and Tasmania (Fig. 275). Few records for species in this genus exist. Only Oroscmorpha eribote's is found in western Australia: the remaining species are eastem. Only 2 species, $O$. reniades and $O$. cribote's, are known from Tasmania. 


\section{Key to Species of Orasemorpha}

Mesoscutum with midlobe reticulate to finely rugulose; scutellum lightly sculptured, often bare medially (Fig. 57); gastral terga at most with very few setac...... .2

- Mesoscutum with midlobe strongly rugose (Figs. $63,69,77)$, or if rugulose or scabriculous then scutellum densely sculptured (Fig. 70); scutellum sometimes smooth medially and often with longitudinal median depression; gastral terga with dense covering of subdecumbent or adpressed setae (Figs. 256-257) .5

2 (1) Forewings without marginal fringe. 3

- Forewings with complete marginal fringe (Fig. 60) o. xeniades (Walker), p. 43

3 (2) Forewing without speculum, evenly pilose; midlobe of mesoscutum and scutellum rugulose; gastral terga weakly coriaceous; mandibles $3 / 2$ dentate.

..O. myrmicae (Girault). p. 44

- Forewing with speculum; midlobe of mesoscutum smooth to weakly rugulose, scutellum smooth to coriaceous; gastral terga smooth; mandibles $3 / 3$ dentate (unknown for some species) . .4

4(3) Gaster weakly coriaceous; midlobe of mesoscutum weakly rugulose; head and mesosoma of both sexes dark green; mandibles $3 / 3$ dentate (Fig. 56) O. tridentata (Girault), p. 45

- Gaster glabrous; midlobe of mesoscutum mostly bare; head and mesosoma black in female, dark blue in male. (Dentition unknown.)

O. goethei (Girault), p. 46

5 (1) Head (including eyes) and mesosoma with moderate to dense covering of long, erect setae (Figs. $66,69)$ . .6

- Head and mesosoma bare or with short subde- cumbent setae (Figs. 70, 73, 77, 217); cye setac, if present, short and sparse (Figs. 76, 187) .......7

6 (5) Marginal fringe of forewing complete; forewing without speculum, the basal area bare but with narrow band of setae extending along impression of cubital vein to base of forewing, and costal cell densely pilose; wing disc densely pilose......

O. pyttalus (Walker), p. 47

- Marginal fringe of forewing restricted to posteroapical margin; forewing with speculum and basal area bare, and costal cell with few minute setae apically; wing disc with setae sparse and fine, hardly visible (Fig. 68)

O. sparsepilosa sp. nov., p. 48

7 (6) Femora yellowish brown; coxae smooth and completely pilose; mesosoma black with strong iridescent reflections, dorsum coarsely rugose, interstices broadly spaced (Fig. 63); gastral terga moderately pilose

O. varidentata (Girault), p. 49

- Femora dark brown, at least over basal third; coxae smooth to rugulose, dorsal surface bare; mesosoma dark green or bluish and sometimes with faint reddish reflections, the dorsum rugose to scabriculous, interstices closely spaced (as in Fig. 187); gastral terga densely pilose .8

8 (7) Hind coxa almost completely smooth; femora and tibia of hind leg with long dense semi-erect setae (Fig. 78); eye of female with sparse short setae (Fig. 76), eye of male with minute setae....

..O. didentata (Girault), p. 50

- Hind coxa rugulose to scabriculous; femora and tibia of hind leg with short dense subdecumbent setae; eye of female with minute setae or bare, eye of male bare (Fig. 73)

O. eribotes (Walker), p. 51 


\section{Orasemorpha xeniades (Walker)}

Figs. 55, 57, 59-61

Eucharis reniades Walker, 1839:14-15. Australia: New

South Wales [BMNH, examined].

Orasemorpha xeniades; Bouček, 1988:519.

\section{TYPE MATERIAL}

Lectotype (designated Bouček, 1988), ơ. "1441." "Sydney." "LECTO-/ TYPE." "Type." "Psilogaster/ xeniades/ Walker." "B. M./ TYPE/ HYM./ 5.620." “ڤ Orasema/ xeniades (Walk.) LT/ det. Z. Bouček, 1986." Remounted $\delta$ on white card, flagella, part of left forewing, and left hind legs missing. Paralectotypes, 2 oे oे labelled "Sydney" and "N.S.W.," otherwise as above.

\section{DIAGNOSIS}

Recognized by the following: marginal fringe distinct, speculum present, and gaster almost entirely bare and smooth. This species is closely related to $O$. goethei, $O$. myrmicae, and $O$. tridentata but can be differentiated by the presence of a distinct marginal fringe on the forewing (Fig. 60).

\section{FEMALE}

Length, 2.4-2.8 mm. Body black with strong bluish-green reflections; antenna, mandible, femora, and apical tarsomeres dark brown; apex of femora and rest of legs yellowish brown (fore and mid tibiae may be dark brown medially). Wings hyaline, venation pale brown.

Head subtriangular, eyes protuberant and inner margins only slightly diverging; occiput broadly emarginate; temples large and broadly rounded behind eyes (Fig. 59); LOL 0.9-1.0× OOL. Face broadly rounded, completely shallow reticulate or finely rugulose; scrobal depression narrow and broadly rounded with finer sculpture, partially including median ocellus. Eycs bare. separated by 2.3-2.4× their height. Malar space 1.0-1.2 $\times$ height of cyc. Clypeal region weakly reticulate, lateral margins of clypeus at tentorial pits decply impressed: supraclypeal arca slightly bulging. Labrum 4-digitate. Mandibles $3 / 2$ dentate. Antenna 12-segmented; anellus small; flagellum $1.3 \times$ height of head: funicular segments with dense short adpressed setac; F2 1.8-2.2x as long as broad, 1.1-1.3x F3, following segments subequal in length. equal in width; clava obconical and as long as preceding 2 segments.

Mesosoma with midlobe of mesoscutum reticulate and lateral lobe strongly swollen and glabrate; axilla swollen and glabrous; scutellum glabrous dorsally, and reticulate laterally and basally (Fig. 57). Notauli sharply impressed and narrowly crenulate. SSS broadly impressed with few transverse carinace. Scutellum 1.5-1.6x als long an broad: frenal line a broad glabrous band dorsally, frenal area rugulose, broadly impressed medially. Propodeum evenly rounded and coriaceous to reticulate with few weak longitudinal carinae; callus and metepimeron swollen and glabrous, callus with weak callar nib. Upper mesepimeron swollen and glabrous, lower mesepimeron flat and glabrous, transepimeral sulcus foveolate: mesepisternum finely reticulate, smooth ventrally. Prepectus broadly triangular, reticulate with pronounced posterior flange. Pronotum rugose-reticulate. Proepisternum coriaceous. Fore and mid coxae and femora coriaceous, hind coxa nearly glabrous; hind leg with tibia and apex of femur densely short-setose. Forewing $2.3-2.5 \times$ as long as broad: basal area and speculum bare; speculum closed basally by broad band of setae; costal cell with narrow band of apical setae; disc densely short pilose, distinct marginal fringe around apical and posteroapical margins: stigmal vein $1.7-3.3 \times$ as long as broad, narrowed basally.

Metasoma with petiole glabrous and $0.3-0.4 \times$ as long as broad. Gastral terga very weakly coriaceous with few fine adpressed setae, almost glabrous: Ms, with constriction deeply impressed and crenulate, anterior region glabrous and semicircular, anterior margin extending forward under petiole. Hypopygium with 1 to 2 minute sublateral setae at apex. (Ovipositor hidden.)

\section{MALE}

Length, 1.7-2.0 mm. Body dark brown to black, head and mesosoma sometimes with faint blue or green reflections: antenna black, scape and pedicel with metallic blue reflections; femora and tibiae mostly black, apices of femora and tibiae, and tarsi brown. Wings weakly infuscate.

Head shape as in female: LOL $0.9-1.2 \times$ OOL. Sculpture reticulate to scabriculous. Antenna 12- or 13segmented; anellus small: flagellum 1.7-2.0× height of head; funicular segments with dense subdecumbent setac, F2 1.8-2.4x as long as broad, 1.2-1.5× F3: clava 1- or 2segmented with varying degrees of fusion.

Mesosoma more slender than female: scutellum and posterior region of axilla weakly reticulate: scutellum 1.6-1.8x as long as broad; frenal area coriaceous, frenal line as shallow dorsal groove. Propodeum with or withoul median carina. Forewing 2.1-2.4x as long as broad: speculum sparsely pilose (Fig. 60).

Metasema with petiole $2.0 \times$ as tong as hroad, $0.9-1.2 \times$ as long as hind coxa. $0.8-1.2 \times$ as long as propodeum and weakly reticulate dorsally, often with few weak striac. Gastrat tergal glabrous: Ms, strongly comstricted, anterior region glabrous. Ms broadly rounded and serose. Gentalia typical for genus: parameres narrow and clongate. sharp median process. digitus with 3 10 4 matrginal spines: acdeagus broad and acuminate at tip. 
BI(O)(x)

Reared from Phoidele tasmaniensis.

\section{DISTRIBLTIO).}

Southeastern Australia including Tasmania (X, Fig. 275).

\section{MATERIAL EXAMHNEI)}

Alstral.1A: New South Wales: Cabramalta, Sydney; Nerriga; Tooloom Scrub; Sawpil Ck. Mt Koscliuskol N. P.: December to February ( $3 q q, 10$, BMNH); South Australia: Mt Lofty, Adelaide, January ( 10 , BMNH); Tasmania: Gladstone, $1 \mathrm{~km}$ SSE; Herrick, $1 \mathrm{~km}$ E by $\mathrm{N}$ (41.06S 147.53E): Marrawah, 4 km SW (40.57S 144.40E); The Lea (42.56S 147.19E); The Lea, $6 \mathrm{~km} \mathrm{~S}$ Hobart: Huon Riv.. Lea. ex Pheidole tasmaniensis (I 0 and partial remains of 5 others mounted with headless ant, USNM); Wayatinch, $3 \mathrm{~km} \mathrm{NE}$ by E; April and December to February $\left(2 q q, 22 \delta^{\circ}{ }^{\circ}\right.$, ANIC); Victoria: Lake Mtn. E of Melbourne; Kinglake N. P. nr Melbourne; January to February ( $\left.7 q q, 22 \delta^{\star}, \mathrm{BMNH}\right)$.

\section{Orasemorpha myrmicae (Girault) comb. nov.}

Fig. 62

Epimetagea myrmicae Girault, 1936:3 [324]. Australia: Victoria [QMB, examined]. Hedqvist, 1978:243 (list). Dahms, 1984:842 (notes on type material). Chalcura myrmicae-Bouček, $1988: 529$ (combination).

\section{TYPE MATERIAL}

Lectotype (designated as holotype by Dahms, 1984), $q$, "Belgrave V./ F. E. Wilson. Jan 1922." "HOLOTYPE/ T. 9262/ E. C. D. 1984." "Eucharomorpha myrmicae Gir." [GH] "LECTOTYPE/ Orasemorpha/ myrmicae (Grlt)/ Det. Heraty, '90." Head removed, body mounted with minor of Plieidole. Head and antenna mounted on slide labelled "Tricoryna ectatommae Gir., Paratype, Encharomorpha myrmicae Gir. Ty. $q . "$ The head is mounted under a separate coverslip closest to the label and is correct for Orasemorpha. The 9-segmented antenna of $T$. ectatommae is mounted under the outer coverslip fragment along with a 10 -segmented antenna attributed to E. myrmicae. A separate 10-segmented antenna, identical to the other, is under a different coverslip fragment. The antennate are atypical for Orasemorpla and it is questionable whether they belong to E. myrmicae. The original description does not specily the number of specimens examined. The slide mount is labelled as a paratype. which indicates that the headless body may not have been a unique specimen, and thus should not be referred to as a holotype: the point-mounted body is therefore designated here as lectotype.

\section{DIACENOSIS}

Similar to $O$. riclemsta and $O$. goethei based on the almost total lack of setae on the gastral terga and no marginal fringe on the forewing. This species is distinguished from $O$. tridentuta by the following: gastral terga weakly coriaceous, mesosoma dorsum (midlobe and scutellum) rugose-areolate, speculum absent, and mandibles with $3 / 2$ dentition. If the antennae are properly assigned to the lectotype then it uniquely possesses a 10-segmented antenna that lacks an anellus (Fig. 62). This last feature is dubious and should not be used as a limitation for assigning individuals to this species.

\section{FEMALE}

Length, $1.75 \mathrm{~mm}$ (mesosoma and gaster). Mesosoma, petiole and coxae black with reddish reflections; gaster and basal two-thirds of femora dark brown with reddish reflections; apex of femora, tibiae and basal tarsomeres yellowish brown; antennal flagellum dark brown, scape lighter brown, pedicel intermediate. Wings hyaline, venation pale brown.

Head (limited information based on poor slide mount) with labrum 6-digitate and with 1-4-1 formula. Mandibles 3/2 dentate. Antenna 10-segmented; anellus absent; funicular segments with short dense setae, F2 $2.1 \times$ as long as broad, $1.4 \times$ as long as F3, following segments equal in length and width; clava obconical and longer than preceding 2 segments, composed of 2 partially fused segments.

Mesosoma with midlobe of mesoscutum and scutellum close-packed rugose-areolate with interstices shallow and rounded, scutellum smooth just anterior to frenal groove; lateral lobe polished and strongly swollen; axilla smooth dorsally and weakly striate posteriorly, strongly angled to meet scutellum. Notauli narrow and deeply impressed, finely crenulate. SSS weakly crenulate. Scutellum rounded dorsally; frenal groove a narrow glabrous band dorsally, frenal area weakly rugose and slightly depressed medially. Propodeum evenly rounded and weakly rugose. impressed dorsally and above base of coxae; callus and metepimeron glabrous, callus with strong medial groove delimiting anterior region. Mesepimeron slightly swollen and glabrous, transepimeral sulcus weak; mesepisternum evenly reticulate laterally. smooth ventrally. Prepectus triangular. reticulate with smooth dorsal and posterior flanges. Pronotum broadly rounded laterally and lightly rugose. Proepistemum weakly coriaceous. Coxae weakly coriaceous: femora scabriculous apically on lateral surface; hind leg with tibia and apex of femur densely shontsetose. Forewing $3.0 \times$ as long as broad; basal area bare: speculum absent: costal cell with sparse medial band of fine setae; disc moderately pilose with short fine setae, no marginal fringe: stigmal vein broad and perpendicular to wing margin.

Metasoma with petiole glabrous and broader than 
long. Gastral terga weakly coriaceous and bare; $\mathrm{Ms}_{2}$ with constriction broad and finely crenulate, anterior region cup-shaped and projecting forward under petiole. (Ovipositor and sheaths hidden.)

\section{MALE}

Unknown.

\section{BIOLOGY}

Taken from nest of Pheidole sp. (Girault, 1936).

\section{DISCUSSION}

No additional material has been assigned to this species. See discussion of variation for Orasemorpha tridentata for similar material.

\section{DISTRIBUTION}

Southeastern Australia (M, Fig. 275).

\section{Orasemorpha tridentata (Girault)}

Figs. 56, 58

Eucharomorpha tridentata Girault, 1915:230. Australia: Queensland [QMB, examined]. Dahms, 1986:597 (notes on type material).

Eucharomorpha wheeleri Brues, 1934:203-205. Australia: New South Wales [MCZ, examined]. New synonymy.

Orasemorpha tridentata-Bouček, 1988:519.

Orasemorpha wheeleri-Bouček, 1988:519.

\section{TYPE MATERIAL}

Lectotype of E. tridentata (designated as holotype by Dahms, 1984), \&, "HOLOTYPE/ Hy. 3287/ E. C. D. 1985." "Eucharomorpha/ tridentata Girault/ Type." [GH] "LECTOTYPE/ Orasemorpha/ tridentata (Grlt)/ Det. Heraty, '90." Smashed body on point, no head. Additional material described by Dahms (1986) was not discussed in the original description. The slide labelled "Eucharomorpha tridentata Gir., \& type" (covered over by label that does not state type status) contains the head, parts of antennae, and 1 forewing. All of the wings are present on the lectotype indicating that the parts on the slide were taken from a different specimen. Sec Dahms (1986) for additional information on type matcrial.

Lectotype of $E$. wheleri (here designated), + . "Wentworth Falts/ N. S. W. 2800 '[854 m]/ Dec. 22. '31." "Harv. Austr. Exp./ W. M. Wheeler." "M.C.Z./ Type/ 1962 [red label]." "Type series/ Eucharomorpha/ wheeleri/ Brues." "LECTOTYPE/ Orasemorpha/ whecleri (Brues)/ Det. Heraty “90." Complete specimen, minuten mounted. Paralectotypes, $3 q q$ with same data. Brues (1934) relerred to "type and numerous paratypes" but only the material mentioned above was located at the $\mathrm{MCZ}$.

\section{DIAGNOSIS}

Recognized by the following: marginal fringe of the forewing lacking, speculum present, gaster almost entirely bare and smooth, and mesosomal dorsum almost entirely smooth or very weakly coriaceous. This species is closely related to Orasemorpha goethei, O. myrmicae. and $O$. xeniades. It may be distinguished from $O$. goethe $i$ and $O$. myrmicae by the presence of a speculum, dorsal sculpture, and broader forewing, and from $O$.xeniades by the presence of a marginal fringe, larger LOL/OOL ratio (1-1.4) of female, and generally narrower scutellum. Additionally, it can be separated from $O$. myrmicae and $O$. xeniades by the tridentate mandible (Fig. 56). However, this last state is unknown for $O$. goethei.

\section{FEMALE}

Length, 1.7-2.4 mm. Head, mesosoma, and gaster. including petiole and coxae, black with strong greenish reflections; scape to anellus light brown, pedicel darker dorsally, flagellum dark brown; mandible dark brown; femora mostly dark brown to black, apex and rest of legs dark yellowish brown, apical tarsomere brown. Wings weakly infuscate, venation pale brown.

Head subtriangular, occiput broadly emarginate; temples large and abrupt behind eyes in dorsal view; LOL 1-1.4× OOL. Face broadly rounded, completely shallow reticulate; scrobal depression narrow and broadly rounded with finer reticulate sculpture, partially including median ocellus. Eyes bare and protuberant, their inner margins slightly diverging; separated by $2.3-2.4 \times$ their height. Malar space 1.0-1.2 $\times$ height of eye. Clypeal region weakly reticulate to scabriculous, lateral margins broadly impressed; supraclypeal area bulging. Labrum 4-digitate, digits short and stout. Mandibles 3/3 dentate. Antenna $12-$ segmented; anellus small; flagellum $1.3 \times$ height of head; funicular segments with dense short adpressed setac (setae not raised above surface, segments appearing barc). F2 1.8-2.2× as long as broad, 1.1-1.4× F3. following segments subequal in length and of increasing width to apex: clava obconical and as long as preceding 2 segments.

Mesosoma with midlobe of scutellum fincly reticulate medially with weakly rounded interstices, the lateral margins reticulate to smooth; lateral lobe glabrous and strongly swollen, llattened along anterior dorsal surface: axilla swollen and glabrous (not narrow as described by Girault), with posterior margin sharply declivous to level of scutellum; scutellum weakly reticulate to smooth. sculpture sometimes appearing weakly striate anterolaterally. Notauli sharply and deeply impressed, narrowly crenulate. SSS weakly cremulate. Scutellum rounded dorsally, 1.5-1.9x as long as hroad: frenal line a narrow 
grouse, frenal areal smooth to coriaceous. vaguely emargunate medially. Propodem evenly rounded and weakly retkulate to smooth; callus and metepimeron swollen and glabrous, separated by sharp metepimeral sulcus; callus with weak callar nib. Upper mesepimeron swollen and glibrate. lower mesepimeron flat and weakly reticulate. with transepimeral sulcus weak; mesepisternum evenly reticulite, smooth ventrally. Prepectus broadly triangular. reticulate with pronounced posterior flange. Pronotum reticulate. Procpisternum reticulate to smooth posteriorly. Coxac smooth to weakly reticulate; femora weakly imbricate: hind leg with apex of femur and tibia moderately pilose with short adpressed setae (hardly visible). Forewing 2.4-2.6x as long as broad; basal area and speculum bare. speculum may be closed proximally by sparse sctae; costal cell pilose posteriorly; disc densely short pilose, marginal fringe absent; stigmal vein narrow, $1.8-2.5 \times$ as long as broad and almost perpendicular to wing margin.

Metasoma with petiole broader than long, finely reticulate or smooth anteriorly (Fig. 58). Gastral terga very weakly coriaceous with sparse, fine, adpressed setae, almost glabrous; $\mathrm{Ms}_{2}$ with deeply impressed crenulate constriction, anterior region glabrous and semicircular with sharp posterior margin, extending forward under petiole. Hypopygium with few minute sublateral setae at apex. Ovipositor typical for genus; first valvula with 3 small teeth along lateral line; second valvula with several strong lateral teeth.

\section{MALE}

Unknown.

\section{VARIATION}

There is little morphological variation among the material examined. The degree of sculpture on the dorsum of the mesosoma varies from almost complete on the midlobe of the mesoscutum to almost absent from the entire scutellum, and the dorsal apical region of the scutellum is always bare.

\section{BIOI.OGY}

Reared from Pheidole proxima Mayr (Brues, 1934). Collections of this species have been taken from a dry sclerophyll Eucalyptus forest and along a riverbank near Gordonvale.

\section{bISTRIBUTION}

Eastern Australia (T, Fig. 275).

\section{MATERIAI. EXAMINED}

Australia: A.C.T.: Black M(n. Jamuary ( 1 ․ ANIC); New South Wales: Nerriga, $5 \mathrm{~km}$ NE. $600 \mathrm{~m}$. diy sclerophyll Eucalyphus forest, January to February (Iq, AEI);
Queensland: Brisbane, 22 km NW: Graham Range, Babinda: Mt Glorious N. P., 630 m; Mt Nebo; Mulgrave Riv., Bruce Highway, $1 / 2 \mathrm{~km}$ S Gordonvale [along river]: October and December to April (2I웅 AEl, ANIC, CNC, QMB, TAMU).

\section{Orasemorpha goethei (Girault)}

Eucharomorpha goethei Girault, 1934:2 [307]. Victoria, Australia [MUV, examined]. Dahms, 1984:654 (notes on type material).

Orasemorpha goethei-Bouček, 1988:519.

\section{TYPE MATERIAL}

Holotype, + " Melbourne. V./ F. E. Wilson/ 3.XII.27.” "]452[?]/ Type \&." "Eucharomorpha/ \& goethei Girault/ Type." "F. E. Wilson/ Collection." "ENT - 578." Complete mesosoma and gaster mounted on point. The slide with the head should be at the Queensland Museum but in its place is a note that the slide is "with Mound." Dahms (1984) states that the type on the slide was remounted at the $\mathrm{BMNH}$.

\section{DIAGNOSIS}

Similar to $O$. tridentata and $O$. myrmicae based on the following: gastral terga almost bare, and marginal fringe of forewing absent. The species is distinguished by having the mesosoma dorsum (midlobe and scutellum) and gastral terga almost completely smooth, and speculum present.

\section{FEMALE}

Length unknown. Mesosoma, petiole and coxae dark brown to black, mesosoma with very faint greenish reflections; gaster and basal two-thirds of femora dark brown: apex of femora, tibiae and basal tarsomeres yellowish brown; antennal flagellum dark brown, scape lighter brown, pedicel intermediate. Wings hyaline, venation pale brown.

Head, missing from only known female.

Mesosoma with midlobe of mesoscutum smooth with weak superficial sculpture anteriorly and scutellum glabrous; lateral lobe polished and strongly swollen; axilla smooth dorsally, broad, and rounded. Notauli narrow and deeply impressed, finely crenulate. SSS weakly crenulate. Scutellum rounded dorsally, on lower plane than axilla; frenal line narrow dorsally and very finely cremulate, frenal area weakly rugose and broadly rounded. Propodeum evenly rounded, finely and weakly reticulate medially, slightly impressed above base of coxae; callus and metepimeron glabrous. with small callar nib. Mesepimeron smooth. transepimeral sulcus distincl; femoral groove weakly reticulate: mesepisternum glabrous. Prepectus triangular, smooth ventrally to reticu- 
late dorsally, with glabrous dorsal and posterior flanges. Pronotum broadly rounded laterally and coriaceous. Proepisternum coriaceous. Coxae weakly coriaceous; femora smooth to lightly scabriculous apically on lateral surface; hind leg with tibia and femora densely shortsetose. Forewing $3.0 \times$ as long as broad; basal area bare; speculum present; costal cell bare; disc moderately pilose with short fine setae, no marginal fringe; stigmal vein narrow and perpendicular to wing margin.

Metasoma with petiole $0.2-0.3 \times$ as long as broad, glabrous. Gastral terga almost completely smooth, with only faint surface sculpture; $\mathrm{Ms}_{2}$ with constriction broad and weakly crenulate, anterior region smooth. Hypopygium bare. Ovipositor subapically expanded; first valvula with subapical ridge followed by 4 sharp lateral teeth; second valvula with 7 to 8 lateral teeth. (Gonostylus hidden).

\section{MALE}

Length, 1.7-1.9 mm. Black, lower face and mesosoma laterally with faint greenish or violaceous reflections; antenna dark brown to black; femora, tibiae, and apical tarsomeres dark brown, apices of femora and tibiae, and basal tarsomeres yellowish brown. Wings hyaline.

Head subtriangular, eye only slightly protuberant. Malar space 1.1-1.3× height of eye. Labrum 4- or 5-digitate. Antenna 12-segmented; anellus present; flagellum 1.6-1.8 $\times$ height of head; funicular segments with dense subdecumbent setae, F2 $1.8-2.0 \times$ as long as broad, $1.2-1.4 \times \mathrm{F} 3$.

Mesosoma more slender than female; scutellum completely smooth to very weakly sculptured, $1.8-2.2 \times$ as long as broad; frenal line indistinct dorsally, frenal area smooth to reticulate. Forewing $2.2 \times$ as long as broad; speculum sparsely pilose; costal cell with single row of small setae.

Metasoma with petiole $0.9-1.1 \times$ as long as hind coxa, $0.7-1.0 \times$ as long as propodeum, reticulate dorsally. Gastral terga glabrous; Ms, strongly constricted, anterior region scabriculous or smooth, cup-shaped and anterior margin extending forward under petiole. Ms 8 broadly rounded and setose. (Genitalia withdrawn and not dissected.)

\section{DISCUSSION}

A female in the BMNH (remnants only, libelled 1440c) probably belongs here as it has the costal cell bare, scutellum slightly indented medially, and the gastral terga entircly smooth. A femalc from Tasmania (Dodges Ferry, 29.xii.1979, J. C. Carrlale. ANIC) appears to be closely related to $O$. goethei but differs in having the scutellum broader, with side lobe of mesoscutum swollen and not flattened above, and the basal flagellar segments longer and narrower than described above. The males described for this species exhibit a strong sexual dimorphism. which makes it difficult to associate specimens with females of the 3 species that lack marginal setae; the male specimens also could be attributed to either $O$. tridentata or $O$. myrmicae. The males are excluded from $O$. myrmicae by the smooth or weakly sculptured scutellum and are considered to belong to $O$. goethei only because of their southern distribution in Australia. Males of the more northern $O$. tridentata are presently unknown. The variation in sculpture of the anterior region of $\mathrm{Ms}_{2}$ is between 2 males from Shepparton and the male from Toolomb Plateau. which has the scabriculous sculpture.

\section{DISTRIBUTION}

Southeastern Australia (G, Fig. 275).

\section{MATERIAL EXAMINED}

Australia: New South Wales: Tooloom Plateau, via Urbanville, 600-700 m, 8.i.1977. I. D. Naumann, sweeping low vegetation, subtropical rainforest ( $\left.1 \delta^{\circ}, \mathrm{UQIC}\right)$; Victoria: Shepparton, 15.xii.1974, I. D. Naumann, sweeping grass by creek, dry sclerophyll forest (2 oै oे UQIC).

\section{Orasemorpha pyttalus (Walker)}

Figs. 64, 66-67

Eucharis pyttalus Walker, 1846:21,87-88. South Australia [BMNH, examined].

Orasemorpha pyttalus-Bouček, 1988:519.

\section{TYPE MATERIAL}

Holotype, \&, "Holo-/ type." "Psilogaster/ pyttalus/ Walker." "B. M. TYPE/ HYM./ 5-615." "o Orasemorpha/ pyttalus (Walker)/ det. Z. Bouček, 1986." Petiole and gaster missing.

\section{DIAGNOSIS}

Recognized by: entire body covered by dense erect setae, head triangular (Fig. 66), basal antennal segments ycllowish brown, and forewing densely pilose with a prominent marginal fringe.

\section{HOLOTYPE FEMALE}

Length, ca. $2.8 \mathrm{~mm}$. Head and mesosoma dark metallic green with scattered regions of dark reddish coloration on clypeus, median line on mesoscutum, axilla, along frenal line, and most of propodeum: coxac dark metallic green: flagellum dark brown: scape to anellus yellowish brown: legs yellowish brown. base of femora slightly darker. Wings hyaline, venation pale brown.

Head triangular; occiput broadly emarginate: $1 \mathrm{emples}$ broadly rounded and densely short ereet setose: LOL 1. IX OOL. Face relatively flat and strongly rugose. lower face 
and bertex eovered by dense erect setale (Fig. 66), froms lateral to scrobal depression sparsely selose; scrobal depression broidly inppressed and rugose. Eyes slightly protuberant. covered by dense ereet selate, and separated b) $2.3 \times$ their height. Malar space $1.2 \times$ height of eye. Clypeal region lightly sculptured and dense setose, lateral margin of clypeus deeply impressed; supraclypeal area slighty bulging. Labrum 4-digitate. Mandibles $3 / 2$ dentate. Antemna 12-segmented (Fig. 64); scape densely pilose: anellus present: flagellum $1.4 \times$ height of head; funicular segments scabriculous with dense short setae along entire length, F2 $1.9 \times$ as long as broad, $1.5 \times$ F2, lollowing segments subequal in length; clava obconical, as long as preceding 2 segments.

Mesosoma with dorsum rugose to rugulose and densely erect pilose: lateral lobe of mesoscutum lightly sculptured and shining: axilla swollen and smooth: scutellum weak rugulose. Notauli narrowly impressed. SSS narrow and crenulate. Scutellum as long as broad; frenal line narrow and glabrous, frenal area rugulose. Propodeum rugulose with several irregular carinae converging on base of petiole: callus glabrate and swollen, with small callar nib. Upper mesepimeron glabrous and swollen. lower mesepimeron light rugulose, with transepimeral sulcus distinct; mesepisternum light rugulose. Prepectus triangular, rugulose with weak dorsal and posterior flanges. Pronotum evenly rugulose. Proepisternum lightly sculptured and sparsely setose. Fore and mid coxae almost smooth and densely setose ventrally, hind coxa weak rugulose to smooth and setose ventrally; femora smooth with dense semi-erect setae. Forewing $2.4 \times$ as long as broad; basal area bare with band of setae extending along cubital vein to base; speculum absent; costal cell pilose; disc densely pilose, marginal fringe distinct; stigmal vein $1.1 \times$ as long as broad, constricted at base.

Metasoma missing, probably similar to $O$. eribotes.

MALE

Unknown.

\section{VARIATION}

One specimen from Queensland (Mt Glorious, AEI) is tentatively assigned to this species. This specimen is close to the type except for the following: lacks any of the reddish coloration; LOL less than OOL; scutellum with longitudinal rugae and entire basal area completely (but sparsely) setose: petiole transverse and weakly rugose laterally with dense erect setae: gastral terga smooth with dense erect setac; Ms, with strong crenulate constriction, and rest of gaster typical. The 2 specimens from New South Wales are similar to the type but have a dark scape and pedicel. wings completely and densely setose to base. and mesepimeron glabrous. Another male (AustraliA: New South Wales: Oxford, in BMNH) represents a close- ly related species that has the wings completely and densely pilose and the scape entirely black and metallic.

\section{DISTRIBUTION}

Eastern Australia (P, Fig. 275).

\section{MATERIAL FXAMINED}

Australia: New South Wales: Sams Rd, Bulahedelah S.F. (32.24S 152.14E), 8.xii.1986. M. M. Stevens and F. E. Frindle ( 2 $q$, ANIC); Queensland: Mt Glorious, 17.xi, [no collector] (1 $q, \mathrm{AEI})$ : Stanthorpe, 15.i.1983, Z. Bouček ( 1 ㅇ, BMNH).

\section{Orasemorpha sparsepilosa sp. nov.}

Figs. 65, 68-69

\section{TYPE MATERIAL}

Holotype, ㅇ, "NSW: Moree/ 1.78. G. Brown." “q Orasemorpha/ sparsepilosa sp. n./ det. Z. Bouček, 1986.” "HOLOTYPE/ Orasemorpha/ sparsepilosa/ Heraty." Deposited in BMNH.

Paratypes: Australia: New South Wales: same data as holotype ( 2 우, $2 \delta$ ఠ。, BMNH).

\section{ETYMOLOGY}

From sparse and pilose, referring to the pilosity of the body.

\section{DIAGNOSIS}

Recognized by: body covered by moderately dense, fine, erect setae (Fig. 69), head subtriangular with broadly rounded gena, basal antennal segments light yellow to nearly white, forewing with fine setae (hardly visible), and marginal fringe restricted to the postero-apical margin of wing (Fig. 68).

\section{FEMALE}

Length, $3.8 \mathrm{~mm}$. Head dark blue, lower face with patches of violet or reddish colour, vertex more greenish; mesosoma dark blue-green with strong reddish coloration on mesoscutum and axilla: dorsomedial regions of lateral lobe, axilla, and apex of scutellum with stronger bluish colour laterally; petiole black with reddish reflections: gaster dark brown with greenish reflections: coxae mostly dark brown with greenish reflections, apices yellowish brown: scape to anellus light yellow to white, rest of flagellum brown: mandible light brown; legs beyond coxae light yellowisl brown to yellow. Wings hyaline, venation clear yellowish brown.

Head subtriangular; occiput broadly emarginate: temple broadly rounded with short erect setae: LOL $0.8 \times$ OOL. Face strongly rugose to rugulose, lower face and vertex evenly covered by moderately dense erect setac: 
scrobal depression shallow and broadly impressed with irregular striae arching over toruli. Eyes slightly protuberant, with short erect setae and separated by $2.5-3.3 \times$ their height. Malar space 1.2-1.6× height of eye. Clypeus nearly smooth with sparse erect setae, lateral margin deeply impressed to tentorial pit; supraclypeal area finely rugulose and swollen. Labrum 7-segmented, digits with 2-3-2 formula. (Mandibles hidden.) Antenna 12-segmented (Fig. 65); anellus present: flagellum 1.3-1.4× height of head; funicular segments with dense subdecumbent setae. F2 1.6-1.9× as long as broad, 1.4-1.5× F3, following segments subequal in length, decreasing slightly in width to apex; clava elongate, almost as long as preceding 2 segments.

Mesosoma with dorsum weakly rugulose and with moderately dense covering of short erect setae (Fig. 69); lateral lobe of mesoscutum strongly swollen, weak rugulose laterally and smooth dorsally; axilla swollen and glabrate, rugulose laterally; scutellum almost entirely smooth dorsally with weak irregular longitudinal rugae basally (Fig. 69). Notauli deeply and broadly impressed. narrowly crenulate. SSS crenulate. Scutellum as long as broad; frenal line narrow and glabrous, frenal area rugulose. Propodeum rugulose with several irregular carinae diverging from propodeal midline, ventrally with several carina converging to base of petiole; callus smooth or weakly sculptured and bare, swollen, callar nib weak or absent; metepimeron separated by deep metepimeral sulcus. Upper mesepimeron swollen and glabrous, lower mesepimeron light rugulose, distinct transepimeral sulcus; mesepisternum finely reticulate. Prepectus broadly triangular, rugulose with strong dorsal and posterior flanges. Pronotum reticulate-rugose. Proepisternum reticulate and bare. Coxae smooth with sparse semi-erect setae ventrally; femora and tibiae smooth with dense semi-erect setae. Forewing 2.1-2.3 $\times$ as long as broad; basal third of wing, including basal area and speculum, bare; costal cell with few minute setae apically; disc with short fine setae (difficult to discern), marginal fringe restricted to extreme posterior apical margin and along marginal vein (Fig. 68): stigmal vein $1.4 \times$ as long as broad with strongly narrowed base, angled about 45 degrees to dorsal margin.

Metasoma with petiole transverse, glabrous medially and finely sculptured with short erect setac laterally. Gastral terga weakly coriaceous with moderately dense covering of fine semi-erect setac; $\mathrm{Ms}_{2}$ with constriction broad and weakly crenulate. Hypopygium with few short sublateral setac at apex. Ovipositor typical for genus; first valvula with 3 sharp teeth forming lateral line; second valvula with 9 to 10 lateral teeth.

\section{MALE;}

Length, 3.0-3.6 mm. As in female except: entire coxac dark: scape, pedicel, and basal thirl of femora brown.
Antennal flagellum $1.7 \times$ height of head, slightly tapering from base to apex. Metasoma with petiole $2-2.3 \times$ as broad as long, $0.5-0.6 \times$ as long as hind coxa, twice as long as propodeum; weakly rugulose dorsally with few erect setae. $\mathrm{Ms}_{2}$ with constriction smooth, anterior region strongly swollen and glabrous. $\mathrm{Ms}_{8}$ broadly rounded and setose. Genitalia with parameres short and stout.

\section{DISCUSSION}

A female from Queensland is similar to the type material except as follows: funicle with 7 segments; scape yellowish brown, pedicel and anellus brown; flagellum black; mandibles 3/3 dentate: mesepisternum rugulose; wing venation pale brown, wing setae slightly darker and more visible; head and mesosoma darker green. and legs orange-brown. The reduction in number of funicular segments may support the reduced number of antennal segments reported for $O$. myrmicae (see discussion for that species).

\section{DISTRIBUTION}

New South Wales and Queensland, Australia (S, Fig. 275).

\section{MATERIAL EXAMINED}

Australia: Queensland: Rockhampton, 26-27.xi.1967. J. and M. Sedlacek ( 1 \% BPBM).

\section{Orasemorpha varidentata (Girault)}

Fig. 63

Eucharomorpha varidentata Girault, 1936:3 [324]. Australia: Tasmania [QMB, examined]. Dahms. 1986:622 (notes on type material).

Orasemorpha varidentata-Bouček, 1988:519.

\section{TYPE MATERIAL}

Holotype, + . "G. H. Hardy/Lindisfarne/ 17/ // 1914/ 43." "HOlOTYPE/ T. $10049 /$ E. C. D. 1985." "Eucharomorpha/ varidentata Girault/ Type" [GH]. Mesosoma with hind wing and mid leg on point, fore and hind leg mounted separately on point: head, antenna, and basal half of forewing mounted separately. See Dahms (1986) for details of type material.

\section{DIAGNOSIS}

Recognized by having the mesosoma broad and strongly rugose (Fig. 63) with strong iridescent reflections. basal flagellar segments yellowish brown, prepectus narrow. coxac completely setose, basal area of forewing bare. speculum absent, and first valvula with 3 sharp tecth along the latteral line. 


\section{HOLOTYPE. FEMAIE}

Lengh unknown. Mesosoma black with strong iridescent (reddish green and violed) reflections; coxac and gaster dark brown with reddish rellections; scape to anellus yellowish brown. rest of flagellum dark brown; legs yellowish brown. femora slightly darker basally. Wings hyaline, venation light brown.

Head (squashed on slide) with labrum 4-digitate. mandibles $3 / 2$ dentate, antenna 12-segmented, anellus present: lunicular segments densely short setose, F2 1.6x as long as broad, $1.1 \times \mathrm{F} 3$, the following segments subequal in length: clava slightly longer than preceding 2 segments.

Mesosoma with dorsum coarsely rugose, interstices shallow and rounded: axilla and lateral lobe of mesoscutum glabrous and strongly swollen, axilla strongly angled posteriorly to meet scutellum. Notauli deeply and narrowly impressed, strongly crenulate. SSS strongly crenulate. Scutellum broad and rouncled, $1.3 x$ as broad as long; frenal line broad and glabrous dorsally, frenal area rugose. depressed medially. Propodeum evenly rounded, coarsely rugose with smooth septa and moderately pilose covering of short fine setae (angled dorsally); callus glabrous and swollen, metepimeron and anterior callar area weakly rugulose, callus with weak callar nib. Upper mesepimeron smooth and swollen, lower mesepimeron flat and weakly rugose, transepimeral sulcus weakly impressed; metepisternum finely reticulate to rugose ventrolaterally, smooth ventrally. Prepectus triangular and rugose-areolate, narrow and $0.4 \times$ as long as high, with strong posterior flange. Pronotum rugose-areolate. Proepisternum rugulose. Coxae smooth and completely setose (pilosity of hind leg not visible on specinen). Forewing with basal area bare; speculum absent (pilose); costal cell pilose; rest of wing densely pilose; stigmal vein as long as broad, narrowed basally.

Metasoma with petiole transverse, rugulose dorsally. Gastral terga smooth to coriaceous with moderately dense covering of fine adpressed setae; $\mathrm{Ms}_{2}$ with constriction broad and finely crenulate, anterior region triangular. Hypopygium bare. Ovipositor typical for genus: first valvula with strong subapical ridge and 3 sharp lateral teeth, second valvula with 6 blunt lateral teeth.

\section{MALE}

Unknown.

\section{DISTRIBUTION}

Tasmania. Australia (V, Fig. 275).

\section{Orasemorpha didentata ((iirault)}

Figs. 74-79

Eucharomorpha didemata Girault, 1940:325-326. Australia: A.C.T. [ANIC, examined]. Dahms. 1983:221-223 (notes on lype material).

Orasemorpha bidentata-Boučck, 1988:519. Misspelling.

\section{TYPE MATERIAL}

Lectotype (here designated), q. "F.C.T. Aust./ Blundell's/ 21.I.1931/ L. F. Graham." "Eucharomorpha viridis / viridis pencilled out]/ \& 27.4.3 I/ L. F. Graham det." "Eucharomorpha/ PARATYPE/ didentata, Gir. [blue label]." "LECTOTYPE/ Orasemorpha/ didentata (Grlt)/ Det. Heraty '90." Left antenna missing beyond pedicel.

Paralectotypes, $5 q$ q. $2 \delta^{\circ} \sigma^{\circ}$ labelled as in lectotype. Two specimens bear pink labels with "HOLOTYPE" and "ALLOTYPE." The specimen labelled "holotype" bears Girault's handwritten determination label, but was not chosen because of its missing head. No holotype was designated in the original publication. See Dahms (1983) for additional notes on the type material.

\section{DIAGNOSIS}

Recognized by: midlobe of mesocutum rugose and dorsum with sparse to dense covering of short subdecumbent or adpressed setae (Fig. 77), dise of forewing, including speculum, pilose with sparse setae continuing to base (Fig. 79). and gastral terga smooth with dense semi-erect setae. Differs from $O$. eribotes by having sparse short setae on the eye (Fig. 76), hind coxa almost smooth, and hind femur and tibia with dense, elongate, and semi-erect setae (Fig. 78).

\section{FENALE}

Length, 2.3-2.8 $\mathrm{mm}$. Head and mesosoma dark green with areas of reddish reflections prominent on clypeal region, ocellar-ocular area, midline of mesoscutum, axilla. frenal line, and propodeum; gaster and coxae dark brown with faint greenish reflections: scape to anellus yellowish brown, rest of flagellum dark brown; mandible dark brown: legs yellowish brown. femora darker brown in basal half. Wings hyaline, venation pale brown.

Head triangular, gena straight: occiput broadly emarginate; temples broadly rounded with short subdecumbent setae; LOL 1.0-1.3× OOL. Face strongly rugose, with subdecumbent pilosity; scrobal depression shallow and broadly impressed, strongly rugose. Eye slightly protruding. with sparse short erect setae, as long as facial setae. eyes separated by $2.4-2.9 \times$ their height. Malar space $1.1-1.3 \times$ height of eye. Clypeal region weakly sculptured, lateral margin of clypeus strongly impressed; supraclypeal area swollen. Labrum 4- 10 7-digitate, digits long. Mandibles 2/2, 3/2, or 3/3 dentate. Antenna 12-segment- 
ed; scape densely setose dorsally; anellus present; flagellum 1.4-1.8× height of head: funicular segments scabriculous with dense semi-erect setae: F2 $1.8 \times$ as long as broad, 1.1-1.3× F3, following segments subequal in length, gradually narrowing to clava; clava elongate, as long as preceding 2 segments.

Mesosoma with dorsum weak rugose, interstices shallow and broadly rounded, with short subdecumbent setae: lateral lobe and axilla swollen and glabrate. Notauli moderately impressed and narrowly crenulate. SSS crenulate. Scutellum subquadrate to elongate. 1.0-1.6× as long as broad with elongate median depression: frenal line broad and glabrous dorsally, frenal area weak rugose. Propodeum strongly rugose with weak verrucose surface: callus swollen and glabrous with small callar nib; metepimeron smooth. Upper mesepimeron glabrous, lower mesepimeron weak reticulate-rugose, transepimeral sulcus distinct: mesepisternum weak reticulate-rugose and smooth ventrally. Prepectus triangular, rugose with dorsal and posterior verrucose flange. Pronotum and proepisternum rugulose. Coxa smooth with sparse semi-erect setae; hind femur and tibia smooth with dense, elongate, semierect setae (Fig. 78). Forewing 2.3-2.5× as long as broad; basal area sparsely setose along impression of cubital vein, otherwise bare: speculum lacking (pilose); costal cell pilose; disc densely pilose with complete marginal fringe; stigmal vein $1.2-2.7 \times$ as long as broad, with or without basal narrowing.

Metasoma with petiole transverse, $0.3-0.5 \times$ as long as broad, posterior region relatively long and weakly reticulate, anterior region as long as broad and glabrous. Gastral terga smooth with dense subdecumbent to semierect setae, basal terga glabrous medially; $\mathrm{Ms}_{2}$ with constriction broad and crenulate, anterior region semicircular. Hypopygium bare. Ovipositor elongate, only slightly curved forward; first valvula with weak subapical ridge and 3 lateral teeth; second valvula with 7 sharp lateral teeth.

\section{MALE}

Length, 2.6-2.9 mm. Body dark brown to black, head and mesosoma with faint blue-green reflections, prominent on lower face, scutellum, and ventral areas of mesosoma; coxac, gaster, and femora dark brown; gaster with laint reddish reflections; antenna dark brown; mandible light to dark brown: apex of femora and rest of legs light brown. LOL 0.9-1.2× OOL. Eyes with sparse minute setae. separated by $2.3-2.5 \times$ their height. Malar space $1.0-1.2 \times$ height of eye. Antenna 12-segmented; flagellum 1.4-1.8x height of head; F2 1.6-1.2x as long as broad. 1.0-1.2x F3. Midlobe of mesoscutum more finely rugulose; scutellum smooth apically, without medial depression. 1.4-1.7x as long as broad. Forewing $2.2-2.3 x$ as long as broad. Metasoma with petiole as long as broad, $0.6-0.8 \times$ ats long as hind coxa, $0.5-0.7 \times$ as long as propodeum; finely reticulate dorsally, glabrous ventrally. $\mathrm{Ms}_{2}$ with constriction weakly striate, anterior region strongly swollen and glabrous. $\mathrm{Ms}_{8}$ broadly rounded and setose. Genitalia hidden.

\section{VARIATION}

Specimens are generally very similar. One female from Queensland (North Pine River) has only minute eye setae and distinct blue coloration of the head and mesosoma, but otherwise agrees with the other material. The series of males from Ainslie are larger and have a more distinct green coloration, but 1 small male is almost identical in colour and size to the paralectotype males.

\section{BIOLOGY}

The only known plant association from the collection records is from the foliage of Protea sp. (Proteaceae).

\section{DISTRIBUTION}

Eastern Australia (D, Fig. 275).

\section{MATERIAL EXAMINED}

Australia: A.C.T.: Ainslie; Canberra, ex swimming pool; Canberra, Black Mtn; January to February ( $5 q q$. $7 \delta^{\circ}$, AEI, ANIC, BMNH); Queensland: Lever's Plateau, via Rathdowney; Nth Pine R[d]; Stanthorpe; Brisbane; December to January and March to April ( 4 $q$, BMNH, UQIC); South Australia: Adelaide; Kangaroo Is.; Kersbrook, ex Protea sp. foliage; December to January ( $7 q q$. ANIC, UQIC).

\section{Orasemorpha eribotes (Walker)}

Figs. 70-71, 73, 187, 217, 256-257

Eucharis eribotes Walker, 1839:13-14. Australia: Tasmania and New South Wales [BMNH, examined].

Encharomorpha dubia Girault, 1913b:95. Australia:

Tasmania [SAMA, examined]. Girault. 1915:230 (redescription). Dahms, 1983:233 (notes on type material). New synonymy.

Eucharomorpha fuscipes Girault, 1913b:95. Australia: Tasmania [SAMA, cxamined]. Girault, 1915:229 (redescription). Dahms, 1984:642 (notes on type material). New synonymy.

Eucharomorpha viridis Girault. 1913b:95. Australia: Tasmanial [SAMA, examined]. Girault, 1915:229 (redescription). Giratult. 1929:331 (new specimen and additional notes). Dahms, 1986:640-641 (notes on type matcrial). New synonym!

Psilogeasteroides erihotes-Girault, 1913b:94.

Eucharomerpha partighabra Girault, 1940):324. Australia: Victorial [QMB. examined]. Dialms, 1986:386 (notes 
on (ype matcrial). New synonymy.

Epimetagea eribotes-Hedquist, 1978:243.

Orasemorpha-Boučck, 1988:519. All above species names were transferred to this genus.

\section{TYPE MATERIAL}

Lectolype of Eucharis erihotes (designated Bouček. 1988). o. "1440b." "LECTO-/ TYPE." "Co-/ type." "Psilogaster/ Eribotes/ Walker.” "B. M. TYPE/ HYM./ 5.619." " (? ठ ) Orascmorpha/ eribotes (Walk.)/ LECTOTYPE/ det. Z. Bouček, 1986." Head and thorax with wings and 1 foreleg mounted on card, antennae missing. Paralectotypc, ơ (headless), same data except "1440a." The lectotype is from Hobart. Tasmania, and the paralectotype is from Sydney, New South Wales. An additional female labelled as "1440c" (Bouček, 1988) belongs to $O$. goethei and is treated under that species.

Holotype of Encharomorpla dubia, of "Swansea/ Tas. Lea." "Eucharomorpha/ viridis, fuscipes/ and dubia $\delta$ types [GH]." "T.1283-4-5./ Eucharomorpha/ viridis Gir/ fuscipes Gir./ dubia Gir ["No. 3" underneath name]/ Tasmania/ see Note Book and Slide" [GH]. One female and 3 males mounted on card and numbered from 1 to 4 , the holotype of $E$. dubia is specimen number 3 ; right antenna in glue, left antenna missing, left hind wing intact. See Dahms (1983) for additional information on type material. The locality on the label is for $E$. viridis (Dahms, 1983); the published locality for $E$. dubia was Hobart, Tasmania (Girault, 1913a).

Lectotype of Eucharomorpha fuscipes (here designated), ơ, specimen number 4 from same card listed above; left antenna and hind tarsi missing. My label "LECTOTYPE/ Orasemorpha/ fuscipes (Grlt)/ Det. Heraty '90" added to specimen. Paralectotype, ơ, specimen number 2; antenna removed, left hind legs and left wings removed, covered in mold. Published locality was Hobart. Tasmania (Girault, 1913a).

Holotype of Eucharomorpha viridis, \&, specimen number 1 from same card listed above; left hind wing, hind legs, and left coxa missing, gaster and petiole mounted separately with ovipositor exposed. Published locality was Swansea, Tasmania (Girault, 1913a).

Lectotype of Eucharomorpha partiglabra (here designated), q "Swan Hill, Vic./ 4.1.31/ F. E. Wilson" "SYNTYPE/ T.9423/ E. C. D. 1985" "Eucharomorpha $\& /$ partiglabra Gir. [with red "Paratype" written over label]" [GH]. "LECTOTYPE/ Orasemorpha/ partiglabra (Gir.)/ Det. Heraty '90"; tip of left antenna broken off, no mid legs. Paralectotypes, 2 q $q$, QMB type numbers T.942 I and T.9422. See Dahms (1986) for additional notes on type material.

\section{NOTESONSYNONYMY}

Bouceh (1988) suggested that a synonymy might be proposed for "didemana, partiglabra, pyonalus, laridemana and viridis, if not morc." Riek (unpublished notes, ANIC) proposed a synonymy of viridis, fuscipes, dubia + varidemata; partiglabra + didemata; and pytalus + viridis. There has been considerable confusion over the species limits in this group. In my opinion, $O$. varidentata. $O$. pyttalus, and $O$. didentata are valid species for reasons discussed in their respective diagnoses. The holotype of $O$. dubia has a 12-segmented antenna, not 11-segmented as described by Girault (1913a), and is virtually identical to that of $O$. fuscipes. Differences between $O$. viridis and $O$. fuscipes or $O$. dubia are sexual and based on darker coloration of the scape and body colour, and smaller mesosoma. Specimens from Tasmania are more similar to the lectotype of $O$. eribotes and are generally darker in colour, have the midlobe of the mesoscutum, scutellum, and coxae scabriculous, and the eyes completely bare. Specimens of $O$. eribotes collected from New South Wales and Victoria (including the paralectotype) have weaker rugulose to smooth sculpture. Differences between $O$. erihotes and $O$. viridis in head shape, presence or absence of minute eye setae, setation of the wing base, and coloration are not consistent over the range of specimens.

Orasemorpha partiglabra appears to be a larger, dark reddish form of $O$. eribotes with a verrucose-foveate prepectus, tridentate mandibles, 7-digitate labrum, and finely sculptured petiole. Within the paralectotype series of $O$. partiglabra, the prepectus is smoothly foveate, the head and mesosoma are distinctly green in colour, and the bases of the femora are slightly darkened. In additional material that could be partially allocated to $O$. partiglabra, the labrum was 4- or 5-digitate. The lectotype of $O$. eribotes has a small intermediate tooth on the left mandible giving it a partial $3 / 3$ dentition (Fig. 73). The mandibles and labral digits of the closely related $O$. diclentata are highly variable and range from $2 / 2$ to $3 / 3$ and from 4 to 7 labral digits.

\section{DIAGNOSIS}

Recognized by: midlobe of mesoscutum strongly rugose to scabriculous (Fig. 70), mesosomal dorsum of female with sparse to dense covering of short subdecumbent or adpressed setae (Fig. 217), disc of forewing including area of speculum pilose, and gastral terga weak to strong coriaceous with moderately dense covering of fine subdecumbent or adpressed setae (Figs. 256-257). Differs from $O$. didentata by having the eyes bare (Fig. 73) or sometimes with minute setae in females (Fig. 187), and hind femur and tibia with dense, short, subdecumbent setae. 


\section{FEMALE}

Length, 2.7-3.5 mm. Head and mesosoma dark green to black with strong metallic reflections, but sometimes bluish or reddish in colour; coxae dark brown with metallic reflections; gaster black with green or red reflections; scape to anellus yellow to light brown, rest of flagellum dark brown to black; basal half of femora weakly infuscate to dark brown. Wings slightly infuscate, venation pale brown.

Head subtriangular; occiput shallowly emarginate; temple broadly rounded with short subdecumbent setae; LOL 0.8-1.3× OOL. Face strongly rugose with sparse short subdecumbent setae; scrobal depression broad and evenly impressed, rugulose, often with irregular curved carinae arching over toruli. Eye slightly protruding (Fig. 187 ), bare or with minute setae, eyes separated by 2.2-2.5× their height. Malar space 1.0-1.1× height of eye. Clypeus weakly rugose and moderately setose, lateral margins deeply impressed at tentorial pits: supraclypeal area strongly swollen medially. Labrum 4- to 7-digitate, digits long. Mandibles $3 / 2$ or $3 / 3$ dentate. Antenna 12segmented; scape densely setose dorsally; anellus present; flagellum 1.3-1.5× height of head; funicular segments scabriculous with dense semi-erect setae, F2 1.6-2.0 $\times$ as long as broad, 1.1-1.4× F3, following segments subequal in length, equal in breadth to clava: clava obconical, about equal in length to preceding 2 segments.

Mesosoma with midlobe of mesoscutum evenly rugulose to scabriculous, scutellum often smooth medially and often with weak median depression, entire dorsum covered by short subdecumbent setae; lateral lobe of mesoscutum and axilla swollen and only lightly sculptured, smooth dorsally. Notauli deeply impressed and weakly crenulate. Scutellum 1.4-1.7x as long as broad; frenal line broad and glabrous dorsally, frenal area rugulose, weakly impressed medially. Propodeum broadly rounded. coarsely rugose-striate laterally, and lightly sculptured medially, with striae converging to midline; callus swollen and glabrous; metepimeron rugulose. Upper mesepimeron weak rugulose to glabrous, lower mescpimeron reticulate to scabriculous, transepimeral sulcus distinct; mesepisternum reticulate to scabriculous and smooth ventrally. Prepectus broadly triangular and rugose to rugulose, posterior flange finely sculptured. Pronotum and procpisternum weakly rugulose. Coxac bare dorsally, weakly rugulose to scabriculous; hind femur and tibia fincly sculptured and covered by dense. short. subdecumbent setac. Forewing $2.3-2.5 \times$ as long as broad: basal area bare, at most with narrow band of setac along impression of cubital vein: speculum lightly to completcly pilose; disc, including costal cell, dense pilose. with complete marginal fringe including along marginal vein: stigmal vein $1.4-1.8 \times$ as long as broad, narrowed basally and club-shaped. slightly angled posteriorly.
Metasoma with petiole transverse, with posterior region several times broader than long and glabrous to weak rugulose, and anterior region narrow, as long as broad, and glabrous. Gastral terga weakly coriaceous to smooth, with dense adpressed setae, basal terga glabrous medially; $\mathrm{Ms}_{2}$ with constriction broad and crenulate, anterior region semicircular. Hypopygium with small clusters of short sublateral setae. Ovipositor elongate, only slightly curved forward; first valvula with weak subapical ridge and 3 to 4 lateral teeth; second valvula with 8 sharp lateral teeth.

\section{MALE}

Length, 2.1-3.1 mm. Body dark brown to black, head and mesosoma with metallic reflections of green, red, or blue (variable); gaster sometimes with faint reddish reflections; mandible dark brown; antenna dark brown to black, scape brown to black with metallic blue or green reflections; femora dark brown with metallic reflections except extreme apex, rest of legs dark yellowish brown. tibiac often darker medially. Wings hyaline or very weakly infuscate, venation pale brown.

Head shape and sculpture as in female; LOL $0.8-1.2 \times$ OOL. Eyes completely bare (Fig. 73), separated by $2.0-2.5 \times$ their height. Malar space $0.8-1.3 \times$ height of eye. Antennal scape stouter than female, only reaching $0.8 \times$ distance to median ocellus; flagellum 1.7-2.0x height of head; apex of F2 and F3 broadest, following segments tapering to apex.

Mesosoma with dorsal sculpture fine rugulose to longitudinally rugulose and appearing weakly striate; scutellum 1.0-1.1 $\times$ as broad as long excluding frenal area (Fig. 70). Forewing 2.1-2.4× as long as broad, basal area bare.

Metasoma with petiole slightly longer than broad. $0.6-0.8 \times$ as long as hind coxae, $0.5-0.6 \times$ as long as propodeum; finely reticulate dorsally. glabrous ventrally, sculpture separated laterally by fine groove. Ms, with constriction striate, anterior region strongly swollen and glabrous. $\mathrm{Ms}_{8}$ broadly rounded and setose. Genitalia typical for genus; paramere narrow and clongate with several long terminal setae, median process sharp. digitus with small marginal spines; aedeagus broad and acuminate at tip).

\section{VARIATION}

Colour variation ranges from green with pattches of reddish iridescence on the head and mesosoma (holotype of $O$. viridis) through a very dark olive green coloration, and in some cases, a very strong bluish coloration. Much of this variation was observed in single collection serics although some was restricted to certain isolated individuals. Males are darker in colour but show similar colour patterns and variation. The basal area of the wing is bare in all of the specimens from eastern Australia and Tasmania. and range from bare to completely pilose in the individuals from Western Australia. 
BIOLO(i)

Reared from Pheidole'sp. (Bouček, 1988). The only plant association for this species is "sweeping long grass, dry sclerophytt forest" in New South Wales.

\section{DISTRIBLTION}

Eastern, southwestern Australia, and Tasmania (E, Fig. 275).

\section{MATERIAL EXAMINED}

Australia: A.C.T.: Picadilly Circus (35.22S 148.48E), $1240 \mathrm{~m}$. FIT: Canberra, February, March $(3 q q, 3 \delta \delta$, ANIC): New South Wales: Pilliga scrub, via Coonabarabran, sweeping long grass, dry sclerophyll for- est; McGarr"s Ck, Sydney: Tooma Reserve, 20 km NNE. Kosciusko N. P.: December to January (3q $q .2 \delta \delta$. ANIC, BMNH, UQIC); Queensland: Kuranda; Brookfield, nr Brisbane: Daintree Riv.: Mt Tibrogargan: December (10 9 ?. BMNH): South Austratia: Adelaide. November (2q $\uparrow$. TAMU): Tasmania: Harford, $5 \mathrm{~km} \mathrm{E}$ by $S$; Dodges Ferry, December to January $\left(7 q q .4 \delta^{\circ}\right.$. ANIC); Victoria: Lake Mtn NE of Mclbourne; Kinglake N. P. nr Melbourne; Mitta Mitta Ck, 25 km NNW Omeo; January to February ( $3 q q, 1 \delta$, ANIC, BMNH); Western Australia: Glen Forest: Mundaring Weir; Serpentine Riv., in nest of Pheidole sp.; October to January (8q $q 12 q q$ mounted on cards with ant host], BMNH, WAM).

\section{Orasema Cameron}

Orasema Cameron, 1884:105. Type species: Orasema stramineipes Cameron; by monotypy.

Semora Cameron, 1909:432-433. Type species: Semora ranthopus Cameron: by monotypy. Not Semora Peckham. 1892: synonymy by Kerrich (1963).

Eucharomorpha Girault, 1913a:62-63. Type species: Eucharomorpha worcesteri Girault; designated by Gahan and Fagan, 1923. Synonymy by Bouček (1988:520). Not Eucharomorpha [= Orasemorpha] Girault, 1913b:95.

Loshamus Ishii, 1932:210. Type species: Loshanus uichancoi Ishii; by monotypy. Watanabe, 1958:26 (redescription of genus and new species). Hedqvist, 1978:229 (redescription and new species). Bouček (1988:521) incorrectly placed Losbamus as senior synonym of Gollumiella Hedqvist. Current synonymy by Heraty (1992:586) with transfer of L. uichancoi to Orasema.

Parasemora Gemignani. 1933:192. Type species: Parasemora freychei Gemignani |location of type unknown]; by monotypy. New synonymy.

Semorata Strand, 1942:393. Replacement name for Semora Cameron.

Semorella Ghesquière, 1946:368. Unnecessary replacement name for Semora Cameron.

Orasema is the most speciose of the orasemine genera. with possibly more than 100 species throughout the world. It is comprised of several distinet species groups that create problems in defining the limits of the genus. Bouček (1988) suggested that Parasemora may be a junior synonym of Orasema. Although the type appears to be lost. this genus is treated here as a junior synonym based on the description and habitus drawing provided by Gemignani (1933). I have seen no other material from
South America similar to the specimens described by Gemignani that would suggest another genus in the Oraseminae. The type species for Loshamus, L. wichancoi 1shii, 1932, was transferred to Orasema based on features of the wings, antenna and larva (Heraty, 1992). Bouček (1988) included O. delicatula (Walker) as part of the Indo-Pacific fauna (labelled "Australia (?)"). I examined the type and it belongs to a group of species from South and Central America that includes $O$. festiva (Fabr.). Orasema ranomafanae Risbec (1952) is transferred here to Stilhula ranomafanae new combination, although it is an aberrant species that lacks apical scutellar spines as found in other species of Stilbula.

Orasema differs from other Oraseminae by the following: scape always elongate, maxilla and labium large, propodeal foramen broadly emarginate, petiole cylindrical with truncate base and dorsal flange (prominent in most species), and gastral terga smooth and polished with few or no setae. Members of Orusema also have the following: petiole usually longer than broad in both sexes, rarely as short as $0.8 \times$ as long as broad in some females; first gastral sternite $\left(\mathrm{Ms}_{2}\right)$ constricted and marked by a transverse furrow; anterior region of $\mathrm{Ms}_{2}$ attached to the apex of the petiole in both sexes; clypeal margin truncate with a distinct bare anteclypeus; and ovipositor expanded. ridged and curved forward in profile (straight only in $O$. communis).

\section{(AENERIC DESCRIPTION}

Head subtriangular, 1.2-1.5x as broad as mesosoma: median ocellus anterior to tateral ocelli (Figs. 92. 129-130): lateral ocellus close to or broadly separated from occiput. Face smooth or reticulate; scrobal depression usually shallow and poorly defined, partially including median ocellus; ocellar-ocular groove present or 
absent; occiput smooth or aciculate, occipital carina rarely present, its dorsal margin usually broadly rounded. Malar depression absent, present, or forming narrow foveate channel; hypostoma well developed and separated from gena by hypostomal carina. Clypeus subquadrate, its apical margin truncate, epistomal sulcus lacking; anteclypeus narrow and bare, distinct from postclypeus. Labrum usually 4 -digitate, rarely multi-digitate, digits and apical setae always long. Mandibles falcate. 2/3 (all Old World species) or rarely $3 / 3$ dentate; maxilla and labium large, labial and maxillary palpi variable in shape, usually 3-segmented. Antenna 11- to 13-segmented; scape variable in length. usually narrow and cylindrical; pedicel as long as broad; anellus present and smooth; funicle 6- to 9-segmented, segments cylindrical, without basal secondary segmentation but with scattered MPS; basal funicular segments usually less than $2.0 \times$ as long as broad; last 2 to 3 flagellomeres usually fused into indistinct clava.

Mesosoma with sculpture of dorsum variable, usually reticulate or rugose-areolate medially. Mesoscutum with notauli usually narrow and deeply impressed along entire length. TSA complete. SSS deeply impressed, angled forward to midline. Scutellum with frenal area sculptured and usually separated dorsally by foveate groove; axillular sulcus present or absent. Metanotum extended laterally as a smooth flange over base of propodeum and partly covering propodeal spiracle which is close to dorsal margin of propodeum; metanotum weakly excavated. Propodeal disc variable in shape and sculpture, rarely smooth; callus prominent and broadly rounded, bare or setose, and lacking vertical furrow; postspiracular furrow and metepimeral sulcus deeply impressed; ventral margin of propodeum above hind coxa even and strongly ridged, without lateral processes. Mesopleuron usually sculptured, upper mesepimeron usually swollen and transepimeral sulcus present; femoral groove lacking or broadly impressed and shallow; mesepistcrnum usually lacking sternaular area (no distinct sulcus or foveae). Prepectus broadly triangular and reaching tegula. rarely narrowed ventrally. Coxae and femora usually sculptured: tibiac with spurs $1-1-2$; hind tarsus $0.7-0.8 \times$ as long as hind tibia.

Wing veins of fore and hind wings well defined. Forewing 1.9-3.1 $\times$ as long as broad, acute to broadly rounded at apex; disc pilose. marginal fringe present (in all Old World species) or absent; basal area barc or setose, speculum and costal cell variable in pilosity; submarginal vein with short setac dorsally; marginal vein $0.2-0.3 \times$ as long as wing, and pilose; stigmal vein sessile or elongate, perpendicular to wing margin; postmarginal vein short or long.

Metasoma with petiole cylindrical and fused ventrally. base abruptly narrowed (truncate) to small. knoblike condyle (Figs. 120-121, 132), and usually with prominent dorsal flange. Petiole of female usually $1-2 x$ as long as broad, rarely as short as $0.8 \times$ as long as broad. Petiole of male longer than in female, usually $2-3 \times$ longer than hind coxa. Gastral terga smooth with scattered short setae, gaster of female as long as head and mesosoma, gaster of male slightly longer than hind femur: $\mathrm{Mt}_{2}$ of female variable in relative size; $\mathrm{Ms}_{2}$ constricted by narrow crenulate or smooth furrow, anterior crescent-shaped region similar in both sexes. Hypopygium bare or with few minute setae laterally. $\mathrm{Ms}_{8}$ of male narrowly rounded and setose. Cerci with variable number of setae of different lengths. Ovipositor sheath broad, reaching or exceeding cercus, gonostylus separated and sparsely setose. Ovipositor subapically expanded, usually strongly curved cephalad; first valvula with strong subapical ridge, followed by $3-10$ sharp teeth along lateral line, rarely with diagonal ridges in place of teeth (O. commumis); second valvula narrow or broad, and with several lateral teeth or complete dorsal ridges. Genitalia of male with well-developed parameres, digitus disclike and bearing several stout marginal spines; aedeagus subacute.

\section{PHYLOGENETIC RELATIONSHIPS}

Orasema as described here is a diverse genus, with the Old World species divided into 6 groups. The relationships between the major groups is shown in Figures 1-2; the same tree topology was obtained in all analyses. In the analysis of higher level relationships, the uichancoi-group was divided into communis and uichancoi subgroups (treated in this section as only the michancoi-group). The Old World species groups are morphologically diverse and future studies may show a need for further division into more genera, but a conservative approach is taken here and only 1 genus is recognized. The New World species groups are distinctive and cannot be placed into any of the Old World species groups. However, most of the New World species can be aligned with either the assectator-group or the michancoi-group.

The wichancoi-group includes 7 species. Orasema bonceki, O. communis, O. ishii, O. promecea, $O$. rugulosa, $O$. seyrigi, and $O$. nichancoi. Monophyly of this group is based on an increase in the number of funicular segments to 8 or 9 in males (4) and to 8 in females (5). Additional features found in both the Malagasy and Indo-Pacific species (but not all species) include a weak malar depression (10), presence of strong transverse ridges on the second valvula (44, state 3), and a distinct ocellar-ocular groove dorsally between the lateral ocellus and eye margin. Association of the Malagasy and IndoPacilic species is also based on phenetic similarity with species having elongate bodics, and long and nalrow. pilose wings. O. commmmis and $O$. serrigi are interpeted as sister taxa based on general similarity but no characters 
distincty support the monophyly of this group. O. seyrigi shares character states with the Indo-l'acific species in the uichancol-group such as: dorsal occipital margin carinate. malar depression weak, and second valvulat with transverse ridges. $O$. communis is a unique species in this group and has a multi-digitate labrum, distinct ocellarocular groove. weak malar depression, and lacks an occipital carina. The monophyly of the Indo-Pacific species in the michancoi-group is justified by the presence of a small terminal projection from the apex of the male clava (Figs. 88-89.95) that is not found elsewhere in the family. $O$. wichancoi is regarded as the sister taxon to the remaining Indo-Pacific species by having the basal area of the forewing bare versus pilose, although it may show closer aflinities to $O$. ishii and $O$. promecea based on the presence of a weak occipital carina and weakly sculptured or smooth face (plesiomorphic with respect to $O$. seyrigi). $O$. mgulosa and $O$. bouceki form a monophyletic group based on a foveate malar depression, strongly sculptured face. distinct ocellar-ocular groove, elongate forewings $(2.7-2.9 \times$ as long as broad), and lack of an occipital carina. Tentatively, relationships within the uichancoi group are postulated as ((commmmis ?+ seyrigi) + (uichancoi ?+ (ishii + promecea + (rugulosa + bouceki)))) (Fig. 276).

The striatosoma-group includes 2 species, $O$. fraudulenta and $O$. striatosoma. These species are monophyletic but are difficult to place with any other species groups of Orasema. The parsimony analysis (Figs. 1-2) places this group as sister taxon to the assectator-group based on having reticulate facial sculpture (8), short postmarginal vein (36; long in $O$. frandulenta), and lateral apex of the second valvula with several minute teeth (43). Internal attachment of the first instar (62) is inferred but this is probably a characteristic of Orasema. Intuitively, I believe this group is probably more distantly related within Orasema, possibly as a sister taxon to species with a distinct speculum (37).

The assectator-group is comprised of 3 species, $O$. assectator, $O$. initiator and $O$. nigra, that form a monophyletic group based on having a completely reticulate face, callar nib, 7 to 10 minute teeth on the first valvula, completely reticulate mesosoma dorsum, and a short postmarginal vein. The assectator-group is placed together with $O$. glabra based on the short postmarginal vein (36), and minute teeth on the second valvula (43), and in part on general morphological similarity. Orasema glahra is unique in its possession of a completely smooth face, scrobal depression with parallel channels (9) (similar facial characters to Psilocharis), evenly rugulose propodeum, and setose callus.

The koghisiana-group is monobasic. This species lacks the broad triangular prepectus (20) and rounded mesepisternum (32) of the other groups (multistates in the wichan(o) -group). and is postulated to have secondarily gained a larger number of labral digits (15). and reduced wing setae (33). This species shares a glabrous propodeum (28) with the valgikes-group, but this character state is also found in Chrysolampinate and basal Eucharitinae and may be plesiomorphic.

The valgins-group includes 2 species. $O$. valgius and $O$. synempora, that form a monophyletic group based on having a mid-ventral sulcus on the mid coxa, 3 to 4 lateral teeth on the first valvula. laterally glabrous propodeal disc, and an elongate postmarginal vein. There is a possibility of closer affinities between the ralgius- and assectator-groups based on having the face at least partially reticulate, the mesepisternum broadly rounded ventrally, and the callus glabrous or with only a few minute setae.

Tentative relationships proposed among the above complex of species. excluding the uichancoi-group, are $(($ koghisiana $+($ synempora + lalgins $))+($ glabra + $(($ assectator + initiator + nigra $)+$ ? (striatosoma + frandulenta)))) (Fig. 276).

\section{BIOLOGY AND IMMATURE STAGES}

The biology and immature stages of Orasema are well known for several species (see earlier section). They have been reared as parasites of Pheidole. Solenopsis. Wasmannia, Tetramorium. Formica, and Eciton. The only known hosts in the Old World tropics belong to Pheidole. The genus Pheidole is shared by widely divergent species groups in Orasema, as well as Orasemorpha, and I postulate that Pheidole is the ancestral host for both genera. The use of an intermediate host (thysanopteran or homopteran) has been documented for both New and Old World species, and may be common for the genus.

Plant hosts have been recorded for several species, and females always oviposit into chambers hollowed within the plant tissue by the ovipositor. The plant structure chosen for oviposition is extremely varied in the Neotropical and Nearctic regions. In the Old World, oviposition into leaf surfaces is the only known strategy (in $O$. uichancoi, $O$. assectator, and $O$. initiator $)$. Choosing other structures, such as involucral bracts, flower stems or fruit structures, may be a derived behaviour of New World species. The ovipositor is very conservative in structure within the genus and similar methods of egg deposition may be assumed for other species. Orasema communis is the only known species with a straight ovipositor (versus ovipositor curved cephalad) and with lateral ridges (versus teeth) on the first valvula (Fig. 82), similar to some Neoloshanus. This may indicate a slightly different oviposition strategy for what is considered to be a very basal member of Orasema. but does not affect the general prediction. for all species, of oviposition into chambers that are hollowed out in plant tissue by the ovipositor.

The first-instar larvae are plesiomorphic for Eucharitidae. The later instar larvae are more distinctive 
and I consider the presence of prominent pustules as a derived feature of Orasema (and possibly Oraseminae). Larvae are unknown for $O$. koghisiana and the ralginsgroup. However, their phylogenetic placement between divergent species-groups of Orasema suggests that larvae of these groups would possess all of the typical character states. Adults of the koghisiana- and valgins-groups share some of the character states of Psilocharitini (smooth propodeum and callus), which I regard as convergent.

\section{DISTRIBUTION}

The distribution and proposed phylogeny of Old Word species of Orasema is presented in Figure 276. Orasema is distributed throughout the Nearctic, Neotropical, Ethiopian, Indo-Pacific, and Australian regions. Collections of Orasema in the Old World tropics are sparse compared to the New World. The uichancoi-group is distributed only in Madagascar and the Indo-Pacific region (Fig. 276), but may be closely related to a group of species found in Central and South America. The IndoPacific species of the uichancoi-group are considered to be monophyletic, and form the sister group to $O$. communis and $O$. seyrigi in Madagascar. Within the uichancoigroup, $O$. rugulosa, and $O$. bouceki form a derived group found only in Papua New Guinea. Members of the striatosoma-group are represented by only a few collections in eastern Africa (Fig. 276). Orasema valgius and $O$. synempora are found only along the eastern coast of Australia, with $O$. synempora confined to the Papuan subregion. Orasema koghisiana is found only on New Caledonia and the New Hebrides in the Polynesian subregion. Orasema glabra is restricted to southern Africa. The assectator-group has a widespread distribution in southern Africa and the Indo-Chinese subregion (Fig. 276 ), and may form a sister group to similar species that are widespread in the Nearctic and Neotropical regions.
The occurrence of distinct species-groups with distant affinities throughout the tropical regions suggests that Orasema may have initially diverged during the late Cretaceous or early Eocene as part of the breakup of Gondwanaland. Only the Hichancoi-group has been successful in the Oriental region with the most derived species of this group found in the Papuan subregion. Relationships within this group to the Madagascar species may represent either a relictual distribution or collecting anomaly within continental Africa. Within the assectatorgroup, $O$. assectator and $O$. initiator may be derived from an Ethiopian ancestor shared with $O$. nigra; although except for affinities with $O$. glabra and possibly the striatosoma-group, there is no morphological evidence within the group to support this hypothesis. The assectatorgroup is restricted to the Indo-Chinese and mainland Western Malayan subregions of the Indo-Pacific. The ralgius- and koghisiana-groups are distinct from other species in the Oriental region and have their closest relationships to the Ethiopian species groups. The geographic isolation of the valgius- and koghisiana-groups from other closely related species groups not found in the IndoPacific region suggests a very old relationship and supports the notion of an Ethiopian-Australian connection as proposed by the phylogenetic hypotheses.

Among New World Orasema, there are at least 7 distinct species groups. Of the species found in the Old World tropics, the uichancoi-group and assectator-group both have affinities to species groups in the New World. These relationships will need to be incorporated into a more complete biogeographic hypothesis. I am presently revising the New World species and a more thorough treatment of the biogeography of this genus will be presented in that work.

\section{Key to Old World Species of Orasema}

Antenna 12- or 13-segmented, funicle 8- or 9segmented (Figs. 84-85, 87-89, 95): propodeal disc evenly sculptured (Figs. 218, 235); forewing without speculum (pilose) and wing slightly infuscate (frontispiece, Figs. 86, 96-97)

nichancoi-group, 2

- Antenna 11-segmented, funicle 7-segmented (Figs. 98-100, 108-109, 123-125); propodeal disc evenly sculptured or glabrate laterally (Figs. 247-248): forewing with or without speculum and wing hyaline (Figs. 104, 110, 117-119. 122)
2 (1) Labrum with 8 to 10 digits, digits long and covering mouthparts (Fig. 80); frenal area abrupt and rugose; axilla usually strongly rugose. smooth in some females: Madagascar.

O. communis Risbec, p. 59

- Labrum with 4 digits; frenal area rounded in profile and smooth or rugose: axilla smooth and shining or at most with very weik surface sculpture (Figs. 83. 92. 235) .......................................

3 (2) Occipital carina raised to form crest behind ocel- 
li. distinct in frontal vien (Figs. 81. 83): posterior margin of frenal line raised into a distinctive carina along dorsal margin of frenal area (Fig. 8.3): Madagascar O. seyrigi Risbec, p. 61

- Occipital carina absent or hardly raised (Figs. 90. 92. 188); frenal area lacking strong ridge or carina dorsally (Figs. 91-92, 218)

4 (3) Forewing with basil area bare except for sparse band of hairs along impression of cubital vein; stigmal vein with large uncus and appearing $Y$ or T-shaped (Fig. 97); antenna 12-segmented in both sexes (Fig. 87); face weakly rugulose to almost smooth (Fig. 188); Philippines

O. uichancoi (Ishii). p. 62

- Forewing completely and densely pilose (frontispiece. Fig. 96) (sometimes sparsely setose in small patch just under submarginal vein); stigmal vein elongate, usually constricted basally but without large uncus (if uncus present then face glabrous); antenna 12- or 13-segmented (Figs. 88-89, 95); face strongly rugose-areolate or smooth and polished 5

5 (4) Antenna of male 13-segmented (Fig. 88); forewing $2.4 \times$ as long as broad, basal area pilose but sparsely setose just below submarginal vein; axillula longitudinally carinate; face and vertex glabrous; lateral lobe of mesoscutum and axilla strongly swollen and smooth; female unknown; Taiwan. O. ishii sp. nov., p. 64

- Antenna of male 12-segmented (Fig. 95); forewing $2.5-2.9 \times$ as long as broad, basal area completely pilose (Fig. 96); axillula smooth or rugose, otherwise head and mesosomal sculpture variable 6

6 (5) Propodeum sharply angled in profile (frontispiece), disc with complete median ridge; occllar-ocular groove sharply impressed and either smooth or areolate: female unknown: New Guinca ...................... O. bouceki sp. nov.. p. 65

- Propodeum slightly rounded in profile (Fig. 91), dise evenly sculptured without complete median ridge; occllar-ocular groove shallow or absent (Fig. 92) 7

7 (6) Face smooth with cheeks lightly pitted; occipital margin carinate; occiput glabrous; cye margined by smooth groove; malar depression shallow and smooth (Fig. 95): lemale unknown: New Guinea O. promecea sp. $110 \mathrm{v}$. p. 66
Face finely and leeply rugulose-areolate (Fig. $\vartheta())$; occipital margin rounded; occiput linely carinate: eyc margined by reticulate groove: malar depression foveate: New Guinea (New Britain, New lreland)

.. rugulosa sp. nov., p. 67

8 (1) Eye small and protuberant; head triangular with deep pit just below median ocellus at dorsal margin of scrobal depression (Fig. 102): forewing lacking speculum (pilose): marginal vein thickened along entire length (Fig. 104); lateral lobe of mesoscutum sculptured and similar to midlobe (Figs. 98, 101). striatosoma-group, 9

- Eye large; head transverse or subtriangular (Figs. $112,114,127,189,191-192$ ), without pit below median ocellus; speculum present; marginal vein thin (Figs. 110,117-119, 122); lateral lobe of mesoscutum polished or reticulate .10

9 (8) Scutellum finely striate, rounded laterally and axillula not distinguishable from dorsum (Fig. 101); forewing completely pilose except along impression of cubital vein (Fig. 104): Southern Africa O. striatosoma sp. nov., p. 68

- Scutellum finely reticulate, abruptly margined laterally and axillula longitudinally carinate, axillular sulcus indistinct; forewing pilose, basal area bare; Northwestern Africa and Yemen.

O. fraudulenta (Reichensperger), p. 70

10 (8) Face, including vertex, completely smooth and polished (Figs. 127, 189-190). 11

- Face completely or partially reticulate (Figs. 112, 191-192) 12

11 (10) Labrum 6- to 8-digitate (Fig. 190); propodeal disc smooth laterally with median areolate band (Fig. 247); antenna with relatively few MPS (Fig. 108): New Caledonia

O. koghisiana sp. nov., p. 71

- Labrum 4-digitate (Fig. 192): propodeal disc evenly rugulose without median carina or furrow; antenna with numerous MPS; Africa

O. glabra sp. nov.. p. 72

12 (10) Face completely reticulate (Figs. 112.114. 191-192); propodeal disc evenly reticulate. larely weakly sculptured, without differentiated median band of sculpture: lower mesepimeron reticulate (Fig. 220); petiole of female $0.8-1.5 \times$ ats long as hind coxa, petiole of male $1.7-2.3 \times$ as 
long as hind coxa; first valvula with 7 to 10 lateral teeth (Fig. 116); mid coxa without mid-ventral sulcus; Africa and Indo-China assectator-group, 13

- Face smooth to reticulate but usually glabrate below lower eye margin; propodeal disc smooth laterally with broad median band of strong sculpture (Fig. 248); lower mesepimeron glabrous (Fig. 221); petiole of female 1.2-1.7x length of hind coxa, petiole of male $2.3-3.0 \times$ as long as broad; first valvula with 3 to 4 lateral teeth (Figs. 262-263); mid coxa with mid-ventral sulcus; Australia .valgius-group, 15

13 (12) Propodeal disc reticulate; head $1.4 \times$ as broad as high, with eye large (Fig. 112); mesoscutum broadly rounded in dorsal view (Fig. 111); hind coxa completely reticulate; India and Sri Lanka

O. assectator Kerrich, p. 74

- Propodeal disc weakly sculptured; head 1.2-1.3x as broad as high, with eye of moderate size (Figs. 114, 191); mesoscutum rounded to sharply angled anteriorly (Fig. 237); hind coxa weakly coriaceous basally to glabrous apically 14

14 (13) Midlobe of mesoscutum with anterolateral margin broadly rounded; pronotum without promi- nence; clypeus and supraclypeal area minutely reticulate (Fig. 114); South Africa

O. nigra sp. nov., p. 75

- Midlobe of mesoscutum with anterolateral margin sharply angled or produced (Fig. 237); pronotum sometimes with conical prominence just below spiracle; clypeus and supraclypeal area glabrous (Fig. 191); Indo-Chinese and Eastern Malayan subregions

O. initiator Kerrich, p. 76

15 (12) Mesosoma with lateral lobe and axilla smooth and polished (Fig. 129), mesosoma robust and elongate ( $1.3 \times$ as long as high); frenal area semicircular in dorsal view; forewing with dense, minute setae; Queensland.

.o. synempora sp. nov.. p. 77

Mesosoma with lateral lobe coriaceous to rugose (Fig. 238) and axilla weakly carinate with surface imbricate to reticulate, mesosoma slender and subquadrate in profile ( $.2 \times$ as long as high) (Fig. 221); frenal area abrupt and hardly visible in dorsal view (Fig. 238): forewing with moderately dense, elongate setae (Fig. 122); eastern and western Australia

O. valgius (Walker), p. 79

\section{Orasema uichancoi-group}

This group of 7 species is restricted in distribution to Taiwan, Philippines. New Guinea and Madagascar. Additional species (not described here: see discussions under various descriptions) are recognized from Papua New Guinea.

\section{GROUP DESCRIPTION}

Head broadly subtriangular; face smooth to rugose, frons often swollen, some species with distinct ocellar-ocular sulcus, malar depression absent or narrow and foveate. Antenna 12-segmented and funicle 8 -segmented in females, antenna 12- or 13-segmented and funicle 8- or 9segmented in males. Mesoscutum and scutellum rugose to rugose-areolate, with lateral lobe of mesoscutum and axilla swollen and glabrate: lower mesepimeron and callus variable in sculpture, the callus with 7 or more elongate hairs. Forewing infuscate, completely pilose or basal area bare, speculum absent: disc pilose and marginal fringe present; stigmal vein variable in shape, postmarginal vein elongate, more than $(0.5 \times$ as long als marginal vein. Petiole variable. Ovipositor usually subapically expanded and slightly curved forward; other features variable.

\section{Orasema communis Risbec}

Figs. 80, 82, 84-85

Orasema communis Risbec, 1952:412-414. Madagascar [MNHP, cxamined].

\section{TYPE MATERIAL}

Lectotype (here designated), o. "MADAGASCAR/ BEKILY/ REG SUD DE L'ILE." "MUSEUM PARIS/ 1.37/ A. SEYRIG." "TYPE." "Orasema/ communis/ Risbec." "LECTOTYPE/ Oralsema/ communis Risbec/ Det. J. Heraty '90." Left flagellum and right foreleg missing. Risbec did not designate a holotype in the original description for Orasema communis. The lectotype male is based on the handwritten determination label and type card on the first specimen of the series. Only 12 of the 17 males mentioned in the original description were examined. Females of Orasema commmnis were labelled as "Orasema bekilensis Risbec." All 11 females are listed in 
the original description and the name is probably an early manuscript name of Risbec. There are some discrepancies with the original label information in Risbec (1952), and the paralectotype ditla is relisted here.

Paralectotypes (examined and here designated): MADAGascar: Bekily, xii.1936 (2ㅇ․ $3 \delta^{\delta} \delta$ ), i.1937

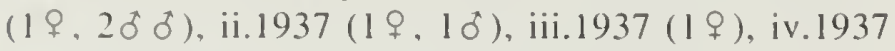

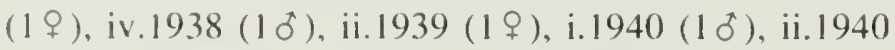
(1q): Taolänaro [Fort Dauphin], xii.1936 (3q ㅇ), v.1937 $\left(3 \sigma^{\circ}\right)$ : all collected by A. Seyrig (MNHP).

\section{DIAGNOSIS}

This species has a distinctive habitus and can be recognized by: body size large, head and mesosoma black, labrum 8- to 10-digitate with digits narrow and elongate (Fig. 80), face relatively smooth and flat, F2 3.5-5.0x as long as broad (Figs. 84-85), lateral lobe and axilla strongly swollen, scutellum rugose with a distinct frenal area, wing with only extreme basal area bare, and postmarginal vein elongate. This species differs from $O$. seyrigi by having the ocellar-ocular channel distinct, occipital carina lacking, vertex not elevated medially (Fig. 80), dorsum of mesosoma more strongly areolate, and ovipositor larger and similar in size to other Oraseminae (Fig. 82).

\section{FEMALE}

Length, 4.5-5.8 $\mathrm{mm}$. Head, mesosoma, petiole, and antennal flagellum black, gaster reddish-brown; scape and pedicel yellowish brown; fore and midlegs, including coxae, light yellowish brown; hind coxa light brown ventrally to black dorsally; femora mostly brown, otherwise legs yellowish brown; mandible yellowish brown with dark brown outline, maxilla and labium pale yellowish brown. Wings hyaline, venation brown.

Head subtriangular, 1.3-1.4 $\times$ as broad as high; occiput transverse; lateral ocellus separated from occiput by own diameter; LOL 0.7-0.9× OOL. Face relatively flat, frons may be weakly impressed lateral to toruli, glabrate with only light punctation in lower half of face; scrobal depression shallow and broadly impressed, finely and irregularly sculptured medially; vertex evenly rounded with smooth, well-defined ocellar-ocular channel; vertex and occiput finely strigate just posterior to ocelli, otherwise glabrous. Eye not especially prominent, eyes separated by 1.9-2.0x their height. Malar space 0.9-1.0× height of eye, malar depression narrow and poorly defined. Clypeus glabrate with only scattered minute setae, epistomal sulcus weakly defined, lateral margin deeply impressed to tentorial pits, anteclypcus subtruncate; supraclypeal area swollen medially and poorly defined laterally. Labrum 8 to 11-digitate, digits elongate and narrow, setae bristlelike. Mandible moderatcly stout; maxilla and labium large, palpi clongate and 3-segmented. Antenna 12-segmented (Fig. 84): scape stout and cylindrical, almost reaching median ocellus; pedicel small and globose: anellus present and small; flagellum 2.()-2.3x height of head: funicle 8 -segmented, segments finely reticulate with dense, small] setae, no MPS evident: F2 1.0-1.2x as long as scape, 3.5-5.0 $\times$ as long as broad, F2 1.3-1.5× F3, following segments subequal in length and equal in width; clava subovate, not differentiated from funicle and shorter than preceding 2 segments.

Mesosoma with midlobe of mesoscutum rugose-areolate and broadly rounded; lateral lobe smooth to very weakly carinate and strongly swollen; axilla irregularly rugose-carinate and swollen, posterior margin abruptly margined at SSS; scutellum broadly rugose-areolate. Mesoscutum with notauli deeply impressed and irregularly carinate. SSS broadly and deeply impressed, irregularly carinate. Scutellum as long as broad, broadly separated from TSA at base, strongly sloped posteriorly to meet frenal line; frenal line crenulate dorsally or with band of crenulate sculpture on either side, frenal area irregularly carinate or rugose-areolate and with abrupt posterior margin; axillular sulcus weak and crenulate. Propodeal disc broadly rounded and evenly alveolate or rugose-areolate; postspiracular sulcus deeply impressed and mostly smooth, lacking prominent carina above hind coxa; callus slightly swollen, smooth laterally and dorsally with dense patch of short hairs; metepimeron weakly sculptured, metepimeral sulcus deep and irregular, continuing dorsally as deep crenulate groove and separating a narrow anterior region. Upper mesepimeron slightly swollen and mostly glabrate, lower mesepimeron smooth to rugose. transepimeral sulcus shallow and irregularly foveate; femoral groove lacking; mesepisternum rugose-areolate to scabrous, glabrate ventrally and only slightly swollen anterior to mid coxa. Prepectus narrow ventrally, upper triangle deep foveate. Pronotum rugose with sharp medial furrow. Proepisternum swollen and smooth or very weakly sculptured. Fore coxa elongate and smooth, mid coxa subglobose and finely carinate, hind coxa subglobose, $1.6 \times$ as long as broad, and glabrate; hind femur glabrate. with short dense setae apically; hind tibia densely short setose, the setae longer on inner margin; hind tibia with 2 large spurs. Forewing 2.3-2.6x as long as broad, 2.6-3.1× as long as mesothorax: basal area and along impression of cubital vein bare; speculum absent; costal cell broad and densely pilose; submarginal vein with dense row of dorsal setae; marginal vein $0.29-0.32 \times$ as long as forewing: stigmal vein subquadrate to elongate and roughly perpendicular to anterior margin of forewing, with distinct apical uncus equal to width of stigma; postmarginal vein long and reaching apex of forewing.

Metasoma with petiole $1.5-2.0 \times$ as long as hind coxa, 1.4-1.9x as long as propodeum; petiole slightly increasing in width to apex, smooth ventrally and weakly rugose dorsally, slightly dorsoventrally compressed. with strong 
basal flange. $\mathrm{Mt}_{2}$ 1.0-1.7× as long as hind femur, glabrous; $\mathrm{Ms}_{2}$ with strong constriction, groove narrow and weakly crenulate, anterior region semicircular. Hypopygium with few short hairs ventroapically. Ovipositor short and straight, thickened along entire length (Fig. 82); first valvula without subapical ridge or apical line of teeth and with 3 diagonal ridges apically; second valvula with 6 strong transverse ridges coalescing dorsally.

\section{MALE}

Length, 4.4-5.8 mm. Colour as in female, gaster dark brown.

Head as in female. Antenna 12-segmented (Fig. 85); scape thickened medially; funicle 8-segmented, segments cylindrical and very slightly broader at apices, covered with dense elongate setae; F2 4.4-5.4× as long as broad; clava constricted medially ( 2 -segmented).

Mesosoma with dorsum more strongly sculptured. Stigmal vein of forewing $6 \times$ as long as broad, sometimes with distinct apical uncus.

Metasoma with petiole $1.4-2.0 \times$ as long as hind coxa, $1.8-2.0 \times$ as long as propodeum, cylindrical, smooth ventrally and weakly to strongly rugose dorsally, with small basal flange. $\mathrm{Mt}_{2} 0.7-0.9 \times$ as long as hind femur; $\mathrm{Ms}_{2}$ narrowly rounded with dense elongate hairs. Genitalia with strong median process, paramere relatively short and stout, digitus with 4 or 5 marginal teeth; aedeagus subacuminate.

\section{VARIATION}

There is little variation among the type material except in the shape of the stigmal vein (short and subquadrate to elongate with a distinct uncus), and sculpture of the propodeal disc (close areolate to strongly rugose-areolate).

\section{DISTRIBUTION}

Madagascar (C, Fig. 276).

\section{MATERIAL EXAMINEI)}

MADAGASCAR: Antananarivo |no datel. Sikora (1?sex, BMNH).

\section{Orasema seyrigi Risbec}

Figs. 81, 83, 86

Orasema Seyrigi Risbec, 1952:414-416. Madagascar [MNHP, examined].

\section{TYPE, MATERIAI.}

Holotype, + , "MADAGASCAR/ ROGEZ/ FORÉT CÔTE EST." "MUSÉUM PARIS/ I.37/ A. SEYRIG."
"TYPE." "Orasema/ Seyrigi Risbec." Antenna missing beyond pedicel. The data and description match the specimen examined, which is a female, not a male as originally stated by Risbec (1952).

\section{DIAGNOSIS}

Recognized by a crest behind the ocelli (Fig. 81), strong carina along dorsal frenal margin (Fig. 83), basal area of forewing bare, and ovipositor minute in relation to the overall body size. This species appears most closely related to Orasema communis.

\section{FEMALE}

Length $6.1 \mathrm{~mm}$. Head black, mesosoma black with blue reflections, petiole black, gaster dark brown to black; scape and pedicel yellowish brown, fore and mid coxae dark brown at base with remainder light yellowish brown, hind coxa dark brown to black; femur dark brown medially, otherwise light yellowish brown; mandible light brown with dark border, maxilla and labium yellowish brown. Wings lightly infuscate, venation dark brown.

Head subtriangular, $1.5 \times$ as broad as high; occiput slightly emarginate; lateral ocellus separated from occipital margin by own radius; LOL $0.8 \times$ OOL. Face relatively flat, frons and cheeks slightly swollen medially, glabrate with only scattered fine punctation over entire face; scrobal depression narrow and weakly rugulose, lateral margin broadly rounded, depression with 2 parallel strigate channels reaching ventral margin of median ocellus. median area swollen and weakly carinate: vertex strongly impressed next to lateral ocellus, continuing weakly as ocellar-ocular depression to eye margin, finely transversecarinate between depression and occipital margin, ocellar triangle rugulose: occipital margin abrupt with strong carina posterior to ocelli, elcvated carina forming crest in frontal view; occiput glabrous medially to very weakly aciculate ventrally. Eye prominent and bulging in Irontal view; eyes separated by $1.7 \times$ their height. Malar space $0.8 \times$ height of eye, malar depression broald and poorly defined. Clypeus glabrate with scattered minute setae. epistomal sulcus weakly defined, lateral margin strongly impressed and deepest at tentorial pit, anteclypeus subtruncate; supraclypeal area swollen medially and poorly defined dorsolaterally. Labrum not discernible (may be reduced or missing). Mandible moderately stout; maxilla and labium normal for genus, palpi elongate and 3-segmented. Scape narrow and cylindrical. converging from base to apex (bowed medially) and reaching median ocellus. pedicel small and globose (antenna broken beyond pedicel).

Mesosoma with midlobe of mesoscutum broadly rounded and rugulose with fine transverse carinac: lateral lobe strongly swollen and smooth; axilla swollen, smooth dorsally and oblicuely carinate posterolaterally; scutellum 
rugose to rugose-areolate. Mesoscutum with notauli sharply impressed and narrowly cremulate. SSS deeply foveatc and U-shaped. Scutellum $1.2 \times$ as long as broad, broadly separated from TSA at base by foveate SSS; frenal line broad dorsally and crenulate forming a sharp ridge at dorsal margin of frenal area, frenal area abruptly margined. rugose-arcolate dorsally to broadly crenulate ventrally: axillular sulcus weak and crenulate. Propodeal disc narrow and strongly rounded, strongly rugose-areolate medially to glabrate laterally; postspiracular groove deeply crenulate, forming small carina above base of hind coxa; callus smooth with patch of dense, long hairs dorsally; metepineron glabrous, metepimeral sulcus strongly impressed and irregularly sculptured. Upper mesepimeron slightly swollen and smooth, lower mesepimeron lightly sculptured, transepimeral sulcus foveate; femoral groove absent; mesepisternum finely rugulose-alveolate to rugose, smooth ventrally and only slightly swollen anterior to mid coxa. Prepectus triangular, only slightly narrowed ventrally, medially colliculate to rugose, swollen and smooth along dorsal and posterior margins. Pronotum irregularly carinate to smooth with broad transverse furrow. Proepisternum glabrous. Fore coxa elongate and smooth, mid coxa globose and finely carinate basally, hind coxa subglobose and glabrate: hind femur slender and smooth with dense fine setae dorsally along entire length; hind tibia slightly expanded to apex, with dense adpressed setae. Forewing $2.7 \times$ as long as broad, 3.0× as long as mesothorax; basal area and along impression of cubital vein bare; speculum absent: costal cell broad and densely pilose; submarginal vein with dense row of dorsal setae; marginal vein $0.28 \times$ as long as forewing; stigmal vein subquadrate and roughly perpendicular to forewing margin, with small uncus; postmarginal vein long and reaching apex of forewing.

Metasoma with petiole $1.6 \times$ as long as hind coxa, $1.4 \times$ as long as propodeum; petiole rugose, very slightly increasing in width to apex, cylindrical with weak basal flange. $\mathrm{Mt}_{2} \mathrm{I} .1 \times$ as long as hind femur. glabrous: $\mathrm{Ms}_{2}$ strongly constricted, groove strongly crenulate, anterior region circular. Hypopygium bare. Ovipositor extremely reduced and somewhat threadlike (first valvula withdrawn and hidden) and shorter than length of hind coxa; second valvula narrow with 4 strong transverse ridges. Ovipositor sheath acute, gonostylus differentiated as setose yellowish brown area, but not scparated at base by suture.

\section{DISTRIBUTION}

Madagascar (E, Fig. 276).

\section{Orasema uichancoi (Ishii)}

Figs. 87,94.97, 188, 218, 235, 258-259

Losbamus wichancoi Ishii, 1932:210. Philippines [NIAS, wing and antenna examined].

Gollumiella nichancoi-Bouček, 1988:522.

Orasema wichancoi-Heraty, 1992:586.

\section{TYPE MATERIAL,}

Lectotype (here designated), + [?], slide of left fore and hind wing and left antenna labelled "Psilogaster/L. Banos." "Losbanus/ uichancoi/ Ishii, 1932/ LECTOTYPE/ det:/ J. Heraty '88." Associated with unlabelled glass slide of planidium (see below).

No other mounted specimens are known from the NIAS collection (personal communication, Kazukiko Konishi, NIAS, and my examination of miscellaneous Oraseminae in NIAS collection). A slide collection was sent to me from the NIAS, which was thought to have been associated with Ishii's 1932 paper. The collection included slides of adult parts and planidia that could all be associated with the species described by Ishii (1932). The wings are distinct among all of the specimens described in that paper and matched Ishii's illustration of the wing. The pattern of wing pilosity and peculiar stigmal vein are sufficient to identify this species. The number of specimens included as "types" by Ishii was not stated but may be numerous as he mentions that adults are "most common" during the dry season, and he was able to make biological observations on oviposition.

\section{DIAGNOSIS}

Recognized by: wing densely pilose, basal area bare except for a band of hairs along the impression of the cubital vein, stigmal vein with long robust uncus longer than width of the stigmal vein (appearing $\mathrm{Y}$ - or $\mathrm{T}$-shaped) (Fig. 97), and the axilla and lateral lobe swollen and glabrous (Fig. 235). This species is similar to $O$. ishii but can be distinguished by having the antenna 12-segmented in males, eye large but not strongly protruding, gena rounded or angled, proepisternum strigate-coriaceous, and labial palpus with terminal segnent $2-3 \times$ times longer than broad.

\section{FEMALE}

Length, 2.8-4.3 $\mathrm{mm}$. Head, mesosoma, and petiole black. mesosoma with strong blue or green reflections dorsally and purple reflections sublaterally: gaster dark brown to black; flagellum dark brown; pedicel. scape and legs yellowish brown; femora yellow to light brown in proximal half. Wings slightly infuscate, venation pale brown.

Head subtriangular to subquadrate, $1.2-1.5 \times$ as broad as mesosoma, posterior margin of gena broadly rounded to sharply angled medially: occiput broadly emarginate; 
lateral ocellus separated from occiput by slightly less than own radius; LOL $0.8-1.0 \times$ OOL. Face relatively flat, weakly rugulose to almost smooth with frons and vertex weakly coriaceous; scrobal depression broad and shallowly impressed, lightly carinate laterally, sculpture delimiting medial glabrous band extending to median ocellus (Fig. 188); vertex rugose to coriaceous, strongly depressed next to lateral ocellus, ocellar-ocular groove shallow and vaguely impressed; temple narrow and rugulose to weakly strigate; occiput aciculate, dorsal margin with weak carina, carina extending just beyond lateral ocellus. Eyes separated by 1.7-2.0 $\times$ their height and margined by narrow sulcus. Malar space $0.6-0.9 \times$ height of eye, malar depression vaguely impressed and weakly sculptured. Clypeus and supraclypeal area glabrate, epistomal sulcus strongly impressed, territorial pits and lateral margin of clypeus strongly impressed, anteclypeus slightly rounded; margin of supraclypeal area deeply impressed ventrally. Each mandible with long apical tooth overlapping base of opposing mandible; maxillary palpus 3-segmented; labial palpus 2-segmented, basal segment short. terminal segment elongate. Antenna 12-segmented; scape stout and cylindrical, reaching $0.6 \times$ distance to median ocellus; pedicel subconate, as long as broad; anellus present and about twice as broad as long; flagellum 1.4-1.6x height of head; funicle 8-segmented, segments densely setose, sculpture relatively smooth, with numerous MPS; F2 $0.5 \times$ as long as scape, $2.1-2.4 \times$ as long as broad, following segments subequal in length, equal in width; clava ovate, as long as preceding 2 segments.

Mesosoma with midlobe of mesoscutum rugose-areolate to weakly longitudinally carinate (pronounced only on SEM specimen; Fig. 235); lateral lobe and axilla swollen and glabrate: scutellum rugose. Mesoscutum with notauli deeply impressed and foveate: midlobe subtriangular and strongly elevated along anterior margins. Scutellum 1.6x as long as broad: frenal line shallow and foveate, frenal area semicircular in dorsal vicw and rugulose; axillula weakly carinate, axillular sulcus obscured by dorsal sculpture. Propodeal disc broadly rounded and only slightly curved in profile, rugulose to rugose-areolate; postspiracular and metepimeral furrow broadly impressed and irregularly sculptured; callus swollen, rugulose dorsally and glabrate laterally, with patch of several elongate hairs dorsally; metepimeron glibrate. Upper mesepimeron swollen and glabrate, lower mesepimeron weakly sculptured, transepimeral sulcus shallow and broadly foveate; femoral groove shallow; mescpisternum rugose-reticulate, swollen, and glabrate ventrally. Prepectus triangular and rugose. Pronotum mostly glabrous. Proepistemum weakly strigatte with verrucose or reticulate surface sculpture. Fore and mid coxac glabrate, hind coxal rugulose dorsally: femora glabrate with denser fine setale apically; hind tibiat with 2 tibial spurs. Forewings $2.7 \times$ as long as mesothorax, 2.4-2.6x as long as broad; basal area setose along impression of cubital vein, always bare just posterior to submarginal vein; speculum absent; costal cell relatively narrow; marginal vein $0.24-0.27 \times$ as long as forewing: stigmal vein slightly longer than broad and weakly constricted basally, apical margin subtruncate, uncus elongate and longer than width of stigmal vein, stigma and uncus appearing $Y$ - or T-shaped (Fig. 97); postmarginal vein $0.5 \times$ as long as marginal vein, reaching half distance to apex of wing.

Mctasoma with petiole $1.3-2.0 \times$ as long as hind coxa. $1.1-2.3 \times$ as long as propodeum; petiole rugulose dorsally and weakly carinate to glabrate ventrally with distinct basal flange (Fig. 94). $\mathrm{Mt}_{2} 1.2 \times$ as long as hind femur, glabrous; $\mathrm{Ms}_{2}$ with constriction shallow and glabrous (Fig. 258). Ovipositor subapically expanded and strongly curved anteriorly; first valvula with 4 strong lateral teeth beyond subapical crest (Fig. 259); second valvulit with several strong transverse ridges apically. Gonostylus broad.

\section{MALE}

Length, $2.5-3.5 \mathrm{~mm}$. Colour as in female. Head as in female. Eyes separated by $1.7-2.0 \times$ their height. Antenna 12-segmented; funicle 8-segmented, segments densely setose, setae papillate and surface appearing scabriculous. no MPS. Forewing 2.6× as long as mesolhorax, 2.2-2.4× as long as broad. Petiole $2.9-3.4 \times$ as long as hind coxal. $2.4-3.9 \times$ as long as propodeum, slender and finely rugulose. $\mathrm{Mt}_{2} 0.9 \times$ as long as hind femur. $\mathrm{Ms}_{2}$ strongly inpressed and smooth. Genitalia with basiparamere truncate apically with strong median process, paramere short and broad, digitus with several marginal tceth; aedcagus broadly rounded.

\section{VARIATION}

Females from Bontoc (Mountain Province) show a large range of variation. These individuals are all large but the sculpture of the face ranges from weakly sculptured (2 specimens) to rugulose, the uncus of the stigmal vein is rarely small (usually elongate), and the shape of the gena ranges from broadly rounded to sharply angled in the same series. One specimen from Lipa has the basal area of the wing almost completely setose.

\section{BIOLOOYY ANI IMMATURE STAGES}

Females deposit their eggs in the lower surface of young leaves of Celtis philippinensis (Ulmaceac) and Lencaena glauca (Leguminoseac) (Ishii, 1932). Eggs are deposited in leaf punclures arranged in 2 shorl parallel rows (Ishii. 1932). Recxamination of the planidimm indicated it was similar to lshii"s (1932) description except for the follow ing discrepancies and additional comments: body 12-segmented with terga 1 and 11 distinctly separated dorsally. 
hatchet-shaped sclerite lacking, tergopleural line lacking. and tergite IXat leaflike. No differences between this planidium and those of other Orasema were noted, and the stalked egg is typical for Orasema. Ishii (1932) described the flight period as throughout the year, but common during the dry season in February.

\section{DISTRIBUTION}

Philippines (U, Fig. 276).

\section{MATERIAL, EXAMINED}

Philippines: Luzon: Lipa Btg., 14.ix.1952, Townes Family. "Losbanus uichancoi 1shii, Balt. '58." (2 $q$, AEl); Mountain Prov., Abatan, Buguio, $60 \mathrm{~km} \mathrm{~S}$ of Bontoc, 1800-2000 m, 25.iv.1964 (5우, I 0 ), 27.iv.1964 (1 \%), 9.v.1964 (1 \%), 12.v.1964 (1 ठ), 22-31.V.1964 (1 ), H. M. Torrevillas (BPBM); Batangas Prov., Citrus Expt. Sta., 26.xi.1953, J. L. Gressitt (1 9. BPBM): Albay Prov.. Mt Mayon, $16 \mathrm{~km} \mathrm{NW}$ of Lagaspi, 1200-1800 m, 15.v.1962, H. M. Torrevillas ( I ठ., BPBM); Biliran: 1927, C. F. Baku (1 ठ, USNM).

\section{Orasema ishii sp. nov.}

Fig. 88

\section{TYPE MATERIAL}

Holotype, ơ. "C. TAIWAN: Tungpu/ $1200 \mathrm{~m}$. Nantou Hsien/ 20-22.VI.1980/ C. C. Chen." "HOLOTYPE/ Orasema/ ishii Heraty, 1990." Left forewing, left hind leg, and tarsi of right hind leg missing. Deposited in TARI. Paratype: TAlwAN: Hassenzan, 21.vi.1932. J. L. Gressitt $(10, \mathrm{CAS})$.

\section{DIAGNOSIS}

Similar to $O$. uichanco $i$ and $O$. promecea. The male is distinguished by: forewing completely pilose except for a sparsely setose region below submarginal vein, face glabrate, axillula longitudinally carinate, and antenna 13 segmented (Fig. 88).

\section{MALE}

Length, $4.2 \mathrm{~mm}$. Body black, mesosoma and petiole with faint greenish-blue reflections: pedicel and flagellum dark brown: scape and legs light yellowish brown. Wings slightly infuscate, venation brown.

Head triangular, 1.3× as broad as mesosoma, posterior margin of gena straight in frontal view; occiput broadly rounded: lateral ocellus almost touching occiput: LOL $0.9 \times$ OOL. Face flat and glabrate; scrobal depression shallow. glabrate with margin broadly rounded; no ocellar-ocular groove, ocellar triangle rugose; temple narrow and glabrate: occipital carina weak, extending just beyond lateral ocellus; occiput vaguely strigate, almost smooth.
Eye protuberint, eyes separated by $1.9 \times$ their height, ocular groove narrow and smooth. Malar space $0.9 \times$ height of cye, malar depression absent. Clypeus glabrous, bulging nedially, epistomal sulcus weakly impressed. tentorial pit and lateral margin of clypeus decply impressed, anteclypeus almost straight. Maxillary palpus 3-segmented, labial palpus 1-segmented and only slightly longer than broad. Antenna 13-segmented; scape stout and cylindrical, just reaching median ocellus; pedicel globose; anellus present; flagellum $2.6 \times$ height of head; funicle 9-segmented, segments with dense short semi-erect papillate setae, no MPS; F2 $0.8 \times$ as long as scape, $2.5 \times$ as long as broad, following segments subequal in length, only slightly decreasing in width toward apex of flagellum; clava ovate and slightly longer than preceding segment, apex with weakly segregated, cylindrical projection.

Mesosoma with midlobe of mesoscutum and scutellum rugose; lateral lobe and axilla strongly bulging and glabrate. Mesoscutum with midlobe subtriangular, vertical face rounded, and anterior lateral margins abruptly elevated; notaulus deeply impressed and narrowly crenulate. SSS broadly impressed and carinate. Scutellum as long as broad; frenal line narrow and weakly crenulate, frenal area rounded in profile and rugose-areolate; axillula longitudinally carinate, axillular sulcus obscure. Propodeal disc rounded, straight in profile, rugose-areolate and with irregular lateral carina along postspiracular furrow that extends to base of petiole; postspiracular furrow broad and deeply impressed with few weak transverse carinae; callus swollen and glabrate with patch of elongate hairs; metepimeral groove broadly and deeply impressed, continuing dorsally to posterior margin of wing base, foveate-carinate dorsally. Upper mesepimeron swollen and glabrous, lower mesepimeron weakly sculptured; femoral groove and transepimeral sulcus broadly and shallowly impressed. Mesepisternum rugose laterally with weak verrucose sculpture. rounded and glabrous ventrally. Prepectus triangular, weakly verrucose with irregular strigae. Pronotum glabrous. Coxae and femora glabrate. Forewing $2.8 \times$ as long as mesothorax, $2.4 \times$ as long as broad: completely pilose except for sparsely setose area just below submarginal vein; marginal vein $0.27 \times$ as long as forewing: stigmal vein twice as long as broad and constricted basally, perpendicular to wing margin, uncus elongate and projecting posteriorly: postmarginal vein $0.8 \times$ as long as marginal vein, almost reaching apex of wing.

Metasoma with petiole $2.7 \times$ as long as hind coxa, $2.8 \times$ as long as propodeum; petiole linear and cylindrical with small basal flange, rugulose. $\mathrm{Mt}_{2}$ as long as hind femur. glabrous; Ms, with constriction broad and smooth. Genitalia with elongate median process, paramere stout basally, abruptly narrowed apically, digitus with 4 marginal spines: aedeagus long and subacute. 
FEMALE

Unknown.

\section{DISTRIBUTION}

Taiwan (H, Fig. 276).

\section{ETYMOLOGY}

Named in honour of Dr. Tei Ishii for his work on the Eucharitidae.

\section{Orasema bouceki sp. nov.}

\section{Frontispiece}

\section{TYPE MATERIAL}

Holotype, ơ, "PAPUA: Kokoda./ 1,200 ft. [365 m] x.1933./ L. E. Cheesman./ B. M. 1934-321." "c.f. T 612/ nigra [boxes]/ NOT /delicatula." "Orasema." "HOLOTYPE/ Orasema/ bouceki Heraty." Right forewing missing. Deposited in BMNH.

\section{DIAGNOSIS}

Recognized by the following: forewing completely pilose. mesosoma elongate with propodeum strongly arched in profile, face and callus rugulose. Similar species with a smooth face will key to $O$. bouceki and are discussed in the included section on related species.

\section{MALE}

Length, $3.6 \mathrm{~mm}$. Head, mesosoma, coxae, and petiole black, mesosoma with faint bluish tinge, not highly reflective: gaster brown with $\mathrm{Ms}$, black basally; antennal flagellum dark brown; scape, pedicel, and anellus yellowish brown; mandibles, apex of coxae, and legs yellowish white, apex of tibiae and tarsi slightly darker. Wings infuscate, venation dark brown.

Head subquadrate, $1.3 \times$ as broad as high; posterior margin of gena straight; occiput broadly cmarginate; ocelli large, lateral ocellus close to occiput; LOL $0.8 \times$ OOL. Face relatively flat, frons slightly bulging just below median ocellus, face including scrobal depression and clypeal area rugose; scrobal depression narrow, lateral margin broadly rounded, distinct vertical carina separating scrobal depression medially; vertex almost smooth. strongly impressed next to lateral ocellus, ocellar-ocular sulcus sharply inmpressed and loveate; temple narrow and weakly sculptured; occiput strigate, occipital carina absent. Eyes separated by $1.7 \times$ their height, margined by narrow reticulate sulcus. Malar space $0.7 \times$ height of eye: malar depression narrow and deeply foveate. Clypeus rugulose, epistomal sulcus weak, tentorial pit and lateral margin deeply impressed, lateral margin of supraclypeal area shallow, anteclypeus broadly rounded all apex. Maxillary palpus 3-segmented and long: labial palpus 2- segmented and very short. Antenna 12-segmented; scape stout and cylindrical, almost reaching median ocellus: anellus slightly broader than long: flagellum $2.0 \times$ height of head; funicle 8-segmented, segments with dense, semierect papillate setae, surface appearing scabriculous, no MPS; F2 2.7 $\times$ as long as broad, 1.3× F3, as long as scape, following segments subequal in length and equal in width; clava tapered to apex, slightly shorter than preceding 2 segments.

Mesosoma with dorsum finely and deeply alveolaterugose: lateral lobe of mesoscutum and axilla strongly bulging, lateral lobe glabrate, axilla narrow and weakly sculptured. Mesoscutum with midlobe subtriangular, strongly elevated along anterior margins; notaulus deeply impressed and transversely carinate. SSS broad and deeply impressed with large transverse carinae. Scutellum slightly longer than broad, separated at base from TSA by deep fovea; frenal area and axillula not distinguishable, apical margin of scutellum crenulate. Propodeal disc rounded, broadly curved in profile, alveolate-rugose, with sharp lateral carina along postspiracular furrow dorsally and extending to base of petiole; postspiracular furrow narrow and crenulate; callus areolate and flush with rest of propodeum, with dense patch of short hairs dorsally; metepimeral furrow vaguely impressed. Upper mesepimeron glabrous and hardly swollen, lower mesepimeron rugose-alveolate; femoral groove and transepimeral sulcus vaguely impressed: mesepisternum finely rugose-alveolate to umbilicate laterally, glabrous and flattened ventrally. Prepectus finely alveolate-rugose and verrucose, posterior margin glabrous and narrowed ventrally. Pronotum irregularly foveate. Proepisternum rugose. Fore and mid coxa glabrate with few weak strigae, hind coxa glabrate with weak dorsolateral sculpture: femora glabrate, tibiac with minute adpressed setac; hind tibia with 2 spurs. Forewing $3.0 \times$ as long as mesothorax, $2.4 \times$ as long as broad: completely pilose, costal cell narrow: marginal vein $0.32 \times$ as long as forewing; stigmal vein slightly longer than broad, perpendicular to wing margin; postmarginal vein $0.5 \times$ as long as marginal vein, reaching half distance to apex of wing.

Metasoma with petiole $2.7 x$ as long as hind coxal, $3.1 \times$ as long as propodeum: petiole slightly sinuate in profile, irregularly reticulate-carinate and verrucose, without hasal llange. $\mathrm{Mt}_{2}, \mathrm{~T} \times$ as long as hind femora, glabrate: $\mathrm{Ms}_{2}$ smooth, constriction only vaguely impressed laterally (considered absent). Genitalia small, additional features could not be observed on holotype.

FEMAIE,

Unknown. 


\section{RELATED SPECIES}

Two specimens from Papua New Guinea represent 2 closely related species that are not described here because the antennat are incomplete on both. These share the following features with Orasema bouceki: propodeum strongly arched with median carina; callus rugulose, not swollen, and with patch of short hairs; malar depression crenulate or weakly sculptured; frenal line obscure; and similar wings. The female (Sepik Riv., Pagwi, 25.viii.1957, Hardy, BPBM) has the face glabrate and weakly punctate ventrally, body black with strong purple and blue reflections, dorsum of mesosoma rugose, proepisternum smooth, and $\mathrm{Ms}_{2}$ with constriction deeply impressed but smooth. The male (Central Prov., 12.vi.1983, J. Ismay, BMNH) has the face polished and weakly punctate to rugulose, body black with purplish reflections (blue on lateral lobe, axilla, and apex of scutellum), dorsum rugose, proepisternum rugulose basally, and $\mathrm{Ms}_{2}$ not constricted. The male petiole is longer $(3.2 \times$ as long as hind coxa) than O. rugulosa and $\mathrm{Mt}_{2}$ is shorter than the hind femora.

Three pupae (1 $9,20^{\circ}$ o. Fulakora, Solomon Islands, W. M. Mann, MCZ) were taken from a nest of Pheidole sp. (det. E. O. Wilson). These represent yet another species that shares the above features but differs by having a strong blue-green coloration, femur dark brown, mesosoma dorsum deep areolate, and frenal line more prominent. The pupae are typical for other members of Orasema. This is the only pupal and ant-host record known for the michancoi-group.

\section{DISTRIBUTION}

New Guinea (B, Fig. 299).

\section{ETYMOLOCY}

Named in honour of Dr. Z. Bouček for his monumental effort on reclassifying and organizing information on the major groups of Chalcidoidea of the Indo-Pacific region. His work has opened a new world for chalcidologists everywhere.

\section{Orasema promecea sp. nov.}

Fig. 95

\section{TYPE MATERIAL}

Holotype, ơ, "Jimmi V. - Baiyer R./ 1750 m. New Guinea/ I1.6-25.1979/ J. Sedlacek." "HOLOTYPE/ Orasema/ promecea Heraty." Deposited in AEI.

Paratype: PAPua New Guinea: Central Dist., Guary [?], $1900-2100 \mathrm{~m}, \mathrm{x} .1968$, N. L. H. Krauss (1 ơ, BPBM).

\section{DIAGNOSIS}

Recognized by having the forewing completely pilose, mesosoma elongate and rugose-alveolate with propodeum broadly curved in profilc, face glabrous, and petiole long and slender with a small basal flange. Additionally, the lateral lobe, axilla, upper mesepimeron, and callus are swollen and glabrate.

\section{MALE}

Length, 3.6-3.9 mm. Head, mesosoma, petiole, and base of coxae black with faint blue-green reflections on head and mesosoma, vertex with violet reflections; antennal flagellum black; scape, pedicel, and anellus yellowish brown; mandibles, apex of coxae, and rest of legs white to yellow, tip of apical tarsomere of each leg slightly darker. Wings lightly infuscate, venation dark brown.

Head subtriangular, $1.3 \times$ as broad as high, posterior margin of gena broadly rounded; occiput broadly rounded; lateral ocellus separated from occiput by own radius; LOL $0.7 \times$ OOL. Face broadly rounded and glabrous with cheek lightly pitted, frons lateral to scrobal depression and cheek swollen; scrobal depression narrow, margins rounded and indistinct, rugose just below median ocellus; vertex between ocelli rugulose, ocellar-ocular groove shallowly impressed; temple narrow and glabrate; occiput glabrate, occipital carina prominent, extending just beyond lateral ocellus. Eyes separated by $1.7-1.8 \times$ their height, margined by narrow smooth ocular groove. Malar space $0.7 \times$ height of eye, malar depression shallowly impressed and glabrate (Fig. 95). Clypeus glabrate, bulging medially, epistomal sulcus weak, tentorial pit deep, lateral margin of clypeus and supraclypeal area shallowly impressed, anteclypeus subtruncate at apex. Maxillary palpi 3-segmented, basal segment elongate, labial palpi 2-segmented and short. Antenna 12-segmented (Fig. 95); scape stout and cylindrical, slightly expanded ventrally, reaching median ocellus; pedicel globose, about $1.5 \times$ as broad as anellus; anellus as broad as long; flagellum $2.0 \times$ height of head; funicle 8-segmented. segments densely setose, setae papillate, no MPS; F2 $2.8-3.8 \times$ as long as broad, $1.1-1.3 \times \mathrm{F} 3,0.8-0.9 \times$ as long as scape, following segments cylindrical and subequal in length; clava narrow and cylindrical, acute at apex, 1.5x preceding segment, with 2 incompletely fused segments.

Mesosoma with dorsum strongly rugose-areolate; lateral lobe of mesoscutum and axilla swollen and glabrous. Mesoscutum with midlobe subtriangular, strongly elevated at margin; notauli deeply impressed and transversely carinate. SSS carinate. Scutellum slightly longer than broad, subtruncate at apcx, separated at base from TSA by SSS; frenal line narrow and foveate, partially obscured by surface sculpture, frenal arca rugulose, crescentshaped in dorsal view; axillula glabrate, axillular sulcus obscure. Propodeal disc rounded and strongly rugose. 
broadly curved in profile; postspiracular furrow broadly foveate; callus glabrous and swollen. dorsally with dense patch of erect hairs: metcpimeral sulcus broadly impressed and glabrate. Mesepimeron glabrate, transepimeral sulcus broadly impressed; femoral groove obscure; mesepisternum areolate-rugose laterally, glabrous ventrally. Prepectus triangular and rugose to foveate. Pronotum glabrate with broad foveate dorsal and medial lines. Proepisternum glabrous. Coxae and femora glabrate, femora with fine, dense setae dorsoapically: hind tibia slender with 2 apical spurs. Forewing $3.0 \times$ as long as mesothorax, $2.7-2.8 \times$ as long as broad; completely pilose; costal cell narrow; marginal vein $0.27-0.33 \times$ as long as forewing; stigmal vein $2.0 \times$ as long as broad; postmarginal vein $0.7 \times$ as long as marginal vein, almost extending to apex of wing.

Metasoma with petiole $3.4-3.7 \times$ as long as hind coxa, $3.5-3.7 \times$ as long as propodeum; petiole long and cylindrical with small basal flange, areolate with longitudinal carinae. $\mathrm{Mt}_{2} 0.8 \times$ as long as hind femur, glabrate; $\mathrm{Mt}_{2}$ constriction narrowly impressed and smooth. Genitalia with elongate median process, paramere narrow and short; aedeagus subtruncate.

\section{FEMALE}

Unknown.

\section{VARIATION AND ADDITIONAL SPECIES}

The paratype is similar to the holotype but differs as follows: head completely black dorsally, scutellum with glabrous area anterior to frenal line, which has prominent violet reflections; hind femur with outer medial surface light brown. Two other males (not here described) from the Papuan subregion are similar but differ in several aspects: male from Papua New Guinea (Wamena. 10-25.ii.1960, BРBM) has dark brown femora, dark scape, reticulate mesosoma dorsum, and broadly alvcolate propodeum; male from Bougainville (Crown Prince Range, 11.vi.1956, BPBM) is similar morphologically but has a completely rugose face excluding the clypeus, a deep ocellar-ocular groove. and a strongly impressed alveolate malar depression as in $O$. rugulosa.

\section{DISTRIBUTION}

Papua New Guinca (P. Fig. 276).

\section{ETYMOLOC:Y}

From Greek promeces, meaning clongatc; referring to the profile of the mesosoma.
Orasema rugulosa sp. nov.

Figs. 89-93, 96

\section{TYPE MATERIAL}

Holotype, o, "NEW BRITAIN/ Gazelle Pen./ Bainings: St./ Paul’s 350 m./ Sept. 9. 1955." "J. L. Gressitt/ Collector." "HOLOTYPE/ Orasema/ rugulosa Heraty." Deposited in BPBM.

Paratypes: Papua New Guinea: New Britain: Gazelle Pen., Gaulim, 130 m, 28.x.1962, J. Sedlacek (1 우, 2 ô ô. BPBM); New Ireland: SW, Gilingil PI'n. 2 m, 5.vii.1956. J. L. Gressitt (1 9, BPBM).

\section{DIAGNOSIS}

Recognized by the following: forewing elongate and completely pilose (Fig. 96), mesosoma elongate with propodeum only slightly curved in profile (Fig. 91), and face finely rugulose-alveolate (Fig. 90).

\section{FEMALE}

Length, $2.4 \mathrm{~mm}$. Head and mesosoma including petiole and coxae dark blue, sometimes with intense purple reflections on face and lateral aspects of mesosoma and coxae; gaster dark brown with weak violet reflections, antenna, mandibles, and legs dark yellowish brown. Wings weakly infuscate, venation brown.

Head subquadrate, 1.5x as broad as mesosoma, posterior margin of gena broadly rounded; occiput shallowly emarginate; lateral ocellus separated from occiput by own radius; LOL $1.2 \times \mathrm{OOL}$. Face rounded, frons bulging latcral to scrobal depression, frons and cheek rugulose-areolate: scrobal depression broad and glabrate with weak medial sculpture, lateral margin marked only by change in sculpture; vertex rugulose-alveolate with rounded interstices (Fig. 90), depressed and glabrous just beyond lateral ocellus, without ocellar-ocular groove: temples narrow and rugulose; occiput weakly strigate; occipital carina absent. Eyes separated by 1.5-1.6× their height, margined by narrow fovcate sulcus. Malar space $0.7 \times$ height of eye, malar depression narrow, deep, and foveatc. Clypeus glabrate, tentorial pit and lateral margin deeply impressed, epistomal sulcus weak, anteclypeus subtruncate: supraclypeal area glabrate. lateral margin of supraclypeal area shallow. Palpi 3-segmented, maxillary palpi long. labial palpi relatively short. Antenna 12-segmented; scape stout and cylindrical, almost reaching median ocellus; pedicel globose, slightly broader than anellus; ancllus broader than long; flagellum $1.5 \times$ height of head: funicle 8-segmented, segments moderately setose, smooth with numerous MPS: F2 $1.8 \times$ as long as broad. 1.2 $\times$ F3, about half length of scape, following segments subequal in length and ejual in width: clava ovate. as leng as preceding 2 segments.

Mesosoma with dorsum rugose-aneolate: lateral lole of 
mesosculum and axilla rounded and glabrous. Mesoscutum with midlobe triangular. strongly elevated along anterior lateral margin; notaulus decply impressed and broadly foveate. SSS carinate. Scutcllum $1.7 \times$ as long as broad: frenal line foveate, partially obscured by dorsal sculpture, frenal area semicircular in dorsal view, rugulose dorsally, strongly foveate ventrally, flat in profile; axillula mostly smooth, without sulcus. Propodeal disc rounded and slightly curved in profile, strongly rugosealveolate; postspiracular and metepimeral sulcus broadly foveate and shallow; callus swollen and glabrous, with 5 to 6 long hairs dorsally. Mesepimeron glabrous, transepimeral sulcus foveate and shallow; femoral groove obscure; mesepisternum rugose, polished along anterior margin and ventrally. Prepectus triangular; strongly narrowed in ventral half, triangle of prepectus broadly impressed. Pronotum glabrous with irregular grooves. Proepisternum glabrous. Coxae and femora glabrate, femora with short setae dorsoapically; hind tibia slender (apex in glue). Forewing $2.9 \times$ as long as mesothorax, $2.7 \times$ as long as broad; completely pilose; costal cell narrow; marginal vein $0.27 \times$ as long as forewing; stigmal vein twice longer than broad, expanded and rounded apically; postmarginal vein $0.4 \times$ as long as marginal vein. reaching half distance to wing apex. Hind wing long and narrow, completely pilose.

Metasoma with petiole $2.1 \times$ as long as hind coxa, $1.8 \times$ as long as propodeum; petiole rugulose and longitudinally carinate with weak basal flange. $\mathrm{Mt}_{2} 1.2 \times$ as long as hind femur, glabrous; Ms, constriction smooth. Hypopygium bare. Ovipositor subapically expanded and strongly curved forward; first valvula with 4 or 5 teeth beyond subapical crest; second valvula with 3 strong. widely spaced, transverse ridges (Fig. 93). Gonostylus broad and not reaching cercus.

MALF:

Length, $3.0 \mathrm{~mm}$. Colour as in female, sometimes with reddish reflections on mesosomal dorsum and gaster.

Head as in female, but with shallow foveate ocellarocular depression; LOL $0.9-1.1 \times$ OOL. Eyes separated by $1.5-1.6 \times$ their height. Malar space $0.6-0.8 \times$ height of eye. Antenna 12-segmented, anellus as long as broad; flagellum 1.5-1.6× height of head; funicle 8 -segmented, segments densely setose, no MPS; F2 $1.9 \mathrm{X}$ as long as broad, following segments subequal in length; clava ovate, $1.5 \times$ as long as preceding segment.

Mesosoma as in female; callus with several erect hairs: mesepisternum shallowly rugose-areolate. Hind tibia with 2 spurs. Forewing $2.7 \times$ as long as mesothorax, 2.6-2.7x as long as broad.

Petiole $2.9-3.4 \times$ as long as hind coxa, $3.2-3.6 \times$ as long as propodeum, and alveolate with irregular, weak carina, and weak basal flange. Gaster with $\mathrm{Mt}_{2}$ as long as hind femur; $\mathrm{Ms}_{2}$ constriction smooth. Genitalia with basiparamere broad and truncate at apex. paramere very narrow and short, (digitus hidden); aedeagus broadly rounded.

\section{DISTRIBUTION}

Papua New Guinea: New Britain Is. (R, Fig. 276).

\section{ETYMOLOGY}

From Latin ruga, meaning wrinkled; referring to the sculpture of the face.

\section{Orasema striatosoma-group}

Two closely related species, $O$. striatosoma and $O$. frandulenta, are included here. This group is very different from other groups of Orasema but the shape of the head is similar to other species of Orasema, including $O$. susanae Gemignani, from southern South America, and to some species of Orasemorpha. Species in the striatosoma-group have a divided callus as in Orasemorpha, but the petiole is elongate and attached apically to the gaster (not anteriorly as in Orasemorpha).

\section{(AROUP DESCRIPTION}

Head triangular with eye small and protuberant (Fig. 102): face finely reticulate with decp, sharply impressed pit just below median ocellus; ocellar-ocular depression absent. Antennat 11 -segmented and funicle 7-segmented in both sexes. Mesoscutum including lateral lobe of mesoscutum fincly reticulate to coriaccous; lower mesepimeron reticulate; callus swollen and glabrous. Forewing hyaline and pilose (Fig. 104); basal area bare or bare only along impression of cubital vein; speculum absent; disc pilose and marginal fringe present; marginal vein thickened along entire length; stigmal vein broad and angled distally; postmarginal vein narrow and short, less than twice length of stigmal vein. Petiole weakly truncate basally with weak dorsal flangc.

\section{Orasema striatosoma sp. nov.}

Figs. 98-105

\section{TYPE MATERIAL.}

Holotype. + . "Kampala. Uganda/ April, 1965/ Denis F. Owen." "HOLOTYPE/ Orasema/ striatosoma Heraty, 1990." Deposited in AEI. 
Paratypes: RWANDA: $40 \mathrm{~km}$ E of Kigali, $1575 \mathrm{~m}$, 9.xii.1959, E. S. Ross and R. E. Leech (2q $q$. CAS). South Africa: Zululand: Spadeni Kop.. 9.v.1926, R. E. Turner ( 1 ㅇ. BMNH); Melmoth, 24.iv.1926, R. E. Turner ( 1 \%, BMNH). UGANDA: Kampala, x.1965, D. F. Owen (I $\delta^{\star}$ AE1); Kampala, 26.vi.1938, H. Hargreaves ( 19 , BMNH); Kawanda, vi.1943, T. H. C. Taylor ( 1 , BMNH).

\section{DIAGNOSIS}

Distinguished from $O$. fraudulenta by the following: scutellum finely striate (Fig. 101), and basal area of forewing pilose except along impression of cubital vein (Fig. 104).

\section{FEMALE}

Length, 2.6-2.8 mm. Head. mesosoma, and petiole dark bluish green, cheek with strong purple reflections, mesoscutum with iridescent green reflections, scutellum with strong green reflections, mesosoma laterally with weak green to blue reflections; propodeum bluish laterally, midline of propodeum and frenal area purple. Gaster, coxae, and femora basally dark brown with faint reddishblue reflections; pedicel and flagellum dark brown; scape. trochanters, apex of femora, and rest of legs yellowish brown; mandible dark brown. Wings hyaline, venation pale brown.

Head $1.4-1.5 \times$ as broad as mesosoma; occiput weakly emarginate; lateral ocellus close to occiput, separated by less than own radius; LOL $0.7-0.9 \times$ OOL. Face relatively flat, frons broadly impressed midway between toruli and lower margin of eye, face and vertex finely reticulate: scrobal depression narrow and shallowly impressed above toruli, weakly reticulate, and including median ocellus; temple minute postcrior to eye; occiput glabrous, occipital carina absent but vertex at occiput sharp. Eycs separated by $2.8-3.1 \times$ their height. Malar space $1.4-1.6 \times$ height of eye, malar depression shallow, obliterated close to cyc. Clypeus and supraclypeal area wcakly rugulose, lateral margin, tentorial pit, and epistomal sulcus very decply impressed, anteclypeus slightly rounded apically. Maxilla and labium saclike with larger sclerites adpressed to membranous sac, no palpi apparent. Antenna 11 -segmented; scape stout and cylindrical, reaching top of median ocellus; pedicel globular; anellus slightly broader than long; flagellum 1.5-1.7× height of head: funicular segments moderately setose, smooth with numerous MPS; F2 $0.4 \times$ as long as scape, F2 2.4-3.0 $\times$ as long as broad. following segments subequal in length. equal in widtlı: clava clongate and cylindrical, as long as preceding 2 segments.

Mesosoma with mesoscutum, including lateral lobe. fincly reticulate to coriaceous: axilla coriaccous to fincly carinate posteriorly: scutellum excluding frenal area finely striate with carinate converging on posterior midline.
Mesoscutum with midlobe subtriangular; notaulus broadly and deeply impressed. SSS finely carinate. Scutellum as long as broad, posterior margin of axilla declivous. and scutellum on distinctly lower level than mesoscutum; frenal line narrow, frenal area abrupt and rugulose; axillula not distinguishable; axillular sulcus absent, axillular area evenly sculptured laterally. Propodeal disc rounded, with irregular vertical carinae and verrucose surface sculpture: callus and metepimeron slightly swollen and glabrous, callus divided into anterior and posterior region by dorsal extension of metepimeral sulcus; postspiracular and metepimeral sulci broadly impressed and coriaceous to smooth. Upper mesepimeron glabrate, lower mesepimeron and mesepisternum finely reticulate to coriaceous, glabrous ventrally. Prepectus triangular and coriaceous, sharply angled to midline from edge of mesoscutum. Proepisternum coriaceous. Coxae glabrate: femora weakly imbricate to smooth with fine short adpressed setae apically; hind tibia slender with fine adpressed setae, narrowed apically. Forewing $3.0 \times$ as long as mesothorax, 1.9-2.1× as long as broad; bare along impression of cubital vein; costal cell relatively broad and pilose; disc with small hairs; marginal vein $0.23-0.26 \times$ as long as forewing and thickened along entire length: stigmal vein broad and slightly angled distally, almost twice longer than broad; postmarginal vein narrow, twice as long as stigmal vein.

Metasoma with petiole $0.9-1.3 \times$ as long as hind coxa, $0.8-1.5 \times$ as long as propodeum; petiole subtriangular in cross-section, weakly carinate to glabrate dorsally, and coriaceous ventrally. $\mathrm{Mt}_{2} 0.5 \times$ as long as hind femur. glabrate with sparse micropunctuation: $\mathrm{Ms}_{2}$ with constriction sharp and smooth. Hypopygium with few short sublateral setae at apex. Ovipositor subapically expanded and strongly curved; first valvula with weak subapical ridge, several fine lateral teeth beyond subapical ridge; second valvula with 9 strong transverse coalescing ridges apically (Fig. 99). Sheath broad at apex, gonostylus separated at base.

\section{MALE}

Length, $2.7 \mathrm{~mm}$. Colour and sculpture as in female Antenna 11-segmented (Fig. 100); ancllus as long as broad; otherwise antemna as in female and lightly sculptured. Petiole $1.8 \times$ as long as hind coxa, $1.7 \times$ as long at propodeum: petiole cylindrical at base and dorsoventrally flattened at apex, weakly coriaccous to smooth with weak median carina dorsally along most of length, apex of petiole emarginate dorsally and separated from $\mathrm{Mt}$, by semicircular membrane. $\mathrm{Mt}_{2}$ and $\mathrm{Ms}$, as in femate. Ms. enlarged and broadly rounded with sparse, short setac. Genitalia large (Fig. 103), basiparamere broad and truncatc apically with sharp median process. paramere long and broad. weakly sclerotized: acdeagus broadly rounded. 


\section{ISTRTHLTIO)}

Eastem and southern Africa (S, Fig. 276).

\section{ETYMOI.OCFY}

From Lattin stria and soma; referring to the striate scutellum.

\section{Orasema fraudulenta (Reichensperger) comb. nov.}

Psilogaster fraudulentus Reichensperger, 1913:211-214, figs. 1-m. 12. Ethiopia: Harrar [ZFMK, examined].

\section{TYPE MATERIAL}

Lectotype (here designated), $q$, "Psilogaster/ fraudulentus/ n. sp./ Type! R." "bei Pheidole/ megaceph./ Fab." "TYPUS." "Harrar, Abesi./ V/ Kristensen." "Coll. Reichensperger." "Museum Koenig BONN." Female with head and antennae enclosed in pupal exuvium and wings missing. mounted on same card with males and ant host; female between 2 males. Paralectotypes: 2 ot $\delta$ and 2 pupae of both sexes, mounted on same card as holotype.

\section{DIAGNOSIS}

Distinguished from $O$. striatosoma by having the scutellum finely reticulate, and basal area of the forewing bare.

\section{FEMALE}

Length, $2.9 \mathrm{~mm}$. Dark metallic blue-green with faint iridescent reflections; mesosoma with bluish reflections sublaterally; gaster dark brown with faint purple or green reflections; antenna pale brown; coxae and most of femora dark brown with greenish reflections; trochanters, apex of femora, and rest of legs yellowish brown. Wings hyaline, venation pale brown.

Head $1.5 \times$ as broad as mesosoma; occiput slightly rounded; lateral ocellus close to occiput, separated by less than own radius; LOL $0.8 \times$ OOL. Face relatively flat. frons broadly impressed midway between toruli and lower margin of eye, face and vertex finely reticulate; scrobal depression narrow and shallowly impressed above toruli, weakly reticulate, and including median ocellus. with deep pit below median ocellus; temple narrow and weakly sculptured; occiput glabrous, occipital carina weak or absent, vertex at occiput sharp. Eyes separated by $2.6 \times$ their height. Malar space $0.7 \times$ height of eye, malar depression absent. Clypeus weakly reticulate, lateral margin of clypeal area, tentorial pit, and basal groove deeply impressed, anteclypeus slightly rounded. Maxilla and labium elongate, no palpi apparent. Antennal segments not discernible within pupal cxuvium; flagellum $1.3 \times$ height of head; flagellomeres densely setose. smooth with sparse MPS.

Mesosoma with dorsum finely reticulate, including lat- eral lobe of mesoscutum and axilla. Notauli and SSS narrowly impressed and weakly foveate. Scutellum slightly longer than broad, posterior margin of axilla rounded, and scutcllum below level of mesoscutum; frenal line a narrow glabrous band, not impressed, frenal area finely rugulose; axillular sulcus absent, axillula longitudinally carinate. Propodeal disc rounded, finely reticulate-rugulose; postspiracular and metepimeral sulcus narrow and shallow; callus divided into anterior and posterior regions by dorsal extension of metepimeral sulcus; callus swollen and glabrous, metepimeron weakly sculptured. Upper mesepimeron weakly reticulate, lower mesepimeron and mesepisternum finely reticulate, glabrous ventrally. Prepectus and pronotum finely reticulate, prepectus weakly angled to midline below mesoscutum. Proepisternum finely reticulate, strongly swollen and smooth posteriorly. Coxae weakly coriaceous to smooth; hind femur imbricate; hind tibia stout along entire length, slightly narrowed apically. Forewing $2.4 \times$ as long as mesothorax, $2.0-2.1 \times$ as long as broad; basal area and costal cell bare; disc moderately pilose with short hairs; marginal vein $0.26 \times$ as long as forewing and thickened along entire length; stigmal vein broad and slightly angled distally. slightly longer than broad; postmarginal vein elongate and broad, $0.5 \times$ as long as marginal vein.

Metasoma with petiole $0.9 \times$ as long as hind coxa, $0.8 \times$ as long as propodeum; petiole cylindrical and slightly flattened dorsoventrally at apex, aciculate to smooth apically. $\mathrm{Mt}_{2} 0.5 \times$ as long as hind femur, glabrate with sparse minute piliferous punctures; $\mathrm{Ms}_{2}$ strongly constricted, furrow glabrous, anterior region circular. Hypopygium bare except for short hairs at apex. Ovipositor subapically expanded and curving slightly cephalad; first valvula with subapical ridge and lateral line of 6 teeth (second valvula withdrawn). Gonostylus broad and separated at base.

\section{MALE}

Length, $3.0 \mathrm{~mm}$. Generally agrees with female.

Head $1.5 \times$ as broad as mesosoma; LOL $0.8-1.0 \times$ OOL. Eyes separated by $2.7-2.9 \times$ their height. Malar space 1.2-1.4x height of eye. Antenna 11 -segmented; scape stout and cylindrical, slightly narrowed at apex, reaching top of median ocellus; pedicel subconate; anellus slightly broader than long; flagellum $1.8-1.9 \times$ height of head; funicular segments moderately setose and lightly sculptured; F2 0.6× as long as scape, F2 2.8× as long as broad; following segments subequal in length, equal in width; clava elongate and cylindrical, as long as preceding 2 segments.

Mesosoma more slender than in female.

Metasoma with gaster elongate, glabrate; $\mathrm{Mt}_{2} 1.1 \times$ as long as hind femur. $\mathrm{Ms}_{8}$ small, rounded, and sparsely setose. Genitalia relatively small, basiparamere truncate, 
and apex with sharp median process; paramere long. broad, and poorly sclerotized with few elongate setae on outer margin; aedeagus broadly rounded.

\section{BIOLOGY AND IMMATURE STAGES}

The type material was taken from a nest of Pheidole megacephala Fab. The pupa of this species is similar to that of other Orasema, and includes 3 nodules along the dorsal margin of the petiole, and a series of raised ridges and nodules along the tergal lines of the gaster (Reichensperger, 1913). Reichensperger refers to the "mittlere Larvenstadium" as attaching to the prosternal region of the Pheidole larva. He stated that the larva is similar to that described for Orasema (Wheeler, 1907) with a series of nodules along the body segments on each side.

\section{DISTRIBUTION}

Ethiopia and Yemen (F, Fig. 276).

\section{MATERIAL EXAMINED}

ETHIOPIA [Abyssinia]: Harrar ( $2 q q$. USNM). YEMEN [W Aden Prot.]: Wadi Dareija, SW of Dhala, ca. $1500 \mathrm{~m}$. 28.ix.1937, H. Scott and E. B. Britton (1 oे, 1 ? ठै [abdomen missing], BMNH).

\section{Orasema koghisiana-group}

This is a monobasic group and is peculiar among Old World Oraseminae in that the face is smooth and relatively flattened, and the labrum has 6 to 8 elongate digits (usually 4 in other orasemine taxa) (Figs. 189-190). It is unusual within Orasema by possession of a prepectus that is narrowed ventrally and with the medial area almost glabrous (Fig. 219), the sternaular area reticulate, and the mesepisternum not strongly swollen.

\section{Orasema koghisiana sp. nov.}

Figs. 107-108, 110, 189-190, 211-212, 219, 236, 247

\section{TYPE MATERIAL}

Holotype, + , "NEW CALEDONIA:/ Muns des Koghis/ 400-600 m, I.1969." "N. L. H. Krauss/ Collector/ BISHOP MUSEUM." "HOLOTYPE/ Orasema/ koghisiana Heraty." Deposited in BPBM.

Paratypes: New Caledonia: Mtns des Koghis, 400-600 m, i.1969 (17ठむ), ii.1973 (2ठす), N. L. H. Krauss (BPBM); same data, 200-400 m, i.1969 (1 0 . BPBM); Yahoue, ii.1966 (1 ठ̊), ii.1978 (l ठै). N. L. H. Krauss (BPBM). New Hebrides: Efate Is.: Vila, 0-200 m,

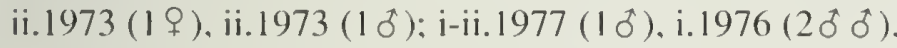

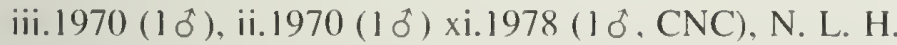
Krauss (all but 1, BPBM); Epi Is.: Vaemali. 100-150 m. 6-10.viii.1967, J. and M. Sedlacek (1 9 , wings and antennae on slide no. 9574 BPBM); Lowekewou, 0-100 m, 31.viii.1979. W. C. Gagne, G. M. Nishidai, and G. A. Samuclson (1 $9.10+$, BPBM): Ambrym Is.: Ranon to Mt Toyo, 0-500 m, 2.ix.1979. Gagne. Nishida, and Samuclson (1 8 , BPBM); Erromango Is.: Dillon Bay, $0-100 \mathrm{~m}$, iii.1978, N. L. H. Krauss (I 8 . BPBM): Maewo Is.: Sounwari, $15^{\circ} 23 \mathrm{~S} 168^{\circ} 07 \mathrm{E},(0-360 \mathrm{~m}, 4-5 . \mathrm{ix} .1979$, Gagne. Nishida, and Samuclson ( 8 б, BPBM): Malckoula Is.: Port Sandwich (10. BPBM): Santo Is.: Matantas. $0-100 \mathrm{~m}, 11 . i \times .1979, \mathrm{G} . \mathrm{M}$. Nishida and G. A.
Samuelson (1 $\delta$, BPBM); Tongariki Is.: 0-300 m, 29.viii.1979, G. M. Nishida (3 ठै ठै. BPBM); Vanoua Lava Is.: Sola to Chelva Riv., 0-260 m, 16.ix.1979, Nishida and Samuelson (1 0 , BPBM).

\section{DIAGNOSIS}

Recognized by the following: face (Fig. 189), lateral lobe, and axilla smooth, labrum 6- to 8-digitate, sternaular area reticulate (Fig. 219), and propodeum glabrous laterally (Fig. 247).

\section{FEMALE}

Length, 2.6-3.1 mm. Head and mesosoma glossy green or blue-green with varied patches of reddish reflections: gaster dark brown to black; mesepimeron and propodeum with blue reflections; coxae dark brown with faint greenish reflections: antennal flagellum black: scape and legs yellowish brown. Wings hyaline, venation dark brown.

Head subtriangular, 1.2-1.4x as broad as mesosoma, occiput weakly rounded; lateral ocellus separated from occiput by own radius; LOL $0.7 \times$ OOL. Face broadly rounded, smootl, and polished with scattered fine selae. cheek lightly pitted, frons swollen lateral to scrobal depression: scrobal depression narrow and strongly impressed, each scrobal channel irregularly foveate (Fig. 189): temple narrow and polished; vertex with weak depression along ocellar-ocular groove: occiput aciculate. dorsal margin lightly strigate, not carinate. Eyes separated by $1.6 \times$ their height. Malar space $0.8 \times$ height of eye. malar depression hardly impressed. Clypeus glabrate. cpistomal sulcus weakly impressed: anteclypeus only slightly rounded. Labrum 8-digitate, sctac bristlelike. Mandible moderately stout; palpi 3-segmented. Antennal 11 -segmented; scape slender, reaching median ocellus: pedicel as long as broatl; ancllus present, very small: flatgellum 1.0x height of head: lunicle 7-segmented: segments densely setose, surface smooth. With numeroms 
MPS: F2 $1.8 \times$ als long als broad, following segments subequal in length. equal in width, eatch clearly separated (Figs. 108, 211-212); claval acute, not diflerentiated from funicle.

Mesosoma with midlobe of mesoscutum transversely carinate anteriorly to rugose posteriorly; laterat lobe and axilla glabrous and swollen: scutellum lightly rugulose to glabrate. Notauli and SSS shallow foveate. Scutellum slightly longer than broad, base separated from TSA by small fovea: frenal line narrowly foveate, frenal area glabrous. crescentic in dorsal view; axillula mostly glabrate, axillular sulcus foveate. Propodeal disc glabrous laterally, narrow median band of alveolate sculpture forming a band dorsally to postspiracular furrow, ventral band deeply foveate; callus polished and rounded, sparsely setose dorsally. Mesepimeron glabrate, transepimeral sulcus weakly foveate: femoral groove broad, weakly carinate anteriorly; sternaular area marked by triangular band of reticulate sculpture. Proepisternum glabrate. Coxae glabrate, mid coxa weakly strigate; femora glabrate, mid and hind femur with fine, dense setae apically. Forewing $2.3 \times$ as long as mesothorax, $2.5 \times$ as long as broad (Fig. 110); basal area and speculum bare; costal cell and disc pilose; stigmal vein broad, only slightly longer than wide; postmarginal vein $5.0 \times$ as long as stigmal vein, reaching half distance to apex of wing.

Metasoma with petiole $1.2 \times$ as long as hind coxa, $1.1 \times$ as long as propodeum; petiole irregularly carinate, with small basal flange. $\mathrm{Mt}_{2}$ longer than hind femur, glabrate; $\mathrm{Ms}_{2}$ with constriction deeply impressed and smooth. Hypopygium with few minute setae. Ovipositor expanded subapically; first valvula with sharp lateral ridge from apex to broadest subapical width (margin of ventral surface that receives second valvula), and 3 to 4 lateral teeth: second valvula broad with several sharp teeth laterally. Gonostylus broad and setose, basal separation not visible in available material.

\section{NALE:}

Length, 2.0-2.6 $\mathrm{mm}$. Colour ats in female except scape and hind femur medially dark brown to black with strong blue-green rellections.

Head $1.4-1.5 \times$ as broad as mesosoma, cheek sparsely punctate; ocelli large, LOL $0.7-1.0 \times$ OOL; occipital carinat presemt or absent (obscured with occipital carinac). Labrum 6- to 8-digitate. Mandible moderately stout: palpi 3-segmented. Antenna 11-segmented; flagellum 1.3-1.4x height of head; funicle 7-segmented, MPS dense.

Mesoscutum with midlobe finely alveolate to scabriculous with faint indication of transverse carinae; scutellum rugose: frenal area abrupt apically. Forewing $2.1-2.2 \times$ as long as broad; stigmal vein $1.0-1.5 \times$ as long as broad, almost perpendicular or distinctly angled distally.

Petiole 1.9-2.7x as long as coxa, 1.9-2.4x as long as propodeum; irregularly carinate with verrucose surface sculpture. $\mathrm{Mt}_{2}$ as long as hind femur. Genitalia elongate, paramere with long subapical seta, basiparamere with sharp median process; aedeagus broad.

\section{VARIATION}

Specimens from New Caledonia and New Hebrides are considered conspecific although there is some minor variation. Specimens from the New Hebrides differ in having the head of females 1.3-1.4× as broad as the mesosoma (versus $1.2 \times$ in New Caledonia), and the mesosoma dorsum with stronger sculpture (scutellum rugose and axilla weakly carinate).

\section{DISTRIBUTION}

New Caledonia and Hew Hebrides (K, Fig. 276).

\section{ETYMOLOGY}

Named after the lype locality, Mount Koghis.

\section{Orasema glabra-group}

This monobasic group is recognized by the completely smooth head (Figs. 126-127), scrobal depression with parallel channels, occipital carina absent, propodeum evenly rugose, basal area of the wings and speculum bare. and first valvula with 9 or 10 minute lateral tecth. Somc features are shared with the $O$. coloradensis-group of species found in the New World.
Orasema glabra sp. nov.

Figs. 119, 125-128, 130, 132

\section{TYPE MATERIAL}

Holotype, ‥ "S. AFRICA; Transvaal/ 15 km E. Klaserie/ 18-31.XII.1985/ H. and A. Howden." "HOLOTYPE/ Orasema/ glabra Heraty." Deposited in CNC.

Paratypes: Soutu Africa: Cape Province: Somerset East [?], 27-31.i. 1931, R. E. Turner (I \&, BMNH): Transvaal: Klaserie. 15 km E, Guernsey Farm, 19-31.xii.1985, W. Mason (1 9, CNC): same locality, 19-31.xii.1985, M. Sanborne, yellow pan trap ( 19 , slide no. 943, CNC). 


\section{DIAGNOSIS}

Recognized by the following: face, lateral lobe, axilla, posterior half of scutellum, and frenal area glabrous (Figs. 127, 130). Distinguished from species in the ralgius- and assectator-groups by the following: propodeal disc evenly rugose and relatively flat, mid coxa without a mid-ventral sulcus, and petiole short $(0.9-1.2 \times$ as long as hind coxa) (Fig. 126).

\section{FEMALE}

Length, 2.2-2.5 mm. Head, mesosoma, and petiole black. head and mesosoma laterally with blue to purple reflections, mesosomal dorsum with green reflections; gaster dark brown; pedicel, flagellum, and femora dark brown; scape, apex of femora, and rest of legs yellowish brown. Wings hyaline, venation pale yellowish brown.

Head subtriangular $1.1 \times$ as broad as long (Fig. 127), 1.2-1.3 $\times$ as broad as mesosoma; occiput transverse; LOL 1.4-1.9 $\times$ OOL. Face broadly rounded, smooth and polished with scattered minute pits; scrobal depression narrow, lateral margin broadly rounded medially with 2 impressed vertical channels ending in shallow pit about $0.6 \times$ distance to median ocellus (Fig. 127); temple broad and weakly aciculate; no ocellar-ocular depression; occiput aciculate, dorsal margin broadly rounded, occipital carina absent. Eyes separated by $1.4-1.5 \times$ their height. ocular groove narrow and smooth. Malar space $0.6 \times$ height of eye, malar depression broad and shallow. Clypeus transverse and glabrate, lateral margin and epistomal sulcus shallowly impressed, anteclypeus subtruncate. Labrum 4-digitate. Mandible moderately stout. palpi 3-segmented. Antenna 11-segmented; scape stout and cylindrical, reaching $0.7 \times$ distance to median ocellus: pedicel $1.7 \times$ as long as broad, slightly broader than anellus at apex; anellus small; flagellum $0.9-1.0 \times$ height of head; funicle 7-segmented, segments densely setose with numerous MPS; F2 1.4× as long as broad, following segments subequal in length, and slightly increasing in width: clava conate, slightly longer than preceding 2 segments.

Mesosoma with midlobe of mesoscutum and scutcllum finely reticulate; lateral lobe and axilla glabrous, lateral lobe strongly swollen, axilla rounded (Fig. 130). Mesoscutum with notauli deeply impressed and crenulate.
SSS foveate. Scutellum as long as broad, separated at base from TSA by narrow foveate SSS; frenal line narrowly and shallowly impressed, frenal area semicircular and glabrous; axillula glabrate, axillular sulcus foveate and prominent. Propodeal disc evenly rugose, subtriangular, and relatively flat; postspiracular and metepimeral sulci narrowly impressed and without transverse carinae; callus and metepimeron glabrous. callus with several short setae. Mesepimeron glabrate, transepimeral sulcus shallow; femoral groove obscure; mesepisternum reticulate laterally, glabrate anteriorly and ventrally. Prepectus reticulate. Pronotum glabrate with irregular medial line. Proepisternum smooth. Coxae and femora smooth to weakly imbricate; hind femur moderately setose dorsally. Forewing $2.4 \times$ as long as mesothorax, $2.4-2.6 \times$ as long as broad; basal area and speculum bare: costal cell relatively narrow; rest of wing moderately pilose: stigmal vein more than twice as long as broad. perpendicular to wing margin; postmarginal vein $0.35-0.4 \times$ as long as marginal vein, reaching less than half distance to apex of wing.

Metasoma with petiole $0.9-1.2 \times$ as long as hind coxa, $0.8-1.0 \times$ as long as propodeum: petiole granulate, with strong basal flange (Fig. 132). $\mathrm{Mt}_{2} 1.1-1.4 \times$ as long as hind femur, glabrate: $\mathrm{Ms}_{2}$ constriction abrupt and rugulose. Ovipositor subapically expanded and gently curved forward; first valvula strongly excavated ventrally, notched subapically beyond subapical crest, with strong lateral ridge from ventral margin of crest to dorsal medial margin, several fine lateral teeth beyond subapical crest, apex finely aciculate; second valvula broad and smooth with several strong lateral teeth (Fig. 128). Gonostylus narrow, setose apically, and distinctly separated from second valvifer.

\section{MALE}

Unknown.

\section{DISTRIBUTION}

South Africa (G. Fig. 276).

\section{ETYMOLOGY}

Name refers to the glabrous face and mesosomal dorsum.

\section{Orasema assectator-group}

The differences between species of this group are small and more material is necessary to verify the stability of character states described. It is noteworthy that both Orasema assectator and $O$. imitiator were found ovipositing on leaves of tea, and $O$. assectaror was reared from Pheidole sp. nesting under a tea plant. Possibly the present Ethiopian/Indo-Chinese distribution of this group may be a recent event associated with the movement of tea throughout the region. Similarity of this group to species of the Orasema bakeri-group in the New World is based on the following: mesosoma and propodeum evenly reticulate. callus bare, stigmal vein narrow and perpendicular, postmarginal vein short, wings hyaline, and petiole short. 


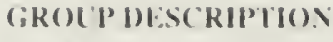

Face completely reticulate; occipital carina absent; without ocellar-ocular depression. Malar depression absent. Antennal 11-segmented and funicle 7-segmented in both sexes. Mesosoma completely reticulate dorsally including lateral lobe and axilla: axillular sulcus absent and axillula indistince from scutellum: callus swollen and glabrous; lower mesepimeron reticulate. Forewing hyaline; basal area and speculum bare; disc moderately setose; stigmal vein narrow and elongate, perpendicular to wing margin or nearly so: postmarginal vein poorly defined and usually less than $0.3 \times$ als long as marginal vein. Petiole $0.8-1.5 \times$ as long as hind coxa in females, $1.7-2.3 \times$ as long as hind coxa in males, with basal flange. Ovipositor expanded, subapical ridge broadly rounded; first valvula with lateral line of several minute teeth from apex to ridge. Gonostylus setose, separated at base from second valvifer.

\section{Orasema assectator Kerrich}

Figs. 111-112

Orasema assectator Kerrich, 1963:367-368. India: Assam [BMNH, examined].

\section{TYPE MATERIAL}

Holotype, 오. “ASSAM/ Tocklai/ 1962/ Ex Ants/ CIE. 18496 [744/5 on left end]." "Type." "Orasema female/ assectator sp. n./ G. J. Kerrich det 1963/ HOLOTYPE." "B.M. TYPE/ HYM./ 5.2066."

Paratypes: $89 q$ (BMNH), 4 우 (USNM), same data, or with "on tea" instead of "ex ants" and CIE No. 18869.

\section{DIAGNOSIS}

Differs from other species in the assectator-group by: head slightly transverse (Fig. 112), supraclypeal area glabrate [stated as finely reticulate in original description]. mesoscutum broadly rounded anteriorly (Fig. 111), axillular sulcus indistinct and scutellum rounded laterally. propodeal disc evenly sculptured and without median carina, pronotum without lateral prominence below spiracle, and coxac completely reticulate. Orasema assectator is known only from the type locality and this may only be a small form of $O$. initiator. However, the differences listed here are distinctive.

\section{FEMALE}

Length, 1.5-1.9 mm. Head, mesosoma, and petiole dark blue; gaster dark brown with faint metallic sheen; femora brown medially with faint metallic reflections: antenna, apex of femora and rest of legs yellowish brown, flagellum slightly darker. Wings hyaline, venation clear.

Head slightly transverse with large eyes, 1.3-1.4x as broad as high, 1.1-1.3x as broad as mesosoma: occiput broadly rounded; lateral ocellus almost touching occipital margin; LOL 1.4-1.9x OOL. Face relatively flat, reticulate; scrobal depression shallow, lateral margin rounded and glabrate, weakly sculptured medially; vertex more fincly reticulate than face; temple narrow and coriaceous; occiput coriaceous, dorsal margin abrupt. Eyes separated by $1.6-1.8 \times$ their height. Malar space $0.7-0.8 \times$ height of eye. Clypeus and supraclypeal area glabrate and slightly swollen, tentorial pits deep, lateral margin of clypeus shallowly impressed, frontogenal sulcus parallel and meeting middle to outer margin of torulus. Labrum 4-digitate. Mandible moderately stout; maxilla and labium large, maxillary palpus 3-segmented and enlarged, labial palpus 1-segmented and elongate. Antenna 11-segmented; scape cylindrical, reaching $0.7 \times$ distance to median ocellus; pedicel subconical; anellus large; flagellum 1.2-1.4x height of head; funicular segments sparsely setose basally to densely setose apically, with numerous MPS; F2 $0.5 \times$ as long as scape, F2 $1.3-1.8 \times$ as long as broad, following segments subequal in length, equal in width; clava ovate, slightly longer than preceding 2 segments.

Mesosoma with dorsum completely and finely reticulate including scutellum and axilla; lateral lobe of mesoscutum coriaceous or more finely reticulate than rest of dorsum. Mesoscutum with midlobe subtriangular with anterior margin broadly rounded; notauli narrowly and deeply impressed. SSS foveate. Scutellum slightly longer than broad, widely separated at base from TSA by single shallow medial extension of SSS; frenal line forming narrow glabrous band dorsally, frenal area finely rugulose to reticulate; axillula reticulate. Propodeal disc slightly rounded, reticulate; postspiracular furrow and metepimeral sulcus shallow and broadly impressed; callus slightly swollen, glabrous laterally with small callar nib: metepimeron reticulate. Upper mesepimeron weakly coriaceous. lower mesepimeron and mesepisternum reticulate, glabrous anteriorly and ventrally, transepimeral sulcus shallow foveate; femoral groove obscure. Prepectus triangular and reticulate. Pronotum finely reticulate. even dorsally and without any prominence. Proepisternum reticulate. Fore and mid coxa umbilicate, hind coxa reticulate; hind femur weakly coriaceous. broad and slightly flattened. Forewing $2.5 \times$ as long as mesosoma, 2.5-2.6x as long as broad: basal area and speculum bare. costal cell with few setae in single medial line; stigmal vein narrow and twice as long as broad, very slightly angled distally: postmarginal vcin indistinct, about twice length of stigmal vein.

Metasoma with petiole $0.6-0.8 \times$ as long as hind coxa, $0.6-0.8 \times$ as long as propodeum; petiole cylindrical and $1.5 \times$ as long as broad, verrucose. $\mathrm{Mt}_{2} 0.8-1.0 \times$ as long as hind femur, glabrous: $\mathrm{Ms}_{2}$ with constriction sharp lateral- 
ly. Second valvula of ovipositor broad with more than 10 strong teeth along lateral margin, transverse ridges extending medially from base of teeth but not complete.

\section{MALE}

Unknown.

\section{VARIATION}

Two specimens from southern India (Yercaud, 7.vi.1982, G. J. Spencer, 1 \% , CNC) and Sri Lanka (Nugegoda Prov., 7.vii.1970, P. B. Karunaratne, I 9, CNC) are similar to the type material of $O$. assectator. The Sri Lankan specimen is more distinctly rugulose than described for $O$. assectator, it has a broader mesosoma and is more similar to $O$. initiator or $O$. nigra. The south Indian specimen has more complete reticulate sculpture, the scutellum flattened dorsally, axillula glabrous, and the axillular carina conspicuous as compared to other species in which the scutellum is broadly rounded laterally. The shape of the head, antenna. sculptured mesepimeron, and short petiole are consistent and are considered diagnostic. Both specimens have a body length of $2.8 \mathrm{~mm}$ and the forewing is only $2.2 \times$ as long as broad. These specimens are considered as closer to $O$. assectator than to $O$. initiator and emphasize the small differences between the 2 species.

\section{BIOLOGY}

The biology of this species was described by Das (1963) and Kerrich (1963). Females deposit their eggs into punctures on the underside of tea leaves. Secondary fungal infections of oviposition punctures resulted in Sewing Leaf Blight on tea (Das. 1963). Larvae were associated with immature stages of Empoasca flavescens (Fabr.) (Hemiptera), which were presumed by the authors to be the intermediate host necessary to gain access to the ant nest. Orasena assectator was reared from a species of Pheidole. Larval and pupal stages were described by Das (1963) and are typical for Orasema.

\section{DISTRIBUTION}

Known only from northeastern India, with questionable records from southern India and Sri Lanka (A, Fig. 276).

\section{Orasema nigra sp. nov.}

Figs. 113-116

\section{TYPE MATERIAI,}

Holotype, \&, "Roy. Natal Natl. Park/ 1.24.71 So. Africal H. and M. Townes." "HOLOTYPE/ Orasema/ nigra Heraty." Deposited in AEI.

Paratypes: SoUtil AFriCA: Natal: Royal Natal N. P.. 27.i.1971. H. and M. Townes (2q 9 . AEI). UGanidA: Kawanda, 30.iv[?].1963. D. J. Greathead, ex Leucoptere sp. [with large handwritten "?"] on coffee arabica (10, $\mathrm{BMNH}$ ).

\section{DIAGNOSIS}

Differs from other species in the assectator-group by: head subtriangular (1.3 $\times$ as broad as high; Fig. 114), supraclypeal area reticulate, mesoscutum broadly rounded anteriorly, propodeal disc weakly sculptured with median carina, pronotum even and without lateral prominence, and coxa weakly coriaceous basally to glabrate apically.

\section{FEMALE}

Length. $2.5 \mathrm{~mm}$. Head and mesosoma dark bluish black. gaster dark brown; flagellum dark brown; coxae and femora black; scape, apex of femora and rest of legs yellowish brown. Wings hyaline, venation pale brown.

Head subtriangular (Fig. 114), 1.3× as broad as high. $1.2-1.3 \times$ as broad as mesosoma; occiput broadly emarginate: lateral ocellus separated from occiput by own radius: LOL 1.0 $\times$ OOL. Face broadly rounded, completely reticulate; scrobal depression narrow, lateral margin broadly rounded, coriaceous medially; temple relatively broad and coriaceous: occiput weakly aciculate; vertex rounded. Eyes separated by $1.9-2.0 \times$ their height. Malar space $0.8-0.9 \times$ height of eye. malar depression broad and vaguely impressed (Fig. 115). Clypeus weakly sculptured, supraclypeal area minutely reticulate, tentorial pit strongly impressed, lateral margins of clypeal area shallowly impressed. Labrum 4-digitate. Mandible moderately stout; maxilla and labium large, maxillary palpus clongate and 3-scgmented, labial palpus elongate and 2-segmented. Antenna 11-segmented; scape slender and cylindrical. reaching $0.7 \times$ distance to median ocellus; pedicel globose: anellus glabrous and small: flagellum $1.1 \times$ height of hearl: funicular segments moderately sctose with numerous MPS; F2 $0.5 \times$ as long as scape, $2.0 \times$ as long as broad, F3 slightly longer than broad, following segments subequal in length and slightly broader; clava ovate, as long as preceding 3 segments.

Mesosoma quadrate in profile; dorsum finely reticulate. Mesoscutum with mid and lateral lobes broadly rounded anteriorly: notauli and SSS narrow, decply impressed, and crenulate. Scutellum slightly longer than broad, broadly separated from TSA at base by deep fovea, both scutellum and frenal arca rounded in profile: frenal area vaguely separated by indistinct frenal line; axillula oblicuely carinate, axillular sulcus indistinct. Propodeal disc broadly rounded, weakly reticulate, median area areolate with irregular vertical carina: postspiracular furrow broad and foveate: callus and metepimeron swollen and glabrous: metepimeral sulcus narrowly impressed. Mesepimeron glabrous. transepimeral sulcus foveate: femoral groove narrow and foveate; mesepisternum fincly reticulate, glabrous mid-ventrally and anteriorly. 
Prepectus triangular, glabrate ventrally and deeply foveate dorsally. Pronotum and proepisternum coriaceous. Coxac coriaccous basally, smooth apically; hind lemur smooth ventrally, coriaceous mid-dorsally, and sparsely setose. Forewing $2.5 \times$ as long as mesothorax, 2.2-2.3x as long as broad; basal area and speculum bare except few sparse setae: costal cell with sparse medial band of sclac; disc of wing moderately setose; stigmal vein narrow, $3.0 \times$ as long as broad, almost perpendicular to wing margin; postmarginal vein $2.0 \times$ as long as stigmal vein.

Metasoma with petiole $1.0-1.5 \times$ as long as hind coxa (Fig. 113), 1.0-1.5x as long as propodeum; petiole cylindrical, weakly rugose-carinate. $\mathrm{Mt}_{2} \mathrm{I.1} \times$ as long as hind femur, glabrate; $\mathrm{Ms}$, constriction sharp and weakly crenulate laterally. Ovipositor (Figs. 113, 116); second valvula broad and glabrous with several strong leeth along lateral margins, connected dorsally by weak transverse ridges.

\section{MALE}

Length, ca. $1.5 \mathrm{~mm}$ (head missing). Colour, sculpture, and wings as in female. Propodeum glabrate with median carina. Petiole $2.0 \times$ as long as hind coxa, $2.2 \times$ as long as propodeum. Genitalia difficult to discern on specimen but apparently typical for genus.

\section{BIOLOGY}

Unknown. The association with Leucoptera (Homoptera: Diaspididae) for I specimen is unlikely, and it was probably collected together with the host plant.

\section{DISTRIBUTION}

South Africa (Natal) and Uganda (N, Fig. 276).

\section{Orasema initiator Kerrich}

Figs. 117-118, 191, 220, 237, 260-261

Orasema initiator Kerrich, 1963:368. India: Assam

[BMNH, examined].

\section{TYPE MATERIAL}

Holotype, ๆ. "ASSAM/ 1955/ G. M. Das/ C.I.E. Coll/ 14226 [S.N.9 on right end, Reg 987/4 on left end]." "Orasema sp. \&/ G. J. Kerrich det 1955/ HOLOTYPE." "B.M. TYPE/ HYM./ 5.2067."

Paratypes: sume data as holotype $[2 \%+. \mathrm{BMNH}]$.

\section{DIAGNOSIS}

Differs from other species in the assectator-group by: head subtriangular (1.2-1.3x as broad as high) (Fig. 191). supraclypeal and clypeal area glabrous and narrowed at toruli. mandibles slender with long subapical teeth, midlobe of mesoscutum with anterior lateral corners promi- nent (Fig. 237), propodeal disc weakly sculptured with median carina, pronotum sometimes with conical prominence just below spiracle (Fig. 237, arrow), and coxae coriaceous basally to glabrate apically.

\section{FEMALE}

Length, 2.1-2.8 mm. Body black; pedicel and flagellum dark brown; coxac and femora (including trochanters) black; scape, apex of femora and rest of legs yellowish brown. Wings hyaline. venation clear.

Head subtriangular, 1.2-1.4x as broad as high, $1.2-1.5 \times$ as broad as mesosoma; occiput broadly emarginate; lateral ocellus separated from occiput by less than own radius; LOL 1.3-1.7× OOL. Face weakly rounded, reticulate; scrobal depression narrow, lateral margin rounded and glabrous, weakly coriaceous medially; vertex more finely reticulate posterior to line drawn across vertex between median and lateral ocelli; temple narrow and coriaceous; occiput coriaceous, dorsal margin abrupt. Eyes separated by $1.6-1.8 \times$ their height. Malar space $0.6-0.9 \times$ height of eye. Clypeus and supraclypeal area glabrous and swollen, tentorial pit strongly impressed, lateral margin of clypeal area shallowly impressed, frontogenal sulcus converging to inner margin of torulus. Labrum 4-digitate. Mandible slender with elongate subapical teeth (Fig. 191): maxillary palpus 3-segmented and stout, labial palpus 2-segmented. Antenna 11 -segmented; scape cylindrical, reaching $0.9 \times$ distance to median ocellus; pedicel globular; anellus small; flagellum $1.1-1.2 \times$ height of head: funicular segments densely setose and reticulate; F2 $0.4 \times$ as long as scape, F2 1.4-1.5x as long as broad, following segments subequal in length. equal in width; clava ovate, as long as preceding 3 segments.

Mesosoma robust, dorsum finely reticulate. lateral lobe of mesoscutum and axilla weakly reticulate, scutellum rugose-reticulate. Mesoscutum with midlobe subtriangular, anterior latcral corners sharp and protruding: notaulus narrowly and deeply impressed crenulate. SSS crenulate and extending to TSA as united medial furrow; frenal line shallowly impressed. Scutellum as long as broad, widely separated at base from TSA, both scutellum and frenal area rounded in profile, frenal area coriaceous; axillula not distinct from surface sculpture. Propodeal disc broadly rounded, coriaccous with weak median carina; postspiracular and metepimeral sulci broad and irregularly foveate; callus slightly swollen and glabrous, with prominent callar nib: metepimeron glabrous. Upper mesepimeron glabrous; transepimeral sulcus shallow foveate; lower mesepimeron and mesepisternum reticulate, mesepisternum glabrous anteriorly and ventrally: femoral groove obscure. Prepectus triangular and finely reticulate. Pronotum weakly reticulate, sometimes (sce variation) with sharp conical projection below spiracle (prominent in dorsal vicw). Proepisternum coriaceous. 
Coxae coriaceous basally and glabrous apically; femora glabrate. Forewing 2.4-2.6x as long as mesothorax, 2.4-2.5x as long as broad (Fig. 118); basal area and speculum bare; costal cell with sparse medial band of setae; disc moderately setose; stigmal vein narrow and longer than broad, very slightly angled distally; postmarginal vein indistinct, $2-3 \times$ as long as stigmal vein.

Metasoma with petiole $0.7-1.1 \times$ as long as hind coxa. $0.9-1.2 \times$ as long as propodeum; petiole rugose to reticulate, broad and narrowed at base. $\mathrm{Mt}_{2} \mathrm{l} .1 \times$ as long as hind femur, glabrous; $\mathrm{Ms}_{2}$ constriction sharp laterally and smooth. Second valvula of ovipositor broad with several prominent lateral teeth at apex. connected dorsally by weak transverse ridges.

\section{MALE}

Length $1.7-2.3 \mathrm{~mm}$. Colour as in female except flagellum light to dark brown; scape black; tibiae dark yellowish brown to black, hind tibia usually black. LOL 1.1-1.5x OOL. Eyes separated by $1.8-2.1 \times$ their height. Flagellum 1.2-1.4× height of head; funicular segments densely setose, setae semi-erect and giving flagellum distinct fuzzy appearance; F2 1.6× as long as broad, following segments quadrate and beadlike: clava with 2 incompletely fused segments and strong ventral notch. Mesosoma as in female. Forewing small (Fig. 117), 2.0x as long as mesothorax, 1.9-2.1 $\times$ as long as broad; marginal vein $0.27-0.32 \times$ as long as forewing. Petiole $1.7-2.8 \times$ as long as hind coxa, 1.7-2.3x as long as propodeum. Genitalia typical for genus; paramere long with 2 apical setae; aedeagus broadly rounded.

\section{VARIATION}

Little geographical variation exists among males and females for the fine reticulation of the vertex, densely setose antennal flagellum of males, or the presence of a prominent nib on the callus. The conical projection just anterior to or below the mesothoracic spiracle is weak in some specimens although usually evident. In the 1 specimen from Vietnam the projection is weak but the anterior lateral corners of the mesoscutum are prominent. In the specimen from Iriomote Island, the prominence is barely discernible and the midlobe is rounded, but it otherwise fits the description.

\section{DISTRIBUTION}

Known from the Indo-Chinese subregion and ranging from India to the southern Ryukyu islands of Japan (I. Fig. 276).

\section{MATERIAL EXAMINED}

JAPAN: Ryukyu Islands: Iriomote Is., Shira Lama, 7.xi.1963, H. Hasagawa ( $10^{\circ}$, NIAS). TAIwAN: Praomonszu, $2 \mathrm{~km}$ S Keelung, 16.viii.1958, K. S. Lin ( 100 , TARI); Nantou Hsien: Lushan, $1000 \mathrm{~m}$, 27-31.v.1960, K. S. Lin and L. Y. Chou (1 o. TARI): Wushe, 1150 m. 7-8.x.1982. K. C. Chou (1 $9.30^{\circ}$ ơ. TARI): Taichung Hsien: Chiapaotai, $750 \mathrm{~m}$. 14-18.x.1980, K. S. Lin and C. H. Wang (2q $q .10$. TARI); Kukuan, 730 m, 14-17.x.1980, K. S. Lin and C. $\mathrm{H}$. Wang $\left(5 \delta^{\circ} \delta^{\circ}, \mathrm{TARI}\right)$ : Pingtung Hsien: Kenting Park, 22.iii.1980, K. S. Lin (1 9 , TARI). VIETNAM: Di Linh (Djiring), 1200 m, 22-28.iv.1960, L. W. Quate (1 $0^{*}$. BPBM).

\section{Orasema valgius-group}

This group consists of 2 species, $O$. valgius and $O$. synempora, that are closely related based on the following: propodeal dise glabrate laterally with a broad median band of sculpture, mid coxa with a mid-ventral sulcus. postmarginal vein elongate, first valvula with 3 to 4 lateral teeth, and the petiole of female generally longer than in other closely related groups of Orasema $(1.2-1.7 \times$ as long as hind coxa versus $0.9-1.2 \times$ in 0 . glabra and $0.8-1.5 \times$ in the assectator-group).

\section{(iROUP DESCRIPTION}

Face at least partially reticulate, often glabrate below lower margin of eyc. Antenna 11-segmented and funicle 7-segmented in both sexes. Mesosomal dorsum variously sculptured; lower mesepineron glabrous; callus rounded and glabrate. with or without setac: mid coxa with midventral sufcus. Forewing hyaline; basal area and specu- lum bare; disc pilose, forewing with marginal fringe: stigmal vein narrow and clongate. perpendicular to wing margin or angled distally: postmarginal vein well defined and more than $0.4 \times$ as long as marginal vein. Petiole $0.9-1.7 \times$ as long as hind coxa in female, 2.3-3.0x as long as hind coxa in male, the base with dorsal flange. Ovipositor subapically expanded and subapical ridge prominent; first valvula strongly narrowed distal to subapical ridge, with 3-4 minute or large teeth along lateral line. Gonostylus broad and setose, separated at base from second valvifer.

\section{Orasema synempora sp. nov.}

Figs. 121, 123, 129

\section{TYPE NATERIAL}

Ilololype, 9. "15.035S 145.09E/ $3 \mathrm{hm} \mathrm{NE} \mathrm{M/} \mathrm{Webl).} \mathrm{1} \mathrm{-} 3$ (0ct. 1980 Q/ J. C. Cardale/ ex ethanol." "collected/at 
light." "AUST. NAT./ INS. COLL." "HOLOTYPE/ Orasemal synemporal Heraty." Deposited in ANIC.

Paratypes: Austral.1A: Queensland: Ayr, 30 S. 9.ix.1950. E. F. Rick (10. ANIC); Ayr. 65 S. 12.ix.1915. E. F. Rick (2ठ ठ์. ANIC); Bowen, 15 W, 24.ix.1950, E. F. Rick (2ठ․ ANIC): Herberton, 12-23 km W, via Watsonville. I.V.1967. D. H. Colless (2ठ゚. ANIC): Hope Vale Mission, $7 \mathrm{~km}$ N. 4.x.1980, J. C. Cardale (1 0 . ANIC); Maitland Downs, $3 \mathrm{~km} \mathrm{S,} \mathrm{15.iv.1980,} \mathrm{G.} \mathrm{F.} \mathrm{Hevel} \mathrm{and}$ J. A. Fortin ( $1 \delta$, USNM): Mt Webb. $3 \mathrm{~km} \mathrm{NE}$, 1-30.x.1980, J. C. Cardale, at light (30े ơ. ANIC); Normanton, 2-8.iii (3ठㅇ. AEI); Rounded Hill, $5 \mathrm{~km} \mathrm{~W}$ by N, nr Hope Vale Mission, 7.x.1980, J. C. Cardale (2 o o. ANIC); Ellis Beach, $9.3 \mathrm{~km} \mathrm{~N}, 30 . i v, 1 . \mathrm{v}$, 8.v.1990, J. Heraty, on kangaroo grass, (4qq, $24 \delta^{\circ}$, JMH, ROM, TAMU): Ellis Beach, 9.7 km N. 18.iv.1987, E. C. Dahms and G. Sarnes (1 0 . QMB).

\section{DIAGNOSIS}

Distinguished from $O$. valgius by the following: mesosoma robust, lateral lobes of mesoscutum, axilla, and frenal area glabrous (Fig. 129), mesepisternum with a narrow glabrate band ventral and anterior 10 frenal line, and wings with minute setae. Additionally, the flagellar segments are tightly adpressed (Fig. 123), and the callus is glabrous and evenly swollen with no projection.

\section{FEMALE:}

Length, 3.1-3.5 mm. Body dark glossy blackish green with irjescent reflections; pedicel and flagellum black; scape and legs yellowish brown, mid and hind femora infuscate near base, hind femur dark brown with faint metallic lustre in basal half on outer side. Wings hyaline, venation brown.

Head subtriangular, $1.1-1.2 \times$ as broad as long, $1.3 \times$ as broad as mesosoma, LOL $0.7-0.9 \times$ OOL. Face broadly rounded and reticulate, with face below torulus mostly glabrate; scrobal depression narrow and rounded, finely reticulate medially with narrow sublateral glabrous bands; temple relatively broad and aciculate: occiput aciculate. dorsal margin abrupt posterior to ocelli and rounded laterally, occipital carina absent. Eyes separated by $1.5-1.6 \times$ their height. Malar space $0.7-0.8 \times$ height of eye malar depression broald and vaguely impressed. Clypeal area glabrate and swollen, epistomal sulcus weak, tentorial pit deeply impressed, lateral margin of clypeal area shallow, anteclypeus truncate. Labrum 4-digitate. Mandibles with apical tooth reaching base of opposing mandible; palpi relatively long and 3 -segmented, second segment short in both. Antenna I l-segmented; scape stout and reaching 0.7× distance to median ocellus; pedicel subconical; anellus large: flagellum $0.9 \times$ height of head: funicular segments appressed, with short adpressed setae becoming denser toward apex (Fig. 123), MPS numerous; F2 $0.5 \times$ as long als scape, F2 2.0 $\times$ as long as broad, following segments quadrate and equal in length: clava ovate, indistinct from lunicular segments, as long as preceding 2 segments.

Me'sosoma robust and elongate (Fig. 129), 1.3x as long as high, midlobe of mesoscutum and sublateral areas of scutellum weakly reticulate; lateral lobe and axilla swollen and glabrate. Notauli and SSS strongly and narrowly impressed. Scutellum as long as broad, narrowly separated at base from TSA; frenal line weakly impressed and crenulate; frenal area glabrate and semicircular in dorsal view: axillula colliculate, axillular sulcus weakly impressed but distinct. Propodeal disc rounded, laterally glabrous to very weakly punctate, medially with broad reticulate furrow, furrow broader at base and weakly rugulose; postspiracular furrow shallow and irregularly foveate; callus rounded and glabrous; metepimeral sulcus narrow and smooth, extending dorsally as narrow sculptured furrow separating small anterior and large posterior areas. Upper and lower mesepimeron glabrous, transepimeral sulcus sharp; femoral groove reticulate with distinct glabrous band anterior to femoral groove; mesepisternum mostly glabrous, broad sternaular area finely reticulate. Prepectus weakly reticulate to smooth. Pronotum mostly glabrate. Proepisternum weakly colliculate along anterior and lateral margins, mostly glabrous. Coxae and femora mostly glabrous. femora apically with weak imbricate sculpture and dense minute setae, mid coxa with longitudinal mid-ventral groove. Forewing $2.0 \times$ as long as mesothorax, $2.5 \times$ as long as broad; basal area and speculum bare, costal cell narrow and with only few scattered and minute setae; disc with dense, minute setae; marginal vein $0.3 \times$ as long as forewing; stigmal vein narrow and more than twice longer than broad, slightly angled distally; postmarginal vein elongate. $0.4 \times$ as long as marginal vein.

Metasoma with petiole $1.2-1.3 \times$ as long as hind coxa, 1.0-1.1 $\times$ as long as propodeum; petiole cylindrical and reticulate, weakly truncate basally and dorsal flange weak (Fig. 121). Mt $1.2 \times$ as long as hind femur. glabrous; $\mathrm{Ms}_{2}$ with constriction sharp and smooth. First valvula of ovipositor with 3 small teeth distal to crest; second valvula broad with 7 strong lateral teeth, ridges strong dorsally but not meeting along midline. Gonostylus broad, setose, and separated from second valvifer.

\section{MALE}

Length. 2.5-3.0 $\mathrm{mm}$. Colour darker and more bluish than in female, rarely more reddish, scape dark brown and sometimes with faint metallic reflections, femora dark brown except at apex. Eyes separated by $1.7-1.9 \times$ their height. Malar space $0.8-0.9 \times$ height of eye. Antenna 11segmented. flagellar segments closely adpressed; F2 1.5x F3; clava indistinct from preceding segments. Mesosomal less robust, sculpture pattern as in female: mesepisternum 
as in female but band anterior to femoral groove may be weakly reticulate. Forewing $2.1 \times$ as long as mesosoma, 2.1-2.6x as long as broad. Petiole 2.1-2.6x as long as hind coxa, 2.1-2.4x as long as propodeum; almost smooth to reticulate dorsally. $\mathrm{Mt}_{2} \mathrm{O} .8 \times$ as long as hind femur; $\mathrm{Ms}_{2}$ with constriction sharp. Genitalia typical for genus, paramere long, broad, and weakly sclerotized, with 2 apical setae, aedeagus broadly rounded.

\section{BIOLOGY}

I collected this species in a relatively small patch of mixed kangaroo grass, Themeda triandra Forskal (Poaceae), and Cassia mimisoides Linnaeus (Leguminoceae), surrounded by an open Eucalyptus forest. Individuals were collected sporadically, and their host plant could not be isolated. Females placed on bouquets of either plant were unresponsive.

\section{DISTRIBUTION}

Australia (Queensland) (M, Fig. 276).

\section{ETYMOLOGY}

From Greek synemporos, meaning fellow traveller: in honour of my wife, Laura, and my daughter. Joanne.

\section{Orasema valgius (Walker)}

Figs. 122, 124, 131, 192, 221, 238, 248, 262-263

Eucharis valgius Walker, 1839:11. New South Wales, Australia [BMNH, examined].

Psilogasteroides valgius-Girault, 1913b:94.

Parapsilogaster valgius-Girault, 1915:233.

Epimetagea valgius-Hedqvist, 1978:243.

Orasema valgius-Bouček, 1988:521.

Orasema pheidolophaga Girault. 1913b:96. Australia: Victoria [SAMA, examined]. Synonymy by Bouček, 1988:521.

\section{TYPE MATERIAL}

Lectotype of $E$. valgins (designated by Bouček, 1988), ơ, "LECTO-/ TYPE " "Type." "N.S.W." "Sydney." "Psilogaster/ Valgius/ Walker." "B.M. TYPE/ HYM./ 5.617." "o Orasema/ valgius (Walker)." Flagellum and hind legs missing, wings and legs in glue.

Lectotype of $O$. pheidolophaga (here designated). ? . "Reared from pupac obtained/ in nest of Pheidole sp/ Geclong Victoria/ H. W. Davey." "Orasema phe-/ dolophaga Gir./ ơ ? types." [GH] "[?].1286/ Orasema/ pheidolophaga Gir/ Victoria/ also slide." "S.A. Muscum specimen." "LECTOTYPE/ Orasema/ pheidolophaga Gir./ Det. J. Heraty "90." Six syntypes of both sexes. mounted on card with headless minor of Pheidole (see Dahms, 1986). Slide: head, antennac, and wings.
"Orasema phedolophaga [= pheidolophaga] Girault, $\delta$. o types" [GH].

\section{DIAGNOSIS}

Distinguished from $O$. synempora by having the body smaller and more slender, lateral lobe and axilla sculptured (Fig. 238), frenal area carinate, mesepisternum broadly reticulate (Fig. 221), and forewing with longer setae (typical of other species).

\section{FEMALE}

Length, 1.7-2.5 mm. Head, mesosoma, and petiole blackish-green, sometimes with greenish or iridescent reflections; gaster dark brown to black with faint greenish reflections, antennal flagellum dark brown; scape, pedicel, and femora dark brown with faint metallic lustre or completely yellow; apex of femora and rest of legs yellow to yellowish brown. Wings hyaline, venation brown.

Head subtriangular, $1.3 \times$ as broad as high, $1.4-1.5 \times$ as broad as mesosoma; LOL $0.6-1.0 \times$ OOL. Face relatively flat, frons reticulate, face below toruli mostly glabrate: scrobal depression shallow, weakly sculptured; temple narrow and weakly sculptured: occiput aciculate, dorsal margin broadly rounded, occipital carina absent. Eyes separated by $1.6-2.0 \times$ their height. Malar space $0.7-1.0 \times$ height of eye, malar depression absent. Clypeal area glabrate, epistomal sulcus absent, tentorial pit decply impressed, lateral margin of clypeal area shallow, anteclypeus subtruncate: supraclypeal area slightly swollcn. Labrum 4-digitate. Mandible with apical tooth just overlapping base of opposing mandible: palpi 3-segmented, second segment of maxillary palpus $3 \times$ as long as broad. second segment of labial palpus short, as long as broad. Antenna 11-segmented (Fig. 124); scape cylindrical, almost reaching median ocellus; pedicel subconical: anellus small: flagellum 1.1-1.4× height of head: funicular segments distinctly scparated. densely setose along entire flagellum, with numcrous MPS: F2 $0.3-0.5 \times$ as long as scape, F2 1.4-1.7x as long as broad. following segments slightly subequal in length, slightly broader than F2; clava ovate, as long as preceding 2 segments.

Mesosoma 1.2× as long as high (Fig. 221): midlobe of mesoscutum reticulate, scutellum rugose-reticulate with verrucose surface: lateral lobe variously sculptured (never glabrous); axilla weakly carinate and imbricate to reticulate. Mesoscutum with notauli deeply and broally impressed and crenulate. SSS broadly impressed and crenulate. Scutellum 1.2X as long as broad, separated at base from TSA by broad fovea (Fig. 238): frenal line broad and irregularly foveate, frenal area vertical and hardly visible in dorsal view, vertically carmate or rarely almost glabrate; axillula rugose. axillular sulcus obscured by sculpture. Propodeal dise broadly rounded, glabrous laterally with broad median band of rugulose sculpture, 
batnd broader dorsally; postspiracular furrow strong and foveate: callus rounded and glabrate with few short setac dorsally: melepimeral sulcus shallow, irregularly impressed withoul dorsal extension. Mesepimeron glabrous, transepimeral sulcus broad and irregularly impressed: femoral groove obscure; mesepisternum reticulate laterally, glabrous anteriorly and ventrally. Prepectus weakly coriaceous to smooth. Pronotum mostly smooth. Proepisternum glabrous. Coxac mostly smooth, weakly coriaceous dorsally with weak mid-ventral sulcus: femora glabrate basally and ventrally, femora imbricate and minutely setose dorsally. Forewing $2.6 \times$ as long as mesothorax, 2.2-2.5x as long as broad (Fig. 122); basal area and speculum bare; costal cell sparsely setose and relatively broad; disc with dense, relatively long setae; marginal vein $0.27-0.29 \times$ as long as forewing; stigmal vein narrow, more than $3 \times$ as long as broad and slightly angled distally; postmarginal vein elongate, $0.6 \times$ as long as marginal vein.

Metasoma with petiole $1.3-1.7 \times$ as long as hind coxa, $1.1-1.6 \times$ as long as propodeum; petiole cylindrical and reticulate to rugose. $\mathrm{Mt}_{2}$ equal to length of hind femur, glabrate: $\mathrm{Ms}_{2}$ constriction broad and smooth (Fig. 262). Ovipositor (Fig. 262); first valvula with lateral line of 2 large and 2 small teeth distal to subapical ridge, inner surface with dense short setae (Fig. 263); second valvula broad, with several strong lateral teeth, connected by weak transverse ridges.

\section{MALE}

Length, 2.3-2.5 mm. Colour as in female but darker. Eyes separated by $1.8-2.2 \times$ their height. Antenna 11 -segmented; scape reaching median ocellus; flagellum 1.4-1.9x height of head; F2 $1.8 \times$ as long as broad. Mesosoma as in female. Forewing 2.1-2.5x as long as broad; stigmal vein stout, sharply angled distally. Petiole $2.1-2.6 \times$ as long as hind coxa, 2.4-3.5x as long as propodeum; petiole cylindrical, reticulate to smooth ventrally and apically. Gaster small, $0.8 \times$ as long as hind femur. Genitalia typical for genus, paramere elongate with terminal seta, small median process, digitus with 5 marginal spines; aedeagus subtruncate.

\section{VARIATION}

There is little variation in shape of the mesosoma, but considerable variation in sculpture. The midlobe of mesoscutum and scutellum are almost always strongly and evenly sculptured, but the lateral lobe varies from weakly to strongly sculptured. Facial sculpture varies from almost completely reticulate to nearly smooth on the face and vertex, and the petiole may be rugose to reticulate. The coloration of the scape ranges from clark brown with a weak metallic lustre to a prominent yellow. This is sometimes correlated with similar coloration of the femo- ra resulting in what could be called a dark and light morph of this species. However, a complete range of scape colour has been found on specimens with darkened lemora at a single locality. Individuals with completely yellow femora have not been collected with the darker colour morphs. Males are always darker in coloration and may have the scape and femora black. Both E. valgilis and $O$. pheidolophaga conform to the dark morph and were described with darkened femora.

\section{ADDITIONAL SPECIES}

A similar, undescribed, species, which occurs in Australia (Mt Glorious, sclerophyll forest, 16-20.ii.1961, L. and M. Gressitt, BPBM), differs by having the face glabrous, lateral lobe of mesoscutum glabrous and swollen, and the midlobe, scutellum, and mesepisternum with fine reticulate sculpture. It shares the smooth propodeum and callus, elongate petiole, and slender mesosoma that are typical for $O$. valgius. The male and female are in poor condition and are not here described.

\section{BJOLOGY}

Reared from Pheidole (Girault, 1913b). The collection records do nol offer much information on habitat other than that individuals were collected in long grass in open forest, or in wet forest. The association with long grasses could suggest a similar habitat preference with $O$. synempora.

\section{DISTRIBUTION}

Known only from eastern Australia (V, Fig. 276). A single female of $O$. valgius was recorded from Kuranda, north Queensland. The northern record suggests that this species is sympatric with $O$. synempora. O. valgius exhibits a similar pattern of distribution to Psilocharis theocles and Orasemorpha eribotes, but has not been recorded from western Australia or Tasmania.

\section{MATERIAL, EXAMINED}

Australia: A.C.T.: Bendora: Black Mtn, $300 \mathrm{~m}$ : Canberra; December to February $(3 q+9,10$. AEI. ANIC); New South Wales: Bateman's Bay, 33-39 km W: Bondi S.F., via Bombala: Botany Bay; Cabramatta; Canley Vale; Casula; Corang Riv. via Nerriga; Dorrigo N. P., $1000 \mathrm{~m}$; Mt Dromedary, $330 \mathrm{~m}$, light trap; Mt Elliot. NE Gosford; Gibraltar Range, via Glen Innes, 900 m: Palm Creck Royal N. P.: Pilliga Scrub, via Coonabarabran; Springwood, Blue Mts, 350 m; Tooloom Platcau, via Urbanville, 600-700 m; Wiangaree N. P., Brindle Ck, $1000 \mathrm{~m}$; October to March $(33 q q, 7 \delta$ ơ. ANIC, BMNH, CNC, MCZ, QMB, UQIC, USNM); Quecnsland: Adelaide; Bald Mtn area, $380-450 \mathrm{~m}$ via Emu Vale; Fleurian Peninsula, Deep Creck Conservation Park: Kangaroo Is., Rocky Riv., Flinders Chase N. P.; Mt 
Byron area, D'Aguilar Range, long grass, open forest; Cooloola, nr Freshwater Lake, open forest; Stanthorpe; Kuranda; Stanthorpe, $700 \mathrm{~m}$; nr Wilson's Peak, via Teviot Gap, 700-800 m; November to January, and March to April (17우, $190^{\circ} \delta^{\circ}$, AEI, ANIC, BMNH, BPBM, JMH, ROM. TAMU, UQIC); Victoria: Cann
Valley Highway. $7 \mathrm{~km}$ SW NSW border: Cann Riv.. 80-120 m, sweeping low vegetation, wet sclerophyll forest: Club Terrace, 120 m; Grampians, Rose`s Gap: Growler Ck, Lind N. P.: Mt Beauty: February to March. October, and December ( $11 \% q, 180^{\circ} \sigma^{\circ}$, ANIC, TAMU, UQIC).

\section{Revision of Psilocharitini (Eucharitinae)}

\section{Psilocharis gen. nov.}

Type Species: Eucharis theocles Walker, 1839:11-12; by present designation.

Psilocharis is included within the Eucharitinae based on: presence of an occipital carina, an acicular ovipositor, and absence of a constriction on the first gastral sternite. This genus is distinguished from other Eucharitinae by: anellus usually present, clypeal margin transverse with row of fine elongate setae along margin of anteclypeus (Figs. 193-198), malar space with complete longitudinal depression (Fig. 223), mesepimeron mostly polished with broadly impressed femoral groove, stigmal vein slightly broader than marginal vein, base of petiole truncate laterally (Figs. 144-145), ovipositor acicular, and ovipositor sheath narrow and cylindrical (Fig. 264). In most species, the apex of the hypopygium has a band of elongate hairs. a character state shared with Gollumiella and Anorasema of the Eucharitinae. Psilocharis, along with Neolosbanus, is placed as the sister group of the rest of the Eucharitinae based on the following combination of plesiomorphic character states: prepectus not fused to pronotum, anellus usually present, and mesothoracic spiracle not enclosed dorsally. The immature stages and ant host are unknown.

\section{GENERIC DESCRIPTION}

Head subtriangular, $1.3-1.5 \times$ as broad as mesosoma; median ocellus anterior to lateral ocelli, lateral ocellus separated from occipital margin by at least its own radius (Fig. 136). Face, vertex, and gena polished; scrobal depression shallow and poorly defined laterally, usually with 2 parallel smooth channels extending part way to median ocellus (Figs. 194-195, 197); occiput fincly aciculate, occipital carina present (Figs. 136, 223); ocellarocular groove absent. Malar depression broally and deeply impressed along entire length: hypostoma large. separated from gena by prominent hypostomal carina and extending mesally over base of mandible. Clypeus slightly broader than long, subecpual to supraclypeal areat apical margin subtruncatc or slightly rounded, epistomal sulcus weak or absent: anteclypeus distinct and with row of line elongate setae along dorsal margin that extends ventrally over labrum (difficult to observe and sometimes visible in sublateral view; Fig. 198). Labrum 4-digitate, setae long and spatulate. Mandibles falcate and 2/3 dentate; maxilla and labium elongate, maxillary and usually labial palpi 2 segmented. Antenna 8- to 11-segmented; scape narrow and elongate, scape of female without pores, scape of male with minute pores ventrally (visible only in slide preparations); pedicel short, at most $1.5 \times$ as long as broad; anellus present or absent; funicle 5-to 7-segmented, segments cylindrical or rarely moniliform, with basal secondary segmentation and scattered multiporous plate sensilla in both sexes: basal funicular segments less than $2.2 \times$ as long as broad, terminal 3 or 4 segments fused into distinct clava.

Mesosoma with dorsum usually strongly sculptured, sometimes weakly reticulate to smootl. Mesoscutum with each notaulus well defined along entire length. TSA complete. SSS broadly curved and angled to midline at TSA. Scutellum with frenal area separated by foveate or crenulate groove; axillular sulcus distinct and foveate. Metanotum extended laterally as smooth flange overlapping base of propodeum and partly covering propodeal spiracle; spiracle close to dorsal margin of propodeum. Propodeal disc rounded and glabrous laterally (Fig. 249) with broad medial band of rugose-areolate sculpture. sculpture broadest dorsally and reaching postspiracular furrow; callus polished and not strongly swollen, with few to several long hairs dorsally, and with or without callar nib; postspiracular furrow and metepincral sulcus marked with narrow foveate groove: ventral margin of propodeum above hind coxa even and strongly ridged. without lateral processes. Mesopleuron mostly smooth: mesepimeron slightly swollen. transepimeral sulcus marked by narrow foveate groove: femoral groove broadly impressed or foveate: sternaular area of mesepistermum with wedge-shaped foveate groove (SA. Fig. 224). Prepectus reaching tegulat as triangular. loveate lobe dorsally, strongly narrowed and smooh ventrally. Coxac and femora smooth and shining: hind tarsus $0.8 \times$ shorter tham 
tibia: fore and mid tibiac with I spur, hind tibia with I or 2 spurs.

IIing. Veins of fore and hind wing well defined. Forewing 2.()-2.5x as long as broad, broadly rounded apically: basal area usually bare: speculum present (bare); costal cell pilose or bare: disc densely pilose and with distinct marginal fringe: submarginal vein with row of dorsal setae; marginal vein $0.26-0.33 \times$ length of forewing and densely pilose as rest of wing; stigmal vein elongate and broader than marginal vein; postmarginal vein less than $1.5 \times$ length of stignal vein (Figs. 146-148).

Metasoma with petiole more than $1.4 \times$ length of hind coxa; petiole subtriangular in cross-section and fused ventrally, lateral margin of petiole base parallel or expanded and abruptly narrowed to articulation (Figs. 144-145), base with or without dorsal flange. Gastral terga polished, gaster of female as long as head and mesosoma, slightly smaller in male; $\mathrm{Mt}_{2}$ of female less than $0.6 \times$ length of gaster; Ms, smooth, without medial transverse constriction. $\mathrm{Ms}_{8}$ of male narrow, rounded apically, and densely setose. Cercus with few long setac and I seta twice length of others. Hypopygium with row of elongate hairs along apical margin (Figs. 149, 264), rarely with 2 minute setae on either side of midline at apex. Ovipositor sheath narrow and elongate, sometimes exceeding cercus by more than its width. Gonostylus indistinctly separated basally, and setose. Ovipositor acicular; first valvula smooth, second valvula with weak dorsal ridges (Fig. 265). Genitalia of male with paramere well developed and bearing 2 stout setae, digitus disclike with 3 to 4 stout marginal spines; aedeagus narrow and subacute (Fig. 151).

\section{ETYMOLOGY}

Combination of Greek psilos, meaning smooth or bare, and encharis, meaning pleasing; feminine gender.

\section{PHYIOGENETIC RELATIONSHIPS}

Monophyly of Psilocharis is supported by several character states, including the following: anteclypeus distinct with marginal setae, petiole with lateral margins parallel and abruptly narrowed at base (39), scrobal depression with short parallel channels and apex of each channel forming smooth circular impression (9), labial palpi usually 2 -segmented, and femoral groove broadly impressed (29). A distinct anteclypeus (without marginal setae) and abrupt base of the petiole are also found in some species of Orasema, and $O$. glabra also has scrobal channels. These character states are treated here as convergent developments within Orasema.

Most species of Psilocharis possess a row of long hairs on the hypopygium (45). A similar marginal row of hairs is found also in Gollumiella and Anoresema, but otherwise it would appear to be a unique character state of Eucharitidae (or Chalcidoidea that I know of). It is pos- sible that the row of hatrs was present in the groundplan of Eucharitinate, with multiple losses or modilications postulated as derived features. I have interpreted this character state as an independent derivation within Psilocharis.

Psilocharis aenigma is the sister group of the remaining species based on the following: mesoscutum completely imbricate (apomorphic), procpisternum glabrous (plesiomorphic), and hypopygium with only 2 small longitudinally aligned hairs (plesiomorphic). A marginal row of hairs on the hypopygium is a derived state shared by the remaining species (unknown for $P$. monilicera). which may have been secondarily lost in $P$. pacifica (present in its sister group. $P$. dahmsi). A completely and strongly sculptured dorsum, as in Neolosbanus, is plesiomorphic. Therefore, a polished lateral lobe and axilla is a derived state for $P$. dahmsi, $P$. joanneae, $P$. pacifica, and $P$. theocles, and the polished axilla and scutellum in $P$. aenigma is independently derived. A single specimen from Argentina, which is closest to $P$. aenigma, has an evenly sculptured scutellum. The former group, which includes $P$. theocles, is further supported by a glabrous frenum, but again this is homoplastic. A polished scutellum, smooth scrobal depression, and dorsal flange at the base of the petiole are shared by $P$. pacifica and $P$. dahmsi. A lack of channels from the scrobal depression and reduction of the callar nib may support a relationship between $P$. joanneac and $P$. pacifica $+P$. dahmsi, but both states are found to some degree in $P$. theocles. There are no derived states to support a relationship between $P$. joanneae and $P$. theocles.

The species $P$. afra, $P$. hypena, $P$. monilicera, and $P$. pentella have prominent channels in the scrobal depression (weak in P. pentella) with a distinct impression at the apex of each channel, a prominent callar nib, and a strigate temple. Any of these states could be plesiomorphic within Psilocharis. The species $P$. afra and $P$. hypena are almost identical, but otherwise have no supporting apomorphies. Psilocharis monilicera and $P$. pentella both have the batsal area of the forewing pilose, the ventral margin of scape in both sexes carinate, and the eyes sparsely setose.

Tentatively, relationships among species of Psilocharis may be hypothesized as (aenigma $+(($ monilicera + pentella $)+$ hypena + afra $)+($ theocles + joanneae $+($ pacifica + dahmsi $)))($ Fig. 277).

\section{BIOLOCYY}

Plant and ant hosts are unknown. I have collected $P$. theocles in dry open Eucalyptus forests near Brisbane and Perth. Australia, and $P$. hypena in rainforest near Kuala Lumpur, Malaysia. Adults were scattered on plants along paths, but no ant or plant hosts could be isolated. 


\section{DISTRIBUTION}

Psilocharis is distributed throughout the southern Ethiopian, Malagasy, and Indo-Pacific regions (Fig. 277). Psilocharis pacifica is 1 of the few species of Oraseminae or Eucharitinae found in the Polynesian subregion, and the only species (other than some Chalcura and Schizaspidia) known to occur as far east as Fiji. Psilocharis theocles has a similar distribution to Orasemorpha eribotes and Orasema valgius along the eastern and southwestern coast of Australia. A single specimen (in CAS) of an undescribed species known from Argentina is morphologically very similar to $P$. aenigma. As with the single specimen of Neolosbanus known from Uruguay, this range extension to the Neotropical region needs to be verified by at least 1 other specimen.

Based on the phylogenetic hypotheses discussed above, it would appear that the Oriental distribution of $P$. hypena (Indo-Chinese + Malayan + Philippine subregions) and $P$. pentella (Malayan) is derived from the
Ethiopian region, and not from the Australian region. The 4 species found in the Australian. Papuan. and Polynesian (New Caledonia and Fiji) subregions ( $P$. dahmsi, $P$. joanneae. $P$. pacifica, and $P$. theocles) appear to form a monophyletic group that may share a common ancestor with the Ethiopian species. The morphological differences between the Oriental and African species and the Australasian species are distinctive, and suggest an early vicariant event between Africa and Australia similar to that found in the Oraseminae. The possible existence of a species in the Neotropical region, which is most closely related to the Malagasy species, would add further support to a hypothesis of an older widespread Gondwanan distribution. Psilocharis hypena (Oriental) and $P$. afra (Ethiopian) exhibit few morphological differences, which could suggest a more recent faunal exchange between the Ethiopian and Oriental regions, rather than vicariance involving a shift of the Indian subcontinent from Africa during the Palaeogene.

\section{Key to Species of Psilocharis}

1 Mesoscutum with midlobe rugose-areolate, lateral lobe glabrous or strongly sculptured but not umbilicate; hypopygium with transverse band of 8 to 10 long hairs along apical margin (unknown for 2 species)

Mesoscutum completely imbricate; hypopygium with 2 minute hairs on each side of midline at apex, hairs aligned longitudinally; Madagascar... P. aenigma sp. nov., p. 84

2 (1) Inner ventral margin of scape carinate and scape cylindrical or strongly expanded, not reaching median ocellus; female without anellus; basal area of forewing setose; dorsum of mesosoma weakly rugose; South Africa. . .3

- Ventral margin of scape evenly rounded; may be slightly expanded apically but then scape long and reaching median ocellus; female with ancllus; basal area of forewing bare or at most with few sparse setae (Figs. 146-148); dorsum of mesosoma and frenal area either strongly sculptured or glabrous

3 (2) Antennal funicle with 6 or 7 segments; anteclypeus narrow and straight; Irenum glabrous: southern Africal ....P. monilicera sp. nov.. p. 8.5

Funicle with 5 segments: anteclypeus broad and rounded; frenum vertically carinate: Sumatra..... P. pentella sp. nov., p. 85

4 (2) Lateral lobe, axilla, and frenum smooth and polished (Fig. 137); temple smooth or at most very weakly aciculate

Lateral lobe and axilla completely rugose or carinate, frenum vertically carinate (smooth in some hypena; Figs. 239-240): temple fincly strigate dorsally. .8

5 (4) Scutellum completely smooth and polished (Fig. 137): mesoscutum with midlobe scabrous .......6

- Scutcllum rugose-areolate, at least in basal half; mesoscutum with midlobe transversely carinate or rugose-arcolate 7

6 (5) Hind tibia and scape yellowish brown: Fiji. New Hebrides P. pacifica sp. nov.. p. 86

Hind libia and scape black with blue reflections: New Guinea P. dahmsi sp. nov.. p. 87

7 (5) Head subcircular in frontal view (Fig. 193); cye large, malar space $0.4-(0.5 \times$ height of eye: antennal tlagellum of females $(0.6-0.7 \times$ height of head (Fig. 138). ().8x height of head in males: Australia I'. joammeae sp. nov.. p. 8.8 
- Head subtriangular in frontal view (Fig. 194); eye smaller (as in other species), malar space 0.6-0.9x height of eye: antennal flagellum of females $0.8-1.0 \times$ height of head (Fig. 139), 1.0-1.2x height of head in males (Fig. 141): Australia. I. theocles (Walker), p. 89

8 (4) Lower face below eye strongly narrowed, posterior margin of gena not or only slightly visible in frontal view (Fig. 195), head width at lower margin of eye, including posterior genal margin, 1.8-2.4x vertical distance between eye margin and apex of clypeus; Africa...

I. afra sp. nov., p. 90

Lower face broad, posterior margin of gena rounded and distinct in frontal view (Figs. 196-197), head width at lower margin of eye 2.5-2.9x vertical distance between eye margin and apex of clypeus; Oriental region

P. hypena sp. nov., p. 91

\section{Psilocharis aenigma sp. nov.}

Fig. 144

\section{TYPE MATERIAL}

Holotype, 우 "Ambohitsitondrona/ X1.55 (Vadon)." "Madagascar/ Ambohitsitondrona/ XI.1955 (Vadon)." "sp. (Oras.)." "HOLOTYPE/ Psilocharis/ aenigma Heraty." Deposited in BMNH.

\section{DIAGNOSIS}

Differs from all other species as follows: mesoscutum completely imbricate (versus rugose or carinate), hypopygium with 2 pairs of sublateral setae, proepisternum glabrous, and gonostylus several times longer than broad.

\section{FEMALE}

Length, $2.4 \mathrm{~mm}$. Body, including coxae, black; antenna, femora, and rest of legs yellowish brown, pedicel and flagellum slightly darker. Wings hyaline, venation clear pale brown.

Head subtriangular; occiput shallow emarginate; LOL $1.2 \times$ OOL. Face broadly rounded and polished with sparse, decumbent setac; scrobal depression not reaching median ocellus, with parallel channels reaching $0.6 \times$ distance to median ocellus, median groove absent; occipital carina weakly developed, extending just past lateral ocellus; temple strigate. Eyes separated by $1.2 \times$ their height. Malar space $0.5 \times$ height of eyc. Clypeus sparsely setose. epistomal sulcus absent. Antenna 11 -segmented: scape reaching $0.8 \times$ distance to median ocellus, cylindrical: pedicel $2.2 \times$ as long as broad; anellus stout; flagellum $0.9 \times$ height of head; funicle 7 -segmented; F2 2.0× as long as broad, slightly shorter than pedicel, following segments subequal in length and slightly broader apically; clava ovate, slightly longer than preceding 2 segments.

Mesosoma with mesoscutum entirely imbricate, axilla and scutellum smooth and polished. SSS foveate with strong transverse carinae. Scutellum $1.3 \times$ as long as broad, narrowly separated from TSA basally, apex subtruncate; frenal line narrow and weakly foveate, frenal area glabrous, broadly crescent-shaped in dorsal view; axillula glabrous, axillular sulcus foveate. Callus with few elongate hairs dorsally, callar nib absent. Femoral groove broad and shallowly impressed, finely reticulate; sternaular area foveate. Proepisternum glabrous. Coxae glabrous, imbricate basally; femora polished with sparse short setae; hind tibia slender with 1 long spur. Forewing $2.4 \times$ as long as broad: basal area bare; speculum moderately sized with regular margins; stigmal vein slightly longer than broad: postmarginal vein $2.4 \times$ as long as stigmal vein.

Metasoma with petiole $1.5 \times$ length of hind coxa, $1.5 \times$ length of propodeum; petiole strigate-verrucose dorsally and carinate laterally: base parallel-sided, without distinct lateral flange (Fig. 144), dorsal flange absent. Gaster typical. Hypopygium with 2 long hairs on each side of midline, first hair directly anterior to second. Ovipositor acicular. Gonostylus narrow and elongate. $6.3 \times$ as long as broad (other species $3-4 \times$ as long as broad).

\section{MALE}

Unknown.

\section{DISTRIBUTION}

Madagascar (E, Fig. 277).

\section{ETYMOI.OCY}

From Latin aenigma, meaning mystery: referring both to the set of character states and to distribution.

\section{AI)ITIONAL SPECIES}

A single undescribed female. similar to $P$. aenigma, is known from Cordoba. Argentina $(2 \mathrm{~km} S$ Dean Funes, 8.ii.1951, E. Ross. CAS). It is similar in sculpture of the mesoscutum and in several other states to $P$. aenigma, but is a distinctly different species. The hypopygium is immersed in glue and the setation of the hypopygium could not be observed. This would be the only Neotropical record of this genus, but needs to be verified by additional collections. 


\section{Psilocharis monilicera sp. nov.}

Fig. 134

\section{TYPE MATERIAL}

Holotype, ô. "S. Afr. Grahamstown/ 5-7.I.86 W. Mason/ $500 \mathrm{~m}$ (MT)." "HOLOTYPE/ Psilocharis/ monilicera Heraty." Deposited in CNC.

Paratypes: SOUTH Africa: E. Transvaal: [Pondoland] Port St. John, 5-30.iv.1923 (1 ô). 16-28.iv.1924 (1 \&), R. E. Turner (both BMNH).

\section{DIAGNOSIS}

Recognized by the following: scape only of male enlarged, both sexes with inner ventral margin of scape carinate, funicular segments of male moniliform (Fig. 134), basal area of the forewing sparsely setose, scutellum lightly rugulose, and lateral lobe of mesoscutum and axilla weakly sculptured.

\section{MALE}

Length, 1.2-1.6 mm. Head, mesosoma, and petiole dark blue or bluish green; coxae, femora, and gaster dark brown; antenna, apex of hind femora, and rest of legs yellow. Wings hyaline, venation clear.

Head subcircular; occiput broadly emarginate; LOL $1.1 \times$ OOL. Face broadly rounded, polished with sparse decumbent setae; scrobal depression with parallel channels reaching just over half distance to median ocellus. apex of each channel with distinct semicircular depression, median groove absent; occipital carina extending to lateral ocellus; temple broad and weakly aciculate. Eye with minute setae, eyes separated by $1.6-1.8 \times$ their height. Malar space $0.7-0.9 \times$ height of eye. Clypeus glabrate, tentorial pit deeply impressed: anteclypeus very narrow and straight. Antenna 11 -segmented: scape reaching $0.8 \times$ distance to median ocellus, enlarged along entire length and inner ventral margin carinate (Fig. 134), apical half broadly emarginate ventrally; pedicel as long as broad; anellus present; flagellum 1.1-1.2 $\times$ height of head; funicle 7-segmented; F2 cylindrical, 1.5-1.6x as long as broad. F3-F8 moniliform and as long as broad; clava ovate, shorter than preceding 2 segments.

Mesosoma with dorsum lightly rugulose; lateral lobe of mesoscutum and axilla completely sculptured but sculpture shallow and irregular. SSS broadly impressed and weakly crenulate. Scutellum $1.6 \times$ as long as broad, subtruncate at apex; frenal line shallow and foveatc. frenal area glabrous, crescent-shaped from above; axillula glabrate, axillular sulcus narrow. Callus with several elongate hairs and prominent callar nib. Femoral groove broad, irregularly reticulate to rugulose in anterior half; sternaular area narrow and shallowly foveate. Procpisternum weakly carinate. Coxac glabrate; hind femora weakly imbricate to smooth, with sparse setac: hind tibia stout with moderately dense fine setae. with 2 spurs, the outer spur small. Forewing $2.0-2.2 \times$ as long as wide; basal area evenly pilose; speculum bare but margins poorly defined; stigmal vein twice as long as broad; postmarginal vein slightly longer than stigmal vein.

Metasoma with petiole $1.5-1.7 \times$ as long as hind coxa, $1.5-1.8 \times$ length of propodeum; petiole subtriangular in cross-section, ribbed dorsally, glabrate to aciculate sublaterally, with weak ventral keel: base parallel-sided, without distinct lateral flange, dorsal flange absent. $\mathrm{Mt}_{2}$ as long as petiole. Genitalia typical for genus.

\section{FEMALE}

Length, $1.5 \mathrm{~mm}$. Colour basically dark brown with dorsum bluish green. Occipital carina weak (difficult to discern from occipital strigae); temple glabrous. Tentorial pit not deeply impressed. Antenna 10-segmented; scape reaching median ocellus, cylindrical and with short carina on inner ventral margin (surrounding depression under pedicel); anellus absent; flagellum broadened apically. F4-F7 enlarged. Mesoscutum with midlobe and anterior region of scutellum weak rugose-areolate; lateral lobe smooth; axilla smooth with weak carinae posteriorly. Forewing with basal area bare and with few scattered setae; gaster typical; ovipositor, sheath. and hypopygium hidden.

\section{DISTRIBUTION}

Known only from 2 localities in South Africa (Cape Province; M, Fig. 277).

\section{ETYMOLOGY}

Combination of Latin monile, meaning necklace or beadlike, and ceros, meaning horned; referring to the rounded antennal flagellomeres.

\section{Psilocharis pentella sp. nov.}

\section{TYPE MATERIAI}

Holotype, + . "INDONESIA: Sumatra. Aceh/ Gunung Leuser Nat. Pk./ Ketambe Res. Sta. Jan. 1990/ per DC Darling. IIS 900003." "Malaise trap. primary/ rainforest. $400 \mathrm{~m}$./ Mature forest, Terrace 4/ Light gap. $3^{\circ} 4 \mathrm{I}^{\prime} \mathrm{N}$, 97³9'E." "HOLOTYPE/ Psilocharis/ pentella Heraty." Deposited in MZB.

Paratypes: INDONESIA: Sumatra: Aceh: same data as hololype (1 $q$. ROM): same locality and collector, $350 \mathrm{~m}$. ii. 1990, young forest. Terrace 3, closed canopy. IIS 900011 MT (1 9 . MZB): same locality and collector. 350 m. primary rainforest 1-30.x.1989. D. C. Datrling. 890000 MT (1 9, ROM). 


\section{D) Acitosis}

Recognized by the following: inner ventral margin of female scape expanded and carinate in the apical third, ancllus absent. funicle with 5 segments, basal area of forewing pilose, and scutellum rugulose-areolate.

\section{FEMALE}

Length, 2.0-2.9 $\mathrm{mm}$. Head, mesosoma, and petiole black, mesosoma with faint bluish reflections; coxa and gaster dark brown; femora mostly light brown, apex of femora, rest of legs, and scape yellowish brown; antennal pedicel and flagellum brown, basal segments lighter. Wings hyaline, venation light brown.

Head subcircular; occiput broadly emarginate; LOL $0.9-1.0 \times$ OOL. Face broadly rounded, polished with dense short adpressed setae; scrobal depression with parallel channels shallow and reaching $0.7 \times$ distance to median ocellus, apex of each channel with distinct semicircular depression, median groove absent; occipital carina extending beyond lateral ocellus; temple broad and weakly aciculate. Eye with minute setae, eyes separated by $1.6-1.7 \times$ their height. Malar space $0.7 \times$ height of eye. Clypeus glabrate, lateral margin and tentorial pit hardly impressed; anteclypeus broad and rounded ventrally. Antenna 9-segmented; scape reaching median ocellus, enlarged ventrally and apical ventral margin carinate, apical half broadly emarginate ventrally; pedicel $1.4 \times$ as long as broad; anellus absent; flagellum $0.9 \times$ height of head; funicle 5-segmented; F2 expanded subapically, $1.8-2.2 \times$ as long as broad, F3-F6 subequal in length; clava oblong, nearly as long as preceding 3 segments.

Mesosoma with midlobe of mesoscutum and scutellum rugulose-areolate; lateral lobe irregularly transverse-strigate, axilla longitudinally strigate. SSS broadly impressed and crenulate. Scutellum $1.5 \times$ as long as broad, subtruncate at apex; frenal line shallow and crenulate, frenal area with broadly spaced vertical carinae, abrupt and hardly visible dorsally: axillula longitudinally carinate, axillular sulcus narrow. Callus with several elongate hairs and prominent callar nib. Femoral groove broad, irregularly rugose-areolate in anterior half; sternaular area narrow and shallowly foveate. Proepisternum and coxae glabrous. Hind femur smooth, with sparse setae; hind tibia slender with moderately dense fine setae, with 2 spurs, the outer spur small. Forewing $2.3-2.4 \times$ as long as wide; basal area evenly pilose; speculum bare but margins poorly defined; stigmal vein $2-3 \times$ as long as broad, strongly angled towarl apex; postmarginal vein $0.6-1.6 \times$ as long as stigmal vein.

Metasoma with petiole $1.8-2.0 \times$ as long as hind coxa, $1.8-2.0 \times$ length of propodeum; petiole subtriangular in cross section, ribbed dorsally and laterally, with weak ventral keel; base parallel-sided, with distinct lateral flange and no dorsal flange. Gaster typical for genus.
Hypopygium with 10 to 11 long hairs along apical margin. Ovipositor acicular. Gonostylus narrow and clongate.

\section{MALE}

Unknown.

\section{DISTRIBUTION}

From Sumatra in Malayan subregion (N, Fig. 277).

\section{ETYMOLOGY}

From Latin penta; referring to number of funicular segments.

\section{Psilocharis pacifica sp. nov.}

Figs. 133, 137

\section{TYPE MATERIAL}

Holotype, + , "FIJI: Vanua Levu I:/ Mt Dalaikoro,/ summit area,/ 700-790 m, 10.X.1979." “\#233." "S. N. Lal, G. A. \& S. L./ Samuelson, Colls./ BISHOP Museum/ Acc. \#1979.387." "HOLOTYPE/ Psilocharis pacifica Heraty." Deposited in BPBM.

Paratypes: New Hebrides: Efate Is. (NW), Maat (Mat, Ambryn Vill.), 3 m, 15.viii.1957, J. L. Gressitt (1 9 , BPBM).

\section{DIAGNOSIS}

Differences from $P$. dahmsi: scape completely yellowish brown, antennal flagellum longer $(1.2 \times$ head height versus $0.9 \times$ : Fig. 133), hind tibia with 1 spur, and petiole of female $1.6 \times$ length of propodeum (versus $2.1-2.2 \times$ ).

\section{FEMALE}

Length, $1.6 \mathrm{~mm}$. Body dark metallic green or reddish; antenna including scape yellowish brown; femora black with strong greenish reflections; scape, pedicel, tibiae, and tarsi dark yellowish brown. Wings hyaline, venation clear yellowish brown.

Head subtriangular, eye large, and face elongate (Fig. 133); occiput broadly emarginate; ocelli small, LOL $1.0 \times$ OOL. Face relatively flat and polished with sparse, decumbent setae; scrobal depression reaching median ocellus, otherwise obscured and probably as in P. dahmsi (smooth and without channels): occipital carina weakly developed, extending to dorsal eye margin; temple narrow and glabrate. Eyes separated by $1.3 \times$ their height. Malar space $0.4-0.5 \times$ height of eye. Clypeus sparsely setose, epistomal sulcus weakly impressed. Antenna 11segmented (Fig. 133); scape reaching $0.8 \times$ distance to median ocellus, cylindrical; pedicel $1.2 \times$ as long as broad; ancllus short; Ilagellum $1.2 \times$ height of head; funicle 7 segmented; F2 2.0 $\times$ as long as broad, slightly longer than pedicel, following segments subequal in length and 
slightly broader apically; clava ovate. slightly shorter than 2 preceding segments.

Mesosoma with midlobe of mesoscutum scabrous; lateral lobe and axilla smooth and polished with sparse setae; scutellum glabrous. SSS deeply foveate with widely spaced, prominent carinae. Scutellum $1.4 \times$ as long as broad, base well separated from TSA by broad depression, apex subtruncate; frenal line narrow and weakly foveate, frenal area glabrous, broadly semicircular in dorsal view; axillula glabrate, axillular sulcus broadly foveate. Callus slightly swollen and glabrous with few small dorsal setae, callar nib absent. Femoral groove broadly and shallowly impressed, glabrous; sternaular area broadly foveate. Proepisternum mostly glabrous. weakly carinate in anterior half. Coxae glabrate: femora polished with sparse short setae; hind tibia slender, slightly expanded apically, with 1 long spur. Forewing distorted and width not measurable but appears typical for genus; basal area bare: speculum small with irregular margins; stigmal vein $1.5 \times$ as long as broad; postmarginal vein slightly longer than stigmal vein.

Metasoma with petiole $1.7 \times$ length of hind coxa, $1.5 \times$ length of propodeum; petiole broad and subtriangular in cross-section, weakly aciculate with prominent carina on lateral margin and prominent dorsal flange basally. Gaster typical for genus. Hypopygium obscured, but 1 long apical hair issuing from between folded tergites (both HT and PT). Ovipositor acicular. Gonostylus narrow and elongate.

\section{MALE}

Unknown.

\section{VARIATION}

The mesosoma of the paratype has a more distinet reddish coloration and the occipital carina does not extend laterally to the dorsal eye margin.

\section{DISTRIBUTION}

P. pacifica is the only species in this genus with an oceanic (Polynesian) distribution, and the only known species within the Orascminae and basal Eucharitinae to reach the Fiji Islands (P, Fig. 277).

\section{ETYMOLOGY}

From Pacific Occan; referring to the oceanic distribution of the species.

\section{Psilocharis dahmsi sp. nov.}

TYPE, MATERIAL

Holotypc, $q$, "NEW GUINEA: NETH./ Swart Vall: W./ ridge $1800-2000$ m./ Nov. 19. 1958." "PICRA-
NOPTERIS." "J. L. Gressitt/ Collector." "HOLOTYPE/ Psilocharis dahmsi Heraty." Right antenna missing. Deposited in BPBM.

Paratypes: PAPUA New Guinea: same data as holotype (2q $9.10 *$, BPBM): Swart Val., Karibaka, $1500 \mathrm{~m}$. 11.xi.1958, Picranoft erus [!] ( $\delta^{\star}$, BPBM).

\section{DIAGNOSIS}

Differences from $P$. pacifica: scape and tibiae dark brown with metallic reflections, antennal flagellum shorter $(0.9 \times$ height of head versus $1.2 \times$ ); hind tibia with 2 spurs, and petiole of female $2.1-2.2 \times$ (versus $1.6 \times$ ) length of propodeum.

\section{FEMALE}

Length, 2.0-2.2 mm. Head and gaster black, mesosoma with strong bluish reflections; antenna dark brown to black, scape and tibiae dark brown with metallic reflections: femora black with strong greenish reflections: scape, pedicel. and tarsi dark yellowish brown. Wings hyaline, venation brown.

Head subtriangular, eye large, and face elongate; occiput narrowly emarginate; ocelli small, LOL $1.1 \times$ OOL. Face relatively flat and polished with sparse, decumbent setae: scrobal depression not reaching median ocellus, without parallel channels but with weak median groove; occipital carina weakly developed, extending half distance to eye margin; temple narrow and glabrate. Eyes separated by $1.4 \times$ their height. Malar space $0.5-0.6 \times$ height of eye. Clypeus sparsely setose, epistomal sulcus weakly impressed. Antenna II-segmented; scape reaching $0.8 \times$ distance to median ocellus, cylindrical: pedicel $1.8 \times$ as long as broad; anellus stout; flagellum $0.9 \times$ hcight of head; funicle 7-segmented; F2 twice as long as broad, slightly shorter than pedicel, following segments subequal in length and slightly broader apically; clava ovate, slightly longer than preceding 2 segments.

Mesosoma with midlobe of mesoscutum rugulose and with faint transverse ridges apparent; lateral lobe and axilla smooth and polished with sparse sctae; scutcllum glabrous. SSS deeply loveate with widely spaced. prominent carinae. Scutellum twice as long as broad, base well separated from TSA by broal depression, apex subtruncate; frenal line narrow and weakly foveate. frenal area glabrous, broadly scmicircular in dorsal view; axillula glabrous, axillular sulcus broadly foveate. Callus with few small dorsal setac, callar nib absent. Femoral groove broadly and shallowly impressed, glabrous; sternaular area broadly foveate. Procpisternum mostly glabrous. weakly carinate in anterior half. Coxae glabrous: femora polished with sparse short setac; hind tibia slender. slightly expanded apically. with 2 long spurs. Forewing 2.4-2.5x as long as broad; basal area setose distally: speculum small with irregular margins: stigmal wein als 
long as broad: postmarginal vein $1-1.3 \times$ as long as stigmal vein.

Metusema with petiole 1.7-2.1 $\times$ length of hind coxal. 2.1-2.2 length of propodeum; petiole ribbed, with prominent dorsal flange basally. Gaster lypical lor genus. Hypopygium with 4 or 5 long hairs along apical margin. Ovipositor acicular. Gonostylus narrow and elongate.

\section{MALE}

Differs in the following characters: F2 $2.4 \times$ as long as broad: petiole $2.4 \times$ length of hind coxa, $3.3 \times$ length of propodeum; petiole slightly subtriangular in crosssection, with 4 strong parallel ribs dorsally; gaster typical (genitalia withdrawn).

\section{BIOLOGY}

Collected from Picranopteris (or Picranoft erus [?]). I assume this is a plant, although I can find no literature reference to this generic name.

\section{DISTRIBUTION}

Known only from New Guinea within the Papuan subregion (D, Fig. 277).

\section{ETYMOLOGY}

Named in honour of E. C. Dahms at the Queensland Museum in appreciation for his work on sorting and clarifying Girault's type material.

\section{Psilocharis joanneae sp. nov.}

Figs. 138, 193

\section{TYPE MATERIAL}

Holotype, + , “15.04S 145.07E/ Mt Webb Nat. Pk/ 27-30 Apr. 1981 Q/ I. D. Naumann/ ex ethanol." "collecting/ at light." "AUST. NAT./ INS. COLL." "HOLOTYPE/ Psilocharis/ joanneae Heraty." Deposited in ANIC.

Paratypes: AustraliA: Queensland: same data as holotype (6q․ $2 \delta^{\jmath} \delta$. ANIC); Hope Vale Mission, $14 \mathrm{~km} \mathrm{~W}$ by N. 15.16S 144.59E, 7-10.v.1981, I. D. Naumann, collected at light ( 1 , ANIC); Mt Webb N. P., 28-30.ix.1980, J. C. Cardale, collected at light (5q $q$. ANIC).

\section{DIAGNOSIS}

$P$. joanneae is closely related to $P$. theocles, $P$. dahmsi, and $P$. pacifica: all have axilla and lateral lobe nearly smooth, scutellum quadrate with reduced sculpture. frenum glabrous, and occiput transverse or only slightly emarginate. It can be distinguished from these species in that the eye is relatively large and the malar space is reduced (Fig. 193), the antennal flagellum is short, and the proepisternum is carinate.

\section{FEMALE.}

Length. 1.6-1.9 mm. Head, mesosoma, and petiole black. mesosoma with strong blue-green reflections; gaster and femora dark brown, apical tergites of gaster with faint greenish reflections: antenna, apex of femora, and rest of legs yellowish brown. Wings hyaline, venation pale brown.

Head subcircular (Fig. 193); occiput broadly emarginate; LOL 1.0-1.2× OOL. Face broadly rounded, polished with sparse decumbent setae; scrobal depression reaching $0.6 \times$ distance to median ocellus, parallel grooves absent, median groove crenulate; occipital carina weak, extending just beyond lateral ocellus; temple narrow and smooth. Eyes large, separated by 1.2-1.4x their height. Malar space $0.4-0.5 \times$ height of eye. Clypeus sparsely setose, lateral margin weakly impressed, cpistomal sulcus barely discernible. Antenna 10- to 11-segmented (Fig. 138): scape not reaching median ocellus, slightly expanded medially, narrowing apically and flattened on ventral surface under pedicel; pedicel $2.3 \times$ as long as broad; anellus stout; flagellum $0.6-0.7 \times$ head height; funicle 6 - or 7 segmented, F8 may be partially to completely fused with clava; F2 only slightly longer than broad, following segments subequal in length and slightly increasing in width; clava ovate, wider than funicular segments and as long as preceding 3 segments.

Mesosoma with midlobe of mesoscutum rugose-areolate, often appearing transversely carinate; lateral lobe and axilla polished with sparse setae; scutellum rugose with apex proximal to frenum glabrous. SSS narrow and deeply impressed, crenulate. Scutellum 1.6x as long as broad, subtruncate at apex, base narrowly separated from TSA; frenal line narrow and shallow foveate, frenal area glabrous, narrow, and crescent-shaped in dorsal view; axillula weakly carinate, mostly glabrous: axillular sulcus narrow and shallow foveate with strong lateral carina. Callus with several short hairs along posterior margin, callar nib weakly developed or absent. Femoral groove broadly impressed, reticulate to lightly rugose; sternaular area reticulate to broadly foveate. Proepisternum carinate. Coxae glabrate, femora smooth to weakly imbricate dorsally; hind tibia slender at base tapering to twice that width at apex, with 2 spurs, outer spur minute and hardly discernible from apical setae. Forewing 2.2-2.4x as long as broad; basal area and speculum bare; stigmal vein twice as long as broad; postmarginal vein $1.5 \times$ as long as stigmal vein.

Metasoma with petiole $1.5-2.1 \times$ as long as hind coxa. $1.4-2.1 \times$ as long as propodeum: petiole subcylindrical in cross-section, fincly carinate to ribbed, ventral keel present. without dorsal flange basally. Gaster typical for genus. Hypopygium with 9 or 10 elongate hairs along apical nargin. 
MALE

Length, $1.7 \mathrm{~mm}$. Colour and sculpture as in female, but lower half of face with prominent reddish reflections. Antenna 11-segmented; anellus as long as broad (not disc-shaped as in other species): shape of antenna and flagellomeres as in female; flagellum $0.8 \times$ height of head.

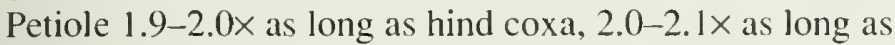
propodeum.

\section{DISTRIBUTION}

North Queensland (Australia) as part of the Papuan subregion (J, Fig. 277). Only 1 specimen of the other Australian species, $P$. theocles, has been collected in north Queensland.

\section{ETYMOLOGY}

Named after my daughter, Joanne.

Psilocharis theocles (Walker) comb. nov.

Figs. 139, 141, 145-146, 151, 194, 213, 223, 264-265

Eucharis theocles Walker, 1839:11-12; Australia: Sydney [BMNH, examined].

Psilogaster theocles-Girault, 1913b:93 (combination); Girault, 1915:232.

Orasema genma Girault, 1934:2; Australia: Queensland [QMB, examined]. Girault, 1936:3 (erroneously published twice). Dahms, 1983:249 (notes on type material). Synonymized by Bouček, 1988:521.

Orasema theocles-Bouček, 1988:521 (combination).

\section{TYPE MATERIAL}

Lectotype of Psilogaster theocles (designated by Bouček, 1988), o , "Lectotype." "Type." "Sydney." "Psilogaster/ theocles (1839)/ Walker." "B.M. TYPE/ HYM. 5.618." "Ò Orasema/ theocles/ (Walk.)/ det. Bouček 1978."

Lectotype of Orasema emma (designated as holotype by Dahms, 1983. and as lectotype by Bouček, 1988), $q$, see discussion of type material by Dahms (1983). Labels added to the card-mounted specimen include "HOLOTYPE/ T.8819/ E.C.D. 1983" and "Lectotype of emma." The label "T8819/ ECD 1983" was added to the slide mount.

\section{DIAGNOSIS}

This species has the following similarities to $P$. joameac, $P$. dahmsi, and $P$. pacifica: lateral lobe, axilla, and frenum smooth and polisheel, scutellum quadrate, and occiput broadly emarginate. It has the following difterences from these species: head subtriangular, eye relatively smaller and malar space larger (0.6-0.9x height of eye; Fig. 194), scutcllum rugose, and procpisternum weakly carinate or smooth.

\section{FEMALE}

Length, 1.8-2.2 mm. Head, mesosoma, and petiole dark brown to black and usually with faint bluish-green or reddish reflections: antennal flagellum, coxae, and gaster dark brown, flagellum sometimes lighter basally: femora dark brown (except apex) to completely yellowish brown or yellow; scape and resı of legs yellowish brown. Wings hyaline to slightly infuscate, venation brown.

Head subtriangular (Fig. 194); occiput only very weakly emarginate; LOL $0.8-1.1 \times$ OOL. Face broadly rounded, polished, and sparsely setose; scrobal depression reaching $0.8 \times$ distance to median ocellus, parallel grooves weakly impressed, median groove, if present, short and smooth; occipital carina weak, extending laterally to dorsal margin of eye; temple narrow and glabrate. Eyes separated by $1.4-1.6 \times$ their height. Malar space $0.6-0.8 \times$ height of eye. Clypeus sparsely setose; lateral margin weakly impressed, epistomal sulcus barely discernible. Antenna 9- to 11-segmented (Fig. 139); scape not reaching median ocellus, cylindrical but flattened ventrally below pedicel; pedicel $2.3 \times$ longer than broad; anellus prominent; flagellum $0.8-1.0 \times$ height of head; funicle 5to 7-segmented; F2 $1.8 \times$ as long as broad and shorter than pedicel, following segments subequal in length and only slightly broader apically: clava ovate, as long as preceding 3 segments, clava and F7-F8 sometines incompletely fused.

Mesosoma with dorsum rugose-areolate: lateral lobe of mesoscutum and axilla smooth and polished with sparse setae; scutellum rugose-areolate with margins weakly sculptured to glabrate. SSS narrow and deeply impressed, crenulate. Scutellum $1.5-1.6 \times$ as long as broad, subtruncate at apex: frenal groove strongly or weakly impressed, frenal area glabrous; axillula glabrous, axillar sulcus deeply impressed and with strong carina. Callus with patch of dense elongate setae dorsally, callar nib prominent or absent. Femoral groove broad (Fig. 223), weakly sculptured to glabrate; sternaular area rugose to lightly reticulate. Proepisternum weakly carinate to glabrate. Coxac glabrate, femora weakly imbricate dorsally. mostly smooth; hind tibia slender. only slightly wider at apex. with 2 spurs. Forewing $2.2-2.4 \times$ as long as broad (Fig. 146): basal area with few sparse setac proximal to speculum; stigmal vein $2-3 x$ as long as broad: postmarginal vein $1.0-1.5 \times$ as long as stigmal vein.

Metasoma with petiole $1.5-2.1 \times$ as long as hind coxa. 1.5-2.(1) as long as propodeum: petiole subtriangular in cross section, ribbed dorsally, aciculate to clongate reticulate sublatcrally, without dorsal flange basally (Fig. 145). Gaster typical (Figs. 264-265). Hypopygium with 81010 elongate hairs along apical margin. 
M. II:

Length, 1.9-2.1 mm. Colour and sculpture as in female, but face with prominent greenish rellections. Antenna 11segmented (Fig. 141), shape of segnents as in female: scape with prominent pores; flagellum 1.0-1.2 $\times$ height of head. Petiole 1.7-2.4x as long as hind coxa, 2.0-2.7x length of propodeum; petiole cylindrical, ribbed dorsally, aciculate ventrally and without ventral keel. Gaster typical, as long as petiole. Genitalia typical (Fig. 151).

\section{HABITAT}

Collections have been made along rainforest margins on low vegetation or in dry sclerophyllus Eucalyptus forests. I have collected this species at 2 locations in Australia: near Brisbanc, adults were collected from short plants in the middle of a hydro-line cut; near Perth, adults were collected from short plants along a trail in an open Jarrah forest. Adults were collected from short, non-flowering, broad-leaf plants, but no direct association with a particular species could be made.

\section{DISTRIBUTION}

Distributed in the Australian subregion in eastern Australia. Tasmania, and southwestern Australia (T. Fig. 277). Numerous records have been made for southeastern Australia and only 1 record from north Queensland (Yungaburra) on the Atherton Tablelands. The western population is almost identical to the eastern populations.

\section{MATERIAL EXAMINED}

Australia: A. C. T.: Black Mtn; Gibraltar Falls; Wombat Ck; Woods Reserve, nr Gibraltar Falls; January to March (6우 $+4 \delta^{\circ} \delta^{\circ}$, ANIC); New South Wales: Brindle Ck: Canley Vale; Casula; Congo, $8 \mathrm{~km} \mathrm{SE}$ by E of Moruya: Dorrigo; Mt Dromedary nr Narooma, 700 m; Gibraltar Range, rainforest margin; Monga State Forest, dry sclero. Eucalyptus forest; Rotary Lookout, 19 km NW Milton: Tooloom Scrub; Tooloom Plateau, via Urbanville, 600-700 m, sweeping low vegetation, rainforest, also at light; nr Wilson's Peak, via Teviot Gap, 700-800 m, sweeping low vegetation, rainforest; October to March, July (39웅. $\left.38 \delta^{\star} \sigma^{\star}, \mathrm{ANIC}, \mathrm{BMNH}, \mathrm{CNC}, \mathrm{UQAB}\right)$ : Queensland: Bald Mtn area, via Emu Vale, 1000-1300 m: Mt Glorious, rainforest, sclerophyll forest; $\mathrm{Mt}$ Tibragargan: Maleny, 7 km SW, 300-450 m, sweeping low vegetation, rainforest/ araucaria cunninghamii plantation boundary; Yungaburra. Atherton Dist.; Decentber to March (17웅, $7 \delta^{\star}$, ANCI, BPBM, BMNH, QMB, ROM, UQAB); Tasmania: Arve Riv. (43.09S, 146.48E); 14 km S Brontc Park (42.15S, 146.29E); Brontc Park. 9 km S; Edwards Rd, Hart\% Mins (43.07S, 146.47E): Franklin Riv. (42.13S, 146.01E); Frodsham's Pass (42.49S 146.23E): Geeveston, $13 \mathrm{~km} \mathrm{W;} \mathrm{Gladstone,} 1 \mathrm{~km}$ SSE (40.58S, 148.01E); Nunamara, $10 \mathrm{~km}$ ENE (41.22S,
147.24E): Port Arthur: Wilmot. $14 \mathrm{~km}$ SW by S (41.30S. 146.05E): January to March (55ㅇ. 31 ठ ठ. AEI, ANIC. BMNH): Victoria: Omeo. $7 \mathrm{~km}$ SW by W; Growler Ck. Lind N. P.: February (2q $q$. ANIC); Western Australia: Crowea S. F. nr Pemberton, October to December ( $3 q$. $1 \delta, \mathrm{ANIC}$ ).

\section{Psilocharis afra sp. nov.}

Figs. 135-136, 148-150, 195, 222

\section{TYPE MATERIAI.}

Holotype, + . "W. Uganda/ Kalinzu Forest/ 5000 ft. [1525 m] July 1972/ H. Falke." "HOLOTYPE Psilocharis/ afra Heraty." Deposited in CNC.

Paratypes: Cameroon [Kamerun]: R. Thaxter (1 $q$, MCZ). KenYA: Malindi, forest near coast, v.1973, H. Falke (10 $q q$, slide no. 883. CNC; $1 q$, ROM): Nanyuki, $2100 \mathrm{~m}, 37^{\circ} 07^{\prime} \mathrm{E}, 0^{\circ} 02^{\prime} \mathrm{S}, 22 . \mathrm{iv} .1973$, Hans Gonget (1 $q$, ZMC); Nairobi, Ngong Rd forest, 11.xii.1990-3.i.1991, B. D. Gill, FIT ( 1 , $1 \sigma^{\circ}$, JMH). Malawi: Nyika Plateau.

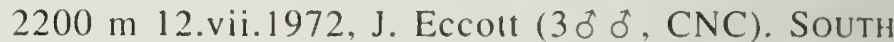
Africa: E. Transvaal, Malta forest, $20 \mathrm{~km} \mathrm{~W}$ Trichardtsdal, 22.xii.1985, M. Sanborne (I oै. CNC); Kruger N. P.. Satara, 16.xii.1985. M. Sanborne (1․ CNC); [Pondoland] Port St. John, 18-31.iii.1924, R. E. Turner ( 1 ठै, BMNH). UGANDA: same data as holotype (10ㅇ․ CNC: 2 우. JMH); Busbinyi(?), iii.1939, H. C.

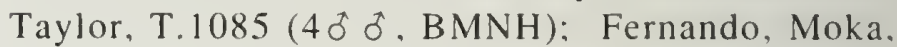
1.ii.1933, W. H. T. Tams (1 9. BMNH); Kayonza forest, Kigezi Dist., v.1972, H. Falke (2웅 CNC); Jinja, Mabira forest, 5-14.iv.1973, H. Falke (1 $q$. CNC); Kawanda, x.1942. T. H. C. Taylor, T.1085 (1 q, BMNH); Kawanda, 1.vii.1942, xi.1942, xii.1943, T. H. C. Taylor. T.1085 (3q ㅇ, 1 đ, BMNH); Lutotoana [?], iii.1939, T. H. C. Taylor (1 ठै, BMNH).

\section{DIAGNOSIS}

Differences from other species: lower face elongate with the posterior margin of the gena hidden in frontal view, scrobal depression with distinct parallel grooves, occipital carina pronounced. midlobe and scutellum completely scabrous to reticulate, and femoral groove of both sexes partially to completely reticulate.

\section{FEMALE}

Length, 1.6-2.0 $\mathrm{mm}$. Black; head, gaster, and mesosoma laterally with laint greenish reflections, mesosomal dorsum with strong greenish reflections (mesosoma all black in some); antennal flagellum and femora brown: scape. tibiac, and tarsi yellowish brown. Wings hyaline, venalion brown.

Head subtriangular, eye large, making face appear narrow and elongate: occiput emarginate: LOL 1.0-1.8x 
OOL. Face relatively flat, polished with sparse decumbent setae; scrobal depression reaching just over half distance between toruli and median ocellus, channels distinct, apex of each channel with distinct semi-circular depression, smooth median groove present (Fig. 195); occipital carina sharp, extending to eye margin; temple broad, obliquely strigate dorsally. Eye with sparse minute setae, separated by $1.2-1.4 \times$ their height. Malar space $0.4-0.6 \times$ height of eye. Clypeus bare to moderately setose; lateral margin sharply impressed. epistonal sulcus absent. Antenna 11-segmented (Fig. 140); scape almost reaching median ocellus, cylindrical; pedicel $1.8 \times$ as long as broad; anellus present; flagellum $0.8-1.0 \times$ height of head; funicle 7-segmented; F2 1.4-2.0× as long as broad, following segments subequal in length, flagellum gradually increasing in width apically; clava acute, as long as preceding 2 flagellomeres.

Mesosoma with midlobe of mesoscutum and scutellum scabrous to reticulate (Fig. 222); lateral lobe irregularly, transverse-carinate: axilla longitudinally carinate. SSS broadly and deeply impressed with several large transverse ribs. Scutellum twice as long as broad, broadly rounded apically, narrowly separated from TSA at base; frenal line narrow and foveate, frenal area vertically carinate, vertical, and hardly visible from above; axillula reticulate, axillular sulcus narrow. Callus with few long setae dorsally and with prominent callar nib. Upper mesepimeron glabrous, lower mesepimeron rugose. transepimeral sulcus broadly foveate; femoral groove broadly impressed, anterior half of groove reticulate. sculpture occurring in irregular patches (Fig. 222); sternaular area narrow and shallowly foveate. Proepisternum smooth to very weakly carinate. Fore and hind coxac weakly imbricate to smooth with sparse setae, mid coxa weakly strigate: femora weakly imbricate with moderately dense setae; hind tibia stout with dense, semi-erect setae and 2 spurs, outer spur minute and barely discernible. Forewing 2.1-2.5x as long as broad; basal area and speculum bare: stigmal vein twice as long as broad; postmarginal vein as long as stigmal vein (Fig. 148).

Metasoma with petiole $1.3-2.1 \times$ length of hind coxa, 1.4-2.0 length of propodeum: petiolc subtriangular in cross section, dorsally ribbed, weakly carinate to aciculate sublatcrally, without dorsal flange at base. Gaster typical for genus. Hypopygium with 10 elongate hairs along apical margin (Fig. 149). Ovipositor acicular, ats in Fig. 150.

\section{MALE:}

Length, 1.3-2.4 mm. Colour and sculpture as in femalte. Antenna 10- or 11-segmented (Fig. 135): scape reaching median ocellus, cylindrical but flattened ventrally: ancllus minute or absent; llagellum 1.6-1.7 $\times$ height of head: F2 $2.0-3.0 \times$ as long as hroad. Petiole $2.0-2.6 \times$ length of hind coxa. 2.3-3.0 length of propodeum; petiole carinate dorsobasally, otherwise aciculate, cylindrical. Gaster small, shorter than petiole. Genitalia typical for genus.

\section{VARIATION}

Little variation was observed in most of the specimens examined including those from Cameroon and South Africa. The male from Lutotoana (Uganda) has a rugose face and completely carinate petiole. A rugose face was found nowhere else in Psilocharis and this specimen was regarded as aberrant. Males collected from the Transvaal are similar to the paratypic males but have a slightly shorter petiole $(2.0 \times$ length of hind coxa). The female from Kruger National Park has very light sculpture on the lateral lobe of the mesoscutum (similar to $P$. monilicera). The females from Kawanda (Uganda) and Malawi have the head and mesosoma black, hind coxa smooth with only a few lateral setae, and the femoral groove almost entirely reticulate.

\section{DISTRIBUTION}

Southern Africa (A, Fig. 277); probably sympatric with $P$. monilicera.

\section{ETYMOLOGY}

From Latin for African; referring to the distribution.

\section{Psilocharis hypena sp. nov.}

Figs. 142-143, 147, 196-198, 224-225, 239-240, 249

\section{TYPE MATERIAI,}

Holotype, + , "BRITISH N. BORNEO:/ Tenompok/ 10-19.11.1959." "T. C. Maa/ Collector/ BISHOP." "HOLOTYPE/ Psilocharis/ hypena Heraty." Deposited in BPBM.

Paratypes: Malaysia: Sabah: Laiwan, 14-19.i.1959. T. C. Maa (1 ठ. BPBM); Mi Matang, 28.i.1914, G. E. Bryant (1 ठै, BMNH); Sensuron, 9-11.i.1959, T. C. Maa (19. BPBM); Tenompok, 10-19.ii.1959, T. C. Maa

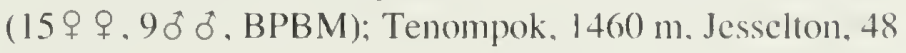
km E, 10-19.ii.1959, T. C. Maa (1 0 . BPBM): Tenompok, 13.ii.1959. T. C. Mila (5q 9.20 ơ. BPBM); Tenompok, 15.ii.1959, T. C. Maa (1 +.10 . BPBM); Salawak: Bau Dist.. Bidi, 90-240 m. 3.ix.1958. T. C. Maal (1,+ BPBM).

\section{DINGNOSIS}

Dilferences from other species: lower lace broad with the posterior margin of the gena rounded and prominent in frontal view (Figs. 196-197). scrobal depression with smooth parallel channels. occipital callina weah. midlobe of mesoscutum and scutellum completely scabrous (1) reticulate (Figs. 239-240), and femoral groove polished 
in female (sometimes coarsely reticulate anteriorly), partially reliculate in male (Figs. 224-225).

\section{FEMALE}

Length. 1.7-2.7 mm. Black. mesosoma with strong greenish reflections. gaster with violaceous reflections basally; antenna and femora dark brown, tibiac and tarsi brown to yellowish brown. Wings hyaline, veins brown.

Head subtriangular (Figs. 196-197): occiput broadly emarginate; LOL 1.0-1.6× OOL. Face broadly rounded, polished with sparse decumbent setae; scrobal depression reaching $0.6 \times$ distance to median ocellus, parallel channels weakly impressed, apex of each channel with distinct semi-circular depression. median groove absent; occipital carina weak or absent, extending to lateral ocellus; temple broad, weakly strigate dorsally. Eye with small erect setae. eyes separated by $1.0-1.3 \times$ their height. Malar space $0.4-0.6 \times$ height of eye. Clypeus sparsely setose to bare except for apical margin of elongate setae, lateral margin weakly impressed, epistomal sulcus absent or weakly impressed. Antenna 11-segmented: scape almost reaching median ocellus, cylindrical but flattened on ventral surface below pedicel; pedicel $2.0 \times$ as long as broad; anellus present; flagellum $0.7-0.9 \times$ height of head; funicle 7-segmented: F2 1.2-1.6× F3, following segments subequal in length, slightly increasing in width to apex; clava conate, as long as preceding 2 segments.

Mesosoma with dorsum rugulose-areolate (Figs. 239-240); lateral lobe and axilla carinate. Scutellum $1.4 \times$ as long as broad, sharply rounded at apex; frenal groove narrow and foveate, frenal area vertically carinate, vertical, and hardly visible in dorsal view; axillula rugose, axillular sulcus narrow and not deeply impressed. Callus with 5 to 13 short hairs, callar nib prominent. Upper and lower mesepimeron smooth, transepimeral sulcus broadly foveate; femoral groove broadly impressed and glabrous; sternaular area broad and deeply foveate anteriorly, abruptly narrowed posteriorly. Proepisternum carinate. Coxae glabrate; hind femora weakly imbricate to smooth with dense short setae; hind tibia narrow basally, broad at apex, with moderately dense, semi-erect setae and 2 spurs, outer spur small. Forewing $2.2-2.4 \times$ as long as broad; basal area and speculum bare; stigmal vein twice as long as broad; postmarginal vein shorter than stigmal vein (Fig. 147).

Metasoma with petiole $1.5-1.8 \times$ as long as hind coxa, $1.5-1.9 \times$ length of propodeum; petiole subtriangular in cross section, ribbed dorsally, aciculate to smooth sublaterally, without dorsal flange at base. Gaster typical for genus. Hypopygium with 8 to 10 elongate hairs along apical margin.
MALE.

Length. 1.7-2.4 mm. Colour and sculpture as in female. Ocelli large, LOL 1.0-1.7× OOL. Eyes separated by $1.1-1.3 \times$ their height. Face generally more setose than in lemale. Antenna II-segmented (Figs. 142-143): scape reaching top of median ocellus, cylindrical, with small pores ventrally; flagellum $0.9-1.1 \times$ height of head; F2 $1.8 \times$ as long as broad. Petiole $1.9-2.5 \times$ length of hind coxa, 1.8-2.8x length of propodeum; petiole cylindrical and strongly carinate, ventral keel not apparent.

\section{HABITAT}

I have collected specimens on understorey plants within a rainforest in Malaysia, and also at 2 localities, both highelevation rainforest, in Nantou Hsien province of Taiwan.

\section{VARIATION}

Over the range of this species. there is variation in the length of the antennal flagellum. density of setae on the callus, presence or absence of setae on the eye, relative size of the eyes to their separation, and relative length of the petiole. Individuals from Borneo consistently have the shortesi flagellum and petiole, eye densely setose, callus with 11 to 13 hairs, and a glabrous frenal area. Individuals from Taiwan are not included within the type material because their antennal flagellum is shorter (0.9-1.0 $\times$ head height for females, 1.0-1.2× for males), petiole is longer $(2.0-2.4 \times$ length of hind coxae for females, 1.9-2.4× for males), dorsal sculpture is weak (Fig. 239), frenal area is glabrous (Figs. 239, 249), and callus has only 3 to 7 hairs. The Taiwanese population is distinct, but collections from Japan have forms that conform with specimens from either Borneo or Taiwan. Specimens from the Indo-Chinese. West Malayan, and Philippine subregions generally agree with the Borneo (East Malayan) forms but have a longer flagellum and petiole (within range of the East Malayan specimens) and various combinations of sculpture and pilosity. The range of variation suggests that only 1 species should be recognized.

\section{DISTRIBUTION}

Widely distributed in the Indo-Chinese and Malayan subregions (H, Fig. 277).

\section{OTHER MATERIAL EXAMINED}

InDIA: H.P.[?]. Newchowk[?], on grass: T. Nadu. Mangarai Forest; September and October (1 $q, 1 \delta^{\circ}$. BMNH, JMH). Indonesia: Sumatra: Aceh, Gunung Leuser N. P., Ketambe Res. Sta., primary young rainforest, closed canopy; same data but $400 \mathrm{~m}$, mature forest, light gap; October to November (1 ㅇ․ I o, MZB, ROM). MALAYSIA: Selangor: 21 km W Gombak, $900 \mathrm{~m}$, rainforest, June ( I đ̃. JMH). JAPAN: Kyushu: Kamiozoegawa. 
Fuji. Saga Prefecture, August and October $\left(4 q q, 3 \delta^{\circ} \delta^{\circ}\right.$ KUEC). PeOPle's RePublic of China: Guangdong: DingHu Mtns, $60 \mathrm{~km} \mathrm{~W}$ of Guangzhou, June (3ठึ ఫ๋. BMNH). Fukien: Chunggan, Bohea Hills, July to August ( $2 q q$, TARI); Kiangsi: Kwangche, Chienmen, August (20 ठे, TARl). PhILIPPINEs: Los Banos ( $1 \%$, USNM). TAIWAN: Nantou Hsien: Meifeng, 2I50 m; Tungpu, $1200 \mathrm{~m}$;
October (21q, $2 \delta$, TARI); Taichung Hsien: Chiapaotai, $750 \mathrm{~m}$, October (1‥10 TARI).

\section{ETYMOLOGY}

From Greek hypene, for mustache; referring to clypeal setae.

\section{Neolosbanus gen. nov.}

Type Species: Eucharis palgravei Girault, 1922:105: by present designation.

Neolosbanus includes a group of species that were originally misplaced in Losbanus Ishii by Watanabe (1958). Watanabe (1958) transferred the species Parapsilogaster laeviceps Gahan and Psilogaster nishidai Ishii and Nagasawa to Losbanus, and described an additional species, Losbanus gressitti Watanabe. Hedqvist (1978) described Losbanus petersoni, and placed Eucharis purpureoventris Cameron in the genus Gollumiella Hedqvist. Bouček (1988) transferred G. purpureoventris to Orasema Cameron and treated L. laeviceps, L. nishidai, and $L$. petersoni as junior synonyms of $O$. purpureoventris. Gollumiella was treated as a subjective junior synonym of Loshanus Ishii based on the description of the type species Losbanus wichancoi Ishii, 1932 (Bouček, 1988). Examination of the type material for L. uichancoi resulted in the transfer of this species to the genus Orasema, and Gollumiella was given revised status in the Eucharitinae by Heraty (1992). Orasema purpureoventris is transferred here to Neolosbanus. Parapsilogaster laeviceps is raised from synonymy with Orasema purpureoventris, and is placed in Neolosbanus. Psilogaster nishidai and Losbanus petersoni are placed here as junior synonyms of $N$. palgravei. which is the type species of Neolosbanus.

Neoloshantis is distinguished from other Eucharitidae by the following features: sculpture of head smooth or punctate, dorsal occipital margin carinate, clypeal margin rounded and without an anteclypeus, palpi 3-segmented, prepectus not fused to pronotum and foveate, femoral groove foveate, petiole gradually narrowed basally, and first gastral sternite smooth (not medially constricted).

\section{(GENERIC DESCRIPTION}

Head subtriangular, 1.2-1.7× as broad as mesosoma; median ocellus anterior to lateral ocelli or arranged in a line. lateral ocellus close to occipital margin. Face smooth and polished or with pits and punctures; serobal depression smooth and broadly impressed: occiput smooth and broadly concave in dorsal view, occipital carina distinct; ocellar-ocular groove absent. Clypeus as high as wide. apical margin rounded and smooth, broadly rounded, or strongly produced over base of mouthparts; epistomal sulcus present or absent; anteclypeus absent. Malar depression present or absent: hypostoma separated from gena by hypostomal carina and extending medially over base of mandible. Labrum 4-digitate, setae of digits long and spatulate. Mandibles falcate and 2/3 toothed (Figs. 200, 203-204, 206); maxilla and labium elongate, maxillary and labial palpi each 3-segmented, palpi long and thin with only few minute setae. Antenna 10- to 13 -segmented; scape elongate and usually cylindrical, usually reaching median ocellus; pedicel short. not much longer than broad; anellus present or absent; funicle 7- or 8-segmented, segments cylindrical with basal secondary segmentation (Figs. 214-216), and densely setose; basal funicular segments more than $2.5 \times$ as long as broad, rarely shorter. terminal 2 or 3 segments fused into clava.

Mesoscutum with notauli well defined along entire length. TSA complete. SSS usually foveate, slightly angled to midline, and reaching TSA through medial depression. Scutellum with frenal area usually separated by distinct frenal groove. frenal area polished or weakly sculptured: axillular sulcus weak. Metanotum usually extended laterally as smooth flange overlapping base of propodeum and partially covering propodeal spiracles: spiracles close 10 dorsal margin of propodeum (Neoloshanus townesi and $N$. laeviceps with weak flange and spiracle exposed; Fig. 250). Propodeal disc rounded and smooth latterally, usually with medial band of rugoseareolate sculpture; callus only slightly swollen and polished with few to many setae but without callar nib. Mesopleuron smooth: mesepimeron relatively flat. transepimeral sulcus usually present (mesopleural sulci absent only in N. townesi): femoral groove narrow and loveate, continuing to ventral margin of mesepistemum; sternaular area of mesepisternum foveate in some species. Prepectus reaching tegula as triangular or fingerlike dorsal lobe. strongly narrowed ventrally, dorsal lohe lioveate (rounded in N. townesi). Procpistermum tlat and glabrous. 
Cosate and femora smooth and shining; tibiac with spurs 1-1-2; hind tarsus only slightly shorter than tibial.

lling veins of fore and hind wings well defined. Forewing 2.3-2.7x als long as broad, broadly rounded apically; disc densely pilose, marginal fringe short; submarginal vein with short setae dorsally; marginal vein $0.25-0.36 \times$ as long as forewing and pilose; stigmal vein less that $3 \times$ longer than broad, as broad as or narrower than marginal vein: postmarginal vein short or long.

Metasoma with petiole of both sexes more than $1.3 \times$ as long as hind coxa, gradually narrowed basally, without dorsal or lateral flange (Fig. 159), cylindrical and fused ventrally. Gastral terga smooth and shining, usually bare, gaster of female as long as head and mesosoma or slightly shorter, gaster of male slightly longer than hind femur; $\mathrm{Mt}_{2}$ of female more than $0.9-1.0 \times$ as long as hind femur; $\mathrm{Ms}_{2}$ smooth and without basal constriction. Hypopygium bare or with few short setae on either side of midline. $\mathrm{Ms}_{8}$ of male densely setose apically. Cercus with few elongate setae of equal length. Gonostylus narrow or broad, fused to second valvifer. Ovipositor needlelike or expanded, sculpture variable between species. Male with paramere well developed and bearing several stout setae, digitus disclike with several stout marginal spines; aedeagus narrow or broad.

\section{ETYMOLOGY}

Combination of Greek neo, meaning new, and loshamus from the genus name originally proposed for specimens collected from Los Banos in the Philippines: gender masculine.

\section{PHYLOGENETIC RELATIONSHIPS}

Of the 4 species-groups recognized in Neolosbamus, the gemma-group has 3 species (apoanus, gemma, and wusheanus), the purpureoventris-group has 3 species (purpureoventris, storeyi, and watanabei), the palgraveigroup has 6 species (laeviceps, nepalensis, palgravei, pilosus, taiw'anensis, and townesi), and the gressitti-group has 4 species (anapetus, gressitti, kokureanus, and violaceus). Unnumbered characters discussed below were not used in the phylogenetic analysis of higher relationships as they are considered of value only at the species level.

The gemma- and purpureoventris-groups both have a needlelike ovipositor (42) and cylindrical gonostylus or sheath (46). Both of these states are plesiomorphic for Neolosbanus and are shared with at least 1, but not all, of the outgroups. The presence of a unique (crenulate) scrobal depression (9), broad gonostylus, and absence of MPS in males distinguish the gemma-group from other species of Neoloshamus. No resolution of species within the gemma-group was possible. The presence of a glabrous frenum suggests a close relationship between $N$. wrusheanus and N. apoanus; however, this character state is found throughout the outgroup taxa and its polarity is uncertain.

The remaining species are interpreted as monophyletic based on an increase in the number of funicular segments in males (from 7108 or 9) (character 4; Table 2), and a glabrous occiput (with reversal in the gressitti-group). Three additional synapomorphies include the apex of the clypeus extended as a strong lobe (12), prepectus narrowed to a fine ridge along the ventral half, and sternaular area smooth, but these are all proposed to have undergone reversal in the gressinti-group. The instability of these last characters suggests that the purpureoventris- and palgravei-groups are sister groups, and that the expanded ovipositor in the palgravei-and gressitti-groups may have been independently derived within Neoloshanus. This is further suggested by morphological differences of the ovipositor found in the gressitti-group. including absence of lateral ridges on the first valvula (43), widely separated lateral teeth on the second valvula (44), and an even thickening of the ovipositor (versus subapical expansion).

The purpureoventris-group is monophyletic based on presence of 9 funicular segments in males (4), and stigmal vein strongly angled distally (35). The ovipositor is needlelike (42). which is regarded as plesiomorphic for Eucharitidae, and the gonostylus is narrow and elongate. sometimes exceeding the cercus. Within the purpureorentris-group, $N$. purpureoventris and $N$. storeyi may be sister species based on having a striate frenum. The raised ocellar triangle of $N$. storey $i$ is autapomorphic within Neoloshanus.

Monophyly of the palgravei-group is based on the following: ovipositor subapically expanded, first valvula with oblique ridges (43), and second valvula narrow with the ridges coalescing dorsally (44), all states that are found in some or all Oraseminae. Except for $N$. townesi, other species in this group share a 7-segmented funicle in females (5), and strong projection of the clypeal margin (12). Neolosbanus townesi is treated as the derived sister species to $N$. laeviceps based on loss of the anellus (1), expansion of the scape of males, and an enlarged truncate $\mathrm{Ms}_{8}$. with autapomorphic reversals to a rounded clypeal margin (12) and independent derivation of an 8-segmented funicle in females (5). Except for loss of the anellus, character states of $N$. townesi are also shared with species in the gressitti-group. Of the remaining species in the palgravei-group. $N$. pilosus and $N$. taiwanensis share a densely pilose mesosoma. and together are treated as the sister group to $N$. nepalensis and $N$. palgravei, although no synapomorphies were found to support this latter group.

Monophyly of the gressitti-group is supported by the 8 -segmented female funicle (5), and second valvula broad and smooth with strong lateral teeth (44). Monophyly of 
this group is proposed by a reversal in clypeal shape (12) and shape of the ventral half of the prepectus (narrow but not ridgelike) (20). A yellow femur is found only in $N$. gressitti and $N$. kokureanus and may support a closer relationship between these species. Monophyly of the remaining species is based on presence of a reduced malar depression (10), and complete facial sculpture (8). The presence of sternaular sculpture and a striate frenum in these taxa may be plesiomorphic. Males of N. gressitti are unknown but may have a more strongly sculptured face, as in $N$. kokureanus. If the reduction of the sternaular sculpture and glabrous frenum are autapomorphic for $N$. gressitti, then $N$. gressitti and $N$. kokurecmus would form the sister group to the remaining species in this group. Monophyly of $N$. anapetus and $N$. violaceus is suggested by the sculptured occiput, expanded scape of males, and brown femur, which may all be plesiomorphic. but adults of both sexes also have a strongly sculptured face and are morphologically very similar. No further relationships among these species could be assessed.

The relationships among species of Neolosbantis may be described as ((gemma + wusheanus + apoanus $)+$ $(($ watanabei $+($ purpureoventris + storeyi $))+(($ townesi + (laeviceps $+(($ pilosus + taiwanensis $)+$ nepalensis + palgravei $)))+(($ gressitti + kokurcanus $)+($ anapctus + violaceus))))) (Figs. 278-279).

\section{BIOLOGY AND IMMATURE STAGES}

The immature stages of $N$. palgravei are described in the earlier section on biology of Psilocharitini. I reared both $N$. gemma and $N$. palgravei from the cocoons of Hypoponera (Formicidae: Ponerinae). There is no question that these 2 species belong to well-separated clades within Neolosbanus and it may be postulated that most species of Neoloshantus are parasitic on Hypoponera. Except for one derived group of Eucharitinae (on Formicinae), other members of this subfamily are almost all parasitic on Ponerinae. Almost all known hosts for Oraseminae are Myrmicinac, with a few rare records of Formicinac and Ecitoninae (Heraty, 1990). No ant host is known for the proposed sister group. Psilocharis.

Detailed plant-host records for $N$. palgravei suggest that eggs are deposited into the leaves of a wide varicty of host plants. Additional plant records are known only for N. townesi; adults were collected on Castanopsis (same as for $N$. palgravei) and bamboo, which suggests similar habits for members of the palgravei-group. The type material of $N$. gemma was collected from a flower and may indicate a different strategy for species with an acicular ovipositor.

First-instar larvac of $N$. laeviceps and $N$. palgravei share derived character states with other Eucharitinac. The mature larvac of $N$. palgravei and the pupae of $N$. gemma and $N$. palgravei are simple and lack any of the derived character states of Orasema (see Wheeler. 1907; Heraty, 1990). The mature larvae and pupae are plesiomorphic in morphology and hence do not support inclusion within Eucharitinae; however, absence of any shared states with Oraseminae argue against this genus" having evolved from within Orasema from groups that share a similar propodeal morphology and expansion of the ovipositor.

Whether the ancestor of a monophyletic group comprised of Oraseminae and Eucharitinae had an expanded, strongly ridged ovipositor is unknown. It is absent (needlelike) from all of the proposed outgroup taxa and is therefore assumed to be plesiomorphic for Eucharitidae. Small differences in the morphology of the first and second valvulae, and incongruence with other characters, suggest that the expanded ovipositor was derived once or twice within Neolosbanus, and independent from Oraseminae. The ovipositor is utilized in a similar way to Oraseminae for depositing eggs into plant tissue in chambers hollowed out by the ovipositor. The method of egg deposition in Psilocharis and the gemma- and purpureoventris-groups, which have a needlelike ovipositor, is unknown; however, other Eucharitinae with a similar ovipositor deposit eggs into preformed cavities in plant tissue or on the leaf surface.

\section{DISTRIBUTION}

Sixteen species of Neolosbanus are distributed throughout the Indo-Pacific region, excluding the Australian subregion (Figs. 278-280). Extreme disjunctions for this genus are represented by records of Neolosbanus palgravei in Algeria and another species (possibly new) in Uruguay (see description of $N$. violaceus). The record of the specimen from Uruguay appears to be valid but odd, considering that it is regarded as a member of a derived group found only in the Malayan. Papuan, and Polynesian subregions.

Hypoponera are widely distributed around the world in tropical and subtropical regions in predominantly mesic habitats (Brown. 1973), and limitations to the distribution of Neolosbanus cannot be attributed to the distribution of the host ant. The same may be said in conjunction with the lack of specificity toward plant hosts. Species of Neolosbanus are virtually all restricted to the Indo-Pacific region. and occur only within the Papuan subregion of Australia. One specimen of $N$. palgravei, which is identical to specimens from the Indo-Chinese subregion. is known from Algeria. This may be an inaccurate data label or a true extension of the range into northern Africa. If true. then I would explain this as western dispersal of the most common Indo-Pacific species.

The disjunct placement of the specimen from Uruguay, as a derived member close to $\mathrm{N}$. violacens of the gressitti-group, is difficult to explain. The most close- 
ly relited species is found in Mallaysia and the collection dital appear to be valid (see description of $N$. violacelas). It is possible that this species was recently colonized in South America by buman intercession as part of ship's balliast or some other accidental means. 1 lind it unlikely that this is part of at relictual distribution of species in this genus, but this is a possibility.

There is little resolution of species relationships to suggest biogeographic hypotheses in the Indo-Pacific region. Relationships do suggest that species found in the
Pilpuan and Polynesian subregions are the more highly derived, and that distributions of extant taxa may have originated from a mainland Indo-Chinese ancestor. Only N. palgravei is widely distributed throughout the region, which indicates good dispersal capacity, but regional variation shows that some isolation is evident. The above hypotheses are concordant with an evolution and radiation of species since the Miocene and connection of the Australian plate to the Malaysian Archipelago (Keast, 1981; Axelrod and Raven, 1982; Noonan, 1985).

\section{Key to Species of Neolosbanus}

Scrobal depression with 2 vertical crenulate channels extending from torulus to median ocellus, median area between channels polished (Figs. 153-154); funicle of both sexes 7-segmented (Figs. 152, 157-158); MPS absent in male, present in female; ovipositor needlelike....

.gemma-group, 2

Scrobal depression completely smooth; funicle of female 7- or 8-segmented, funicle of male 8or 9-segmented (Figs. 168, 171, 180-186); MPS present in both sexes; ovipositor needlelike or expanded ..4

2 (1) Frenal area roughly sculptured and vertical; hind tibia dark brown to black; eye large (Fig. 153); Australia N. gemma (Girault), p. 98

- Frenal area glabrous and angled 45-80 degrees to dorsum (Fig. 152); hind tibia yellowish brown; eye moderate in size (Fig. 154)..............3

3 (2) Postmarginal vein 3.3-4x length of stigmal vein (Fig. 160); sternaular area rugose-alveolate; antennal flagellomeres closely appressed and cylindrical (Fig. 157); funicular segments of male enlarged basally, F2 broader than pedicel, following segments tapering to apex; IndoChinese subregion .

.N. wusheanus sp. nov., p. 99

Postmarginal vein $2.8-3.2 \times$ length of stigmal vein; sternaular sculpture foveate; antennal flagellomeres of male elearly separated and slightly flared apically (Fig. 158); F2 as broad as pedicel. following segments equal in width: female unknown; Philippines.

.N. apoanus sp. nov., p. 100
4 (1) Stigmal vein strongly angled relative to anterior wing margin (Fig. 169); postmarginal vein more than $3 \times$ as long as stigmal vein (Fig. 169): ovipositor needlelike (Figs. 271-272); gonostylus long and narrow, sometimes exceeding cercus; antenna of male 13-segmented

.purpureoventris-group, 5

- Stigmal vein almost perpendicular relative to anterior wing margin (Figs. 162, 164-165): postmarginal vein short, at most slightly longer than stigmal vein; ovipositor expanded and strongly ridged (Figs. 266-270); gonostylus broad and tapering to apex. not exceeding cercus; antenna of male 11-or 12-segmented

5 (4) Head with shallow groove along anterior margin of ocellar triangle, groove extending from anterior margin of median ocellus to outer margin of lateral ocellus and continuing around ocellus 10 occipital carina (Fig. 179); New Guinea. Queensland.... N. storeyi sp. nov., p. 101

Head without any indication of groove, vertex and ocellar triangle evenly rounded .6

6 (5) Frenum glabrous, at most with single faint median carina; Philippines, Palau Islands. .N. watanabei sp. nov., p. 102

Frenum vertically striate; Indo-Chinese, Malayan, Sulawesi subregions

N. purpureoventris (Walker), p. 103

7 (4) Face and frenum completely polished (Figs. 201-205); stigmal vein more than $1.5 \times$ as long as broald, postmarginal vein more than $1.5 \times$ as long as stigmal vein (Figs. 162, 165); ovipositor 
usually subapically expanded, rarely thickened along entire length; first valvula with diagonal lateral ridges (Figs. 267, 269); second valvula narrow, apical ridges meeting along midline ...... palgravei-group, 8

- Face smooth, partially punctate, or completely sculptured (Figs. 176, 206-208), and frenum glabrous or carinate (Fig. 254); stigmal vein as long as broad, postmarginal vein less than $1.5 \times$ as long as stigmal vein (Fig. 164); ovipositor thickened along entire length; first valvula completely smooth (Fig. 270); second valvula broad, smooth medially with strong teeth on lateral margin gressitti-group, 13

8 (7) Anellus absent; scape expanded apically, strongly so in male (Figs. 171, 184); frenal groove absent or weakly impressed dorsally; dorsum of mesosoma lightly sculptured (Figs. 241-242): $\mathrm{Ms}_{8}$ of male broader than petiole and truncate apically . .9

- Anellus present (may be small and indistinct but always visible with transmitted light); scape narrow and cylindrical (Figs. 180-182); frenal groove foveate; dorsum of mesosoma strongly rugose-areolate to areolate (Figs. 243-244); $\mathrm{Ms}_{8}$ of male narrower than petiole, rounded apically.

10

9 (7) Prepectus swollen medially (Fig. 226); mesosoma almost completely glabrous dorsally and laterally (Figs. 241, 250); funicle of female 8-segmented; New Guinea.

N. townesi sp. nov., p. 104

- Prepectus foveate medially (Fig. 227); mesosoma lightly sculptured dorsally (Fig. 242); funicle of female 7-segmented; Indo-Chinese

N. laeviceps (Gahan), p. 105

10 (8) Head, mesosoma, and petiole moderately to densely pilose (Figs. 202, 229); length of head in dorsal view short at median ocellus, not exceeding diameter of median ocellus (Fig. 178); scrobal depression broadly and deeply impressed 11

Body sparsely setose (Figs. 227-228, 230-233). petiole completely bare; length of head in ctorsal vicw long at median ocellus, exceeding diameter of median ocellus by more than $1.5 \times$ (as in Fig. 179): scrobal depression shaltow and indistinct
11 (10) Head and mesosoma moderately pilose, eye with sparse setae; propodeum with median carina: hind tibia dark brown to black; in male, petiole $2.2-2.9 \times$ as long as hind coxa and $2.2-2.7 \times$ as long as propodeum; female unknown; China, Taiwan ................ taiwanensis sp. nov., p. 106

- Head and mesosoma densely pilose, eye with dense setae (Fig. 202); propodeum smooth, without median carina; hind tibia yellowish brown: in male, petiole $2.6-3.5 \times$ hind coxa and 2.7-3.4x length of propodeum; Malayan subregion, ?New Guinea.. N. pilosus sp. nov., p. 107

12 (10) Flagellum of female more than $1.5 \times$ height of head, flagellum of male more than $2.2 \times$ height of head; callus with more than 15 hairs (Figs. 230. 252 ) hind tibia white or yellowish brown in both sexes; Nepal.....

N. nepalensis sp. nov., p. 108

- Flagellum of female less than $1.4 \times$ height of head, flagellum of male less than $2.1 \times$ height of head; callus bare or with few hairs (Figs. 231. 253), if pilose (India, Nepal, and Algeria) then hairs short, fine, and less than 10 are present; hind tibia white to dark brown in female, always dark brown in male; Indo-Pacific region and ?Algeria N. palgravei (Girault), p. 109

13 (7) Femora yellow; frenum polished (may be rugose in male); face of female polished with few scattered pits lateral to supraclypeal area (Fig. 176). face of male punctate to weakly rugose; $\mathrm{Ms}_{8}$ of male broad and truncate 14

Femora dark brown to black except extreme apex; frenum with widely spaced longitudinal carinae (Figs. 232-233, 245, 254); face in both sexes completely pitted, coriaceous, or rugulose (Figs. 206-208): $\mathrm{Ms}_{8}$ of male narrow and rounded.

14 (13) Anellus absent; head and mesosoma dark brow'n to black: lateral lobe weakly sculptured to smooth, scutellum partially carinate: male unknown; E. Caroline Islands (Ponape).

$$
\text { N. gressitfi (Watanabe), p. } 114
$$

Anetlus present (Fig. 177): head and mesosoma dark blue-green: lateral lobe transversely striate, scutellum rugose-areolate; New Guinea and Solomon Islands

N. kokureanus sp. nov., p. 114 
15 (1.3) Midlobe of mesoscutum and scutellum linely and shallowly rugose-areolate dorsally (Fig. 245): hind tibia yellowish brown: scape of male expanded apically and with distinct apical flange on inner side; basal flagellomeres of male compressed, F2 noticeably broader than F3 (Fig. 186): mesosoma dark green; Borneo and Philippines

N. anapetus sp. nov., p. 115
Midlobe of mesoscutum and scutellum scabrous or deeply rugose-areolate dorsally; hind tibia yellow or brown: scape of male cylindrical or expanded medially (not apically); basal flagellomeres of male cylindrical, F2 not noticeably broader than F3 (Fig. 185); mesosoma dark blue or black, sometimes with strong violaceous reflections; New Guinea

N. violaceus sp. nov., p. 116

\section{Neolosbanus gemma-group}

This group of 3 species has the ovipositor acicular, scrobal channels crenulate, funicle of both sexes 7-segmented, and the clypeal margin weakly rounded. These species are uncommon but widespread in the Indo-Pacific region from Taiwan to northern Australia.

\section{GROUP DESCRIPTION}

Head $0.3-0.4 \times$ as long as wide; ocelli arranged in triangle, median ocellus not exceeding line drawn across anterior margin of lateral ocelli. Face smooth with scattered short setae; scrobal depression shallow with 2 parallel crenulate grooves extending from torulus to median ocellus, surface slightly raised and polished between grooves; occiput aciculate. Clypeal margin broadly rounded with line of fine setae along apical margin, clypeus not strongly produced over base of mouthparts, epistomal sulcus weak or absent. Malar depression linear and strongly impressed along entire length. Antenna 11 segmented; scape narrow and cylindrical in both sexes, presence of pores on male scape not assessed; anellus present; funicle of both sexes 7-segmented; female with sparse MPS, male without MPS.

Mesosoma with dorsum of mesoscutum transversely carinate (Fig. 155) or irregularly transverse-areolate (appearing striate); scutellum rugose-alveolate; frenal line foveate: frenal area glabrous or carinate, vertical angle to dorsum variable; axillula glabrous, axillular sulcus weak. Mesepimeron mostly smooth: femoral groove and transepimeral sulcus foveate; mesepisternum with wedgeshaped sternaular sculpture. Prepectus foveate and triangular dorsally, gradually narrowed ventrally, polished below upper triangular lobe. Forewing $2.4 \times$ as long as broad (Fig. 160); speculum and basal area bare: stigmal vein narrow, $1.5-2.5 \times$ as long as broad; postmarginal vein more than $2 \times$ as long as stigmal vein.

Gaster with basal tergat glabrous. Ovipositor needlelike; first valvula smooth; second valvula with minute dorsal ridges connecting medially. Gonostylus elongate and broad (partially concealed on material available), not exceeding cercus. $\mathrm{Ms}_{8}$ of male narrow and rounded api- cally. Genitalia of male with paramere narrow and elongate, bearing 2 stout setae; aedeagus subacute.

\section{Neolosbanus gemma (Girault) comb. nov.} Figs. 26, 153, 159

Orasema gemma Girault, 1932:4 [289]. Queensland, Australia [QMB, examined]. Dahms, 1984:646 (notes on type material).

\section{TYPE MATERIAL}

Lectotype (designated Bouček, 1988), + , "ex. flower." "Kuranda, Q./ March 1921 F.P.D." "LECTOTYPE." "SYNTYPE/ T.8969/ E.C.D. 1983." "Orasema/ gemma Gir/ Cotypes." "LECTOTYPE/ + Orasema/ gemma Grlt./ det. Z. Bouček, 1986."

Paralectotypes: same data as lectotype, type numbers T.8967-68, T.8970-71, 4 우. Additional slide material: "Orasema/ gemma Gir/ o type." "SYNTYPES/ T.8967-T.8971 ECD 1983 [red label]."

\section{DIAGNOSIS}

Close to $N$. w'usheanus but differs in that frenum abrupt and roughly sculptured, femora, trochanters. and hind tibia uniform brown with reddish reflections, LOL/OOL ratio large, and antennal segments distinctly separated.

\section{FEMALE}

Length, $2.2 \mathrm{~mm}$. Head and mesosoma dark metallic green. strongest colour on mesosomal dorsum: mesosoma laterally and coxae with additional faint reddish reflections; gaster black; antennal flagellum dark brown; femora, trochanters, and hind tibia uniform brown with reddish rellections; scape, fore and mid tibiac, and tarsi dark yellowish brown. Wings hyaline, venation clear yellowish brown.

Head subcircular (Fig. 153); occiput broadly rounded: median ocellus separated from occiput by own diameter; LOL $1.2 \times$ OOL. Face broadly rounded, smooth or with 
several weak punctures lateral to torulus, setae moderately dense and minute; occipital carina extending to dorsal eye margin; temple narrow and weakly aciculate. Eyes large, separated by $1.4 \times$ their height. Malar space $0.4 \times$ height of eye. Antenna 11-segmented; pedicel slightly longer than broad; flagellum $1.0 \times$ height of head; funicular segments densely setose with scabriculous surface sculpture; F2 narrow, $2.7 \times$ as long as broad, about twice as long as pedicel, following segments subequal in length, slightly wider towards apex of flagellum; clava ovate, as long as preceding 2 segments.

Mesosoma with dorsum deeply rugose-alveolate to scabrous, septa of midlobe of mesoscutum aligned in transversely carinate pattern; lateral lobe transversely carinate; axilla obliquely carinate. Scutellum slightly longer than broad; frenal line weak and obscured by dorsal sculpture, frenal area polished with irregular vertical carinae, nearly vertical in profile. Propodeum smooth with rugose-areolate median band; callus with several short setae. Coxae polished with sparse setae; femora polished with moderately dense short setae; hind tibia with 2 distinct spurs. Forewings $2.2 \times$ as long as broad, $2.7 \times$ as long as mesothorax; stigmal vein perpendicular to wing margin, $2.5 \times$ as long as broad; postmarginal vein $3.2 \times$ as long as stigmal vein.

Metasoma with petiole $1.8 \times$ length of hind coxa, $1.6 \times$ length of propodeum; petiole ribbed dorsally and carinate ventrally (Fig. 159). Ovipositor acicular.

\section{MALE}

Unknown.

\section{VARIATION}

The lectotype has sparse setiferous punctation similar to that found in $N$. gressitti and N. kokureanus of the gressitti-group. All other specimens have the face completely smooth.

\section{BIOLOGY}

Removed from cocoon of Hypoponera sp. in a colony also parasitized by $N$. palgravei. Pupa (Fig. 26). No host remains or cast skins of earlier instars remained in the cocoon. 1 collected this species along a path in a rainforest. The type material was collected from an unidentificd flower near this locality.

\section{DISTRIBUTION}

Known only from a single locality in north Queensland (Australia), which falls within the Papuan subregion (G, Fig. 278).

\section{MATERIAL EXAMINED}

Australia: Quccnsland: Kurandia, $1.5 \mathrm{~km}$ SE, 16-17.v.1980. I. D. Naumann and J. C. Cardale, collected at light ( 1 ㅇ, ANIC): Kuranda, $2.8 \mathrm{~km} \mathrm{~N}$ on Black Mountain Rd, 23.iv.90, J. Heraty, ex cocoon of Hypoponera sp. (1 9 pupa, JMH).

\section{Neolosbanus wusheanus sp. nov.}

Figs. 152, 154-157, 160

\section{TYPE MATERIAL}

Holotype, + , "Wushe, Taiwan/ 1150 m IV-2-83/ Henry Townes." "HOLOTYPE/ Neolosbanus/ wusheanus Heraty." Deposited in AEI.

Paratypes: TAIWAN: Nantou Hsien: same data as holotype ( 1 o, AEI); Tungpu, 1200 m, 16-20.iv.1984, K. C. Chou and C. H. Yung ( 1 \& , TARI).

\section{DIAGNOSIS}

Distinguished from $N$. gemma by the following: frenum glabrous and extended in dorsal view (Figs. 152, 155), hind tibia and trochanter yellowish brown, hind femur black with greenish reflections, LOL/OOL ratio small, and flagellar segments closely appressed (Fig. 152). The antennal flagellum of the male is distinct from $N$. apoanus.

\section{FEMALE}

Length, 2.2-2.4 $\mathrm{mm}$. Head, mesosoma, and petiole dark metallic green; gaster black with green reflections; antennal flagellum dark brown to black; coxae and femora black with green reflections; scape, trochanters, apex of femora, and rest of legs yellow to light brown. Wings hyaline, venation brown.

Head subcircular (Fig. 154); occiput weakly emarginate; median ocellus separated from occiput by less than own diameter; LOL $0.7 \times$ OOL. Face broadly rounded, polished, sctac sparse and minute; occipital carina weak and extending to lateral ocellus; temple narrow and aciculate dorsally. Eyes large, separated by 1.6-1.7× their height. Malar space $0.6 \times$ height of eye. Antenna $11-\mathrm{scg}-$ mented; pedicel as long as broad: flagellum $0.9-1.0 \times$ height of head, funicular segments densely setose with reticulate surface sculpture; F2 $1.8 \times$ as long as broad. following segments subequal in length, only slightly wider towards apex of llagellum; clava ovate, as long as preceding 2 segments.

Mesosoma dorsally with scutellum and posterior half of midlobe of mesoscutum arcolate. midlobe anteriorly and lateral lobe transversely carinate: axilla obliquely carinate (Fig. 155). Scutellum as long as broad; frenal line narrow and shallow, frenal area crescent-shaped in dorsal view, broadly rounded in profile and angled ahout 45 degrees to dorsum, glabrous. Propodeum smooth with rugose-areolate median band: callus with several short setie. Coxac glabrate: femora polished with moderatcly 
dense short setale: hind tibia with I spur surrounded by long apicall fringe. Forewing $2.4-2.5 x$ als long as broad (Fig. 160), Iw ice as long as mesosoma; stigmal vein perpendicular to wing margin. twice as long as broad; posterior marginal vein $2.6 x$ as long as stigmal vein.

Metasoma with petiole $1.7-1.8 \times$ as long as hind coxa, $1.5-1.7 \times$ as long as propodeum; petiole ribbed dorsally and carinate ventrally. Ms, with weak medial constriction (as in Fig. 273). Ovipositor acicular (Fig. 152).

\section{MALE}

Length, $2.4 \mathrm{~mm}$. Colour and sculpture as in female. Ocelli larger, and wings slightly infuscate. Antenna 11 -scgmented: scape almost reaching median ocellus: anellus small; flagellum $2.0 \times$ height of head; F2 stout, $2.3 \times$ as long as broad and as long as scape, following segments subequal in length and width: clava cylindrical, twice length of preceding segment. Petiole $2.4 \times$ length of hind coxa, $2.4 \times$ length of propodeum. Gaster as long as petiole; $\mathrm{Ms}_{2}$ with weak medial constriction. Genitalia typical for genus, with strong median process, paramere elongate with long terminal seta and 3 long setae basally: aedeagus narrow and weakly sclerotized.

\section{VARIATION}

Single specimens from Thailand and Vietnam differ slightly from the type material and are not included as part of the species description. The female from Vietnam has a distinctive reddish coloration, all tibiae are dark brown with reddish reflections, and the petiole is strongly ribbed. The female from Thailand is similar to the type material but differs in the length of the petiole $(2.3 \times$ length of hind coxa) and enlarged eyes (malar space $0.4 \times$ height of eye).

\section{DISTRIBUTION}

This species, as broadly defined, occupies an IndoChinese distribution (U, Fig. 278).

\section{OTHER MATERIAL, EXAMINED}

THAILAND: Chingdao, 5-11.iv.1958, native collector ( 1 \% BPBM). Vietnam: Karyu Danar, 200 m, 13-28.ii.1961, N. R. Spencer ( 1 \&, BPBM).

\section{ETYMOLOGY}

From Wushe, the type locality.

\section{Neolosbanus apoanus sp. nov.}

Figs. 158, 161

\section{TYPE MATERIAI.}

Holotype, ơ, "Galog Riv./ $6.000 \mathrm{ft}$ [1830 m] Sept. 12." "Mt Apo, Mindanao/ Phil. Islds., C. S. Cligg." "HOLO-
TYPE/ Neolosbanus/ apoanus Heraty." Deposited in MCZ.

Paratypes:Philupernes: Mindanao: Mt Apo, Galog Riv. $6000^{\circ}[1830 \mathrm{~m}$ ], 28.ix, C. F. Clagg (10, MCZ); Mt Apo, Tia Ridge. $6500^{\circ}[1980 \mathrm{~m}$ ], ix. C. F. Clagg (1 ठ . MCZ).

\section{DIACiNOSIS}

Recognized by: flagellar segments separated, elongate. and slightly flared (Fig. 158), frenum smooth, and legs honey yellow.

\section{MALE}

Length, 2.7-2.9 mm. Black with bluish green reflections, strongest reflections on mesosoma dorsum; gaster black; antennal flagellum black; coxae black with greenish reflections; mid and hind femora brown medially; scape, trochanters, base, and apex of mid and hind femora, all of fore femur. tibiac, and tarsi light honey yellow. Wings hyaline, venation brown.

Head subtriangular; occiput broadly rounded; median ocellus separated from posterior margin by less than own radius; LOL 1.1-1.4× OOL. Face broadly rounded, polished; occipital carina sharp. extending almost to eye margin; temple narrow and smooth. Eyes separated by 1.4-1.6× their height. Malar space $0.6-0.7 \times$ height of eye. Antenna 11-segmented (Fig. 158): pedicel as long as broad, only slightly broader than F2 at base; flagellum 2.4-2.5x height of head; funicular segments with dense, semi-erect setae and scabriculous surface sculpture: F2 $2.6 \times$ as long as broad. slightly longer than scape. following segments subequal in length. only slightly decreasing in width, each funicular segment elongate, cylindrical, and widely separated between segments; clava cylindrical, $1.5 \times$ as long as preceding segment.

Mesosoma with dorsum rugose-areolate: lateral lobe of mesoscutum transversely carinate; axilla obliquely carinate. Scutellum $1.3 \times$ as long as broad, broadly rounded at apex; frenal line narrowly impressed, frenal area glabrous, crescentic in dorsal view. angled 70 to 80 degrees to dorsum. Propodeum smooth with rugose-areolate median band; callus with several short setae. Coxae glabrate; hind femur polished with sparse short setae; hind tibia with 2 spurs. Forewing $2.1-2.3 \times$ as long as broad, $2.2 \times$ as long as mesothorax; stigmal vein angled distally, $1.5 \times$ as long as broad (Fig. 161); postmarginal $v e i n 3 \times$ as long as stigmal vein.

Metasoma with petiole $2.2-2.3 \times$ as long as hind coxa. $2.1-2.7 \times$ as long as propodeum; petiole carinate to ribbed dorsally. finely carinate to aciculate ventrally. Gaster as long as petiole. Genitalia not visible in available material.

\section{FEMALE:}

Unknown. 
DISTRIBUTION

Known only from a single collection from the Philippines (A, Fig. 278).
ETYMOLOGY

From Mount Apo, the type locality.

\section{Neolosbanus purpureoventris-group}

This group of 3 species is recognized by: ovipositor acicular, scrobes smooth, and stigmal vein sharply angled. These species are common and widespread in the IndoPacific region including northern Australia.

\section{GROUP DESCRIPTION}

Head $0.3-0.4 \times$ as long as wide; ocelli arranged in triangle, median ocellus meeting line drawn across anterior margin of lateral ocelli. Face smooth with scattered short setae; scrobal depression shallow and completely smooth, partially including median ocellus; occiput glabrous. Clypeal margin lobate and bare, strongly produced over base of mouthparts, epistomal sulcus weak or absent. Malar depression linear and strongly impressed along entire length. Antenna 11 -segmented in females, 13-segmented in males; scape narrow and cylindrical in both sexes, pores present on ventral surface of male scape; anellus present; funicle 7-segmented in females, 9-segmented in males; both sexes with MPS.

Mesosoma with dorsum scabrous to rugose-areolate dorsally; frenal line narrow and foveate. frenal area glabrous or carinate and angled 80 to 90 degrees to dorsum; axillula glabrous, axillular sulcus present or absent. Mesepimeron mostly smooth; femoral groove and transepimeral sulcus foveate; mesepisternum without wedge-shaped sternaular sculpture, at most with single fovea anteriorly. Prepectus foveate and fingerlike dorsally, reduced to a narrow ridge in ventral half. Hind tibia with 2 apical spurs. Forewing $2.3-2.5 \times$ as long as broad (Fig. 169); speculum and basal area bare; stigmal vein at least $3 \times$ as long as broad, angled approximately 45 degrees to anterior margin of forcwing; postmarginal vein more than $3 \times$ as long as stigmal vein.

Gaster with basal terga glabrous. Ovipositor needlelike; first valvula smooth; second valvula with minute dorsal ridges connecting medially. Gonostylus elongate and narrow, sometimes exceeding cercus by more than its width. Ms of male narrow and rounded apically. Genitalia of male with paramere narrow and elongate. bearing 2 stout sctac: acdeagus subacute.
Neolosbanus storeyi sp. nov.

Fig. 179

\section{TYPE MATERIAI}

Holotype, ㅇ, "NEW GUINEA: NE./ Nondugl, 2200-/ 2700 m. V-28-1959." “C. D. Michener/ Collector/ BISHOP." "HOLOTYPE/ Neolosbanus/ storeyi Heraty." Deposited in BPBM.

Paratypes: AUSTRALIA: Queensland: Cape York, Lankelly Ck, Mcllwraith Range, vi.1932. Darlington (I $9, \mathrm{MCZ}$ ); same data, 28.vi.1932 (1 0 , MCZ). INDONESIA: SERAM [Amboina]: F. Muir ( $6 \delta^{\circ} \delta, \mathrm{MCZ}$ ). PAPUa New Guinea: Port Moresby, $20 \mathrm{~km}$ SE, 26.i.1985. J. Ismay (1 9 . BMNH); Riv. Tor (mouth), $4 \mathrm{~km}$ E of Hol Maffen. 4.vii.1959, T. C. Maa (1 ․ B BBM); Bulolo, $900 \mathrm{~m}$, 13.ii-13.iii.1979, J. Sedlacek (I o, AEI); Baiyer Riv., 1100 m, 25.i-6.ii.1979, J. Sedlacek (3ठ ठे, AEI); Lae. 0-100 m, ix.1968, N.L.H. Krauss (1 ơ, BPBM); Brown Riv., 30.ix.1959, T. C. Maa (1 0 , BPBM): Eliptamin Valley, 1200-1350 m. 1-15.vii.1959, W. W. Brandt (1 ơ. BPBM); Bougainville (S.): Kokures 690 m. 16.vi.1956, E. J. Ford, Jr. ( 1 o , BPBM).

\section{DIAGNOSIS}

Recognized by the following: ocellar triangle slightly raised above surface of the vertex and anterior margin with a shallow curving sulcus (Fig. 179), ocellar-ocular sulcus shallow. mesosomal dorsum scabrous-alveolate. frenal areal carinate, and propodeum with a deep areolate median channel.

\section{FEMALE}

Length, 2.2-3.2 mm. Head and mesosoma black with blue or purplish-blue reflections, gaster and femora dark brown to black with reddish reflections: pedicel and liagellum dark brown: tibiac brown medially: scape. apices of tibiae, and tarsi honey yellow. Wings slightly infuscate or hyaline, venation pale brown.

Head subcircular; occiput weakly emarginate: LOL 1.0-1.4× OOL. Face broadly rounded, polished with sparse sctac: ocellar triangle raised and bordered by shallow sulcus (Fig. 179): occipital carina weak. extending 10 lateral ocellus. Eyes separated by 1.2-1.6x their height. Malar space (0.4-(0.8× height of eye. Anteclypeus lohate. lateral margin of anteclypeus sinuate. extending well below ventral margin of gena. Antennal 11 -segmented: 
Hagellum (1.9-1.2x height of head: funicular segments with short. dense, semi-ereet setae and numerous MPS: F2 2.()-3.() $\times$ as long as broad; clava acuminate.

Mesosoma dorsally with moderately spaced scabrousareolate sculpture; posterior hall of axilla and SSS longiIudinally carinate. Scutellum as long as broad; frenal area vertically carinate; axillular sulcus not apparent. Propodeum with median band of deep areolate sculpture. Coxae and femora glabrate, hind femur with dense, fine setac in apical half. Forewing 1.9-2.9 $\times$ longer than broad.

Metasoma with petiole $1.6-2.5 \times$ as long as hind coxa, $1.5-2.1 \times$ as long as propodeum; petiole subtriangular, almost completely smooth dorsally, and carinate to ribbed sublaterally. Ms, smooth, otherwise gaster typical for species-group. Gonostylus not extending beyond apex of melasoma.

\section{MALE}

Length, 2.7-2.9 mm. Coloration as female. Antenna 13segmented; pores present on ventral surface of scape; flagellum 2.0-2.3× height of head: F2 3.1-4.0x as long as broad. $0.9-1.1 \times$ as long as scape. Petiole $2.3-2.6 \times$ as long as hind coxa. 1.9-3.3 $\times$ as long as propodeum.

\section{DISTRIBUTION}

Papuan subregion (S, Fig. 278). This species occurs in strict sympatry with $N$. palgravei in Australia (Cape York Peninsula), and Papua New Guinea (Bulolo, Baiyer River).

\section{ETYMOLOGY}

Named in honour of Ross Storey from the Department of Plant Industries in Mareeba, Queensland-a truly outstanding individual.

\section{Neolosbanus watanabei sp. nov.}

Losbamus sp._- Watanabe, 1958:28. Hedqvist, 1978:230 (list and key).

\section{TYPE MATERIAI}

Holotype, + , "PHILIPPINES, Negros/ Oriental: Cuernos de/ Negros 7 km W Valencia/ 700 m. 7-13 JUN 1987/ ROM 873057. DC Darling." "HOLOTYPE/ Neolosbanus/ watanabei Heraty." Deposited in ROM.

Paratypes: Caroline ISLANDS: Palau Islands. Koror Island, 10.ii.1948. H. S. Dykas, limestone ridge ( $1 \delta^{\circ}$. BPBM). Pillippines: Luzon: Mountain Prov., Ifuagao. Mayoyao, 1200-1500 m, 3.ix.1966. H. M. Torrevillas (1 9 , BPBM); same locality. 1000-1500 m, 6.vii. 1966. H. M. Torrevillas, light trap ( 1 , BPBM); Negros Oriental: same data as holotype ( 10 , ROM); L. Balinsasayao, 1-7.x.1959, L. Quate and C. M. Yoshimoto, bait traps, chicken intestines, (I $\delta, B P B M)$; Basilan: 1sland of Basilan, Baker ( 10 . MCZ).

\section{MIAGivosis}

Recognized by the following: margins of ocellar triangle smooth and not separated from the vertex. mesosomal dorsum broadly spaced rugose-alveolate, frenal area glabrous, and propodeum will a shallow areolate median channel.

\section{FEMAIE}

Length, 2.5-3.3 $\mathrm{mm}$. Head and mesosoma dark metallic green; metasoma, coxae, and femora dark brown to black with faint reddish reflections: flagellum dark brown, becoming darker apically; scape and rest of legs honey yellow. Wings hyaline, venation pale brown.

Head subcircular; occiput weakly emarginate: LOL 1.0-1.2× OOL. Face broadly rounded, polished with sparse setae: occipital carina weak, extending to lateral ocellus. Eyes separated by 1.2-1.3× their height. Malar space $0.6 \times$ height of eye. Anteclypeus broadly rounded, lateral margin of anteclypeus evenly rounded; extending well beyond ventral margin of gena. Antenna 11 -segmented; flagellum 1.2-1.3× height of head: funicular segments with short. dense, semi-erect setae and numerous MPS: F2 2.4-2.8 $\times$ as long as broad: clava acuminate or rounded.

Mesosoma with dorsum, including lateral lobe of mesoscutum, with broadly spaced rugose-areolate sculpture; posterior half of axilla and SSS longitudinally carinate. Scutellum as long as broad; frenal area glabrous; axillular sulcus weakly carinate. Propodeum with median band of shallow areolate sculpture. Coxae and femora glabrate, hind femur with dense. fine setae in apical half. Forewing 2.3-2.4x longer than broad.

Metasoma with petiole $1.7-1.8 \times$ as long as hind coxa. $1.5-1.8 \times$ as long as propodeum; petiole subtriangular in cross-section. weakly carinate to smooth dorsally and sublaterally, weakly ribbed on lateral and ventral corners. $\mathrm{Ms}_{2}$ smooth, otherwise gaster typical for species-group. Gonostylus sometimes extending beyond apex of metasoma by more than its width (not exceeding width in holotype).

\section{MALE}

Length, 2.3-2.6 mm. Colour as in female. Eyes scparated by $1.3-1.4 \times$ their height. Antenna 13-segmented; unknown il pores on ventral surface of scape. Flagellum 1.9-2.2 $\times$ height of head; F2 2.9-4.4x as long as broad. $0.9-1.0 \times$ as long as scape. Forewing $2.3-2.4 \times$ as long as broad. Petiole 2.2-2.5 $\times$ as long as hind coxa, 2.4-2.8x as long as propodeum.

\section{I)ISTRIBUTION}

Philippine subregion and Caroline lslands (W. Fig. 278). 


\section{ETYMOLOGY}

Named for Dr. Watanabe for his works on Micronesian eucharitids.

Neolosbanus purpureoventris (Cameron) comb. nov. Figs. 166-169, 209-210, 234, 246. 255, 271-272

Eucharis purpureoventris Cameron, 1909:232. Kuching, Borneo [BMNH, examined].

Orasema purpureoventris—Bouček, 1988:520.

\section{TYPE MATERIAL}

Lectotype (designated by Bouček, 1988), q, "LECTO-/ TYPE." "Kuching/ Hewitt." "Hy. 6." "P. Cameron Coll./ 1914-110." "Eucharis/ purpureoventris/ Cam. Type/ Borneo." "B.M. TYPE/ HYM./ 5.367." "ठ Gollumiella/ purpureoventris/ (Cameron)/ see Hedqvist, 1978/ det. Z. Bouček, 1980." "LECTOTYPE/ ठ̊ Orasema/ purpureoventris/ (Cam.)/ det. Z. Bouček, 1986." Point-mounted male with no head. Housed in BMNH.

\section{NOTES ON SYNONYMY}

This species was placed in the genus Orasema by Bouček (1988) as a senior synonym of Psilogaster laeviceps Gahan, Psilogaster nishidai Ishii and Nagasawa, and Losbanus petersoni Hedqvist. It is distinct from these other species based on the features outlined in the group diagnosis. Psilogaster nishidai and L. petersoni are transferred here to Neolosbanus palgravei as junior synonyms, and $P$. laeviceps is given species status in Neoloshanus.

\section{DIAGNOSIS}

Recognized by the following: margins of ocellar triangle smooth and not separated from vertex, dorsal sculpture of mesosoma closely spaced rugose-alveolate or scabrous, frenal area carinatc, and propodcum completely smooth or with areolate median channel.

\section{FEMALE}

Length, 2.2-4.0 $\mathrm{mm}$. Head black, mesosoma black with bluish reflections, gaster dark brown to black; coxae and femora dark brown to black and sometimes with metallic reflections; antenna testaceous to black; hind tibia honcy yellow to dark brown, tarsi yellowish brown. Wings hyaline, venation pale brown.

Head subcircular to subtriangular (Fig. 209): occiput weakly cmarginate; LOL 1.0-1.2× OOL. Face broadly rounded, polished with sparse setac; occipital carina weak, extending halfway between ocellus and eye margin. Eyes large, separated by $1.2-1.3 \times$ their height. Malar space $0.5-0.8 \times$ height of eye. Anteclypeus lobate, lateral margin of anteclypeus sinuate. extending well below ventral margin of gena (Figs. 209-210). Antenna I l-seg- mented (Fig. 166): flagellum 1.1-1.2× height of head; funicular segments with short, dense, semi-erect setae and numerous MPS; F2 2.5-2.7× as long as broad, about $0.5 \times$ length of scape; clava acuminate.

Mesosoma with dorsum, including lateral lobe of mesoscutum, closely spaced rugose-areolate to scabrous (Fig. 246); posterior half of axilla longitudinally carinate. Scutellum as long as broad; frenal area with weak, widely spaced transverse carinae; axillular sulcus weakly carinate. Propodeum completely smooth or with median band of foveate sculpture (variable within localities; Fig. 255). Coxae and femora glabrate, hind femur with dense, fine setae in apical half. Forewing $2.4-2.5 \times$ as long as broad (Fig. 169).

Metasoma with petiole $1.5-1.8 \times$ as long as hind coxa. $1.4-1.8 \times$ as long as propodeum; petiole subtriangular. smooth dorsally and sublaterally, weakly carinate on lateral and ventral corners. Gaster typical of species-group; $\mathrm{Ms}_{2}$ smooth. Gonostylus exceeding apex of gaster in specimens from Malaya and Vietnam. otherwise withdrawn or shorter than apex of gaster.

\section{MALE}

Length, 1.9-2.9 mm. Colour as in female. Antenna 13segmented (Fig. 168); scape with patch of minute pores on the ventral surface (Fig. 167); flagellum 1.7-2.3x height of head; F2 $4.3 \times$ as long as broad. $0.8-1.2 \times$ as long as scape. Petiole $2.1-2.5 \times$ as long as hind coxa, 2.6-2.9× as long as propodeum. $\mathrm{Ms}_{2}$ sometimes with weak indentation along line of constriction (as in Fig. 273).

\section{VARIATION}

There is considerable variation over the range of this species due to the amalgamation of 2 or 3 distinct forms. Extremes of variation are found in single collections from a broad range of localities. Specimens from Borneo. Malaya (Malaysia), and Larat conform to the lectotype in coloration (head and mesosoma dark blue to blue-green, hind tibia honey yellow), sculpture of the mesosomal dorsum (scabrous), and propodeum (strong areolate medial band). However, all females from Malaya have the gonostylus exceeding the apex of the gaster. This last feature occurs sporadically in different collections, and may be an artifact of preservation. Specimens from southern Thailand, Victnam, and Taiwan form a group with similar dorsal sculpture. but differ in having the head and mesosoma almost entirely black, hind tibia usually dark brown. and propodeum completely smooth or with a laint median carina. A northern group from Nepal, north Thailand, Laos, and Fukien province (China) include larger individuals that have the head and mesosoma dark green. hind tibia yellow or dark brown (locality dependent), mesosomal dorsum with closely packed arcolite sculpture, and propodeum with a narrow band of weak areolate sculp- 
ture. Differences are difficult to quantify and I believe that only a single species should be recognized here.

\section{BIOLO()}

The host-ant and larval stages are unknown. The egg, as dissected from the abdomen, is stalked, and similar to those of other Eucharitidae. I collected adults from broadleaf understory plants in rainforests of Taiwan and Thailand, but could not determine the host plant. The overall elevation of the collections ranges from $300 \mathrm{~m}$ in Thailand to $2000 \mathrm{~m}$ in Nepal.

\section{DISTRIBUTION}

Widespread in the Indo-Chinese, Malayan, and Sulawesi (Larat) subregions (P. Fig. 278). This species occurs in strict sympatry (same locality and collection date) with $N$. palgra'ei (Taiwan: Tungpu; Vietnam: Da Lat), N. laeviceps (Taiwan: Sun Moon Lake, Tungpu), N. pilosus (Vietnam: Da Lat), N. townesi (Papua New Guinea: Bulolo), and N. nepalensis in Nepal.

\section{MATERIAI, EXAMINIE)}

INDONESIA: Tanimbar: Larat, xii ( $1 \delta$, MCZ). LAOS: Vientianne Prov.: Ban Van Eue. April (19. BPBM). Malaysia: Panang, Cameron Highlands, Tanah Pata, $1700 \mathrm{~m}$. August ( 1 ठ . BMNH). NLPAL: Godavari, $2000 \mathrm{~m}$, July ( 1 ․, CNC). People's Republic of China: Hainan Is., Tien Fong Mıns, May; Fukien: Shuipeikich, Shaowu: Kwatun. Chungan; Tachulan, Shaowu; July to September (13우, $4 \delta \delta, B M N H, T A R I)$. TAIWAN: Nantou Hsien: Sun Moon Lake, W of Techuache, $900 \mathrm{~m}$, edge of rainforest; Tungpu, $1200 \mathrm{~m}$; March to April, June to July, September to October ( $2 q q .20 \delta \delta, J M H, R O M$, TARI). Thalland: Chiangmai Prov.: Doi Suthep, 500-900 m; Wat Suthep; November ( $7 q$, $10^{\circ}$, BPBM); Suphanburi Prov.: Khao Yai N. P., elephant-crossing trail, $300 \mathrm{~m}$, rainforest undergrowth; Khao Yai N. P. Haew Sawat waterfall, $300 \mathrm{~m}$, rainforest undergrowth; July ( $1 q, 8 \delta^{\circ}$. JMH, ROM). VIETNAM: $20 \mathrm{~km} \mathrm{~S}$ Da Lat, 1300 m; Mt Lang, Bian, 1500-2000 m: Fyan, 1200 m; Ap Hung-Lam, $21 \mathrm{~km}$ NW of Di Linh, $1100 \mathrm{~m}$; May 10 October $\left(3 q q, 26 \delta^{\circ} \delta^{\circ}, \mathrm{BPBM}\right)$.

\section{Neolosbanus palgravei-group}

This group of 6 species is recognized by: face smooth. clypeal margin well developed, and ovipositor broad with lateral ridges on the second valvula. Species are common and widespread in the Indo-Pacific region including northern Australia. Females deposit eggs into punctures in the leaves of a wide variety of broad-leaf plants.

\section{GROUP DESCRIPTION}

Head $0.2-0.4 \times$ as long as wide; ocelli arranged in line, median ocellus close to occipital margin and exceeding line drawn across anterior margin of lateral ocelli (Fig. 178); face glabrous; scrobal depression glabrous and shallowly or deeply impressed; occiput glabrous. Clypeal margin strongly produced as rounded lobe over mouthparts (rounded in N. townesi), usually with well-defined epistomal sulcus. Malar depression absent. Antenna 10or 11-segmented, scape cylindrical or expanded apically. scape of male with pores on ventral surface below pedicel: anellus present or absent: funicle 7- or 8-segmented in females, 8-segmented in males; both sexes with MPS.

Mesosoma with dorsum rugose-areolate to smooth: frenal area glabrous, angled 601090 degrees to dorsum of mesosoma; axillula and axillular sulcus diagnostic. Mesepimeron glabrate, transepimeral sulcus shallow foveate (absent in N. townesi); femoral groove foveate or absent, continuing ventrally between fore and mid coxac to midline, glabrous between groove and base of coxa (Figs. 227-231). Prepectus foveate (smooth in $N$. townesi) and narrowly triangular dorsally, reduced to narrow ridge in ventral half. Forewing $2.2-2.6 \times$ as long as broad; basal pilosity diagnostic: stigmal vein of forewing usually narrow and elongate, more than $1.5 \times$ as long as broad; postmarginal vein $1.5-2.0 \times$ as long as stigmal vein.

Gaster with basal terga setose or glabrous. Ovipositor subapically expanded and straight or only slightly curved; first valvula with 2 or 3 oblique ridges apically; second valvula narrow with several strong transverse ridges. ridges connecting medially. Gonostylus broad, gradually narrowing to apex, not exceeding cercus. $\mathrm{Ms}_{8}$ of male narrow or broad. Genitalia of male with paramere narrow and elongate, bearing 2 or 3 stout setae; aedeagus subacute to truncate apically.

\section{Neolosbanus townesi sp. nov.}

Figs. 170-175, 199, 226, 241, 250

\section{TYPE IATERIAL}

Holotype. + . "Kassam Pass/ 1300 m. N. Guinea/ 1.10-23.1979/ J. Sedlacek." "HOLOTYPE/ Neolosbanus/ lownesi Heraty." Deposited in AEI.

Paratypes: Papua New Guinea: Bulolo, $900 \mathrm{~m}$, 13.ii-13.iii.1979. J. Sedlacek (14 ठ̊ ơ. AEI): Mt Suckling, Matu 1, 300-1000 m. 13.vii.1979, J. L. Gressitt, on Castanopsis (1 9. BPBM); Morobe Dist.. Wau, $1400 \mathrm{~m}$. 20.xii.1961, L. W. Quate (I + , BPBM): Wau, Mt 
Mission, 1800 m, 22.iii.1966, J. L. Gressitt, on bamboo (1 9 , slide no. 88-23-19, ВPBM); Tаро (= Tарu), $3 \mathrm{~km} \mathrm{~W}$ of Kainantu, 1650 m, 22.x.1959, T. C. Maa (1 $q$, BPBM); Minj, W Highlands, 8-13.ix.1959, T. C. Maa (1 + , BPBM); New Ireland: Ridge above "Camp Bishop," 15 km up Kait Riv., 250-750 m, 14.vii.1956, J. L. Gressitt $\left(1 \sigma^{*}, \mathrm{BPBM}\right)$.

\section{DIAGNOSIS}

Differs from other Neolosbantis by the following: anellus absent, prepectus smooth and evenly rounded (Fig. 226), mesosoma with dorsum almost completely smooth (Fig. 241), frenal line only faintly indicated, and $\mathrm{Ms}_{2}$ of female with a transverse band of fine rugulose sculpture.

\section{FEMALE}

Length, 2.2-2.7 mm. Dark brown to black; scape and pedicel light brown; extreme apex of femora, tibiae, and tarsi white to pale yellowish brown. Wings lightly infuscate, venation brown.

Head subtriangular (Fig. 199); occiput broadly and deeply emarginate; ocelli large, median ocellus separated from occipital margin by more than its own radius; $\mathrm{LOL}$ 1.1-1.4× OOL. Face broadly rounded, cheek sunken, posterior margin of gena abrupt and finely punctate: scrobal depression shallow and smooth; occiput glabrous, occipital carina extending just beyond lateral ocellus. Eyes separated by $1.8-2.1 \times$ their height. Malar space $0.8-1.0 \times$ height of eye. Clypeus broadly rounded, slightly extending over base of labrum. Antennae 11-segmented (Figs. 170-171); pedicel short, slightly broader than F2; scape reaching median ocellus, expanded apically and broadly excavated on ventral surface (Fig. 199); anellus absent; flagellum 1.6-1.9× height of head: funicle 8-segmented. segments with MPS sparse and small: F2 4.2-5.7× as long as broad, 1.4-1.7× F3, following segments about equal in length and width.

Mesosoma with dorsum glabrous, except midlobe of mesoscutum with weak transverse sculpture; lateral lobe smooth and swollen (Fig. 241); axilla smooth and rounded. SSS deeply impressed and carinate. Scutcllum as long as broad, apex broadly rounded in dorsal view: frenal area glabrous; axillula glabrous, axillular sulcus absent. Propodeum completely smooth (Fig. 250): callus with patch of several short setae. Femoral groove absent. Prepectus smooth and swollen medially (Fig. 226). Coxae clongate, hind femur moderately sctose, tibiac and tarsi densely setose. Forewing (Fig. 175).

Metasoma with petiole 1.3-2.0x as long as hind coxac. I.6-2.0 $\times$ as long as propodeum: petiole glabrous with few weak longitudinal carinae. Basal metasomal tergites glabrous; Ms, weakly sculptured basally (Fig. 172). Ovipositor (Fig. 174), diagonal ridges of second valvula strong and converging medially.
MALE

Length, 2.2-2.6 mm. Colour as in female. Antenna longer and stouter than in female; scape more strongly expanded. Petiole 2.0-2.3x as long as hind coxae, 2.5-3.2x as long as propodeum. $\mathrm{Ms}_{8}$ twice as broad as petiole, apex broadly emarginate. Genitalia enlarged and prominent; aedeagus broad and emarginate apically (Fig. 173).

\section{BIOLOGY}

Collected on Castanopsis (Fagaceae) and bamboo (Poaceae).

\section{DISTRIBUTION}

New Guinea including New Ireland (T, Fig. 279).

\section{ETYMOLOGY}

Named in memory of Dr. Henry Townes.

Neolosbanus laeviceps (Gahan) comb. nov. Figs. 183-184, 200, 227, 242, 251, 268-269

Psilogaster lacviceps Gahan, 1940:429-430. Peradeniya, Sri Lanka [USNM, examined].

Parapsilogaster laeviceps-Ghesquière, 1946:368 (replacement name).

Losbamus laeviceps-Watanabe, 1958:26: Hedqvist, 1978:230 (list and key).

Orasema purpureoventris-sensu Bouček. 1988, in part.

\section{TYPE MATERIAL}

Holotype, q. "Peradinyia/ Ceylon 11-'30." "CP Clausen/ Coll." "Clausen no./ 2435." "6336/ 4 m." "Type No./ 53550/ USNM." "Parapsilogaster/ laeviceps/ Gahan/ $q$ Type" (USNM).

Paratypes: SRI Lanka [Ceylon]: Peradeniya, ii. 1930. C. P. Clausen 2435 ( $2 q q$, no. 53550, USNM); Peradeniya. 25.vii.1913 ( 1 \% , no. 53550, USNM). Additional slide. "Parapsilogaster/ laeviceps Gah/ Max. palpus and Antenna from Clausen No 2435." "Para 53550/ Type No. USNM [red labcl|."

\section{NOTISS ON SYNONYMY}

Bouček (1988) incorrectly treated this species as a junior synonym of $N$. (= Orasema) purpureolentris. The enlarged ovipositor, expanded scape, and consistently reduced pattern of sculpture belonging to $\mathrm{N}$. lacviceps clearly distinguish this species from $N$. purpureoventris.

\section{DIAGNOSIS}

Recognized by the following: ancllus absent (Figs. 183-184), mesosomal dorsum weakly sculptured. scape of male expanded apically and grooved ventrally to receive the pedicel (Fig. 184), and scutellum rounded in 
lateral profile. Distinguished from $N$. lownesi by: margin of the clypeus lobate and extending ventrally over the labrum (Fig. 2(0)), funicle of femile 7-segmented (versus 8), and prepectus foveate. The female was thoroughly described by Gahan (1940). The male was previously unknown and is described here in detail.

\section{MALE,}

Length. $2.2 \mathrm{~mm}$. Dark brown 10 black; antenna, trochanters, and legs beyond apex of femora yellowish brown. Wings hyaline, venation pale brown.

Head subtriangular, occiput broadly emarginate: median ocellus separated from occipital margin by less than own diameter; LOL $0.9 \times$ OOL. Face rounded and glabrate: scrobal depression narrow and strongly impressed, lateral margin indistinct; occiput glabrous; occipital carina weak, not reaching dorsal eye margin. Eyes separated by $2.0 \times$ height of eye. Malar space $1.0 \times$ height of eye. Clypeus extended as strong lobe ventrally over labrum, epistomal sulcus present, tentorial pit deep. Antenna 11-segmented; pedicel short, slightly broader than F2; scape strongly expanded apically, inner margin strongly produced, ventrally excavated to receive pedicel, with minute pores on ventral surface below pedicel (Fig. 184); anellus absent; flagellum $1.6 \times$ height of head; funicular segments with MPS sparse and small; F2 $2.5 \times$ as long as broad, 1.7× F3; following segments subequal in length and width, base of each segment narrower than apex: clava 1-segmented.

Mesosoma with dorsum lightly rugose (Fig. 242); lateral lobe of mesoscutum and axilla smooth and very lightly sculptured. SSS carinate. Scutellum longer than broad, apex narrowly rounded in dorsal view; frenal area glabrous; axillula weakly carinate, dorsal margin obscure. Propodeum almost completely glabrous; callus with few, small setae dorsally (Fig. 25I). Femoral groove narrow and weakly foveate. Prepectus triangular and foveate above, strongly narrowed ventrally. Pronotal sulcus sharp and smooth. Coxae and femora glabrate, hind femora slightly expanded medially, hind tibia gradually expanded to apex and slightly flattened. Forewing (Fig. 162).

Metasoma with petiole $2.2 \times$ as long as hind coxa, $2.5 \times$ as long as propodeum; petiole carinate dorsally. Basal metasomal tergites glabrous. Ms, broad and subtruncate at apex. Genitalia large and broad, paramere short and bearing 3 stout setac: aedeagus broad and subtruncate (Fig. 163).

\section{FEMALE:}

Length. 1.9-2.1 mm. Colour as in male. Tentorial pits shallow. Antenna 10-segmented and more slender; scape slightly expanded with inner margin produced as apical flange: funicle 7-segmented; F2 3.0-4.3x as long as broad. 1.3-1.8 F F3: clava usually 1 -segmented (distinctly 2-segmented in 1 specimen from Ceylon). Mesoscutum and axilla rugose 10 weakly carinate; propodeum smooth or weakly sculptured medially. Petiole weakly or strongly carinate. Ms, glabrous. Ovipositor with diagonal ridges of first valvula reduced or absent.

\section{BIOLOC;Y}

Clausen (1940b, 1940c, 1941) discussed biology and the morphology of the first-instar larva of $N$. laeviceps (see earlier discussion in biology section). Adults are known to deposit single eggs into leaves of Artocarpus (Moraceac) (Clausen, 1940b).

\section{DISTRIBUTION}

Broadly distributed in the Indo-Chinese and mainland Malayan subregions (L, Fig. 279). The most northern record is from Tsushima Island, which lies between Korea and Japan and would be included in the Palaearctic realm according to Gressitt (1956) and Schuh and Stonedahl (1986). This species is broadly sympatric with $N$. pilosus and N. taiwanensis and has been collected in strict sympatry with Neoloshanus purpureoventris in Taiwan (Sun Moon Lake. Tungpu).

\section{MATERIAL EXAMINED}

InDIA: Tamil Nadu: Anamalai Hills, Cinchona, 1150 m; Kerala: Periyar A. San.; Thadripukudisai; September to October ( $14 q q, \mathrm{BMNH}, \mathrm{CNC}, \mathrm{IARI})$. JAPAN: Honshu: Aichi Prefecture, Yakusa, Toyota, PT, July to August $(2 \circ 9, \mathrm{CNC})$; South Ryukyu Islands: Ishigakishima Is., Omoto-dake, 100-250 m: Tsushima Island, IzuharaAriakeyama: May and September ( $2 q$ q. BPBM, KUEC). LAOS: Namgueng Riv.. Phou Kan Khouei, 300-600 m. Sayaboury Prov.: Sayaboury; Vientianne Prov.: Ban Van Eue, February, April, and December ( $3 q$, BPBM). SRI LANKA: Kandy, $10 \mathrm{~km}$ W: Katugastota. $550 \mathrm{~m}$ : Nugegoda: Udugama, Kanneleya Jungle, at light: February, May, August ( $\left.\sigma^{3}\right)$, and November (10 $q$. BPBM, BMNH). TAIWAN: Yangminshan, Site 2, 1991, H. Y. Yong. YPT $(2 q q, \mathrm{CNC})$ : Nantou Hsien: Sun Moon Lake: Tianmu. Tungpu, 1200 m; Taipei: Keelung; Paomenszu, 2 km S Keelung City: Taipei: June to July, October to November (136 $q$, TARI). VIETNAM: Pleiku, $20 \mathrm{~km} \mathrm{~N}, 650 \mathrm{~m}$, May (1 9. BPBM).

\section{Neolosbanus taiwanensis sp. nov.}

\section{TYPE MATERIAL}

Holotype, o. "N. TAIWAN: Wufeng/ 400 m., Hsinchu Hsien/ 14-16.V1I.1982/ K. C. Chou and C. C. Pan." "HOLOTYPE/ Neolosbanus/ taiwanensis Heraty." Deposited in TARI.

Paratypes: Talwan: Hsinchu Hsien: same data as holo- 
type (80े ơ, TARI); Chienhsi, 5.xi.1981, K. S. Lin ( 1 oे. TARI); [in Chinese characters], 9.xii.1961, S. C. Chiu ( 10 , TARI). People's Republic of China: Hunan: Changteh, Yangshan, 11.x.1938, T. C. Maa (1 ठे, TARI).

\section{DIAGNOSIS}

Distinguished from $N$. pilosus by the following: eye with sparse setae, body moderately pilose with elongate setae, propodeum with a median carina, petiole of male robust and as broad as the hind coxa $(2.2-2.9 \times$ as long as hind coxa), and hind tibia dark brown.

\section{MALE}

Length, 2.5-3.0 mm. Body black; antennal flagellum, all femora, and hind tibia dark brown to black; scape brown; fore and mid tibiae and tarsi yellowish brown. Wings hyaline, venation clear yellowish brown.

Head subtriangular to subcircular; occiput slightly emarginate; head strongly narrowed medially, dorsal length not much broader than median ocellus, median ocellus separated from occiput by less than its own radius; LOL 1.6-1.7× OOL. Face relatively flat, glabrate with moderately dense, fine hairs; scrobal depression broadly impressed; occiput glabrous, occipital carina prominent, extending laterally to eye margin. Eyes separated by $1.6-1.7 \times$ height of eye. Malar space $0.7-0.8 \times$ height of eye. Clypeus extended as strong lobe ventrally over labrum, epistomal sulcus weak. Antenna 12-segmented; pedicel short, as wide as F2; scape narrow, not reaching median ocellus; anellus presemt: flagellum 1.7-1.9× height of head; funicle 8-segmented, with few MPS; F2 3.8× as long as broad; F2 1.2-1.4× F3, following segments subequal in length; clava with 2 incompletely fused segments.

Mesosoma with dorsum rugose-areolate, with moderately dense covering of short, fine hairs; lateral lobe of mesoscutum and anterior face of midlobe transversely carinate. SSS longitudinally carinate. Scutellum $1.4 \times$ as long as broad, apical margin narrowly rounded in dorsal view; frenal area angled about 45 degrees to dorsum. crescent-shaped in dorsal view: axillula glabrous to weakly carinate, axillular sulcus weakly foveate. Propodeum smooth with medial carina and sparse erect hairs: callus with patch of dense hairs. Mesepimeron with few scattered setae; femoral groove broad, foveate to weakly crenulate. Pronotal sulcus foveate. Coxae and lemora smooth with moderately dense setae. Forewing 2.3-2.4x as long as broad; speculum and basal area bare; stigmal vein more than twice as long as broad, and perpendicular to wing margin.

Metasoma with petiole $2.2-2.9 \times$ as long as hind coxa. $2.2-2.7 \times$ ats long ats propodeum; petiole longitudinally carinate with sparse erect hairs dorsally, thick in crosssection and as broad or broaler than hind coxa. Mt, to
$\mathrm{Mt}_{5}$ with semi-erect elongate hairs. $\mathrm{Ms}_{8}$ narrow and rounded. Genitalia moderately sized, paramere narrow and elongate; aedeagus subacute.

\section{FEMALF}

Unknown, but based on $N$. pilosus, the sexes are not expected to differ greatly.

\section{DISTRIBUTION}

Tajwan (I. Fig. 279).

\section{ETYMOLOGY}

From Taiwan; referring to the type locality.

Neolosbanus pilosus sp. nov.

Figs. 178, 180, 202, 229, 243

\section{TYPE MATERIAL}

Holotype, + , "VIET NAM: Fyan/ 900-1000 m./ II.VII9.VIII. "61." "N. R. Spencer/ Collector." "Collection of B1SHOP MUSEUM." "HOLOTYPE/ Neolosbanus/ pilosus Heraty." Right antenna broken. Deposited in BPBM. Paratypes: VIETNAM: same data as holotype (18 $q$. $14 \delta^{\circ}$, BPBM); Fyan, 1200 m, 11.vii-9.viii.1961, N. R. Spencer $\left(7 q+q, 10 \delta^{\circ}, \mathrm{BPBM}\right)$; Da Lat. $6 \mathrm{~km} \mathrm{~S}$. 1400-1500 m. 9.vi-7.vii.1961, N. R. Spencer (3우. BPBM): Da Lat, $20 \mathrm{~km} \mathrm{~S}, 1300 \mathrm{~m}$, 12.ix.1960, J. L. Gressitt (1 + , BPBM); Di Linh (Djiring), $1200 \mathrm{~m}$. 22-28.iv.1960. L. W. Quate (5ㅇ․, BPBM); Di Linh. 28 km N, 22-28.iv.1960. S. Quate (I o, BPBM): Blao (Balao), $500 \mathrm{~m}, 14-21 . x .1960, \mathrm{C} . \mathrm{M}$. Yoshimoto (1우. BPBM).

\section{DIAGNOSIS}

Distinguished from N. taiwanensis by the following: body with denser and shorter pilosity, eye with very minute setac, propodeum completely smooth without median carina, petiole longer and narrower than hind coxa. and hind tibiac yellowish brown.

\section{FEMAIE}

Length, 2.6-3.4 mm. Body dark brown to black, mesosoma with faint greenish reflections; antenna. coxac, and femora dark brown to black; tibiae. tarsi. and apex of femora yellowish brown. Wings hyaline, venation clear testaceous.

Head subtriangular; occiput deeply emarginate; head strongly narrowed medially, dorsal length not much longer than median ocellus (Fig. 178): median ocellus separated from occipital margin by less than its own radius; LOL 0.7-1.1× OOL. Face broadly rounded. smooth with covering of dense, line setac: scrobal depression broad and strongly impressed, including median 
ocellus; occiput glabrate: occipital carina extending to cye margin but widely separated from it in dorsal view (Fig. 178). Eyes separated by $1.5-1.7 \times$ their height. Malar space $0.7-0.9 \times$ heiglit of eye. Clypeus extended as strong lobe ventrally over labrum, without epistomal sulcus. Antenna 11-segmented; pedicel slightly longer than broad, as wide as F2: scape reaching median ocellus; anellus present: flagellum $1.3 \times$ height of head; funicle 7 segmented, segments with few MPS; F2 $4.2 \times$ as long as broad, F2 1.2 F F3, following segments subequal in length: claval segments not discernible.

Mesosoma with midlobe of mesoscutum irregularly transverse-carinate (Fig. 243); lateral lobe weakly transverse-carinate; axilla carinate, carinae widely spaced; scutellum with widely spaced and deep rugose-areolate to scabrous sculpture; entire dorsum with dense, short setae. Scutellum only slightly longer than broad, apex broadly rounded in dorsal view; frenal area angled 70 to 80 degrees to dorsum, not visible in dorsal view; axillula glabrous, axillular sulcus weakly carinate. Propodeum glabrous and without median sculpture; callus and metepimeron densely setose. Mesepimeron sparsely setose posteriorly and ventrally; femoral groove broadly foveate dorsally and narrowly foveate ventrally. Prepectus and most of pronotum setose. Pronotal sulcus smooth. Coxae smooth and densely setose; femora weakly imbricate and densely setose. Forewing $2.3-2.6 \times$ as long as broad; completely pilose on both surfaces (speculum absent); stigmal vein perpendicular or slightly angled to wing margin; postmarginal vein indistinct but longer than stigmal vein.

Metasoma with petiole $1.9-2.6 \times$ as long as hind coxa, 1.8-2.1 $\times$ as long as propodeum: petiole subtriangular in cross-section and carinate dorsally, smooth sublaterally with 2 parallel carinae ventrally, and dorsal patch of dense setae basally. $\mathrm{Mt}_{2}$ to $\mathrm{Mt}_{5}$ sparsely setose. Genitalia moderately sized. paramere narrow and elongate; aedeagus subacute.

\section{MALE}

Length, 2.6-3.6 mm. Colour as in female, hind tibia darker brown medially. Antenna 12-segmented (Fig. 180); flagellum 1.7× height of head; funicle 8 -segmented; F2 $1.3 \times$ F3. Forewings $2.3-2.4 \times$ as long as broad. Petiole 2.6-3.5x as long as hind coxa, 2.7-3.4x as long as propodeum. $\mathrm{Mt}_{2}$ to $\mathrm{Mt}_{5}$ with semi-erect hairs. Genitalia typical for group.

\section{ETYMOLOGY}

From Latin pilosus, meaning hairy; referring to the pilose covering of the head and mesosoma.

\section{DISTRIBUTION}

Vietnam (P. Fig. 279) and likely a similar species on Irian Jaya.

\section{ADIDITIONAL SPECIES}

A male from lrian Jaya (Vogelkop: Kebar Val. W. of Mano Kwari, 550 m, 4-31.i.1962, Quate, BPBM) is similar to $N$. pilosus, but the propodeum is carinate and the petiole has only 2 parallel carinae dorsally. This probably represents another closely related species.

\section{Neolosbanus nepalensis sp. nov.}

Figs. 203-204, 230, 252

\section{TYPE MATERIAL}

Holotype, + , “NEPAL, Kimd./ Godavari, 5000” [1525 m]/ 12.viii. [handwritten] 1967/ Mal. Tr., Can. Exp." "HOLOTYPE/ Neolosbanus/ nepalensis Heraty." Deposited in CNC.

Paratypes: NePAL: Kathmandu: Godavari, $1525 \mathrm{~m}$,

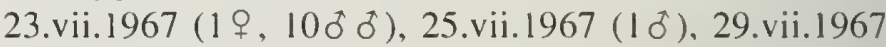




16.viii.1967 (1ठ̊), Can. Exp. MT (all CNC); Godavari. 1525 m, Royal Botanical Gardens, July, Can. Nepal Exp. (2q q, 1 đo, CNC); Godavari, 1830 m, l-3.viii.1967, MT, Can. Exp. ( 1 o, CNC); Godavari 7.2, 5.ix.1972 (4q $q$, $\left.1 \delta^{\circ}\right), 10 . \mathrm{ix} .1972\left(7 \%\right.$ $\left.q, 12 \delta^{\circ}\right)$, Mani and party (all USNM); Godavari 7.4, 20-21.ix.1972, Mani and party $\left(6 q\right.$ \% $29 \delta^{\circ} \delta$, USNM).

\section{DIAGNOSIS}

Distinguished from $N$. palgravei by the following: stigmal vein angled proximally, callus with dense patch of hairs (Fig. 252), antennal flagellum long in both sexes, hind tibia of both sexes white. and mesosomal dorsum with sparse setae (Fig. 230).

\section{FEMALE}

Length, 2.4-2.9 mm. Mesosoma and petiole dark brown to black with green reflections; head, gaster, antennal flagellum, coxae, and femora dark brown; scape yellowish to light brown, apex of femora, tibiae, and tarsi light yellowish brown to white. Wings hyaline, venation pale brown.

Head subtriangular; occiput broadly emarginate: median ocellus separated from occiput by slightly less than its own diameter; LOL 0.8-1.0× OOL. Face broadly rounded, glabrate; scrobal depression narrow and weakly impressed, including median ocellus: occipital carina extending to dorsal margin of cye. Eyes separated by 1.6-2.0× height of eye. Malar space $0.7-0.9 \times$ height of cye. Clypeus extended as strong lobe ventrally over labrum, epistomal sulcus absent. Antenna 11 -segmented; 
pedicel short, slightly broader than F2; scape not reaching median ocellus; anellus present; flagellum 1.5-1.7x height of head; funicle 7-segmented, segments with numerous MPS; F2 3.5-4.2× as long as broad, 1.1-1.3× F3, following segments subequal in length; clava with 1 or 2 segments incompletely fused.

Mesosoma with dorsum rugose-areolate and bare; lateral lobe of mesoscutum and anterior face of midlobe transversely carinate; posterior margin of axilla longitudinally carinate. Scutellum as long as broad, apical margin rounded in dorsal view; frenal area angled 90 degrees to dorsum; axillula glabrous, axillular sulcus carinate. Propodeum with irregular sculpture, sometimes strongly or weakly developed as median furrow; callus with patch of fine elongate hairs (more than 15; Fig. 252). Femoral groove broad and shallowly foveate. Coxae and femora glabrate. Forewing $2.3-2.5 \times$ as long as broad; basal area and speculum bare; stigmal vein angled distally about 70 to 80 degrees to wing margin, rarely perpendicular.

Metasoma with petiole $1.9-2.4 \times$ as long as hind coxa, 1.7-2.0 $\times$ as long as propodeum; petiole longitudinally carinate with weak ventral keel. Basal metasomal tergites glabrous.

\section{MALE}

Length, 2.2-2.7 mm. Colour as in female. Antenna 12segmented; pedicel narrower than $\mathrm{F} 2$; ancllus present; flagellum 2.2-2.5x length of head; funicle 8-segmented; F2 only slightly longer than F3. Petiole $2.6-3.3 \times$ as long as hind coxa, 2.7-3.4× as long as propodeum. $\mathrm{Ms}_{8}$ narrow and rounded. Genitalia moderately sized, paramere narrow and elongate; aedeagus subacute.

\section{DISTRIBUTION}

Nepal (N. Fig. 279).

\section{ETYMOLOGY}

From Nepal; referring to the type locality.

Neolosbanus palgravei (Girault) comb. nov.

Figs. 13-14, 17-25, 165, 181-182, 201, 205, 228, 231. $244,253.266-267$

Orasema palgravei Girault, 1922:105-106. Australia: Quecnsland [QMB, examined]. Dahms, 1986:376 (notes on type material).

Psilogaster nishidai 1shii and Nagasawa, 1941:292-294. Caroline 1slands: Elgi, Airai and Palau /not examined. type not localed]. Synonymy with Orasema purpureoventris (Cameron) by Bouček, 1988:520. New synonymy.

Loshemus nishidai-Watanabe, 1958:27-28; Hedquist. 1978:230 (list and kcy).
Losbanus petersoni Hedqvist, 1978:229. Philippines: Palawan. Tagembung [ZMC, examined]. Synonymy with Orasema purpureoventris by Bouček, 1988:520. New synonymy.

Orasema purpureoventris—sensu Bouček, 1988, in part.

Orasema indica Snehalatha and Narendran. 1992:355. India: Kerala, Trichur [USNM, examined]. New synonymy.

\section{TYPE MATERIAL}

Lectotype (here designated) of Orasema palgravei, intact q, no. T.9405 (number 3 from outer specimen), mounted with 3 other $q$ syntypes (no. T.9403-T.9404. T.9406) on card labelled "Orasema palgravei Gir., of $q$ types [GH]." Published data: "Greenhills, Cairns, May 31, jungle, many specimens." Additional type material: slide 4 (Dahms, 1986), "Type male, Orasema palgrarei Gir." [GH]. See Dahms (1986) for details. Type material for Psilogaster nishidai not found. Holotype of Loshanus petersoni, + , "Philippines, Palawan/ Mantalingajan/ Tagembung 1150 meters/ 19 Sept 1961/ Noona Dan Exped. 61-62." Holotype of Orasema indica, ㅇ, "Holotype" Snehalatha, S. and Narendran, T. C., 1991." "SL 151."

\section{NOTES ON SYNONYMY}

Bouček (1988) treated N. palgravei and N. purpureoventris as different species of Orasema, with $O$. purpureoventris being the senior synonym for Parapsilogaster laeviceps Gahan. Psilogaster nishidai 1shii and Nagasawa, and Losbanus petersoni Hedqvist. Type material was examined for all of the above species, except for $P$. nishidai, which could not be located. However, $P$. nishidai was well represented by material from the Caroline Islands. Neolosbanus palgravei is treated here as a widespread species in the Indo-Pacific region. Loshamus petersoni and Orasema indica are junior synonyms of Neoloshamus palgravei.

Specimens of both $P$. nishidai and $N$. purpuresoventris have been collected in the western Caroline lslinds. There is no doubt that $P$. nishidai belongs to Neoloshamus based on the subapically expanded and strongly ridged ovipositor (1shii and Nagasawa. 1941). Specimens of $P$. nishidai from the Caroline lslands match the original description, and have a sessile stigmal vein, which I hive secn from no other comparable species at this locality. Psilogaster nishidai is similar to what 1 recognize as the Papuan race of $N$. palgravei and is treated here as a jumior synonym.

\section{DIACNOSIS}

The morphological limits of this species are hroad and encompass considerable regional variation (sec Variation). This species is recognized by the following: 
face glabrate (Fig. 205), occiput broadly emarginate, second 17agellomere elongate (Figs. 181-182), stigmal vein perpendicular (Fig. 165), and femora dark brown. It may be further distinguished from $N$. nepalensis by the shorter llagellum in both sexes, and callus bare or with few short selate (Figs. 227, 231, 253).

\section{FEMALE}

Length, 1.9-2.7 mm. Dark brown to black with faint bluish reflections; coxae and femora dark brown to black except extreme apex of femora; antenna yellowish brown to dark brown; scape, fore and midlegs beyond femur, and hind tarsi ycllowish brown to white; hind tibia white to dark brown (see Variation). Wings hyaline, venation light or dark brown.

Head subtriangular; occiput broadly emarginate; median ocellus separated from occipital margin by less than its own diameter; LOL about equal to OOL. Face broadly rounded; scrobal depression shallow and poorly defined; occipital carina extending laterally to eye margin. Eyes separated by $1.4-1.7 \times$ their height. Malar space $0.6-0.9 \times$ height of eye. Clypeus extended as strong lobe ventrally over labrum, with or without epistomal sulcus (see Variation). Antenna 11-segmented (Fig. 180); scape narrow, sparsely setose, reaching median ocellus; pedicel short, narrower or equal in width to flagellum; anellus present; flagellum 1.3-1.4× height of head; funicle 7-segmented ( 8 -segmented in 2 females from Nepal), segments with numerous MPS; F2 about 1.2-1.3× F3, following segments subequal in length; clava with 2 or 3 fused segments usually discernible.

Mesosoma with dorsum rugose-areolate or areolate (Fig. 244); lateral lobe of mesoscutum usually transversely carinate; axilla irregularly carinate. Scutellum slightly longer than broad, apex rounded in dorsal view; frenal area angled 90 degrees to dorsum; axillula glabrate, axillular sulcus weakly carinate. Propodeum with median carina (Fig. 253) or irregular foveate channel; callus bare or with sparse (less than 10) short setae. Femoral groove broad and shallowly foveate (Figs. 228, 231). Pronotal sulcus broad and foveate. Coxae and femora glabrate. Forewing 2.2-2.6x as long as broad; basal area and speculum bare; stigmal vein elongate, more than twice as long as broad, rarely sessile (short and as long as broad), but always perpendicular to wing margin (Fig. 165).

Metasoma with petiole $1.8-2.8 \times$ as long as hind coxa, $1.5-2.8 \times$ as long as propodeum; petiole longitudinally carinate, usually linear in profile but sometimes slightly sinuate. Basal metasomal tergites bare. Ovipositor straight or weakly curved forward (Fig. 267).

\section{MALE}

Length, 2.1-2.6 $\mathrm{mm}$. Colour as in femalc. hind tibia always dark brown with apex white or yellowish brown.
Antenna 12-segmented (Fig. 181); anellus present: flagellum 1.9-2.1 $\times$ height of head; funicle 8 -segmented; F2 $1.2 \times \mathrm{F} 3$, following flagellomeres cylindrical and subequal in length; clava with 2 fused segments. Forewings $2.2-2.4 \times$ as long as broad. Petiole carinate, long, and narrow, 2.8-4.1 $\times$ as long as hind coxa, 2.1-3.4x as long as propodeum (regionally variable). $\mathrm{Ms}_{\mathrm{y}}$ narrow and rounded. Genitalia moderate sized, paramere narrow and elongate; aedeagus subacute.

\section{B1OL.OGY (Figs. 17-25)}

1 observed the habits of individuals from populations in Queensland and West Malaysia. At both localities, females deposited eggs on the underside of a wide range of broad-leaf plants. In Australia, host plants included Tetrasynandra laxiflora (Monimiaceae), Lygodium retic"latum (Schizaeaceae), Macaranga subdentata (Euphorbiaceae), and the most common host plant, Flindersia pimenteliana (Rutaceae). Plant hosts were similar in Malaysia where eggs were deposited into new growth of broad-leaf understorey shrubs or saplings, including ferns. One additional host record was made on Castanopsis (Fagaceae) in Papua New Guinea, which is the same plant record as for $N$. townesi. Females deposited about 20 eggs in short double rows of alternating punctures on the underside of a leaf. Oviposition was extremely dense on some leaves and the entire underside of each leaf (new growth) was saturated with oviposition scars. Where numbers of adults were high, females and males were observed congregating on sunlit vegetation.

Females deposited single eggs into each leaf puncture formed by the ovipositor. Freshly deposited eggs could be observed through a small circular hole in the leaf surface, which was not marked by any alteration of the surrounding leaf tissue. Eggs were deposited nearly vertical to the leaf surface, with the stalk erect and protruding from the opening. As eggs matured, the leaf tissue formed a brown cyst around the egg, and the margins of the cyst elevated around the opening of the oviposition chamber. This was more pronounced in the Australian plants than in the Malaysian plants, which showed similar encrustments of the punctures after the planidia had emerged. The undersides of many leaves were almost completely encrusted by this scar tissue. Older leaves showed that leaf tissue recovered from the scarring.

First-instar larvae were lightly sclerotized (pale yellowish brown) and barely visible against the surface of the leaf. Planidia were able to move by either slow inching movements or by jumping 10 to $20 \mathrm{~mm}$. No thrips or immature Homoptera were observed on the leaves that could be interpreted as an intermediate host carrier. The host ants were not found on the vegetation, but were common on the forest floor. 1 assume that the planidia "rain" down upon the host below, but did not observe this behaviour. 
All stages of $N$. palgravei were observed within the host-ant nest in the Australian population. On the larval ant host, planidia were attached to the lateral posterior edge of the larval head capsule. Planidia remained external and were attached only by the mouthparts. First-instar larvae were turgid, showing evidence of some feeding, but never greatly distended. Further development took place on the host pupa within the cocoon, as is typical for other Eucharitidae. Each parasite completed development on a single ant host. Morphology of life stages and comparison with other Eucharitidae is presented in the earlier section on biology.

I collected this species from undergrowth in rainforest habitats in Australia and Malaysia and from a mixed dipterocarp forest in Malaysia. Collections have also been taken from a mixed dipterocarp forest and mangrove swamp in Papua New Guinea and from a treefern ravine in the Caroline Islands. Plant-host records suggest that this species is associated with lush vegetation in a closed forest.

\section{VARIATION AND DISTRIBUTION}

Neolosbanus palgravei is widely distributed throughout the Indo-Pacific region (Fig. 280), with a single specimen belonging to this species known from Algeria (Bouček, 1988; BMNH, examined). Different patterns of geographical variation are found in the Indo-Pacific region, which can be categorized into 4 distinct groups as outlined in Table 5. Each of these forms may represent different species but there are no patterns of variation that indicate clear breaks in the populations. Variation is most evident in the presence (Fig. 205) or absence (Fig. 201) of the epistomal sulcus between the clypeus and supraclypeal area, presence of a median groove or channel on the propodeum (Fig. 253), white or dark hind tibia in the female, and relative size of the petiole and hind coxa. Although regional variants appear distinct, each character state can usually be found to some degree in another region. The distribution of the 4 geographical races is shown in Figure 280. The 4 variants are discussed below followed by a discussion of intermediate or disjunct distributions of character states.

Neolosbanus nepalensis can be used to polarize character states among the races of $N$. palgravei outlined below. Using this assumption, the absence of an epistomal sulcus, white hind tibia in males and females, and a relatively short female petiole $(1.5-2.0 \times$ longer than propodeum) would place the Malayan race as having a plesiomorphic form, the Australian form as intermediate, and the Papuan and Carolinean populations as derived. Alternatively, it may be that the present distribution is the result of morphological differentiation from a widespread ancestor similar to the Australian race.

Malayan (M. Fig. 280). All of the specimens collected on Borneo, Java, the island of Mindanao in the
Philippines, and Malaysia (peninsular) can be attributed to this group based on the lack of a clypeal groove, white tibia in both the males and females, and a smaller ratio of the petiole to propodeal length (Table 5). The coxae and petiole are generally more robust than in the other regions, but this is difficult to quantify. Unlike the eastern races. the Malayan race lacks an epistomal sulcus except for females from Selangor (Malaysia), which have a weak depression. Tibial colour is intermediate in western Malaysia, with a faded brown coloration of the hind tibia in both males and females; however, females collected in Selangor (Malaysia) are identical to females from Australia.

Australian (A, Fig. 280). Specimens collected from Australia (Queensland) and Papua New Guinea are recognized by having a white tibia in females and a dark tibia in males (with no intermediates). The clypeus has a distinct epistomal sulcus in all specimens. The propodeum is carinate in females and grooved in males. The ratio of petiole to propodeal length $(1.8-2.8 \times)$ is large in both sexes. Females collected in Taiwan and the Okinawa Islands are similar to the Australian forms, but the epistomal sulcus is intermediate as a narrow, transverse depression. Wing veins of southern forms are all dark brown but to the north and in Malayan forms the wing veins are a light yellowish brown colour.

The Malayan and Australian races are difficult to separate based only on females. Males differ by having the hind tibia white in the Malayan race and dark in specimens from Australia and Taiwan. Females from Borneo, Singapore, and Thailand have a subcircular head and short petiole (Table 5) and lack an epistomal sulcus (swollen medially). Specimens attributed to the Australian form from India, Nepal, and Algeria have a slightly longer petiole and a subtriangular head and there is a vague indication of an epistomal sulcus. The propodeum has a distinct median carina in specimens from India, Nepal, and Algeria, and a foveate or areolate groove in specimens from Borneo. Java. Malaya, Thailand, the Philippines, and Australia. The specimen from Algeria is the only record of this genus from outside of the Indo-Pacilic region (except for a single South American specimen), and is virtually identical to the individuals from India and Nepal. Confusion in the separation of females of the Australian and Malayan races emphasizes the lack of distinct boundaries between races.

Papuan (P. Fig. 280). This race occurs throughout New Guinea and extends north to the Philippines. Females and males have the hind tibial dark. the epistomal sulcus usually distinct (may be absent or intermediate). and the wing veins usually dark. The propodeal line may be distinctly carinate, irregularly carinate, or areolate. The petiole is usually very thin and elongate in males, and the hind coxale are sulall in proportion to the mesosomit. 
TABb1: 5. Maljor geographic variants of Neoloshomes polgravei (Girault) with associated character states. Measurements are the ratio of the petiole length to the hind coxall length (PTL/CXL) and to the propodeal length (PTL/PPL); the mean value is given first, followed by the number of specimens measured, in parentheses, then the minimum-to-maximum range.

\begin{tabular}{|c|c|c|c|c|c|}
\hline Character & Sex & Malayan & Australian & Papuan & Carolinean \\
\hline Clypeal groove & & Absent & Present & Present & Present \\
\hline $\begin{array}{l}\text { Medial propodeal } \\
\text { channel or line }\end{array}$ & & $\begin{array}{l}\text { Foveate channel; } \\
\text { both sexes may } \\
\text { have parallel or } \\
\text { single carinae }\end{array}$ & $\begin{array}{l}\text { I carinate; } \\
\text { channel in } \delta \\
\text { or may be } \\
\text { obliterated }\end{array}$ & $\begin{array}{l}\text { Channel } \\
\text { or groove }\end{array}$ & $\begin{array}{l}\text { Channel with } \\
\text { parallel } \\
\text { carinae }\end{array}$ \\
\hline \multirow[t]{2}{*}{ Tibial colour } & $q$ & light & light & dark & dark \\
\hline & $\delta$ & most light & dark & dark & dark \\
\hline Stigmal vein & & elongate & elongate & elongate & sessile \\
\hline \multirow[t]{2}{*}{ PTL/CXL } & $q$ & $\begin{array}{l}2.47(9) \\
2.08-3.04\end{array}$ & $\begin{array}{l}2.30(11) \\
1.89-2.50\end{array}$ & $\begin{array}{l}2.48(9) \\
1.87-2.64\end{array}$ & $\begin{array}{l}2.14(10) \\
1.65-2.41\end{array}$ \\
\hline & $\delta$ & $\begin{array}{l}3.04(5) \\
2.79-3.36\end{array}$ & $\begin{array}{l}3.12(10) \\
2.98-3.46\end{array}$ & $\begin{array}{l}3.18(8) \\
2.76-4.11\end{array}$ & \\
\hline \multirow[t]{2}{*}{ PTL/PPL } & $q$ & $\begin{array}{l}1.78(9) \\
1.47-2.01\end{array}$ & $\begin{array}{l}2.22(11) \\
1.82-2.79\end{array}$ & $\begin{array}{l}2.21(9) \\
1.87-2.64\end{array}$ & $\begin{array}{l}2.23(10) \\
1.92-2.54\end{array}$ \\
\hline & $\delta$ & $\begin{array}{l}2.59(6) \\
2.14-3.3\end{array}$ & $\begin{array}{l}3.17(10) \\
62.91-3.39\end{array}$ & $\begin{array}{l}2.97(8) \\
2.60-3.34\end{array}$ & \\
\hline
\end{tabular}

Carotinean (C, Fig. 280). This form can be recognized by a rugose-areolate mesosoma with a vague median depression on the scutellum, and small petiole-to-hindcoxa ratio. The propodeum has a median areolate channel which is sometimes bordered by weak carinae. The hind tibia is dark in both males and females, and the stigma is short and visible only as a swelling on the marginal vein. This form was previously treated as Neoloshanus nishidai. The variation of character states overlaps with similar states found in the Papuan forms, and the synonymy proposed by Bouček (1988) appears justified. This may just be an isolated island population of the Papuan form.

\section{MATERIAL EXAMINED}

|Australian form| Algeria [?]: Biskra (BMNH). Australia: Queensland: Dunk Is.; Gillies Highway, 3.3 km W of Little Mulgrave; Hope Valle Mission, $14 \mathrm{~km} \mathrm{~W}$ by $\mathrm{N}$ (15-I6S 144.5E); Hope Valle Mission, $14 \mathrm{~km}$ W by
N: Iron Range, Cape York Peninsula; Kuranda, 3, 2.8. and $5.4 \mathrm{~km}$ N on Black Mtn Rd, Kuranda Range, rainforest; Kuranda 200 m, 1000 m; Kuranda Range S. F.; Kuranda, 1.5 km SE; Lankelly Ck, Mcllwraith Range, C. York; Leo Creek Rd, $500 \mathrm{~m}$, McIlwraith Range, $20 \mathrm{~km}$ NE Coen: Moses Ck, $4 \mathrm{~km}$ W by E Mt Finnigan (15.47S 145.17E); Mossman Gorge; Mt Tozer, 9 km ENE (12.43S 143.17E); Rocky Scrub, McIlwraith Range, C. York; Tam O'Shanter S. F., Mission Beach, N Rd, 50 m; Upper Mulgrave Riv.. via Gordonvale; Shipton's Flat (15.47S 145.14E); all months except September (136 $q$. $163 \delta^{\circ} \delta^{\circ}$, ANIC, BMNH, BPBM, CNC, JMH, MCZ, QMB, ROM, TAMU). INDIA: Karnataka: Mudigere, October $(1 q, \mathrm{BMNH})$; Kerala: Periyar, October $(5 q q$, BMNH). JAPAN: Ryukyu Islands: Okinawa Is., Yona; Amami-Oshima ls.: Hatsuno; Shinmura: Tojyomura; Tokuno Shima Is., Mikyo, $200 \mathrm{~m}$; Macaranga [?]. J. L. Gressitt; July, October to November $(5 q q, 500$. BPBM. KUEC). NEPAL: Lothar, nr Birganj, $150 \mathrm{~m}$; 
Pokhara, 910 m; September ( 3 ㅇ, BPBM. CNC). PAPUA New GuineA: Amok; Baiyer Riv., 1100 m; Brown Riv., 5 m; Bulolo, 900 m; Port Moresby, 20 km NE; October, December to March ( 7 우, 10 . AEI, BPBM, BMNH). Talwan: Nantou Hsien: Tungpu, 1200 m; Wushe. 1250 m; Taitung Hsien: Hung t'ou Hsu [Lanyu], May, August to October $(4 q 9, \mathrm{TARI})$.

[Malayan form] INDONESIA: Java: Pekalongan; Pelaboean, Ratoe, no dates ( $3 \circ$ 인 10 . MCZ. USNM); West Kalimantan: Gunung Palung N. P.. 100-400 m. $1^{\circ} 15^{\prime} \mathrm{S} 110^{\circ} 5^{\prime} \mathrm{E}$, primary rainforest, closed canopy $\mathrm{MT}$ ( 2 우 , MZB, ROM). MalaysIa: Brunei: Labi, $200 \mathrm{~m}$, mixed dipterocarp forest. August to October ( $2 q q$. BMNH). Selangor: Gombak. 26.4 km W, Univ. Malaysia F.S.C.; Kuala Lumpur. Univ. Malaya, Rimba Ilma rainforest trail, $100 \mathrm{~m}$; June, October, December $(6 \circ+9,20$, JMH, TAMU); Sarawak: Forest Camp, $19 \mathrm{~km} \mathrm{~N}$ Kalabakan; Sandong, Kampong Tapuh, 300-400 m: Sarikei Dist., Rejang Delta: Semongok: SW of Tapulı; Tawan District. Kalabakan, primary forest: January, July, November ( $16 q q, 7 \delta$ ơ, BPBM, CNC). PhILIPPINES: Misamis Oriental [Mindanao Is.], Dinawihan Gingoog, 26 km E Gingoog City, 100-300 m: Negros Oriental: 16 km W Dumaguete; May, August ( 1 \% $10^{\circ}$, BPBM, ROM). SingaPORE: Nee Soon Water Res.; Singapore Botanical Garden; December (20े, BPBM). ThaILAND: Ban Na: Fang, April ( $19,1 \delta$, BPBM). VIETNAM: $20 \mathrm{~km} \mathrm{~S}$ Da Lat, $1300 \mathrm{~m}$, September ( 1 ठै, BPBM).

[Papuan form] INDONESIA: Seram [Amboina]: no date and October ( $\left.3 q q, 1 \delta^{*}, \mathrm{MCZ}\right)$; Irian Jaya: Biak Is., $50-100 \mathrm{~m}$, sweeping in mangrove swamp. May $(10$, BPBM). Papua New Guinea: Adelbert Mts: Wanuma. 800-1000 m: Banz, Wahgi Valley, $1500 \mathrm{~m}$; Banz, $16 \mathrm{~km}$
NW, 1700 m; Central Prov., 20 km SE Port Moresby: Bisianumu, E of Port Moresby, $500 \mathrm{~m}$; Guega, W of Swart Valley, 1200 m; Kougel Riv.. 1250 m: Kundiawa, Chimbu Riv.; Morobe Dist., Mindik, 1200-1600 m; Mt Hagen, $25 \mathrm{~km}$ E: Mt Suckling. Mau I [?], 500-1000 m. collected on Castanopsis; Nenguag, Asaro-Chimbu div., $2500 \mathrm{~m}$; W Highlands, Goiburung, E of Korn Farm. 1560-1650 m: W Highlands. Kamang nr Minj. 1840 m: September to February, April to July ( $19+9.60^{\star} \delta^{\star}$. AEl, ANIC, BPBM); Bougainville: Kokure, nr Crown Prince Range, $900 \mathrm{~m}$; Kokure, $690 \mathrm{~m}$; June (2ㅇ․ $2 \delta^{\text {t }}$, BPBM); Goodenough Is.: $400 \mathrm{~m}$, September (1 $q$, AEI). PhilıpPInes: Davao Prov. [Mindanao Is.]. Calian; Negros Oriental [Negros Is.], L. Balinsasayao, bait traps with chicken intestines; Camp Lookout, 16 km W Dumaguete, $300 \mathrm{~m}$; May ( 2 q ㅇ, 2 ㅎ․, BPBM, MCZ, ROM). Solomon ISLANDS: Guadalcanal, Suta (Suta-Gold Ridge), Jonapau Mt. 1000 m; Suta, 500-1200 m; June (2 $q$, BPBM).

[Carolinean form] CAROLINE ISLANDS: Palau Islands: Arakabesan Is.; Auluptagel Is.; Aurapushekaru Is.; Babelthuap Is.: Airai, Ngarsung, along streams: Airai, Ngerimal Riv., treefern ravine: Gakip: Imeluk. Netkeng: Melekeiok; Ngaremeskang, 25 m; E Ngatpang, $65 \mathrm{~m}$. light trap: Ngerchelong; Ngiwal, jungle: SW of Ulimang. wooded peak; Ulimang; Koror Is., limestone ridge: Peleiu Is., Amiangal Mt; Uruklethapel Is., (NE), Palau Ngerem. $180 \mathrm{~m}$ : January, April to July, September, December (3I $+q, 17 \delta^{\circ}$, BPBM, USNM). Yap Islands: Yap Is.: Kolonia, along streams; Dugai, with ants; Mt Gillifits, 150 m; Mı Matade. 95 m; Ruul Dist.; nr Yaptown; Yap Hill, behind Yaptown, $50 \mathrm{~m}$ : Yap Is.: June to August, November to December (13ㅇ․ $8 \delta^{\circ} \delta^{\star}, \mathrm{BPBM}$. USNM).

\section{Neolosbanus gressitti-group}

The 5 species in this group all have the following: clypeal margin weakly rounded. face sculptured in most species, ovipositor enlarged along the entire length, first valvula smooth and without ridges or teeth, and second valvula with lateral tecth. Species are widespread in the IndoPacific region with none known from Australia. A single specimen is known from Uruguay and the record. if valid, represents a significant range extension for this genus.

\section{(BROTP DESCRIPTION}

Head $0.3-0.4 \times$ as long as wide: ocelli arranged in obtuse subtriangle (not line), median ocellus mecting or only slightly exceeding line drawn across anterior margin of lateral ocelli: face smooth to completely rugulose or punctate; scrobal depression smooth and shallowly impressed: occiput aciculate or glabrous. Clypeal margin broadly rounded and only slightly produced over mouth- parts. epistomal sulcus distinct. Malar depression absent or reduced. Antenna 11- or 12-segmented; scape cylindrical or expanded apically; anellus present or absent: funicle 8-segmented in botl sexes, segments with MPS in both sexes.

Mesosoma with dorsum weakly sculptured to scabrous; frenal area glabrous or carinate, angled 80 to 90 degrees to dorsum of mesosomia (Fig. 254). Mesepimeron glabrate: femoral groove continuing ventrally, dividing at ventrolateral margin, and separate sulcus continuing posteriorly to meet base of mid coxa (Figs. 232-233): mesepisternum witl wedge-shaped sternatular sculpture in some species. Prepectus foveate and triangular dorsally. gradually narrowed ventrally, polished below upper triangular lobe (ridgelike in some $N$. violecens). Forew ing 2.3-2.6x as long as broidd: speculum and hasal area of forewing hare: stigmal vein of forewing broad and at 
most $1.5 \times$ as long as broad: postmarginal vein shorter than stignal vein and abruptly narrowed.

Gasfer with basal terga glabrous. Ovipositor thickened along entire length and straight (Fig. 270); first valvulat glabrous. without ridges or teeth; second valvula broad, glabrous medially, and apically with 5 to 6 sharp leeth on lateral margin. Ms, and genitalia of male diagnostic for species.

Neolosbanus gressitti (Watanabe) comb. nov.

Losbamus gressitti Watanabe, 1958:28, fig. 5. Caroline Islands [USNM, examined].

\section{TYPE MATERIAL}

Holotype, + , "PONAPE: Mt Tamatamansakir/ 180 m. I19-'53." "Caroline Is./ Pac. Sci. Bd./ J. L. Gressitt." "Type No./ 64015/ USNM." Gaster and petiole missing. Deposited in USNM.

Paratypes [examined]: PONAPE: same data as holotype except collected on 18.i.1953, (BPBM); N.2, SE. Nanponmal, 7.i.1953, J. L. Gressitt, light trap (I \&, ElHU).

\section{DIAGNOSIS}

Recognized by the following: lateral lobe almost smooth, anellus absent, and femora completely yellow. This species bears a strong resemblance in general form to species of Golluniella, especially in head shape, antenna, femora, and wing venation.

\section{FEMALE}

Length, 1.7-1.8 mm. Dark brown to black; antenna, coxae, and gaster dark brown; scape and legs yellow. Wings hyaline, venation pale brown.

Head subcircular in frontal view; occiput transverse to slightly emarginate; median ocellus separated from occiput by more than its own diameter; LOL 1.2-1.5x OOL. Face broadly rounded, polished with sparse setiferous punctures; occiput glabrous, occipital carina weak, not reaching dorsal eye margin. Eyes separated by $1.5-1.7 \times$ height of eye. Malar space $0.8-0.9 \times$ height of eye, malar depression absent. Lateral margin of clypeus sharply impressed. Antenna 11-segmented; pedicel 1.5x as long as broad, $1.5 \times$ wider than F2 at base; scape narrow, reaching $0.6-0.8 \times$ distance to median ocellus: anellus absent; flagellum 1.3-1.4× height of head; funicular segments with numerous MPS; F2 3.7-3.9x as long as broad, 1.3-1.6× F3, following segments subequal in length: clava with 2 incompletely fused segments.

Mesosoma dorsally with midlobe, axilla anteriorly, and apical half of scutcllum rugose-areolate; lateral lobe smooth or very weakly carinate, axillat and anterior half of scutellum widely spaced carinate. Scutellum slightly longer than broad, rounded apically: frenal area completely polished: axillula glabrate, axillular sulcus indistinct. Propodeum with irregular median sculpturc and weak median carina; callus with few sparse hairs. Coxae and femora polished with few short setae; hind tibia with sparse setae. Forewing 2.4-2.5x as long as broad; stigmal vein $1.5 \times$ as long as broad (speculum bare, not pilose as figured in the original description).

Metasoma with petiole $1.8-1.9 \times$ as long as hind coxa, $1.5-1.7 \times$ as long as propodeum; petiole longitudinally carinate.

MALE

Unknown.

\section{DISTRIBUTION}

Eastern Caroline Is. (G, Fig. 279).

\section{Neolosbanus kokureanus sp. nov.}

Figs. 176-177

\section{TYPE MATERIAL}

Holotype, $q$, "SOLOMON IS./ BOUGAINVILLE (S.)/ Kokure, 690 m./ June 12, 1956." "E. J. Ford, Jr./ Collector." "HOLOTYPE/ Neolosbanus/ kokureanus Heraty." Deposited in BPBM.

Paratypes: PAPUA NEw GuINEA: Bougainville: Kokure, nr Crown Prince Range, 900 m., 9.vi.1956, J. L. Gressitt (1 ㅇ, BPBM); New Guinea: Mi Kaindi, 1790 m, 20-23.vii.1977, J. L. Gressitt, malaise trap (1 ơ, BPBM).

\section{DIAGNOSIS}

This species is closest to $N$. gressitti. Both species have the femora yellow, face of female polished with sparse pits (Fig. 176), frenal area polished medially (in female), and face broadly rounded. $N$. kokureanus differs by: anellus distinct (Fig. 177), lateral lobe of mesoscutum carinate, and coloration strongly metallic blue-green.

\section{FEMALE}

Length, 2.1-2.2 mm. Body, including coxae, dark metallic blue-green; legs and antenna yellow, antenna darker apically. Wings hyaline, venation pale brown.

Head subtriangular, cheek broadly rounded; occipur weakly emarginate; median ocellus separated from occipital margin by more than its own diameter: LOL $1.5 \times$ OOL. Face rounded, polished with few minute setiferous punctures lateral to supraclypeal area; occiput glabrous, occipital carina weak and extending just beyond lateral ocellus. Eyes separated by $1.4 \times$ their height. Malar space $0.7-0.8 \times$ height of eye, malar depression weakly impressed near base of mandible. Lateral margin of 
clypeus deeply impressed; epistomal sulcus distinct. Antenna 12-segmented; pedicel longer than broad, slightly wider than F2; scape narrow, reaching median ocellus; anellus present; flagellum $1.7 \times$ height of head; funicular segments with sparse MPS; F2 5.0× as long as broad, $1.2 \times \mathrm{F} 3$, following segments subequal; clava appearing 1 segmented.

Mesosoma with dorsum strong rugose-areolate; lateral lobe transversely carinate; axilla longitudinally carinate. Scutellum as long as broad, apically rounded; frenal area glabrous medially; axillula glabrous, axillular sulcus indistinct. Propodeum with prominent median carina becoming areolate band dorsally; callus with sparse setae. Coxae and femora smooth with sparse setae; hind tibia moderately setose. Forewing $2.6 \times$ as long as broad; stigmal vein as long as wide.

Metasoma with petiole $2.1 \times$ as long as hind coxa, $2.2 \times$ as long as propodeum; petiole longitudinally ribbed dorsally, weakly sculptured sublaterally with weak ventral keel.

\section{MALE}

Length, $2.6 \mathrm{~mm}$. Colour as in female except antenna completely yellowish brown. Median ocellus separated by less than its diameter from occipital margin. Face with cheek and frons next to eye shallowly punctate becoming weakly rugose to punctate dorsally; occipital carina prominent. Antenna 12-segmented; scape strongly expanded apically but clublike and without flange; anellus present; F2 $1.1 \times$ F3, F3 $1.2 \times$ F4, following segments subequal in length. Scutellum with frenal area strongly rugose. Petiole $1.9 \times$ as long as hind coxa, $2.7 \times$ as long as propodeum. $\mathrm{Ms}_{8}$ broad and truncate. Genitalia broad, paramere short, aedeagus broad.

\section{DISTRIBUTION}

Known only from Bougainville and New Guinea (K, Fig. 279).

\section{ETYMOLOGY}

From Kokure; referring to the type locality.

Neolosbanus anapetus sp. nov.

Figs. 186. 207-208, 233. 254, 270. 273-274

\section{TYPE MATERIAI.}

Holotype. 9. "PHILIPPINES:/ MI Province/ Mayoyao. Ifugao/ 1200-1500 m/ 19.1X.1966." "H. M. Torrevillas/ Collector/ BISHOP." "HOLOTYPE/ Neolosbanus/ anapetus Heraty." Deposited in BPBM.

Paratypes: Malaysia: Sabah: W Coası Residency, Ranau, $13.2 \mathrm{~km} \mathrm{~N}$. of Poring Hot Springs, $500 \mathrm{~m}, 8-11 . x .1958$. T. C. Maa, sweeping (1 9.10 \% BPBM); Ranat. 500 m. 28.ix-7.x.1958, T. C. Mala (I. BР BM): Tawan Dist..
Kalabakan, primary forest, 8-15.xi.1958, T. C. Maa (1 9 , BPBM); Forest Camp, 9.8 km SW of Tenom, 19.xii.1962. K. L. Kuncheria (1 옹 BPBM): "Borneo West" (1오. BMNH). Philippines: Mt Province: Mayoyao, Ifugao. 1200-1500 m, 3,4.6-7.10,13.ix.1966 (9 q q. 8 oे oे.

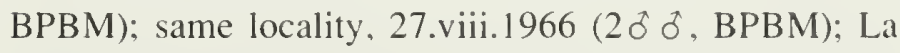
Lune Mtns, Davao, Mindano, 5.vii C. S. Clagg (1 $q$. MCZ); Davao, Mindano, Baker (1 $9 . \mathrm{MCZ}$ ); Los Banos. Baker (1 ơ, BPBM).

\section{DIAGNOSIS}

Recognized by the following: head and mesosoma dark green, lower region of face strongly rounded, clypeus flush with lower face (Fig. 207), scape of male with strong inner flange apically (Fig. 186), and mesosoma with dorsal sculpture shallow rugose-areolate.

\section{FEMALE}

Length, 2.0-3.0 mm. Mesosoma black with strong greenish reflections, head dark green with reddish reflections, metasoma dark brown to black; femora and apical segments of antenna dark brown; most of antenna, apex of femora, tibiae, and tarsi yellowish brown. Wings hyaline. venation pale brown.

Head subtriangular, cheek broadly rounded; occiput broadly emarginate; median ocellus separated from occiput by slightly less than its own diameter; LOL 0.9-1.3× OOL. Face strongly rounded in lower half, punctation widely separated. interstices glabrate (Figs. 207-208); occiput weakly aciculate, occipital carina extending laterally below dorsal margin of eye. Eyes separated by $1.4-1.7 \times$ their height. Malar space $0.7 \times$ height of eye; malar depression shallow and poorly defined, broader next to oral margin. Clypeal region polished and covered by short setae with several elongate sctae near apex, lateral margin sharply impressed and clypeus flush with lower face. Antenna 11-or 12-segmented; scape slender, not reaching median ocellus: pedicel slightly longer than broad, wider than F2 at base: ancllus present. but in various degrees of fusion with F2; flagellum 1.3-1.9 $\times$ height of head: funicle with few MPS: F2 $3.3-4.3 \times$ as long as broad, $1.4 \times \mathrm{F} 3$; clava 1 -segmented; llagellomeres cylindrical and subcqual in lenglh.

Mesosoma with dorsum finely and shallowly rugoseareolate; lateral lobe of mesoscutum transversely carinate: axilla longitudinally carinate. Scutellum as long as broad. base well separated from TSA; frenal area irregularly carinatc: axillula glabrate, axillular sulcus obscured by surface sculpture. Propodeum evenly rounded with shallow. irregular rugose-areolate sculpture medially; callus with several sparse, short setac. Femoral groove broad and deeply foveate to carinate. Coxac glahrous; lemorat wealkly coriaceous to glabratc. Forewing 2.3-2.5x an long an broad: stignal vein broader than long. 
Me'fesema with petiole 1.7-2.()x as long as hind coxa. 1.3-2.2x as long as propodeum; petiole longitudinally ribbed, sublatcrally weakly sculptured and with weak ventral heel. Ovipositor as described for group (Fig. 270).

\section{MIIE}

Lengtl. 2.2-2.6 m. Colour as in female. Antenna 11 - or 12-segmented; scape expanded apically, inner margin with protruding flange apically bordering broad excavated region below pedicel (Fig. 186); anellus absent or parlially fused to F2: flagellum $1.7 \times$ height of head; F2 $2.2-2.9 \times$ as long as broad, 1.2 $\times$ F3. distinctly broader than F3, basal flagellar segments compressed and becoming cylindrical distally, apex of each segment abruptly enlarged. Petiole $2.1-3.1 \times$ as long as hind coxa, 2.2-2.6x as long as propodeum. $\mathrm{Ms}_{2}$ with weak constriction near base (Fig. 273). $\mathrm{Ms}_{8}$ rounded apically. Genitalia as in Figure 274, paramere long.

\section{VARIATION}

Sculpture on dorsum of the mesosoma on the Sabah material is finer and more closely spaced than any of the Philippines specimens, but otherwise the material is identical.

\section{DISTRIBUTION}

Philippines and Malaysia (Sabah; A, Fig. 279).

\section{ETYMOLOGY}

From Latin anapetes, meaning expanded; referring to the widened male scape.

\section{Neolosbanus violaceus sp. nov.}

Figs. 185, 206, 232

\section{TYPE MATERIAL}

Holotype, q, "Baiyer R., N. Guinea/ XII.24-26.1978/ 1100 m. J. Sedlacek." "HOLOTYPE/ Neolosbanus/ violaceus Heraty." Deposited in AEI. A male was chosen as holotype because neither female has a complete antenna. Paratypes: PAPuA New Guinea: Guega, W of Swart Valley, 1200 m, 15.xi.1958, J. L. Gressitt (I ․ BPBM): Brown Riv., 22.v.1958, E. J. Ford, Jr. (1 $q$, BPBM); Baiyer Riv., 1100 m, 24-26.xii.1978 (1 ठ) ), 25.i-6.ii.1979 (3ठ̋ ठै), 25.ii-9.iii.1979 (3ठ̋ ठै), J. Sedlacek (AEI); Karimui, S of Goroka, 1000 m, 5.vi.1961, J. L. Gressitt and M. Gressitt (1 ठै, BPBM): Morobe Dist., Wau, Kunai Ck, $1250 \mathrm{~m}, 26$. viii.1963, J. Sedlacek, Malaise trap ( 10 , BPBM).

\section{DIAGNOSIS}

Distinguished by the following: ancllus large (Fig. 185), scape of female slender and scape of male medially expanded (Fig. 185), supraclypeal and clypeal areas laterally delimited by weak narrow groove (Fig. 206), cheek not broadly rounded and not flush with clypeal region, mesosoma with strong dorsal sculpture, and petiole of male long and sinuate.

\section{FENALE}

Length, 2.3-2.6 mm. Head, mesosoma, and petiole dark blue with strong violaceous reflections; coxae. femora, and gaster dark brown; antenna, tarsi, and apex of femora yellowish brown; tibiae dark brown or yellowish brown medially. Wings hyaline, venation brown.

Head subtriangular, cheek broadly rounded; occiput weakly emarginate; median ocellus scparated from posterior margin by less than its own diameter; LOL $1.0 \times$ OOL. Face weakly rounded, moderately setiferous-punctate with interstices glabrate to weakly colliculate (Fig. 206); occiput weakly aciculate, occipital carina weak, extending halfway between ocellus and eye margin. Eyes separated by $1.5 \times$ their height. Malar space $0.7 \times$ height of eye, malar depression narrow and shallowly impressed next to oral margin. Clypeal region glabrous, lateral margin distinctly impressed. Antenna 12-segmented; pedicel slightly longer than broad, wider than F2 at base; scape narrow and cylindrical, almost reaching median ocellus; anellus present or partially fused to $\mathrm{Fl}$; F2 $3.8-6.3 \times$ as long as broad, 1.2 $\times$ F3, F2 slender with dense, small setae (rest of antenna missing).

Mesosoma with dorsum, including lateral lobe of mesoscutum, scabrous to deeply rugose-areolate; posterior half of axilla longitudinally carinate. Scutellum as long as broad; frenal area irregularly carinate to areolate dorsally; axillula glabrous, axillular sulcus lacking. Propodeum with irregular median carina in posterior half, bordered by irregular medial band of areolate sculpture, callus with sparse patch of setae. Femoral groove broad and weakly foveate. Coxae and femora weakly sculptured and with fine sparse setae. Forewing $2.4 \times$ as long as broad; stigmal vein slightly longer than broad.

Metasoma with petiole $1.8-1.9 \times$ as long as hind coxa, $1.9-2.1 \times$ as long as propodeum; petiole longitudinally ribbed, interstices of ribs weakly rugulose. (Ovipositor hidden in sheath.)

\section{MALE}

Length, 2.1-3.1 mm. Colour as in female, hind tibia dark brown to black medially, apices yellowish brown. LOL 0.9-1.2× OOL. Antenna 11-segmented; scape not reaching median ocellus, swollen medially and flattened below pedicel (Fig. 185): anellus minute; funicular segments cylindrical to slightly compressed laterally, uniform along entire length, subequal in length and width; F2 1.1-1.3x F3. slightly broader than F3; clava with 2 incompletely fused segments. Propodeum with median carina bordered 
by medial band of rugose or areolate sculpture. Petiole $2.3-2.8 \times$ as long as hind coxa, 3.0-3.3x as long as propodeum. $\mathrm{Ms}_{8}$ rounded. Genitalia typical, paramere narrow and elongate.

\section{DISTRIBUTION}

New Guinea (V, Fig. 279).

\section{ETYMOLOGY}

From Latin violaceus, meaning violet coloured; referring to the colour of the head and mesosoma.

\section{ADDITIONAL SPECIES}

Two species, similar to $N$. violaceus, are known from Malaya (X, Fig. 279), and apparently Uruguay. The single specimen from Uruguay (Tacuarembo: $40 \mathrm{~km} \mathrm{NW}$ Tacuarembo, 10-16.ii.1963, J. K. Bouseman; AMNH) represents an anomaly for the genus, which is otherwise restricted to the Indo-Pacific. J. K. Bouseman (INHS) was contacted regarding the validity of the label. He took part in the 1963 expedition to Uruguay, and malaise trap material was returned to AMNH for processing. This specimen is covered with lepidopteran scales, suggesting that it was collected in a malaise trap. I have seen no other eucharitid material in the AMNH collection collected from the Indo-Pacific region, and chances for mislabeling of the specimen would appear to be remote. I prefer not to describe this species until the locality can be verified. It is a distinct species and is closer to the male from Thailand, described below, than to $N$. violaceus.

A single male specimen (not described because of its poor condition) from Thailand (Trang Prov.. Khaophoppha Khaochang, 200 m, 9-11.i.1964, G. A. Samuelson, BPBM) differs in having a shorter petiole, very slender scape and antennal segments, F2 as broad as F3, hind coxa polished, femora yellow, mesoscutum transversely carinate laterally and anteriorly, and $\mathrm{Ms}_{8}$ narrowly rounded. 


\section{Summary}

The Oraseminate and Eucharitinac are recognized as a monophyletic group that fits the traditional concept of the Eucharitidae (Burks. 1979: Graham, 1969); Heraty, 1985, 1989). Females of both subfamilies deposit their eggs in or on plant tissue and are parasites of ant pupac through the larval stage of the host. First-instar larvac possess several character states that justify the monophyly of Eucharitinae + Oraseminac, and provide reliable evidence for determining phylogenetic relationships with respect to the Perilampidae. Other subfamily groupings proposed by Bouček (1978. 1988) are not dealt with, and placement in the Eucharitidae for these taxa is problematical. The Echthrodapinae and Philomidinae are parasites of bee pupae and Philomidinae have a planidiaform larva that is distinct from those of Perilampidae and Eucharitidae and should therefore not be included in Eucharitidae (Darling, 1992). The biology of species of Akapalinae is unknown. Character states that are deemed ancestral for Oraseminae + Eucharitinae are either typical of most Chalcidoidea or justify the monophyly of the 2 subfamilies. No character states were found that would clarify relationships with the other subfamilies proposed by Bouček.

Oraseminae were previously defined as a subfamily based on the presence of an anelliform first flagellomere. independent prepectus, constricted first gastral sternite, and subapically expanded ovipositor. These character states of adults that were used to support the earlier concept of Oraseminae are either plesiomorphic (as recognized in earlier studies) or homoplastic and uninformative in defining relationships. In particular, I postulate that an expanded ovipositor has arisen independently in at least 5 unrelated taxa (Oraseminae, Neoloshanus, Anorasema, Schizaspidia, and Chalcura montana). The habit of depositing eggs into plant tissue likely provides a functional basis for convergent development of the ovipositor. The constriction of the first gastral sternite $\left(\mathrm{Ms}_{2}\right)$ is plesiomorphic and shared with the Perilampidae. It is found in all species of Oraseminae, and 1 propose that its loss is an apomorphy of Eucharitinae.

The Oraseminac is recognized as a monophyletic group that includes the genera Indosema, Orasema, Orasemorpha, and Timioderus. Certain species previously treated as Orasema were transferred to 2 new genera that are included in the Eucharitinae. The morphological limits of the Eucharitinae were expanded to include the new genera Neoloshamus and Psilocharis. Both genera are placed in a new tribe, the Psilocharitini. Anorasema + Gollumiella + Eucharitinae s.s. are interpreted as a monophyletic group and placed together in a new tribe, Eucharitini. The Eucharitinate s.s. (excluding Anorasema and Gollumiella) is monophyletic as based on characters treated in previous studies.

The biology of Oraseminate and Eucharitinae was reviewed based on new larval collections and host records for Orasema, Orasemorpha, and Neolosbanus. The conservative nature of the morphology of first-instar larvae was supported in all of the taxa examined. A recxamination of larvac described by other authors removed evidence of conflicting hypotheses of character states within Oraseminae. Additional characters were used for defining eucharitid relationships based on later immature stages including the pupa, characters of eggs. characteristics of oviposition, and ant host. The phylogeny of Eucharitidae as based on an analysis of characters of adults was robust with respect to larval characters. Inclusion of larval characters along with characters of adults in the cladistic analysis supported the realignment of Oraseminae and Eucharitinae. Larval characters and within-nest behaviour of Neolosbamus are the same as for other members of the Eucharitinae. The previous classification of species of Neolosbanus within Orasema would have provided a false prediction of larval characters, behaviour within the nest, and ant host.

There are strong correlations between ant hosts and phylogenetic relationships for Eucharitidae. Myrmicinae are regarded as the ancestral host for Oraseminae. Pheidole is the only known host in the Old World, but New World species of Orasema are also found on other Myrmicinae, Formicinae, and Ecitoninae. The known ant host of Neolosbanus is Hypoponera, and Ponerinae are postulated as the ancestral host for Eucharitinae. Within Eucharitinae, several derived lineages have switched to Formicinae. Either the Ponerinae and Myrmicinae are treated as derived sister groups, or the Myrmicinae (including Myrmeciinae + Pseudonyrmecinae) are treated as the sister group (excluding or including the formicoid subfamilies) to the Ponerinae + army ants; Formicinae are not closely related to Ponerinae (BaroniUrbani, 1989; Bolton, 1990; Hölldobler and Wilson. 1990; Baroni-Urbani et al., 1992; Shattuck. 1992). Coevolution or "tracking" of the host evolution cannot be ruled out among basal groups of eucharitids. However. I propose an invasive or colonizing form of host adaptation with eucharitids overcoming host defences and radiating within a particular ant lineage. The best evidence for this strategy was observed in the Obeza-clade, in which females deposit their eggs in association with fruit or offer egg secretions as an attractant for Camponorus (Formicinae) (Heraty and Barber. 1990). Behaviour of the planidial stage is recognized as a means of gaining access to the host, and changes in behaviour may be responsible for host shifts in Formicidale. 
The number of species found in each geographic region is summarized and presented along with a cladogram derived from the analysis of relationships at the species-group level (Fig. 281). Only Orasema and Psilocharis have representative species in all of the regions of the Old World tropics. Orasemorpha, Timioderus, and Indosema have restricted continental distributions, and almost all collections of Neolosbanus were confined to the Indo-Pacific region. These differences occur because different geographical and evolutionary histories affect lineages of supposedly different ages. Of the 6 genera treated in this analysis, the distribution of each species was limited, and only a few species were found in more than one geographical subregion. The single records of Psilocharis from Argentina and Neolosbanus from Uruguay are difficult to dismiss, and may be the result of a relict distribution, dispersal, human transport (e.g., ships' ballast), or possibly mislabelled specimens; however, in both cases the label data appear to be accurate.

Phylogenetic hypotheses and present disjunctions among Oraseminae and Psilocharitini support the broad patterns proposed in Fig. 282. The Australasian fauna is distinct from the Indo-Pacific fauna, and species of Orasema, Psilocharis, and Neolosbanus in the Papuan region appear to be derived from ancestral species in the Indo-Chinese + Malayan subregions, as postulated also by Gressitt (1982), Noonan (1985), and Schuh and Stonedahl (1986). Species of Orasema and Psilocharis found in the Australian region are phylogenetically isolated from the most closely related Indo-Chinese species and have closer relationships to Ethiopian species. Relationships between Orasemorpha, Timioderus, and Indosema also suggest an early Ethiopian/Australian disjunction, supporting a Gondwanan pattern of distribution, although only Orasema is found in South America (with questionable records of Psilocharis and Neolosbanus). Thus, Oraseminae and Psilocharis may have originated during the late Cretaceous or early Eocene. Neoloshamus is largely restricted to the Indo-Pacific region and may have radiated eastward through to the Papuan subregion some time after the Miocene uplift of islands in the IndoPacific region (Noonan. 1985). Species in the Orasema uichancoi-group exhibit a similar pattern of radiation to Neolosbanus but are most closely related to species found in the Malagasy region. The proposed faunal shifts between the Ethiopian and Indo-Chinese regions, as based on phylogeny, agree with patterns found in Carabidae and Miridae (Noonan, 1985; Schuh and Stonedahl, 1986).

The distribution of Neolosbanus suggests that the northern limits of the Indo-Chinese subregion should be extended north to include the islands Kyushu, southern Honshu, and Tsushima (Figs. 279-280, 284). Orasema koghisiana is the only orasemine known from $\mathrm{New}$ Caledonia and the New Hebrides and it shows a closer phylogenetic relationship to species from Australia rather than from the Indo-Pacific region as proposed by Gressitt (1956). Otherwise, the boundaries of subregions outlined by Gressitt (1956) and Schuh and Stonedahl (1986) are supported.

Revisionary studies were carried out on 6 genera of Eucharitidae belonging to Oraseminae and Eucharitinae in the Old World: 56 species are treated, of which 31 belong to the Oraseminae and 25 to the Psilocharitini (Eucharitinae). Phylogenetic hypotheses are proposed for species within each of the genera. This is the first comprehensive treatment of the Eucharitidae of the Old World tropics. I do not expect it to encompass all of the species in this area, and I expect that more species remain to be discovered.

Prediction is the ultimate goal of any scientific endeavour. Phylogenetic studies were used to develop a new classification for Eucharitidae. The present classification is correlated with information on morphology of adults and immatures, behaviour, and host relationships, and also with faunistic histories of the Old World tropics. There are many gaps in our knowledge of geographical distributions, host records, and immature stages, and relationships of Eucharitinae need to be more complctely resolved. New information on these groups can be used to modify and refine the hypotheses as I halve presented them, and I would like to think that this work provides the challenge to others to continue studies on this fascinating group of insects. 


\section{Acknowledgements}

This study was initiated at Texals A\&M University and completed at Carleton University and the Biosystematics Research Centre (BRC). Ottawa. I thank my Ph.D. examining committee who reviewed a version of this manuscript and offered helpful suggestions: J. B. Woolley, R. A. Wharton, M. V. Sweet, and S. B. Vinson (all Texas A\&M University). I also thank G. Gibson and J. Huber (BRC), C. Darling (ROM), and J. LaSalle and J. Noyes (BMNH) for thoroughly reviewing the final version of this manuscript and providing additional suggestions for improvement. Numerous people oflered assistance during my stay at Texas A\&M and I would like to thank G. Zolnerowich, D. Judd. J. C. Schaffner, H. R. Burke, M. Rose. and many others. My studies in Ottawa were greatly enhanced by the support from J. Huber and G. Gibson (BRC), R. S. Anderson (Canadian Museum of Nature), and H. Howden and S. Peck (Carleton University).

I am grateful to the individuals and institutions listed in the materials sections for the loans of specimens. I would also like to acknowledge the assistance on my collecting and museum expeditions from the following: E. C. Dahms (QMB); R. Storey (Department of Plant Industries, Queensland); I. D. Naumann (ANIC); LiangY. Chou, K.-C. Chou, and Soo-Min (TARI); R. Loo
(Taipei. Taiwan): H. S. Yong (University of Malaya, Malaysia); Chaweewan Hutacharern and Surochai Choldrumkul (Royal Forestry Department. Thailand): S. I. Faroogi, Manickivasagam (IARI); J. S. Noyes and Z. Bouček (BMNH). The Socio-Economic Unit of Malaysia and the National Research Council of Thailand gave their permission to conduct research in their countries.

I also thank David Swofford and Dave Maddison for making available test versions of PAUP and MACLADE for use in my analyses.

This work was supported in part by a Snodgrass Memorial Research Grant, a Natural Sciences and Engineering Research Council of Canada (NSERC) Postdoctoral Fellowship and a Smithsonian Postdoctoral Fellowship to the author, and a United States National Science Foundation Dissertation Improvement Grant (BSR 8914680) to the author and J. B. Woolley.

I would like to give special thanks to Jim Woolley for providing me with the environment that was needed to complete this work. Over the years Zdenek Bouček has provided assistance, encouragement, and some tremendous material for which I am truly grateful. Finally, I would like to dedicate this work to my wife, Laura, and my daughter, Joanne, for all that they have had to endure over the course of this study. 


\section{Literature Cited}

ALEXANDER, B.

1990 A preliminary phylogenetic analysis of sphecid wasps and bees. Sphecos 20:7-16.

ANANTHAKRISHNAN, T. N.

1984 Bioecology of thrips. Oak Park. Michigan. Indira Publishing. $233 \mathrm{pp}$.

ARNETT. R. J., Jr., and G. A. SAMUELSON

1986 The insect and spider collections of the world. Gainesville, Florida, E. J. Brill. 228 pp.

ASHMEAD, W. H.

1888 Descriptions of three new eucharids from Florida with a generic table of the Eucharinae. Entomologica Americana 3:186-188.

1892 Notes on the eucharids found in the United States. Proceedings of the Entomological Society of Washington 2:354-358.

1895 Some parasitic Hymenoptera from Baja California and Tepic Mexico. Proceedings of the California Academy of Sciences 5:539-555.

AXELROD, D. I. and P. H. RAVEN

1982 Paleobiogeography and origin of the New Guinea flora. In Gressitt, J. L., ed., Biogeography and ecology of New Guinea, Vol. 2, pp. 919-945. The Hague, Junk.

AYRE, G. L.

1962 Pseudometagea schwarzii (Ashm.) (Eucharitidae: Hymenoptera), a parasite of Lasius neoniger Emery (Formicidae: Hymenoptera). Canadian Journal of Zoology 40:157-164.

BARONI-URBANI, C.

1989 Phylogeny and behavioral evolution in ants, with a discussion of the role of behavior in evolutionary processes. Ethology, Ecology and Evolution 1:137-168.

BARONI-URBANI, C., B. BOLTON, and P. S. WARD

1992 The internal phylogeny of ants (Hymenoptera: Formicidae). Systematic Entomology 17:301-329.

BESHEAR, R. J.

1974 A chalcidoid planidium and thrips larvae in Georgia. Journal of the Georgia Entomological Society 9:265-266.

BLANCHARD, E.

1840 Histoire naturelle des insectes III. Paris, Duméril. $672 \mathrm{pp}$.

BOLTON, B

1990 Army ants reassessed: the phylogeny and classification of the doryline section (Hymenoptera, Formicidac). Joumal of Natural History 24:1339-1364.

BOUČI:K, Z.

1956 A contribution to the hiology of Encharis adscendens (F.) Hymenoptera. Acta Societatis Zoologicade Bohemoslovenicac 20:97-99.

1978 A generic key to Perilampinac (Hymenoptera, Chalcidoidea), with a revision of Krmmbeimms n. gen. and Euperilampus Walker. Entomologica Scandinavica 9:299-307.

1988 Australasian Chalcidoidea (Hymenoptera). Wallingford: C. A. B. 1nternational. $832 \mathrm{pp}$.

BOUČEK, Z. and J. S. NOYES

1987 Rotoitidae, a curious new family of Chalcidoidea (Hymenoptera) from New Zealand. Systematic Entomology 12:407-412.

BRETHES, J.

1927 Hyménoptères Sud-Américains du Deutches Entomologisches Institut: Terebrantia. Entomologische Mitteilungen (Berlin) 16:319-335.

BROWN, W. L.. Jr.

1954 Remarks on the internal phylogeny and subfamily classification of the family Formicidae. Insectes Sociaux 1:2l-31.

1973 A comparison of the Hylean and Congo-West African rain forest ant faunas. In Meggers, B. J., A. S. Ayensu, and W. D. Duckworth, eds., Tropical forest ecosystems in Africa and South America: a comparative review, pp. 161-185. Washington, D.C.. Smithsonian Institution Press.

BRUES, C. T.

1919 A new chalcid fly parasitic in the Australian bulldog ant. American Entomological Society of America 12:13-23.

1934 Some new eucharidid parasites of Australian ants. Bulletin of the Brooklyn Entomological Society 29:201-207.

BUCHER, G. E.

1948 The anatomy of Monodontomerus dentipes Boh., an entomophagous chalcid. Canadian Journal of Research 26:230-281.

BURKS, B. D.

1979 Eucharitidae. In Krombein, K. V., P. D. Hurd. Jr.. D. R. Smith, and B. D. Burks, eds.. Catalog of Hymenoptera in America north of Mexico, Vol. 1, Symphyta and Apocrita (Parasitica), pp. 875-878. Washington, D.C., Smithsonian Institution Press.

\section{CAMERON, P}

1884 Hymenoptera. In Godman, F. D., and O. Salivia, eds., Biologia Centrali-Americana. Insecla Hymenoptera (Familias Tenthredinidac-Chrysididlae), pp. 81-144. London. Taylor and Francis. $487 \mathrm{pp}$.

1909 A contribution to the knowledge of the parasitic Hymenoptera of Argentina. Transactions of the American Entomological Socicty 35:419-450

CLANCY. D. W

1946 The insect palasites of loe Chrysopidac (Neuroptera). Eniversity of Califormia Publications in Entomology 7:403-496. 
CL.ALISEN, C. P

1923 The biology of Schizaspidia remicornis Ashnead, a eucharid parasite of $C$ ampomoms. Annals of the Entomological Society of America 16:195-217.

1928 The manner of oviposition and the planidium of Sehizaspidia mamipurensis n. sp. (Hymenoptera, Eucharidae). Proceedings of the Entomological Society of Washington 30:81-85.

1940 a Entomophagous insects. New York, McGraw-Hill. $688 \mathrm{pp}$.

$1940 \mathrm{~b}$ The oviposition habits of the Eucharidae (Hymenoptera). Journal of the Washington Academy of Sciences 30:504-516.

1940c The immature stages of the Eucharidae. Proceedings of the Entomological Society of Washington 42:161-170.

1941 The habits of Eucharidae. Psyche 48:57-69.

\section{DAHMS, E. C.}

1983 A checklist of the types of Australian Hymenoptera described by Alexandre Arsene Girault: II. Preamble and Chalcidoidea species A-E with advisory notes. Memoirs of the Queensland Museum 21:1-255.

1984 A checklist of the types of Australian Hymenoptera described by Alexandre Arsene Girault: III. Chalcidoidea species $\mathrm{F}-\mathrm{M}$ with advisory notes. Memoirs of the Queensland Museum 21:579-842.

1986 A checklist of the types of Australian Hymenoptera described by Alexandre Arsene Girault: IV. Chalcidoidea species $\mathrm{N}-\mathrm{Z}$ and genera with advisory notes and corrigenda. Memoirs of the Queensland Museum 22:319-739.

DALLA TORRE, K. W. VON

1898 Catalogus Hymenopterorum hucusque descriptorum systematicus et synonymicus, Vol. V, Chalcididae et Proctotrupidae. Leipzig. 598 pp.

DARLING, D. C.

1983a Systematic studies of the Perilampidae (Hymenoptera: Chalcidoidea). Ph.D. diss., Cornell University. $278 \mathrm{pp}$.

1983b A revicw of the New World species of Euperilampus (Hymenoptera: Chalcidoidea), with notes about host associations and phylogenetic relationships. Questiones Entomologicae 19:1-40.

1986 Revision of the New World Chrysolampinae (Hymenoptera: Chalcidoidea). Canadian Entomologist 18:913-940.

1988a Comparative morphology of the labrum in Hymenoptera: the digitate labrum of the Perilampidae and Eucharitidac (Chalcidoidea). Canadian Journal of Zoology 66:281 1-2835.

1988b A review of the genus Krombeimus (Hymenoptera: Perilampidate) with a reexamination of generic limits and phylogenetic relationships and the descriptions of generic limits and the descriptions of two new species. Journal of the New York Entomological Socicty 96:63-81.

1992 The life history and larval morphology of
Aperilampus (Hymenoptera: Chalcidoidea: Philomidinae), with a discussion of the phylogenetic affinities of the Philomidinae. Systcmatic Entomology 17:331-339.

DARLING, D. C. and T. MILLER

1991 Life history and larval morphology of Chrysolampus sisymbrii (Hymenoptera: Chalcidoidea: Chrysolampinae) in western North America. Canadian Journal of Zoology 69: 2168-2177.

DAS, G. M.

1963 Preliminary studies on the biology of Orasema assectator Kerrich (Hym., Eucharidae) parasitic on Pheidole and causing damage to leaves of tea in Assam. Bulletin of Entomological Research 54:373-378.

DAVIS, L. R., Jr., and D. P. JOUVENAZ

1990 Obeza floridana, a parasitoid of Camponotus abdominalis floridanus from Florida (Hymenoptera: Eucharitidae, Formicidae). Florida Entomologist 73:335-337.

DE SANTIS, L.

1968 Una nueva especie de "Orasema" del Uruguay (Hymenoptera: Eucharitidae). Revista Sociedad Entomologica Argentina 31:1-3.

\section{EADY, R. D.}

1968 Some illusirations of microsculpture in the Hymenoptera. Proceedings of the Royal Entomological Society 43:66-72.

FABRICIUS, J. C.

1804 Systema Piezatorum. Brunsvigae, Reichard. 439 pp. FAHRINGER, J. and F. TÖLG.

1912 Beiträge zur Kenntnis der Lebensweise und Entwicklungsgeschichte einiger Hautflügler. Verhandlungen des naturforschenden Vereins in Brün 50:242-269.

GAHAN, A. B.

1940 A contribution to the knowledge of the Eucharidae (Hymenoptera: Chalcidoidea). Proceedings of the United States National Museum 88:424-458.

GAHAN, A. B. and M. M. FAGAN

1923 The type species of the genera of Chalcidoidea or chalcid flies. Bulletin of the United States National Muscum 124:1-173.

GEMIGNANI, E. V .

1933 La familia "Eucharidae" (Hymenoptera: Chalcidoidea) en la república Argentina. Anales del Museo Nacional de Historia natural de Buenos Aires 37:477-493.

1937 Nueva nota sobre la familia Eucharidae (Hymenoptera: Chalcidoidea). Anales del Museo Argemtino de Cienciass Naturales "Bernardino Rivadavia" 39:157-166.

1947 Nuevas especies de la familia Eucharidae (Insecta, 
Hymenoptera: Chalcidoidea). Comunicaciones del Museo Argentino de Ciencias Naturales "Bernardino Rivadavia" $1: 1-15$.

GHESQUIÈRE, J

1946 Contributions à l'étude des Microhyménoptères du Congo belge X-XI. Revue de Zoologie et de Botanique Africa 39:367-373.

GIBSON, G. A. P.

1985 Some pro- and mesothoracic structures important for phylogenetic analysis of Hymenoptera, with a review of terms used for the structures. Canadian Entomologist 117:1395-1443.

1986 Evidence for monophyly and relationships of Chalcidoidea, Mymaridae, and Mymarommatidae (Hymenoptera: Terebrantes). Canadian Entomologist 118:205-240.

1989 Phylogeny and classification of Eupelmidae, with revision of the world genera of Calosotinae and Metapelmatinae (Hymenoptera: Chalcidoidea). Memoirs of the Entomological Society of Canada 149:1-121.

1990 Revision of the genus Macronewra in America north of Mexico (Hymenoptera: Eupelmidae). Canadian Entomologist 122:837-873.

GIRAULT, A. A.

1913a More new genera and species of chalcidoid Hymenoptera from Paraguay. Archiv für Naturgeschicte 79, Abt. A, Hft. 6:51-69.

1913b New genera and species of chalcidoid Hymenoptera from the South Australia Museum: Adelaide. Transactions of the Royal Society of South Australia 37:67-115.

1915 Australian Hymenopteran Chalcidoidea Eucharidae. Memoirs of the Queensland Museum 4:225-237.

1922 New chalcid flies from eastern Australia (Hymenoptera). Insector Inscitae Menstruus 10:100-108.

1929 Notes on and descriptions of chalcid wasps in the South Australian Museum. Transactions of the Royal Society of South Australia 53:309-346.

1932 New pests from Australia, X. Reprinted in Gordh, G., A. Menke, E. C. Dahms, and J. Hall (1979). The privately printed papers of A. A. Girault. Memoirs of the American Entomological Institute 28:286-291.

1934 Eucharidae, Cynipidae, Proctotrupidae et Thysanoptera nova australiensis. Reprinted in Gordh. G., A. Menke, E. C. Dahms, and J. Hall (1979), The privately printed papers of A. A. Girault. Memoirs of the American Entomological Institute 28:306-307.

1936 Terror-errors, and novitates of pterygota (or earth realities not state-bound). Reprinted in Gorlh, G.. A. Menke, E. C. Dihms, and J. Hall (1979), The privately printed papers of A. A. Girault. Memoirs of the American Entomological Institute 28:322-325.

1940 New genera and species of Australian Elasmidac and Eucharitidae. Revista de la Sociedad Entomologica Argentima 10:321-326.
GOODPASTURE, C.

1975 Comparative courtship behavior and karyology in Monodontomerus (Hymenoptera: Torymidae). Annals of the Entomological Society of America 68:391-397.

GORDH. G.

1979 Superfamily Chalcidoidea. In Krombein. K. V.. P. D. Hurd, Jr., D. R. Smith, and B. D. Burks, eds., Catalog of Hymenoptera in America north of Mexico, Vol. 1, Symphyta and Apocrita (Parasitica), pp. 743-748. Washington, D.C., Smithsonian Institution Press.

GRAHAM, M. W. R. de V.

1969 The Pteromalidae of north-western Europe (Hymenoptera: Chalcidoidea). Bulletin of the British Museum (Natural History), Entomology Supplement 14:1-908.

GRESSITT, J. L.

1956 Some distribution patterns of Pacific island faunae. Systematic Zoology 6:12-32.

1982 Zoogeographic summary. In Gressitt, J. L., ed., Biogeography and ecology of New Guinea, Vol. 2. pp. 897-919. The Hague, Junk.

HABU, A.

1960 A revision of the Chalcididae (Hymenoptera) of Japan with descriptions of sixteen new species. Bulletin of the National Institute of Agricultural Sciences, Tokyo, Series C, 11:131-358.

HARRIS, R. A.

1979 A glossary of surface sculpturing. Occasional Papers in Entomology, State of California Department of Food and Agriculture 28:1-31.

HEDQVIST, K. J.

1978 Some Chalcidoidea collected in the Philippines, Bismark, and Solomon Islands. 2. Eucharitidae. with keys and check-lists to Indo-Australian genera (Insecta, Hymenoptera). Steenstrupia 4:227-248.

HEPPNER, J. B. and G. LAMAS

1982 Acronyms for world museum collections of insects, with an emphasis on Neotropical Lepidoptera. Bulletin of the Entomological Society of America 28:305-315.

HERATY. J. M.

1985 A revision of the Nearctic Eucharitinac (Hymenoptera: Chalcidoidea: Eucharitidae). Procecdings of the Entomological Society of Ontario 85:61-103.

1986 Psendochalcura (Hymenoptera: Eucharitidae): a New World genus of chalcidoids parasitic on ants. Systematic Entomology 1 1:183-212.

1989 Morphology of the mesosoma of Kapala (Hymenoptera: Eucharitidae) witl emphasis on its phylogenetic implications. Canadian Journal of 7 oology $67: 115-125$.

1990 Classification and evolution of the Oraseminac (Itymenoptera: Eucharitidate). Ph.1). dis.. Tevals A \& M University. $336 \mathrm{pp}$.

1992 Revision of the general Gellumbellat Hedysint and 
Anorasema Bouček (Hymenoptera: Eucharitidae). lnvertebrate Taxonomy 6:583-604.

HERATY, J. M. and K. N. BARBER

1990 Biology of Obeza floridana and Psendochalcura gibhosa (Hymenoptera: Eucharitidae). Proceedings of the Entomological Society of Washington 92:248-258.

HERATY, J. M. and D. C. DARLING

1984 Comparative morphology of the planidial larvae of Euchariridae and Perilampidae (Hymenoptera: Chalcidoidea). Systematic Entomology 9:309-328.

JIERATY, J. M., D. P. WOJCIK, and D. P. JOUVENAZ

1993 Species of Orasema parasitic on the Solenopsis Saevissima-complex in South America (Hymenoptera: Eucharitidae, Formicidae). Journal of Hymenoptera Research 2:169-182.

HEYDON, S. L.

1989 Review of Nearctic Rhinocoelia and Callimerismus with a discussion of their phylogenetic relationships (Hymenoptera: Pteromalidae). Journal of the New York Entomological Society 97:347-357.

HÖLLDOBLER. B. and E. O. WILSON

1990 The ants. Cambridge, Belknap Press of Harvard University Press. 732 pp.

HOWARD, L. O.

1896 On the Chalcididae of the island of Grenada, B. W. I. Journal of the Linnean Society 86:129-178.

1897 Report on the Chalcididae of the subfamilies Chalcidinae, Eucharinae, Perilampinae, Encyrtinae, Aphelininae, Pireninae, Elasminae, and Elachistinae. Journal of the Linnean Society 6, Zoology 26:79-108.

HUBER, J. T.

1988 The species groups of Gonatocerns Nees in North America with a revision of the sulphuripes and ater groups (Hymenoptera: Mymaridae). Memoirs of the Entomological Society of Canada 141:1-109.

HUSAIN, T. and M. AGARWAL

1983 Indosema indica gen. et sp. nov. (Hymenoptera: Eucharitidae) described from India. Bolletino del Laboratorio di entomologia agraria "Filippo Silvestri" 40:103-107.

ISHII, T

1932 Some Philippine Eucharids with notes on their oviposition habits. Bulletin of the Imperial Agricultural Experimental Station, Nishigahara $3: 203-212$.

ISHII, T. and S. NAGASAWA

1941 Description of a new eucharid from Palau Islands. Tenthredo 3:291-294.

JOINSON, D. W

1988 Eucharitidac (Hymenoptera: Chalcidoidea): biology and potential for biological control. Florida Entomologist 71:528-537.
JOIINSON, J. B., T. D. MILL.ER, J. M. HERATY, and F. W. MERICKEL

1986 Observations on the biology of two species of Orasema (Hymenoptera: Eucharitidae). Proceedings of the Entomological Society of Washington $88: 542-549$.

KEAST, A.

1981 Distributional patterns, regional biotas, and adaptations in the Australian biota: a synthesis. In Keast, A., ed., Ecological biogeography of Australia, Vol. 3, pp. 1891-1997. The Hague, Junk.

KERRICH, G. J.

1963 Descriptions of two species of Eucharitidae damaging tea, with comparative notes on other species (Hymenoptera: Chalcidoidea). Bulletin of Entomological Research 54:365-371.

KIRBY, W. F.

1886 A synopsis of the genera of the Chalcidoidea, subfamily Eucharinae, with descriptions of several new genera and species of Chalcidoidea and Tenthredinidae. Journal of the Linnean Society, Zoology 20:28-37.

KISTNER, D. H.

1979 Social and evolutionary significance of social insect symbionts. In Hermann, H. R., ed., Social insects. Vol. 1, pp. 340-414. New York, Academic Press.

KÖNIGSMANN, E.

1978 Das phylogenetische system der Hymenoptera. Teil 3: Terebrantes (Unterordnung Apocrita). Deutsche Entomologische Zeitschift 23:253-279.

LAING, J. E. and J. M. HERATY

1981 The parasite complex of the overwintering population of Epiblema scudderiana (Lepidopiera: Olethreutidae) in Southern Ontario. Proceedings of the Entomological Society of Ontario 112:59-67.

LASALLE, J.

1987 New World Tanaostigmatidae (Hymenoptera: Chalcidoidea) Contributions of the American Entomological Institute 23:1-181.

MADDISON. W. P., M. J. DONOGHUE, and D. R. MADDISON

1984 Outgroup analysis and parsimony. Systematic Zoology 33:83-193.

MANN, W. M.

1914 Some myrmecophilous insects from Mexico. Psyche 21:171-184.

MATSUDA, R.

1980 The insect head. Memoirs of the American Entomological lnstitute 4:1-334.

MICHENER, C. D.

1969 Immature stages of a chalcidoid parasite tended by allodapine bees (Hymenoptera: Perilampidae and Anthophoridac). Journal of the Kansas Entomological Society 42:247-250. 
MITTER, C. and D. R. BROOKS

1983 Phylogenetic aspects of coevolution. In Futuyna, D. J., and M. Slatkin, eds., Coevolution. pp. 65-98. Sunderland, Mass., Sinauer Associates.

NOONAN, G. R.

1985 The influences of dispersal, vicariance, and refugia on patterns of biogeographical distributions of the beetle family Carabidae. In Ball, G. E., ed., Taxonomy, phylogeny and zoogeography of beetles and ants, pp. 322-350. Series Entomologica 33. Dordrecht, Junk. 514 pp.

PARKER, H. L.

1937 The oviposition habits of Stilbula cynipiformis Rossi (Hymenoptera: Eucharidae). Proceedings of the Entomological Society of Washington 39:1-3.

1942 Oviposition habits and early stages of Orasema sp. Proceedings of the Entomological Society of Washington 44:142-145.

REICHENSPERGER, A.

1913 Zur Kenntnis von Myrmecophilen aus Abessinien, I. Zoologische Jahrbücher, Abteilung für Systematik, Geographie und Biologie der Tiere 35:185-218.

REIMER, N. J.

1988 Predation on Liothrips ulrichi Karny (Thysanoptera: Phlaeothripidae): a case of biotic interference. Environmental Entomology 17: 132-134.

RICHARDS, O. W.

1977 Hymenoptera. Introduction and key to families. Handbooks for the Identification of British Insects 6:1-103. London, Royal Entomological Society.

RIEK, E. F.

1970 Hymenoptera (Wasps, bees, ants). In The insects of Australia, pp. 867-959. Melbourne, Melbourne University Press.

RISBEC, J,

1952 Contribution à l'étude des Chalcidoödes de Madagascar. Mémoires de l'Institut scientifique de Madagascar, Sér. E. 2:1-449.

1958 Chalcidoïdes nouveaux d'Afrique du Sud. Occasional Papers. National Museum of Southern Rhodesia, Bulawayo 3, no. 22B:147-162.

SCIIAUFF, M. E.

1984 The Holarctic genera of Mymaridae (Hymenopica: Chalcidoidea). Memoirs of the Entomological Society of Washington 12:1-67.

1991 The Holarctic genera of Entedoninac (Hymenoptera: Eulophidae. Contributions of the American Entomological Institutc 26:1-109.

SCHUII, R. T. and G. M. STONIDAII,

1986 Historical biogeography in the Indo-Pacilic: a cladistic approach. Cladistics 2:337-35.5.
SHATTUCK, S. L.

1992 Higher classification of the ant subfamilies Aneuritinae, Dolichoderinae and Formicinae (Hymenoptera: Formicidae). Systematic Entomology 17:199-206.

SMITH, H. S.

1912 Technical results from the gipsy moth parasite laboratory. IV. The chalcidoid genus Perilampus and its relations to the problem of parasite introduction. United States Department of Agriculture Technical Series 19:33-69.

1917 The habit of leaf-oviposition among the parasitic Hymenoptera. Psyche 24:63-68.

SNEHALATHA, S. and T. C. NARENDRAN

1992 On a new species of Orasema Cameron (Hymenoptera: Eucharitidae), with a key to Indian species. Journal of the Bombay Natural History Society 89:355-357.

SNODGRASS, R. E.

1935 Principles of insect morphology. New York. McGraw-Hill. 667 pp.

1956 Anatomy of the honey bee. Ithaca, Comstock Publ. Associates, Cornell University Press. 334 pp.

STEYSKAL, G.

1980 Errors in nomenclatural grammar. In Krombein et al.. Catalog of Hymenoptera in America north of Mexico (1979). Sphecos 3:43-46.

STRAND. R.

1942 Miscellanea nomenclatoria zoologica et palaeontologica X-XIl. Folia Zoologica et Hydrobiologica 11:386-402.

SWOFFORD, D. L.

1990 PAUP: Phylogenetic Analysis Using Parsimony, Version 3.0n. Computer program distributed by the Illinois Natural History Survey, Champaign, Illinois.

TAYLOR, R. W

1978 Nothomymecia macrops: a living-fossil ant rediscovered. Science 201:979-985.

VAN PELT, A. F.

1950 Orasema in nests of Pheidole dentata Mavr (Hymenoptera: Formicidate). Entomological News $71: 161-163$.

VANDER MEER. R. K.. D. P. JOUVENAZ, and D. P. WOJCIK

1989 Chemical mimicry in a parasitoid (Hymenoptera: Eucharitidae) of fire ants (Hymenoptera: Formici(ac). Journal of Chemical Ecology 15:2247-2261.

IVALKLR, F.

1839 Monographia Chalciditum, Vol. 2. London. 100 pp.

1846 Pall 1 - Chalcidites. I.ist of the specimens of hymenopterous insects an the collection of the British Musemm. Pt. I chalcidites. Pl. 2 addhoronal species. I nndon. 237 pp.

1862 Mr. F. Walker" noter on chalcidites and chalracters 
of undescribed species. Transactions of the Entomological Society of 1 ondon 1:380-385.

WARD.PS

1990) The ant subfamily P'seudomrymecinae (Hymenoptera: Formicidae): generic revision and relationship to other formicids. Systematic Entomology $15: 449-489$

WATANABE, C.

1958 Hymenoptera: Eucharitidac. Insects of Micronesia 19:19-34. Honolulu, Bishop Museum.

WATERSTON, J.

1916 Notes on African Chalcidoidea, IV. Bulletin of Entmological Research 6:413-423.

WHEELER, G. C. and E. W. WHIEELER

1937 New hymenopterous parasites of ants (Chalcidoidea, Eucharidae). Annals of the Entomological Society of America 30:171-172.

WHEELER. W. M.

1907 The polymorphism of ants with an account of some singular abnormalities due to parasitism. Bulletin of the American Museum of Natural History 23:1-93.

1910 Ants: their structure, development and behavior. New York, Columbia University. 663 pp.

WILLIAMS, R. N. and W. H. WHITCOMB

1973 Parasites of fire ants in South America. Proceedings of the Tall Timbers Conference on Ecology. Animal Control and Habitat Management 5:49-59.
WILSON. E. O.

1971 The insect societies. Cambridge, Belknap Press of Harvard University Press. $584 \mathrm{pp}$.

WILSON. E. O., F. M. CARPENTER, and W. L. BROWN, Jr.

1967 The first Mesozoic ants. Science 157:1038-1040.

WILSON, T. H. and T. A. COOLEY

1972 A chalcidoid planidium and an entomophilic nematode associated with the western flower thrips. Annals of the Entomological Society of America $65: 414-418$

WOJCIK. D. P.

1988 Survey for biocontrol agents in Brazil - a final report, with comments on preliminary research in Argentina. Proceedings of the Imported Fire Ant Conference (1988):50-62.

WOOLLEY, J. B.

1988 Phylogeny and classification of the Signiphoridae (Hymenoptera: Chalcidoidea). Systematic Entomology 13:465-501.

YOSHIMOTO, C. M.

1977 Revision of the Diparinae (Pteromalidae: Chalcidoidea) from America north of Mexico. Canadian Entomologist 109:1035-1056. 
Figures 


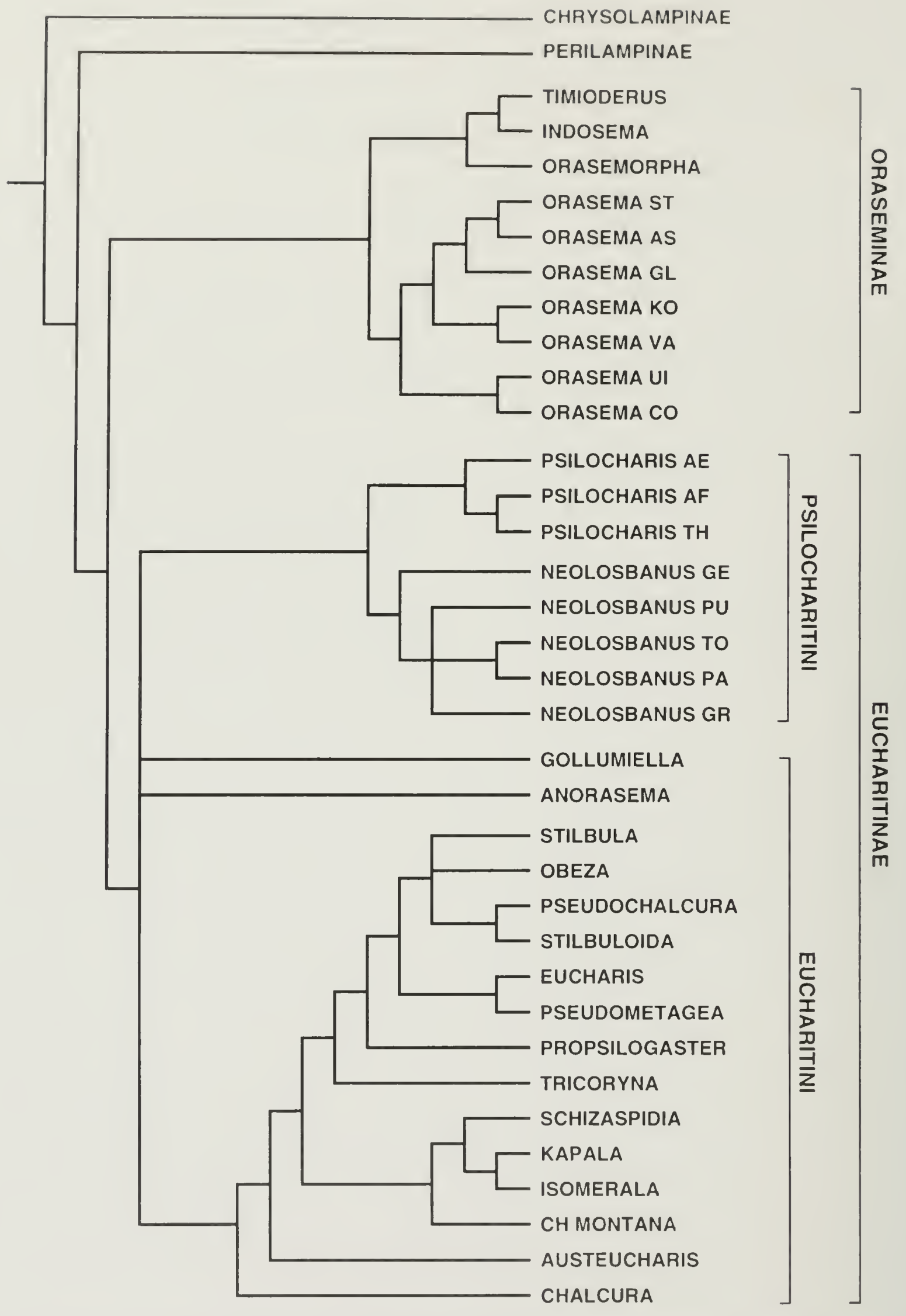

FIG. I. Strict consensus cladogram for reduced data set using adult characters and egg shape feharacters 1-48; Table 2). Group names based on consensus cladogram in Figure 2. Length = 156. 18 trees, consistency index $=0.51$, retention index $=0.79$. 




FIG. 2. Strict consensus cladogram for complete data sel (characters 1-62: Table 2). Length = 18.3, 20 trees. consistency index $=0.53$, retention index $=0.79$. Character states listed and described in Table 2 and Appendix 1. Multiple states for teminal OTUs and outgroup stattes are not shown. Superseripts reler to slattes of multistate characters, otherwise derived states are assumed to be I. Characters mathed by a batl had different distributions on different tree fopologies. Squares indicate comsistency index of 1.0). blach circles are derived states that are unigue for the clate but that show homoplasy on the tree, gray circles show bomoplasy within the elate, and open circles indicate reversals (shading also applies to bars). 

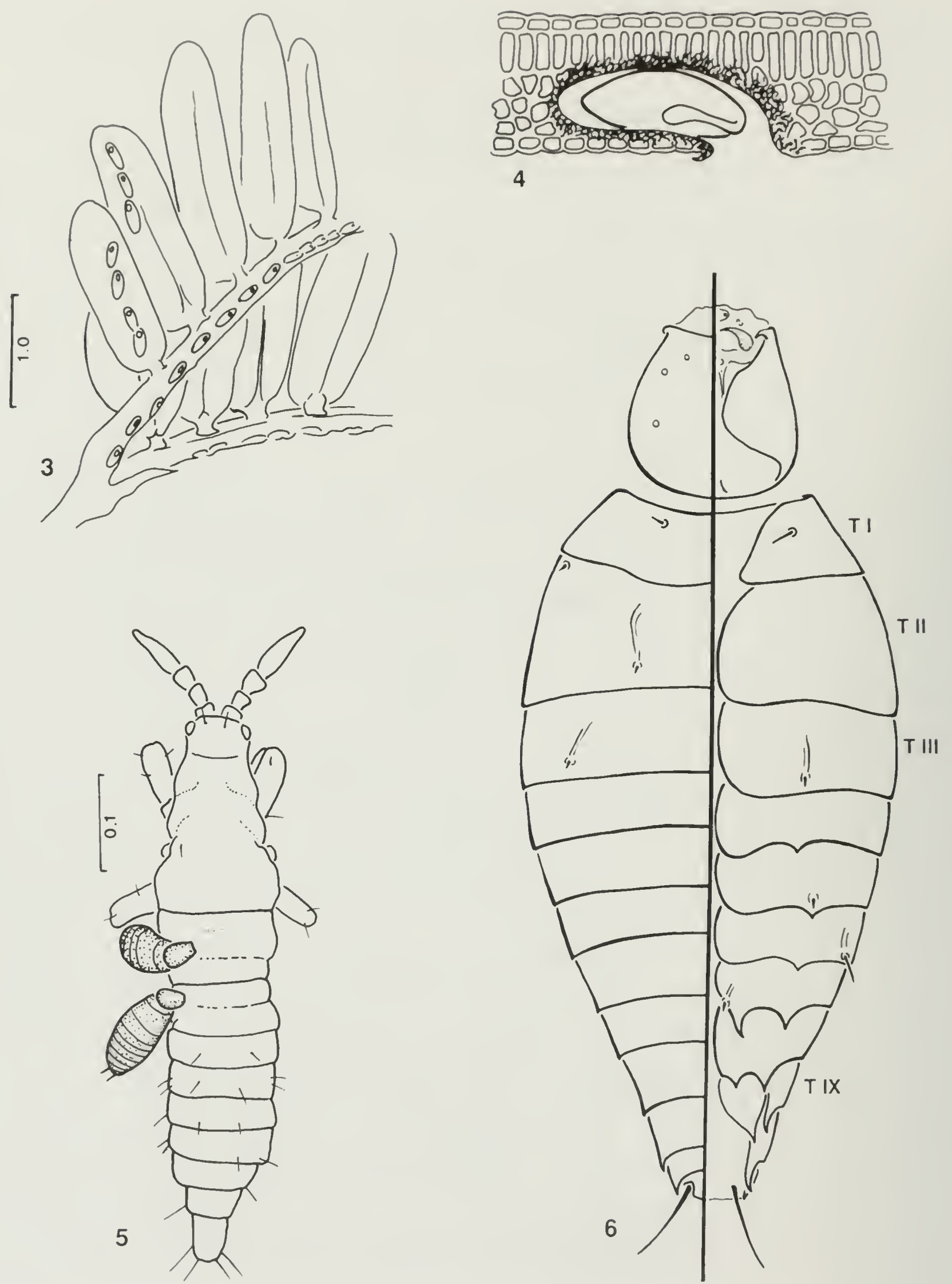

Figs. 3-6. Orasema. 3. Oviposition scars on Acacia, O. sp. nr bakeri. Texals. U.S.A. 4. Egg in oviposition puncture. 5. Planidia of $O$. viridis on immature thrips. 6. First instal of $O$. xamliopus, dorsal and lateral aspect of unfed planidium. Scale in mm. Abbreviations: T = tergite. 

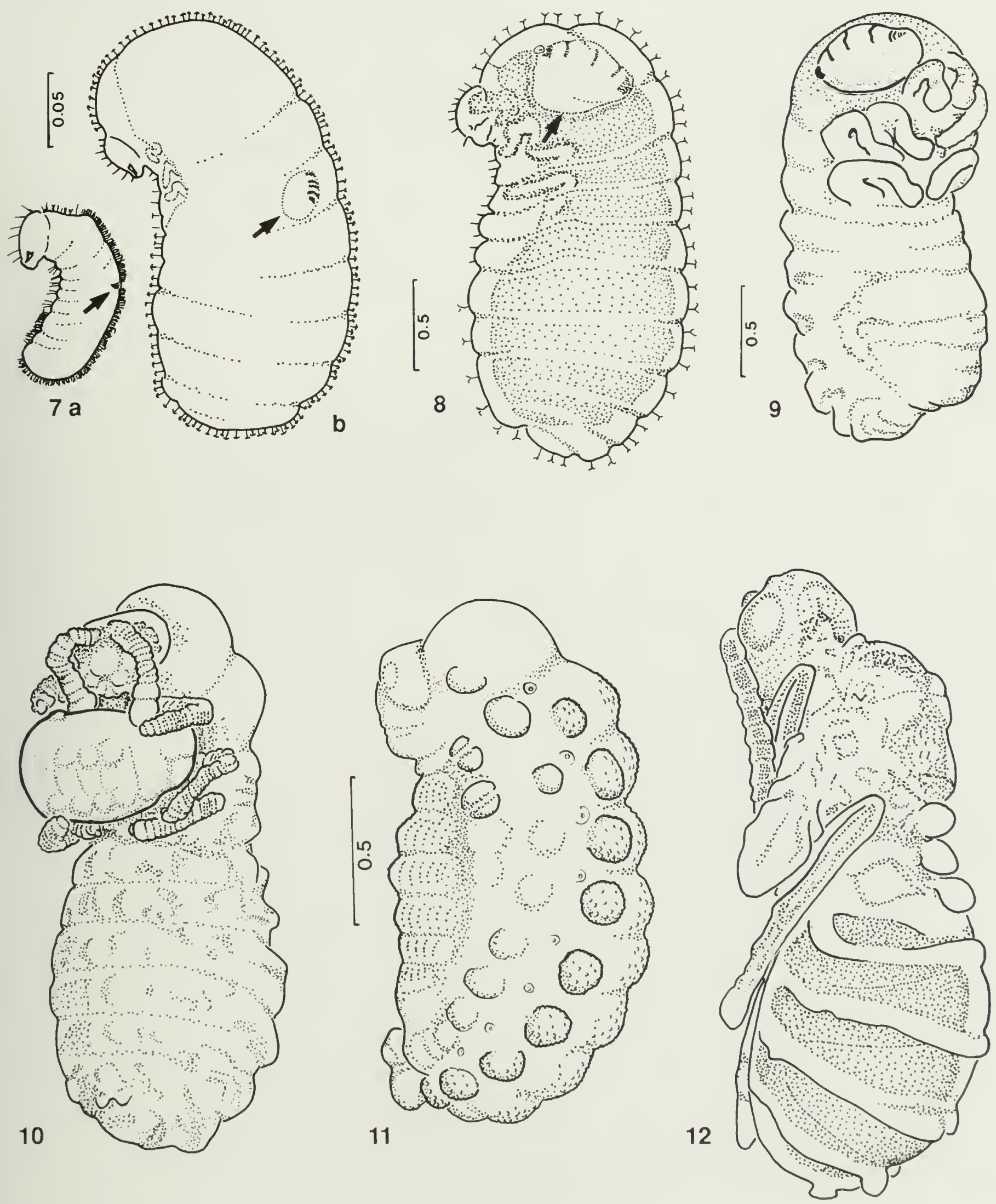

Figs. 7-12. Orasema. 7. O. ranthopus on Solenopsis imicta: a, extemal planidium (arrow) on second-instar host: b, distended first instar internal in mature host. 8-9. O. sp. nr costaricensis on Pheidole dentata: 8. Distended lirst instar internal in mature host: 9. First instar external on host pupa. 10. O. romlhopus carly thirel instar on host pupa. 11-12. O. nr costaricensis: 11. thircl-instar larva: 12. f pupa. Scale in mm. 

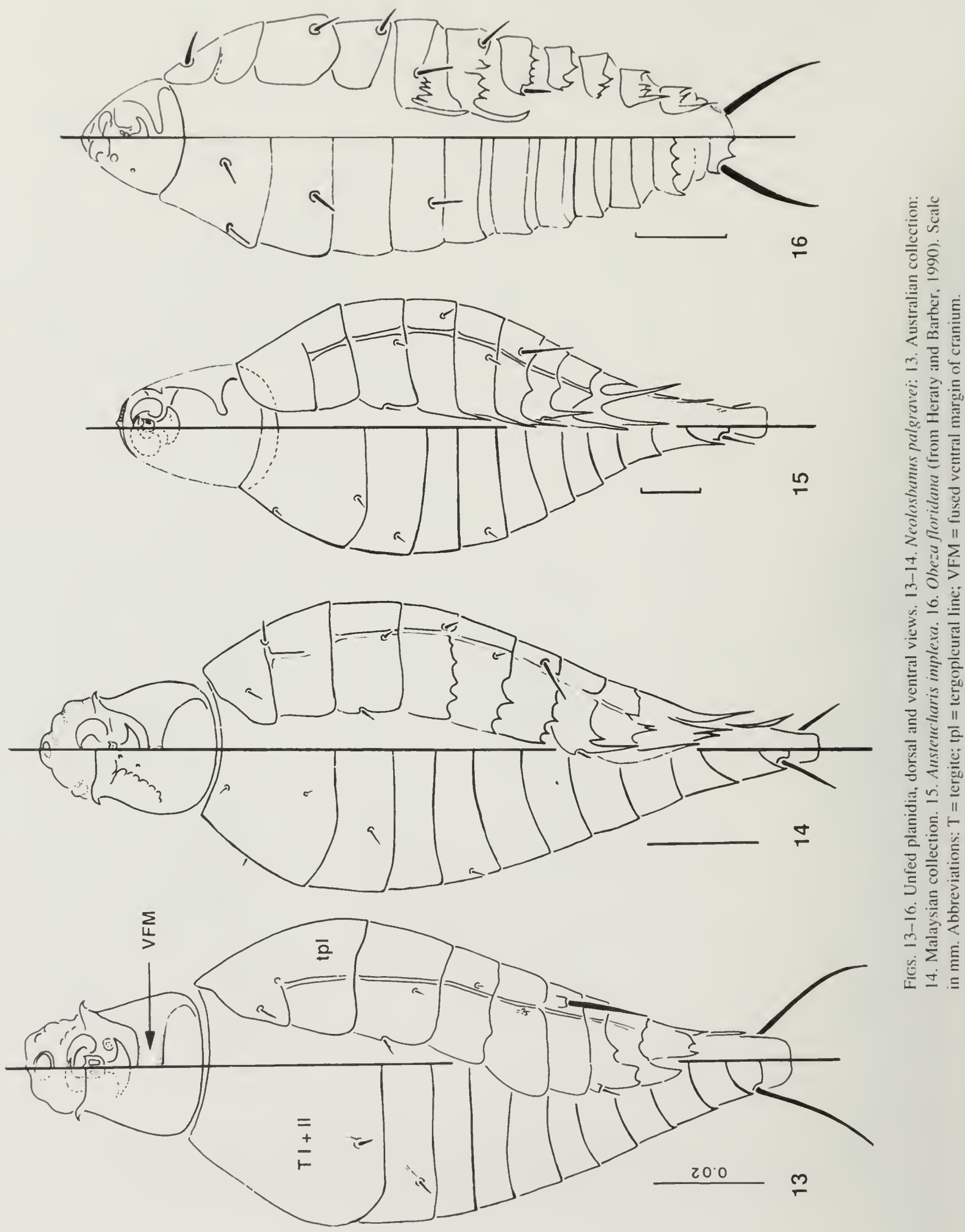



20
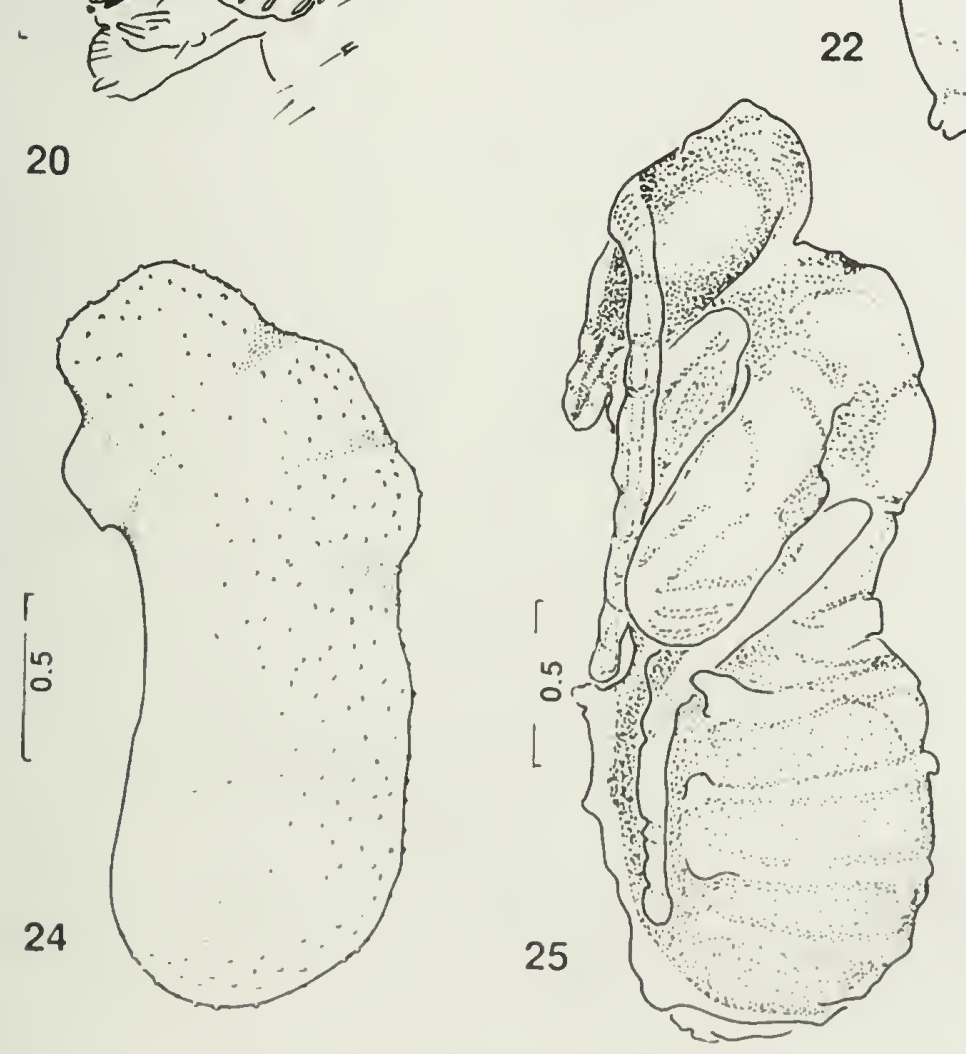

Figs. 17-26. 17-25. Neoloshamus palgrater: 17. Mature egg: 18. Freshly deposited egg in oviposition chamber in leaf tissue; 19. Scarified plant tissue surrounding mature egg; 20. Partially distended first-instar larva attached externally to lateral region of head of host ant; 21. Second instar; 22. Second instar on prepupal stage of host within cocoon: 23. Second instal on partially developed pupa of host: 24. Thirel instar: 25. ? pupar. 26. Neolosbanus gemmers. \& pupar. Scalle in mm. 


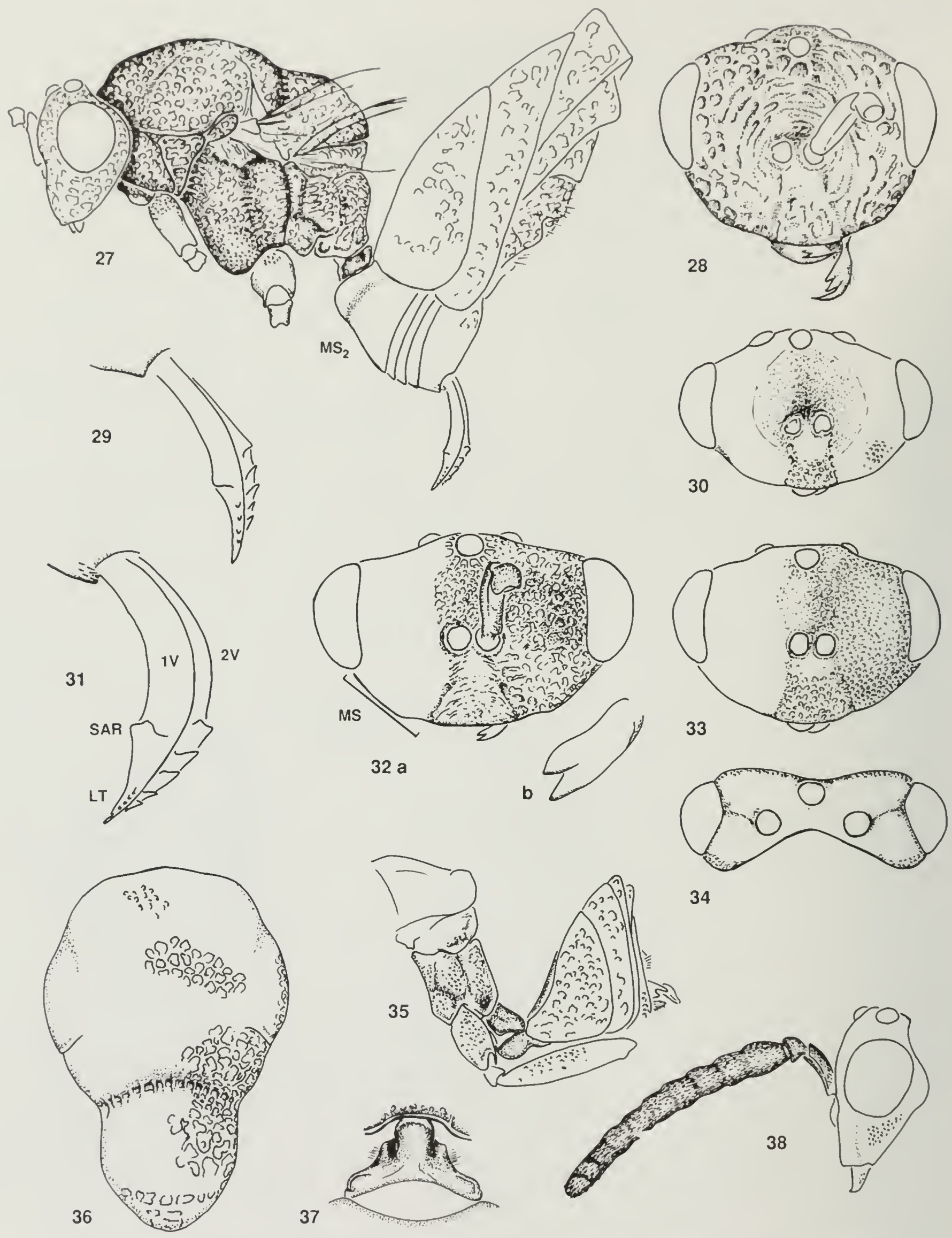

FIGS. 27-38. Timioderus. 27. T. acuminams, habitus, 9. 28. T. peridemutus, head, ९. 29. T. acuminatus, ovipositor. 30-31. T. ramosus: 30. Head, o: 31. Ovipositor. 32. T. refringens. head, \&: frontal view (a); mandible closeup (b). 33-34. T. ramosns, head, $q: 33$. Frontal view; 34. Dorsal view. 35. T. corommla. propodeum and metasoma in lateral view, 8. 36-37. T. peridentans: 36. Mesothorax in dorsal view, $9: 37$. Petiole in dorsal view, 9. 38. T. comomala, head in lateral view. 8. Abbreviations: LT = lateral teeth: MS = malar space length; $\mathrm{Ms}_{2}=$ second metasomal sternite: $\mathrm{SAR}=$ subapical ridge: $\mathrm{IV}=$ lïst valvula, $2 \mathrm{~V}=$ second valvula. 

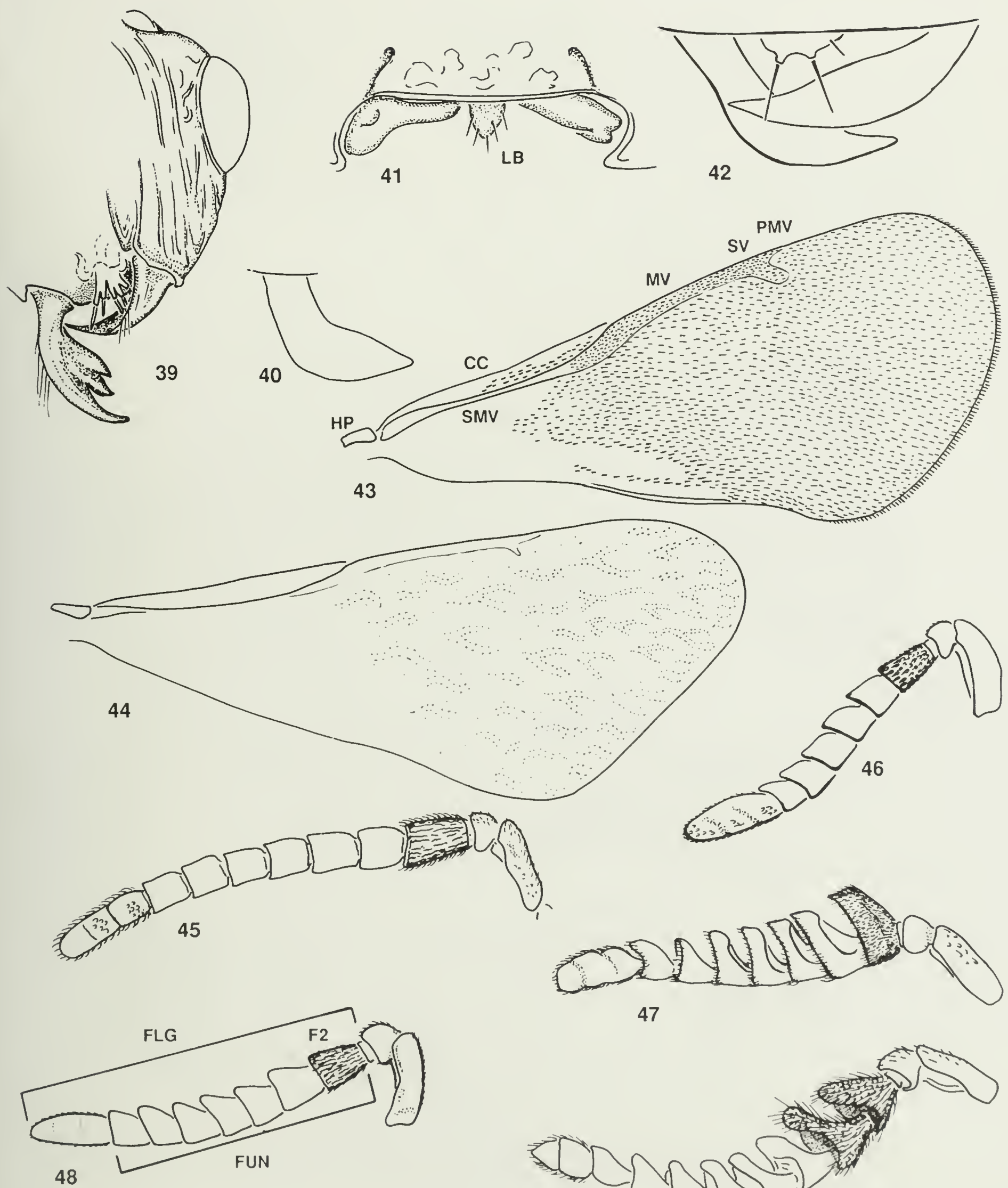

47

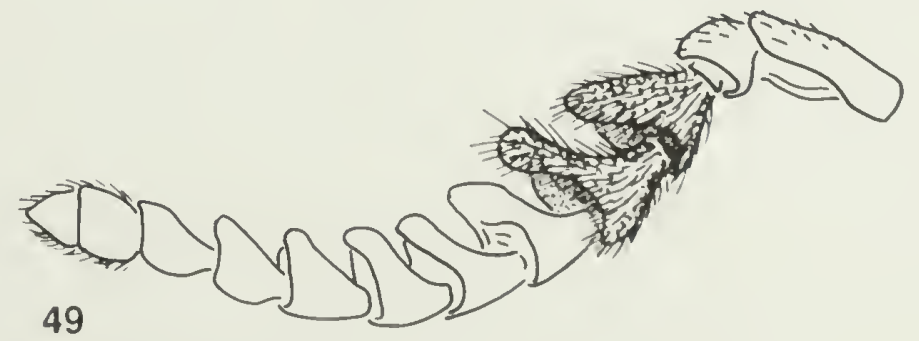

Figs. 39-49. Timioderus. 39. T. peridentatus, partial head in posterolateral view, $\& .40 . T$. ramosus, left mandible, o. 41.T. refringens, oral fossa showing labrum (LB), o. 42. T. acuminatus, labrum and mandibles. 43. T. refringens, forewing, 9. 44. T. ramosus, forewing, $9.45 . T$. refringens, antenna, o . 46-47. T. ramosus, antenna: 46. $\$ ; 47 . \delta .48-49$. T. acuminatus, antenna; 48. $9 ; 49 . \delta$. Abbreviations: CC $=$ costal cell; $\mathrm{F}=$ flagellomere 2; $\mathrm{FLG}=$ flagellum; $\mathrm{FUN}=$ funicle; $\mathrm{HP}=$ humeral plate; $\mathrm{LB}=$ labrum; $\mathrm{MV}=$ marginal vein; $P M V=$ postmarginal vein; $S M V=$ submarginal vein; $S V=$ stigmal vein. 


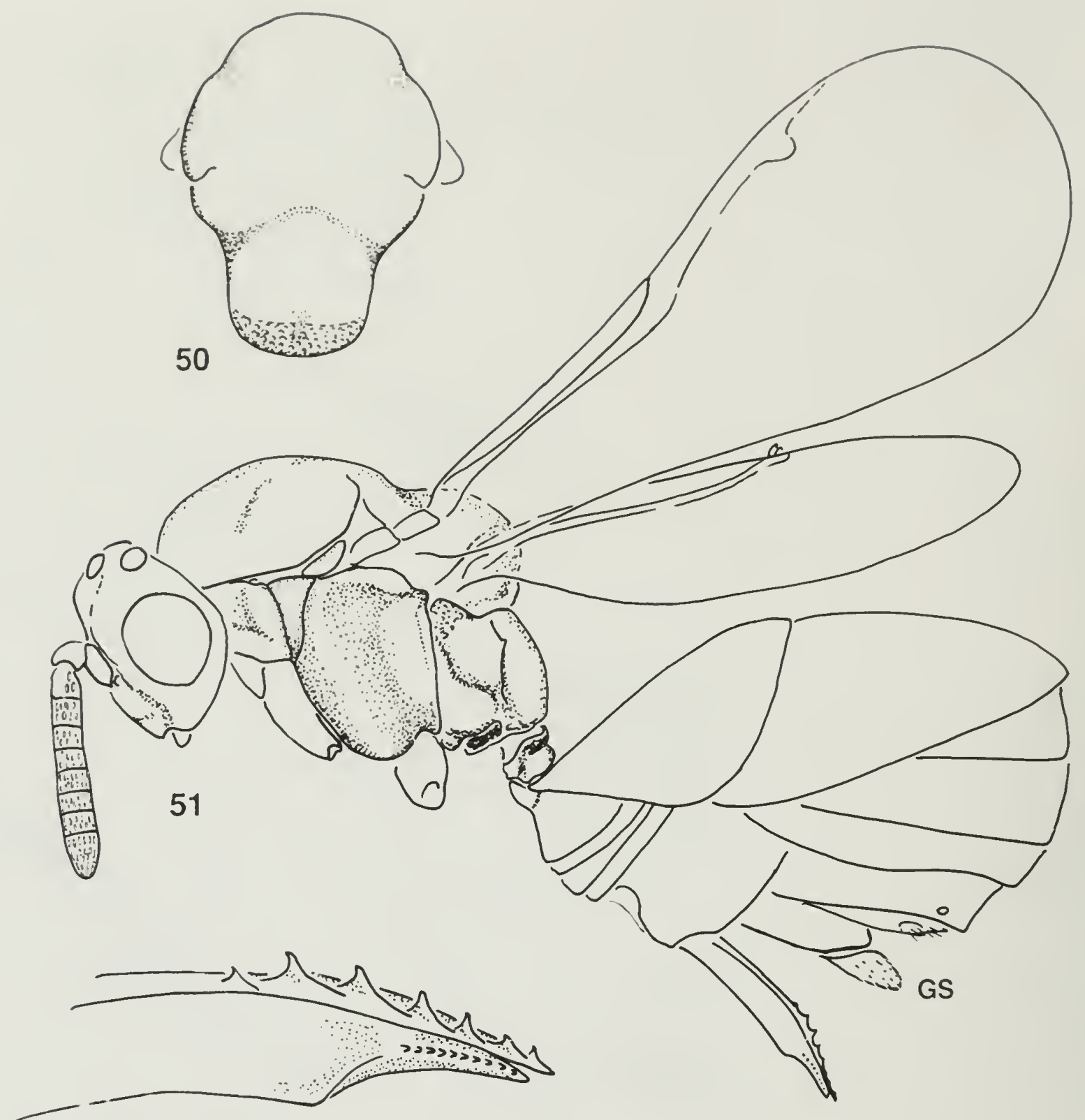

52

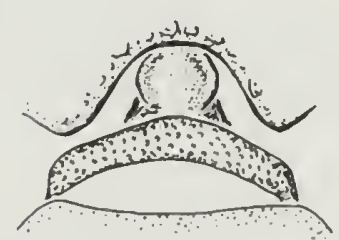

53

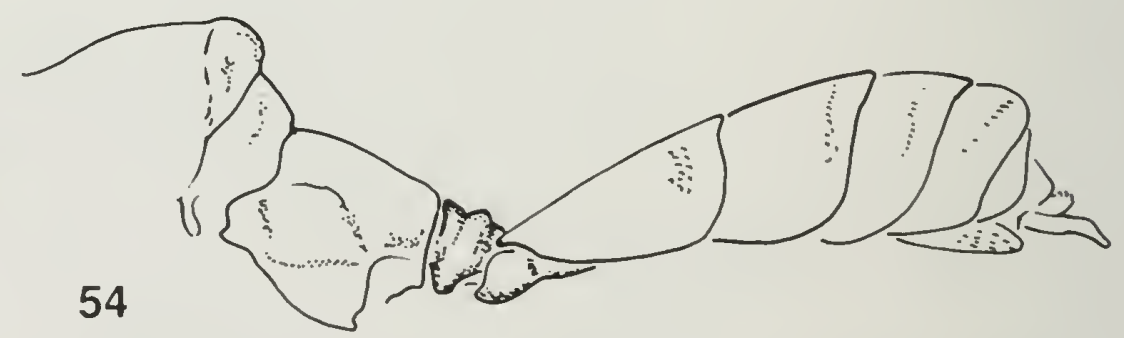

FIgs. 50-54. Indosema indica. 50. Mesothorax in dorsal view, +.51 . Habitus, $q .52$. Ovipositor in lateral view. 53. Petiole in dorsal view, +.54 . Posterior region of mesosoma and metasoma in lateral view, $\delta$. Abbreviation: $\mathrm{GS}=$ gonostylus. 

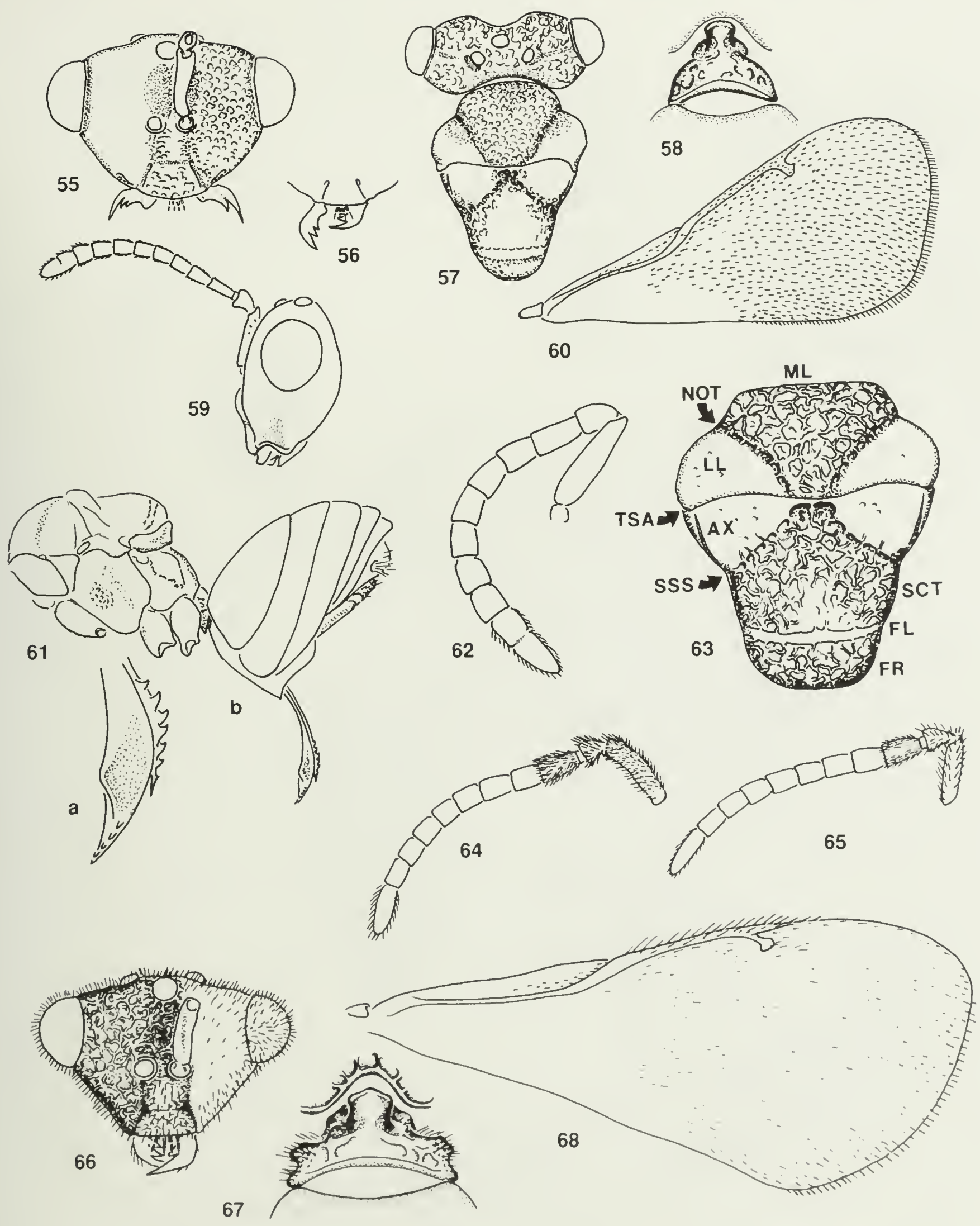

Figs. 55-68. Orasemorpha. 55. O. tenudes, head in frontal view, \$. 56. O. Iridentata. lower face and mandibles, +. 57. O. xeniades, head and mesothorax in dorsal view, 9. 58. O. Midentala, petiole in dorsal view. 59 -61. O. xeniades: 59. Head in lateral view, 9; 60. Forewing, o; 61. Ovipositor (a) and hathitus (h).

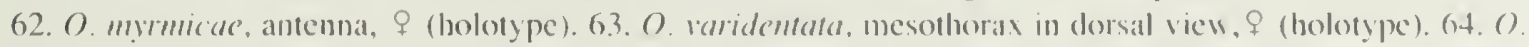

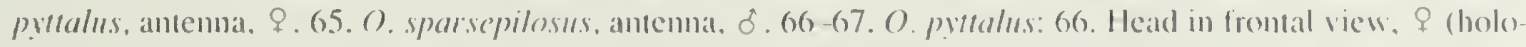

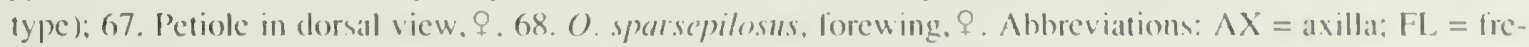
nal line; $F R=$ irenum; $L L=$ lateral lobe; $M 1 L$ = midlobe of mesoscutum; NOT = notaulus; SCT = sculellum; SSS = scuroscutellar sulcus; TSA = transisulal anticulation. 

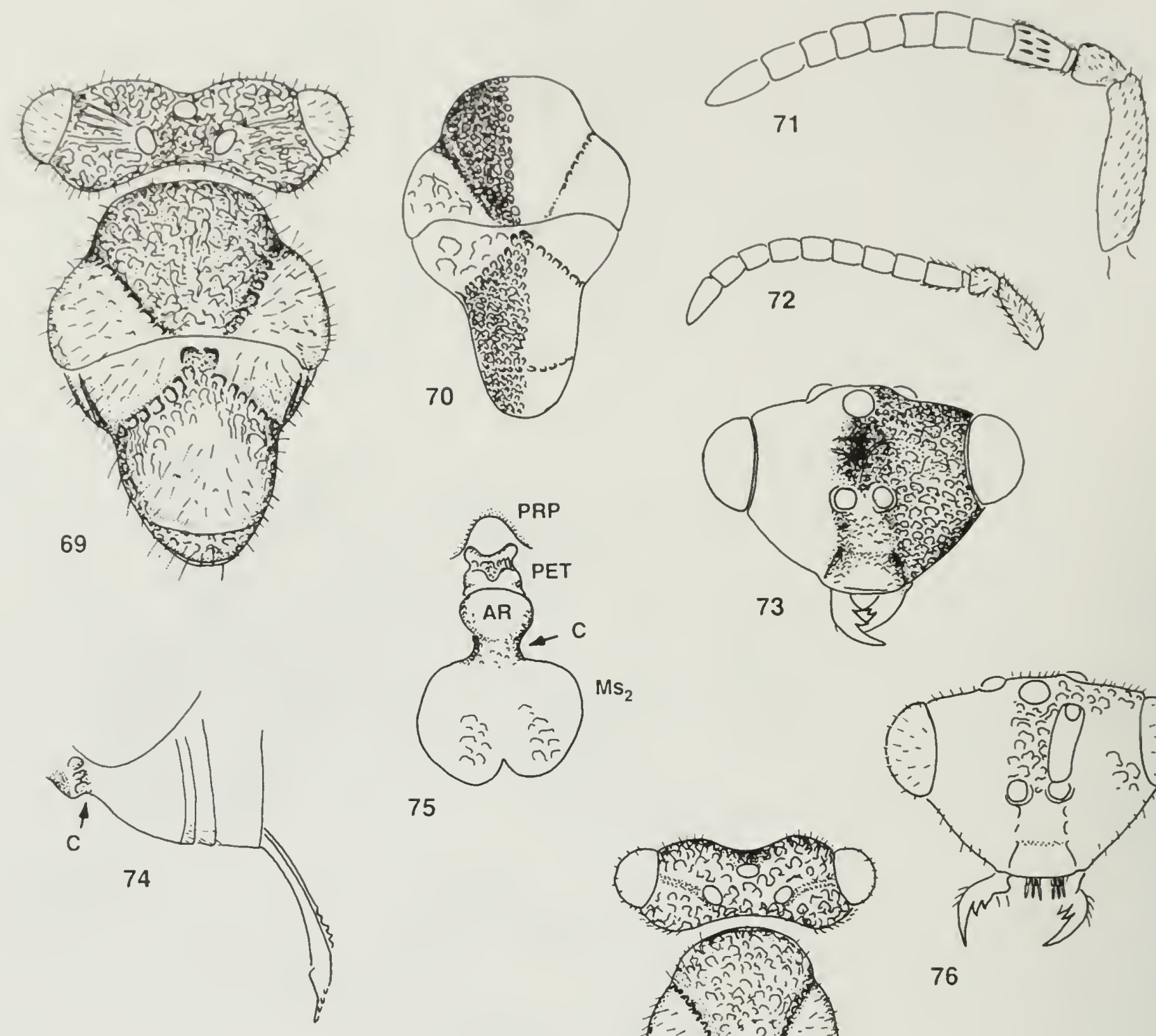

75
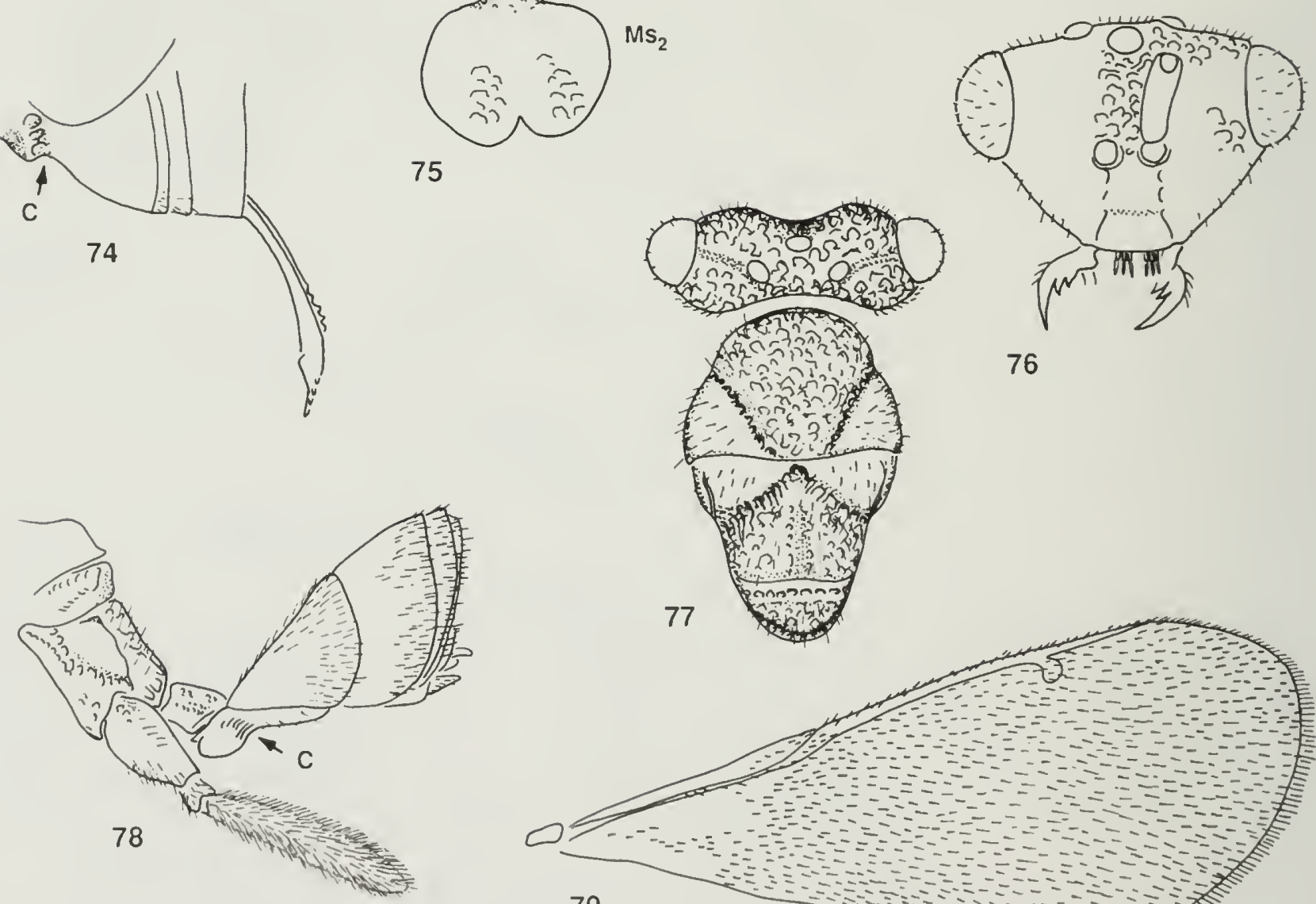

76

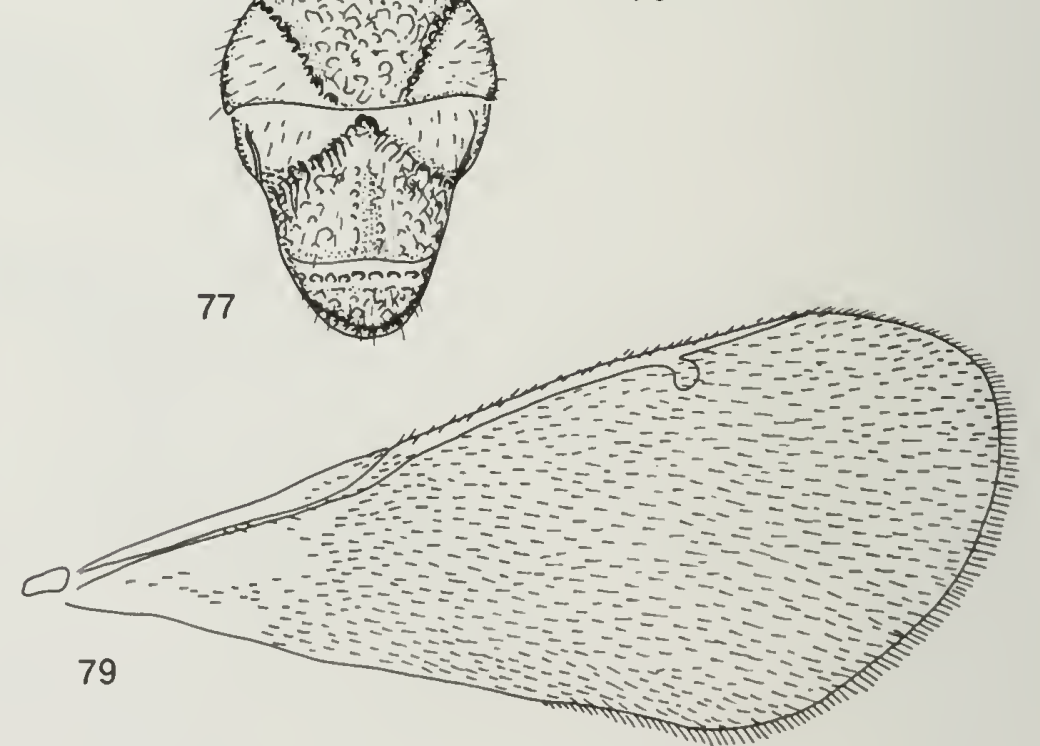

FIGS. 69-79. Orasemorpha. 69. O. sparsepilosus, head and mesosoma in dorsal view, $\$ .70-71$. O. cribotes: 70. Mesothorax in dorsal view. ó (holotype): 71. Antenna. \& (HT of E. viridis). 72. $O$. didentata, antenna. 9 (lectotype). 73. O. eribotes, head in frontal view. of(holotype). 74-79. O. didemata: 74. Ventral region of gaster, $q ; 75$. Petiole and first gastral sternite in ventral view; 76. Head in frontal view, $9: 77$. Head and mesosoma in dorsal view. $+: 78$. Posterior region of mesosoma and metasoma. 0 ; 79. Forewing. $q$. Abbreviations: $\mathrm{AR}=$ anterior region: $\mathrm{C}=$ constriction: $M \mathrm{~s}_{2}=$ second metasomal sternite; $\mathrm{PRP}=$ propodeum: PET $=$ petiole. 

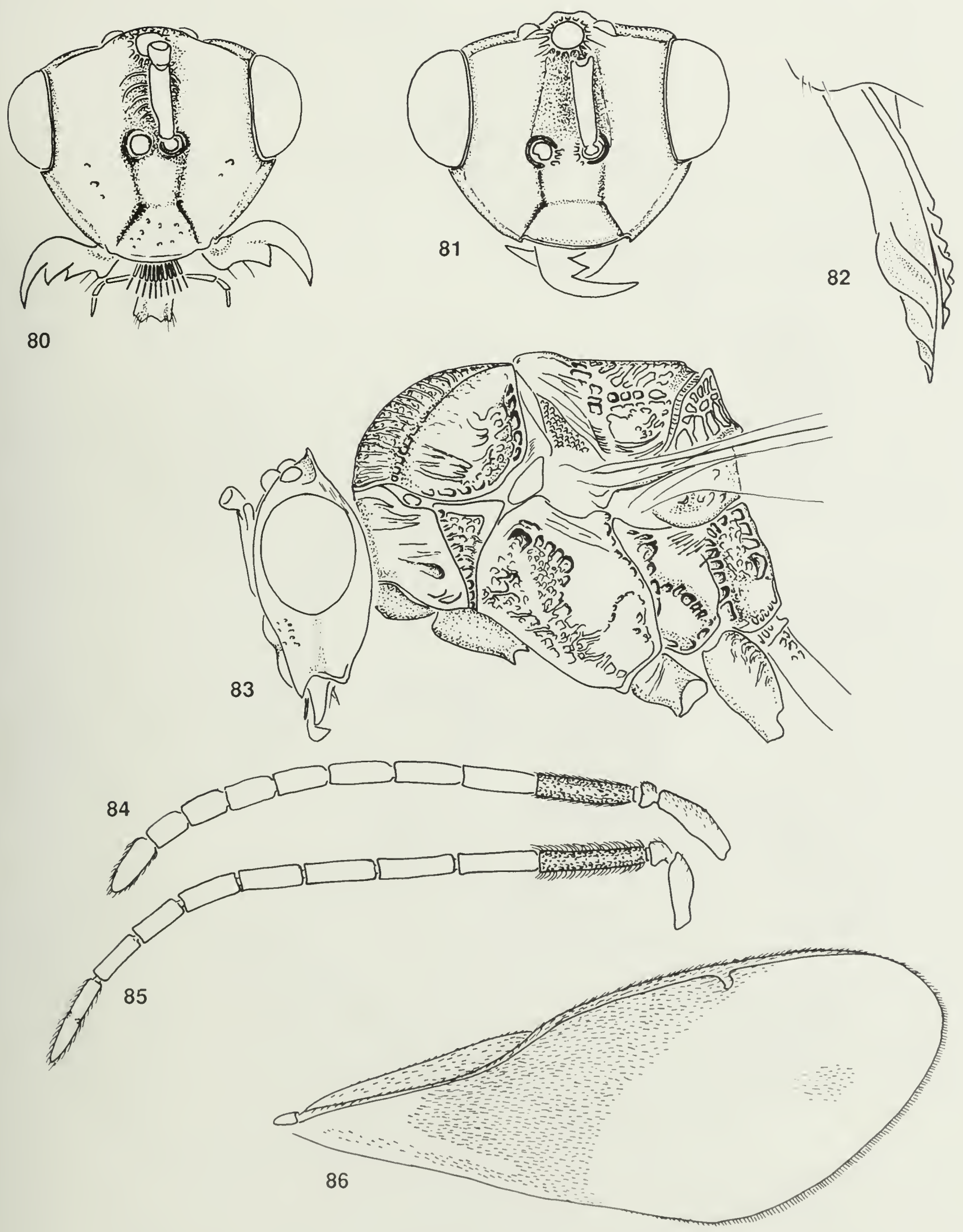

FIgs. 80-86. Orasema. 80. O. commmnis, head in frontal view. 9 . 81. O. seyrigi. head in lrontal view. ? (HT). 82. O. communis, ovipositor in lateral view. 83. O. seyrigi, head and mesosomin in lateral view. ? (HT). 84-85. O. commumis, antenna: 84. 9; 85.0.86. O. seyrigi. forcwing. 

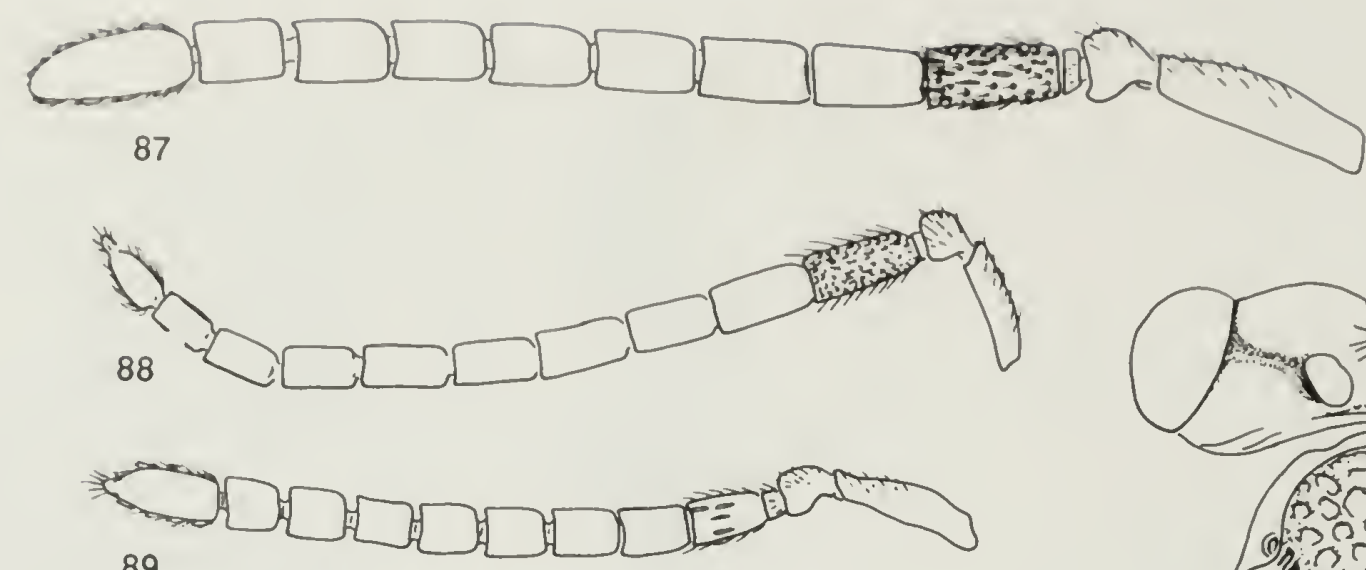

89
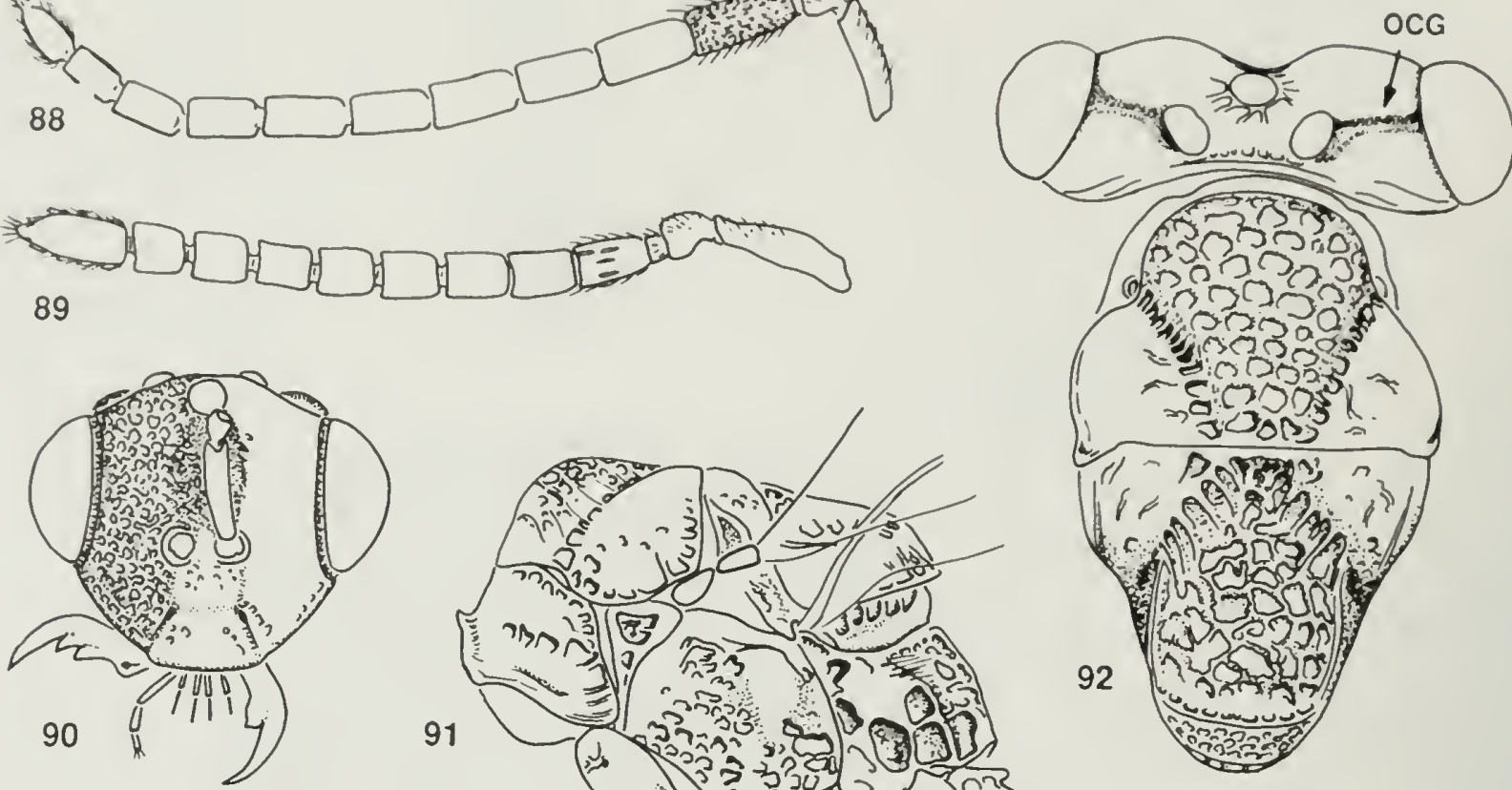

91



92
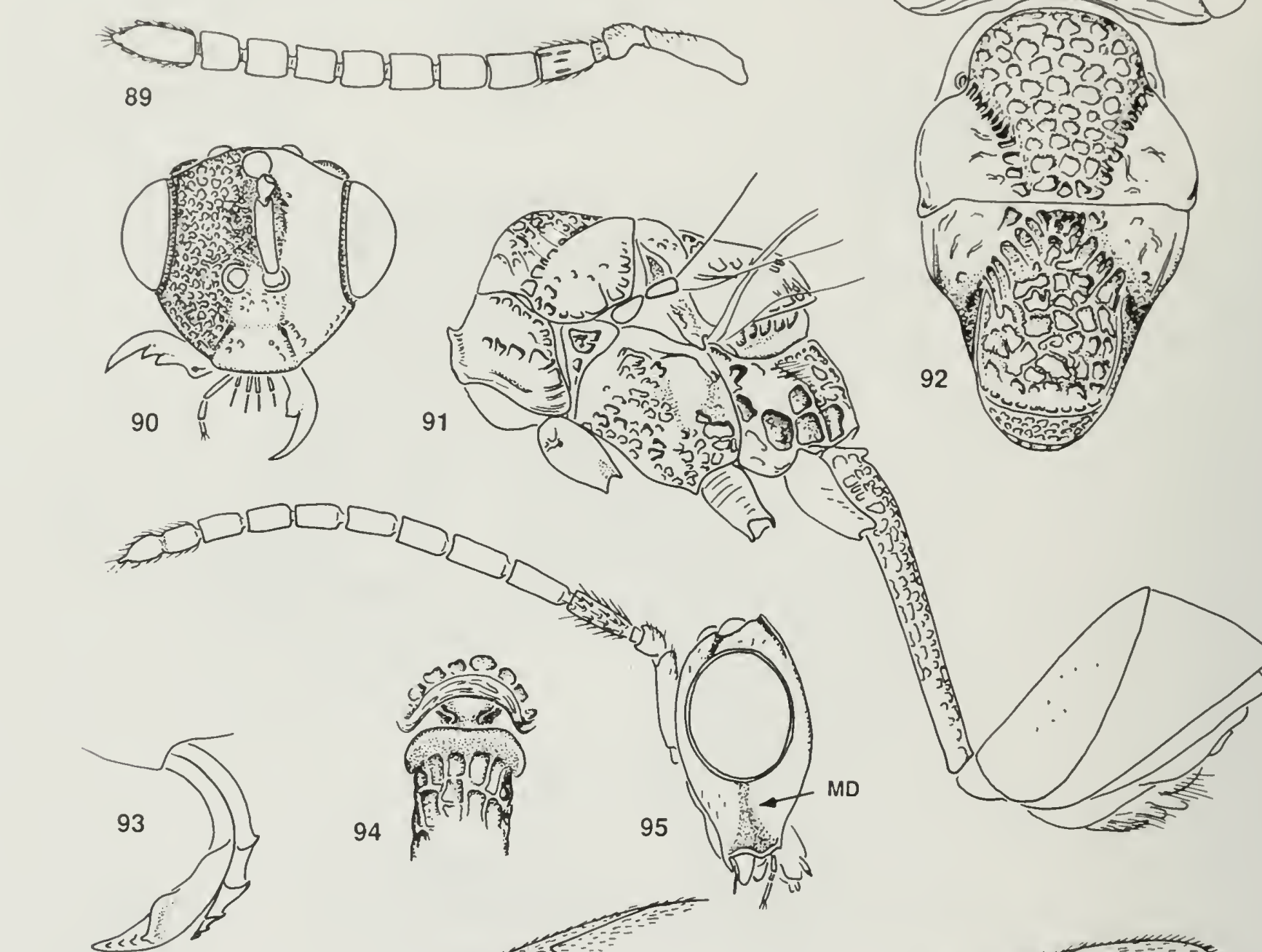

94
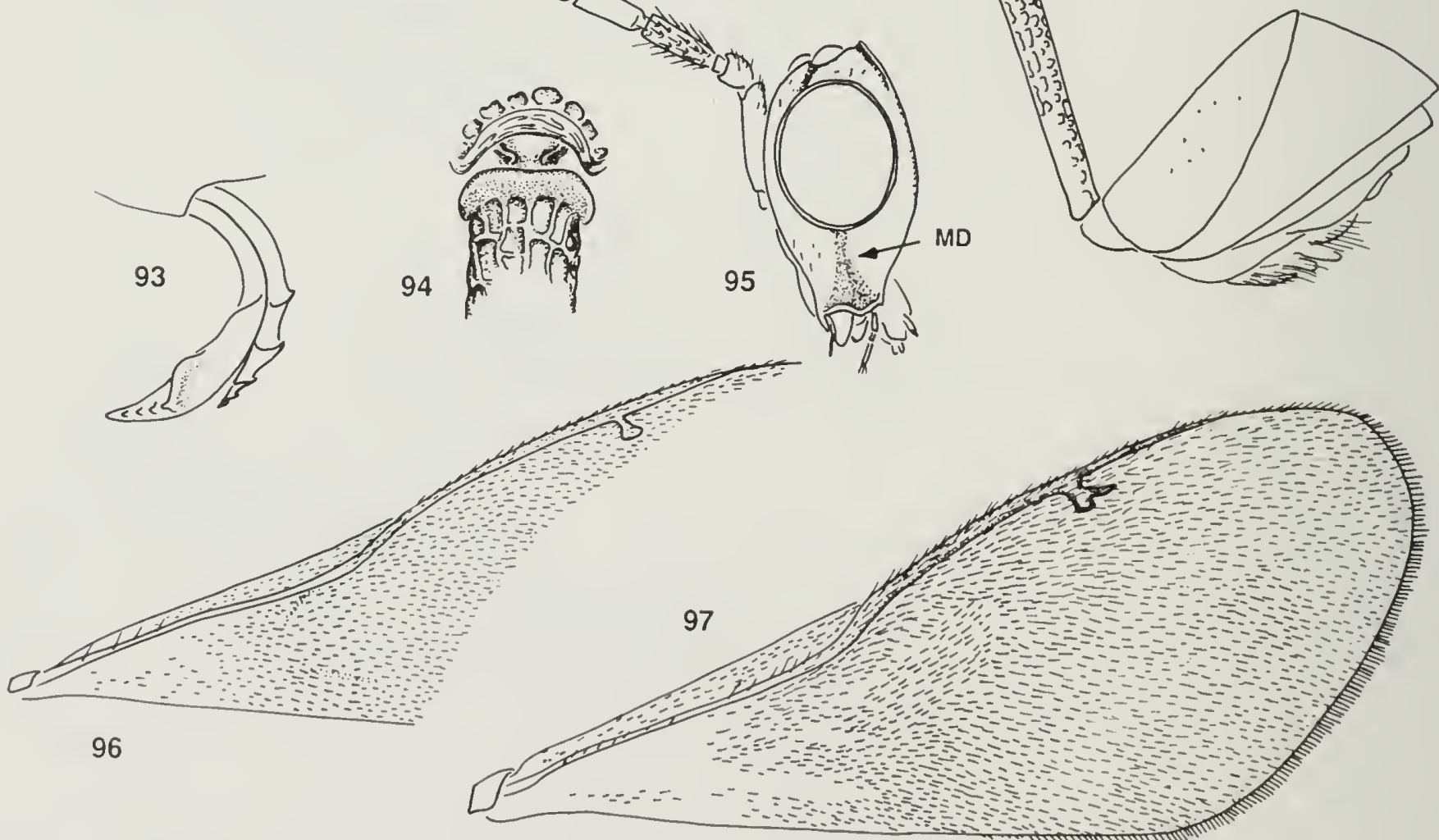

Figs. 87-97. Orasema. 87. O. wichancoi, antenna (lectotype). 88. O. ishii, antenna, P. 89-92. O. rugulosa: 89. Antenna, $q ; 90$. Head in frontal view, $\delta: 91$. Mesosoma and metasoma in lateral view, $\delta: 92$. Head and mesothorax in dorsal view, of (holotype). 93. O. mgulosa, ovipositor in lateral view. 94. O. uichancoi, base of petiole in dorsal view. 95. O. promecea, head in lateral view, o. 96-97. Forewing: 96. O. 1uzulosa, б; 97. O. wichancoi, forewing, $९$ (lectotype). Abbreviations: $\mathrm{MD}=$ malar depression; $\mathrm{OCG}=$ ocellar-ocular groove. 


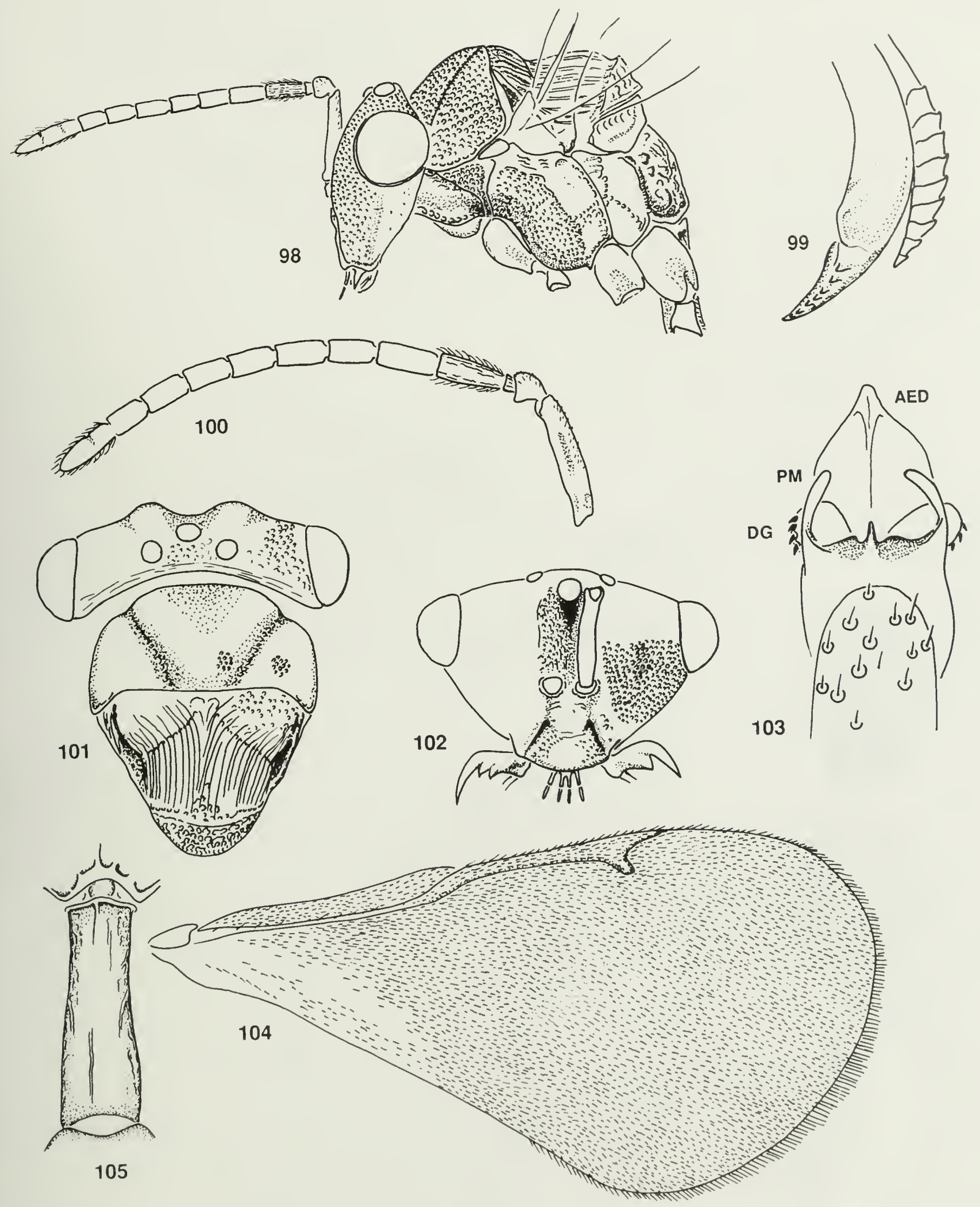

Figs. 98-105. Orasema striatosoma. 98. Head and mesosona in lateral view, f (ho!otype). 99. Ovipositor in lateral view. 100 . Antenna, o. 101. Head and mesothorax in dorsal view, $q$ (holotype). 102. Head in fromal view, $\delta$. 103. Genitalia and $\mathrm{Ms}_{*}$ in ventral view. 104. Forewing, $\{$. 105. Petiole in dorsal view. $q$. Abbreviations: $A E D=$ acdeagus; $D G=$ digitus: $P M A$ paramere. 

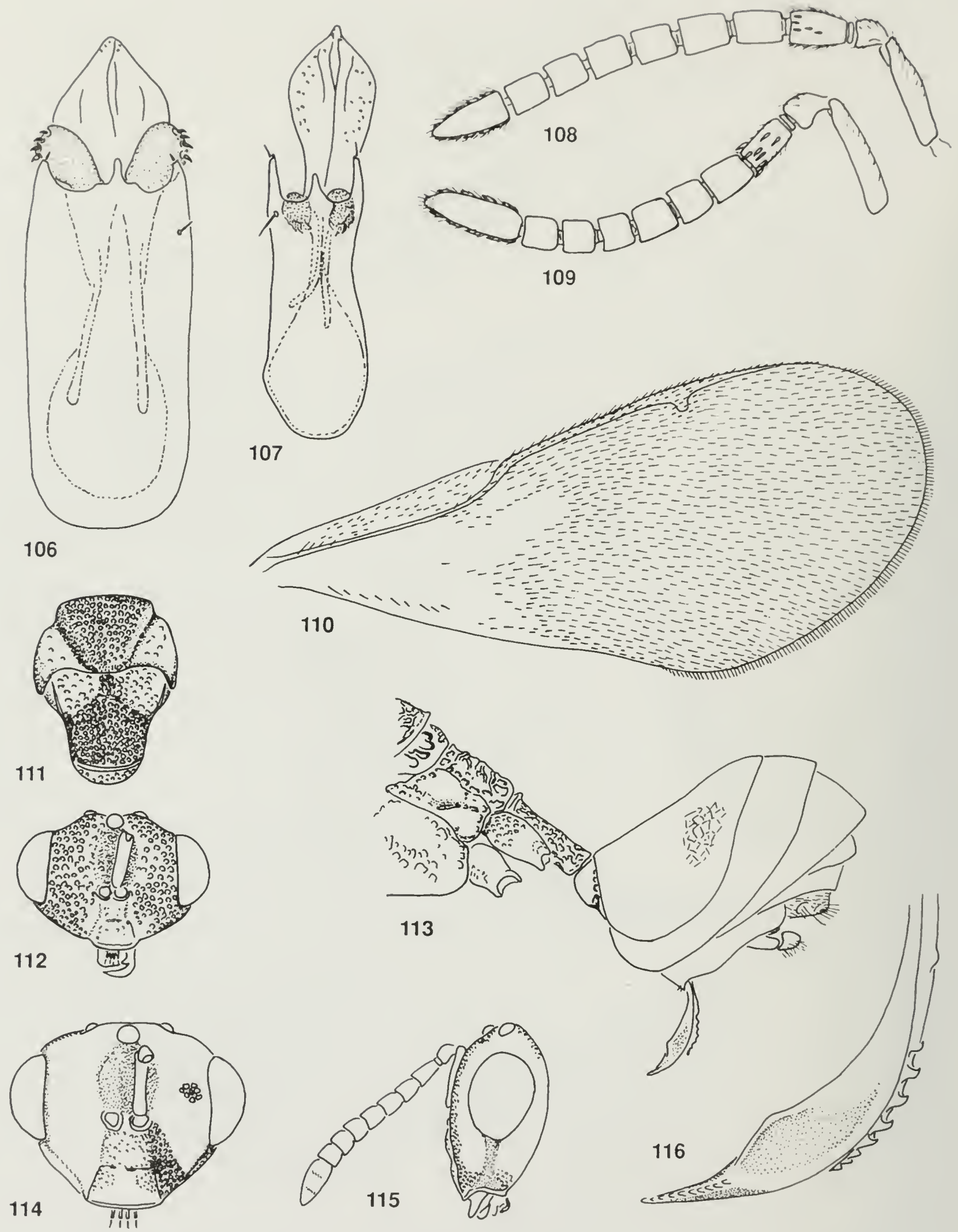

FIGS. 106-116. Oraseme. 106-107. Male genitalia in ventral view: 106. O. uichancoi: 107. O. Koghisiana. 108-109. Antenna: 108. O. koghisiana, \$: 109. O. intiator. \$. 110. O. koghisiana, forewing. 9. 111-112. O. asse'tator, + : 111. Mesothorax in dorsal view; 112. Head in frontal view. 113-116. O. nigra. $9: 113$. Posterior region of mesosoma and metasoma; 114 . Head in frontal view: 115. Head in lateral view; 116. Ovipositor in lateral vicw. 

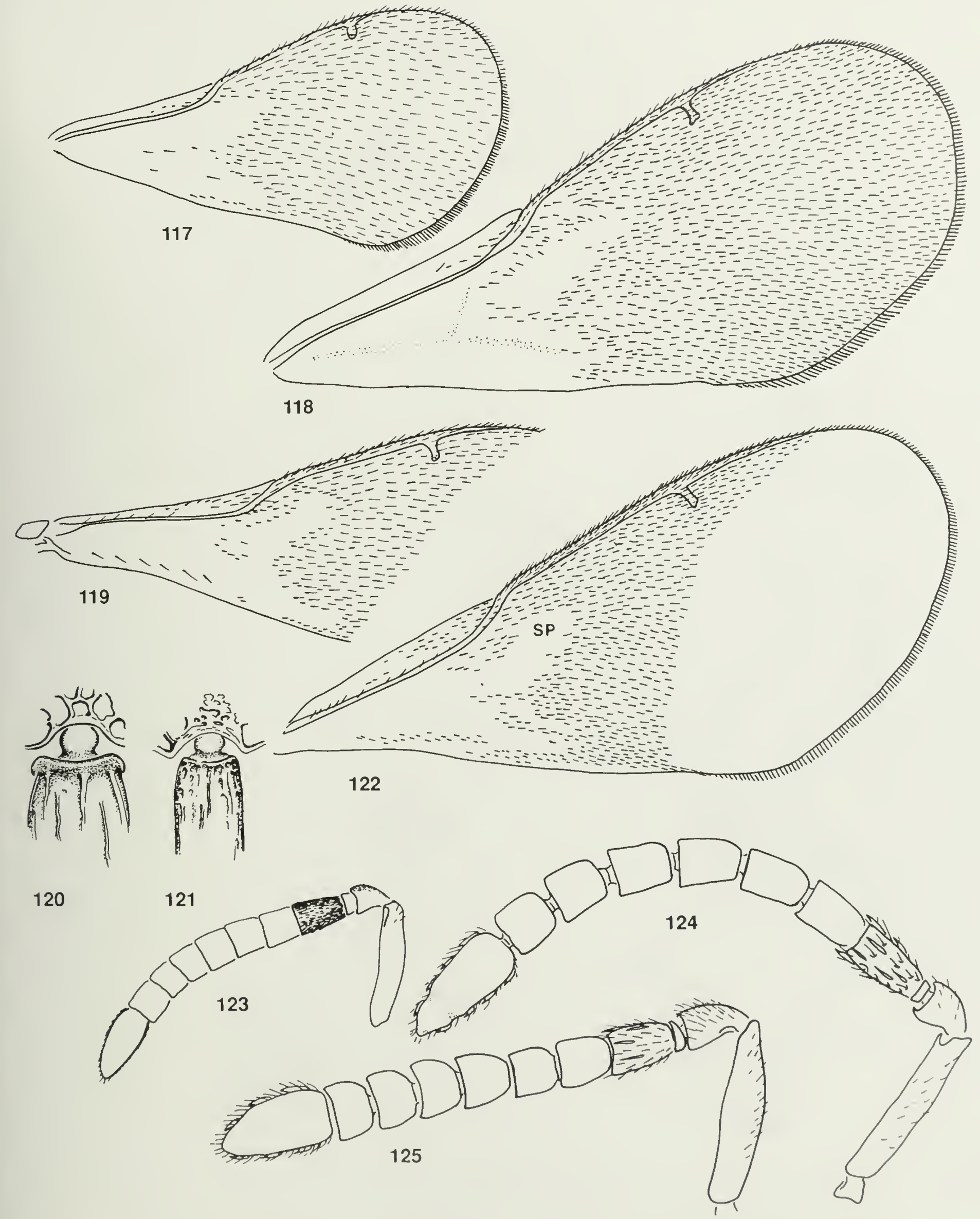

Figs. 117-125. Orasema. 117-118. O. intrator, forewing: 117. 8: 118. 9. 119. O. glabra. base of forewing.

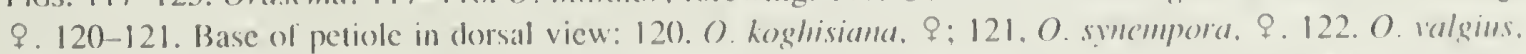
forewing. 9. 123-125. Antenna, \$: 123. O stmempora: 124. O. valgias: 125. O. glabra. Abbreviation: SP $=$ speculum 


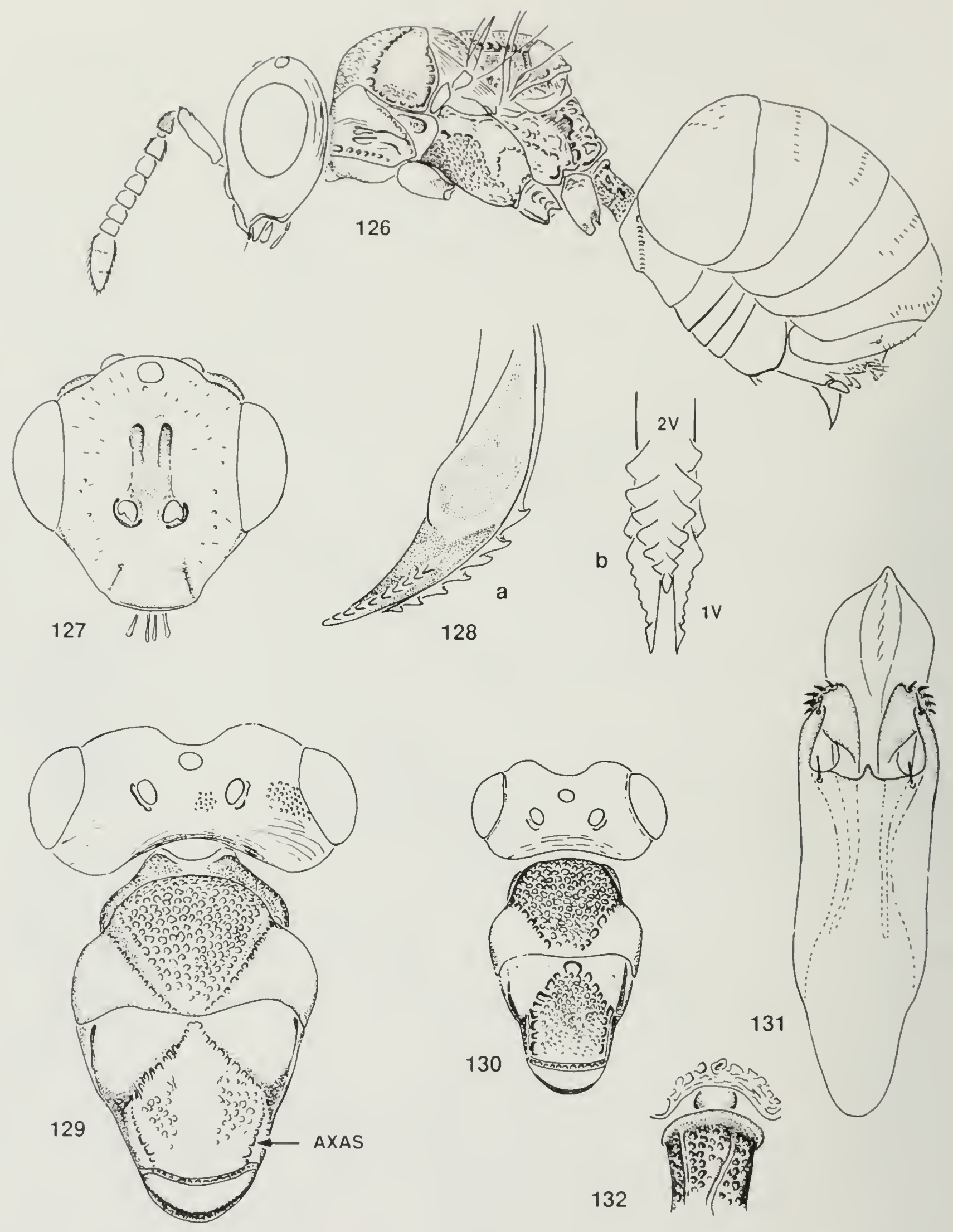

Figs. 126-132, Orasema. 126-128. O.g/abra. 9: 126. Habitus: 127. Head in frontal view: 128. Ovipositor in lateral (a) and dorsal (b) views. 129. O. symempora, head and mesothorax in dorsal view, 9.130 .0$. glahra. head and mesothorax in dorsal view, 9. 131. O. valgins, genitalia, 6. 132. O. glalma, base of petiole in dorsall view, Abbreviations: $\mathrm{AXAS}=$ axillular sulcus: IV-2V = first and second valvulace, 


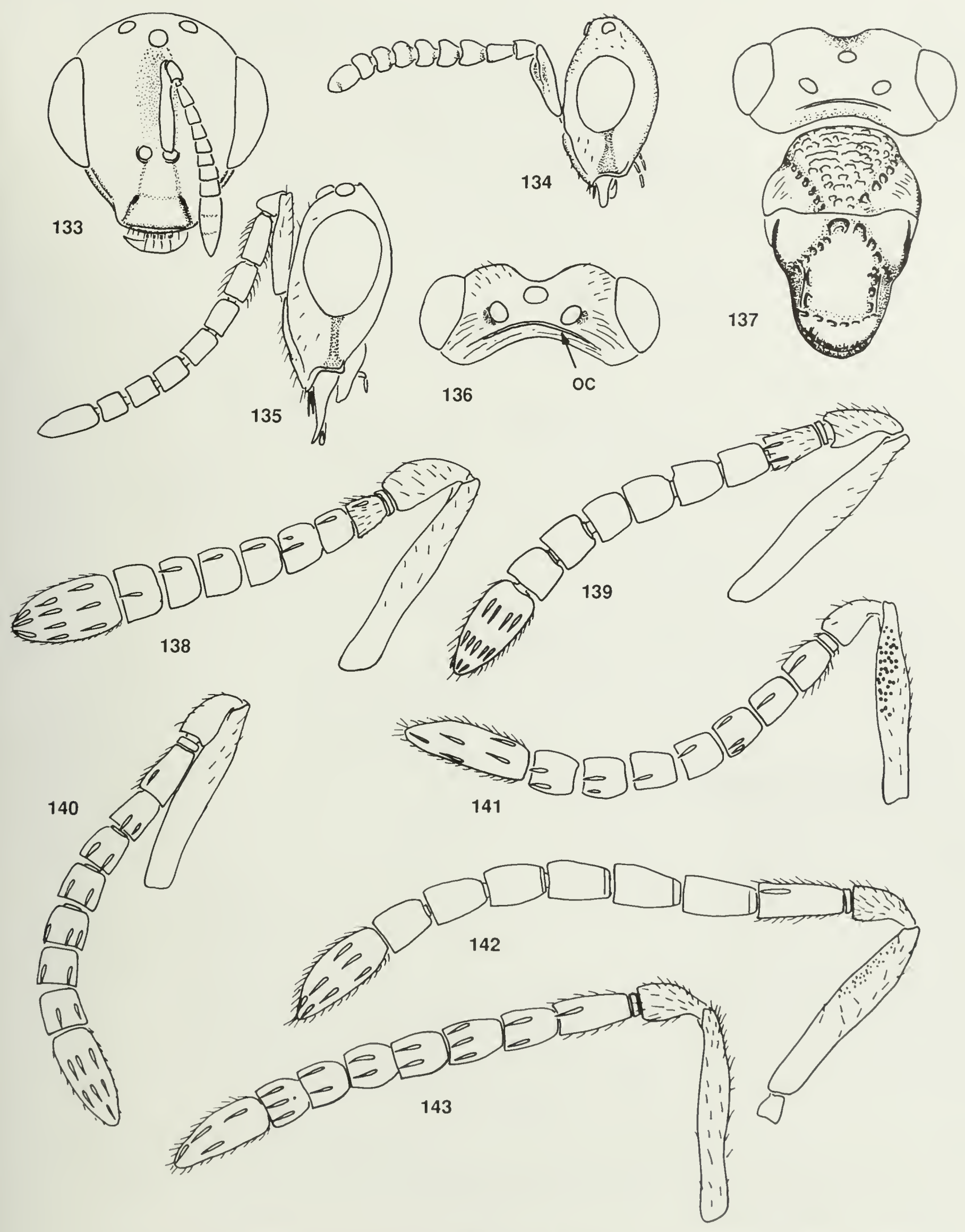

Figs. 133-143. Psilocharis. 133. P. pacifica, head in frontal view, Q. 134. P. monilicera, head in lateral view. ठ. 135-136. P. afra. o : 135. Head in lateral view; 136. Head in dorsal view. 137. P. pacifica, head and


141. P. theocles, o; 142. P. hypena (Taiwan), 8: 143. P. hypena (Boneo). ठ. Abbreviation: OC $=$ occipital carina. 




Figs. 144-151. Psilocharis. 144-145. Base ol petiole in dorsal view, $+: 144$. $P$. aenigma; 145. P. theocles. 146-148. Forewing, $9:$ 146. P. theocles; 147. P. hypena; 148. P. afra. 149-150. P. afica: 149. Apical margin of hypopygium in ventral view, $9: 150$. Ovipositor in ventral view. 151. $P$. theocles. o genitalia. 


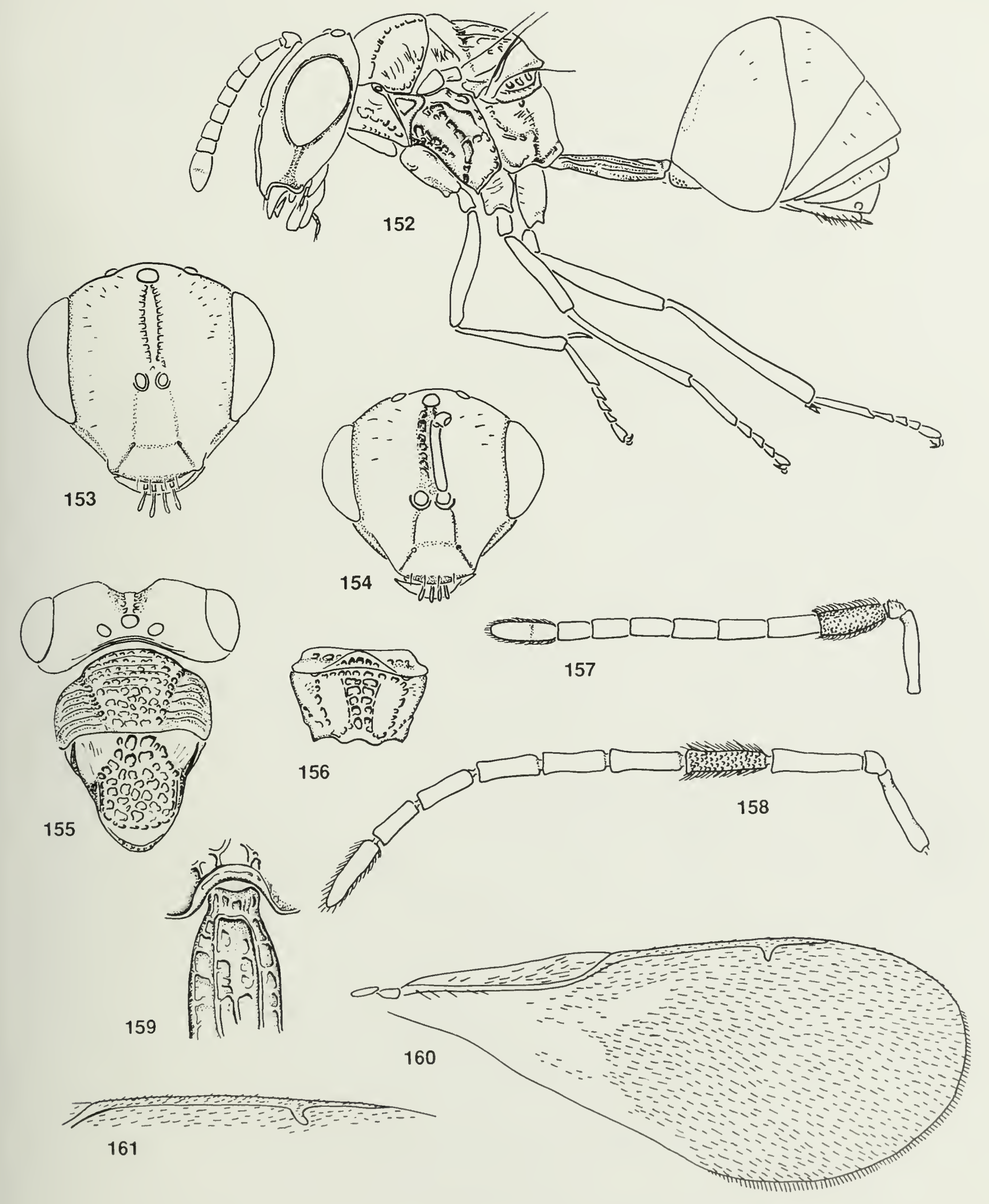

Figs. 152-161. Neolosbaums. 152. N. wusheamus, lateral habitus. 9.153. N. gemma, head in frontal view, $\mathcal{Q}$ 154 157. N. w'usheamu: 154. Head in frontal view. $\$: 155$. Head and mesothorax in dorsal view, $9: 156$. Metanotum and propodeum in rear view, $9: 157$. Antenna, o. 158. N. apoamms, antemna, o. 159. N. gemmuts. base of periole in dorsal view, $9.160 . N$. wusheamus, forewing, +.161 . N. apoames, forewing margin. $\delta$. 


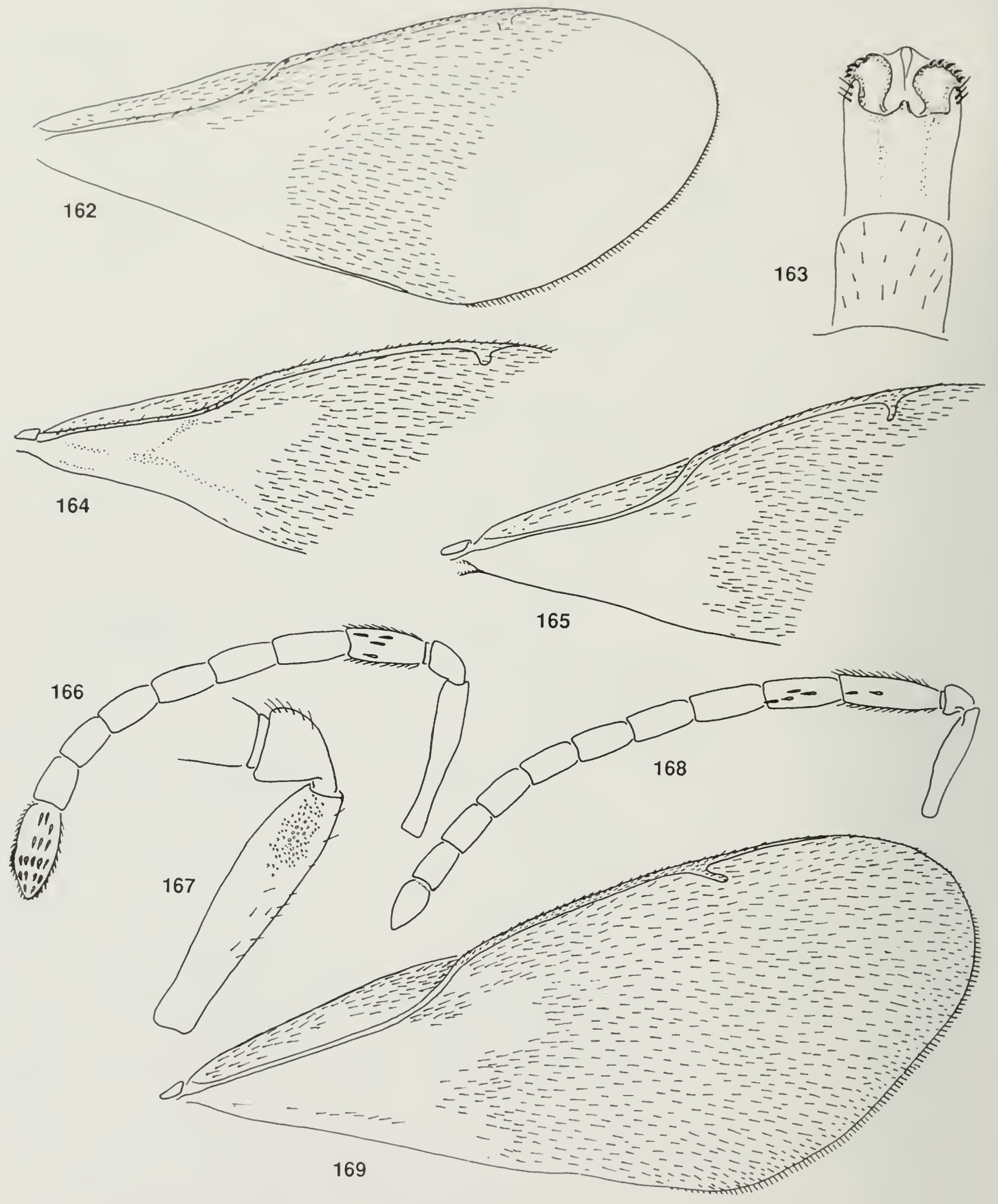

Figs. 162-169. Neoloshamms. 162. N. laeviceps, forewing. 9. 163. N. laeviceps, of genitalia and Ms, in ventral view. 164-165. Forewing: 164. N. violacens. 6; 165. N. palgravei. ㅇ. 166-169. N. purpmerorenuris: 166. Antenna, $+: 167$. Basal articles of antenna, $\delta: 168$. Antenna, $\delta: 169$. Forewing. + . 

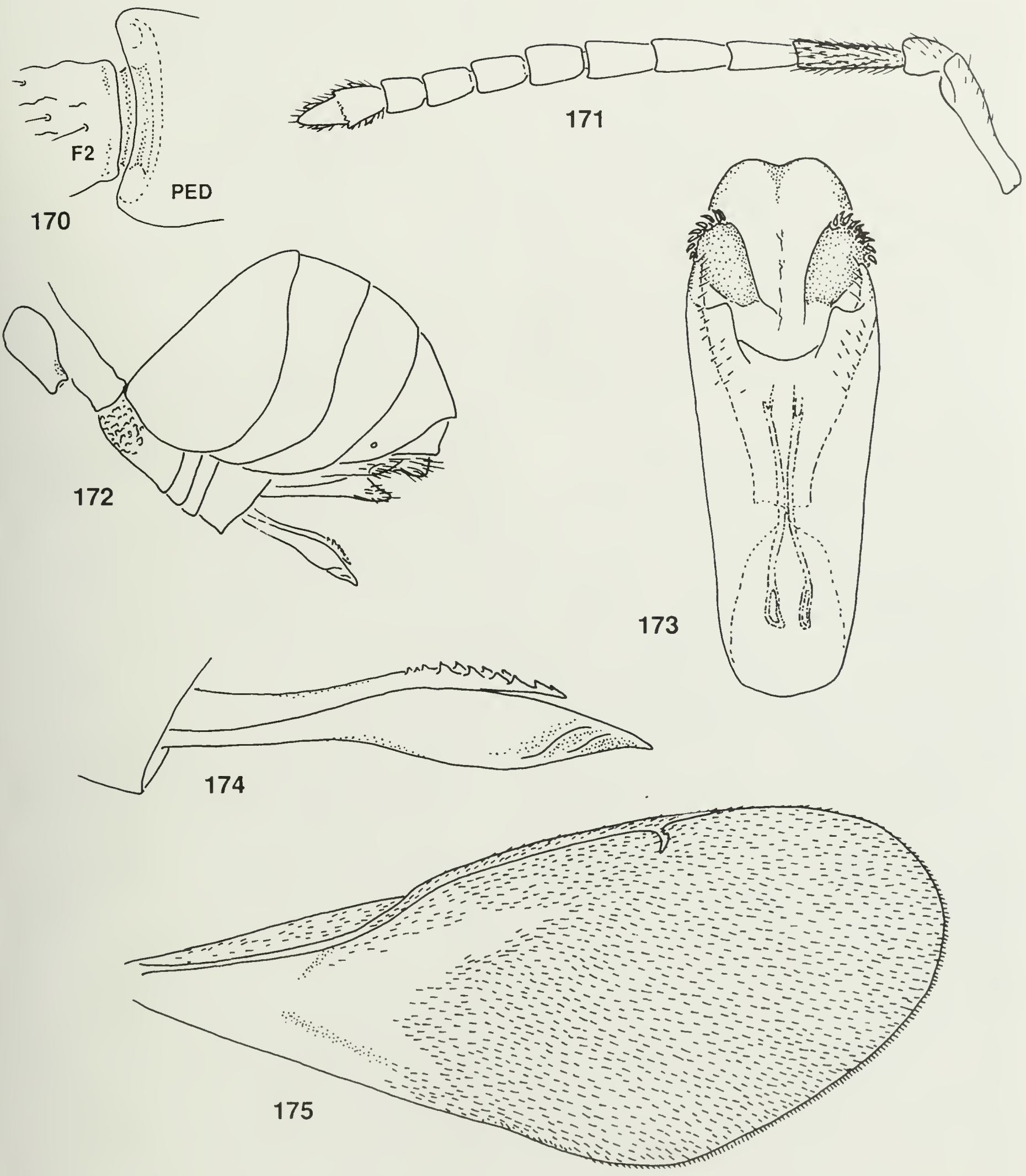

Figs. 170-175. Neoloshanus townesi: 170. Pedicel and basal flagellomere, +.171. Antenna, 9.172. Metasoma, 9.173 . ơ genitalia. 174. Ovipositor in lateral view. 175. Forewing, 9. 


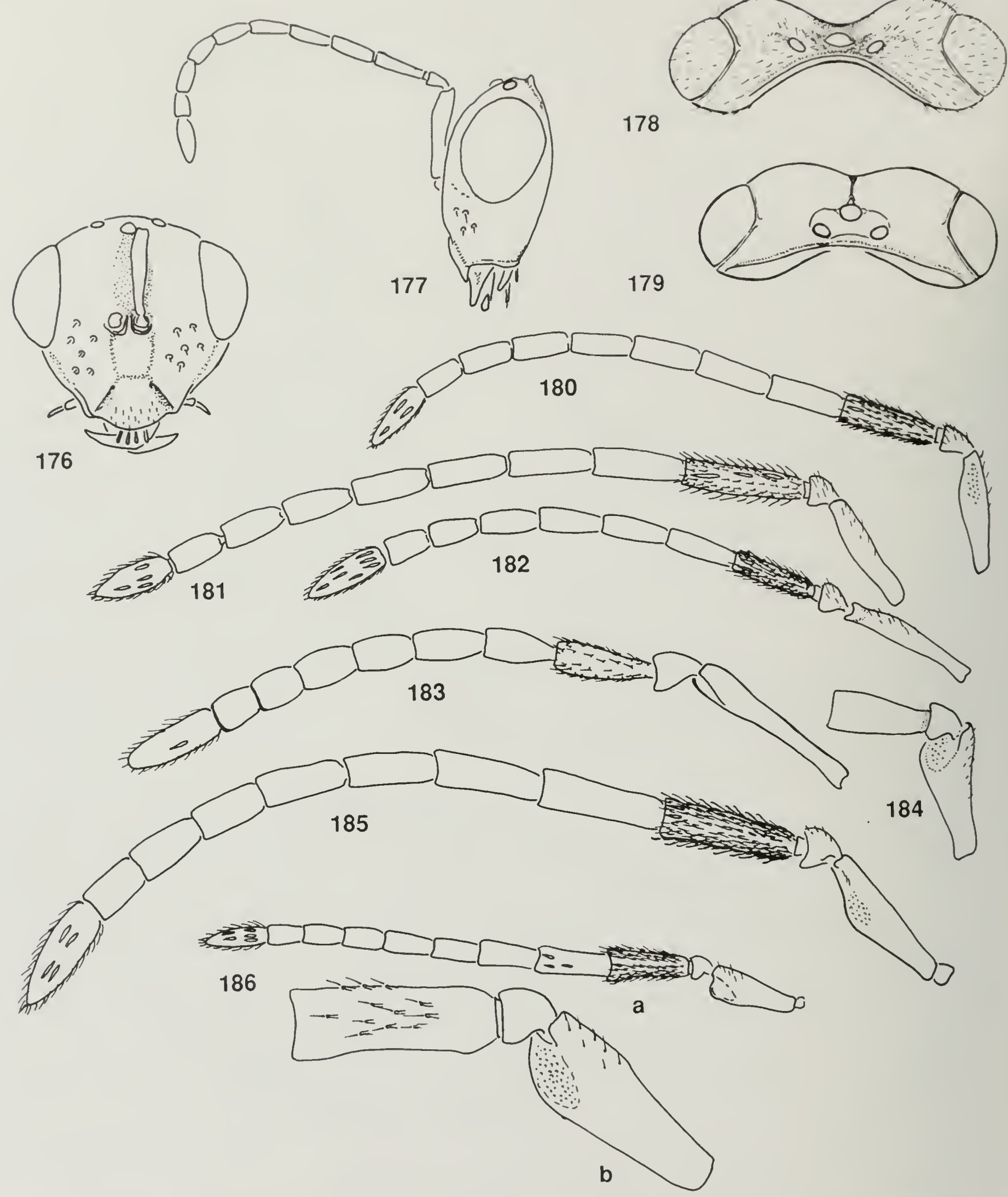

Figs. 176-186. Neoloshumus. 176-177. N. kokureanus. 9 : 176. Head in trontal view; 177. Head in lateral view. 178-179. Head in dorsal view, \&: 178. N. pilosus; 179. N. storeyi. 180-186. Antenna: 180. N. pilosus,

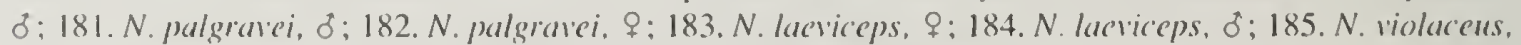
ठ: 186. N. ancipetus, o antenna (a) with enlargement of basal articles (b). 



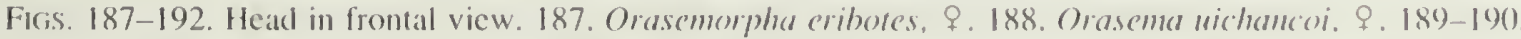
Orasene koghisiana, f. 191. Oreaseme initanor. ․ 192. Orasema redgins. \&. Abbreviations: $\Lambda=$ anteclypeus: CLY = clypeus; $\mathrm{gl}=$ glahrate; $r \mathrm{e}=$ reticulate; $r u=$ rugose. 

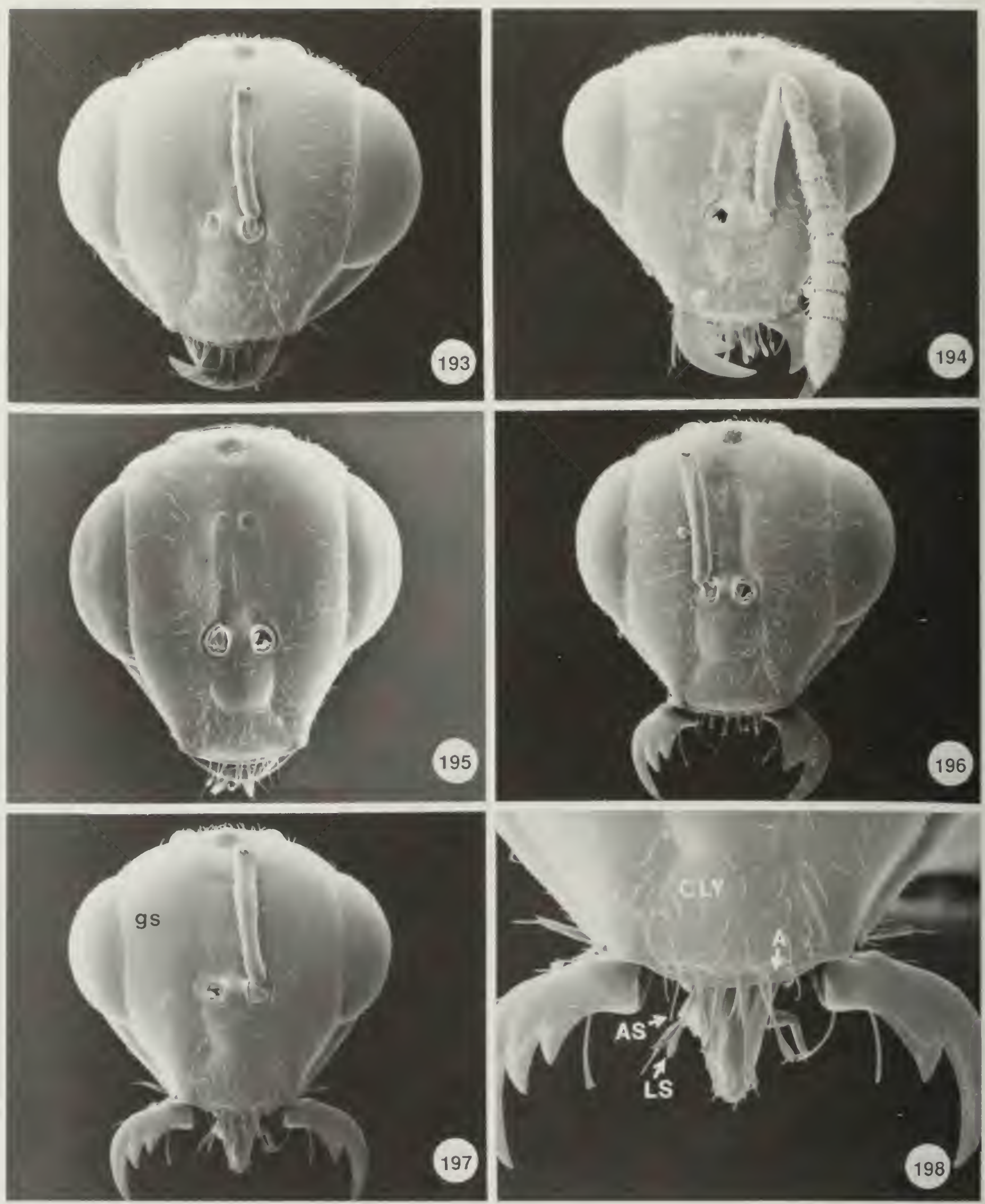

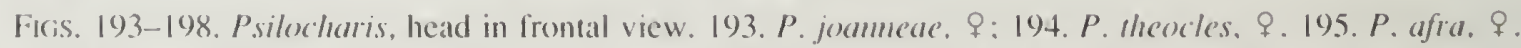
196. P. hypena (13orneo), \&. 197-198. P. hypena (Taiwan). $\&$. Abbreviations: $A=$ antecylpeus; $A S=$ anteclypeal seta; $C L Y=$ clypeus; $L S=$ labral seta; gs = glabrous. 

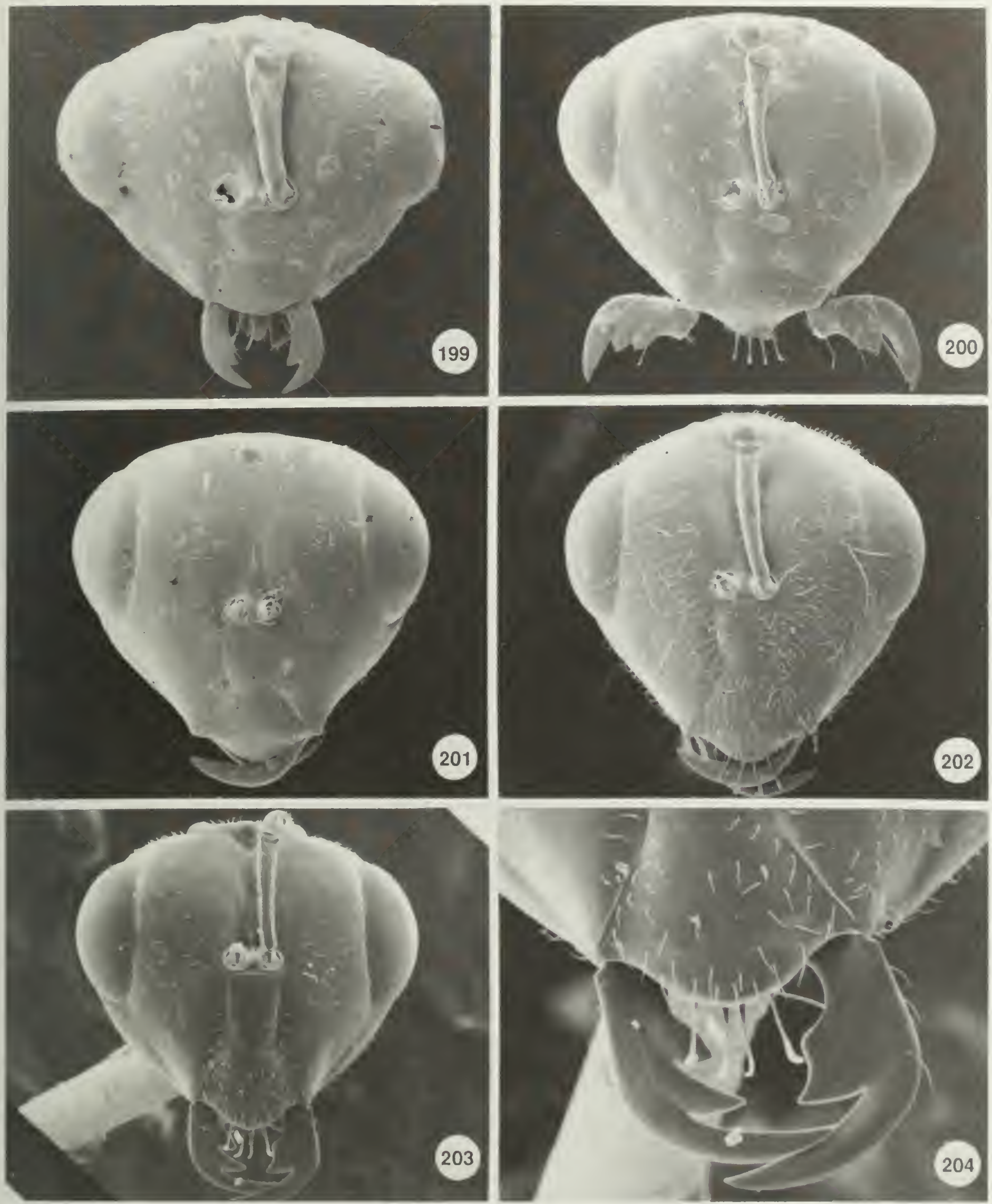

Figs. 199-204. Neoloshames, head in frontal view. 199. N. townesi. P. 200. N. laciveps. 9. 201. N. pulgravei (Malayan) 9. 202. N. pilosus, ?. 203-204. N. nepalensis. +?. 

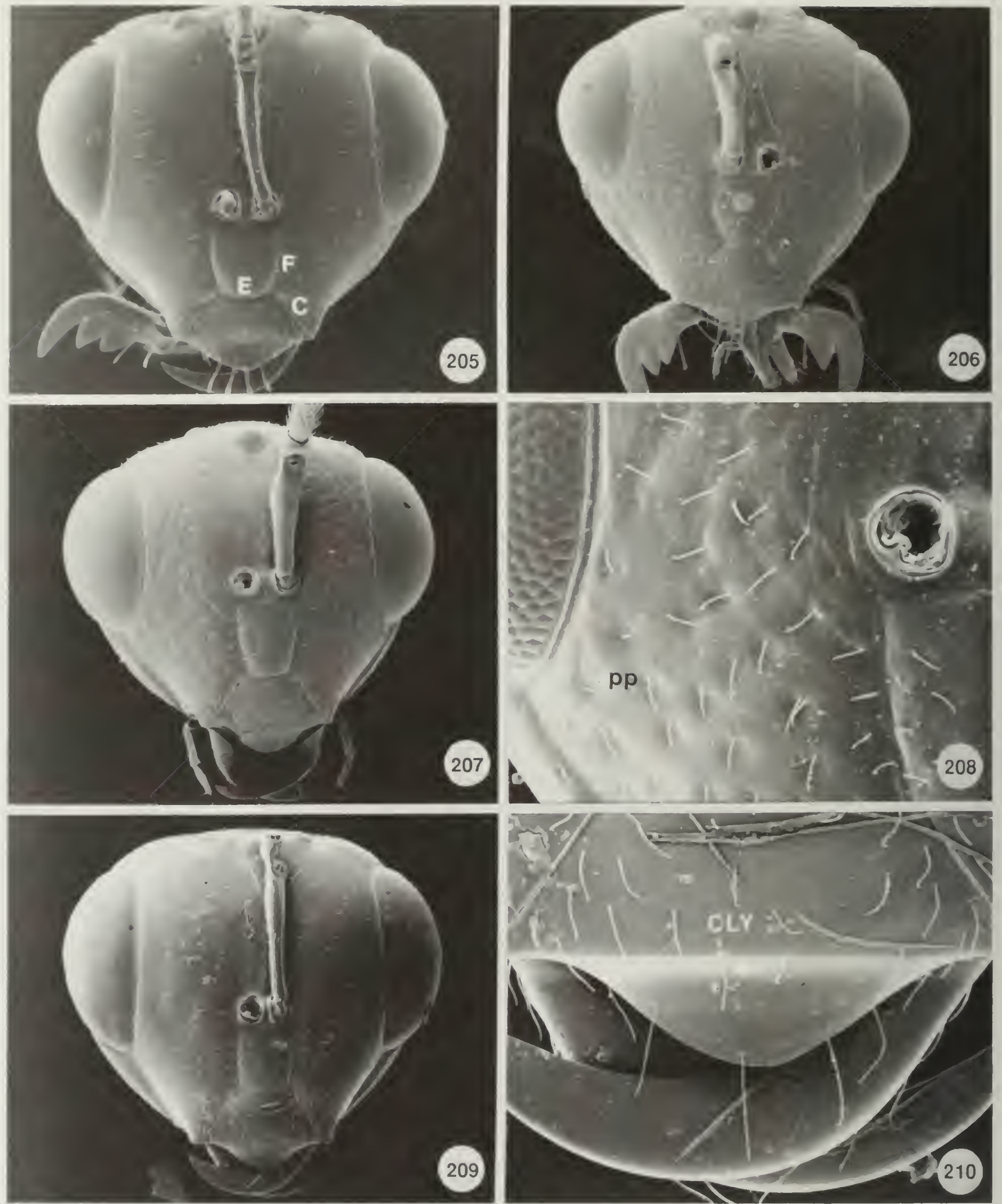

Ficis. 205-210. Neoloshamus, head in frontal view. 205. N. pulgravei (Australian). 9. 206. N. violaceus, o. 207-208. N. amapemus. o: 207. Head: 208. Closeup of fice lateral to torulus. 209-210. N. purpureorenris. $:$ :209. Head: 210 . Closeup of clypeal area. Abbreviations: $\mathrm{C}=$ clypeogenal sulcus, $\mathrm{Cl}, \mathrm{Y}=\mathrm{clypeus} . \mathrm{E}=$ epistomal sulcus, $\mathrm{F}=$ frontogenal sulcus; $\mathrm{p} p=$ pilose-punctate. 

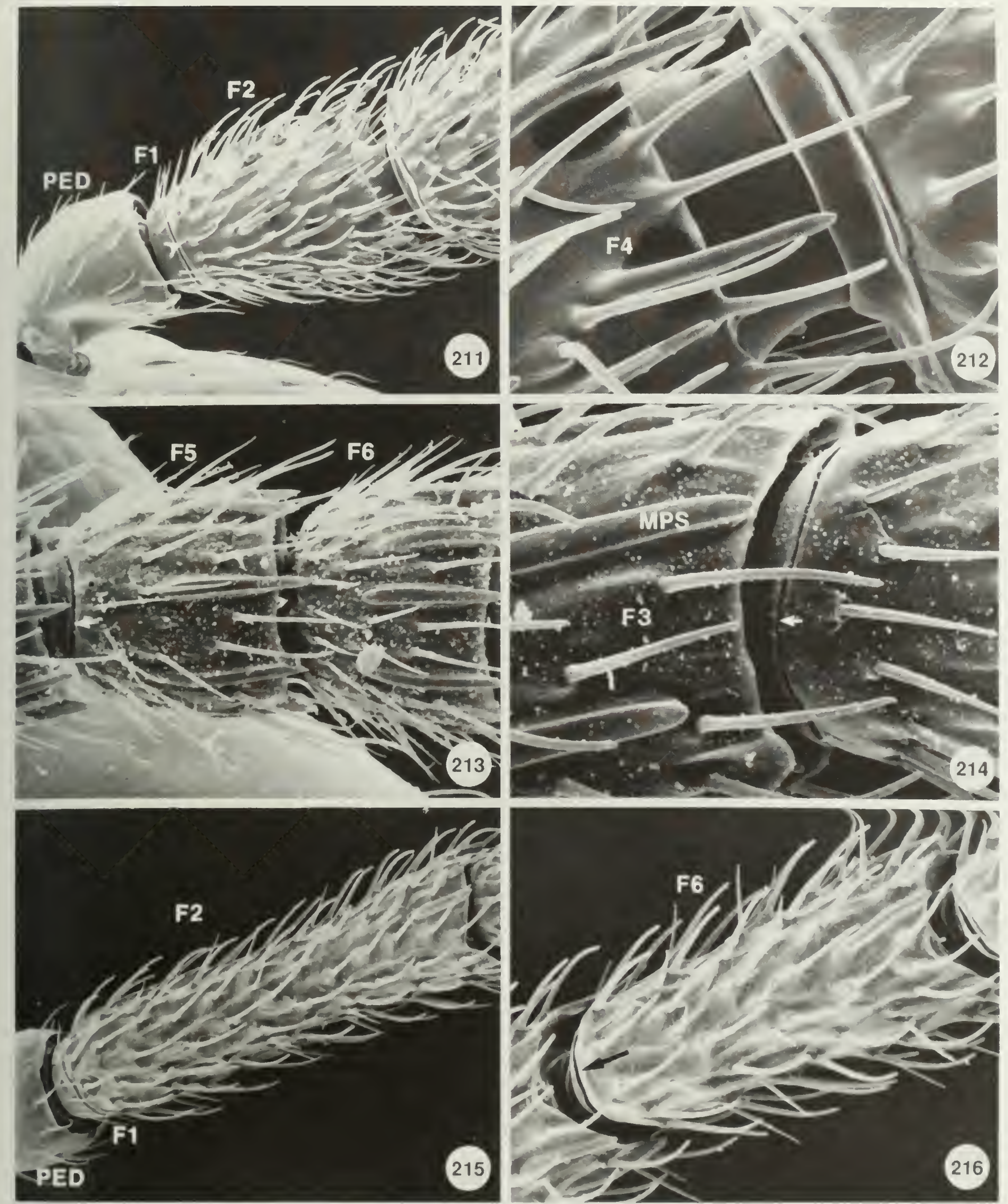

Figs. 211-216. Antennal flagellomeres. 211-212. Orasema koghisiana, o. 213. Psilocharis theocles. Q. 214

Neoloshanus palgranci, $9.215-216$. Neoloshamus anapenus. Abbreviations: F1 -6 = 17agellomeres 1-6; MPS

= multiporous plate sensillum; PED = pedicel 

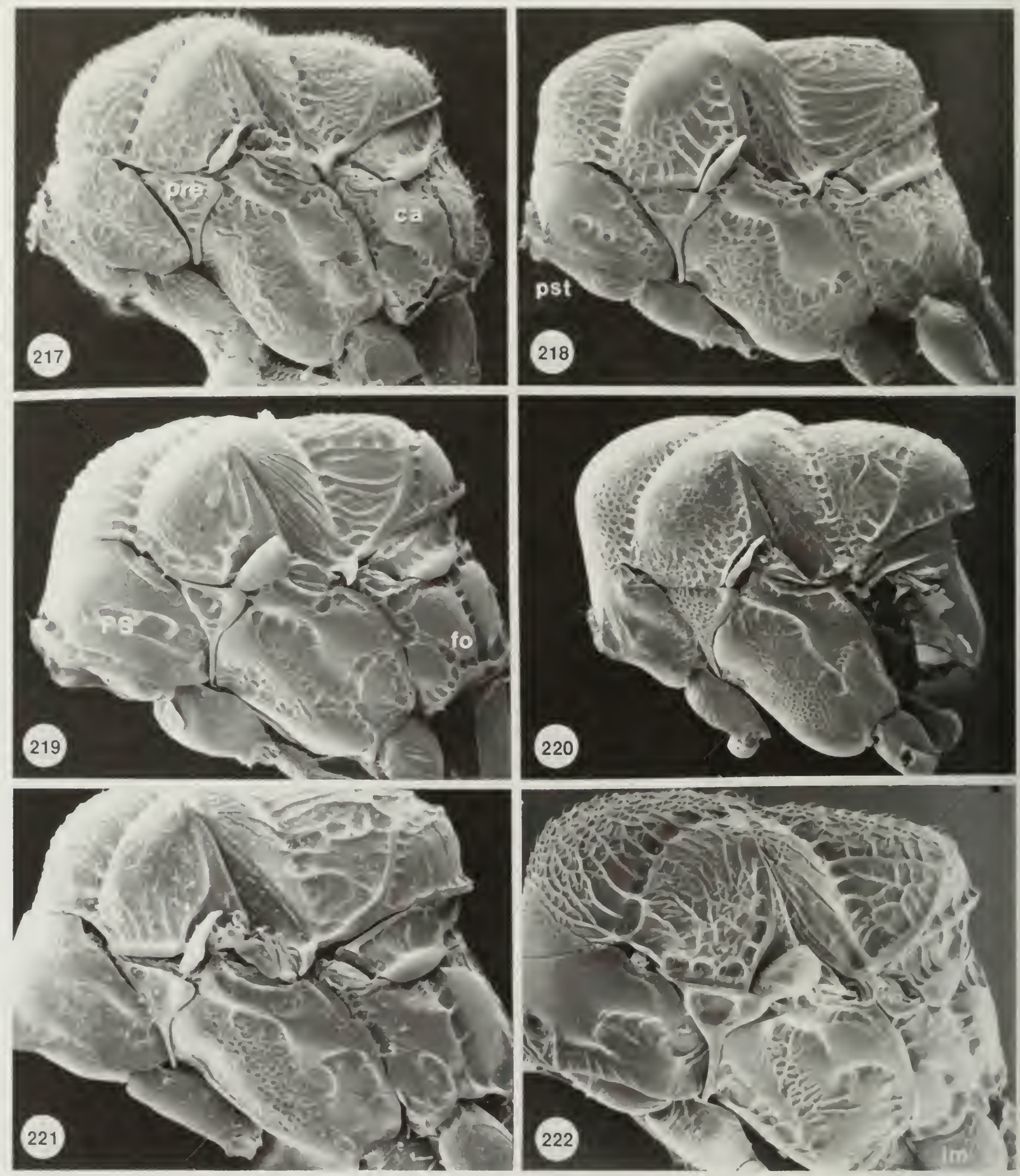

Figs. 217-222. Mesosoma in lateral view. 217. Orasemorpha cribotes, \&. 218. Orascma nichancoi. 9.219 Orasema koghisiana, of. 220. Orasema intitator, ?. 221. Orasema valgins, \&. 222. Psilocharis afra, of. Abbreviations: $\mathrm{ca}=$ callus; $\mathrm{fo}=$ foveate; $\mathrm{im}=$ imbricate: pre = prepectus: $P S=$ pronotal sulcus: $p s t=$ procpisternum. 



Figs. 223-228. Mesosoma in lateral view. 223. Psilocharis theocles, \$. 224. Psilocharis hypend (Taiwan).

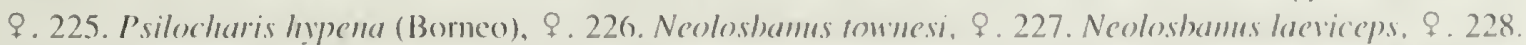
Neoloshanus palgravei (Malayan) . Abbreviations: $\mathrm{ac}=$ aciculate; $\mathrm{CN}=$ callar nib; $\mathrm{fg}=$ femoral groove: $\mathrm{MD}=$ malar depression; $\mathrm{SA}=$ stemaular area. 

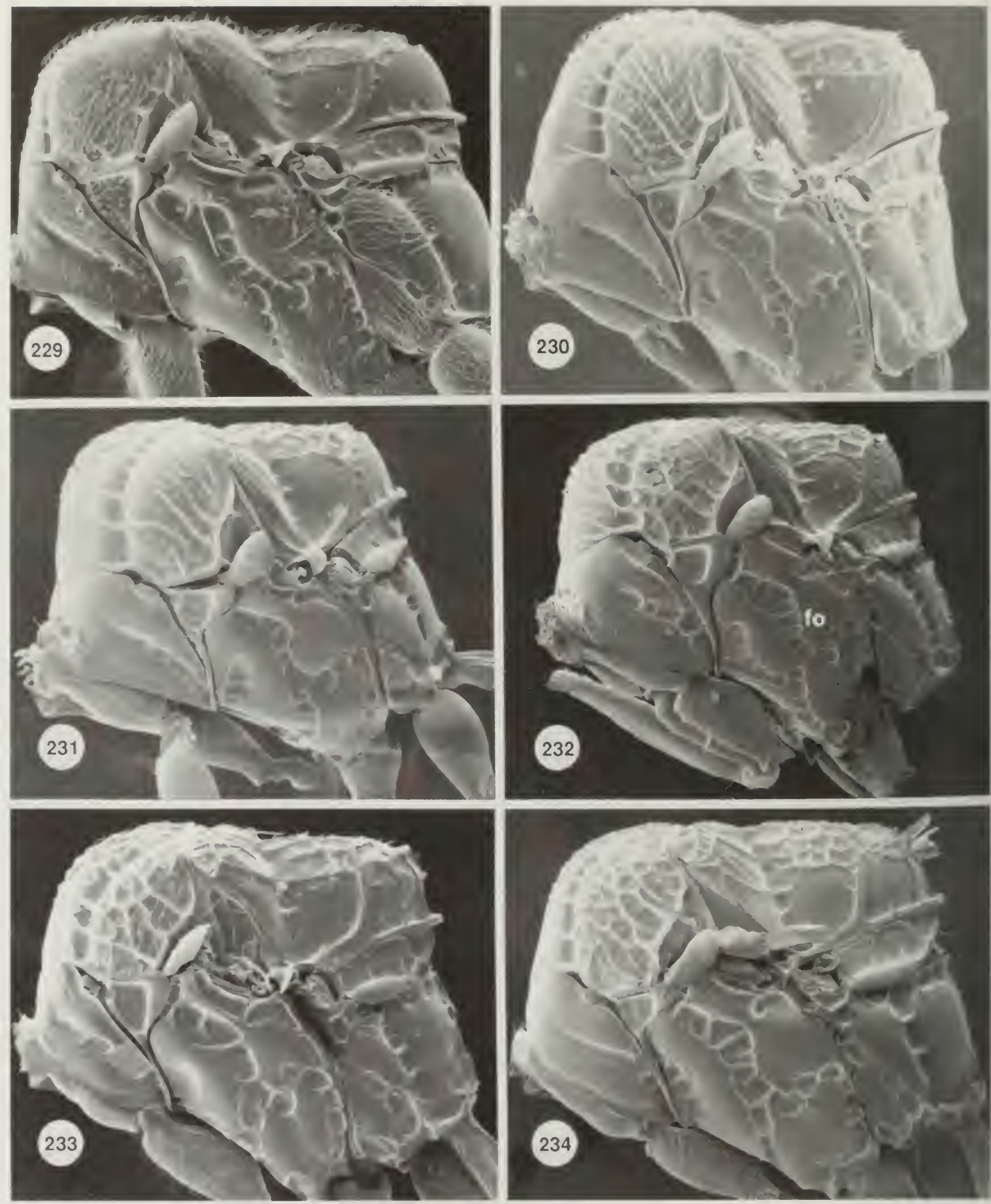

Fugs. 229-234. Neoloshamus, mesosoma in lateral view. 229. N. pilosus, 9. 230. N. nepaleusis, \&. 231. N. palgravei (Australian), +. 232. N. violaceus, o. 233. N. anaperws, o. 234. N. purpureovemris, ?. Abbreviation: $f o=$ foveate . 

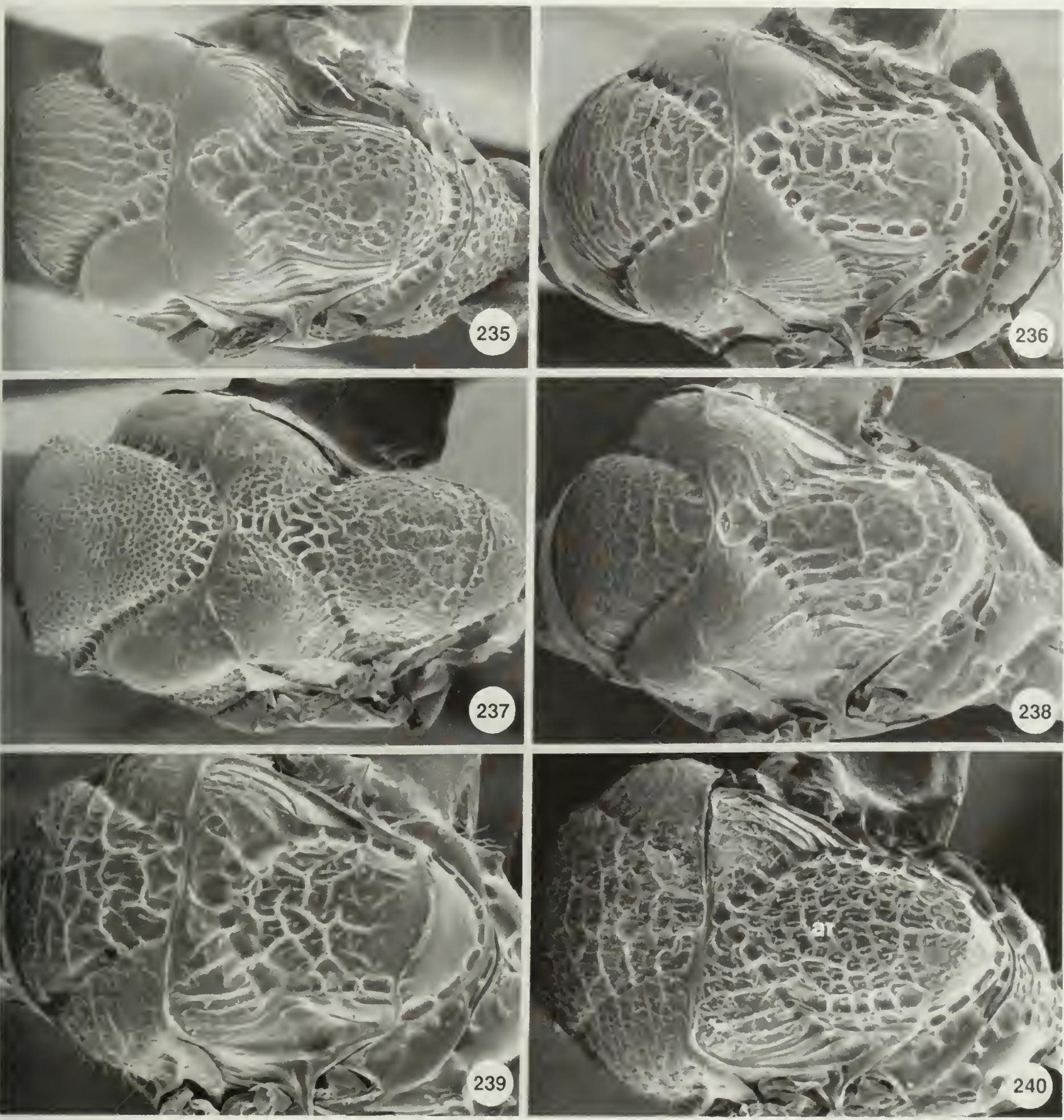

Figs. 235-240. Mesosoma in dorsal view. 235. Orasema michancoi, +. 236. Orasema koghisiana, \&. 237

Orasema initiator, ?. 238. Orasema valgius. \&. 239. Psilocharis hypena (Taiwan), +. 240. Psilocharis hypena (Borneo), ㅇ. Abbreviation: ar = areolate. 



Figs. 241-246. Neoloshanus, mesosoma in dorsal view. 241. N. lonnesi, ․ 242. N. laeviceps, ․ 243. N. pilosus, ․ 244. N. palgravei (Australian), ?. 245. N. anapetus, ơ. 246. N. purpureoventris, $q$. 



Figs. 247-255. Propodeum. 247. Orasema koghisiana, +. 248. Orasema valgins, ․ 249. Psiloxharis hypena (Taiwan), 9. 250. Neolosbanus monesi, \&. 251. Neolosbamus laeviceps. \&. 252. Neoloshanus nepalensis, \&. 253. Neoloshamus palgravei (Australian), \&. 254. Neoloshamus anapems. 8. 255. Neoloshamus purpureone'nIris, + . Abbreviations: $\mathrm{fr}=$ frenum; prp $=$ propodeum. 

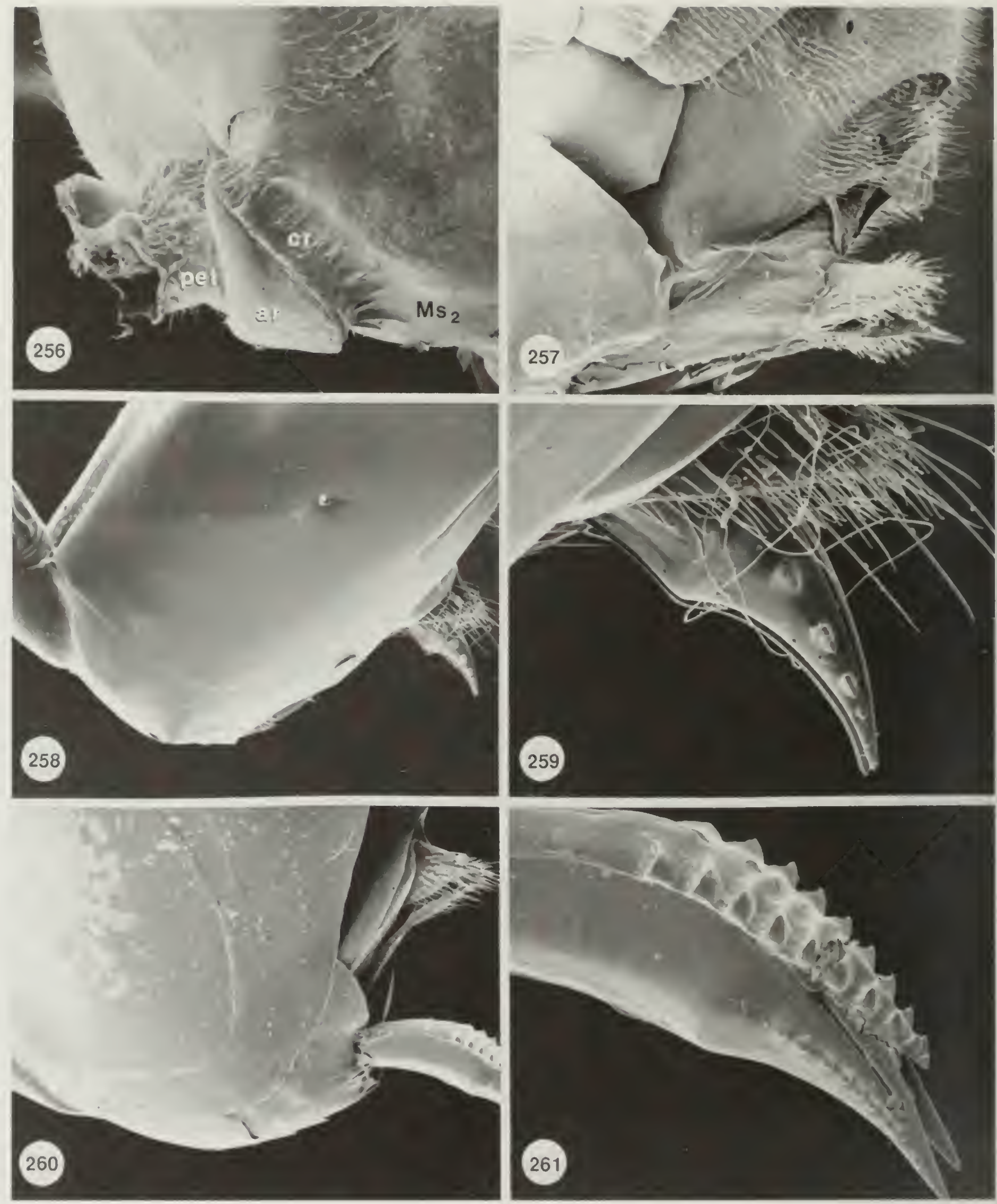

Figs. 256-261. 256-257. Orasemorpha eribotes, $q$ : 256. Petiole and firsi gastral sternite in ventrolateral view: 257. Apex of gaster in subventral view. 258-259. Orasema nichancoi,,$: 258$. Gaster in ventrolateral view: 259. Ovipositor. 260-261. Orasema initiator, $q$ : 260. Gaster in ventrolateral view; 261. Ovipositor. Abbreviations: ar = anterior region; $\mathrm{cr}=$ crenulate; $M \mathrm{~s}_{2}=$ second metasomal sternite: $p e t=$ petiole. 

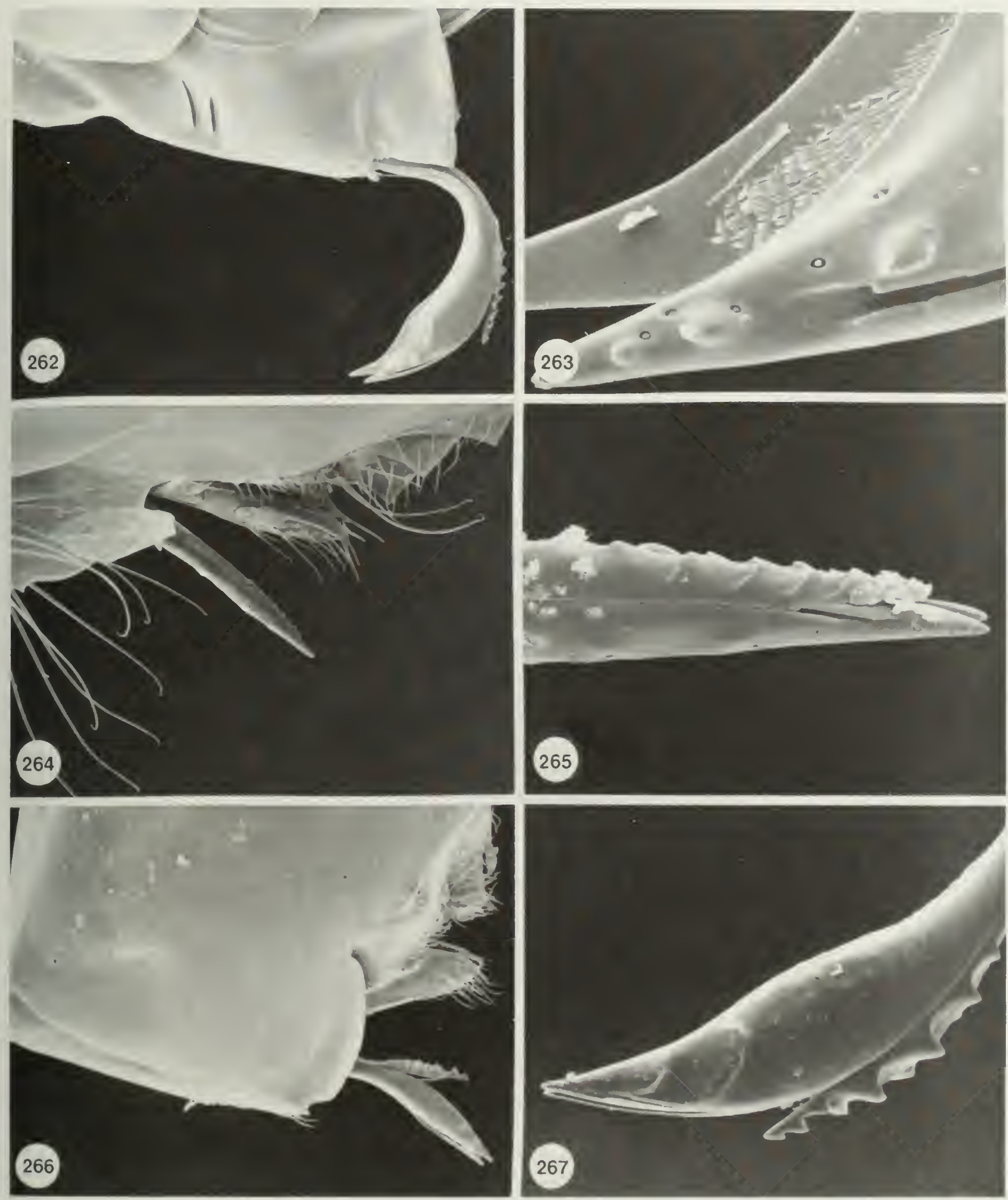

FIGS. 262-267. 262-263. Orasema valgins, 9: 262. Gaster in ventrolateral view: 263. Ovipositor. $264-265$. Psilocharis theocles, $\$$ : 264. Apex of gaster: 265. Tip of ovipositor. 266-267. Neoloshamus palgratel (Australian), $+: 266$. Gaster in lateral view; 267. Ovipositor. 

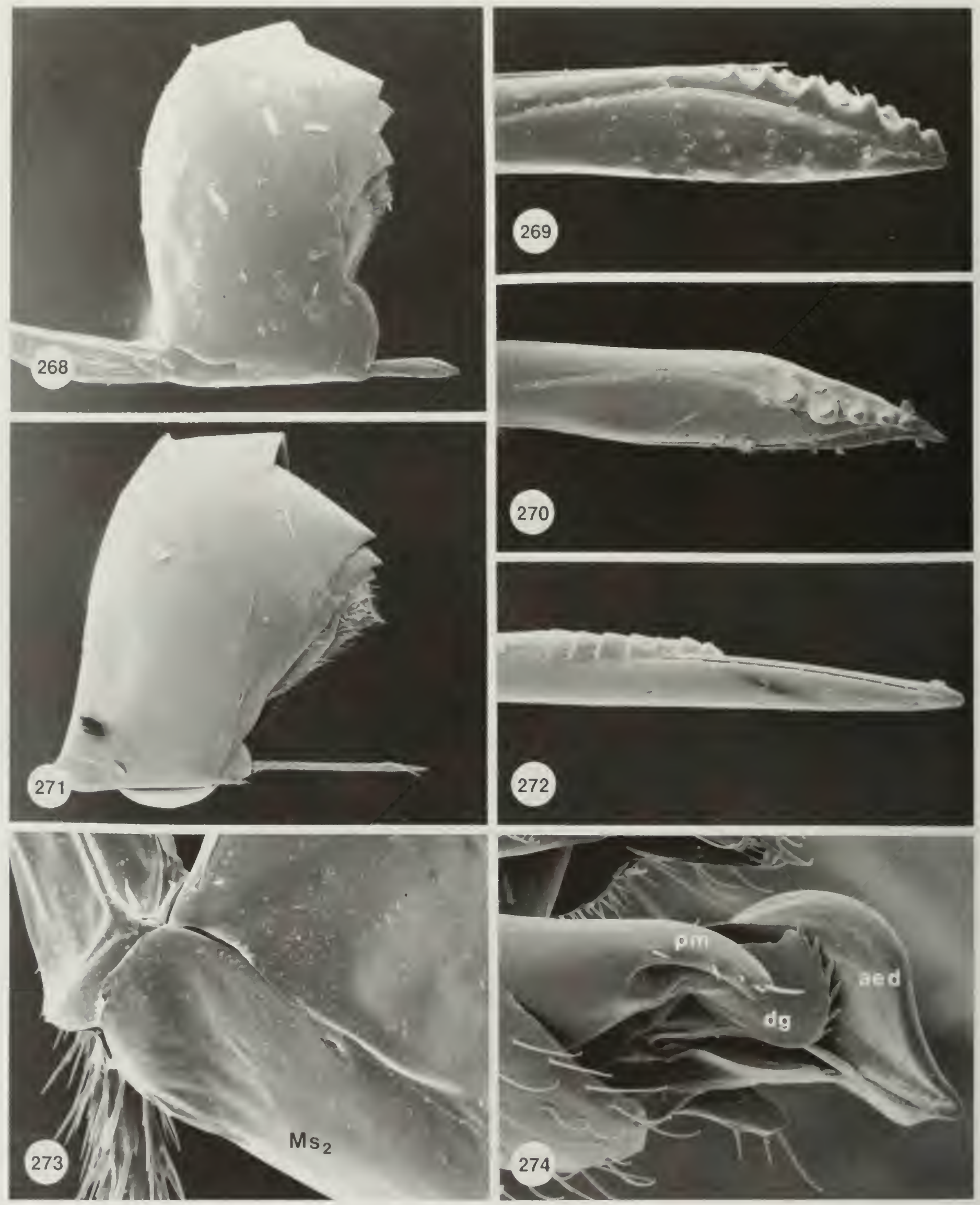

Fuss. 268-274. Neolosbumis. 268-269. N. lacviceps, 9: 268. Metasoma in lateral view; 269. Ovipositor in lateral view. 270. N. anapetus, ovipositor. 271-272. N. purpureoventis, $9: 271$. Gaster: 272. Tip of ovipositor. 273-274. N. anapelus, o : 273. Base of gaster in lateral view: 274. Genitalia in subventral view. Abbreviations: aed = aedeagus, $\mathrm{dg}=$ digitus; $\mathrm{M} \mathrm{s}_{2}=$ second metasomal sternite; $\mathrm{pm}=$ paramere. 


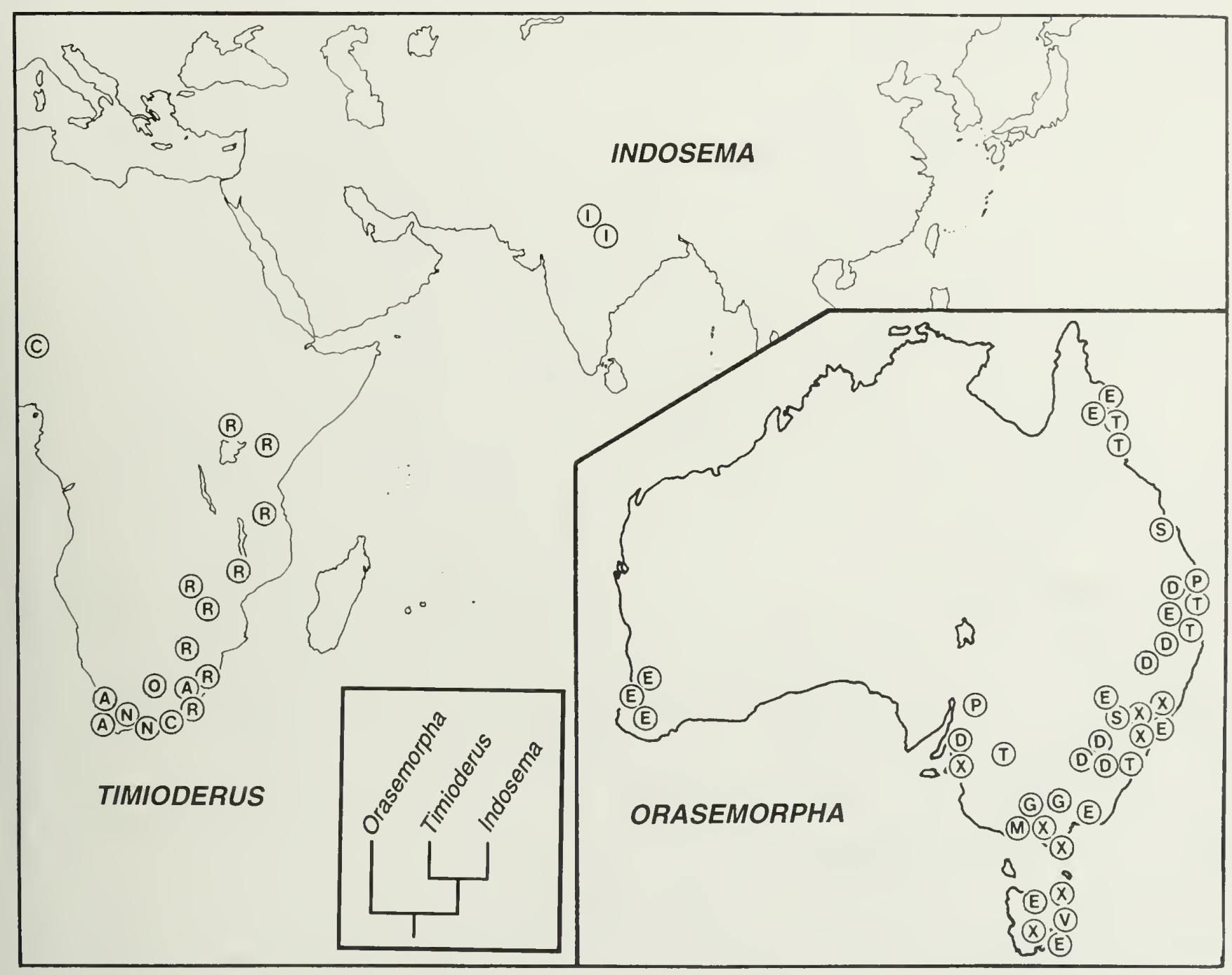

FIG. 275. Geographic distribution and phylogeny of Orasemorpha. Timioderus, and Indosema. Letters refer to species discussed in text. $\mathrm{A}=T$. acuminatus $; \mathrm{C}=T$. coromula $; \mathrm{D}=O$. didentata; $\mathrm{E}=O$. eribotes: $\mathrm{G}=O$. goethei; $\mathrm{I}=I$. indica; $\mathrm{M}=O$. myrmicae; $\mathrm{N}=T$. peridentatus; $\mathrm{O}=T$. ranosus; $\mathrm{P}=O$. pyttalus; $\mathrm{R}=T$. refringens; $\mathrm{S}=O$. sparsepilosus; $\mathrm{T}=O$. tridentata; $\mathrm{V}=O$. v'aridentata; $\mathrm{X}=O$. xeniades. 


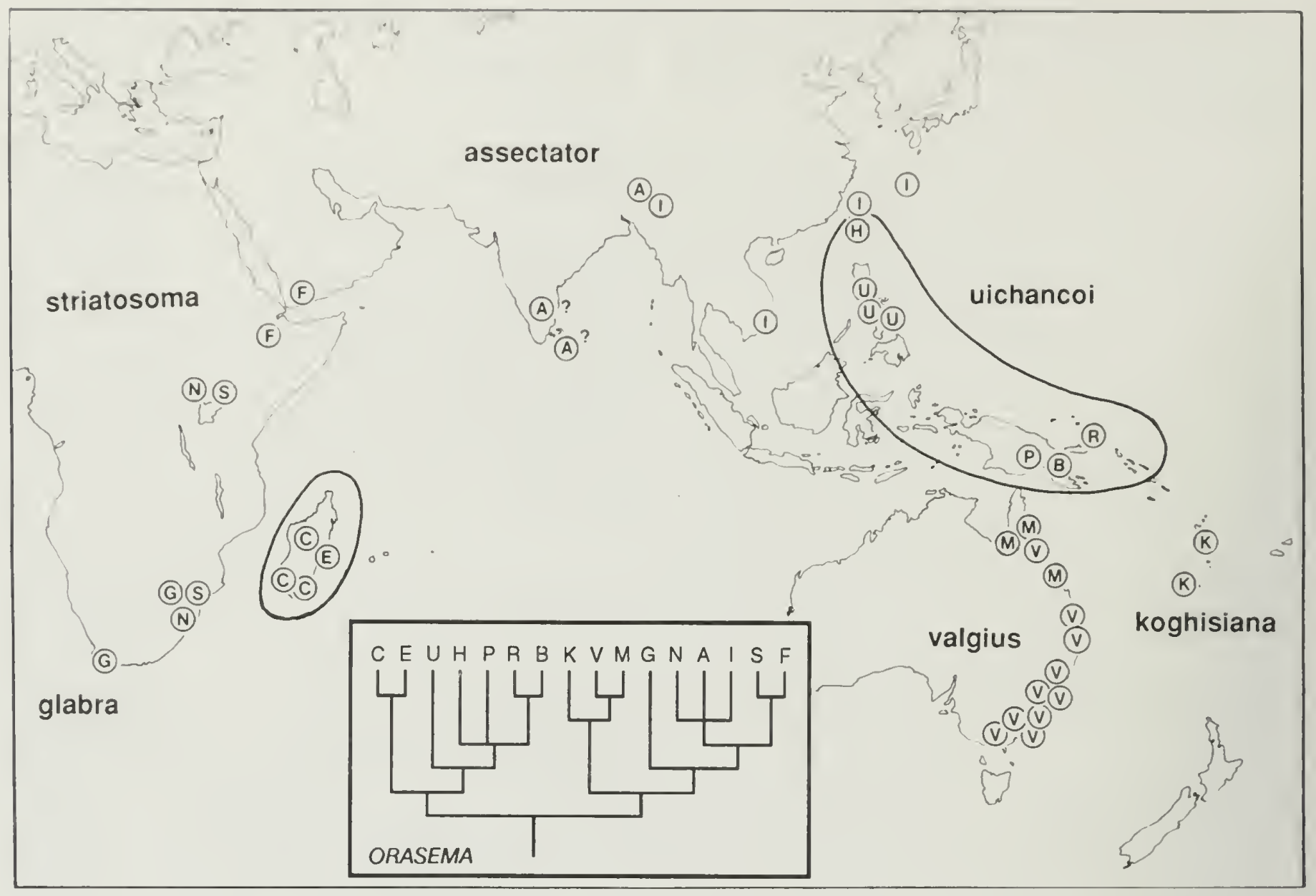

FIG. 276. Geographic distribution and phylogeny of Orasema. Lower-case names refer to species-groups. Letters refer to species discussed in text. Question marks refer to questionable species assignments. Solid line encloses the distribution of the $O$. uichancoi-group. Abbreviations: $\mathrm{A}=$ assectator; $\mathrm{B}=$ bonceki; $\mathrm{C}=$ commminis: $\mathrm{E}=$ seyrigi: $\mathrm{F}=$ firandulenta $\mathrm{G}=$ glabra $; \mathrm{H}=$ ishii $\mathrm{I}=$ initiator: $\mathrm{K}=$ koghisiana: $\mathrm{M}=$ synempora: $\mathrm{N}=$ nigra; $\mathrm{P}=$ pronece $;, \mathrm{R}=$ rugulosa $\mathrm{S}=$ striatosona: $\mathrm{U}=$ uichancoi: $\mathrm{V}=$ valgius. 


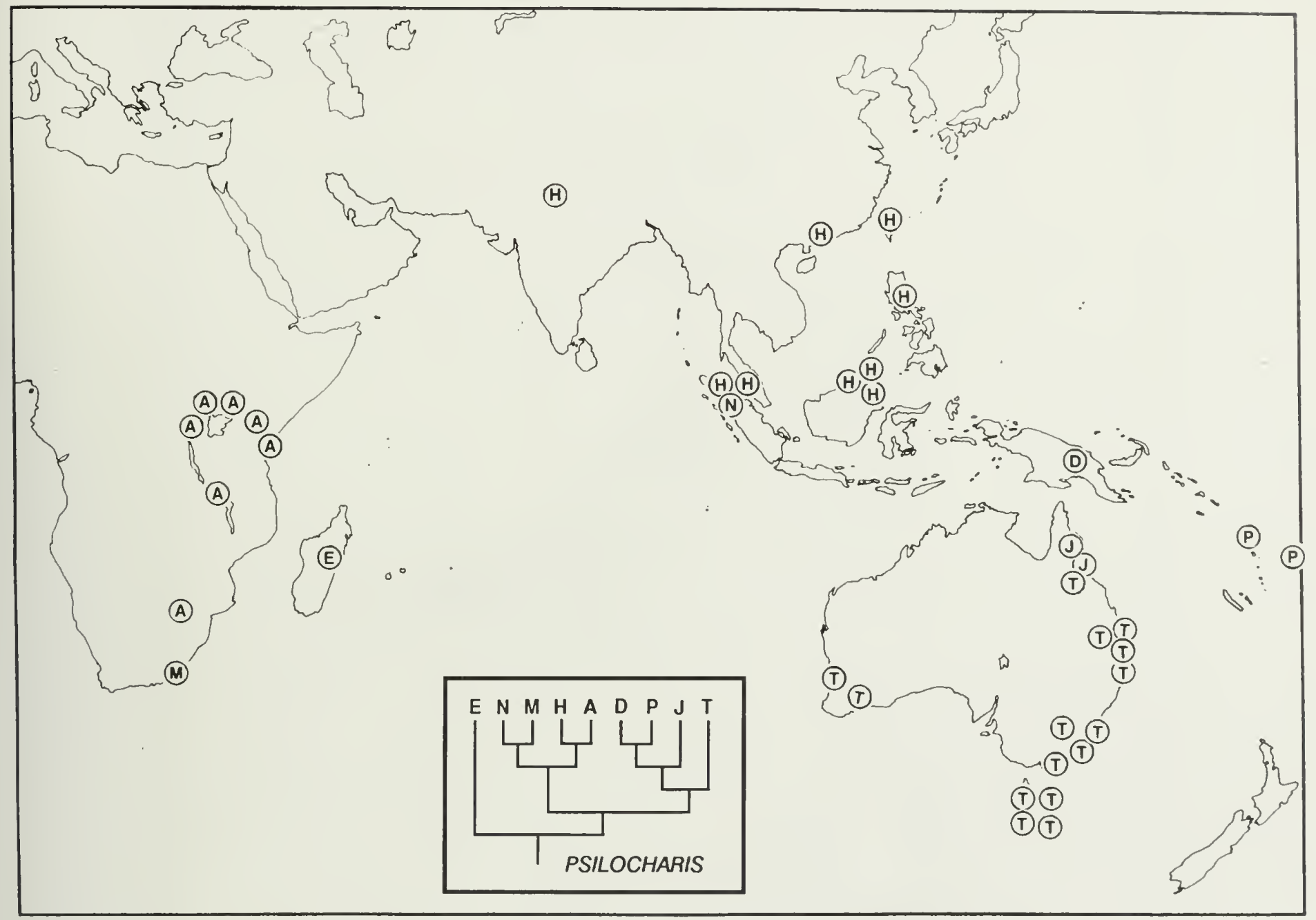

FIG. 277. Geographic distribution and phylogeny of Psilocharis. Lower-case names refer to species-groups. Letters refer to species names discussed in text. Abbreviations: $\mathrm{A}=$ afra; $\mathrm{D}=$ dahmsi; $\mathrm{E}=$ aenigma; $\mathrm{H}=$ hypena; $\mathrm{J}=$ joanneae; $\mathrm{M}=$ monilicera; $\mathrm{N}=$ pentella; $\mathrm{P}=$ pacifica $; \mathrm{T}=$ theocles. 


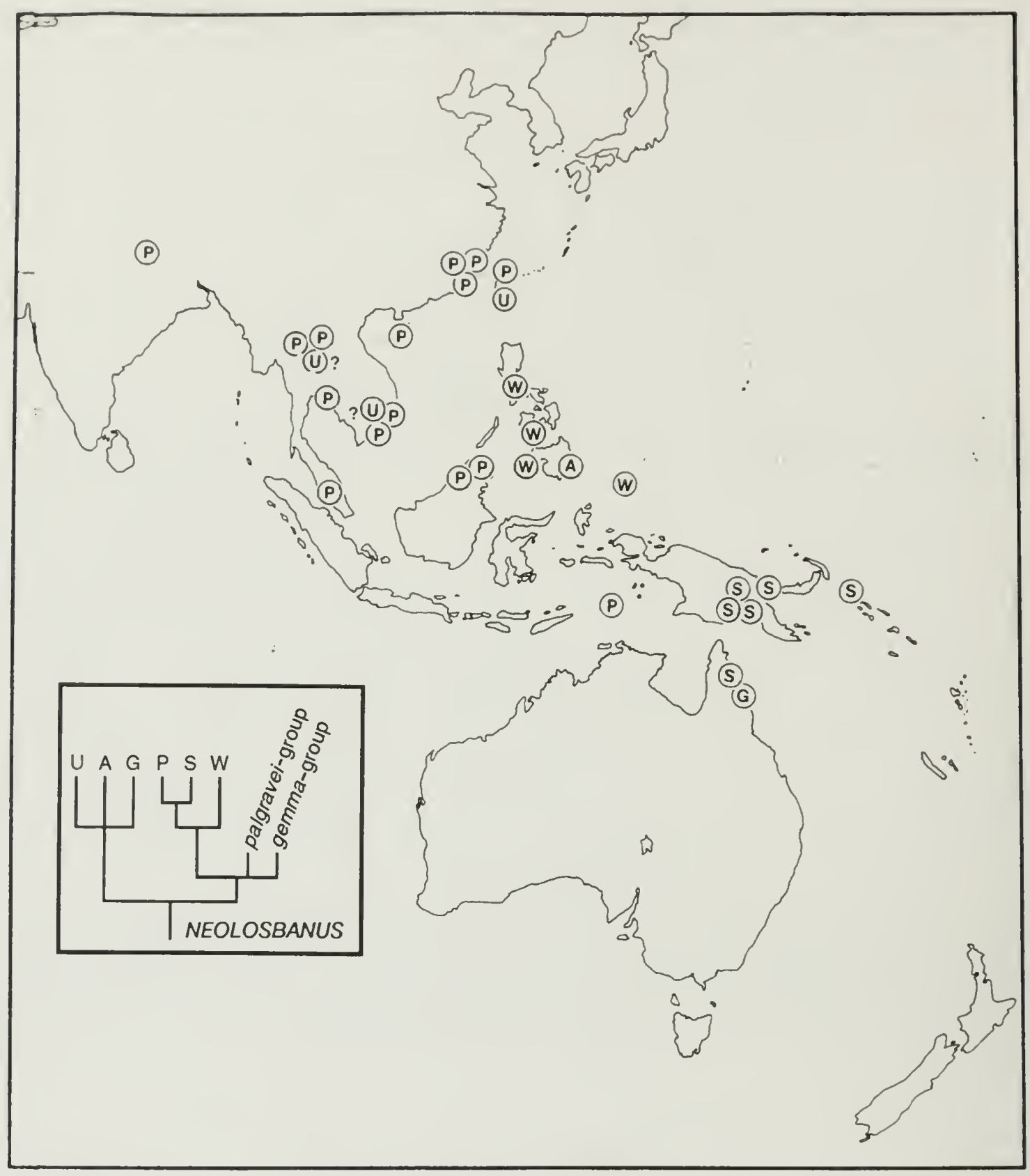

FIG. 278. Geographic distribution and phylogeny of the Neoloshamus genma- and purpureoventrisgroups. Letters refer to species names discussed in text. Question marks refer to questionable species assignments. Abbreviations: $\mathrm{A}=$ apoanus; $\mathrm{G}=$ gemma; $\mathrm{P}=$ purpureoventris; $\mathrm{S}=$ storeyi; $\mathrm{U}=$ wusheanus; $\mathrm{W}=$ watanabei. 


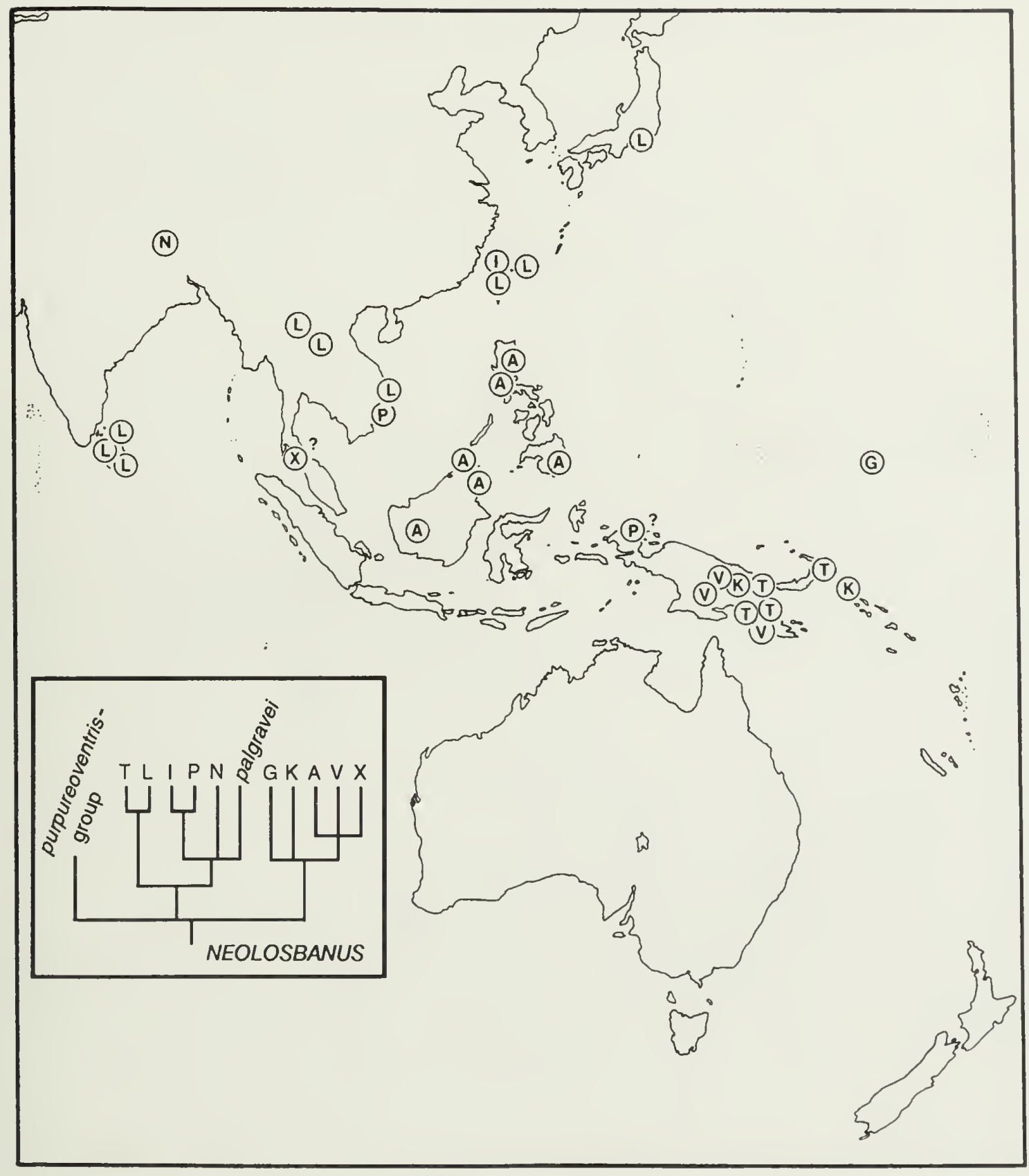

FIG. 279. Geographic distribution and phylogeny of the Neolosbamus gressitti- and palgravei-groups (except $N$. palgravei). Letters refer to species names discussed in text. Question marks refer to questionable species assignments. Abbreviations: $\mathrm{A}=$ anapetus; $\mathrm{G}=$ gressitti; $\mathrm{I}=$ taiwanensis; $\mathrm{K}=$ kokureamus; $\mathrm{L}$ =laeviceps; $\mathrm{N}=$ nepalensis; $\mathrm{P}=$ pilosus; $\mathrm{T}=$ tonnesi; $\mathrm{V}=$ violaceus; $\mathrm{X}$ ? = sp. nr violaceus. 


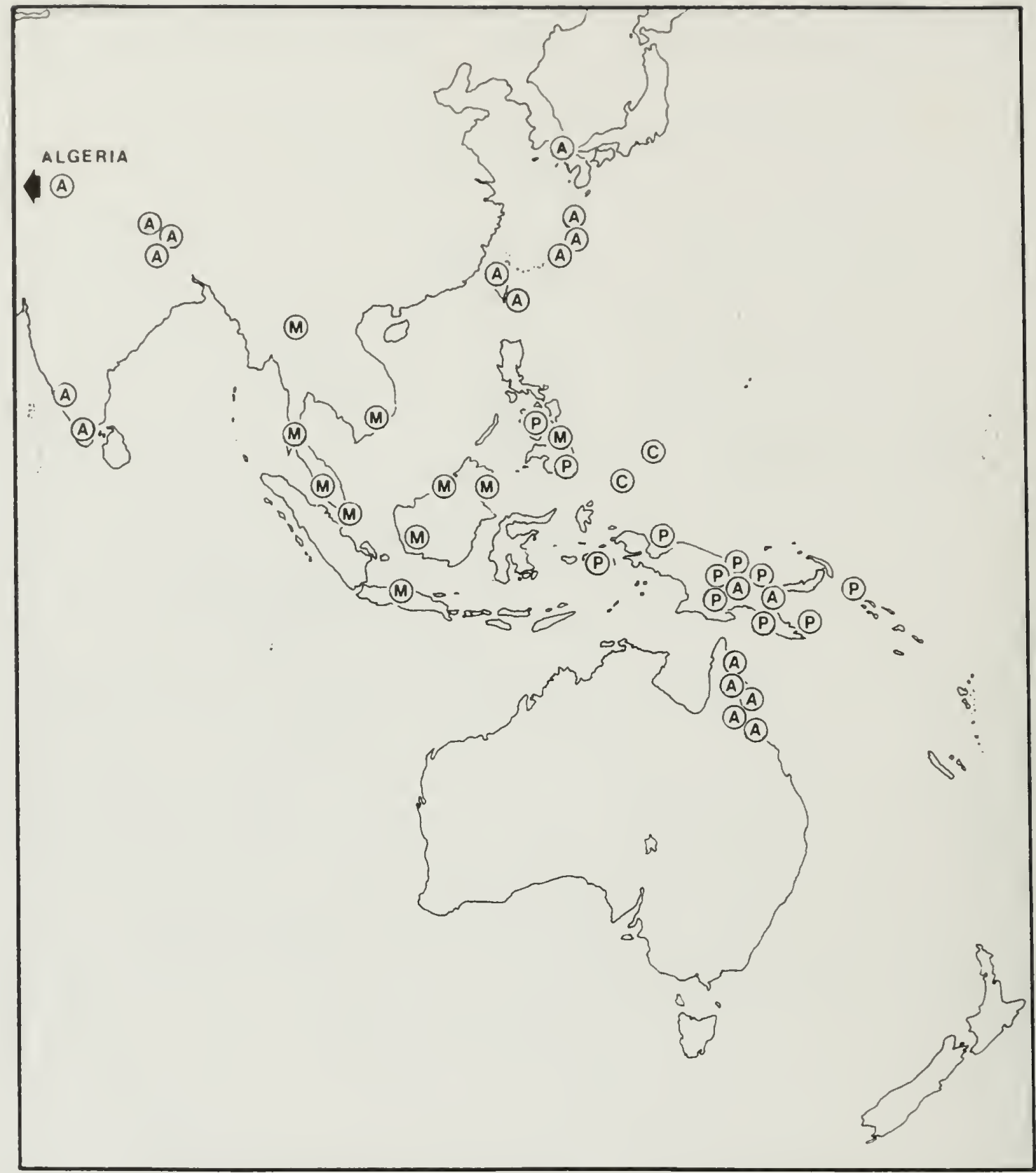

FIG. 280. Geographic distribution of Neolosbanus palgravei. Letters refer to population assignments discussed in text. Abbreviations: $\mathrm{A}=$ Australian; $\mathrm{C}=$ Carolinean; $\mathrm{M}=$ Malayan; $\mathrm{P}=$ Papuan. 
NUMBER OF SPECIES IN EACH SUBREGION

\begin{tabular}{|l|l|l|l|l|l|l|l|l|l|l|l|l|l|l|}
\hline ETHIOPIAN & 5 & & & 2 & 2 & 1 & 1 & 2 & 1 & 4 & & & & \\
\hline INDO-CHINESE & & 1 & & 1 & & 2 & & 2 & 2 & 1 & 1 & 1 & 4 & \\
\hline MALAYAN & & & & & & 1 & & & & 2 & & 1 & 3 & 2 \\
\hline PHILIPPINE & & & & 1 & & & & & & 1 & 1 & 1 & 1 & 1 \\
\hline PAPUAN & & & $(2)$ & 3 & & & & $(1)$ & & 2 & 1 & 1 & 5 & 2 \\
\hline POLYNESIAN & & & & & & & & & 1 & 1 & & 1 & 1 & 2 \\
\hline AUSTRALIAN & & & 9 & & & & & 1 & & 1 & & & & \\
\hline PALAEARCTIC & & & & & & & & & & & & & $2 ?$ & \\
\hline \hline TOTAL & 5 & 1 & 9 & 7 & 2 & 3 & 1 & 2 & 1 & 8 & 3 & 3 & 6 & 4 \\
\hline
\end{tabular}

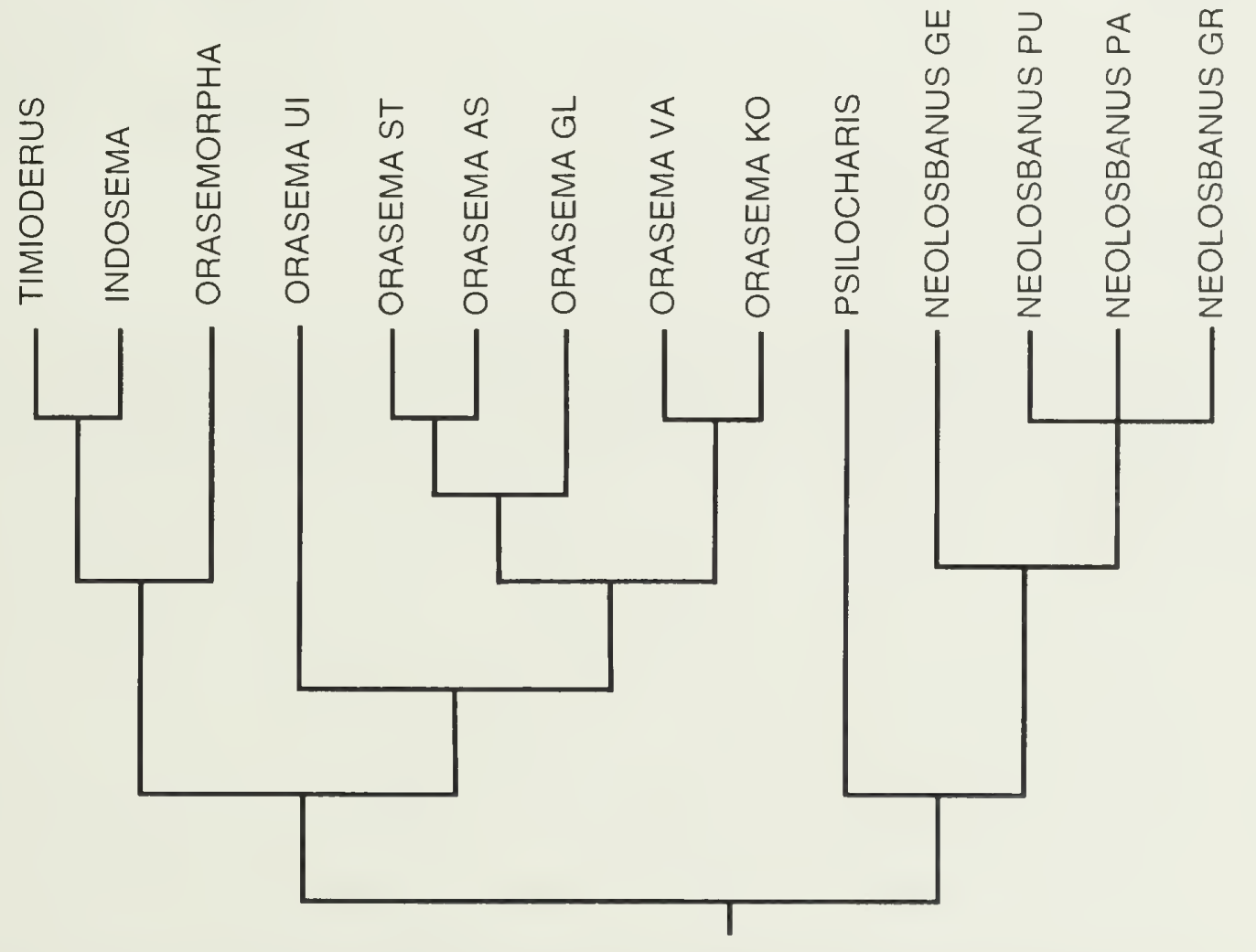

FIG. 281. Number of species of Oraseminae and Psilocharitini represented in cach of eight biogeographic zones recognized by Gressitt (1956), and arranged according to the phylogeny presented in Figure 2. A species may occur in more than one region and numbers do not necessarily add up to the total number of species. Bracketed values for the Papuan subregion indicate species found only in northem Australia. Of the two questionable Paliearctic records, one is from Algeria and the other a single record from Tohono Shima Is., Japan. 




FIG. 282. General distributions of Oraseminae and Psilocharitini in the Old World. Elements are divided into Ethiopian, Malagasy, Indo-Pacific, and Australian regions, with each region represented by a different shading pattern. Derivation of species within each region is discussed in the text. Arrow indicates the proposed direction of evolution of species in the Indo-Pacific region; the most highly derived species are found in the southeast. 


\section{Appendix 1: Character Matrix Used for Phylogenetic Analyses}

Taxon names refer to genera, and the following abbreviations to species groups discussed in the text. Numbers correspond to character states listed in Table 2. Character states are ordered from presumed plesiomorphic to apomorphic states. Question marks denote missing data. Stacked values for character state refer to multiple states within taxon.

\section{CHARACTERS}

TAXON

11111191112222222222333333333344444444445555555555666

CHRYSOLAMPIHAE 00077000000700000000000000100000009000000000002170000000000070 111

PERILAMPIHA TIMIOOERUS

00077000000701000030000000200002000001000000002019001919101000

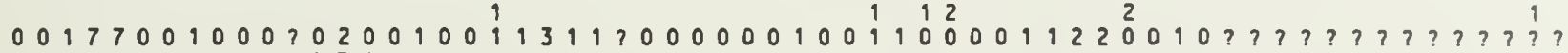

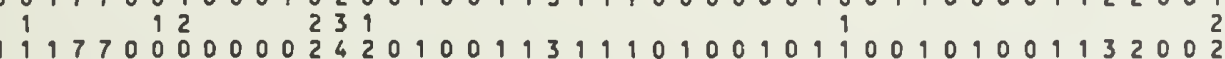

INOOSEMA

0

ORASEMORPHA

ORASEMA ST

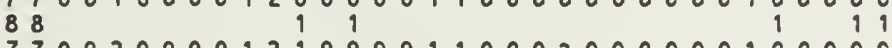

ORASEMA UI 00978700200000129000019100070000001000000

ORASEMA CO

ORASEMA KO

ORASEMA VA

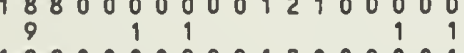

ORASEM GL

ORASEMA AS

PSILOCHARIS AE PSILOCHARIS AF

PSILOCHARIS IH $00077100010012100100900000091000000192310000102 ?$ ?? ??????? ? ?


NEOLOSBANUS PU 000097100011111210001002100000000120000001012 ?

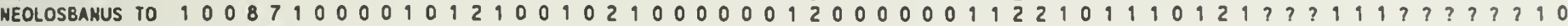
UEOLOSBanus $P$ A NEOLOSBANUS GR

GOLLUMIELLA

AMORASEM

STILBULA

OBEZA

PSEUDOCHALCURA

STILBULOIOA EUCHARIS

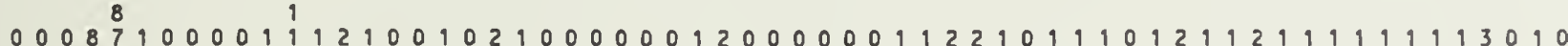

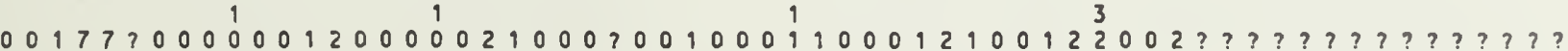

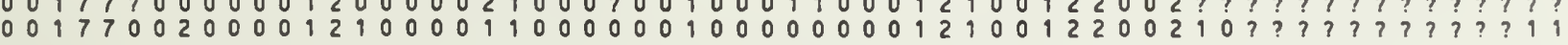

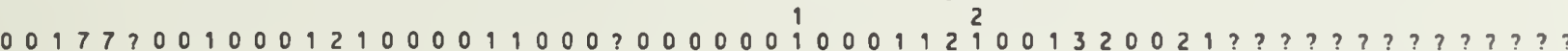

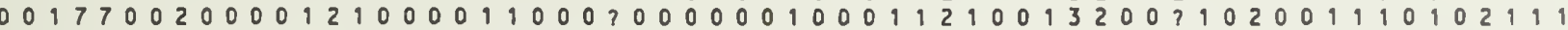
$000779001100129001021000000190000001923100000021 ?$ ? ? ? ? ?? ? ??

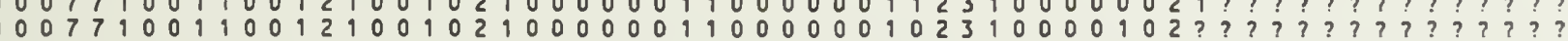
00088100001012100102100070012000000192210102012 ? ? ? ? ? ? ? ? ??

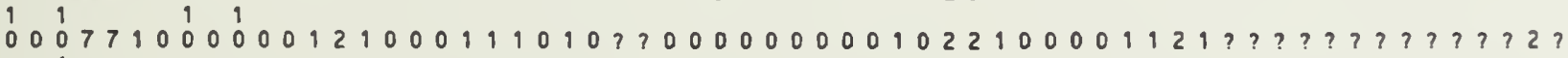
177000000001

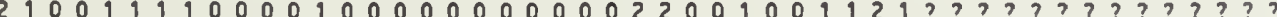
119990000000120001231100192000001190021122210000001921002101111115020 $1199800300001201912319001210001901091221000021210010119019 ? ? 2 ?$ 19187020000012019123110012000001112192210000210103100191195020

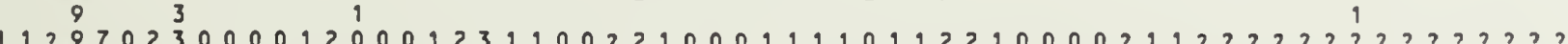
$11 ? 87000000001220000241100191000010001010022100000212112111911914020$ 98 19

AUSTEUCHARIS 10197000000012000124110071000002000002290000292 ? 129119191 ? 40 ?

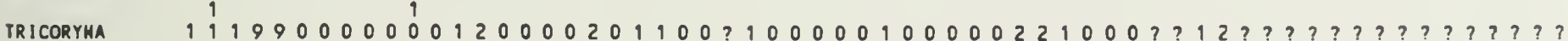

1199000000001200002001

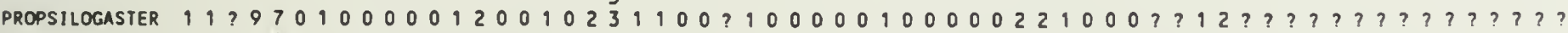
PSELDOMETAGEA CHALCURA

11977000000012100020110019000001901090222100000212192119119114021



SCHIZASPIDIA

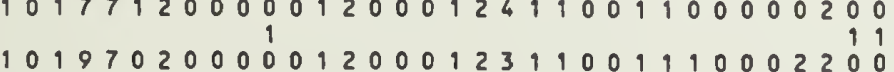

KAPALA $1000122100000921921 ? 91919 ? 3020$ $000221002021217 ? 91911191301$ 1019902000000120001251200191900193200001022210000002121912119191913020 $10 ? 970200000120001251200191001320001022100002929 ? ? ? ? ? ? ? ? ? ? ? ? ? ?$ 


\section{Appendix 2: New Synonymies}

\section{General}

() rascma Camlerom. Isist

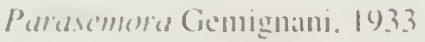

\section{Species}

Timienderas refiringens Waterston, 1916 Oraseme viridic vanea Risbec, 1958

Orasemonplua triclenuat (Girault). 1915 Eucharomorpha whecheri Brues. 1934

Orasemorplace eribotes (Walker), 1839 Encharomerpha dabia Girault, 1913a Eucharomorplia fuscipes Girault, 1913a Encharomonpha partiglabra Girault, 1940 Eucharomorpha viridis Girault. 1913a Neoloshamis palgravei (Girault), 1922

Psilogaster mishidai lshii and Nagasawa, 1941 Loshamus petersoni Hedqvist, 1978

Orasema indica Snehalatha and Narendran, 1992

\section{Appendix 3: New Combinations}

Orasemorpha myrmicae (Epimetagea)

Orasema fraudulenta (Psilogaster)

Psilocharis theocles (Orasema)

Neoloshamis sermma (Orasema)

Neolosbanus purpureoventris (Eucharis)

Neoloshanus lacriceps (Psilogaster)

Neoloshamus palgravei (Orasema)

Neolosbanu.s gressitti (Loshumus)

Stilbula ranomafanae (Orasema)

\section{Appendix 4: Lectotypes Designated}

Encharomorpha dedentata Girault (Orasemorpha) Eucharomorpha fiuscipes Girault (Orasemorpha) Eucharomorpha partiglabra Girault (Orasemorpla) Encharomorpla wheeleri Brues (Orasemorpha)

Orasema commmums Risbec

Orasema palgeravei Girault (Neolosbamus)

Orasema pheidolophage Girault

Orasema michaneroi (Loshanus)

Psilocharis frandulenta Reichensperger (Orasona)

\section{Appendix 5: New Taxa Described}

\section{Genera}

Neoloshenmis

Psilochares

\section{Species}

acuminutus, Timioderus coromula, Timioderus peridemanus, Timiodenus ramosus, Timioderus

sparsepilosa, Orasemorpha

bonceki. Orasema glabra, Orasema ishii. Orasema koghisiana, Orasema nigra, Orasema promecea, Orasema rugulosa. Orasema striatosoma. Orasema syenenpora, Orasema

aenigma, Psilocharis afra. Psilocharis

dahmsi, Psilocharis hypena. Psilocharis joanneae. Psilocharis monilicera, Psilocharis pacifica, Psilocharis pentella. Psilocharis

anapetus. Neoloshanus apoamis, Neoloshamis kokureamus. veolosbamus nepalensis, Neoloshamus pilosus. Neolushamus storevi, Neolosbanus ainamensis, Neoloshamus townesi. Neoloshermis violaceas, Neolesbamus "alanabii. Neoloshamms wusheamus. Veolosbamus 



\section{ROYAL ON'TARIO MUSEUM LIFE SCIENCES PUBLICATIONS INSTRUCTIONS TO AUTHORS}

Authors should prepare their manuscripts carefully according to the following instructions; failure to do so will result in the manuscript's being returned to the author for revision. All manuscripts are considered on the understanding that they are not currently offered for publication elsewhere.

1. General Papers for publication are accepted from ROM staff members and research associates, and from researchers reporting on work done with ROM collections. Monographs on the flora and/or fauna of Ontario by authors not affiliated with the ROM may be considered for publication. Financial contributions towards publication may be required. Authors are expected to write clearly and concisely and to omit any material not essential for an understanding of the main theme of the paper.

2. Format Manuscripts (including captions, synonymies, literature cited, and tables) should be typed double-spaced on standard letter-size paper with a 4 $\mathrm{cm}$ (1") margin on all sides. Three photocopy copies should be submitted to the Head of Publications and Print Services; the original should be retained by the author. The submission should include a separate sheet giving the author(s) names and affiliations, the title of the publication, the series if applicable, the number of typed pages, the number of tables, and the number of plates and figures. Manuscripts should normally be organized in the following order: contents, abstract, introduction, materials and methods, results, discussion, conclusions, summary (if manuscript is long), acknowledgements, appendices, and literature cited. Authors are encouraged to include foreign-language translations of the summary, if appropriate. Main headings should be centred; subheadings should be left-justified to the text margin. The first line of the first paragraph in each new section should not be indented. A single space only should be left between sentences. Material intended to be typeset as italic must be provided as italic, not as underlined roman type. Literature citations in the text should be in one of the following forms: "Jones (1994)" or "(Jones, 1994)" or "(Smith, 1990:71-79. fig. 17)."

3. Standard Sources The primary authority on questions of format and style is the Guide to Authors and Editors, available from ROM Publications and Print
Services. For matters not covered in the guide, consult the CBE Style Manual. Other standard sources are as follows: for English spelling. The Concise Oxford Dictionary; for Canadian place names and coordinates, Canada Gazetteer Atlas; for the spelling of geographic names, The Times Atlas of the World.

4. Abstract All papers must be preceded by a short, factual abstract, about one per cent of the text in length. The abstract may be followed by four to six key words in parentheses.

5. Taxonomy The name of a taxon should be given in full in headings, at the beginnings of paragraphs, and at its first occurrence in the text. Give the authority and date, if appropriate, with the first mention of each taxon, but not thereafter. Taxonomic papers, particularly synonymies, should follow the layout in the Guide to Authors and Editors. International Codes of Biological Nomenclature must be followed.

6. Literature Cited A complete list of references, in alphabetical order of authors, must be given at the end of the paper. When two or more works of one author are cited, they should be listed chronologically. The names of journals should not be abbreviated. For correct bibliographic form, see the Guite to Authors and Editors.

7. Tables All tables should be typed on separate sheets and numbered consecutively in arabic numerals in the order of their first mention in the text. Mark the location of each table in the margin of the text.

8. Plates, Figures, and Text-figures Illustrations may be designated according to the conventions of the author's discipline: in some disciplines grouped photographs of scientific subject matter are commonly termed Plates. while line drawings and locality and other illustrations that occupy a full page or less are Text-figures. Usage must be consistent throughout the paper. A full-page illustration with its caption should be sized to fit an area of $17.3 \times 22.75 \mathrm{~cm}$ $(6.8 " \times 9$ ") for a Contribution; for Occasional Papers, the area is $14.1 \times 21.2 \mathrm{~cm}\left(5.5^{\prime \prime} \times 8.3^{\prime \prime}\right)$. If captions are lengthy, they may be placed on the facing page. A scale or magnification factor should be included. Authors are reminded that when illustrations are reduced, magnification lactors will change, and that they are responsible for the conversion. For details, see the Guide to Authors and Editors. 


\section{ROYAL ONTARIO MUSEUM LIFE SCIENCES CONTRIBUTIONS}

Life Sciences Contributions are a numbered series of scientific publications of varied subject matter. Most recent contributions include the following:

156 Conodonts of the Lower Border Group and Equivalent Strata (Lower Carboniferous) in Northern Cumbria and the Scottish Borders, U.K. Mark A. Purnell

1992. 80 pp., ill., \$19.95

ISBN 0-8854-405-7

155 Revision of the World Species of Spalangiopelta (Hymenoptera: Chalcidoidea: Pteromalidae: Ceinae)

D. Christopher Darling 1991, 48 pp., ill., $\$ 11.00$ ISBN 0-88854-395-6

154 Shallow-Water Hydroids of Bermuda: The Thecatae, Exclusive of Plumularioidea Dale R. Calder 1991, 144 pp., ill., $\$ 24.50$ ISBN 0-88854-354-9

153 Silurian Trilobites from the Northern Yukon Territory Rolf Ludvigsen and Ronald P. Tripp 1990, 64 pp.. ill.. \$12.95 ISBN 0-88854-349-2

152 The Type Species of the Ordovician Trilobite Genus Isotelus: I. gigas Dekay, 1824 David M. Rudkin and Ronald P. Tripp 1989, 24 pp., jll., \$10.25 ISBN 0-88854-345-X

151 The Structure of the Call Note System of the WarblingVireo

Daryl Howes-Jones and Jon C. Barlow 1988, 40 pp. ill.. \$11.00

ISBN 0-88854-343-3

150 Late Cretaceous-Early Tertiary

Dinoflagellates and Acritarchs from the Kashi Area, Tarim Basin, Xinjiang Province, China Mao Shaozhi and Geoffrey Norris 1988, 100 pp., ill., $\$ 25.00$ ISBN 0-88854-334-4

149 Occurrence of the Cladid Inadunate Crinoid Thalamocrimus in the Silurian (Wenlockian) of New York and Ontario Cirorge C. Mi.Intosh and Carlton E. Brett 1988, 20 pp., ill.. $\$ 7.75$ ISBN ()-88854-.342-5
148 Shallow-Water Hydroids of Bermuda: The Athecatae

Dale R. Calder

1988, 112 pp., ill., $\$ 24.50$

ISBN 0-88854-339-5

147 Biostratigraphy and Palaeontology of the Scollard Formation, Late Cretaceous and Paleocene of Alberta

Loris S. Russell

I987, 23 pp., ill., $\$ 7.00$

ISBN 0-88854-338-7

146 Stipatocrinus, a New and Unusual Camerate Crinoid from the Lower Silurian of Western New York

James D. Eckert and Carlton E. Brett 1987, 17 pp., ill., $\$ 6.00$ ISBN 0-88854-336-0

145 An Annotated Checklist of the Fishes of the Chagos Archipelago, Central Indian Ocean Richard Winterbottom, Alan R. Emery, and Erling Holm 1987, 240 pp., ill., $\$ 50.00$ ISBN 0-88854-329-8

144 Revision of the Caddisfly Genus Psilotreta (Trichoptera: Odontoceridae) Charles R. Parker and Glenn B. Wiggins 1987, 55 pp.. ill., $\$ 12.00$ ISBN 0-88854-332-8

143 Phylogeny, Speciation, and Palaeoecology of the Early Carboniferous (Mississippian) Conodont Genus Mestognathus Peter H. von Bitter, Charles A. Sandherg, and Michael J. Orchard 1986, 115 pp., ill., $\$ 25.00$ ISBN 0-88854-319-0

142 Review of the Gobioid Fishes of the Chagos Archipelago, Central Indian Ocean Richard Winterbottom and Alan R. Emery 1986, 82 pp., ill.. \$1 5.00 ISBN 0-88854-320-4

\section{A catalogue of ROM publications in print is} available from

University of Toronto Press 10 St. Mary Street, Suite 700 Toronto, Ontario M4Y 2W8 Canada

Tel. (416) 978-2229 Fax (416) 978-4738 